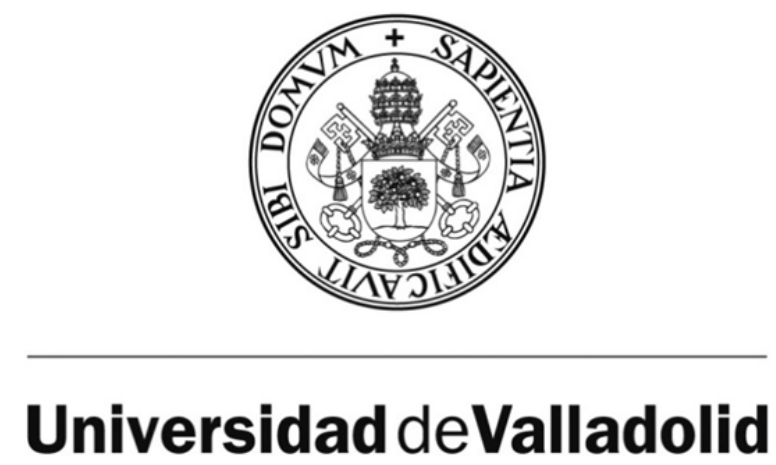

FACULTAD DE CIENCIAS

DEPARTAMENTO DE

QUÍMICA-FÍSICA Y QUÍMICA INORGÁNICA

TESIS DOCTORAL:

\title{
Complejos de Reniotricarbonilo con Amidinos: Síntesis, Mecanismo y Propiedades
}

Presentada por Patricia Gómez Iglesias para optar al grado de doctora por la Universidad de Valladolid.

Dirigida por Fernando Villafañe González 

1. SÍNTESIS GENERAL 3

1.1. Summary 5

2. INTRODUCCIÓN 9

2.1. El fragmento fac $^{-}$"Re(CO) $)_{3}$ " 9

2.1.1. Luminiscencia, estudios fotofísicos y dispositivos moleculares fotoactivos 10

2.1.2. Química bioorganometálica 12

2.1.3. Reducción de $\mathrm{CO}_{2} \quad 13$

2.1.4. Electroquímica $\quad 13$

2.1.5. Enlaces supramoleculares y especies polinucleares, aparatos y aplicaciones 14

\begin{tabular}{ll} 
2.2. & El ligando amidino \\
\hline
\end{tabular}

2.2.1. El ligando pirazolilamidino 17

2.2.2. Mecanismo de formación del ligando pirazolilamidino 25

2.2.3. $\quad$ Ligandos amidino derivados de nucleobases 27

3. OBJETIVOS 31

4. RESUMEN DE RESULTADOS 35

4.1. Estudio del mecanismo de formación del pirazolilamidino 35

4.2. Estudio de las propiedades fotofísicas de los complejos 41

4.2.1. Estudios fotofísicos $\quad 42$

4.2.2. Estudios electroquímicos 43

4.2.3. Cálculos teóricos $\quad 45$

4.3. Formación de complejos amidino a partir de nucleobases 47

5. ARTÍCULO 1 51

Pyrazolylamidino Ligands from Coupling of Acetonitrile and Pyrazoles: a Systematic Study

\section{ARTÍCULO 2}

Luminescent Rhenium(I) Tricarbonyl Complexes with Pyrazolylamidino Ligands:

Photophysical, Electrochemical and Computational Studies

\section{ARTíCULO 3}

Amidino Ligands from Coupling 1-Methylcytosine and Nitrile: a New Way to Incorporate Biomolecules to Luminiscent Rhenium(I) Tricarbonyl Complexes

8. DOCTORADO INTERNACIONAL

8.1. Introducción

8.2. Discusión de resultados

8.2.1. Síntesis de los compuestos

8.2.2. Estudios de la capacidad transportadora en vesículas 
8.3. Parte experimental 136

$\begin{array}{ll}\text { 8.3.1. } & \text { Preparación de las vesículas } \\ \text { 8.3.2. } & 136\end{array}$

$\begin{array}{ll}\text { 8.3.2. } & \text { Síntesis de los compuestos } \\ \end{array}$

9. CONCLUSIONES 143

$\begin{array}{lll}\text { 9.1. Conclusions } & 145\end{array}$

10. METODOLOGIA EMPLEADA 149

10.1. Condiciones generales de reacción 149

$\begin{array}{llr}\text { 10.2. Caracterización } & 149\end{array}$

$\begin{array}{lll}\text { 10.2.1. } & \text { Espectroscopia de infrarrojo } & 149\end{array}$

10.2.2. Espectroscopia de resonancia magnética nuclear 150

10.2.3. Análisis elemental de $C, H$ y $N$.

10.2.4. Difracción de Rayos $X \quad 151$

10.2.5. Experimentos fotofísicos 151

10.2.6. Estudios electroquímicos 151

10.2.7. Detalles computacionales 152

11. BIBLIOGRAFÍA

Anexo I

Anexo II

Anexo III

Anexo IV

Anexo V

Anexo VI

Anexo VII

Anexo VIII 


\section{AUTORIZACIÓN DEL DIRECTOR DE TESIS}

(Art. 2.1. c de la Normativa para la presentación y defensa de la Tesis Doctoral en la UVa)

D. Fernando Villafañe González, con D.N.I. N09256946K Profesor Titular del departamento de Química Física y Química Inorgánica de la Facultad de Ciencias de la Universidad de Valladolid e investigador del IU CINQUIMA, como Director de la Tesis Doctoral titulada "Complejos de Reniotricarbonilo con Amidinos: Síntesis, Mecanismo y Propiedades" presentada por $\mathrm{D}^{\mathrm{a}}$. Patricia Gómez Iglesias alumno del programa "Doctorado en Química: Química de Síntesis, Métodos de Separación, Catálisis y Materiales Avanzados" impartido por el IU CINQUIMA autoriza la presentación de la misma, considerando que ha cumplido todos los requisitos.

Valladolid, 15 de septiembre de 2015

El Director de la Tesis,

Fdo.: Fernando Villafañe González 



\section{LISTA DE ABREVIATURAS EMPLEADAS}

En el texto:

A: $\quad$ Contraión aniónico

ADN: $\quad$ Ácido desoxirribonucleico

bipy: Bipiridina $\quad\left(\mathrm{C}_{5} \mathrm{H}_{4} \mathrm{~N}\right)_{2}$

Bz: Bencilo $\quad \mathrm{C}_{6} \mathrm{H}_{5} \mathrm{CO}$

CNXyl: 2,6-dimetilfenilisocianuro o 2,6-xililisocianuro $\quad \mathrm{C}_{9} \mathrm{H}_{9} \mathrm{~N}$

$\mathrm{Cp:} \quad$ Ciclopentadienilo $\left(\mathrm{C}_{5} \mathrm{H}_{5}\right)^{-}$

DFT Teoría del funcional de la densidad

dmpzH: 3,5-dimetilpirazol $\quad \mathrm{C}_{5} \mathrm{H}_{8} \mathrm{~N}_{2}$

DMSO: Dimetilsulfóxido o 2,6-xililisocianuro

HOMO: orbital molecular ocupado de mayor energía

IL: $\quad$ Transición dentro del ligando

indH: Indazol $\quad \mathrm{C}_{7} \mathrm{H}_{6} \mathrm{~N}_{2}$

L: $\quad$ Ligando dador de dos electrones

LC: $\quad$ Transición centrada en el ligando

LLCT: $\quad$ Transferencia de carga ligando - ligando

LMCT: Transferencia de carga ligando - metal

LUMO: Orbital molecular no ocupado de menor energía

MC: $\quad$ Transición centrada en el metal

Me: $\quad$ Metilo

$\mathrm{CH}_{3}$

$\mathrm{Me}_{2} \mathrm{Ad}: \quad N^{6} N^{6}$-dimetiladenina

MeAd: $\quad N^{9}$-metiladenina

$\mathrm{MeCyH}_{2}:$ 1-metilcitosina

MLCT: Transferencia de carga metal ligando 
N-N: $\quad$ Ligando quelato tipo diimina

$\mathrm{N}-\mathrm{N}-\mathrm{N}: \quad$ Ligando quelato trípode nitrógeno dador

OLED: Diodo orgánico de emisión de luz

OTf: $\quad$ Anión trifluorometanosulfonato

phen: $\quad$ Fenantrolina $\quad \mathrm{C}_{12} \mathrm{H}_{8} \mathrm{~N}_{2}$

POPC: $\quad$ 1-palmitol-2-oleoelfosfatidilcolina

pzH: Pirazol $\quad \mathrm{C}_{3} \mathrm{H}_{4} \mathrm{~N}_{2}$

R: $\quad$ Alquilo, arilo

RMN: Resonancia magnética nuclear

$\mathrm{T}^{\mathrm{a}}: \quad$ Temperatura

TD-DFT Teoría del funcional de la densidad tiempo dependiente

Tp* hidrotris(3,5-dimetilpirazolil)borano

X: $\quad$ Ligando aniónico

XLCT: $\quad$ Transferencia de carga halógeno - ligando

$\eta^{6}-\mathrm{C}_{6} \mathrm{Me}_{6}: \quad$ Hexametilbenceno $\quad \mathrm{C}_{12} \mathrm{H}_{18}$

En los espectro de resonancia magnética nuclear (RMN)

$\begin{array}{ll}\text { s: } & \text { Singlete } \\ \mathrm{d}: & \text { Doblete } \\ \mathrm{m}: & \text { Multiplete } \\ \mathrm{t}: & \text { Triplete } \\ \mathrm{Hz}: & \text { Herzios } \\ \mathrm{ppm}: & \text { Partes por millón } \\ \mathrm{J}: & \text { Constante de acoplamiento } \\ \mathrm{a}: & \text { Señal ancha }\end{array}$


1. Síntesis General 



\section{SÍNTESIS GENERAL}

La presente memoria se encuentra enmarcada dentro de la química de la coordinación de complejos de renio(I) con ligandos bidentados de tipo diimina. En concreto, durante el desarrollo de la memoria se describe la síntesis, caracterización y las propiedades físicas de nuevos complejos con el fragmento $\mathrm{fac}$ - " $\mathrm{Re}(\mathrm{CO})_{3}$ ” coordinado a ligandos amidinos bidentados, formados bien a partir del acoplamiento de un nitrilo y un pirazol, bien de un nitrilo y una nucleobase.

El presente trabajo se presenta como compendio de publicaciones. En la Introducción, con el objetivo de que el lector se familiarice con la temática de este trabajo, se repasa el estado actual de los elementos centrales de la memoria, es decir, el fragmento $f a c$-" $\operatorname{Re}(\mathrm{CO})_{3}$ " y el ligando amidino. A continuación, en los Capítulos 3 y 4, se discuten respectivamente los objetivos y los resultados del trabajo, que se enumeran muy brevemente a continuación:

Primero se realiza un estudio sistemático y exhaustivo del mecanismo de la reacción de formación de los ligandos pirazolilamidino coordinados a un fragmento metálico, concretamente al fragmento $f a c$ - " $\operatorname{Re}(\mathrm{CO})_{3}$ ”. Se estudia la influencia que ejercen en la reacción diversos factores como son el pirazol, el disolvente, la temperatura y la presencia de sales en la disolución. Como consecuencia de este estudio, se han podido desarrollar nuevos métodos de síntesis de complejos pirazolilamidino. Se pretende encontrar vías de síntesis alternativas a la clásica térmica que reduzcan los tiempos de reacción y mejoren los rendimientos hasta ahora obtenidos. Esta apertura de nuevas vías sintéticas podría abrir el camino a la síntesis de nuevas especies amidino que hasta ahora no eran accesibles.

La elección para este trabajo del fragmento $\mathrm{fac}$-" $\mathrm{Re}(\mathrm{CO})_{3}$ " se basa en las interesantes propiedades que generalmente poseen los complejos que contienen coordinados ligandos del tipo diimina. Por ello, el segundo objetivo del trabajo se centra en el estudio de las propiedades fotofísicas y electroquímicas de los compuestos obtenidos. Para complementar estos estudios se realizaron cálculos teóricos DFT y TD-DFT de los compuestos sintetizados que apoyan las conclusiones extraídas de los datos experimentales.

Como tercer objetivo, se procede a extender la reacción de acoplamiento con nitrilo a otro sistema de interés como son las nucleobases. De este modo se aborda un aspecto de creciente interés en el campo de la química médica, como es la incorporación de biomoléculas al fragmento $\mathrm{fac}$ - $\mathrm{Re}(\mathrm{CO})_{3}$ " y sus posibles usos como marcador o biosonda. 
Los resultados obtenidos de los objetivos anteriores se encuentran recogidos en el Capítulo 4 y dieron lugar a la publicación de una serie de artículos, los cuales conforman esta memoria, y se encuentran recogidos en los Capítulos 5, 6 y 7.

En el desarrollo de la presente tesis doctoral se realizaron dos estancias cortas. Durante la primera de ellas, en el grupo del Prof. Michael Knorr en la Universidad Franche-Comté (Francia), se realizaron las primeras medidas de luminiscencia y electroquímica de complejos de renio(I) y manganeso(I) con el fragmento pirazolilamidino. Algunos de dichos resultados se recogen en el segundo artículo que conforma esta tesis. La segunda estancia se realizó en el grupo del Prof. Philip Gale en la Universidad de Southampton (Reino Unido). En aras de obtener el título de doctorado internacional se incluye el Capítulo 8, en el que se expone el trabajo realizado durante dicha estancia. Dicho trabajo, unido al que se estaba desarrollando en aquel momento por el grupo del Prof. Gale, dio lugar a un artículo que se encuentra recogido en el Anexo I.

Las principales conclusiones que se derivan de la investigación desarrollada se recogen en el Capítulo 9. Tras las conclusiones, en el Capítulo 10 se detalla la metodología de síntesis y la caracterización estructural seguida durante el trabajo. Por último, en el Capítulo 11 se encuentra la relación de referencias bibliográficas empleadas en la elaboración de la presente memoria.

Para finalizar, en los anexos finales se incluyen una serie de artículos ordenados cronológicamente en los que la doctoranda ha trabajado durante la realización de la tesis aunque no formen parte del núcleo de la misma. En los Anexos II, III, IV y VIII se encuentran los artículos centrados en la síntesis y caracterización de complejos con el fragmento fac-"Mn(CO), y el ligando pirazolilamidino, mientras que en los Anexos V, VI y VII se recogen artículos en los que la doctoranda ha trabajo en colaboración con otros grupos. 


\subsection{Summary}

This thesis deals with rhenium(I) tricarbonyl complexes containing coordinated diimine type ligands. In particular, the synthesis, characterization and several physical properties of new fac" $\operatorname{Re}(\mathrm{CO})_{3}$ " complexes with bidentate amidino ligands are herein described. These amidino ligands are obtained by the coupling reaction of either a nitrile and a pirazol or a nitrile and a nucleobase.

This work is being presented as "compendium of publications", what means that the thesis should contain at least three indexed papers. The Chapter "Introducción" is intended to establish the state of the art of the thesis main topics, which include the $f a c$ - "Re(CO) $)_{3}$ " fragment and the amidino ligand. The objectives and results of the thesis are thereafter discussed in Chapters 3 and 4, and they are now briefly summarized:

First of all, a systematic study of the metal-mediated reaction mechanism between organonitriles and amines is performed. The metal fragment used is $f a c$-" $\operatorname{Re}(\mathrm{CO})_{3}$ " and the influence of the pirazol, the solvent, the temperature and the presence of ionic salts is evaluated. This study has allowed the understanding of the coupling reaction. The ultimate target is to find new synthetic pathways in order to improve the reaction yields and to reach less time-consuming reactions. Also developing new synthetic methods could open the way to obtain new pyrazolylamidino complexes in the future.

The photophysical properties of rhenium(I) tricarbonyl complexes have been intensively studied due to their interesting luminescent properties. Therefore, the second objective of this thesis is centered on the study of the promising photophysical and electrochemical properties of the amidine complexes synthetized. DFT and TD-DFT computational studies were also performed in order to support the previous experimental data.

Finally, the coupling reaction between metal activated nitriles and biologically relevant substrates, such as nucleobases, is studied in the third part of the work. The incorporation of biomolecules to the $f a c$ - $\mathrm{Re}(\mathrm{CO})_{3}$ " fragment and their possible use as probes is one of the main topics of medical chemistry.

The above mentioned work resulted in the publication of three papers, which form this thesis and are collected in Chapters 5, 6 and 7.

I have carried out two short stays in foreign universities in order to improve my academic training. The first one was in the UTINAM institute, at Franche-Comté University (France), under the supervision of Prof. Michael Knorr. The first photophysical and electrochemical measurements of rhenium(I) and manganese(I) pyrazolylamidino tricarbonyl 
complexes collected in this work were performed during this stay. The second one took place at Southampton University, under the supervision of Prof. Philip Gale. In order to obtain the "Doctorado Internacional" degree a brief summary of the work carried out during this stay is included in Chapter 8. The results of this work along with the results of other members of the group lead to the publication of an article which is collected in Appendix I.

The main conclusions of the thesis and the experimental section are collected in Chapter 9 and 10, respectively. The references used during the thesis are listed in Chapter 11. Finally, in the final Appendixes a series of articles that I have co-authored are attached. Those in Appendix II, III, IV and VIII deal with pyrazolylamidino manganese (I) tricarbonyl complexes whereas those in Appendix V, VI and VII are the result of different collaboration projects with other research groups. 
2. Introducción 



\section{INTRODUCCIÓN}

Todos los compuestos de este trabajo tienen como nexo de unión el fragmento $f a c$-" $\operatorname{Re}(\mathrm{CO})_{3}$ ", por lo que el primer apartado de la Introducción se dedica a repasar las aportaciones más relevantes sobre sus propiedades y sus aplicaciones de mayor interés.

En esta memoria, los ligandos que se coordinan al citado fragmento metálico son de tipo amidino. Debido a ello, se revisa su química en sucesivos apartados, haciendo especial hincapié en los amidinos derivados de pirazol y de nucleobases, que son los que se describen en este trabajo. Para finalizar, se incluye un breve apartado dedicado al mecanismo de formación del ligando pirazolilamidino.

\subsection{El fragmento $\mathrm{fac}^{-}$" $\mathrm{Re}(\mathrm{CO})_{3}$ ”}

El número de complejos con el fragmento reniotricarbonilo ha crecido exponencialmente en los últimos años, convirtiéndose en el fragmento más empleado dentro de la extensa química de este metal. Los tres ligandos carbonilo en los complejos octaédricos de configuración $d^{6}$ con estequiometria $\left[\operatorname{Re}(\mathrm{CO})_{3} \mathrm{~L}_{3}\right]^{\mathrm{z}}(\mathrm{z}=0$ cuando $\mathrm{L}$ son ligandos neutros; $\mathrm{z}=1$ cuando uno de los ligandos es aniónico) pueden presentar dos conformaciones estereoquímicas: facial ( $f a c$ ) o meridional (mer). La configuración $f a c$ es abrumadoramente predominante, debido al fuerte carácter $\pi$-aceptor de los carbonilos, que tienden a tener ligandos dadores coordinados en trans. De hecho, se conoce un número relativamente escaso de complejos que presentan geometría mer. ${ }^{1,2}$ La gran mayoría de los complejos $f a c-\left[\operatorname{Re}(\mathrm{CO})_{3} \mathrm{~L}_{3}\right]^{\mathrm{z}}$ descritos en la bibliografía se han preparado teniendo en mente el estudio de sus propiedades, bien sea para entender los mecanismos relacionados con sus propiedades fotofísicas, bien sea para conseguir objetivos específicos dentro de áreas biológicas aplicadas. En la Figura 1 se representan diferentes complejos $f a c-\left[\operatorname{Re}(\mathrm{CO})_{3} \mathrm{~L}_{3}\right]^{\mathrm{z}}$ en función de la carga del complejo y de la denticidad del ligando. 


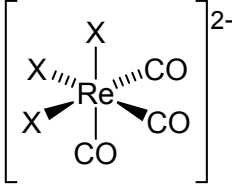

I

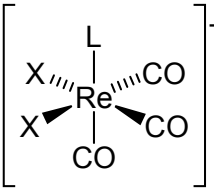

II

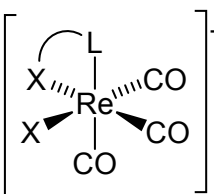

III

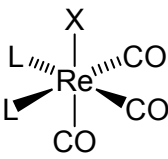

IV

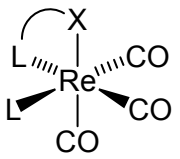

$\mathrm{V}$

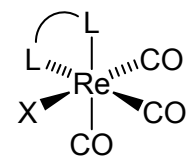

VI

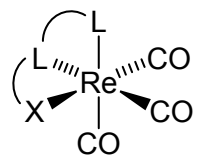

VII

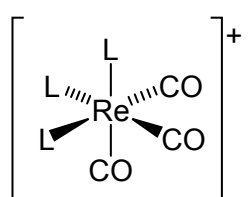

VIII

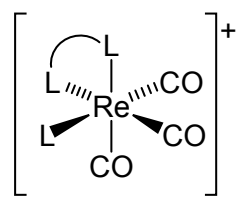

IX

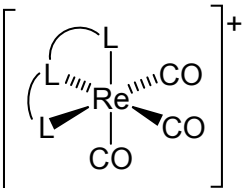

$\mathbf{X}$

$$
\begin{array}{ll}
X=\text { Ligando monodentado aniónico } & \mathrm{L} L=\text { Ligando bidentado neutro } \\
\mathrm{L}, \mathrm{L}, \mathrm{L}=\text { = Ligando monodentado neutro } & \widetilde{L L}=\text { Ligando tridentado neutro } \\
\widetilde{X L}=\text { Ligando bidentado aniónico } & \widetilde{X L L}=\text { Ligando tridentado aniónico }
\end{array}
$$

Figura 1. Tipos de complejos $f a c-\left[\operatorname{Re}(\mathrm{CO})_{3} \mathrm{~L}_{3}\right]^{\mathrm{z}}$ en función de los ligandos coordinados.

En la mayoría de los complejos descritos en la bibliografía el ligando X (Figura 1) corresponde a un halógeno o pseudohalógeno, mientras que los ligandos bidentados son generalmente ligandos de tipo diimina, como la bipiridina o la fenantrolina, aunque también se han diseñado numerosos ligandos bidentados N-L $(\mathrm{L}=\mathrm{N}, \mathrm{P}, \mathrm{O}, \mathrm{S})$ para propósitos específicos. El número de complejos aniónicos de los tipos I-III es relativamente pequeño, ya que no tienen aplicación práctica. Algunos presentan interés sintético como compuestos de partida, como por ejemplo el complejo $f a c-\left[\operatorname{Re}(\mathrm{CO})_{3} \mathrm{X}_{3}\right]^{2-},(\mathrm{X}=\mathrm{Cl}, \mathrm{Br})$, que se ha utilizado como precursor de diferentes complejos de renio. Lo mismo ocurre con los complejos de tipo VIII, que generalmente se emplean como compuestos de partida. El resto de los complejos suelen estar diseñados para una aplicación concreta, como se detalla a continuación para las más importantes.

\subsubsection{Luminiscencia, estudios fotofísicos y dispositivos moleculares fotoactivos}

El termino luminiscencia fue utilizado por primera vez en 1888 por Eilhard Wiedemann para denominar cualquier fenómeno en que la emisión de la luz no estuviese solamente producido por el incremento de la temperatura, es decir por la incandescencia. Actualmente la 
luminiscencia se define como "la emisión espontánea de radiación de una especie excitada electrónicamente o vibracionalmente que no este en equilibrio térmico con el medio". ${ }^{3}$ Los diferentes tipos de luminiscencia existentes se clasifican en función del modo de excitación, de esta manera existe la quimioluminiscencia, bioluminiscencia, fotoluminiscencia, electroluminiscencia, catodoluminiscencia, radioluminiscencia, sonoluminiscencia, termoluminiscenica y triboluminiscencia. La fotoluminiscencia es aquella luminiscencia en que el estado excitado desde el que se produce la emisión de luz se genera mediante la absorción de ración ultravioleta, visible o infrarroja. Este tipo de luminiscencia es de gran importancia en muchos campos científicos y tecnológicos como son la física, la química, la ciencia de los materiales, la biología o la medicina. La fluorescencia y la fosforescencia son tipos de fotoluminiscencia. Durante mucho tiempo después de que G. G. Stokes introdujese el término fluorescencia, la distinción entre fluorescencia y fosforescencia estaba basada en la duración de la emisión al finalizar la excitación. ${ }^{4}$ La fluorescencia se consideraba como la emisión de luz que desaparecía a la vez que la fuente de excitación, mientras que en la fosforescencia la emisión perduraba después del fin de la excitación. Pero este criterio dejo de ser válido debido a la existencia de fluorescencia de vida larga (sales de europio divalentes) y de fosforescencias de vida corta (sulfuro de zinc). En 1929, F. Perrin propuso por primera que la condición para que ocurra la fosforescencia es que la especia excitada pase por un estado intermedio antes de la emisión. ${ }^{5}$ Por la tanto, actualmente la fluorescencia se definiría como una emisión de radiación espontánea desde un estado molecular excitado con retención de la multiplicidad de espín mientras que la fosforescencia incluye un cambio en la multiplicidad de espín, generalmente de triplete a singlete o viceversa (Figura 2). ${ }^{3}$

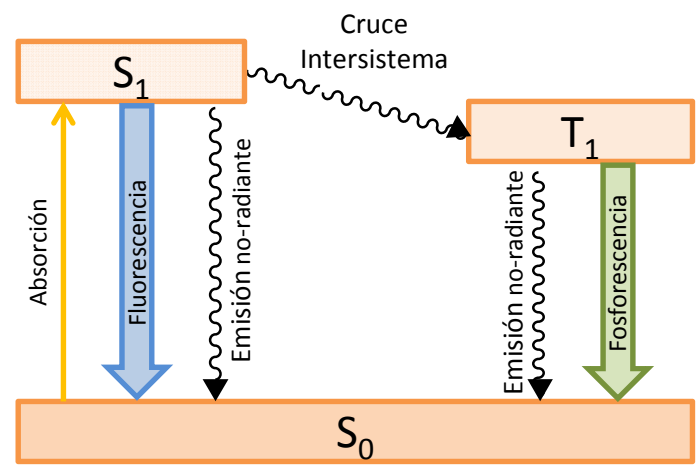

Figura 2. Representación de la fluorescencia y la fosforescencia.

El interés en las propiedades fotofísicas y fotoquímicas de los complejos $f a c-\left[\operatorname{ReX}(\mathrm{CO})_{3}(\alpha\right.$-diimina $\left.)\right]$ y $f a c-\left[\operatorname{ReL}(\mathrm{CO})_{3}(\alpha \text {-diimina })\right]^{+}$comenzó en la década de los setenta, 
cuando Wrighton describió por primera vez la luminiscencia del complejo fac-[ReCl(CO) $)_{3}($ bipy $\left.)\right] .{ }^{6,7}$ Después de la excitación de los complejos octaédricos $d^{6}$ de bajo espín, los estados energéticos más altos se pueblan como resultado de varias transiciones electrónicas: centrada en el metal (MC), centrada en el ligando (LC), transferencia de carga del metal al ligando (MLCT) y transferencia de carga del ligando al metal (LMCT). ${ }^{8}$ Mientras que en los complejos $d^{3}$ predominan las emisiones centradas en el metal, en estos complejos de renio(I) se observan todas las posibles excepto las transferencias de carga del ligando al metal (LMCT). ${ }^{8}$ Debido a esta riqueza de posibilidades se publicaron un gran número de trabajos en los que se estudiaban las propiedades de estos compuestos, haciendo especial hincapié en su fotoactividad. $^{9-15}$ La mayoría de los trabajos iniciales estaban enfocados al estudio de la luminiscencia de los complejos, a la identificación de los estados emisivos envueltos en el proceso y a la determinación de los procesos de transferencia energética que dependen de la naturaleza del ligando. También se han publicado varias revisiones sobre las diversas aplicaciones de las propiedades fotofísicas de estos compuestos, entre las que destacan su actividad como emisores de luz (OLED) $)^{16}$ o como fotointerruptores ${ }^{17,18}$

\subsubsection{Química bioorganometálica}

El descubrimiento de la estabilidad en agua y en aire de los complejos con el fragmento fac-" $\operatorname{Re}(\mathrm{CO})_{3}$ ", unido al hecho de que también pueden ser sintetizados en disoluciones acuosas, llevo a la expansión de la tecnología llamada " $\operatorname{Re}(\mathrm{CO})_{3}$ core" utilizada mayoritariamente en el desarrollo de aplicaciones radioterapéuticas y de radio-imagen. ${ }^{19-23} \mathrm{El}$ interés de este tipo de compuestos como sensores o agentes de contraste en bio-imagen se debe a las siguientes características: $^{24-26}$ (a) alta fotoestabilidad, que permite la exposición continua de los complejos a la fuente de irradiación; (b) largos tiempos de vida de fosforescencia ( $\tau \approx \mu \mathrm{s})$; (c) los estados tripletes desde los que ocurre la emisión en complejos de metales de transición generalmente están asociados a transiciones de Stoke amplias, lo que minimiza posibles efectos de autodesactivación; (d) alta capacidad de absorción a través de los tejidos. En los complejos con ligandos tridentados (Figura 1, tipo $\mathbf{X}$ ) se ha observado un perfil farmacocinético más favorable que en los del tipo VIII (Figura 1), como $\left[\operatorname{Re}(\mathrm{CO})_{3} \mathrm{~L}_{2}\left(\mathrm{H}_{2} \mathrm{O}\right)\right]^{+}$, ya que in vivo se eliminan más fácilmente, lo que es un factor muy importante en sustancias radioactivas. ${ }^{22}$

El uso de este tipo de complejos como marcadores biológicos está en constante crecimiento, ${ }^{21,24}$ por ejemplo para la detección de especies marcadas mediante biotina (ADN, péptidos o proteínas). ${ }^{27,28}$ Otros complejos con el fragmento $f a c$-“Re(CO) $)_{3}$ ” han empezado a ser estudiados como agentes anticancerígenos. ${ }^{29}$ 


\subsubsection{Reducción de $\mathrm{CO}_{2}$}

Es bien sabido que el incremento del uso de combustibles fósiles ha producido un aumento en la concentración del dióxido de carbono atmosférico, dando lugar a problemas medioambientales como el efecto invernadero. Por ello, han cobrado especial interés los procesos de eliminación de $\mathrm{CO}_{2}$, entre los que destaca su reducción a $\mathrm{CO} \mathrm{u}$ otros productos. Se han descrito varios intentos para conseguirlo, basados en mecanismos biológicos, ${ }^{30}$ en técnicas de copolimerización, ${ }^{31}$ en técnicas de hidrogenación, ${ }^{32}$ o en la reducción del $\mathrm{CO}_{2}$ a $\mathrm{CO}$ mediante vía fotoquímica ${ }^{33}$ o electroquímica. ${ }^{34}$ En estos dos últimos métodos es donde el papel del fragmento $\mathrm{fac}_{\text {- }}$ " $\mathrm{Re}(\mathrm{CO})_{3}$ " presenta especial interés. El detonante de este interés fue un artículo publicado en 1983 por Lehn y su grupo en el que demostraban que el complejo $f a c-\left[\operatorname{ReCl}(\mathrm{CO})_{3}(\right.$ bipy $\left.)\right]$ catalizaba la reducción de $\mathrm{CO}_{2}$ a $\mathrm{CO}$ bajo condiciones fotoquímicas. ${ }^{2}$ Desde entonces se han ido sucediendo diversos estudios sobre las propiedades del sistema, y sobre cómo mejorar su efectividad.

\subsubsection{Electroquímica}

En 1978, el grupo de Wrighton observó una transferencia electrónica fotoinducida en el complejo $f a c-\left[\operatorname{ReCl}(\mathrm{CO})_{3} \mathrm{~L}\right] \quad(\mathrm{L}=1,10$-fenantrolina, 4,7-difenil-1,10-fenantrolina $)$ y la formación de productos de vida larga como resultado de la transferencia de un electrón. Este hecho les llevó a caracterizar las propiedades electroquímicas de estos complejos de renio mediante voltamperiometría cíclica. ${ }^{7}$ La reactividad de una molécula en su más bajo estado excitado posible de un electrón debe de estar relacionada con el estado fundamental de la molécula oxidada tras eliminar un electrón y del mismo estado de la molécula reducida por adición de un electrón. Una visión muy simplificada de esta situación se muestra en la Figura 3, en la que se observan las diferentes ocupaciones de los orbitales HOMO y LUMO de un complejo. La localización de los electrones en los orbitales moleculares es de vital importancia para entender la reactividad y la estructura de los estados reducidos, dado que el HOMO y el LUMO de las moléculas generalmente juegan un papel muy diferente e importante en el enlace. Por ejemplo, se observa como la sustracción de un electrón del HOMO genera labilización del ligando L, mientras que la adición de un electrón al LUMO no produce labilización. ${ }^{35}$ 


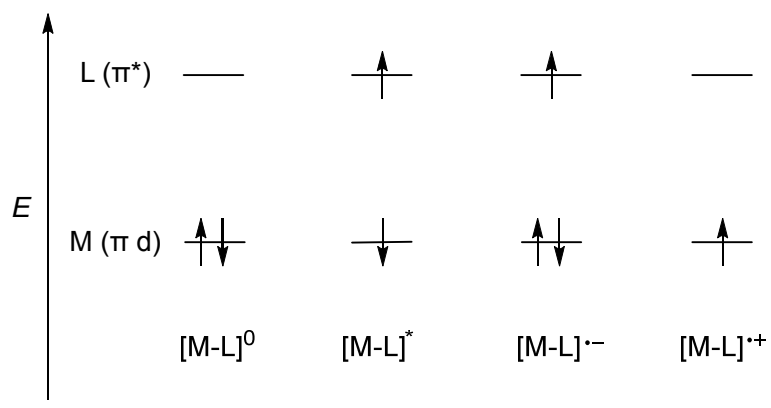

Figura 3. Diagramas orbitales de un electrón para un complejo metálico M-L, es su estado base, en su estado excitado MLCT, reducido con un electrón y oxidado con un electrón.

\subsubsection{Enlaces supramoleculares y especies polinucleares, aparatos y aplicaciones}

Debido a la capacidad coordinativa y alta estabilidad del fragmento $f a c$-" $\operatorname{Re}(\mathrm{CO})_{3}$ ", el número de complejos bi- y polinucleares formados a partir de este fragmento es muy alto. Sus aplicaciones van desde la catálisis a la formación de sistemas con interesantes propiedades luminiscentes o redox. ${ }^{36}$ Este es un campo de investigación muy activo, ya que los complejos polinucleares de metales de transición con el fragmento $f a c$-" $\operatorname{Re}(\mathrm{CO})_{3}$ ” podrían llegar a presentar funcionalidad inducida por la luz y/o redox. Un ejemplo sería la catálisis fotoinducida, para la que ya han mostrado su utilidad diversos complejos polinucleares de renio(I). ${ }^{37}$

Las especies polinucleares simples pueden estar unidas por medio de ligandos puente que funcionan como espaciadores entre los centros metálicos. Para este papel se han utilizado ampliamente diversas polipiridinas, ${ }^{14,38}$ ya que ofrecen distancias y fragmentos electrónicos bien definidos, aunque también se han empleado espaciadores de otras características, incluso unidos en algún caso por enlaces de hidrogeno. ${ }^{13}$ También se ha descrito el uso de estos compuestos como fotointerruptores, como la serie de complejos $\left[\left\{\text { fac- }\left[\operatorname{Re}(\mathrm{CO})_{3}(\alpha \text {-diimina })\right]_{3}\right\}^{3+}(\mu-\mathrm{L})^{3-}\right]$ donde $\mathrm{L}$ es un ligando fotoisomerizable de cis a trans y viceversa. ${ }^{39}$ Otro área en la que estos fragmentos supramoleculares se han utilizado exhaustivamente es el reconocimiento de aniones, debido a su alta sensibilidad y a sus bajos límites de detección. ${ }^{40,41}$ Un tema de reciente interés en el que los compuestos con el fragmento $f a c$ - $\operatorname{Re}(\mathrm{CO})_{3}$ " también están implicados es la formación de nuevos materiales supramoleculares con forma rectangular, cuadrada o triangular. Debido a sus propiedades luminiscentes, estos suprametalaciclos de renio(I) son una excelente plataforma para el estudio de interacciones huésped-anfitrión con moléculas aromáticas planas. ${ }^{42,43}$ Un paso más allá es la construcción de estructuras tridimensionales tipo caja, en las que las paredes serían grandes moléculas planas, como las porfirinas. ${ }^{44}$ Este tipo de compuestos podría albergar una gran variedad de especies moleculares en la cavidad formada y por lo tanto podría ser usado como sensor. ${ }^{45}$ 


\subsection{El ligando amidino}

El grupo amidina fue sintetizado por primera vez por Gerhardt en 1858 mediante la reacción de anilina con cloruro de $\mathrm{N}$-fenilbenzamida. ${ }^{46} \mathrm{Su}$ interés radica en su versatilidad sintética en química orgánica ${ }^{47,48}$ y en su capacidad de coordinación a metales. ${ }^{49}$ Además, el grupo amidina se encuentra en varias moléculas biológicas como: histidina, citosina, adenina, guanina y vitamina B12, lo que le hace atractivo por su actividad en química médica. ${ }^{50,51}$

Es bien conocido que el desarrollo de un método eficiente y catalítico para la formación de enlaces C-N que conduzca a la formación de amidas es de extraordinaria importancia, debido a la gran utilidad sintética de las amidas en general y de las amidinas en particular. La reacción de Pinner (Esquema 1) se describió por primera vez en 1877 pero sigue siendo el método más común para preparar amidinas primarias. ${ }^{52}$ Un tercio de todos las amidinas obtenidas a partir de nitrilos en el periodo 1994-2003, fueron sintetizados por el método de Pinner. ${ }^{52}$ En él se hace reaccionar al nitrilo con alcohol en condiciones anhídras en presencia de cloruro o bromuro de hidrogeno para obtener la sal de iminoéster. La posterior reacción de este compuesto con amoniaco o aminas genera la correspondiente amidina (Esquema 1). Esta vía sintética basada en reactivos de bajo coste puede ser apropiada para la síntesis a gran escala pero consume mucho tiempo.

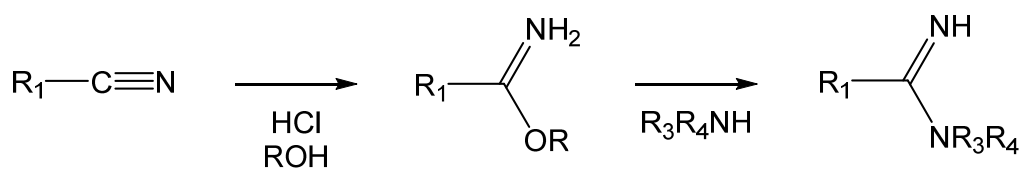

Esquema 1. Reacción de Pinner.

Los complejos con el ligando amidino se preparan generalmente por adición directa del ligando amidino, previamente sintetizado, al metal. La posibilidad de generar complejos amidinos in situ por medio de reacciones asistidas por metales entre nitrilos coordinados y aminas constituye una ruta alternativa al método anterior muy atractiva. Tanto en el laboratorio como en la industria las transformaciones de organonitrilos juegan un papel muy importante debido a su gran versatilidad química. La adición de nucleófilos, ${ }^{53}$ electrófilos ${ }^{54}$ o la cicloadición asimétrica dipolar ${ }^{55,56}$ al triple enlace $\mathrm{C} \equiv \mathrm{N}$ son rutas de interés para la formación de nuevos enlaces C-C, C-N, C-O y C-S. Uno de los principales problemas que se producen en estas reacciones de adición nucleófila es la insuficiente activación electrófila del carbono del nitrilo $\mathrm{RC} \equiv \mathrm{N}$, incluso cuando $\mathrm{R}$ es un grupo con elevado carácter aceptor. Sin embargo, estas 
dificultades se superan fácilmente coordinando el nitrilo a iones metálicos. El centro metálico se comporta como un fuerte ácido de Lewis activando el carbono del nitrilo para que se pueda producir el ataque nucleófilo. De hecho, esta activación puede resultar en un incremento de la velocidad de reacción, que se puede llegar a multiplicar por $10^{6}$ y hasta por $10^{8}$, incluso pudiendo llegar ocasionalmente a $10^{18}$. Por esta razón la síntesis de fragmentos amidino a partir de nitrilos activados por metales es una alternativa muy atractiva respecto a la reacción de Pinner.

La reacción se produce mediante el ataque del nucleófilo sobre el carbono del nitrilo, formándose un nuevo enlace carbono-nucleófilo y pasando el triple enlace $\mathrm{C} \equiv \mathrm{N}$ a doble enlace, ya que el átomo de nitrógeno del nitrilo termina enlazándose al hidrógeno del nucleófilo. Esta reacción se puede producir a partir de diferentes nucleófilos como son alcoholes, oximas, pentacloruro de fosforo o aminas. En el Esquema 2 se representa la reacción general para la formación de amidinos.

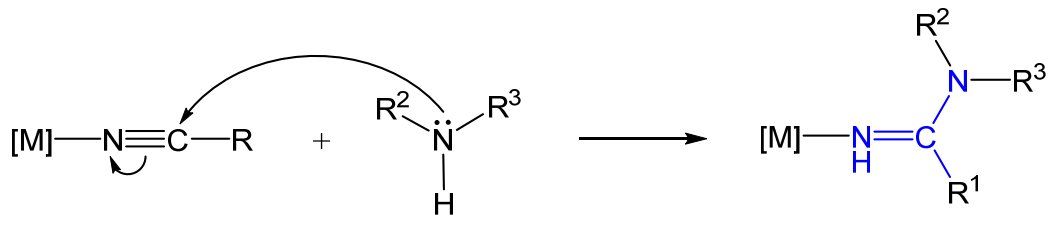

Esquema 2. Esquema general de formación de amidinos a partir de nitrilos coordinados.

El producto final es el resultado de la inserción formal del nitrilo en el enlace $\mathrm{Nu}-\mathrm{H}$ presente en el nucleófilo inicial, motivo por el que esta reacción se puede denominar de inserción. A la vez, puesto que se produce la unión de dos fragmentos orgánicos para formar una sola molécula, se puede entender también como una reacción de acoplamiento. Por lo tanto esta reacción se puede denominar de acoplamiento o de inserción y ambos términos son utilizados indistintamente en esta memoria.

En los últimos años en nuestro grupo de investigación se ha estudiado el comportamiento de un tipo especial de ligandos quelato nitrógeno dadores en los que cada átomo de nitrógeno forma parte de un grupo dador diferente. ${ }^{57-69}$ Estos ligandos se suelen denominar "mixtos" y presentan un atractivo especial, debido a la diferente estabilidad y reactividad de cada uno de los fragmentos. Tras estos precedentes y lo expuesto anteriormente sobre el ligando amidino, decidimos centrar nuestros estudios en el ligando pirazolilamidino (Figura 4, B). Este ligando fue uno de los temas centrales del trabajo desarrollado con ligandos quelato con fragmentos pirazol por la Dra. Arroyo en su tesis doctoral. ${ }^{70}$ En la presente memoria 
se continúa el estudio sobre el fragmento pirazolilamidino y en la parte final se extiende a otros complejos con ligandos amidino derivados de la 1-metilcitosina (Figura 4, C). Como se observa en la Figura 4 el ligando pirazolilamidino puede formar quelatos estables de cinco eslabones mediante su coordinación a centros metálicos. Del mismo modo, el amidino derivado del acoplamiento de la 1-metilcitosina con un nitrilo coordinado generaría un quelato de seis eslabones. En ambos casos se obtendría un ligando quelato neutro mixto, en el que dos átomos de nitrógeno de grupos dadores diferentes están coordinados al centro metálico. En los apartados 2.2.1 y 2.2.3 se detalla el estado del arte de estos dos tipos de ligandos en concreto.<smiles>[R2]N=C([R])N([R])[R]</smiles>

A

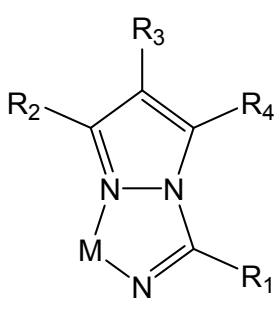

B

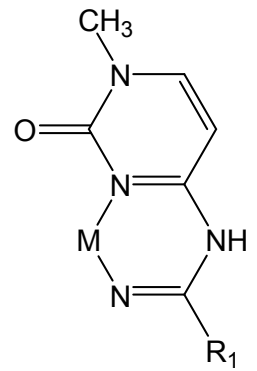

C

Figura 4. Esquema general de (A) amidinas; (B) pirazolilamidinos; (C) amidino derivado de la 1-metilcitosina.

\subsubsection{El ligando pirazolilamidino}

Los ligandos bidentados con fragmentos derivados del pirazol han despertado siempre interés, como se desprende de la revisión de Mukherjee del año $2000 .{ }^{71}$ Dentro de esta familia de ligandos, el ligando pirazolilamidino presenta, como su nombre indica, un grupo pirazol y un fragmento amidino. Cuando actúa como ligando, estos dos grupos se encuentran coordinados formando un quelato de cinco miembros coordinado al metal por dos átomos de nitrógeno. El interés del ligando pirazolilamidino se debe a sus especiales características:

a) Los electrones del ligando pirazolilamidino se encuentran deslocalizados de la misma forma que en los ligandos bipiridina o fenantrolina, por lo que las propiedades de un complejo con un ligando de este tipo deberían ser muy similares a las de los complejos que contienen coordinados estos ligandos. Hay que recordar que este tipo de ligandos nitrógeno dadores de tipo diimina se han venido utilizando tradicionalmente, tanto en Química de la Coordinación como en Química Organometálica, donde han cumplido generalmente un papel de ligandos estabilizadores. Todos ellos se caracterizan por ser buenos dadores, y por su capacidad para formar quelatos relativamente fuertes y estables. ${ }^{72}$ No suelen participar en la reactividad de los 
complejos, ya que no se activan fácilmente, por lo que se comportan generalmente como ligandos espectadores.

b) Se genera in situ por acoplamiento entre un pirazol y un nitrilo coordinado, permitiendo así controlar las propiedades electrónicas y estéricas del ligando quelato final, lo que permite acceder de manera sencilla a diferentes pirazolilamidino con sólo variar los sustituyentes del nitrilo y del pirazol (Esquema 3). Esta es una ventaja evidente respecto a los ligandos diimina que se utilizan habitualmente, en los que la introducción de sustituyentes requiere métodos sintéticos generalmente complicados y tediosos. En cambio, por medio de este sencillo método sintético se pueden obtener ligandos pirazolilamidino "a la carta".

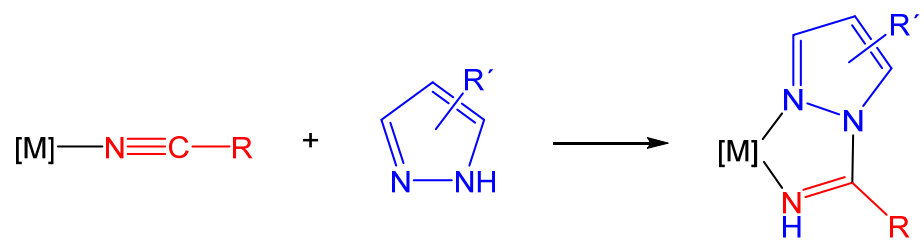

Esquema 3. Mecanismo general de la síntesis del ligando pirazolilamidino.

c) El hidrógeno enlazado al átomo nitrógeno dador del ligando pirazolilamidino que proviene del nitrilo es ligeramente ácido, por lo que es previsible que juegue un papel relevante a la hora de formar enlaces de hidrógeno o que pueda ser deprotonado, generando en ambos casos nuevas especies de interés. En el primer caso, la formación de enlaces de hidrógeno podría generar agregados polimetálicos, lo que está relacionado con uno de los grandes retos de la química actual, como es comprender y controlar cómo se organizan las moléculas. ${ }^{73,74}$ En el segundo, la deprotonación también permitiría el acceso a especies polimetálicas, en este caso enlazadas por enlaces covalentes. El interés de los complejos en los que hay dos o más átomos metálicos próximos se basa en que pueden considerarse como un nexo de unión entre los complejos de coordinación y las superficies sólidas. ${ }^{75}$

A pesar de estas interesantes propiedades, se han descrito relativamente pocos compuestos con este ligando, la mayoría de ellos con rutenio y solo con elementos de los grupos 6 al 10. Esta escasez de ejemplos permite que se pueda hacer aquí una revisión exhaustiva, que se detalla a continuación.

Los primeros complejos con el ligando pirazolilamidino fueron descritos en 1986 casi a la vez, por los grupos de McCleverty y Santos, ambos con rutenio(II) como átomo central (Figura 5). McCleverty describe la reacción como una adición nucleófila del enlace N-H del 
pirazol al enlace $\mathrm{C} \equiv \mathrm{N}$ del nitrilo, cuyo carácter electrófilo se ve aumentado por coordinación al fragmento metálico que actúa como un ácido de Lewis. ${ }^{76}$ El grupo de Romero et al. fue el primero en publicar la estructura cristalina de un complejo con el ligando pirazolilamidino (Figura $5, \mathbf{B}) \cdot{ }^{77}$ En un trabajo posterior realizaron un estudio más extenso sobre la reacción de diferentes complejos de rutenio(II) con pirazol y 3,5-dimetilpirazol. El estudio de la fortaleza del ligando pirazolilamidino formado les permitió concluir que es análoga a la de otros ligandos bidentados como bipiridina o fenantrolina. ${ }^{78}$

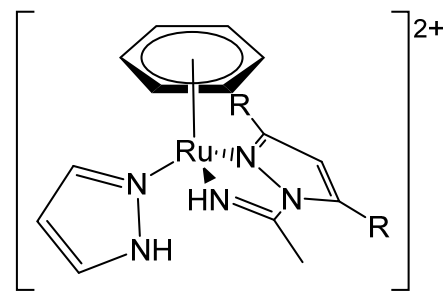

A

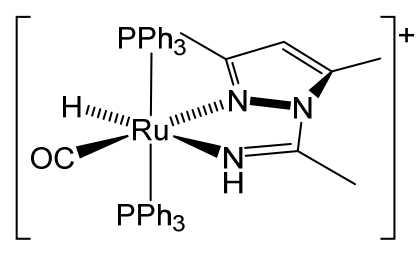

B

Figura 5. Primeros compuestos de rutenio descritos por McCleverty (A) y Romero (B).

A continuación la revisión de complejos con ligandos pirazolilamidino prosigue en función del grupo del metal al que están coordinados.

En el grupo 6 se han descrito ejemplos de ligandos pirazolilamidino coordinados a molibdeno o wolframio. Los dos únicos ejemplos de molibdeno con el ligando pirazolilamidino fueron obtenidos por casualidad. En 1987 el grupo de Trotter cristalizó inesperadamente un complejo pirazolilamidino de molibdeno (Figura 6, A), cuando intentaba sintetizar un compuesto bimetálico de molibdeno y galio. ${ }^{79}$ Más recientemente, en 2001, el grupo de Bolte describió la estructura cristalina de un nuevo oxocomplejo de molibdeno con el ligando pirazolilamidino, cuando un compuesto previamente sintetizado fue expuesto a la humedad y al aire (Figura 6, B). ${ }^{80}$ 


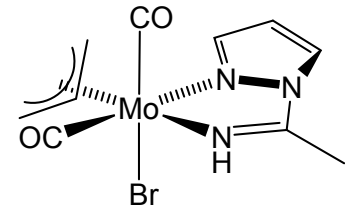

A

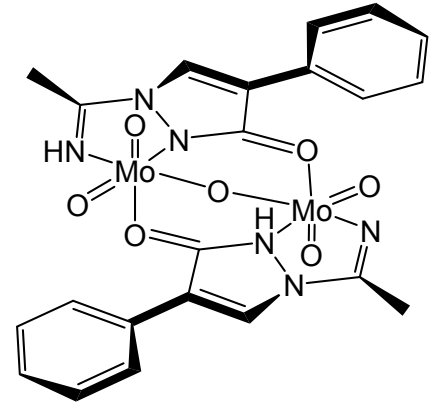

B

Figura 6. Únicos compuesto de molibdeno con el ligando pirazolilamidino.

Los ejemplos con wolframio se deben a resultados previos de nuestro grupo de investigación que están incluidos en la tesis de la Dra. Arroyo. Los complejos $f a c-\left[\mathrm{WI}_{2}(\mathrm{CO})_{3}\left(N \mathrm{H}=\mathrm{C}\left(\mathrm{CH}_{3}\right) \mathrm{pz}^{*}-\kappa^{2} N, N\right)\right]\left(\mathrm{pz}^{*}=\right.$ pirazol o 3,5-dimetilpirazol) se sintetizaron al hacer reaccionar $f a c-\left[\mathrm{WI}_{2}(\mathrm{CO})_{3}(\mathrm{NCMe})_{2}\right]$ con los correspondientes pirazoles en proporciones molares 1/1 en acetonitrilo. El interés de la estructura del complejo $f a c-\left[\mathrm{WI}_{2}(\mathrm{CO})_{3}\left(N \mathrm{H}=\mathrm{C}\left(\mathrm{CH}_{3}\right) \mathrm{dmpz}_{-\kappa^{2}} N, N\right)\right]$ (Figura 7) radica en la escasez de ejemplos ${ }^{81,82} \mathrm{de}$ complejos de estequiometria $\left[\mathrm{MX}_{2}(\mathrm{CO})_{3} \mathrm{~L}_{2}\right](\mathrm{X}=$ halógeno, $\mathrm{L}=$ ligando $\mathrm{N}$ dador $)$ con una disposición cis de los halógenos, ya que generalmente los halógenos están coordinados en trans cuando L es un ligando nitrógeno dador y en cis cuando L es distinto a nitrógeno. ${ }^{83}$

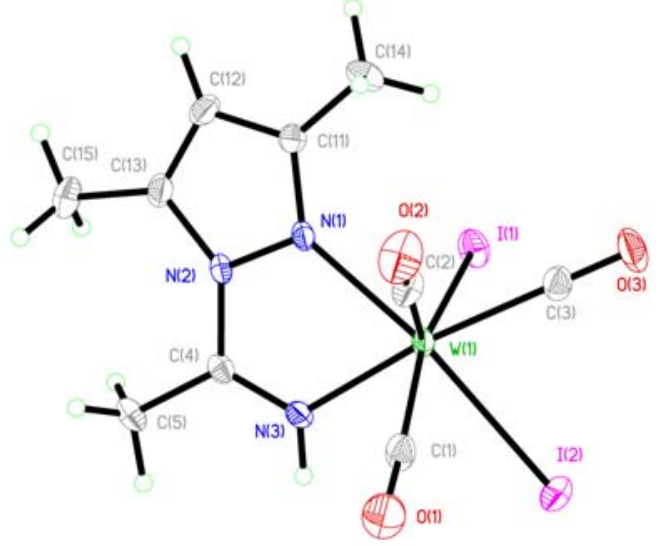

Figura 7. Vista en perspectiva de $f a c-\left[\mathrm{WI}_{2}(\mathrm{CO})_{3}\left(N \mathrm{H}=\mathrm{C}\left(\mathrm{CH}_{3}\right) \mathrm{dmpz}-\kappa^{2} N, N\right)\right]$.

Todos los ejemplos del grupo 7 corresponden a trabajos previos de nuestro grupo de investigación. Hasta la fecha, hemos descrito diferentes complejos de manganeso ${ }^{69,84}$ y renio, ${ }^{85}$ 
tanto neutros como catiónicos, en los que el ligando pirazolilamidino se forma a partir de un nitrilo y un pirazol (Figura 8). También se estudió la capacidad de algunos complejos de renio para captar aniones, en este caso en colaboración con el Prof. Julio Pérez. ${ }^{85}$

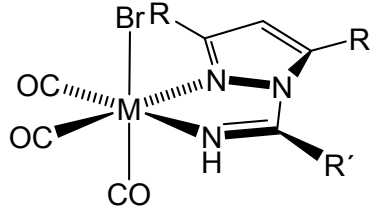

$M=M n, R e ; R=H, C H_{3} ; R^{\prime}=\mathrm{CH}_{3}$ $\mathrm{M}=\mathrm{Mn} \quad \mathrm{R}=\mathrm{H}, \mathrm{CH}_{3} ; \mathrm{R}^{\prime}=\mathrm{Ph}$

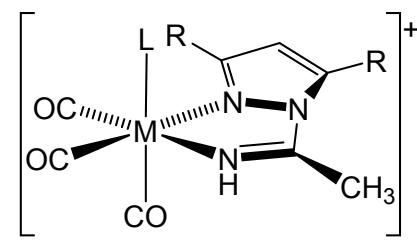

$\mathrm{M}=\mathrm{Mn} ; \quad \mathrm{L}=\mathrm{H}_{2} \mathrm{O} ; \quad \mathrm{R}=\mathrm{H}, \mathrm{CH}_{3}$

$\mathrm{M}=\mathrm{Mn} ; \quad \mathrm{L}=\mathrm{CNXyl} ; \quad \mathrm{R}=\mathrm{H}, \mathrm{CH}_{3}$

$\mathrm{M}=\mathrm{Mn}, \mathrm{Re} ; \mathrm{L}=\mathrm{pzH} ; \quad \mathrm{R}=\mathrm{H}$

$\mathrm{M}=\mathrm{Mn}, \mathrm{Re} ; \mathrm{L}=\mathrm{dmpzH} ; \mathrm{R}=\mathrm{CH}_{3}$

$M=M n, R e ; L=N C M e ; \quad R=H, C H_{3}$

Figura 8. Complejos de renio y manganeso conteniendo el ligando pirazolilamidino.

Nuestro grupo también amplió el estudio de este tipo de compuestos a otros precursores para dar reacciones de acoplamiento entre pirazoles y nitrilos no convencionales, como es el caso de la dicianamida ${ }^{57}$. Las conclusiones de este trabajo remarcan la importancia del centro metálico para la formación del ligando pirazolilamidino, ya que sólo se observan procesos de inserción para el manganeso, pero no para renio o molibdeno. El trabajo permitió acceder a nuevos ligandos pirazolilamidino coordinados a un centro metálico (Esquema 4) o como puente entre dos átomos metálicos, como se verá al final de este apartado (Esquema 5).

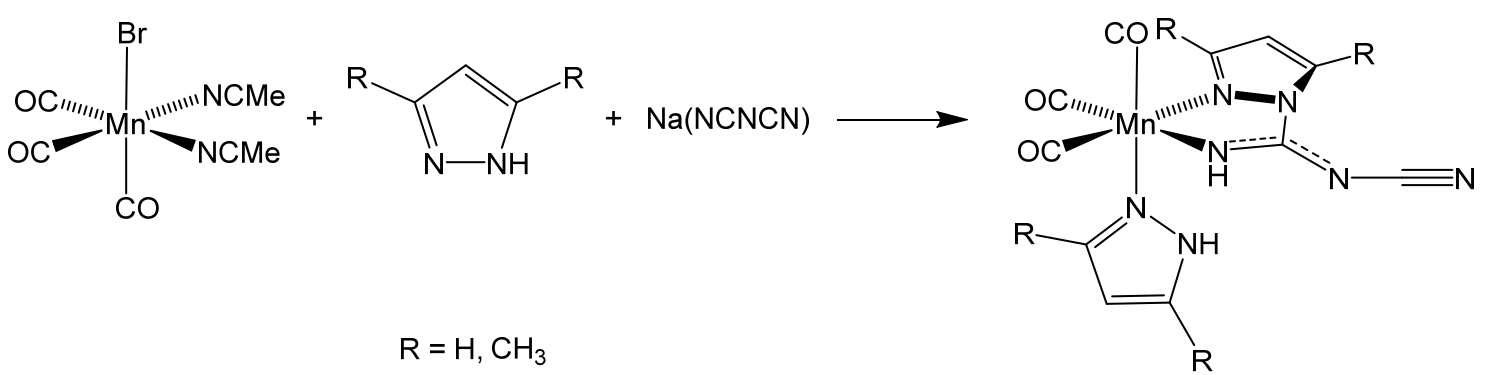

Esquema 4. Complejos con el ligando pirazolilamidino generados a partir de dicianamida y pirazoles.

Como se expuso anteriormente, el elemento para el que se encuentra la mayor variedad de ejemplos de pirazolilamidino coordinados es el rutenio. Tras el trabajo de McCleverty, al que se ha hecho referencia anteriormente, el grupo de Kollipara ${ }^{86,87}$ publicó varios trabajos en los 
que estudió la reactividad de $\eta^{6}$-arenos de rutenio(II) frente a pirazoles usando acetonitrilo como disolvente. Estos estudios permitieron concluir que el tamaño de los sustituyentes presentes en el resto $\eta^{6}$-areno es determinante para la formación del ligando pirazolilamidino. Así, cuando el resto es muy voluminoso $\left(\eta^{6}-\mathrm{C}_{6} \mathrm{Me}_{6}\right)$ solo se produce la coordinación del pirazol, mientras que la inserción ocurre con árenos menos voluminosos, como $\eta^{6}-p$-cimeno (Figura 9).

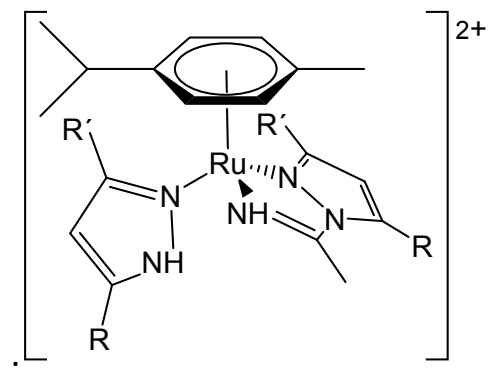

$$
\begin{aligned}
\mathrm{R}, \mathrm{R}^{\prime} & =\mathrm{H} \\
& =\mathrm{H}, \mathrm{CH}_{3} \\
& =\mathrm{C}_{6} \mathrm{H}_{5} \\
& =\mathrm{CH}_{3}, \mathrm{C}_{6} \mathrm{H}_{5} \\
& =\mathrm{OCH}_{3} \\
& =\mathrm{OC}_{2} \mathrm{H}_{5}
\end{aligned}
$$

Figura 9. Complejos con pirazolilamidino obtenidos por el grupo de Kollipara.

El grupo de Arion y Kepler publicó un par de artículos sobre compuestos de rutenio con el ligando pirazolilamidino. En el primero de ellos, de 2005, se presenta por primera vez un complejo con pirazolilamidino en el que el pirazol es un indazol ${ }^{88}$ y sugieren un mecanismo intramolecular para la reacción de formación de este pirazolilamidino de rutenio(II). Posteriormente en 2008, describieron los primeros ejemplos de rutenio(III) con un ligando pirazolilamidino coordinado. Como cabría esperar, con rutenio(III) la reacción ocurre mucho más rápidamente que con rutenio(II), ya que los altos estados de oxidación potencian la activación del nitrilo, ${ }^{89}$ de modo que la reacción para obtener el complejo mer, trans- $\left[\mathrm{RuCl}_{3}(\mathrm{indH})\left(N \mathrm{H}=\mathrm{C}(\mathrm{Me})\right.\right.$ ind $\left.\left.-\kappa^{2} N, N\right)\right]$ tarda solo unos segundos. Además en este artículo se describe por primera vez un compuesto que contiene dos ligandos pirazolilamidino coordinados a un único centro metálico (Figura 10). 

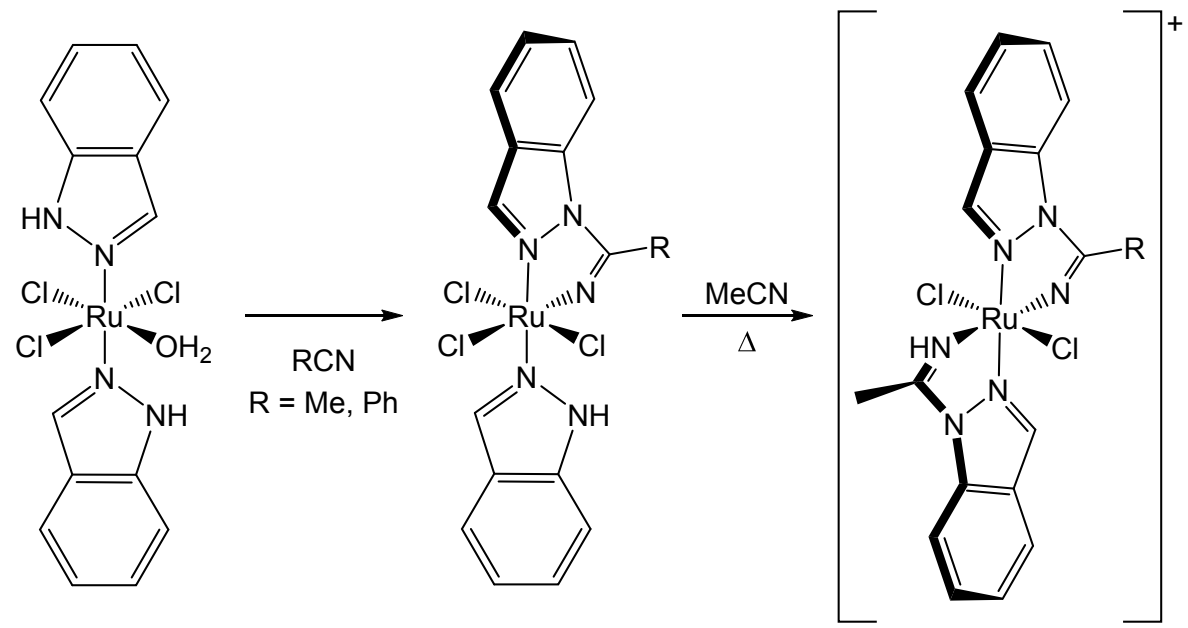

Figura 10. Primer compuesto con dos ligandos pirazolilamidino coordinados.

En 2012 el grupo de Chen describió el complejo $\left[\mathrm{Ru}(\mathrm{L})\left(\mathrm{NCCH}_{3}\right)\left(N \mathrm{H}=\mathrm{C}\left(\mathrm{CH}_{3}\right) \mathrm{dmpz}_{-}{ }^{2} N, N\right)\right] \mathrm{PF}_{6}(\mathrm{~L}=$ bis$(\mathrm{N}-$ piridilimidazonildenil $)$ metano $)$, que es el último ejemplo publicado hasta la fecha de un complejo de rutenio(II) con el ligando 3,5-dimetilpirazolilamidino. ${ }^{90}$

El grupo de Carmona et al. describió los únicos ejemplos descritos hasta la fecha de complejos con iridio que contienen el ligando pirazolilamidino coordinado: $\left[\operatorname{Ir}\left(\eta^{5}-\mathrm{C}_{5} \mathrm{Me}_{5}\right)(\mathrm{pzH})\left(N \mathrm{H}=\mathrm{C}(\mathrm{R}) \mathrm{pz}-\kappa^{2} N, N\right)\right]\left[\mathrm{BF}_{4}\right]_{2}(\mathrm{R}=\mathrm{Me}, \mathrm{Bz}){ }^{91}$

En cuanto al grupo 10, se han descrito complejos pirazolilamidino de níquel y de platino. En 2009, el grupo de Horng describió nuevos complejos bis(pirazolilamidino) de níquel, y además realizó un estudio sobre el papel que juega la presencia de contraiones en la reacción de formación de los complejos. ${ }^{92}$ Dos grupos diferentes han descrito complejos de platino con el ligando pirazolilamidino coordinado (Figura 11). Los complejos $\left[\mathrm{PtCl}_{2}\left(N H=\mathrm{C}(\mathrm{R}) \mathrm{pz}-\kappa^{2} N, N\right)\right](\mathrm{R}=\mathrm{Me}, \mathrm{Ph})$ fueron descritos por Cinellu et al. en $1989 .{ }^{93}$ Posteriormente, en 2006, Kukushkin y colaboradores publicaron un extenso estudio sobre la formación y reactividad de los ligandos pirazolilamidino, en el que discuten la influencia del centro metálico empleado (platino(II) vs. platino(IV)) y el tipo de pirazol. ${ }^{94}$

Hvastijová et al. estudiaron la reactividad de complejos de cobre con pirazoles y nitrilos de especiales características, como tricianometanuro $\left(\mathrm{C}(\mathrm{CN})_{3}{ }^{-}\right)$o dicianamida $\left(\mathrm{N}(\mathrm{CN})_{2}{ }^{-}\right)$, y plantearon la posible formación de complejos de cobre con el ligando pirazolilamidino. ${ }^{95}$ Años más tarde conseguirían cristalizar el complejo $\left[\mathrm{Cu}\left(\mathrm{NH}=\mathrm{C}(\mathrm{pz})\left(\mathrm{CH}(\mathrm{CN})_{2}\right)-\mathrm{K}^{2} N, N\right)_{2}\right]^{96}$, que es uno de los complejos pirazolilamidino de cobre descritos hasta la fecha, el único metal del grupo 11 para el que se conocen este tipo de complejos. Otro ejemplo con cobre es el 
compuesto [CuTp* $\left(\mathrm{NH}=\mathrm{C}\left(\mathrm{CH}_{3}\right) \mathrm{dmpz}-\mathrm{K}^{2} \mathrm{~N}, \mathrm{~N}\right.$ ] $] \mathrm{ClO}_{4},{ }^{97}$ donde el ligando pirazolilamidino se forma por la condensación del 3,5-dimetilpirazol (formado por la descomposición del NaTp*) con el acetonitrilo usado como disolvente.

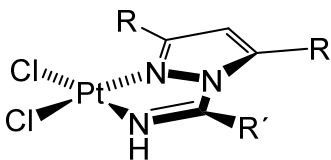

$\mathrm{R}=\mathrm{H} ; \quad \mathrm{R}^{\prime}=\mathrm{CH}_{3}, \mathrm{Et}, \mathrm{Ph}$

$\mathrm{R}=\mathrm{CH}_{3} ; \mathrm{R}^{\prime}=\mathrm{Et}$

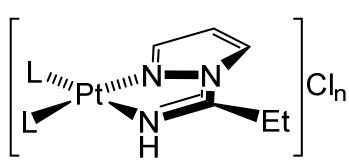

$\mathrm{L}=\mathrm{Cl}, \mathrm{pzH} ; \quad \mathrm{n}=1$

$\mathrm{L}=\mathrm{pzH}, \mathrm{pzH} ; \mathrm{n}=2$

Figura 11. Complejos pirazolilamidino de platino obtenidos hasta la fecha.

En todos los ejemplos revisados hasta el momento, el ligando pirazolilamidino forma únicamente complejos monometálicos en los que actúa como ligando quelato. Sin embargo, existen algunos ejemplos de complejos polimetálicos en los que el ligando pirazolilamidino se coordina como puente entre dos átomos metálicos. En este caso, el ligando pirazolilamidino puede exhibir dos formas de coordinación; la primera de ellas sería a causa de la deprotonación del grupo amino del amidino (Figura 12, a), y la segunda a través de la coordinación del grupo $\mathrm{R}$ del amidino a otro centro metálico (Figura 12, b).

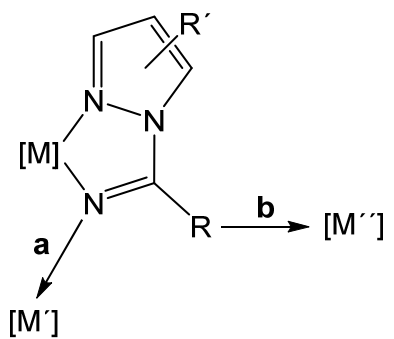

Figura 12. Coordinación del ligando pirazolilamidino como puente entre centros metálicos.

Existen dos ejemplos de complejos polimetálicos en los que el ligando pirazolilamidino actúa como puente tras la deprotonación del grupo NH. El primero de estos ejemplos fue publicado en 1987 por Alberts et al., quienes describieron por primera vez un ligando amidino coordinado a la vez como quelato y como puente entre dos átomos metálicos. ${ }^{98}$ Este inusual complejo agostico de dirutenio de 18 y 16 electrones, $\left[\mathrm{Ru}_{2} \mathrm{H}\left(\eta^{4}-\mathrm{C}_{8} \mathrm{H}_{12}\right)_{2}\left\{\mu-N=\mathrm{C}(\mathrm{Me}) \mathrm{pz}-\kappa^{2} N, N\right\}(\mu-\mathrm{pz})(\mu-\mathrm{H})\right]$ es el resultado de la fragmentación del 
bis(1-pirazolil)borato y del acoplamiento entre el pirazol y el acetonitrilo. El segundo ejemplo de este tipo de coordinación del ligando pirazolilamidino esta descrito por el grupo de Carmona y Oro y es el complejo tetranuclear $\left[\left\{\operatorname{Ir}\left(\eta^{5}-\mathrm{C}_{5} \mathrm{Me}_{5}\right)(\mu-\mathrm{pz})\left(\mu-N=\mathrm{C}(\mathrm{R}) \mathrm{pz}-\kappa^{2} N, N\right) \mathrm{Ag}_{2}\right]\left[\mathrm{BF}_{4}\right]_{2}(\mathrm{R}=\right.$ $\mathrm{Me}, \mathrm{Ph}, \mathrm{Bz}){ }^{91}$

El último ejemplo de este grupo de complejos polimetálicos corresponde a un complejo en el que el metal se coordina a través del grupo $\mathrm{R}$ del amidino. Este complejo, que fue sintetizado por nuestro grupo de investigación, se sintetiza a partir del complejo fac-[Mn $\left.(\mathrm{CO})_{3}(\mathrm{pzH})\left(\mathrm{NH}=\mathrm{C}(\mathrm{NCN}) \mathrm{pz}-\kappa^{2} N, N\right)\right]$, visto con anterioridad, por acoplamiento con fac-[MnBr$\left.(\mathrm{CO})_{3}(\mathrm{pzH})_{2}\right]($ Esquema 5$){ }^{57}$
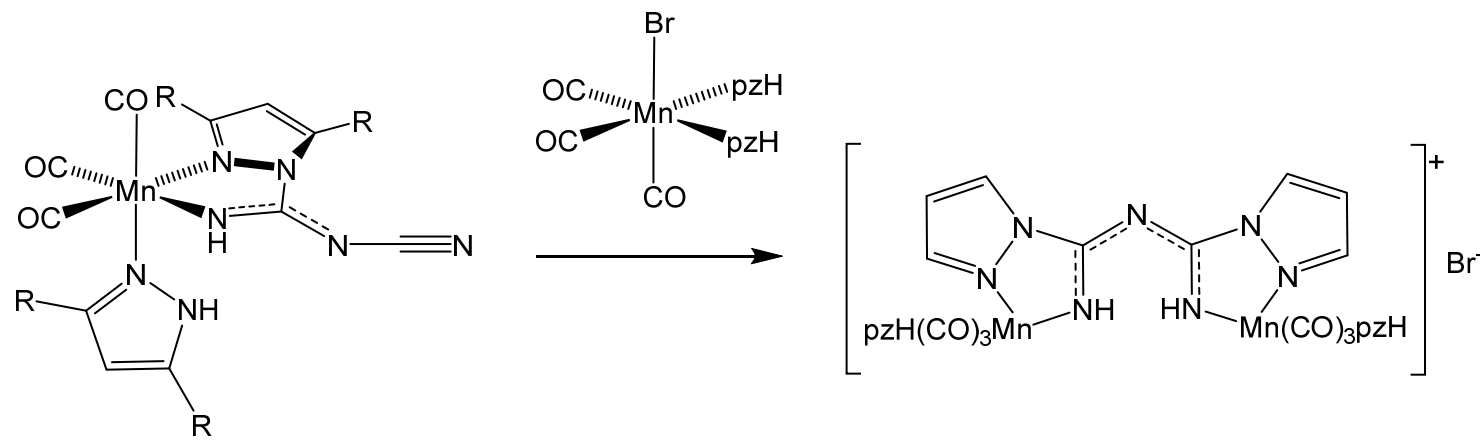

Esquema 5. Formación del complejo $\left[\left\{f a c-\mathrm{Mn}(\mathrm{CO}){ }_{3}(\mathrm{pz} \mathrm{H})\right\}_{2}\left(\mu-N \mathrm{H}=\mathrm{C}(\mathrm{pz}) \mathrm{NC}(\mathrm{pz})-\kappa^{4} N, N, N, N\right)\right] \mathrm{Br}$.

\subsubsection{Mecanismo de formación del ligando pirazolilamidino}

Dado el número relativamente bajo de complejos pirazolilamidino descritos previamente en la bibliografía, no sorprende que las aportaciones acerca del mecanismo de su formación sean también reducidas. Como se observa en el Esquema 3 (página 18) el pirazol posee dos átomos de nitrógeno diferentes, denominados comúnmente piridínico y pirrólico por su similitud a los grupos a los que hacen referencia. Las diferentes propiedades electrónicas de estos átomos hacen que se puedan proponer varias vías para el mecanismo de formación de los pirazolilamidino. Generalmente, en trabajos anteriores se ha asumido que la reacción transcurre mediante un ataque intramolecular del pirazol, que actúa como nucleófilo, sobre el nitrilo cuando ambos están coordinados en cis al centro metálico. ${ }^{77,91}$ Los grupos que hacen esta propuesta se basan en el mecanismo de formación de otros ligandos amidinos publicados con anterioridad. ${ }^{99,100}$ Este planteamiento presenta un problema conceptual ya que el nitrógeno tipo pirrolico del pirazol no presenta propiedades nucleófilas debido a que su par electrónico pertenece al sistema aromático. El grupo de Arion y Kepler plantearon una posible solución a 
este problema, postulando que la capacidad del metal para retener los electrones del nitrógeno coordinado aumenta la acidez del protón del N-H. La deprotonación de este grupo dejaría un par de electrones en el nitrógeno, que estarían disponibles para el ataque nucleófilo sobre el carbono del nitrilo, cuya capacidad electrófila ha sido simultáneamente incrementada debido también a la coordinación al centro metálico (Esquema 6, ruta a). ${ }^{88}$ Más tarde, el grupo de Kukushkin y Pompeiro propusieron que la reacción pueda transcurrir mediante un mecanismo intermolecular o intramolecular en función de la configuración electrónica del centro metálico. ${ }^{94}$ En el mecanismo intermolecular la reacción transcurriría a través del ataque del nitrógeno piridínico del pirazol al carbono del nitrilo, seguido de una transferencia de un protón (bien directamente del nitrógeno pirrólico del pirazol o mediante un mecanismo asistido por el disolvente) al grupo iminato coordinado al metal formado después de la adición (Esquema 6, ruta b).

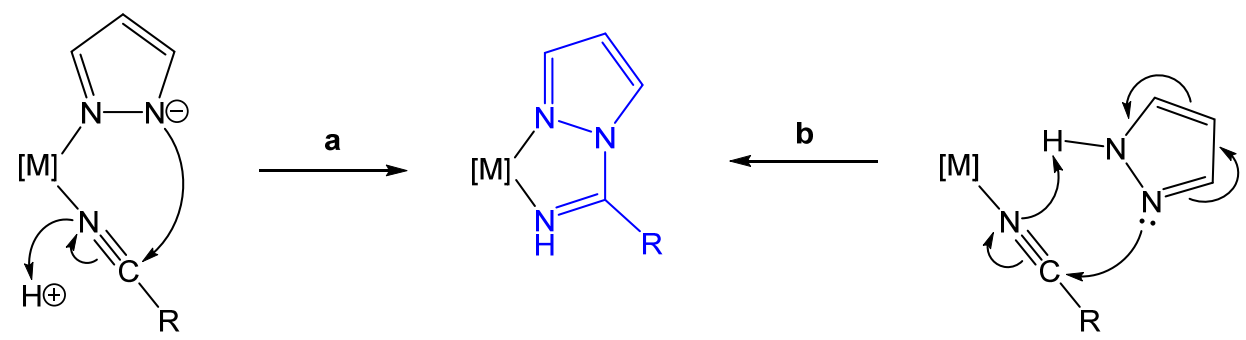

Esquema 6. Mecanismos intramolecular (a) e intermolecular (b) de la reacción de acoplamiento entre nitrilos y pirazoles.

Hasta el presente trabajo, la última aportación al mecanismo de formación de los ligandos pirazolilamidino había sido propuesta por el grupo de Horng en $2009 .{ }^{92}$ En ella se planteaba un mecanismo plausible para la deprotonación del pirazol coordinado al metal y para la transferencia del protón durante la reacción de acoplamiento. En esta propuesta la reacción de acoplamiento del nitrilo activado por coordinación y el pirazol transcurriría a través de una ruta asistida por medio de un enlace de hidrógeno con un anión presente en el medio de reacción. Esta propuesta se basa en el hecho de que la reacción es más rápida cuanto más fuerte es el enlace de hidrógeno entre el nitrógeno pirrólico del pirazol y el anión. El estado de transición propuesto se representa en el Figura 13. El anión catalítico, que actúa a la vez como ácido y como base, realiza la transferencia del protón del pirazol al nitrilo. 


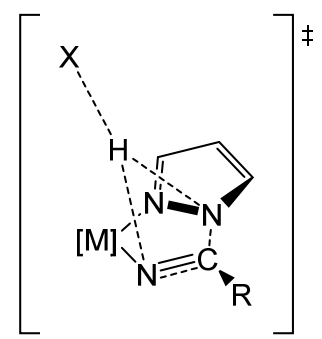

Figura 13. Estado de transición propuesto para la formación del ligando pirazolilamidino $(\mathrm{X}=$ anión catalítico).

\subsubsection{Ligandos amidino derivados de nucleobases}

Como se ha comentado en el apartado 2.1.2, el fragmento $f a c$-" $\operatorname{Re}(\mathrm{CO})_{3}$ " es de gran interés por su posible uso como marcador o sonda de biomoléculas. Por lo tanto la incorporación de sustratos biológicamente relevantes a este fragmento es uno de los grandes retos de la química inorgánica medicinal. Tras la experiencia adquirida previamente por nuestro grupo y los estudios realizados a lo largo de este trabajo sobre el mecanismo de formación de los ligandos pirazolilamidino y sobre las propiedades luminiscentes de sus complejos con el fragmento fac-" $\operatorname{Re}(\mathrm{CO})_{3}$ ", pareció una buena idea completar este trabajo coordinando al fragmento $f a c$-" $\operatorname{Re}(\mathrm{CO})_{3}$ " un ligandos amidino que contuviera un fragmento de interés biológico, como es una nucleobase, ya que esta reacción no había sido descrita con anterioridad para este fragmento metálico.

Se han descrito numerosos ejemplos en los que una nucleobase está coordinada directamente al metal. ${ }^{101-104}$ Pero cuando se considera la coordinación de biomoléculas a fragmentos del tipo $f a c$ - $\left[\operatorname{ReX}(\mathrm{CO})_{3}(\mathrm{~N}-\mathrm{N})\right]^{\mathrm{n}}$, (donde $\mathrm{N}-\mathrm{N}$ es un ligando quelato tipo diimina; y si $\mathrm{n}=0$ entonces $\mathrm{X}$ es un halógeno o pseudohalógeno mientras que $\mathrm{n}=+1$ cuando $\mathrm{X}$ es un ligando tipo piridina) hasta la fecha sólo se han descrito tres posibles estrategias. El primero de estos métodos consiste en que la biomolécula se encuentre enlazada directamente al ligando diimina. ${ }^{105-107}$ El ligando diimina participa en los estados emisivos de transferencia electrónica metal-ligando (MLCT) y la emisión MLCT de los complejos polipiridina de renio(I) es normalmente muy sensible a cambios es su entorno, por lo que el enlace con la biomolécula tendrá una fuerte influencia sobre las propiedades de emisión del complejo y podría actuar adecuadamente como sonda o marcador. Un segundo método sería la incorporación de la biomolécula al ligando tipo piridina. ${ }^{108-110}$ En este caso, como en el anterior, se espera un cambio en las propiedades luminiscentes del complejo. Por último, la tercera opción es enlazar la biomolécula en un ligando tridentado nitrógeno dador, en un complejo tipo $f a c-\left[\operatorname{Re}(\mathrm{CO})_{3}(\mathrm{~N}-\mathrm{N}-\mathrm{N})\right]((\mathrm{N}-\mathrm{N}-\mathrm{N})=$ ligando trípode nitrógeno dador $) .{ }^{111,112}$ 
El método que se propone en la presente memoria para incorporar biomoléculas al fragmento $f a c$-" $\operatorname{Re}(\mathrm{CO})_{3}$ " consiste en la formación de un nuevo ligando quelato amidino mediante la reacción de la nucleobase con un nitrilo previamente coordinado al metal. Presumiblemente este nuevo ligando quelato tendrá interesantes propiedades fotofísicas, como la mayoría de los complejos del fragmento $f a c$-" $\operatorname{Re}(\mathrm{CO})_{3}$ " que contienen coordinados ligandos de tipo diimina. Aunque hay numerosos estudios dedicados a la coordinación de nucleobases a fragmentos metálicos, ${ }^{101-104}$ hay muy pocos precedentes de reacciones de acoplamiento entre nitrilos coordinados a metales y nucleobases o sus derivados. A continuación se recopilan los pocos ejemplos existentes.

El único ejemplo de una reacción de acoplamiento entre una nucleobase y un nitrilo data de 1998. El grupo de Beauchamp hizo reaccionar el complejo cis-[ $\left.\mathrm{ReCl}_{4}(\mathrm{NCMe})_{2}\right]$ con $N^{6}, N^{6}$-dimetiladenina $\left(\mathrm{Me}_{2} \mathrm{Ad}\right)$ en acetonitrilo, obteniendo el complejo con el ligando amidino derivado del ataque del nitrógeno amínico $\mathrm{N}^{9}-\mathrm{H}$ sobre el carbono del nitrilo, $\left[\operatorname{ReCl}_{4}\left(N \mathrm{H}=\mathrm{C}\left(\mathrm{CH}_{3}\right) \mathrm{Me}_{2} \mathrm{Ad}-\kappa^{2} N, N\right)\right]$ (Figura 14, A). ${ }^{113}$

En el resto de los ejemplos que se pueden encontrar en la bibliografía la reacción de acoplamiento entre la nucleobase y el nitrilo se produce siempre con deprotonación de la nucleobase. Las reacciones de 1-metilcitosina $\left(\mathrm{MeCyH}_{2}\right)$ o 9-metiladenina (MeAd) con el hidroxocomplejo cis-[ $\left.\mathrm{PtL}_{2}(\mu-\mathrm{OH})\right]_{2}\left(\mathrm{NO}_{3}\right)_{2}\left(\mathrm{~L}=\mathrm{PPh}_{3}, \mathrm{PMePh}_{2} ; \mathrm{R}=\mathrm{CH}_{3}, \mathrm{Ph}\right)$ da lugar a los complejos $\quad c i s-\left[\mathrm{PtL}_{2}\left(N \mathrm{H}=\mathrm{C}(\mathrm{R})\left\{\mathrm{MeAd}(-2 \mathrm{H})-\kappa^{2} N, N\right\}\right)\right] \mathrm{NO}_{3} \quad($ Figura $\quad 14, \quad$ B) $\quad \mathrm{y}$ cis- $\left[\mathrm{PtL}_{2}\left(N \mathrm{H}=\mathrm{C}(\mathrm{R})\left\{\mathrm{MeCy}-\kappa^{2} N, N\right\}\right] \mathrm{NO}_{3}\right.$ (Figura 14, C). Los autores proponen que en primer lugar se produce la deprotonación del grupo amino de las nucleobases y a continuación tiene lugar la coordinación del nitrilo (que es a la vez disolvente) al centro metálico. Por tanto, el grupo amino deprotonado actúa como nucleófilo, atacando al carbono del nitrilo y produciéndose la reacción de acoplamiento.

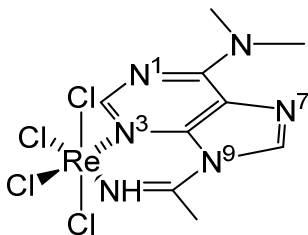

A

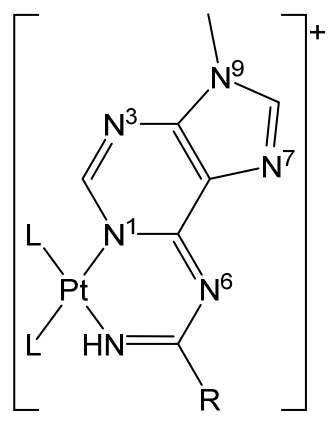

B

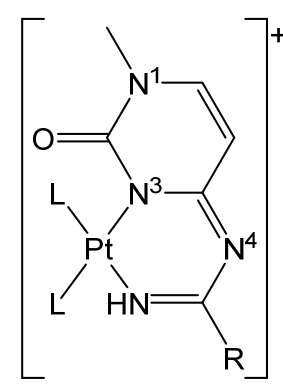

C

Figura 14. Representación de los ligandos amidinos derivados de nucleobases existentes en la bibliografía, $(\mathrm{L}=$ $\left.\mathrm{PPh}_{3}, \mathrm{PMePh}_{2} ; \mathrm{R}=\mathrm{CH}_{3}, \mathrm{Ph}\right)$. 
3. Objetivos 



\section{OBJETIVOS}

En la Tesis Doctoral de la Dra. Arroyo se pudo aislar un complejo de renio que contenía coordinado a la vez un ligando pirazol y un ligando acetonitrilo. Este complejo es un posible precursor en la formación del ligando pirazolilamidino, que sería el resultado de su acoplamiento. Los primeros experimentos llevados a cabo en aquel trabajo no permitieron obtener los datos suficientes sobre el mecanismo de esta reacción, por lo que el objetivo inicial de este trabajo fue completar aquellos estudios iniciales con un estudio exhaustivo y sistemático, con el objeto de elucidar en lo posible el mecanismo de la reacción. Ello permitiría además mejorar los rendimientos de este atractivo tipo de complejos e incluso la síntesis de nuevos pirazolilamidino hasta el momento inaccesibles.

Alcanzado el primer objetivo, la posibilidad de acceder de manera más selectiva a nuevos complejos pirazolilamidino con diferentes sustituyentes y el hecho de trabajar con el sistema $\mathrm{fac}_{\text {- }} \mathrm{Re}(\mathrm{CO})_{3}$ " nos llevó a plantearnos la posibilidad de estudiar sus propiedades fotofísicas y electroquímicas, que se verían completadas con un estudio teórico de los complejos obtenidos. Para ello fue determinante la estancia de esta doctoranda en el grupo del Prof. Michael Knorr, donde pude comenzar estos experimentos. Como se ha comentado en la Introducción, la ventaja evidente del ligando pirazolilamidino frente a las diiminas convencionales es que permite la obtención de los ligandos a la carta "in situ", evitando tediosos procesos sintéticos previos. El segundo objetivo sería por tanto hacer un estudio sistemático de la influencia de los sustituyentes del ligando pirazolilamidino y del resto de ligandos en la variación de las propiedades fotofísicas de los complejos obtenidos.

La posibilidad de obtener nuevos ligandos amidino nos llevó a completar este trabajo con nuevas reacciones de acoplamiento entre un nitrilo coordinado y nucleófilos diferentes al pirazol. De entre todas las posibilidades que se nos ofrecían nos pareció de interés estudiar la incorporación de nucleobases al fragmento $f a c$-" $\operatorname{Re}(\mathrm{CO})_{3}$ ”, ya que la luminiscencia de estos complejos permitiría la posible utilización de esta técnica para marcaje o sonda de las citadas nucleobases. Este sería el tercer y último objetivo del presente trabajo. 

4. Resumen de Resultados 



\section{RESUMEN DE RESULTADOS}

Los resúmenes de los resultados de este trabajo se presentan divididos de acuerdo a las publicaciones que lo componen.

\subsection{Estudio del mecanismo de formación del pirazolilamidino}

Como se ha señalado en la Introducción, la mayoría de los trabajos publicados hasta la fecha postulaban que la formación del ligando pirazolilamidino puede provenir de un complejo en el que tanto el pirazol como en nitrilo estuvieran coordinados en cis al centro metálico. Previamente en nuestro grupo de investigación se había obtenido el compuesto $f a c-\left[\operatorname{ReBr}(\mathrm{CO})_{3}(\mathrm{NCMe})(\mathrm{dmpzH})\right]{ }^{85}$ que cumple las características necesarias para ser un precursor adecuado para la formación del ligando pirazolilamidino. Por ello, pareció interesante centrar los estudios del mecanismo de formación de los pirazolilamidino en el uso de los complejos $f a c-\left[\operatorname{ReBr}(\mathrm{CO})_{3}(\mathrm{NCMe})\left(\mathrm{pz}^{*} \mathrm{H}\right)\right](\mathrm{pz} * \mathrm{H}=\mathrm{dmpzH}$, indH), como productos de partida.

Cuando se procedió al calentamiento de estos compuestos y monitorización de la reacción por RMN se obtuvieron los siguientes datos:

a) La reacción de inserción solo se produce a altas temperaturas $\left(\mathrm{T}^{\mathrm{a}} \approx 80{ }^{\circ} \mathrm{C}\right)$. A temperaturas inferiores solo se obtienen rendimientos muy bajos tras largos tiempo de reacción.

b) Cuando la reacción se lleva a cabo en disolventes distintos al acetonitrilo solo se obtienen pequeñas cantidades del producto de acoplamiento. Este es un resultado esperado ya que las condiciones de reacción que desfavorezcan la coordinación del nitrilo al metal impiden la reacción de acoplamiento. Sin embargo, como se ve más abajo, el desarrollo de este trabajo nos ha permitido finalmente llevar a cabo reacciones de acoplamiento en disolventes diferentes al nitrilo coordinado.

c) $\mathrm{Al}$ calentar durante 12 horas los complejos $f a c-\left[\operatorname{ReBr}(\mathrm{CO})_{3}(\mathrm{NCMe})\left(\mathrm{pz}^{*} \mathrm{H}\right)\right](\mathrm{pz} * \mathrm{H}=$ dmpzH, indzH) en $\mathrm{CD}_{3} \mathrm{CN}$ a $80^{\circ} \mathrm{C}$ se obtienen mezclas en las que están presentes diferentes complejos (Esquema 7): el propio producto de partida $f a c$ - $\left[\operatorname{ReBr}(\mathrm{CO})_{3}\left(\mathrm{NCCD}_{3}\right)(\mathrm{pz} * \mathrm{H})\right](\mathbf{A})$, el producto de inserción buscado $f a c-\left[\operatorname{ReBr}(\mathrm{CO})_{3}\left(N \mathrm{H}=\mathrm{C}\left(\mathrm{CD}_{3}\right) \mathrm{pz}^{*}-\kappa^{2} N, N\right)\right] \quad$ (B), y otros subproductos, como son $f a c-\left[\operatorname{ReBr}(\mathrm{CO})_{3}\left(\mathrm{pz}^{*} \mathrm{H}\right)_{2}\right]$ (C) y $f a c-\left[\operatorname{ReBr}(\mathrm{CO})_{3}\left(\mathrm{NCCD}_{3}\right)_{2}\right]$ (D). También se detectan otras señales minoritarias que corresponden a los complejos catiónicos 
$f a c-\left[\operatorname{Re}(\mathrm{CO})_{3}(\mathrm{NCMe})\left(N \mathrm{H}=\mathrm{C}\left(\mathrm{CD}_{3}\right) \mathrm{pz}^{*}-\kappa^{2} N, N\right)\right]^{+}$

$f a c-\left[\operatorname{Re}(\mathrm{CO})_{3}\left(\mathrm{pz}^{*} \mathrm{H}\right)\left(\mathrm{NH}=\mathrm{C}\left(\mathrm{CD}_{3}\right) \mathrm{pz}^{*}-\kappa^{2} N, N\right)\right]^{+}(\mathbf{F})$, cuya presencia no es sorprendente ya que la sustitución del halógeno por un acetonitrilo a altas temperaturas es un proceso bien conocido para compuestos de renio y manganeso. ${ }^{114,115}$

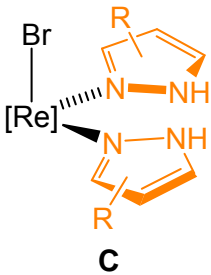

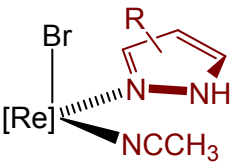

A

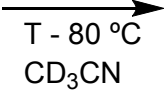
$\mathrm{CD}_{3} \mathrm{CN}$

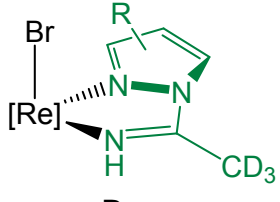

B

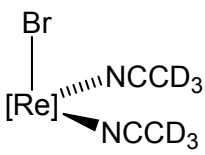

D

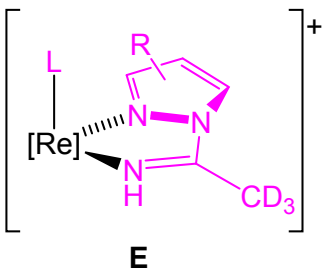

$\mathrm{L}=\mathrm{NCCH}_{3}, \mathrm{pz}^{*} \mathrm{H}$

Esquema 7. Complejos detectados al calentar el complejo $\mathbf{A}$ en acetonitrilo deuterado a $\mathrm{T}^{\mathrm{a}}=80^{\circ} \mathrm{C}$ durante $12 \mathrm{~h}$. $\left([\mathrm{Re}]=f a c-\left[\operatorname{Re}(\mathrm{CO})_{3}\right] ; \mathrm{pz} * \mathrm{H}=\mathrm{dmpzH}\right.$, indzH $)$.

La presencia de estos compuestos catiónicos en la mezcla de reacción es indicativa de que el paso clave de la reacción de inserción de los complejos neutros se podría producir a través de sus derivados catiónicos. Esta suposición tiene sentido ya que en dichos complejos el nitrilo va a poseer un carácter más electrófilo y por lo tanto será más susceptible al ataque nucleófilo del pirazol. A la vez, esta carga positiva en el metal incrementa el carácter ácido del hidrógeno del NH en el pirazol, aumentando la nucleofilia del átomo de nitrógeno del pirazolato formado (Esquema 6, a). Estos hechos llevaron a proponer una posible vía para esta reacción (Esquema 8) en la que se produciría en primer lugar la descoordinación del bromuro del metal (paso I); a continuación sucedería el paso determinante de la reacción que es la formación del ligando pirazolilamidino (paso II), una vez formado dicho ligando el último paso sería la vuelta a la esfera de coordinación del ión bromuro (paso III). 


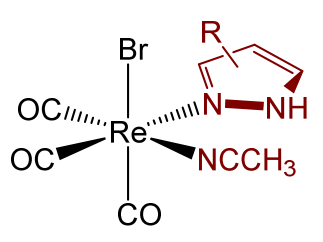

1

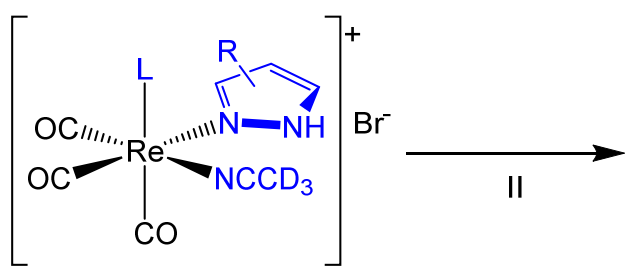

$\mathrm{T}-80^{\circ} \mathrm{C}$ $\mathrm{CD}_{3} \mathrm{CN}$<smiles>CC(C)C</smiles>

$$
L=p z^{*} H, C D_{3} C N ; p z^{*} H=d m p z H, \text { indzH }
$$

Esquema 8. Vía sintética propuesta para la síntesis de pirazolilamidinos neutros a través de sus derivados catiónicos.

Debido a la complejidad del sistema con complejos neutros se decidió simplificar el sistema abordando el estudio del paso en el que realmente se produce el acoplamiento (Esquema 8, paso II). Para ello se sintetizaron los complejos catiónicos $f a c-\left[\operatorname{Re}(\mathrm{CO})_{3}(\mathrm{NCMe})(\mathrm{pz} * \mathrm{H})_{2}\right]^{+}$ ( $\mathrm{pz} * \mathrm{H}=\mathrm{pzH}, \mathrm{dmpzH}$, indzH) y se estudió su comportamiento.

El seguimiento por RMN del calentamiento de los complejos $f a c-\left[\operatorname{Re}(\mathrm{CO})_{3}(\mathrm{NCMe})\left(\mathrm{pz}^{*} \mathrm{H}\right)_{2}\right]^{+}(\mathrm{pz} * \mathrm{H}=\mathrm{pzH}, \mathrm{dmpzH}$, indzH) en acetonitrilo y condujo a los siguientes resultados:

a) $\mathrm{Su}$ conversión en los complejos pirazolilamidino $f a c-\left[\operatorname{Re}(\mathrm{CO})_{3}\left(\mathrm{pz}^{*} \mathrm{H}\right)\left(N \mathrm{H}=\mathrm{C}(\mathrm{Me}) \mathrm{pz}^{*}-\kappa^{2} N, N\right)\right]^{+}$se produce limpiamente sin ningún subproducto, lo que indica que se trata de un proceso intramolecular (Figura 15). 


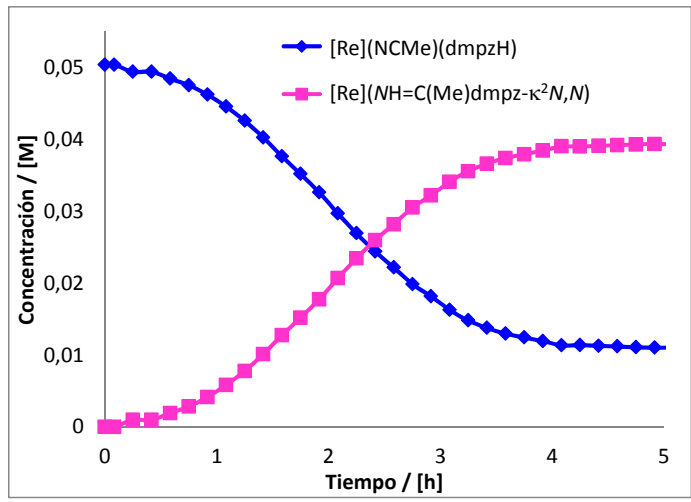

Figura 15. Seguimiento por RMN de la conversión del complejo $f a c-\left[\operatorname{Re}(\mathrm{CO})_{3}(\mathrm{NCMe})(\mathrm{dmpzH})_{2}\right] \mathrm{OTf}$ en $f a c-\left[\operatorname{Re}(\mathrm{CO})_{3}(\mathrm{dmpzH})\left(N \mathrm{H}=\mathrm{C}(\mathrm{Me}) \mathrm{dmpz}^{2} \kappa^{2} N, N\right)\right] \mathrm{OTf}$ al calentar a $40{ }^{\circ} \mathrm{C}$ en acetonitrilo deuterado. $[\mathrm{Re}]=$ $f a c-\left[\operatorname{Re}(\mathrm{CO})_{3} \mathrm{dmpzH}\right] \mathrm{OTf}$.

b) Se determinó que la reacción ocurre a través de un proceso intramolecular en el que el pirazol y el nitrilo están coordinados en cis al centro metálico. Esta suposición se pudo demostrar cuando se hizo reaccionar un equivalente de $f a c$ - $\left[\mathrm{Re}(\mathrm{CO})_{3}(\mathrm{NCMe})(\mathrm{pz} * \mathrm{H})_{2}\right]^{+}$con un equivalente de un pirazol diferente al coordinado, obteniéndose siempre únicamente el producto de acoplamiento con el pirazol que estaba previamente coordinado. El resultado fue el mismo cuando se llevaron a cabo las reacciones del complejo con dmpzH coordinado en presencia de indzH, así como la contraria, es decir del complejo con indzH coordinado en presencia de dmpzH libre.

c) Se pudo determinar la temperatura óptima para que la reacción de acoplamiento conduzca únicamente al complejo pirazolilamidino buscado. A temperaturas inferiores a $40^{\circ} \mathrm{C}$ la reacción de acoplamiento no tiene lugar. Cuando la temperatura es superior a $60^{\circ} \mathrm{C}$, después de la formación del complejo $f a c-\left[\operatorname{Re}(\mathrm{CO})_{3}\left(\mathrm{pz}^{*} \mathrm{H}\right)\left(N \mathrm{H}=\mathrm{C}(\mathrm{Me}) \mathrm{pz}^{*}-\kappa^{2} N, N\right)\right]^{+}$se produce una reacción secundaria en la que el $\mathrm{pz}^{*} \mathrm{H}$ coordinado es sustituido por una molécula de acetonitrilo del disolvente (Esquema 9). Este proceso secundario vendrá favorecido por la mayor temperatura de reacción y por el fuerte carácter cis-labilizador de los ligandos pirazolilamidino. Por lo tanto el intervalo óptimo de temperaturas se vería comprendido entre los 40 y $60^{\circ} \mathrm{C}$.

d) La reacción de inserción en este tipo de complejos es un proceso de equilibrio químico entre los productos inicial y final. Para comprobarlo se calentaron los complejos pirazolilamidino finales $f a c-\left[\operatorname{Re}(\mathrm{CO})_{3}(\mathrm{pz} * \mathrm{H})\left(N \mathrm{H}=\mathrm{C}(\mathrm{Me}) \mathrm{pz}^{*}-\kappa^{2} N, N\right)\right]^{+}$obteniéndose en todos los casos una mezcla de dicho compuesto y de complejo inicial $f a c-\left[\operatorname{Re}(\mathrm{CO})_{3}(\mathrm{NCMe})(\mathrm{pz} * \mathrm{H})_{2}\right]$ en una proporción igual a la de la reacción directa. 


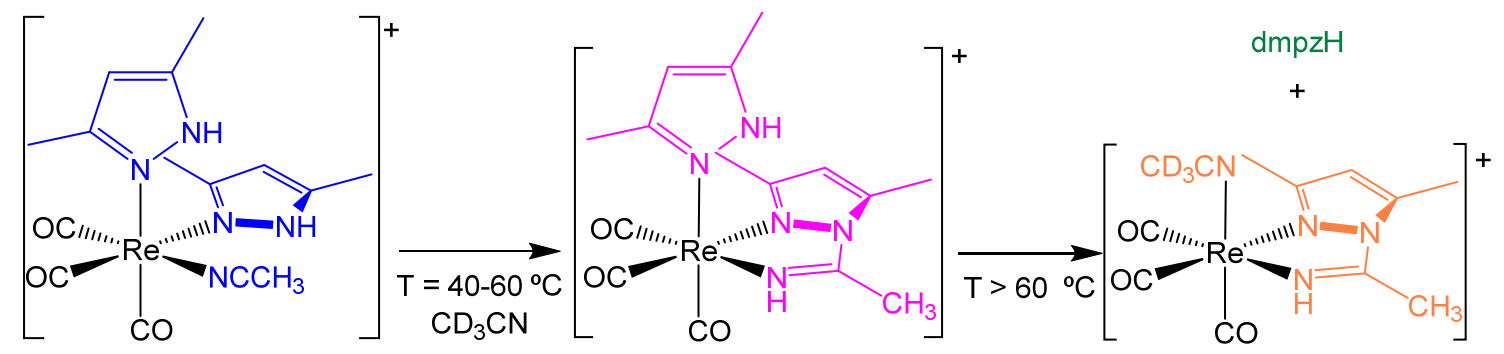

Esquema 9. Reacción de acoplamiento en función de la temperatura.

e) No es necesario que la reacción de inserción se produzca usando acetonitrilo como disolvente, también tiene lugar en disolventes no coordinantes como nitrometano o tetrahidrofurano.

La conclusión final de los experimentos reseñados es que los complejos catiónicos $f a c-\left[\operatorname{Re}(\mathrm{CO})_{3}(\mathrm{NCMe})\left(\mathrm{pz}^{*} \mathrm{H}\right)_{2}\right]^{+}$son los únicos precursores de los correspondientes complejos pirazolilamidino, y que este es un proceso reversible e intramolecular. Para obtener más información acerca de este mecanismo de acoplamiento, decidimos abordar un estudio sistemático para determinar el papel que juegan todos los posibles factores que afectan a la reacción, es decir: temperatura, naturaleza del pirazol y del anión presente como contraión y disolvente. Como los anteriores, este estudio se llevó a cabo siguiendo las reacciones por RMN y como se ve a continuación, nos permitió encontrar un catalizador para esta reacción.

a) Un estudio dentro el rango de temperaturas donde no tienen lugar reacciones secundarias permitió determinar que las temperaturas moderadas favorecen el equilibrio a favor del complejo que contiene el ligando pirazolilamidino.

b) En idénticas condiciones de reacción se ha observado que el orden de velocidad de reacción varía en función del pirazol coordinado en el complejo de partida de la siguiente manera: indzH $>$ pzH $>$ dmpzH. Este hecho esta en correlación con la acidez del nitrógeno pirrólico del pirazol que sigue el mismo orden, ${ }^{116,117}$ y estaría en consonancia con el mecanismo intramolecular que se expuso anteriormente en el que se producía la deprotonación del NH del pirazol como primer paso para la reacción de inserción (Esquema 6, ruta a).

c) Tomando como referencia un trabajo previamente publicado ${ }^{92}$ se estudió la influencia del contraión en la velocidad de reacción. Se sintetizaron los complejos 
$f a c-\left[\operatorname{Re}(\mathrm{CO})_{3}(\mathrm{NCMe})\left(\mathrm{pz}^{*} \mathrm{H}\right)_{2}\right] \mathrm{A}\left(\mathrm{A}=\mathrm{BF}_{4}^{-}, \mathrm{ClO}_{4}^{-}, \mathrm{OTf}^{-}\right)$, y se estudiaron las diferentes velocidades de reacción en cada caso $\left(\mathrm{OTf}^{-}>\mathrm{ClO}_{4}^{-}>\mathrm{BF}_{4}^{-}\right)$, que no se pudieron relacionar con ninguna propiedad (basicidad, capacidad dadora) del contraión presente en la disolución. Este hecho nos llevó proponer que el factor que aceleraba las reacciones no estaba en la propia naturaleza del anión, sino en alguna impureza que catalizase el proceso de inserción. De la bibliografía se deduce que algunas de las reacciones de adición de nitrilos activadas por metales están catalizadas por bases. La medida del pH de una disolución $1 \mathrm{M}$ de las sales en disolución, nos permitió concluir que la mayor velocidad estaba relacionada con una mayor presencia de impurezas básicas en las sales empleadas (OTf $11.1>\mathrm{ClO}_{4}^{-} 9.3>\mathrm{BF}_{4}^{-}$2.6). Cuando el experimento se repitió con sales puras $(\mathrm{pH}=7$ de disoluciones $1 \mathrm{M})$, no se produjo ningún efecto sobre la reacción. Por tanto, se repitieron las reacciones en presencia de cantidades catalíticas de bases, ácidos y agua. El resultado de estos experimentos fue una evidente aceleración del proceso en presencia de bases $(0.5 \%$ de $\mathrm{NaOH}$ en una disolución acuosa 0.02 M), mientras que la presencia de ácidos o el medio acuoso neutro tiene una menor y similar incidencia sobre la velocidad de reacción (Figura 16). En presencia de una cantidad catalítica de base las reacciones de formación de los complejos pirazolilamidino son prácticamente instantáneas para los complejos catiónicos y muy rápidas para los complejos neutros. Conviene recordar aquí que los bromocomplejos neutros no conducían limpiamente a los complejos pirazolilamidino por simple calentamiento. Estos datos permiten concluir por tanto, que el proceso de formación de los pirazolilamidino es un proceso catalizado por bases. Este hecho es de especial interés para la síntesis de los complejos neutros ya que permite suavizar en gran medida las condiciones de reacción lo que permite la práctica desaparición de productos secundarios y un incremento en el rendimiento de la reacción. En cuanto al papel que juega el medio básico en la catálisis, parece evidente que es facilitar la deprotonación del pirazol coordinado (Esquema 6, a, página 26).

d) La rapidez con que se producen las reacciones en presencia de una cantidad catalítica de base nos llevó a reexaminar la posibilidad de llevar a cabo estas reacciones en disolventes diferentes al acetonitrilo. Para los compuestos neutros, las reacciones de inserción sólo se pueden llevar a cabo con éxito en acetonitrilo, pero las inserciones de los complejos catiónicos se pueden realizar en otros disolventes, como nitrometano o acetona de forma prácticamente cuantitativa, muy rápida y a temperatura ambiente. 


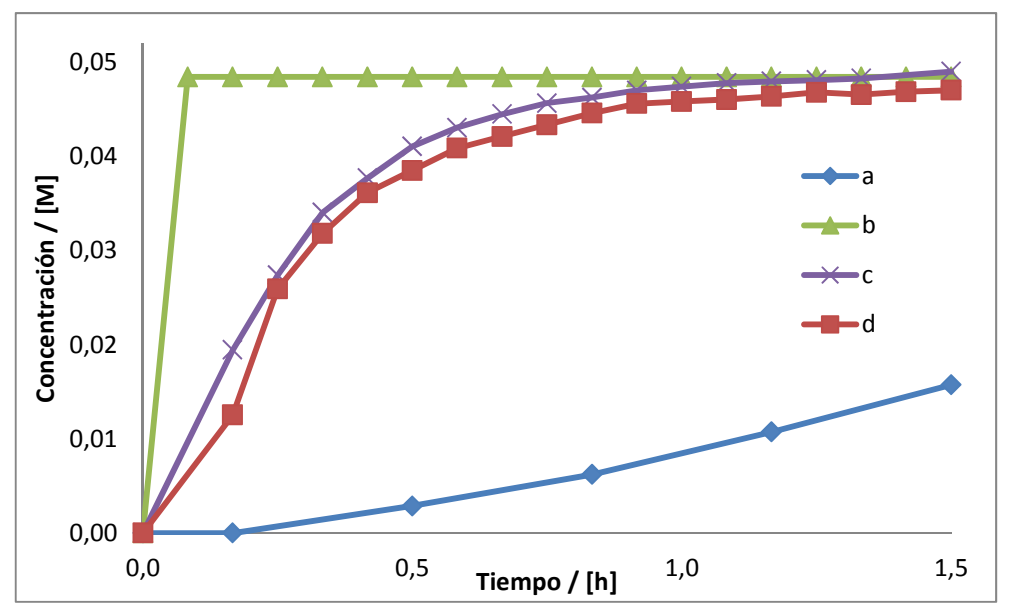

Figura 16. Representación de las concentraciones observadas cuando $f a c-\left[\operatorname{Re}(\mathrm{CO})_{3}(\mathrm{NCMe})(\mathrm{dmpzH})_{2}\right]^{+}(\mathbf{a})$ se calienta $40{ }^{\circ} \mathrm{C}$, o se añade (b) $6.2 \mu \mathrm{L}$ de $\mathrm{NaOH}$ (aq) al 0,5\%, (c) $6.2 \mu \mathrm{L}$ de $\mathrm{HBF}_{4}$ (aq) al 0.5\%, (d) $6.2 \mu \mathrm{L}$ de $\mathrm{H}_{2} \mathrm{O}$. Todas las reacciones se llevaron a cabo en $\mathrm{CD}_{3} \mathrm{CN}$. $0.05 \mathrm{M}$ es el rendimiento del $100 \%$.

\subsection{Estudio de las propiedades fotofísicas de los complejos}

Como se ha señalado en la Introducción, en la bibliografía se pueden encontrar multitud de ligandos del tipo diimina coordinados al fragmento $f a c$-“Re(CO) 3 ”, sin embargo uno de los retos pendientes en este campo es encontrar un método de síntesis accesible para este tipo de ligandos. Los ligandos pirazolilamidino podrían son una buena opción, debido a la posibilidad de sintetizarlos "in situ" y la facilidad para variar las propiedades del complejo simplemente variando el pirazol o el nitrilo. Por ello nos propusimos abordar la síntesis de una familia de compuestos en los que se variaba el pirazol, el sustituyente del nitrilo o el "sexto" ligando que acompaña a los carbonilos y al quelato nitrógeno dador, para llevar a cabo un estudio sobre la variación de sus propiedades fotofísicas y electroquímicas. También se realizó un estudio teórico sobre la composición de los orbitales moleculares de los complejos para justificar los resultados experimentales.

Para poder evaluar la contribución de cada uno de los fragmentos del pirazolilamidino se sintetizó la familia de compuestos que aparece en la Tabla 1. Como se comentó en el apartado anterior, para la síntesis de complejos pirazolilamidino neutros la catálisis básica aporta grandes ventajas, ya que reduce el tiempo de reacción y permite el uso de condiciones más suaves de reacción. Por ello este método resultó muy efectivo para la síntesis de los complejos 3 - 8 (Tabla 1). En el caso de los complejos 1 y 2 (Tabla 1), este método no resulto ventajoso ya que el equilibrio químico de la reacción esta desplazado hacia los complejos $f a c-\left[\operatorname{ReCl}(\mathrm{CO})_{3}(\mathrm{pz} * \mathrm{H})_{2}\right]\left(\mathrm{pz}^{*} \mathrm{H}=\mathrm{pzH}, \mathrm{dmpzH}\right)$. 
Tabla 1. Complejos con el ligando pirazolilamidino sintetizados para el estudio de sus propiedades fotofísicas. ${ }^{\text {a }} \mathrm{Se}$ presentan como sales de $\mathrm{ClO}_{4}{ }^{-}+\dagger$ Complejos sintetizados para esta memoria.

\begin{tabular}{cccccc}
\hline & $\mathbf{n}$ & $\mathbf{L}$ & $\mathbf{p z}-\mathbf{R}$ & $\mathbf{R}$ & ref. \\
\hline $\mathbf{1}$ & 0 & $\mathrm{Cl}$ & $\mathrm{pz}$ & $\mathrm{Me}$ & $\dagger$ \\
$\mathbf{2}$ & 0 & $\mathrm{Cl}$ & $\mathrm{dmpz}$ & $\mathrm{Me}$ & $\dagger$ \\
$\mathbf{3}$ & 0 & $\mathrm{Cl}$ & $\mathrm{indz}$ & $\mathrm{Me}$ & $\dagger$ \\
$\mathbf{4}$ & 0 & $\mathrm{Br}$ & $\mathrm{pz}$ & $\mathrm{Me}$ & 85 \\
$\mathbf{5}$ & 0 & $\mathrm{Br}$ & $\mathrm{dmpz}$ & $\mathrm{Me}$ & 85 \\
$\mathbf{6}$ & 0 & $\mathrm{Br}$ & indz & $\mathrm{Me}$ & $\dagger$ \\
$\mathbf{7}$ & 0 & $\mathrm{Br}$ & $\mathrm{dmpz}$ & $\mathrm{Ph}$ & $\dagger$ \\
$\mathbf{8}$ & 0 & $\mathrm{Br}$ & indz & $\mathrm{Ph}$ & $\dagger$ \\
$\mathbf{9}^{\mathrm{a}}$ & 1 & $\mathrm{NCMe}$ & $\mathrm{dmpz}$ & $\mathrm{Me}$ & 85 \\
$\mathbf{1 0}^{\mathrm{a}}$ & 1 & $\mathrm{NCMe}$ & indz & $\mathrm{Me}$ & $\dagger$ \\
$\mathbf{1 1}^{\mathrm{a}}$ & 1 & $\mathrm{dmpzH}$ & $\mathrm{dmpz}$ & $\mathrm{Me}$ & 85 \\
$\mathbf{1 2}^{\mathrm{a}}$ & 1 & indzH & indz & $\mathrm{Me}$ & $\dagger$ \\
\hline
\end{tabular}

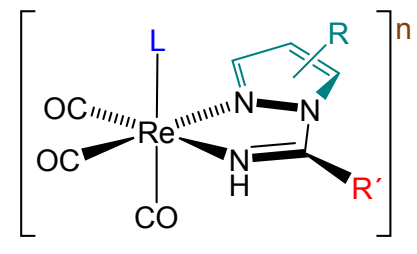

\subsubsection{Estudios fotofisicos}

Uno de los principales objetivos de este trabajo es determinar la influencia de los sustituyentes en las propiedades luminiscentes de los complejos pirazolilamidino, para ello se procedió a medir los espectros de absorción y de emisión de los complejos anteriormente citados. Todos los complejos presentan espectros de absorción con máximos entre 230 y $300 \mathrm{~nm}$ y una cola que llega a $480 \mathrm{~nm}$. Los espectros de absorción de los complejos coinciden cualitativamente con el de otros complejos $f a c$-" $\operatorname{Re}(\mathrm{CO})_{3}$ " ya publicados, ${ }^{118-120}$ debido a ello se asignaron las bandas de absorción de manera análoga que en estos casos. Las bandas de más alta energía (230 - $300 \mathrm{~nm}$ ) se asignan a transiciones dentro del ligando (IL), mientras que las bandas de menor energía corresponderían a una mezcla de transiciones metal - ligando (MLCT), ligando - ligando (LLCT) y halógeno - ligando (XLCT).

El estudio detallado de los espectros de emisión de los complejos permite llegar a las siguientes conclusiones:

a) La introducción de grupos dadores en el esqueleto del pirazol produce un débil desplazamiento de $\lambda_{\mathrm{em}}$ a valores más bajos. Este hecho se observa en los ejemplos en los que los hidrógenos en las posiciones 3 y 5 del pirazol son sustituidos por metilos.

b) La sustitución del sustituyente del grupo amidino de un grupo metilo por un grupo fenilo produce un aumento de $\lambda_{\mathrm{em}}$. 
c) La sustitución de un bromo por un cloro produce un efecto hipsocrómico. Este es el perfil típico de la emisión desde estados excitados MLCT/XLCT. ${ }^{107}$

d) La sustitución en el "sexto" ligando de un ligando aniónico $\sigma$-donador/ $\pi$-donador (como un halógeno) por un ligando neutro $\sigma$-donador (como acetonitrilo o pirazol) produce un marcado desplazamiento hacia el azul, produciéndose a la vez un incremento en el valor de la constante de desexcitación no radiativa. Esto se debe a la generación de un camino de desexcitación vibracional no emisivo, y se comprueba por la fuerte caída en el valor del tiempo de vida. El hecho contrario se da cuando en el complejo fac- $\left[\operatorname{Re}(\mathrm{CO})_{3}(\operatorname{indzH})\left(N \mathrm{H}=\mathrm{C}(\mathrm{Me}) \operatorname{indz}_{-} \kappa^{2} N, N\right)\right]^{+}$el indazol coordinado es sustituido por acetonitrilo. En este caso una disminución considerable de la constante no-radiativa da lugar a un incremento sustancial en el tiempo de vida medio.

e) Todos los complejos son fosforescentes y el valor de su rendimiento cuántico coincide con el de otros complejos previamente descritos con el fragmento $f a c$-" $\operatorname{Re}(\mathrm{CO})_{3}$ ".

\subsubsection{Estudios electroquímicos}

Un estudio en profundidad de la electroquímica de los complejos de la Tabla 1 (página 42) ha permitido correlacionar las propiedades fotofísicas con la electroquímica de los complejos y caracterizar los productos que resultan de los procesos rédox. El estudio de las propiedades electroquímicas de los complejos permite proponer los procesos electroquímicos recogidos en el Esquema 10, que se resumen a continuación. Se observa una onda catiónica irreversible entre $-1.80 \mathrm{y}-2.25 \mathrm{~V}$, que se asigna a una reducción centrada en el pirazolilamidino. Este proceso está más favorecido para los complejos indazolilamidino que para sus análogos con pirazol o 3,5-dimetilpirazol. Este hecho está en consonancia con lo obtenido en los cálculos teóricos en los que se observa que el LUMO, principalmente formado por la contribución del grupo amidino, es más estable para los indazolilamidino.

En los voltamperogramas de los compuestos neutros se observan dos procesos de oxidación, siendo el primero de ellos irreversible mientras que el segundo es reversible. En los complejos catiónicos solo se observa el segundo de ellos, es decir el proceso de oxidación reversible. Debido a que estos potenciales de oxidación son independientes del ligando, el proceso se considera una oxidación centrada en el metal. Con los datos obtenidos en los voltamperogramas se propone el proceso que se detalla en el Esquema 10. En los complejos neutros lo primero que ocurre es una oxidación centrada en el metal que lleva a la formación de la especia monocationica de 17 electrones, A. La sustracción de un electrón del HOMO produce 
la labilización del enlace Re-X, lo que conduce a la posterior disociación del halógeno y a la consiguiente coordinación de una molécula de acetonitrilo del disolvente para dar el compuesto B. Este complejo de renio(II) se reduce por reacción con el halogenuro liberado para generar el catión de renio(I) de 18 electrones $\mathbf{C}$, que a su vez se oxida reversiblemente para dar $\mathbf{D}$.

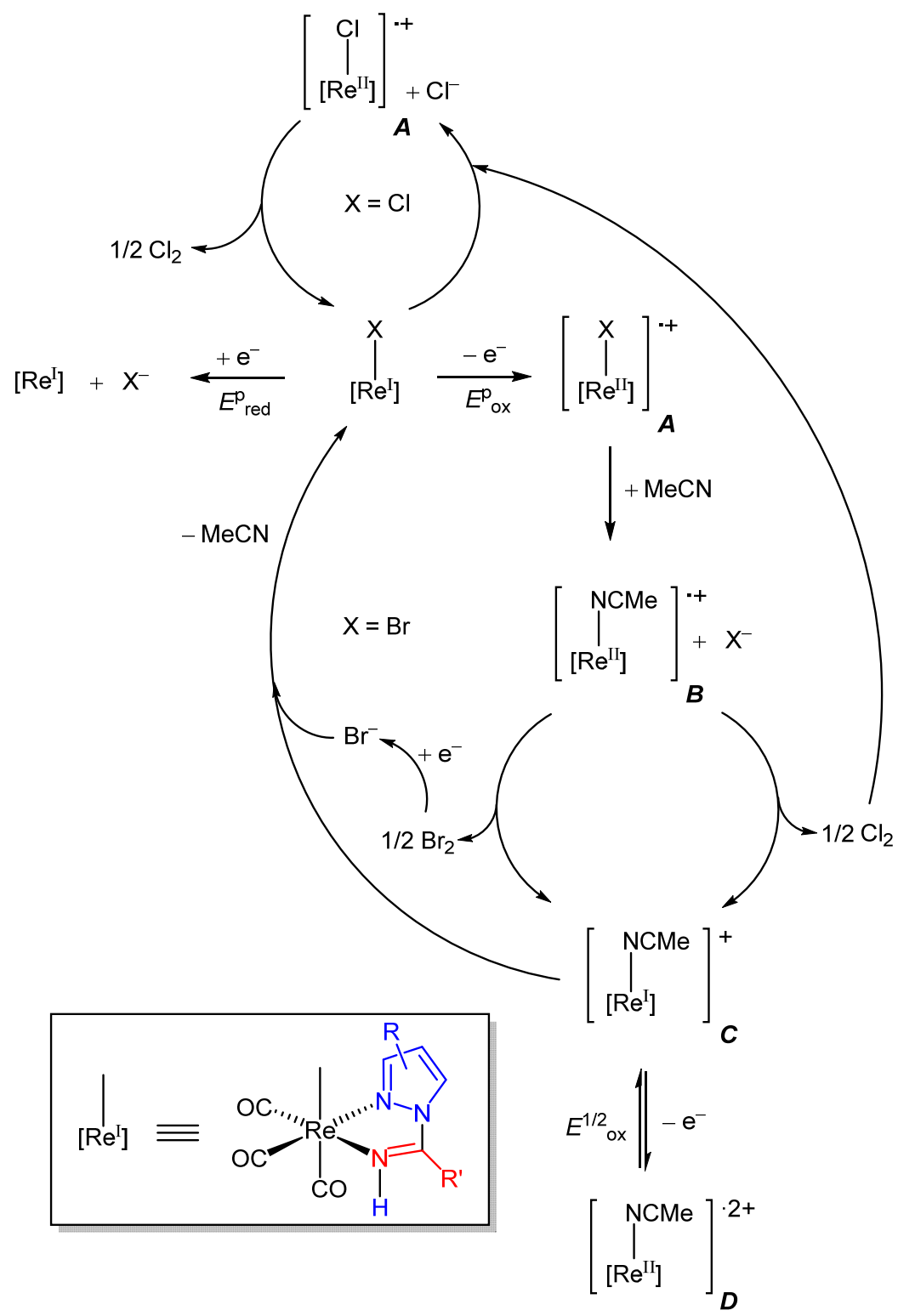

Esquema 10. Proceso electroquímico propuesto para los complejos neutros $f a c-\left[\operatorname{Re}(\mathrm{X})(\mathrm{CO})_{3}\left(N \mathrm{H}=\mathrm{C}(\mathrm{R}) \mathrm{pz} \mathrm{z}^{*}\right)\right]$. 


\subsubsection{Cálculos teóricos}

Todos los compuestos presentados en esta parte del trabajo fueron estudiados teóricamente para corroborar y reforzar los resultados obtenidos mediante los estudios fotofísicos y electroquímicos. Los complejos pirazolilamidino fueron estudiados teóricamente mediante la teoría de funcionales de la densidad (DFT) y mediante la teoría de funcionales de la densidad dependientes del tiempo (TD-DFT). La geometría calculada de los estados fundamentales de los complejos en el nivel de exactitud PBE1PBE coincidió con la estructura obtenida mediante difracción de rayos X. De manera general se puede observar que el HOMO tiene principalmente un carácter $\mathrm{Re} / \mathrm{CO} / \mathrm{X}$ para los compuestos neutros (Tabla 2), mientras que para los compuestos catiónicos la contribución del ligando pirazolilamidino no puede ser desestimada (Tabla 3). En ambos casos el LUMO está principalmente centrado en ligando amidino. Esta distribución de los orbitales apoya el proceso electroquímico expuesto en el apartado 4.2.2.

Tabla 2. Composición de los orbitales moleculares frontera (\%) en el estado fundamental para el complejo $f a c-\left[\operatorname{ReCl}(\mathrm{CO})_{3}\left(\mathrm{NH}=\mathrm{C}(\mathrm{Me}) \mathrm{pz}-\kappa^{2} N, N\right)\right]$ calculado con PBE1PBE.
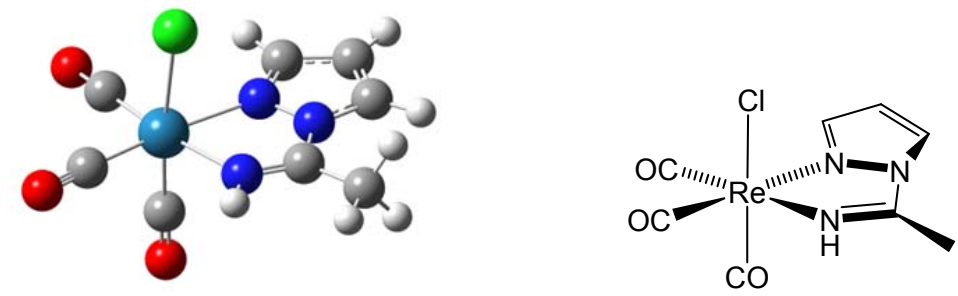

\begin{tabular}{|c|c|c|c|c|c|c|}
\hline \multirow[b]{2}{*}{ Orbital } & \multicolumn{6}{|c|}{ Contribución (\%) } \\
\hline & $\begin{array}{c}\text { Energía } \\
(\mathrm{eV}):\end{array}$ & Re: & Cl: & CO: & amidino: & Tipo principal de enlace \\
\hline HOMO-4 & -7.76 & 12.29 & 55.89 & 3.97 & 27.85 & $\mathrm{~d}(\mathrm{Re})+\mathrm{p}(\mathrm{Cl})+\pi($ amidino $)$ \\
\hline HOMO-3 & -7.66 & 9.84 & 58.90 & 3.35 & 27.91 & $\mathrm{~d}(\mathrm{Re})+\mathrm{p}(\mathrm{Cl})+\pi($ amidino $)$ \\
\hline HOMO-2 & -6.98 & 68.90 & 0.53 & 28.57 & 2.00 & $\mathrm{~d}(\mathrm{Re})+\pi(\mathrm{CO})$ \\
\hline HOMO-1 & -6.40 & 46.90 & 25.98 & 20.78 & 6.33 & $\mathrm{~d}(\mathrm{Re})+\mathrm{p}(\mathrm{Cl})+\pi(\mathrm{CO})$ \\
\hline HOMO & -6.32 & 47.08 & 25.77 & 22.84 & 4.32 & $\mathrm{~d}(\mathrm{Re})+\mathrm{p}(\mathrm{Cl})+\pi(\mathrm{CO})$ \\
\hline LUMO & -2.04 & 4.60 & 1.68 & 5.82 & 87.91 & $\pi^{*}($ amidino $)$ \\
\hline LUMO+1 & -0.55 & 29.29 & 1.08 & 65.50 & 4.14 & $\mathrm{p}(\mathrm{Re})+\pi^{*}(\mathrm{CO})$ \\
\hline $\mathrm{LUMO}+2$ & -0.31 & 27.97 & 2.90 & 61.25 & 7.89 & $\mathrm{p}(\mathrm{Re})+\pi^{*}(\mathrm{CO})$ \\
\hline
\end{tabular}


Tabla 3. Composición de los orbitales moleculares frontera (\%) en el estado fundamental para el complejo fac- $\left[\mathrm{Re}\left(\mathrm{NCCH}_{3}\right)(\mathrm{CO})_{3}\left(N \mathrm{H}=\mathrm{C}(\mathrm{Me}) \mathrm{pz}-\kappa^{2} N, N\right)\right] \mathrm{ClO}_{4}$ calculado con PBE1PBE.
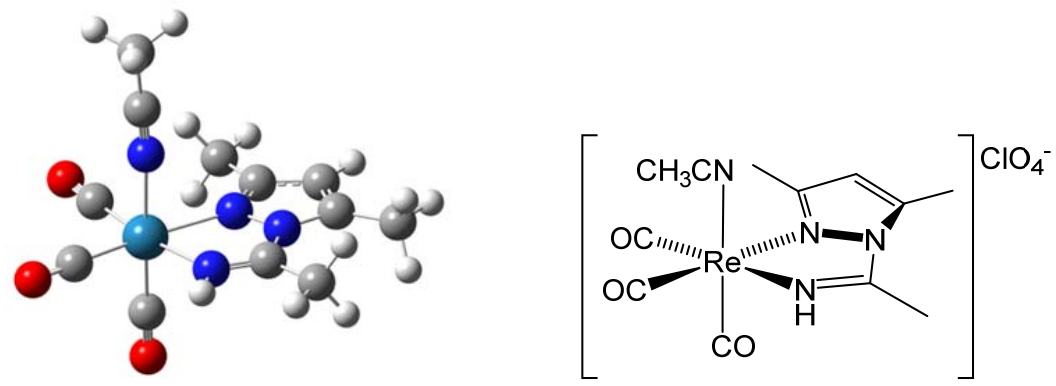

\begin{tabular}{lcccccl}
\cline { 3 - 5 } Orbital & \multicolumn{5}{c}{ Contribución (\%) } & \\
& $\begin{array}{c}\text { Energía } \\
(\mathbf{e V}):\end{array}$ & Re: & NCCH $_{3}$ : & CO: & amidino: & Tipo principal de enlace \\
\hline HOMO-3 & -8.39 & 6.21 & 1.44 & 2.11 & 90.25 & $\pi($ amidino $)$ \\
HOMO-2 & -7.5 & 69.58 & 0 & 27.9 & 2.52 & $\mathrm{~d}(\mathrm{Re})+\pi(\mathrm{CO})$ \\
HOMO-1 & -7.17 & 59.02 & 4.74 & 23.04 & 13.21 & $\mathrm{~d}(\mathrm{Re})+\pi(\mathrm{CO})+\pi($ amidino $)$ \\
HOMO & -7.11 & 54 & 4.09 & 21.28 & 20.63 & $\mathrm{~d}(\mathrm{Re})+\pi(\mathrm{CO})+\pi(\operatorname{amidino})$ \\
LUMO & -2.37 & 5.65 & 0.5 & 7.38 & 86.48 & $\pi^{*}(\operatorname{amidino})$ \\
LUMO+1 & -1.27 & 26.08 & 18.09 & 51.59 & 4.23 & $\mathrm{p}(\mathrm{Re})+\pi^{*}(\mathrm{CO})+\pi^{*}\left(\mathrm{NCCH}_{3}\right)$ \\
LUMO+2 & -0.93 & 19.19 & 25.13 & 51.32 & 4.36 & $\mathrm{p}(\mathrm{Re})+\pi^{*}(\mathrm{CO})+\pi^{*}\left(\mathrm{NCCH}_{3}\right)$ \\
\hline
\end{tabular}

El cálculo de la energía de absorción asociada con la fortaleza del oscilador y el carácter de la transición permitió concluir que los valores teóricos obtenidos para los compuestos están en correlación con los máximos de absorción observados experimentalmente. De hecho, en los datos calculados se observa cómo los complejos catiónicos son hipsocrómicos de sus derivados neutros, como se justifica comprobando la composición de los orbitales moleculares involucrados en cada caso. En los complejos catiónicos la contribución al HOMO y al HOMO-1 del fragmento amidino del complejo es mucho mayor que en el caso de los complejos neutros, lo que hace que el carácter de transferencia de carga de esta transición sea menor. Dado que la transición MLCT juega un papel importante en la excitación, la intensidad de la absorción de los complejos catiónicos será más fuerte que la de los complejos neutros, como se observa experimentalmente.

Por último, para calcular la emisión fosforescente se llevaron a cabo una serie de cálculos TD-DFT. Se calculó el estado triplete de más baja energía $\mathrm{T}_{1}$ para todos los complejos, obteniéndose una composición muy similar de los orbitales HOMO y LUMO a la del estado fundamental singlete. Aunque los cálculos TD-DFT no han permitido reproducir con exactitud los valores experimentales, si se han obtenido valores razonables que siguen la misma tendencia que los experimentales. 


\subsection{Formación de complejos amidino a partir de nucleobases}

Como se ha señalado en la Introducción, la última parte del trabajo versa sobre la incorporación de biomoléculas al fragmento $f a c$-" $\operatorname{Re}\left(\mathrm{CO}_{3}\right)$ ", y más concretamente sobre la formación de ligandos quelato amidinos mediante el acoplamiento de un nitrilo y 1-metilcitosina. De este modo se obtuvieron complejos neutros y catiónicos con el fragmento $f a c$ - $R e(\mathrm{CO})_{3}$ " (Esquema 11). Cabe recalcar que estos son los primeros ejemplos en los que se produce la incorporación de nucleobases a este fragmento por formación de un ligando amidino.
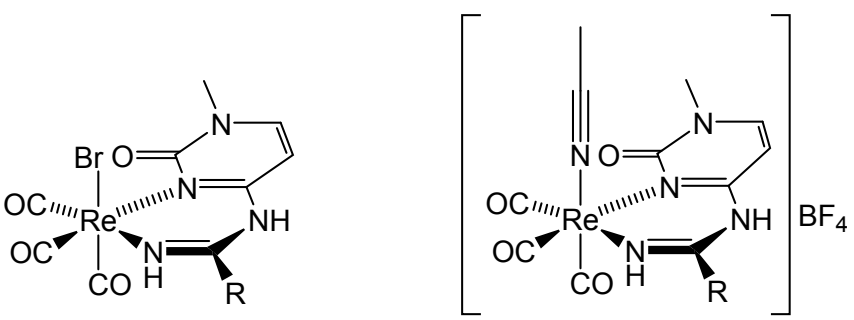

$\mathrm{R}=\mathrm{Me}, \mathrm{Ph}$

Esquema 11. Complejos sintetizados mediante inserciones de nitrilos y 1-metilcitosina

En esta parte del trabajo se consiguió dar un paso más en la mejora de la reacción de síntesis de complejos con el ligando amidino mediante la introducción del uso de radiación microondas como método sintético. La síntesis de los complejos anteriores se realizó por dos vías, la térmica convencional y la asistida por microondas. A continuación se comparan los resultados obtenidos por cada una de las vías. Para la síntesis de los complejos neutros se calienta a reflujo durante $5 \mathrm{~h}$ el complejo $f a c$ - $\left[\operatorname{ReBr}(\mathrm{CO})_{3}(\mathrm{NCMe})_{2}\right]$ en presencia de la nucleobase y se usa como disolvente el nitrilo deseado (Esquema 12, a). Los catiónicos se obtienen a partir de los complejos amidinos formados mediante reacción con $\mathrm{AgBF}_{4}$ usando como disolvente el correspondiente nitrilo (Esquema 12, b). Cuando las mismas reacciones se realizan en microondas se hace reaccionar los complejos $f a c-\left[\operatorname{ReBr}(\mathrm{CO})_{3}(\mathrm{NCMe})_{2}\right]$ o fac- $\left[\mathrm{Re}(\mathrm{CO})_{3}(\mathrm{NCMe})_{3}\right]^{+}$con la nucleobase usando como disolvente el nitrilo correspondiente 10 min a $180{ }^{\circ} \mathrm{C}$ en el equipo de microondas (Esquema 12, a y c). Aparte de una reducción significativa en los tiempos de reacción y en la cantidad de disolvente empleada, en el caso de los catiónicos se obtiene también un incremento en el rendimiento global de la reacción. Por lo tanto, considerando la economía atómica total, el uso de microondas para la síntesis de las especies catiónicas es una clara mejora sintética. Sin embargo para la síntesis de las especies neutras los rendimientos obtenidos por la vía asistida por microondas son inferiores. Creemos 
que este es el primer trabajo en el que se utiliza la radiación de microondas para la síntesis de amidinos a partir de nitrilos y aminas.

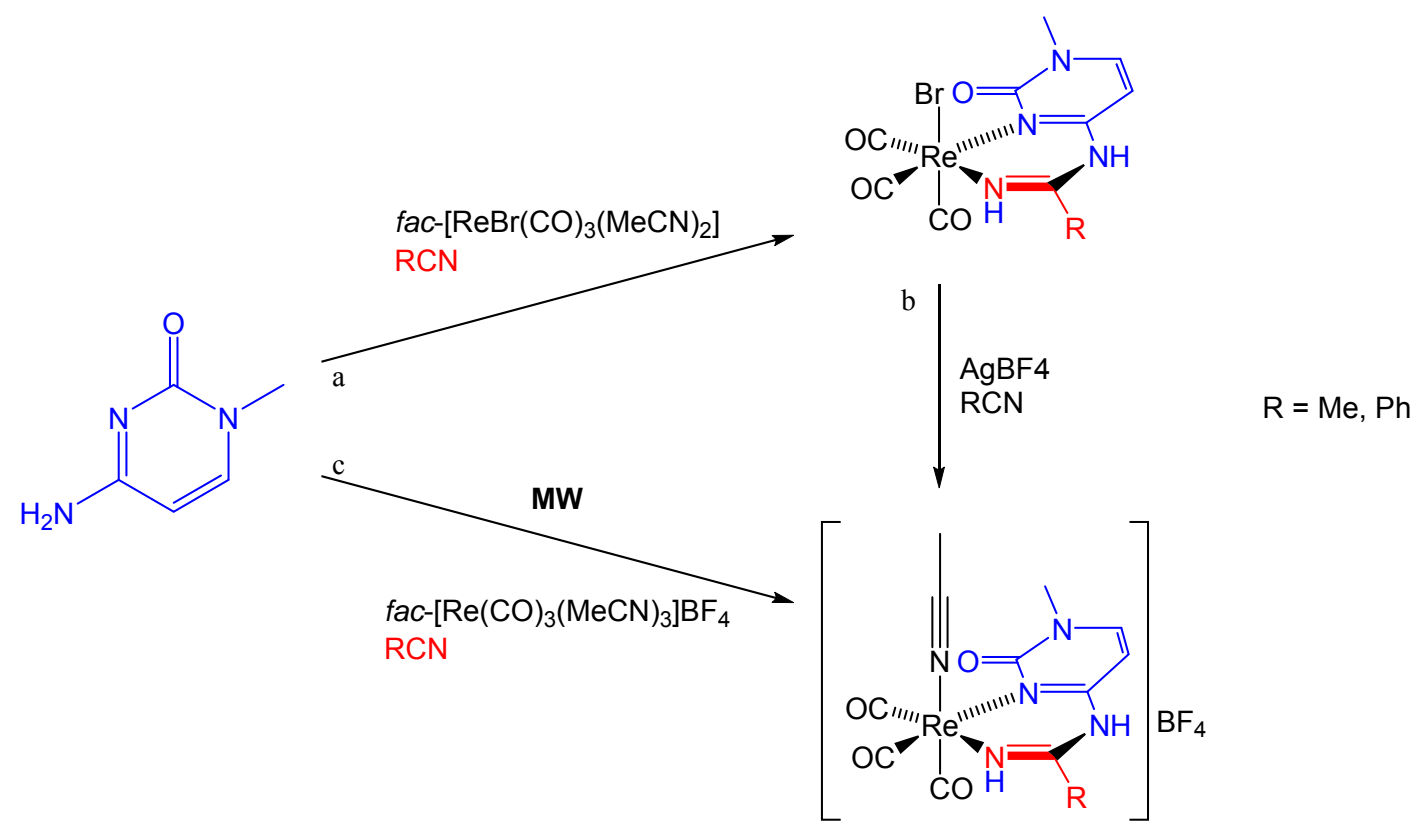

Esquema 12. Síntesis de los complejos con el ligando amidino y 1-metilcitosina.

En las estructuras de rayos X (Figura 17) de los complejos se observa que las distancias y ángulos del ligando amidino concuerdan esencialmente con las esperadas para el tautómero esperado, representado en el Esquema 11. Sin embargo, puesto que se pueden proponer más formas resonantes, se calcularon los índices de Wilberg del ligando quelato (Figura 18) que confirman que puede haber una pequeña contribución de otras formas resonantes.

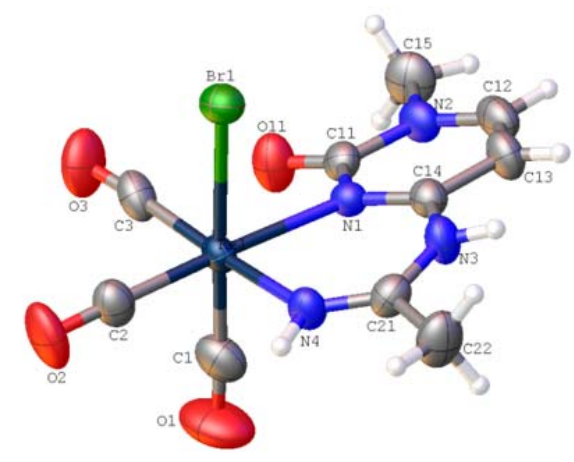

Figura 17. Estructura de rayos $\mathrm{X}$ del complejo $f a c-\left[\operatorname{ReBr}(\mathrm{CO})_{3}\left\{N \mathrm{H}=\mathrm{C}(\mathrm{Me})\left(\mathrm{MeCyH}-\kappa^{2} N, N\right)\right\}\right]$. 

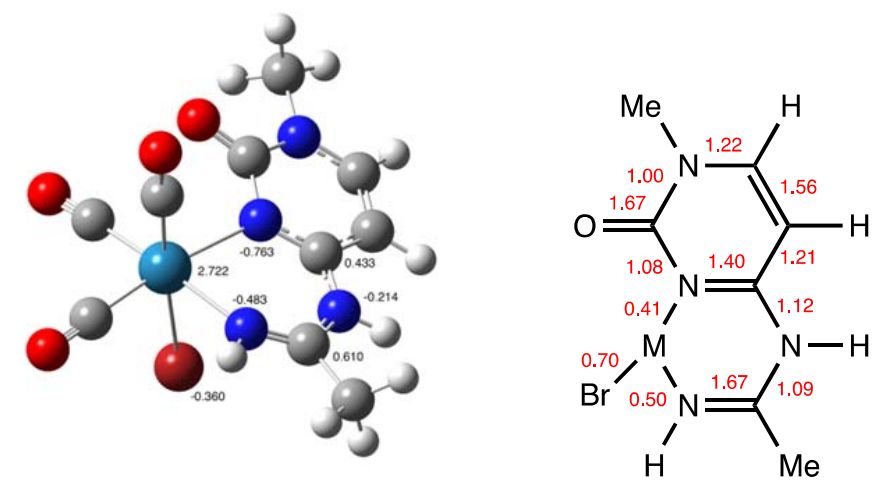

Figura 18. Índices de Wilberg y cargas $\mathrm{NBO}$ calculadas para $f a c-\left[\operatorname{ReBr}(\mathrm{CO})_{3}\left\{N \mathrm{H}=\mathrm{C}(\mathrm{Me})\left(\mathrm{MeCyH}-\kappa^{2} N, N\right)\right\}\right]$.

El interés de la coordinación del amidino derivado de la nucleobase al fragmento fac-"Re(CO) $)_{3}$ " se basa en la luminiscencia de estos complejos para su posible utilización posterior como sonda o marcador. El estudio de las propiedades fotofísicas de estos compuestos reveló que los derivados de acetonitrilo son fosforescentes. Como se hizo en el apartado 4.2.3 se llevaron a cabo cálculos teóricos para confirmar la asignación de las bandas de transferencia metal-ligando. Se calculó la composición de los orbitales moleculares HOMO y LUMO en los estados fundamental, y se comprobó que el LUMO está principalmente centrado en el ligando, confirmando la naturaleza MLCT de las transiciones observadas. 



\section{Artículo 1:}

Pyrazolylamidino Ligands from Coupling of Acetonitrile and Pyrazole:

a Systematic Study 



\title{
Inorganic Chemistry
}

\section{Pyrazolylamidino Ligands from Coupling of Acetonitrile and Pyrazoles: A Systematic Study}

\author{
Patricia Gómez-Iglesias, ${ }^{\dagger}$ Marta Arroyo, ${ }^{\dagger}$ Sonia Bajo, ${ }^{\dagger}$ Carsten Strohmann, ${ }^{\dagger}$ Daniel Miguel, ${ }^{\dagger}$
} and Fernando Villafañe ${ }^{*, \dagger}$

†GIR MIOMeT-IU Cinquima-Química Inorgánica, Facultad de Ciencias, Campus Miguel Delibes, Universidad de Valladolid, 47011 Valladolid, Spain

"Anorganische Chemie, Technische Universität Dortmund, Otto-Hahn-Strasse 6, D-44227 Dortmund, Germany

Supporting Information

ABSTRACT: Mixed pyrazole-acetonitrile complexes, both neutral fac-[ReBr$\left.(\mathrm{CO})_{3}(\mathrm{NCMe})(\mathrm{pz} * \mathrm{H})\right](\mathrm{pz} * \mathrm{H}=\mathrm{pzH}$, pyrazole; dmpzH, 3,5-dimethylpyrazole; or indz $\mathrm{H}$, indazole $)$ and cationic fac- $\left[\mathrm{Re}(\mathrm{CO})_{3}(\mathrm{NCMe})(\mathrm{pz} * \mathrm{H})_{2}\right] \mathrm{A}\left(\mathrm{A}=\mathrm{BF}_{4}, \mathrm{ClO}_{4}\right.$, or OTf), are described. Their role as the only starting products to obtain final pyrazolylamidino complexes $f a c-\left[\operatorname{ReBr}(\mathrm{CO})_{3}\left(\mathrm{NH}=\mathrm{C}(\mathrm{Me}) \mathrm{pz}^{*}-\kappa^{2} \mathrm{~N}, N\right)\right]$ and $f a c-$ $\left[\operatorname{Re}(\mathrm{CO})_{3}\left(\mathrm{pz}^{*} \mathrm{H}\right)\left(\mathrm{NH}=\mathrm{C}(\mathrm{Me}) \mathrm{pz}^{*}-\kappa^{2} \mathrm{~N}, N\right)\right] \mathrm{A}$, respectively, is examined. Other products involved in the processes, such as $f a c-\left[\operatorname{ReBr}(\mathrm{CO})_{3}\left(\mathrm{pz}^{*} \mathrm{H}\right)_{2}\right]$, fac$\left[\operatorname{Re}(\mathrm{CO})_{3}(\mathrm{NCMe})\left(\mathrm{NH}=\mathrm{C}(\mathrm{Me}) \mathrm{pz}^{*}-\kappa^{2} \mathrm{~N}, \mathrm{~N}\right)\right] \mathrm{A}$, and $f a c-\left[\operatorname{Re}(\mathrm{CO})_{3}(\mathrm{pz} * \mathrm{H})_{2}(\mathrm{OTf})\right]$ are also described. Warming $\mathrm{CD}_{3} \mathrm{CN}$ solutions of $f a c-\left[\operatorname{Re}(\mathrm{CO})_{3}(\mathrm{NCMe})(\mathrm{pz} * \mathrm{H})_{2}\right] \mathrm{A}$

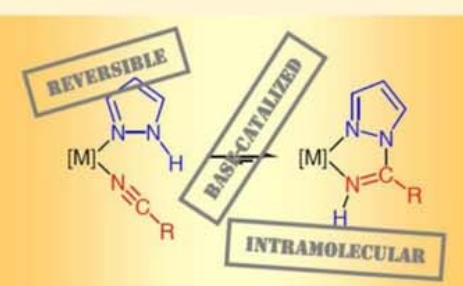
at $40{ }^{\circ} \mathrm{C}$ gives cleanly the pyrazolylamidino complexes $\left[\mathrm{Re}(\mathrm{CO})_{3}\left(\mathrm{pz}^{*} \mathrm{H}\right)\left(\mathrm{NH}=\mathrm{C}(\mathrm{Me}) \mathrm{pz}^{*}-\kappa^{2} \mathrm{~N}, N\right)\right] \mathrm{A}$ as the only products, pointing to an intramolecular process. This is confirmed by carrying out reactions in the presence of one equivalent of a pyrazole different from that coordinated, which affords complexes where the pyrazolylamidino ligand contains only the pyrazole previously coordinated. When the reactions lead to an equilibrium mixture of the final and starting products, the reverse reaction gives the same equilibrium mixture, which indicates that the coupling reaction of pyrazoles and nitriles to obtain pyrazolylamidino ligands is a reversible intramolecular process. A systematic study of the possible factors which may affect the reaction gives the following results: (a) the yields of the direct reactions are higher for lower temperatures; (b) the tendency of the pyrazoles to give pyrazolylamidino complexes follows the sequence indzH $>\mathrm{pzH}>\mathrm{dmpzH}$; and (c) the reaction rates do not depend on the nature of the anion even when a large excess is added. The presence of a small amount of aqueous solution of $\mathrm{NaOH}$ catalyzes the reaction. Thus, addition of $0.5-1 \%$ of $\mathrm{NaOH}(\mathrm{aq})$ to solutions of $f a c-\left[\operatorname{ReBr}(\mathrm{CO})_{3}(\mathrm{NCMe})(\mathrm{pz} * \mathrm{H})\right]($ in $\left.\mathrm{CD}_{3} \mathrm{CN}\right)$ or $f a c-\left[\mathrm{Re}(\mathrm{CO})_{3}(\mathrm{NCMe})(\mathrm{pz} * \mathrm{H})_{2}\right] \mathrm{A}\left(\right.$ in $\mathrm{CD}_{3} \mathrm{CN}, \mathrm{CD}_{3} \mathrm{NO}_{2}$ or $\left(\mathrm{CD}_{3}\right)_{2} \mathrm{CO}$ ) allowed the syntheses of the corresponding pyrazolylamidino complexes $\left[\operatorname{ReBr}(\mathrm{CO})_{3}\left(\mathrm{NH}=\mathrm{C}(\mathrm{Me}) \mathrm{pz}^{*}-\kappa^{2} \mathrm{~N}, N\right)\right]$ or $\left[\mathrm{Re}(\mathrm{CO})_{3}(\mathrm{pz} * \mathrm{H})\left(\mathrm{NH}=\mathrm{C}(\mathrm{Me}) \mathrm{pz}^{*}-\kappa^{2} N, N\right)\right] \mathrm{A}$ with better yields, more rapidly, and in milder conditions.

\section{INTRODUCTION}

The electrophilic character of nitriles is enhanced by coordination to a Lewis-acidic metal fragment, and therefore, coordinated nitriles react with different nucleophiles to obtain a wide variety of ligands. ${ }^{1}$ When the nucleophile is a pyrazole, pyrazolylamidino complexes are obtained (Scheme 1).,

Pyrazolylamidino ligands belong to the family of pyrazole- or pyrazolyl-containing chelating ligands. Complexes containing these ligands are receiving the most attention because they are involved in different and interdisciplinary aspects, such as synthesis of supramolecular assemblies, design of molecules

Scheme 1. Coupling Reaction of a Coordinated Nitrile and a Pyrazole To Obtain a Pyrazolylamidino Ligand<smiles></smiles>

displaying physical properties of interest, or their role in catalysis or materials science. ${ }^{4}$ In particular, pyrazolylamidino ligands present several appealing features: (a) their synthesis in situ (Scheme 1) allows one to obtain easily new bidentate chelating ligands of distinct electronic and steric properties just using different nitriles and pyrazoles, both readily available; (b) the different properties of the two donor atoms and the electron delocalization within the ligand makes them potentially interesting for electron transfer processes and related physical properties; and (c) the $\mathrm{NH}$ group may give rise to further reactivity, as it may be involved in noncovalent interactions or may be deprotonated.

Although the reaction displayed in Scheme 1 has been described for several metals, the mechanism of this process remains unclear. It is generally assumed to be an intramolecular nucleophilic attack of the pyrazole to the nitrile, once both are coordinated cis (Scheme 2). ${ }^{2 e, j}$ This suggestion is difficult to

Received: July 25, 2014

Published: November 7, 2014 
Scheme 2. Intramolecular (a) and Intermolecular (b)

Mechanisms for the Coupling Reaction of a Pyrazole and a Coordinated Nitrile

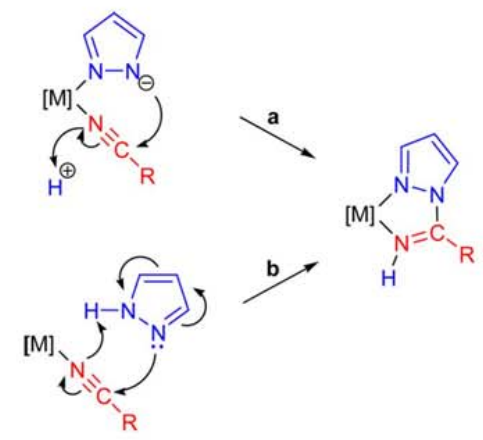

reconcile with the lack of nucleophilicity of the uncoordinated nitrogen of the pyrazole, similar to a pyrrole. A possible solution to this problem has been proposed by considering the previous deprotonation of the $\mathrm{NH}$ group (Scheme 2, path a). ${ }^{5}$

The group of Kukushkin and Pombeiro reported both intramolecular or intermolecular paths depending on the electronic configuration of the metal center. ${ }^{2 \mathrm{~b}}$ The intermolecular mechanism, based on the attack of a uncoordinated pyrazole, is depicted in Scheme 2, path b. The more recent contribution to this problem is the report of a mechanism driven by anion-mediated/hydrogen-bonding proton transfer. ${ }^{2 a}$

No direct evidence supporting either intra- or intermolecular coupling has been given so far. Path a in Scheme 2 shows that complexes containing both pyrazoles and nitriles can be considered as the only precursors of pyrazolylamidino complexes if the mechanism is intramolecular. There are very few reports of this type of complex..$^{2 a, e, 6}$ During the course of our studies on pyrazolylamidino rhenium complexes we were able to obtain mixed acetonitrile-pyrazole complexes such as fac-[ReBr$\left.(\mathrm{CO})_{3}(\mathrm{NCMe})(\mathrm{pzH})\right](\mathrm{pzH}=$ pyrazole $)$, fac- $[\mathrm{ReBr}-$ $\left.(\mathrm{CO})_{3}(\mathrm{NCMe})(\mathrm{dmpzH})\right](\mathrm{dmpzH}=3,5$-dimethylpyrazole $)$, and cationic $f a c-\left[\operatorname{Re}(\mathrm{CO})_{3}(\mathrm{NCMe})(\mathrm{dmpzH})_{2}\right]^{+3 \mathrm{c}}$ Therefore, we decided to explore their reactivity as well as the processes where they are involved in order to support or discard the intramolecular mechanism. On the other hand, no previous research has been carried out on the ideal conditions to obtain pyrazolylamidino complexes. Herein, a systematic study of the factors which may affect the process is reported.

\section{RESULTS AND DISCUSSION}

All complexes involved in this study are collected in Table 1 and Chart 1. In addition to the mixed acetonitrile-pyrazole complexes fac- $\left[\operatorname{ReBr}(\mathrm{CO})_{3}(\mathrm{NCMe})(\mathrm{pz} * \mathrm{H})\right]$ (1) $\left(\mathrm{pz}^{*} \mathrm{H}=\right.$ pzH, pyrazole; dmpzH, 3,5-dimethylpyrazole; or indzH, indazole) and cationic fac- $\left[\operatorname{Re}(\mathrm{CO})_{3}(\mathrm{NCMe})(\mathrm{pz} * \mathrm{H})_{2}\right]^{+}(4)$, which play the leading role in this work as starting materials, we also describe herein other complexes which are either byproducts $(3,5)$ or final products of the processes studied $(2,6$, and 7$)$. Most of the $\mathrm{pzH}$ and $\mathrm{dmpzH}$ complexes had been previously reported by the group of Ardizzoia and Masciocchi ${ }^{7}$ or by us. ${ }^{3 c}$ We decided to synthesize a similar family of complexes with a third pyrazole, i.e., indazole, in order to have a wider range of complexes to carry out in the study. The syntheses and characterization of the species involved in these processes are described next, before discussing the coupling reaction.
Table 1. Complexes Used in This Study ${ }^{a}$

\begin{tabular}{|c|c|c|c|}
\hline & $\mathrm{pzH}$ & dmpzH & indzF \\
\hline$f a c-\left[\operatorname{ReBr}(\mathrm{CO})_{3}(\mathrm{NCMe})\left(\mathrm{pz}^{*} \mathrm{H}\right)\right]$ & $1 a^{3 c}$ & $1 b^{3 c}$ & $1 \mathrm{c}$ \\
\hline$f a c-\left[\operatorname{ReBr}(\mathrm{CO})_{3}\left(\mathrm{NH}=\mathrm{C}(\mathrm{Me}) \mathrm{pz}^{*}-\kappa^{2} \mathrm{~N}, N\right)\right]$ & $2 a^{3 c}$ & $2 \mathbf{b}^{3 c}$ & $2 \mathrm{c}$ \\
\hline$f a c-\left[\operatorname{ReBr}(\mathrm{CO})_{3}\left(\mathrm{pz}^{*} \mathrm{H}\right)_{2}\right]$ & $3 a^{7}$ & $3 b^{7}$ & \\
\hline$f a c-\left[\operatorname{Re}(\mathrm{CO})_{3}(\mathrm{NCMe})\left(\mathrm{pz} \mathrm{H}^{*}\right)_{2}\right]^{+}$ & $4 a$ & $4 b^{3 c b}$ & $4 \mathrm{c}$ \\
\hline$f a c-\left[\operatorname{Re}(\mathrm{CO})_{3}\left(\mathrm{pz}^{*} \mathrm{H}\right)_{2}(\mathrm{OTf})\right]^{c}$ & $5 a$ & $5 b$ & \\
\hline$f a c-\left[\operatorname{Re}(\mathrm{CO})_{3}\left(\mathrm{pz}^{*} \mathrm{H}\right)\left(\mathrm{NH}=\mathrm{C}(\mathrm{Me}) \mathrm{pz}^{*}-\kappa^{2} \mathrm{~N}, \mathrm{~N}\right)\right]^{+}$ & $6 a^{3 c}$ & $6 b^{3 c}$ & \\
\hline $\begin{array}{l}f a c-\left[\operatorname{Re}(\mathrm{CO})_{3}(\mathrm{NCMe})\left(\mathrm{NH}=\mathrm{C}(\mathrm{Me}) \mathrm{pz}^{*} \text {. }\right.\right. \\
\left.\left.\kappa^{2} N, N\right)\right]^{+}\end{array}$ & $7 a^{3 c}$ & $7 b^{3 c}$ & \\
\hline
\end{tabular}

${ }^{a}$ Complexes 4, 6, and 7 have been isolated as $\mathrm{BF}_{4}, \mathrm{ClO}_{4}$, or OTf salts. Only one of them is described for each complex in the Experimental Section, since the spectroscopic data are esentially the same. ${ }^{b}$ Previously described with the anion $\mathrm{BAr}_{4}^{\prime}\left(\mathrm{Ar}^{\prime}=3,5\right.$-bis(trifluoromethyl)phenyl). ${ }^{c}$ Complexes with coordinated perchlorate gave similar spectroscopic data.

Syntheses and Characterization of the Complexes. Reactions between $f a c$ - $\left[\operatorname{ReBr}(\mathrm{CO})_{3}(\mathrm{MeCN})_{2}\right]$ and indzH occur similarly to those previously reported for $\mathrm{pzH}$ or $\mathrm{dmpzH},{ }^{3 c, 7}$ giving the substitution $(1 \mathrm{c}, 3 \mathrm{c})$ or the insertion (2c) products depending on the ratio and temperature used (eqs 1-3). Thus, 0 ${ }^{\circ} \mathrm{C}$ and a $1 / 1$ ratio allow one to obtain the mixed acetonitrileindazole complex $f a c-\left[\operatorname{ReBr}(\mathrm{CO})_{3}(\mathrm{NCMe})(\right.$ indzH) $](1 \mathrm{c})$, whereas a $1 / 2$ ratio at room temperature gives the disubstituted product, $f a c$ - $\left[\operatorname{ReBr}(\mathrm{CO})_{3}(\text { indzH })_{2}\right], 3 \mathrm{c}$. A $1 / 1$ ratio, but at $80^{\circ} \mathrm{C}$, leads to the pyrazolylamidino ligand resulting from the coupling of indazole and acetonitrile, that is, $f a c$ - $\left[\operatorname{ReBr}(\mathrm{CO})_{3}(\mathrm{NH}=\right.$ $\mathrm{C}(\mathrm{Me})$ indz- $\left.\left.\kappa^{2} N, N\right)\right], 2 \mathrm{c}$.

$$
\begin{aligned}
& f a c-\left[\operatorname{ReBr}(\mathrm{CO})_{3}(\mathrm{MeCN})_{2}\right]+\text { indzH } \\
& \underset{-\mathrm{MeCN}}{\stackrel{1 / 1,0^{\circ} \mathrm{C}}{\longrightarrow}} f a c-\left[\operatorname{ReBr}(\mathrm{CO})_{3}(\mathrm{NCMe})(\text { indzH })\right](1 \mathrm{c}) \\
& f a c-\left[\operatorname{ReBr}(\mathrm{CO})_{3}(\mathrm{MeCN})_{2}\right]+\text { indzH } \\
& \quad \underset{-\mathrm{MeCN}}{\stackrel{1 / 1,80^{\circ} \mathrm{C}}{\longrightarrow}} f a c-\left[\operatorname{ReBr}(\mathrm{CO})_{3}\left(\mathrm{NH}=\mathrm{C}(\mathrm{Me})\left(\mathrm{indz}^{2} \kappa^{2} N, N\right)\right]\right.
\end{aligned}
$$

$$
\begin{aligned}
& f a c-\left[\operatorname{ReBr}(\mathrm{CO})_{3}(\mathrm{MeCN})_{2}\right]+2 \text { indzH } \\
& \underset{-2 \mathrm{MeCN}}{\stackrel{1 / 2, \text { r.t. }}{\longrightarrow}} f a c-\left[\operatorname{ReBr}(\mathrm{CO})_{3}(\text { indzH })_{2}\right](3 \mathbf{c})
\end{aligned}
$$

Their spectroscopic data are collected in the Experimental Section. $\mathbf{2 c}, 3 \mathbf{b},{ }^{8}$ and $3 \mathbf{c}$ were subjected to crystallographic studies, shown in Figure 1 (2c), 2 (3c), and S1 (3b), Supporting Information. The distances and angles (available from the CIF in the Supporting Information) are similar to those found in other pyrazolylamidino- and bis(pyrazole)rhenium complexes., As observed in the structures of similar manganese complexes, ${ }^{3 \mathrm{~d}}$ dimethylpyrazole ligands in $\mathbf{3 b}$ are tilted in the same sense around the $\mathrm{Re}-\mathrm{N}$ bonds in order to reduce the steric hindrance of the methyl groups, in this case $34^{\circ}$ and $39^{\circ}$ with respect to the "ideal" orientation, perpendicular to the $\mathrm{ReN}_{2}$ plane. This is not observed in the structure of $3 \mathrm{c}$, where less hindered indazoles are coordinated perpendicular to the $\mathrm{ReN}_{2}$ plane.

Cationic acetonitrile-pyrazole mixed complexes fac-[Re$\left.(\mathrm{CO})_{3}(\mathrm{NCMe})\left(\mathrm{pz}^{*} \mathrm{H}\right)_{2}\right]^{+}, 4$, are easily obtained from complexes 3 by extracting the bromido ligand with the appropriate silver salt in THF and ulterior addition of an excess of MeCN (eq 4). Synthesis and characterization of the pyrazole and indazole complexes $4 a$ and $4 c$ are herein described, whereas the 
Chart 1. Complexes Used in This Study<smiles></smiles>

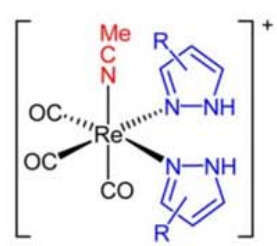

4

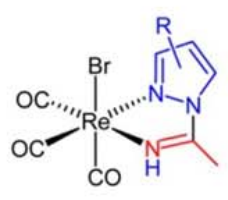

2<smiles></smiles><smiles></smiles>

3

a: $p z H$
b: $d m p z H$
c: indzH

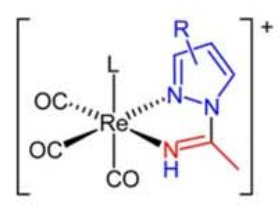

$6\left(L=p z^{*} H\right)$
$7(L=N C M e)$

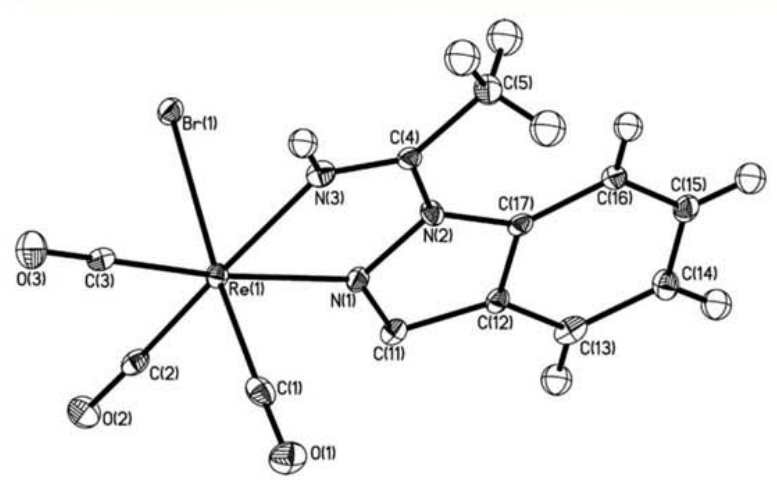

Figure 1. Perspective view of $f a c-\left[\operatorname{ReBr}(\mathrm{CO})_{3}(\mathrm{NH}=\mathrm{C}(\mathrm{Me})\right.$ indz$\left.\left.\kappa^{2} N, N\right)\right], 2 c$, showing the atom numbering. Ellipsoids are drawn at $30 \%$ probability.

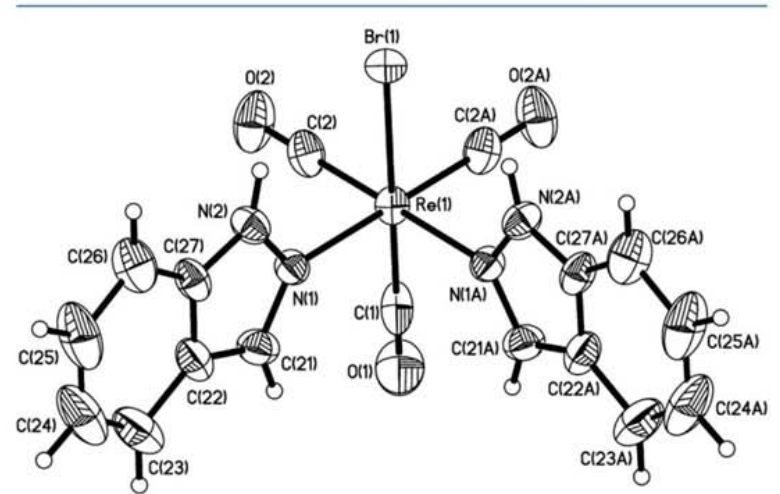

Figure 2. Perspective view of $f a c-\left[\operatorname{ReBr}(\mathrm{CO})_{3}(\text { indzH })_{2}\right], 3 c$, showing the atom numbering. Ellipsoids are drawn at $30 \%$ probability.

dimethylpyrazole complex $\mathbf{4 b}$ has been previously reported. ${ }^{3 c}$ As indicated in Table 1 , they can be isolated as $\mathrm{BF}_{4}, \mathrm{ClO}_{4}$, or OTf salts, although only one of them $\left(\mathrm{BF}_{4}\right.$ salts $)$ is described in the Experimental Section, since the spectroscopic data are esentially the same. Their spectroscopic and analytical data support the proposed structure, which was confirmed by an X-ray diffraction study for $4 \mathrm{a}-\mathrm{ClO}_{4}$. Figure 3 shows a perspective view of the
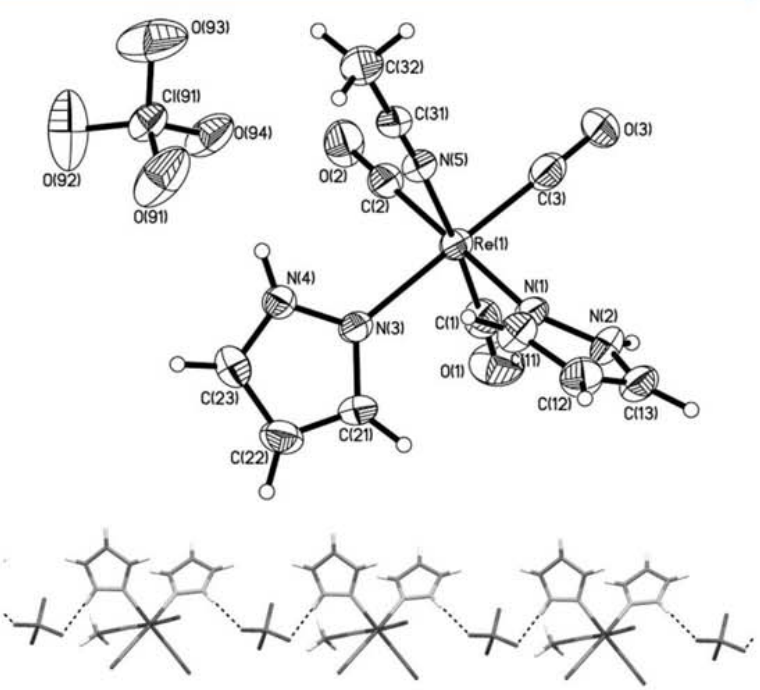

Figure 3. Perspective view showing the atom numbering (top, ellipsoids are drawn at $30 \%$ probability) and hydrogen bonds (bottom) of fac$\left[\mathrm{Re}(\mathrm{CO})_{3}(\mathrm{NCMe})(\mathrm{pzH})_{2}\right]^{+}, 4 \mathrm{a}-\mathrm{ClO}_{4}$.

molecule as well as the hydrogen bonds detected in the solid state structure: the N-bound hydrogens of each pyrazole and the oxygens of the perchlorate form a chain structure. The distances and angles detected $(\mathrm{H}(2) \cdots \mathrm{O}(92) 1.974(10) \AA, \mathrm{N}(2) \cdots \mathrm{O}(92)$ 2.953(12) $\AA, \mathrm{N}(2)-\mathrm{H}(2) \cdots \mathrm{O}(92) 157.9(5)^{\circ}$, and $\mathrm{H}(4) \cdots$

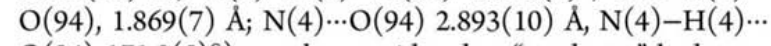
$\left.\mathrm{O}(94) 171.9(5)^{\circ}\right)$ may be considered as "moderate" hydrogen bonds.

$$
\begin{aligned}
& f a c-\left[\operatorname{ReBr}(\mathrm{CO})_{3}\left(\mathrm{pz}^{*} \mathrm{H}\right)_{2}\right](3) \\
& \underset{(2)+\mathrm{MeCN}}{\stackrel{(1)+\mathrm{Ag}^{+} \mathrm{A}^{-}, \mathrm{AgBr}}{\longrightarrow}} \mathrm{fac}-\left[\operatorname{Re}(\mathrm{CO})_{3}(\mathrm{NCMe})(\mathrm{pz} * \mathrm{H})_{2}\right]^{+} \mathrm{A}^{-}(\mathbf{4})
\end{aligned}
$$

Substitution of the acetonitrile ligand present in complexes 4 by the corresponding counterion was observed during their reactivity studies. Therefore, we decided to isolate and characterize the neutral complexes containing the coordinated anion. Their synthesis was carried out by extracting the bromido 
ligand of complexes 3 with the appropriate silver salt in the absence of MeCN (see eq 5 for OTf complexes). As expected, tetrafluoroborate complexes were shown to be very unstable, which precluded their characterization. Both perchlorate and triflate could be isolated, giving almost coincident spectroscopic data, and again only one of them (containing coordinated OTf) is described in the Experimental Section. The crystal structure of the dimethylpyrazole complex $\mathbf{5 b}$ containing either triflato or perchlorato ligands could be obtained. They are shown in Figures 4 and S2, Supporting Information, respectively. Distances and
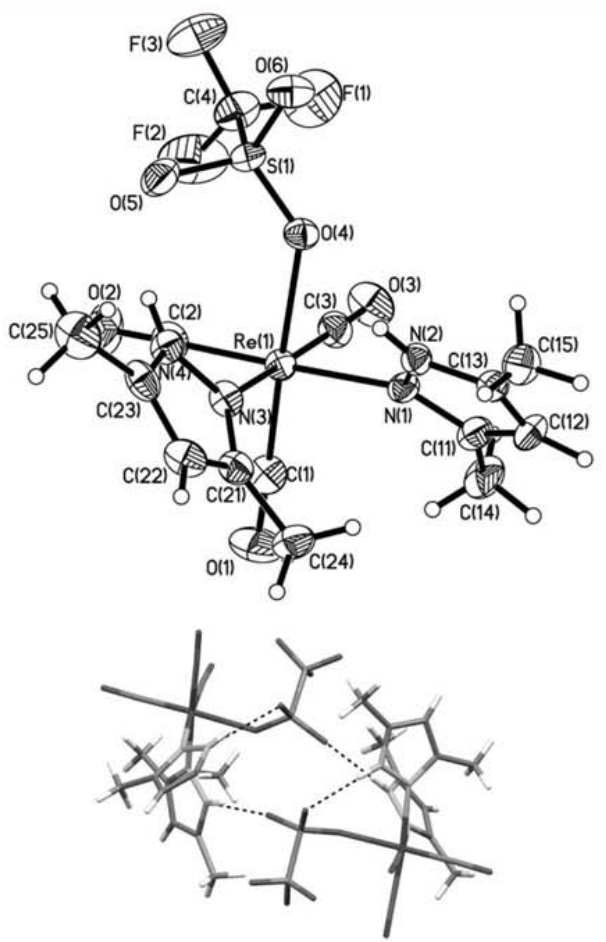

Figure 4. Perspective view of $f a c-\left[\operatorname{Re}(\mathrm{CO})_{3}(\mathrm{dmpzH})_{2}(\mathrm{OTf})\right]$, $5 \mathbf{b}$-OTf (above), and hydrogen bonds (below), showing atom numbering. Ellipsoids are drawn at $30 \%$ probability.

angles, which are available from the CIF in the Supporting Information, show the analogy between these structures and that of $3 \mathbf{b}$.

$$
\begin{aligned}
& f a c-\left[\operatorname{ReBr}(\mathrm{CO})_{3}\left(\mathrm{pz}^{*} \mathrm{H}\right)_{2}\right](\mathbf{3}) \\
& \stackrel{+\mathrm{AgOTf}}{\underset{-\mathrm{AgBr}}{\longrightarrow}} f a c-\left[\operatorname{Re}(\mathrm{CO})_{3}\left(\mathrm{pz}^{*} \mathrm{H}\right)_{2}(\mathrm{OTf})\right](\text { 5-OTf })
\end{aligned}
$$

Opposite to 4a, which forms anion-cations hydrogen-bonded chains (Figure 3, below), the solid crystal structure of $\mathbf{5 b}$ indicates that in these cases hydrogen bonds generate discrete dimer ionic pairs (Figure 4, below). Uncoordinated oxygen atoms of the coordinated triflate are hydrogen bonded with $\mathrm{N}$ bound hydrogens of dimethylpyrazoles. The distances and angles detected $(\mathrm{H}(2) \cdots \mathrm{O}(56) 1.938(6) \AA, \mathrm{N}(2) \cdots \mathrm{O}(56) 2.933(9) \AA$, $\mathrm{N}(2)-\mathrm{H}(2) \cdots \mathrm{O}(56) 161.5(4)^{\circ}$, and $\mathrm{H}(4) \cdots \mathrm{O}(5)$ 1.903(5) $\AA$; $\mathrm{N}(4) \cdots \mathrm{O}(5) 2.862(8) \AA \AA ; \mathrm{N}(4)-\mathrm{H}(4) \cdots \mathrm{O}(5) 153.4(5)^{\circ}$ for $5 \mathbf{b}-$ OTf) indicate that these may be considered again as "moderate" hydrogen bonds. ${ }^{9}$

Cationic pyrazolylamidino complexes $f a c-\left[\operatorname{Re}(\mathrm{CO})_{3}(\mathrm{indzH})\right.$ $\left(\mathrm{NH}=\mathrm{C}(\mathrm{Me})\right.$ indz- $\left.\left.\kappa^{2} N, N\right)\right]^{+}, 6 \mathrm{c}$, and $f a c-\left[\operatorname{Re}(\mathrm{CO})_{3}(\mathrm{NCMe})-\right.$
$\left(\mathrm{NH}=\mathrm{C}(\mathrm{Me})\right.$ indz $\left.\left.-\kappa^{2} \mathrm{~N}, \mathrm{~N}\right)\right]^{+}, 7 \mathrm{c}$, were obtained as previously described for similar pyrazolilamidino complexes with pyrazole or dimethylpyrazole. Alternatively, $6 \mathrm{c}$ could also be obtained by substituting the coordinated anion in 5 by $\mathrm{MeCN}$ and subsequent coupling (eqs 6-8). Their spectroscopic and analytic data (Experimental Section) are as expected given this analogy. ${ }^{3 c}$ As discussed below, the reaction conditions are milder for pyrazolilamidino complexes derived from indazole with respect to pyrazole or dimethylpyrazole. The crystal structure of $7 \mathrm{c}-\mathrm{ClO}_{4}$

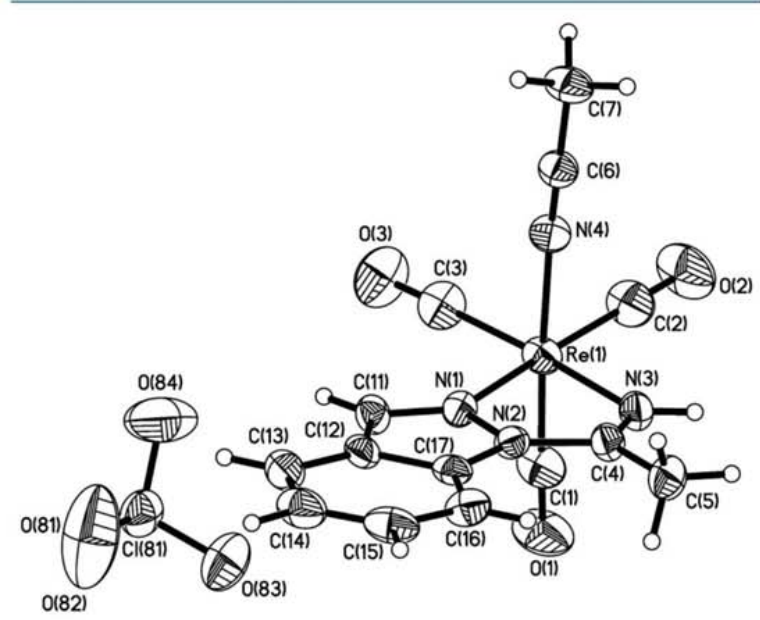

Figure 5. Perspective view of $f a c-\left[\operatorname{Re}(\mathrm{CO})_{3}(\mathrm{NCMe})(\mathrm{NH}=\mathrm{C}(\mathrm{Me})\right.$ indz- $\left.\left.\kappa^{2} \mathrm{~N}, \mathrm{~N}\right)\right] \mathrm{ClO}_{4}, 7 \mathrm{c}-\mathrm{ClO}_{4}$, showing the atom numbering. Ellipsoids are drawn at $30 \%$ probability.

is depicted in Figure 5, and distances and angles are available from the CIF in the Supporting Information.

$$
\begin{aligned}
& \text { fac- }\left[\mathrm{Re}(\mathrm{CO})_{3}(\mathrm{NCMe})(\text { indzH })_{2}\right] \text { OTf }(4 \mathrm{c}-\mathrm{OTf}) \rightarrow
\end{aligned}
$$

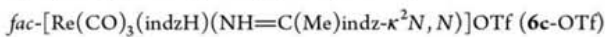

$$
\begin{aligned}
& \text { fac- }\left[\operatorname{Re}(\mathrm{CO})_{3}(\text { indzH })_{2}\right] \text { (OTf) }(5 c-O T f) \stackrel{+\mathrm{MeCN}}{\longrightarrow} \\
& f a c-\left[\operatorname{Re}(\mathrm{CO})_{3}(\text { indz } \mathrm{H})\left(\mathrm{NH}=\mathrm{C}(\mathrm{Me}) \text { indz }-\kappa^{2} N, N\right)\right] \mathrm{OTf}(6 \mathrm{c}-\mathrm{OTf}) \\
& \text { fac }-\left[\operatorname{ReBr}(\mathrm{CO})_{3}\left(\mathrm{NH}=\mathrm{C}(\mathrm{Me}) \text { indz- }-\kappa^{2} N, N\right)\right](2 \mathrm{c}) \frac{(1)+\mathrm{AgOT}_{6}-\mathrm{Ag}_{\mathrm{gr}}}{(2)+\mathrm{MecN}} \\
& \text { fac- }\left[\mathrm{Re}(\mathrm{CO})_{3}(\mathrm{NCMe})\left(\mathrm{NH}=\mathrm{C}(\mathrm{Me}) \text { indz- } \kappa^{2} N, N\right)\right] \mathrm{OTf}(7 \mathrm{c}-\mathrm{OTf})
\end{aligned}
$$

Kinetic Studies of the Coupling Processes. The first attempt to obtain pyrazolylamidino complexes from mixed acetonitrile-pyrazole complexes as the only starting material was carried out using neutral bromido complexes $1 \mathbf{b}$ or $1 \mathrm{c}$ in $\mathrm{CD}_{3} \mathrm{CN}$ solution. ${ }^{10}$ Heating any of these complexes at $80{ }^{\circ} \mathrm{C}$ leads to a mixture of complexes $\mathbf{2}$ and $\mathbf{3}$, unreacted $\mathbf{1}$, as well as other very minor products, which were identified mainly as a mixture of 6 and 7. Figure 6 shows the concentrations of the species present in solution when $\mathbf{l b}$ is heated in $\mathrm{CD}_{3} \mathrm{CN}$ at $80^{\circ} \mathrm{C}$. Similar mixtures were obtained when using $\mathbf{1 c}$ as starting material or solutions of different concentrations. When the processes were attempted at lower temperatures, the reactions were too slow. On the other hand, the reactions were repeated with a noncoordinating solvent, but heating 1 at $80{ }^{\circ} \mathrm{C}$ in $\mathrm{CD}_{3} \mathrm{NO}_{2}$ led to residual amounts of the pyrazolylamidino complexes $\mathbf{2 b}$ or $\mathbf{2 c}$, with bis(pyrazole) complexes 3 being the main products (ca. $50 \%$ ). This expected result shows that conditions favoring uncoordination of acetonitrile preclude the coupling process. 


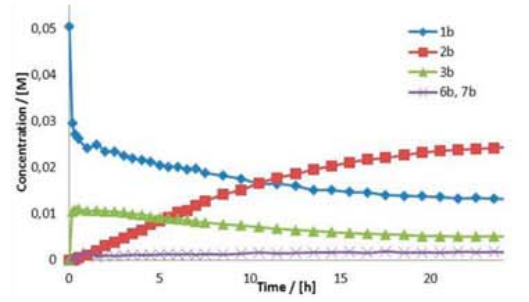

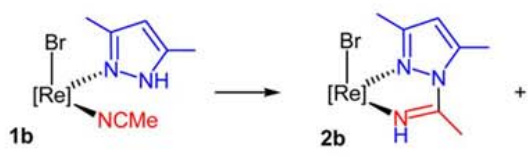

$[\mathrm{Re}]=\operatorname{Re}(\mathrm{CO})_{3}$

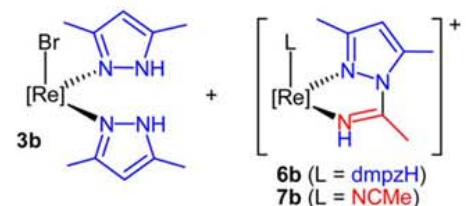

Figure 6. Representation of the concentrations of $\mathbf{1 b}, \mathbf{2 b}, \mathbf{3 b}$, and the mixture $\mathbf{6 b}+\mathbf{7 b}$ vs time when $\mathbf{1 b}$ is heated in $\mathrm{CD}_{3} \mathrm{CN}$ at $80{ }^{\circ} \mathrm{C}$. Final ratio: $\mathbf{1 b} / \mathbf{2 b}$ / $3 b /(6 b+7 b)=25 / 50 / 10 / 5^{13}$

The most striking feature about the processes carried out in $\mathrm{CD}_{3} \mathrm{CN}$ at $80{ }^{\circ} \mathrm{C}$ was the presence of small amounts of the cationic complexes 6 and 7. In a cationic complex, the coordinated acetonitrile should be more activated than when coordinated to a neutral complex, and therefore, the coupling process to form the pyrazolylamidino ligand should be easier. This led us to consider the possibility of the presence of cationic complexes as intermediates for the process, as depicted in Scheme 3. It is well known that $\mathrm{MeCN}$ may coordinate to $\mathrm{Mn}$

Scheme 3. Proposal of the Coupling Process of Neutral Complexes through Cationic Intermediates

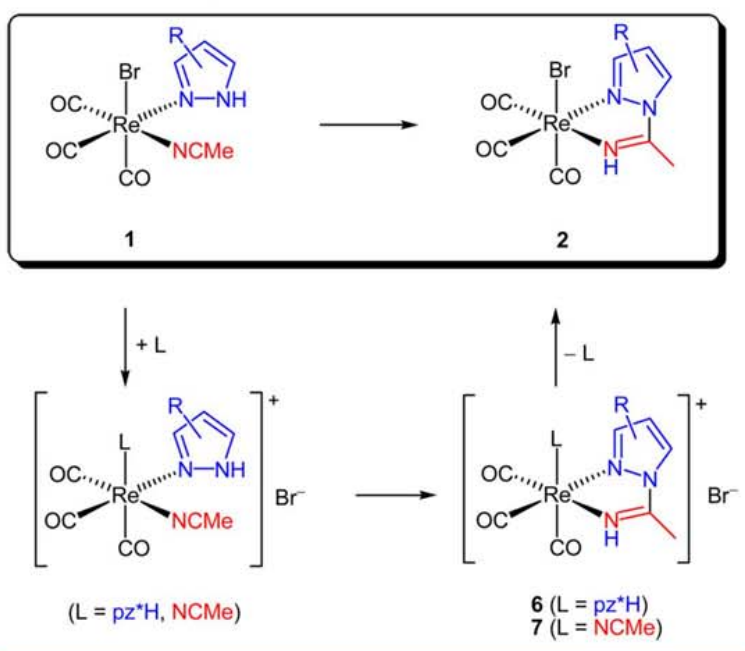

and $\operatorname{Re}$ complexes by substituting the halide ligand. ${ }^{11}$ This process would give rise to cationic complexes, where the electrophilic character of the nitrile should be enhanced, and thus, the coupling process should be favored. Therefore, we decided to focus our work on the cationic acetonitrile-pyrazole complexes and investigate whether they could be intermediates in the coupling process to obtain cationic pyrazolylamidino complexes.

Heating cationic complexes 4 in the same conditions, $\mathrm{CD}_{3} \mathrm{CN}$ at $80{ }^{\circ} \mathrm{C}$, gave a mixture of the pyrazolylamidino cationic complexes 6 and 7 as well as unreacted 4 and free pyrazole. Figure 7 shows the concentrations of the species detected in solution for reaction of $\mathbf{4 b}-\mathrm{BF}_{4}$. Although this result may seem disappointing, close study of the first minutes of the process reveals that conversion of $4 b$ to $6 b$ is clean (Scheme 4 , framed reaction). Only after $\mathrm{ca} .30 \mathrm{~min}$, the concentration of $6 \mathbf{b}$ reaches a maximum and starts to decrease whereas the concentations of equimolar amounts of $\mathbf{7 b}$ and free pyrazole increase. This indicates that the pyrazole coordinated in $6 \mathbf{b}$ is being substituted by acetonitrile from the solvent to give $7 \mathbf{b}$ and free pyrazole (Scheme 4, right). This is a somehow surprising result, because pyrazoles are better ligands than nitriles, but in this case the high temperature might favor this entropy-driven process. As this secondary process is favored by higher temperatures and the coupling process should be easier for cationic complexes, the reaction was repeated at $40^{\circ} \mathrm{C}$.

In these conditions, conversion of $\mathbf{4}$ into $\mathbf{6}$ is clean (Scheme $\mathbf{4}$, framed reaction), as shown in Figure 8 for $4 \mathbf{b}$-OTf (see Figure $\mathrm{S} 3$, Supporting Information, for $\mathbf{4 a}-\mathrm{ClO}_{4}$ and $\left.4 \mathrm{c}-\mathrm{ClO}_{4}\right)$, which supports that the coupling reaction of pyrazoles and nitriles to obtain pyrazolylamidino ligands is an intramolecular process. However, mild temperatures are crucial to obtain this result, as at $60{ }^{\circ} \mathrm{C}$ or higher temperatures substitution of the coordinated pyrazole in 6 by $\mathrm{CD}_{3} \mathrm{CN}$ from the solvent to get 7 and free pyrazole is favored (Scheme 4, right). Another process observed when the reaction is carried out above $40^{\circ} \mathrm{C}$ is the scrambling of the coordinated $\mathrm{CH}_{3} \mathrm{CN}$ with the solvent, $\mathrm{CD}_{3} \mathrm{CN}$. This scrambling process is detected by examining the methyl group signal in the ${ }^{1} \mathrm{H}$ NMR spectra, which integrates at lower values than expected. In fact, the framed reaction leads to a mixture of $6 b$ and "deuterated" $6 b$ in a ca. $40 / 60$ ratio when the reaction was carried out at $80^{\circ} \mathrm{C}$ but to neat $6 \mathrm{~b}$ when the reaction ocurs at 40 ${ }^{\circ} \mathrm{C}$. However, this scrambling at higher temperatures should occur before the coupling process and does not affect the intramolecular nature of the reaction. Therefore, all data support that the methyl group in the pyrazolylamidino ligand, either deuterated or not, is present in the coordinated acetonitrile.

When the same reaction was attempted using $\mathrm{CD}_{3} \mathrm{NO}_{2}$ as solvent, conversion of 4 into $\mathbf{6}$ was not so clean as in $\mathrm{CD}_{3} \mathrm{CN}$, because the final pyrazolylamidino complexes 6 were usually mixed with neutral complexes 5 (Scheme 4, left, and Figure S4, Supporting Information). However, addition of a slight excess of $\mathrm{MeCN}$ to complexes 5 did not afford back 4 in the reaction conditions.

Clean conversion of 4 into 6 (Figure 8 and Scheme 4, framed reaction) clearly demonstates that the coupling reaction occurs 

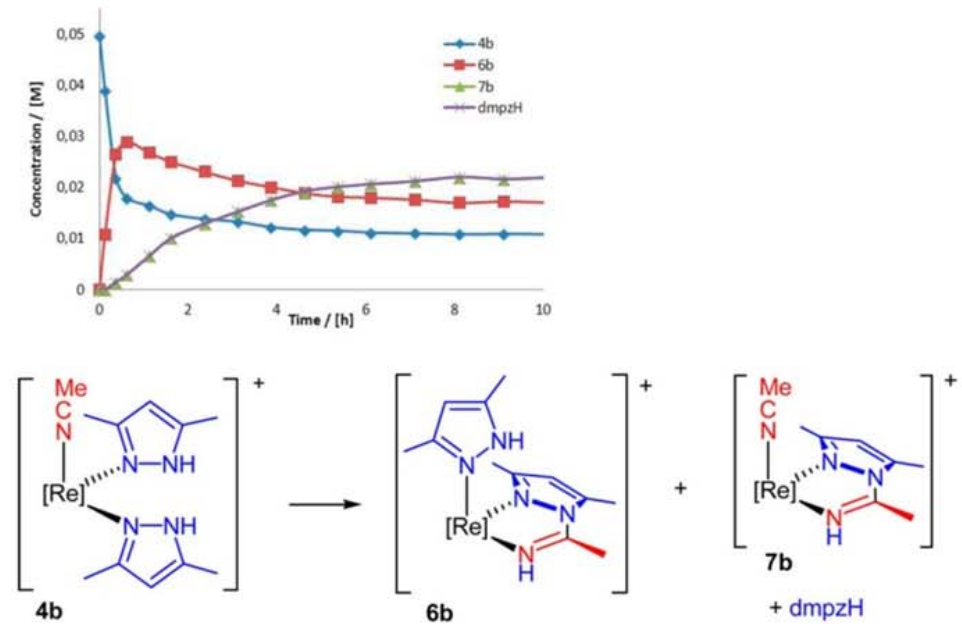

$[\mathrm{Re}]=\operatorname{Re}(\mathrm{CO})_{3}$

Figure 7. Representation of the observed concentrations of $4 \mathbf{b}-\mathrm{BF}_{4}, 6 \mathbf{b}-\mathrm{BF}_{4}, 7 \mathbf{b}-\mathrm{BF}_{4}$, and dmpzH vs time when $4 \mathbf{b}$ is heated in $\mathrm{CD}_{3} \mathrm{CN}_{\text {at }} 80{ }^{\circ} \mathrm{C}$. Final ratio $4 \mathbf{b}-\mathrm{BF}_{4} / 6 \mathbf{b}-\mathrm{BF}_{4} / 7 \mathbf{b}-\mathrm{BF}_{4}=22 / 34 / 44$.

Scheme 4. Conversions of 4 Into 6 in $\mathrm{CD}_{3} \mathrm{CN}$ (framed reaction) and Byproducts Detected When the Process Is Carried out at Higher Temperatures (right) and in $\mathrm{CD}_{3} \mathrm{NO}_{2}$ (left)
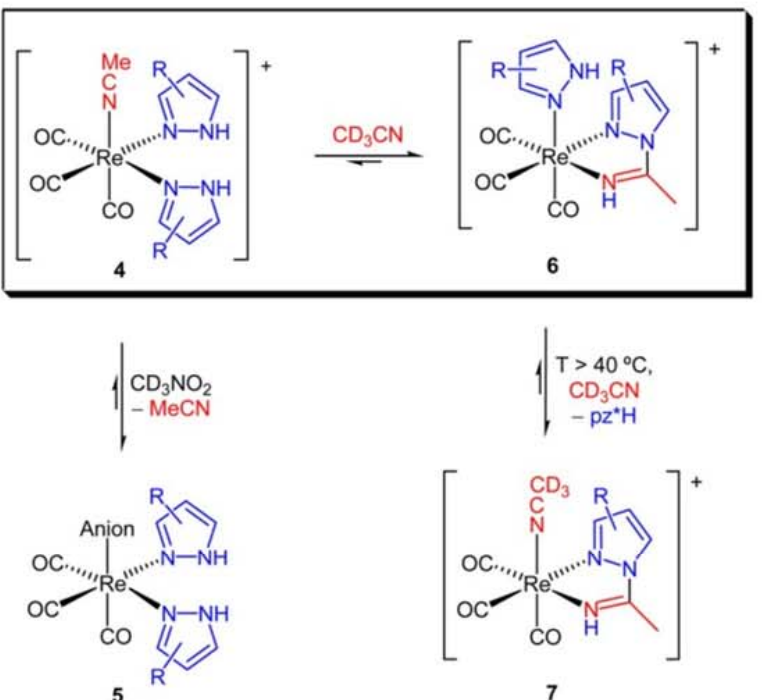

when both the nitrile and the pyrazole are coordinated, and therefore, it is an intramolecular process. In order to confirm this proposal, the coupling process was carried out in the presence of a pyrazole different from that coordinated. Thus, a solution of $4 \mathbf{b}-$ OTf and an equimolar amount of indz $\mathrm{H}$ in $\mathrm{CD}_{3} \mathrm{CN}$ was heated at $40{ }^{\circ} \mathrm{C}$, giving only $6 \mathbf{b}$-OTf and unreacted indzH (Scheme 5 , above). The results were the same after exchanging the role of the pyrazoles, and reaction of $4 \mathrm{c}-\mathrm{ClO}_{4}$ and a equimolar amount of dmpzH in $\mathrm{CD}_{3} \mathrm{CN}$ at room temperature again gave only $6 \mathrm{c}-\mathrm{ClO}_{4}$ and unreacted dmpzH (Scheme 5, below). These results confirm that the pyrazole which undergoes the coupling process is that previously coordinated, thus supporting definitively a intramolecular mechanism for this reaction.
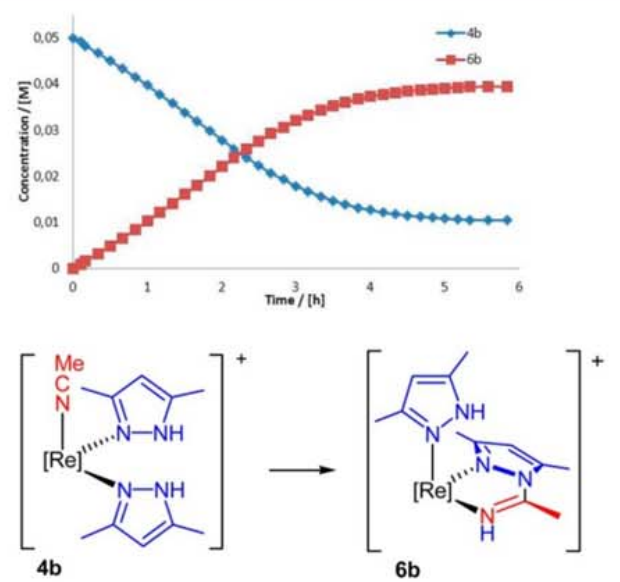

$[\mathrm{Re}]=\operatorname{Re}(\mathrm{CO})_{3}$

Figure 8. Representation of the observed concentrations of $4 b-O T f$ and 6b-OTf when $4 \mathbf{b}$-OTf is heated in $\mathrm{CD}_{3} \mathrm{CN}$ at $40{ }^{\circ} \mathrm{C}$. Final ratio: $4 \mathbf{b}$ OTf $/ 6 \mathbf{b}-$ OTf $=21 / 79$.

A $100 \%$ conversion is not usually achieved in all these processes where mixed acetonitrile-pyrazole cationic complexes convert into the corresponding pyrazolylamidino ligands; instead, a constant ratio mixture of species is commonly obtained (for example, 79/21 for the process depicted in Figure 8, although $100 / 0$ for that shown in Figure S3, Supporting Information). According to the principle of microscopic reversibility, if the reaction were reversible the same mixture should be obtained by the reverse reaction, which is using the final product as starting material. In order to confirm this, different experiments were designed in order to carry out the inverse experiments to those described in the framed reaction of Scheme 4. Thus, heating $6 \mathrm{~b}-\mathrm{OTf}$ at $40^{\circ} \mathrm{C}$ in $\mathrm{CD}_{3} \mathrm{CN}$ afforded a mixture of 6 b-OTf and 4 b-OTf in a $80 / 20$ ratio, that is, similar to that obtained in the direct process described in Figure 8.

On the other hand, in a separate experiment, reaction of $\mathbf{4 b}$ OTf in $\mathrm{CD}_{3} \mathrm{CN}$ at $40{ }^{\circ} \mathrm{C}$ was allowed to reach to the final 
Scheme 5. Reactions Supporting That the Coupling Process Proceeds via an Intramolecular Mechanism
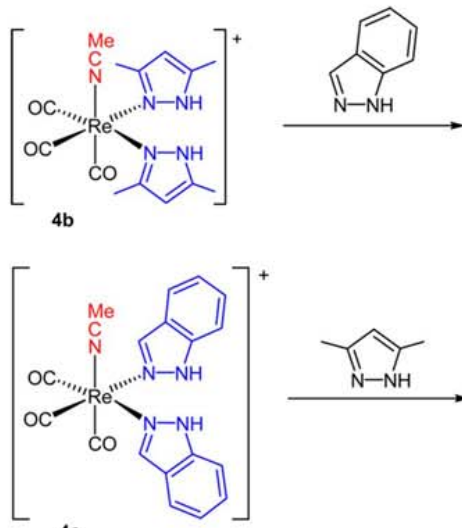

$4 c$
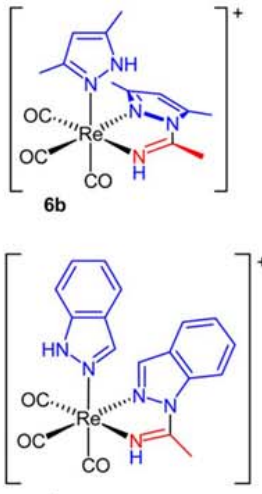

equilibrium, giving the expected mixture of $79 / 21$ of $6 \mathbf{b}$-OTf/4bOTf (Figure 8 ), and then $5 \mathrm{mg}$ of $4 \mathbf{b}$-OTf was added. When the reaction was heated again to $40^{\circ} \mathrm{C}$, the final ratio was the same (Figure S5, Supporting Information), thus supporting that the coupling reaction of pyrazoles and nitriles to obtain pyrazolylamidino ligands is a reversible intramolecular process.

In order to obtain more information about the mechanism of the coupling process, a systematic study was carried out considering the possible factors which may affect the reaction, that is, temperature, pyrazole, anion, and solvent. As shown below, this study allowed us to find a catalyst for this reaction.

All of the following experiments were carried out with cationic complexes 4 , since conversion of neutral bromido complexes 1 to the corresponding pyrazolylamidino complexes $\mathbf{2}$ is not clean nor reversible. The proposal suggested in Scheme 3 for the neutral bromido complexes is confirmed by the experiments just described, carried out with cationic complexes 4 . Removal of the bromido ligand in $\mathbf{1}$ and substitution by acetonitrile would afford cationic complexes of the type fac-[Re$\left.(\mathrm{CO})_{3}(\mathrm{NCMe})_{2}(\mathrm{pz} * \mathrm{H})\right]^{+12}$, which would give the pyrazolylamidino complexes 7 by the reversible intramolecular process explained above. Substitution of the labile acetonitrile in 7 by the bromide present in solution would afford the neutral pyrazolylamidino complexes 2 (Scheme 3 ). However, the high temperatures needed to remove the bromido ligand and thus to start the coupling process may give rise to other secondary reactions, such as substitution of nitriles by pyrazoles to afford bis(pyrazole) complexes $3 .^{13}$ However, the proposed path through cationic complexes might not be the only way to obtain pyrazolylamidino neutral ligands, because they are also formed, although in lower yield, when the process is carried out with an excess of ${ }^{n} \mathrm{Bu}_{4} \mathrm{NBr}$, which should prevent formation of cationic complexes. Nevertheless, drawing conclusions from the latter experiment is difficult, since new species (probably polybromide anionic complexes) are present and contaminate the whole process.

(a) Temperature. As indicated above, clean conversion of 4 to 6 occurs at $40^{\circ} \mathrm{C}$ in $\mathrm{CD}_{3} \mathrm{CN}$, whereas at $80^{\circ} \mathrm{C}$ substitution of the pyrazole by $\mathrm{CD}_{3} \mathrm{CN}$ is observed (Scheme 4). In order to know the optimal temperature for this process, we determined the yields for the synthesis of $6 \mathrm{c}$-OTf from $4 \mathrm{c}$-OTf at different temperatures (from 20 to $60{ }^{\circ} \mathrm{C}$ ) in $\mathrm{CD}_{3} \mathrm{CN}$. In this range of temperatures the results (Table S1, Supporting Information) demonstrate that yields are higher for low temperatures, indicating that the reverse reaction (formation of the pyrazole-nitrile mixed complex from the pyrazolylamidino complex) is more favorable at higher temperatures. This result might be explained considering that the presence of a chelating ligand in the pyrazolylamidino complexes 6 represents a decrease in the entropy, and therefore, increasing temperatures prevents its formation.

(b) Pyrazole. Considering the temperatures and the time needed to achieve the reaction, the tendency of the pyrazoles used in this study to give pyrazolylamidino complexes follow the sequence indzH $>\mathrm{pzH}>\operatorname{dmpzH}$ (Figure 9, Table S2,
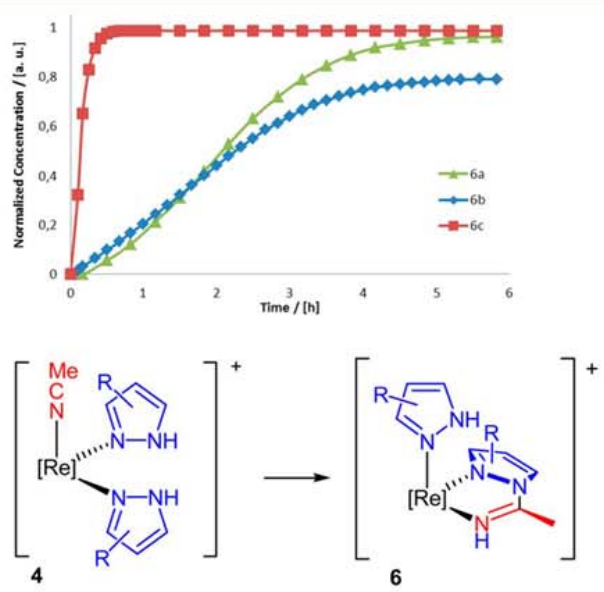

$[\mathrm{Re}]=\operatorname{Re}(\mathrm{CO})_{3}$

Figure 9. Representation of the observed concentrations vs time of complexes 6 when 4 are heated in $\mathrm{CD}_{3} \mathrm{CN}$ at $40^{\circ} \mathrm{C}$.

Supporting Information). This is in accordance with the acidity of the pyrazoles used, which has been experimentally demonstrated to be that theorically expected, indzH $>\mathrm{pzH}>$ $\mathrm{dmpzH} .{ }^{14}$ Therefore, the more acidic pyrazoles facilitate proton transfer from the pyrazole to the donor nitrogen atom of the pyrazolylamidino ligand. This is in accordance with a coupling process with concomitant deprotonation of the pyrazole, as mentioned in the Introduction (Scheme 2, path a).

(c) Anion. As indicated also in the Introduction, the influence of the anion in the coupling process of a coordinated nitrile and pyrazole to give pyrazolylamidino complexes has been already reported, and a transition state for the metal-activated pyrazolenitrile coupling reaction was then proposed. ${ }^{2 a}$ However, in our case, use of different anions $\left(\mathrm{BF}_{4}^{-}, \mathrm{ClO}_{4}^{-}, \mathrm{OTf}^{-}\right)$did not allow us to establish clear differences between them. Therefore, conversion reactions of 4 to 6 were repeated using an excess of sodium salts (usually $3 / 1$, as a larger excess causes precipitation of the salts). Surprisingly, addition of a sodium salt of the anion present in the complex has two effects on the process: reducing both the reaction time and the temperature needed to observe the coupling process. On the other hand, the product/substrate final ratio does not change compared to that obtained without an excess of anion. These experiments allowed us to propose the following sequence for the accelerating role of the anions used in this reaction: $\mathrm{OTf}^{-}>\mathrm{ClO}_{4}^{-}>\mathrm{BF}_{4}^{-}$. However, this sequence does not coincide with the strength of the acids involved, neither in the gas phase nor in MeCN. ${ }^{15}$ Therefore, there must be something else accelerating the reaction, and it might be an 
impurity present in the sodium salts used, which points to a catalyst, given the small amount present and its decisive effect on the reaction.

The review of Kukushkin and Pombeiro on additions to metalactivated organonitriles described that some of them are base catalyzed, ${ }^{1 \mathrm{c}}$ although this had not been previously reported for additions of pyrazoles to metal-activated organonitriles. This led us to conclude that the sodium salts used might be mixed with small amounts of a base. Then we measured the $\mathrm{pH}$ of $1 \mathrm{M}$ solutions in $\mathrm{H}_{2} \mathrm{O}$ of the sodium salts used, and the amount of impure base is directly related to the observed sequence ( $\mathrm{pH}$ of 1 $\mathrm{M}$ solutions in $\left.\mathrm{H}_{2} \mathrm{O}\right)$ : $\left.\mathrm{OTf}^{-}(11.1)>\mathrm{ClO}_{4}{ }^{-}(9.3)>\mathrm{BF}_{4}{ }^{-}(2.6)\right)$. When the experiment was repeated with pure salts $(\mathrm{pH}$ of $1 \mathrm{M}$ solutions in $\mathrm{H}_{2} \mathrm{O}=7$ ) the excess of anions did not have any evident effect on the reaction time nor on the reaction yield (Figure S6, Supporting Information).

(d) Catalyst for the reaction. Therefore, we decided to repeat the coupling process in the presence of a small amount of aqueous solution of $\mathrm{NaOH}$. Formation of pyrazolylamidino complexes 6 after addition of a $0.5 \% \mathrm{NaOH}$ (as ca. $0.02 \mathrm{M}$ aqueous solution) to $\mathrm{CD}_{3} \mathrm{CN}$ solutions of 4 was immediate, occurring at room temperature and quantitatively (for $\mathrm{pzH}$ or indzH) or with very high yield (for dmpzH),

As described above, formation of pyrazolylamidino neutral bromo complexes $\mathbf{2}$ from 1 was not clean (Figure 6). However, when these processes were repeated in the presence of $1 \%$ of $\mathrm{NaOH}$ (again as ca. $0.02 \mathrm{M}$ aqueous solution), formation of 2 occurred in milder conditions and with higher yields with respect to those reactions carried out without base (see the synthesis of $2 \mathrm{c}$ in the Experimental Section, carried out by both methods, and Table S3, Supporting Information). As indicated above, reactions are not so favored for neutral complexes as for cationic complexes, since the nitrile is less activated. These experiments lead us to conclude that the coupling reaction of pyrazoles and acetonitrile to give pyrazolylamidino ligands is base catalyzed.

As we are using an aqueous solution of $\mathrm{NaOH}$, we decided to explore the role in the reaction of (a) water and (b) acids (since the $\mathrm{NaBF}_{4}$ first used was contaminated with acid). Figure 10 shows the concentration vs time of $6 \mathrm{a}$, when the parent complex 4a was heated at $40{ }^{\circ} \mathrm{C}$ in dry $\mathrm{CD}_{3} \mathrm{CN}$ or treated with either $0.5 \%$ of $\mathrm{NaOH}(\mathrm{aq}), 0.5 \%$ of $\mathrm{HBF}_{4}$ (aq), or the same amount of neutral $\mathrm{H}_{2} \mathrm{O}$ in $\mathrm{CD}_{3} \mathrm{CN}$ at room temperature. Figure 10 shows that the reaction is immediate when $\mathrm{NaOH}(\mathrm{aq})$ is added (the reaction had already concluded when the first NMR spectrum is obtained), whereas the reaction carried out in the presence of the same amount of $\mathrm{H}_{2} \mathrm{O}$ is slower. The reaction rate of the latter is almost identical to that carried out when of $0.5 \%$ of $\mathrm{HBF}_{4}$ is added; therefore, strong acids have no effect on the reaction rate. The concentration of the final product when the reaction is carried out in dry $\mathrm{CD}_{3} \mathrm{CN}$ is shown at the bottom, but these data correspond to the reaction at $40^{\circ} \mathrm{C}$, because it is too slow in dry $\mathrm{CD}_{3} \mathrm{CN}$ at room temperature.

We also explored the behavior of weaker bases than $\mathrm{NaOH}$. Figure S7, Supporting Information, shows how addition of weaker bases than $\mathrm{NaOH}(\mathrm{aq})$, such as acetate or fluoride, produces the expected results considering their $\mathrm{pH}$, which is a faster process than those with neutral or acid water but slower than those with the same amount of $\mathrm{NaOH}$ (aq). Surprisingly, addition of cyanide gives rise to an even slower process. Unfortunately, so far we have no explanation for this surprising behavior of the cyanide ion.

As indicated in the Introduction, intramolecular nucleophilic attack of the pyrazole to the coordinated nitrile coordinated cis is
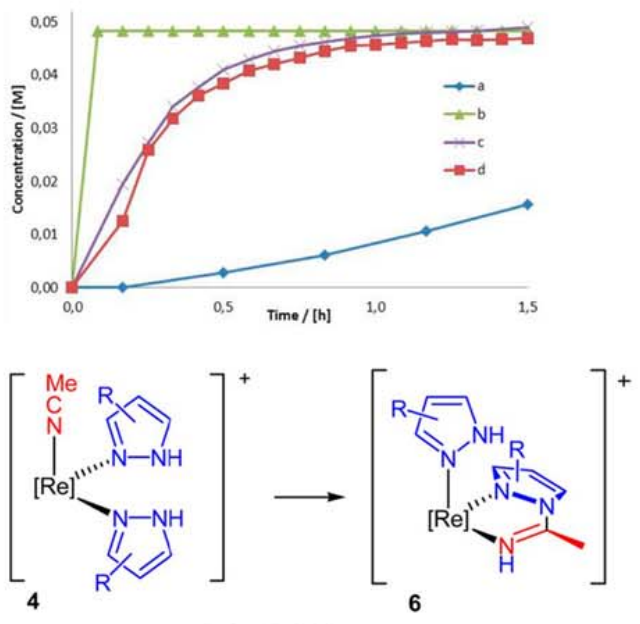

$[\mathrm{Re}]=\operatorname{Re}(\mathrm{CO})_{3}$

Figure 10. Representation of the observed concentrations of $6 \mathrm{a}$ when (a) $4 \mathrm{a}-\mathrm{ClO}_{4}$ is heated at $40{ }^{\circ} \mathrm{C}$ and when $4 \mathrm{a}-\mathrm{BF}_{4}$, is stirred at room temperature with (b) $6.2 \mu \mathrm{L}$ of $0.5 \%$ of $\mathrm{NaOH}$ (aq), (c) $6.2 \mu \mathrm{L}$ of $0.5 \%$ of $\mathrm{HBF}_{4}(\mathrm{aq})$, or (d) $6.2 \mu \mathrm{L}$ of $\mathrm{H}_{2} \mathrm{O}$ are added. All reactions are carried out in $\mathrm{CD}_{3} \mathrm{CN}$; $0.05 \mathrm{M}$ is $100 \%$ yield.

only possible by considering the previous deprotonation of the $\mathrm{NH}$ group (Scheme 2, path a). Therefore, the actual role of the base as catalyst for this process may be facilitating this deprotonation. The fact that small amounts of water (either neutral or acidic) also accelerate the process (although less efectively compared to the aqueous base solution, Figure 10) might indicate that autoprotolysis occurring in aqueous media may also help this deprotonation and therefore the coupling process. Furthermore, a clear dependence of the basicity is established, as the effect of weaker bases is feebler than that of $\mathrm{NaOH}$.

(e). Solvent. As indicated above, all kinetic studies were carried out in $\mathrm{CD}_{3} \mathrm{CN}$ because the attempts to carry out the reactions in $\mathrm{CD}_{3} \mathrm{NO}_{2}$ led to total or partial substitution of the acetonitrile ligand. However, as the reactions base catalyzed are immediate (starting from cationic complexes 4 ) or very fast (for neutral complexes 1), we decided to explore the use of other solvents in this case. For the latter, the processes could be carried out only in $\mathrm{CD}_{3} \mathrm{CN}$, since use of other solvents led again to mixtures of products. However, for cationic complexes 4, the results of the base-catalyzed coupling processes in $\mathrm{CD}_{3} \mathrm{NO}_{2}$ or $\left(\mathrm{CD}_{3}\right)_{2} \mathrm{CO}$ are similar to those obtained in $\mathrm{CD}_{3} \mathrm{CN}$, that is, the reactions are quantitative and immediate and occurred at room temperature.

\section{CONCLUSIONS}

Synthesis of different rhenium complexes containing both pyrazole and nitrile ligands has allowed us to study the mechanism of the coupling reaction between these two ligands to afford pyrazolylamidino complexes. The study was carried out on cationic complexes because the nitrile is more electrophilic than in neutral complexes, and thus, for the latter higher temperatures are needed, which facilitates formation of different byproducts. All of the data obtained starting from pyrazolenitrile mixed cationic complexes support that the coupling process to give pyrazolylamidino ligands occurs by a reversible intramolecular mechanism. The systematic study carried out on this process revealed that the coupling process is favored: (a) at 
moderate temperatures (and unfavored as the temperature increases), opposite to what was commonly accepted, since pyrazolylamidino complexes had been traditionally synthesized by refluxing or heating pyrazole complexes in nitriles as solvents, and (b) with the acidity of the pyrazole. We found that the coupling process is base catalyzed, and the reactions to obtain cationic pyrazolylamidino complexes are quantitative and immediate and occurred at room temperature for different solvents when $\leq 1 \%$ of $\mathrm{NaOH}$ (aq) is added to the parent complex solution. Neutral bromido pyrazolylamidino complexes are obtained rapidly and at room temperature when $1 \%$ of $\mathrm{NaOH}$ (aq) is added to the parent complex $\mathrm{CD}_{3} \mathrm{CN}$ solution. We believe that these results open a broad range of synthetic possibilities to obtain new pyrazolylamidino complexes in the future.

\section{EXPERIMENTAL SECTION}

General Remarks. All manipulations were performed under $\mathrm{N}_{2}$ atmosphere following conventional Schlenk techniques. Solvents were purified according to standard procedures. ${ }^{16} \mathrm{fac}-[\mathrm{ReBr}$ $\left.(\mathrm{CO})_{3}(\mathrm{NCMe})_{2}\right]$ was obtained as previously described. ${ }^{17}$ Table 1 collects references for the preparation and characterization of some of the complexes herein used. All other reagents were obtained from the usual commercial suppliers and used as received. Caution! Although no difficulties were experienced with the perchlorate complexes described herein, all perchlorate species should be treated as potentially explosive and handled with care. Infrared spectra were recorded in a PerkinElmer FT-IR spectrum $\mathrm{BX}$ apparatus using $0.2 \mathrm{~mm} \mathrm{CaF}_{2}$ cells for solutions or on $\mathrm{KBr}$ pellets for solid samples. NMR spectra were recorded in Bruker AV-400 or Varian MR500 instruments at room temperature and are referred to the internal residual solvent peak for ${ }^{1} \mathrm{H}$ and ${ }^{13} \mathrm{C}\left\{{ }^{1} \mathrm{H}\right\}$ NMR. Assignment of the ${ }^{13} \mathrm{C}\left\{{ }^{1} \mathrm{H}\right\}$ NMR data was supported by $2 \mathrm{D}$ heteronuclear experiments and relative intensities of the resonance signals. Elemental analyses were performed on a PerkinElmer 2400B microanalyzer.

fac- $\left[\operatorname{ReBr}(\mathrm{CO})_{3}(\mathrm{NCMe})(\right.$ indzH) $], 1 c$. Indazole $(0.059 \mathrm{~g}, 0.50 \mathrm{mmol})$ was added to a solution of $f a c-\left[\operatorname{ReBr}(\mathrm{CO})_{3}(\mathrm{NCMe})_{2}\right](0.216 \mathrm{~g}, 0.50$ $\mathrm{mmol})$ in THF $(15 \mathrm{~mL})$. The solution was stirred at $0{ }^{\circ} \mathrm{C}$ for $10 \mathrm{~min}$. Hexane (ca. $25 \mathrm{~mL}$ ) was added, and the solution was concentrated in vacuo and cooled to $-20{ }^{\circ} \mathrm{C}$, giving a colorless microcrystalline solid, which was decanted, washed with hexane $(3 \times 3 \mathrm{~mL}$ approximately), and dried in vacuo, yielding $0.154 \mathrm{~g}(61 \%)$. IR (THF, $\left.\mathrm{cm}^{-1}\right): 2030 \mathrm{vs,}, 1930$ vs, 1900 vs. IR $\left(\mathrm{KBr}, \mathrm{cm}^{-1}\right): 3378 \mathrm{~m}, 2028$ vs, 1903 vs br, $1628 \mathrm{w}, 1560$ w, 1508 w, 1438 w, 1358 m, 1273 w, 1246 w, 1150 w, 1096 m, 1029 w, 964 w, 749 m, 640 w, 529 w, 487 w. ${ }^{1} \mathrm{H}$ NMR (399.8 MHz, Me $\left.\mathrm{MO}_{2} \mathrm{CO} d_{6}\right)$ : $2.58\left(\mathrm{~s}, \mathrm{NCCH}_{3}, 3 \mathrm{H}\right), 7.30\left(\mathrm{t}, J=7.5 \mathrm{~Hz}, H^{6}\right.$ indzH, $\left.1 \mathrm{H}\right), 7.56(\mathrm{t}, J=7.5$ $\mathrm{Hz}, H^{5}$ indzH, $\left.1 \mathrm{H}\right), 7.76\left(\mathrm{~d}, J=8.5 \mathrm{~Hz}, H^{4}\right.$ indzH, $\left.1 \mathrm{H}\right), 7.91(\mathrm{~d}, J=8.0$ $\mathrm{Hz}, H^{7}$ indzH, $\left.1 \mathrm{H}\right), 8.68$ (s, $H^{3}$ indzH, $\left.1 \mathrm{H}\right), 12.64(\mathrm{~s}, \mathrm{NH}, 1 \mathrm{H})$. ${ }^{13} \mathrm{C}\left\{{ }^{1} \mathrm{H}\right\}$ NMR $\left(100.5 \mathrm{MHz}, \mathrm{Me}_{2} \mathrm{CO}-d_{6}\right): 112.1$ (s, $\mathrm{C}^{4}$ indzH), 122.1 (s, $\left.\mathrm{NCCH}_{3}\right), 122.4$ (s, $\mathrm{C}^{7} \mathrm{H}$ indzH), 123.9 (s, $\mathrm{C}^{6}$ indzH), 124.5 (s, $\mathrm{C}^{3 \mathrm{a}}$ indzH), $130.6\left(\mathrm{~s}, \mathrm{C}^{5}\right.$ indzH), $141.2\left(\mathrm{~s}, \mathrm{C}^{3}\right.$ indzH), $142.4\left(\mathrm{~s}, \mathrm{C}^{7 \mathrm{a}}\right.$ indzH), $163.6\left(\mathrm{~s}, \mathrm{NCCH}_{3}\right), \mathrm{CO}$ not observed. Anal. Calcd for $\mathrm{C}_{12} \mathrm{H}_{9} \mathrm{BrN}_{3} \mathrm{O}_{3} \mathrm{Re}$ : C, 28.30; H, 1.78; N, 8.25. Found: C, 27.98; H, 2.00; N, 8.58.

fac- $\left[\operatorname{ReBr}(\mathrm{CO})_{3}\left(\mathrm{NH}=\mathrm{C}(\mathrm{Me})\right.\right.$ ind $\left.\left.z-\kappa^{2} \mathrm{~N}, \mathrm{~N}\right)\right]$, 2c. Method $\mathrm{A}$. Indazole $(0.059 \mathrm{~g}, 0.50 \mathrm{mmol})$ was added to a solution of $\mathrm{fac}$-[ReBr$\left.(\mathrm{CO})_{3}(\mathrm{NCMe})_{2}\right](0.216 \mathrm{~g}, 0.50 \mathrm{mmol})$ in $\mathrm{CH}_{3} \mathrm{CN}(15 \mathrm{~mL})$. The solution was stirred at $80^{\circ} \mathrm{C}$ for $17 \mathrm{~h}$. Volatiles were removed in vacuo, and the yellow residue was crystallized in acetone/hexane at $-20^{\circ} \mathrm{C}$, giving a yellow microcrystalline solid, which was decanted, washed with hexane $(3 \times 3 \mathrm{~mL}$ approximately), and dried in vacuo, yielding $0.172 \mathrm{~g}$ (67\%). Method B. Indazole $(0.035 \mathrm{~g}, 0.30 \mathrm{mmol})$ was added to a solution of $f a c-\left[\operatorname{ReBr}(\mathrm{CO})_{3}(\mathrm{NCMe})_{2}\right](0.130 \mathrm{~g}, 0.30 \mathrm{mmol})$ in $\mathrm{CH}_{3} \mathrm{CN}(15$ $\mathrm{mL}$ ), and the solution was stirred for $20 \mathrm{~min}$ at $40^{\circ} \mathrm{C}$. Then $0.17 \mathrm{~mL}$ of $\mathrm{NaOH}$ aqueous solution $(0.018 \mathrm{M}, 0.003 \mathrm{mmol})$ was added, and the solution was stirred for another $30 \mathrm{~min}$ at $40^{\circ} \mathrm{C}$. Volatiles were removed in vacuo, and the residue was crystallized in acetone/hexane at $-20^{\circ} \mathrm{C}$, yielding $135 \mathrm{mg}(89 \%)$. IR (THF, $\left.\mathrm{cm}^{-1}\right): 2021 \mathrm{vs,} 1923 \mathrm{vs,} 1894$ vs. IR $\left(\mathrm{KBr}, \mathrm{cm}^{-1}\right): 3183 \mathrm{~s}, 2020$ vs, $1925 \mathrm{vs}, 1889$ vs, $1632 \mathrm{~m}, 1509 \mathrm{~m}, 1474 \mathrm{~m}$, $1449 \mathrm{~m}, 1355 \mathrm{~m}, 1280 \mathrm{~m}, 1218 \mathrm{w}, 1201 \mathrm{~m}, 1160 \mathrm{w}, 1102 \mathrm{w}, 1063 \mathrm{~m}$, 1016 w, 984 w, 913 w, 883 w, 839 w, 788 w, 768 m, 646 w, 623 w, 532m,
506 w, 492 w, 471 m. ${ }^{1} \mathrm{H}$ NMR (399.8 MHz, Me 2 CO- $d_{6}$ ): 3.28 (s, $\left.\mathrm{NCCH}_{3}, 3 \mathrm{H}\right), 7.59\left(\mathrm{t}, J=7.5 \mathrm{~Hz}, H^{6}\right.$ indz, $\left.1 \mathrm{H}\right), 7.82\left(\mathrm{t}, J=8.0 \mathrm{~Hz}, H^{5}\right.$ indz, $1 \mathrm{H}), 8.11\left(\mathrm{~d}, J=8.0 \mathrm{~Hz}, H^{7}\right.$ indz, $\left.1 \mathrm{H}\right), 8.19\left(\mathrm{~d}, J=9.0 \mathrm{~Hz}, H^{4}\right.$ indz, $1 \mathrm{H}), 9.07$ (s, $H^{3}$ indz, $\left.1 \mathrm{H}\right), 10.92(\mathrm{~s}, \mathrm{NH}, 1 \mathrm{H}) .{ }^{13} \mathrm{C}\left\{{ }^{1} \mathrm{H}\right\} \mathrm{NMR}(100.5$ $\left.\mathrm{MHz}, \mathrm{Me}_{2} \mathrm{CO}-d_{6}\right): 20.3\left(\mathrm{~s}, \mathrm{NCCH}_{3}\right), 112.2\left(\mathrm{~s}, \mathrm{C}^{4}\right.$ indz), $122.6\left(\mathrm{~s}, \mathrm{C}^{7}\right.$ indz), $125.1\left(\mathrm{~s}, \mathrm{C}^{6}\right.$ indz), $131.3\left(\mathrm{~s}, \mathrm{C}^{5}\right.$ indz), $143.8\left(\mathrm{~s}, \mathrm{C}^{3} \mathrm{indz}\right), 163.6(\mathrm{~s}$, $\mathrm{NCCH}_{3}$ ), $\mathrm{C}^{3 \mathrm{a}}$ (indz), $\mathrm{C}^{7 \mathrm{a}}$ (indz) and $\mathrm{CO}$ were not observed due to the low solubility of the compound. Anal. Calcd for $\mathrm{C}_{12} \mathrm{H}_{9} \mathrm{BrN}_{3} \mathrm{O}_{3} \mathrm{Re}$ : C, 28.30; H, 1.78; N, 8.25. Found: C, 28.36; H, 1.73; N, 8.28.

fac- $\left[\operatorname{ReBr}(\mathrm{CO})_{3}(\mathrm{indzH})_{2}\right], 3 \mathrm{c}$. Indazole $(0.071 \mathrm{~g}, 0.60 \mathrm{mmol})$ was added to a solution of $f a c-\left[\operatorname{ReBr}(\mathrm{CO})_{3}(\mathrm{MeCN})_{2}\right](0.130 \mathrm{~g}, 0.30 \mathrm{mmol})$ in THF $(20 \mathrm{~mL})$. The solution was stirred for $1 \mathrm{~h}$ at room temperature. Hexane (ca. $20 \mathrm{~mL}$ ) was added, and the solution was concentrated and cooled to $-20{ }^{\circ} \mathrm{C}$, giving a colorless microcrystalline solid, which was decanted, washed with hexane $(3 \times 3 \mathrm{~mL}$ approximately), and dried in vacuo, yielding $0.143 \mathrm{~g}(81 \%)$. IR (THF, $\left.\mathrm{cm}^{-1}\right)$ : $2026 \mathrm{vs,} 1924 \mathrm{vs}, 1895$ vs. $\operatorname{IR}\left(\mathrm{KBr}, \mathrm{cm}^{-1}\right): 3311 \mathrm{~s}, 2020$ vs, 1910 vs, $1891 \mathrm{vs,} 1629 \mathrm{~m}, 1511 \mathrm{w}$, $1356 \mathrm{~m}, 1244 \mathrm{~m}, 1002 \mathrm{w}, 961 \mathrm{w}, 832 \mathrm{~m}, 752 \mathrm{~m}, 744 \mathrm{~m}, 673 \mathrm{w}, 660 \mathrm{~m}, 648$ $\mathrm{m}, 542 \mathrm{~m}, 430 \mathrm{w} .{ }^{1} \mathrm{H}$ NMR $\left(399.8 \mathrm{MHz}, \mathrm{Me}_{2} \mathrm{CO}-d_{6}\right): 7.26(\mathrm{t}, J=7.5 \mathrm{~Hz}$, $H^{6}$ indzH, $\left.2 \mathrm{H}\right), 7.52\left(\mathrm{t}, J=7.5 \mathrm{~Hz}, H^{5}\right.$ indzH, $\left.2 \mathrm{H}\right), 7.69(\mathrm{~d}, J=8.5 \mathrm{~Hz}$, $H^{4}$ indz $\left.\mathrm{H}, 2 \mathrm{H}\right), 7.85\left(\mathrm{~d}, J=8.0 \mathrm{~Hz}, H^{7}\right.$ indz $\left.\mathrm{H}, 2 \mathrm{H}\right), 8.56\left(\mathrm{~s}, \mathrm{H}^{3}\right.$ indz $\mathrm{H}, 2$ $\mathrm{H}), 12.63$ (s, NH, 2 H) $\left.{ }^{13} \mathrm{C}^{1}{ }^{1} \mathrm{H}\right\} \mathrm{NMR}\left(100.5 \mathrm{MHz}, \mathrm{Me}_{2} \mathrm{CO}-d_{6}\right): 112.3$ (s, $\mathrm{C}^{4}$ indzH), 122.7 (s, $\mathrm{C}^{7}$ indzH), $124.2\left(\mathrm{~s}, \mathrm{C}^{6}\right.$ indzH), $124.8\left(\mathrm{~s}, \mathrm{C}^{3 \mathrm{a}}\right.$ indzH), 130.8 (s, $\mathrm{C}^{5}$ indzH), $141.6\left(\mathrm{~s}, \mathrm{C}^{3}\right.$ indzH), 142.7 (s, $\mathrm{C}^{7 \mathrm{a}}$ indzH), 191.9 (br, 1 CO), 197.4 (br, 2 CO). Anal. Calcd for $\mathrm{C}_{17} \mathrm{H}_{12} \mathrm{BrN}_{4} \mathrm{O}_{3} \mathrm{Re}$ : C, 34.82; H, 2.06; N, 9.55. Found: C, 34.75; H, 1.86; N, 9.09.

fac- $\left[\operatorname{Re}(\mathrm{CO})_{3}(\mathrm{NCMe})(\mathrm{pzH})_{2}\right] \mathrm{BF}_{4}, 4 a-\mathrm{BF}_{4}$. Silver tetrafluoroborate $(0.054 \mathrm{~g}, 0.28 \mathrm{mmol})$ was added to a solution of $3 \mathrm{a}(0.122 \mathrm{~g}, 0.25$ $\mathrm{mmol})$ in THF $(20 \mathrm{~mL})$, and the mixture was stirred for $1 \mathrm{~h}$ at $40^{\circ} \mathrm{C}$ in the absence of light. The reaction mixture was dried in vacuo, and the residue was extracted with $\mathrm{CH}_{2} \mathrm{Cl}_{2}(20 \mathrm{~mL})$, filtered, and dried in vacuo. The white residue was dissolved in $\mathrm{CHCl}_{3} / \mathrm{MeCN}(5 \mathrm{~mL} / 5 \mathrm{~mL})$, and the solution was stirred for $4 \mathrm{~h}$ at $0{ }^{\circ} \mathrm{C}$. The solvent was then removed in vacuo to give a white solid, which was recrystallized from $\mathrm{CHCl}_{3} /$ hexane at $-20^{\circ} \mathrm{C}$, giving a colorless microcrystalline solid, which was decanted, washed with hexane $(3 \times 3 \mathrm{~mL}$ approximately $)$, and dried in vacuo, yielding $87 \mathrm{mg}(60 \%)$. IR (THF, $\mathrm{cm}^{-1}$ ): 2034 vs, 1934 vs, 1922 vs. IR $\left(\mathrm{KBr}, \mathrm{cm}^{-1}\right): 3222 \mathrm{~m}, 3160 \mathrm{~m}, 2040 \mathrm{vs}, 1950 \mathrm{vs}, 1918 \mathrm{vs}, 1290 \mathrm{~s}, 1257 \mathrm{~s}$, 1244 s, 1224 m, 1182 s, 1131 m, 1070 w, 1055 m, 1026 s, 950 w, 878 w, 777 m, 652 w, 637 m, 606 w, 575 w, 519 w, 494 w, 411 w. ${ }^{1}$ H NMR $\left(399.8 \mathrm{MHz} \mathrm{CDCl}_{3}\right): 2.67\left(\mathrm{~s}, \mathrm{NCCH}_{3}, 3 \mathrm{H}\right), 6.39\left(\mathrm{~s}, \mathrm{H}^{4} \mathrm{pzH}, 2 \mathrm{H}\right), 7.71$ (s, $\left.H^{3,5} \mathrm{pzH}, 2 \mathrm{H}\right), 7.77\left(\mathrm{~s}, H^{5,3} \mathrm{pzH}, 2 \mathrm{H}\right), 12.19(\mathrm{~s}, \mathrm{NH}, 2 \mathrm{H}) \cdot{ }^{13} \mathrm{C}\left\{{ }^{1} \mathrm{H}\right\}$ NMR (100.5 MHz, $\left.\mathrm{CDCl}_{3}\right): 5.8(\mathrm{~s}, \mathrm{NCCH} 3), 107.7\left(\mathrm{~s}, \mathrm{C}^{4} \mathrm{pzH}\right), 125.3$ (s, NCCH3), 133.5 (s, C $\left.\mathrm{C}^{5,3} \mathrm{pzH}\right), 145.3$ (s, C $\left.\mathrm{C}^{3,5} \mathrm{pzH}\right), 191.7$ (s, $\left.3 \mathrm{CO}\right)$. ${ }^{19} \mathrm{~F}$ NMR (376.2 $\left.\mathrm{MHz}, \mathrm{CDCl}_{3}\right):-149.8\left(\mathrm{~s},{ }^{10} \mathrm{BF}_{4}, 4 \mathrm{~F}\right),-149,9(\mathrm{~s}$, $\left.{ }^{11} \mathrm{BF}_{4}, 4 \mathrm{~F}\right)$. Anal. Calcd for $\mathrm{C}_{11} \mathrm{H}_{11} \mathrm{BF}_{4} \mathrm{~N}_{5} \mathrm{O}_{3} \mathrm{Re}: \mathrm{C}, 24.67 ; \mathrm{H}, 2.07 ; \mathrm{N}$, 13.08. Found: C, 24.44; H, 1.71; N, 12.78 .

fac- $\left[\operatorname{Re}(\mathrm{CO})_{3}(\mathrm{NCMe})(\text { indzH })_{2}\right] \mathrm{BF}_{4}, 4 \mathrm{c}-\mathrm{BF}_{4}$. Silver tetrafluoroborate $(0.107 \mathrm{~g}, 0.55 \mathrm{mmol})$ was added to a solution of $3 \mathrm{c}(0.293 \mathrm{~g}, 0.50 \mathrm{mmol})$ in THF $(30 \mathrm{~mL})$. Working up as for $4 \mathrm{a}-\mathrm{BF}_{4}$ gave $173 \mathrm{mg}(53 \%)$ of $4 \mathrm{c}-$ $\mathrm{BF}_{4}$ as a colorless microcrystalline solid. IR (THF, $\mathrm{cm}^{-1}$ ): $2036 \mathrm{vs}, 1929$ vs. IR $\left(\mathrm{KBr} \mathrm{cm}^{-1}\right): 3338 \mathrm{~m}, 3138 \mathrm{~m}, 2291 \mathrm{w}, 2041 \mathrm{vs,} 1943 \mathrm{vs}, 1925$ vs, $1630 \mathrm{~m}, 1515 \mathrm{~m}, 1388 \mathrm{~m}, 1377 \mathrm{~m}, 1360 \mathrm{~m}, 1285 \mathrm{w}, 1247 \mathrm{w}, 1226 \mathrm{w}$, 1084 vs, 1062 vs, 1031 s, 902 w, 840 w, 782 w, 753 m, 647 w, 534 w, 482 w, 432 w. ${ }^{1} \mathrm{H}$ NMR (499.7 MHz, $\mathrm{CDCl}_{3}$ ): $2.82\left(\mathrm{~s}, \mathrm{NCCH}_{3}, 3 \mathrm{H}\right), 7.24$ (partially overlapped by the solvent signal, $H^{6}$ indzH, $\left.2 \mathrm{H}\right), 7.51(\mathrm{t}, \mathrm{J}=$ $8.0 \mathrm{~Hz}, H^{5}$ indzH, $\left.2 \mathrm{H}\right), 7.69\left(\mathrm{~d}, \mathrm{~J}=7.5 \mathrm{~Hz}, \mathrm{H}^{7}\right.$ indzH, $\left.2 \mathrm{H}\right), 7.82(\mathrm{~d}, \mathrm{~J}=$ $8.5 \mathrm{~Hz}, H^{4}$ indzH, $\left.2 \mathrm{H}\right), 8.32\left(\mathrm{~s}, \mathrm{H}^{3}\right.$ indzH, $\left.2 \mathrm{H}\right), 11.74(\mathrm{~s}, \mathrm{br}, \mathrm{NH}, 2 \mathrm{H})$. ${ }^{13} \mathrm{C}\left\{{ }^{1} \mathrm{H}\right\}$ NMR $\left(499.7 \mathrm{MHz}, \mathrm{CDCl}_{3}\right): 5.9\left(\mathrm{~s}, \mathrm{NCCH}_{3}\right), 112.1\left(\mathrm{~s}, \mathrm{C}^{4}\right.$ indzH), 120.4 (s, $\mathrm{C}^{7}$ indzH), 122.8 (s, $\mathrm{C}^{3 a}$ indzH), 123.5 (s, $\mathrm{C}^{6}$ indzH), $126.4\left(\mathrm{~s}, \mathrm{NCCH}_{3}\right), 130.2$ (s, $\mathrm{C}^{5}$ indzH), 141.0 (s, $\mathrm{C}^{3}$ indzH), 141.8 (s, $\mathrm{C}^{7 a}$ indzH), $191.3(\mathrm{~s}, 2 \mathrm{CO}), 192.0(\mathrm{~s}, \mathrm{CO}) .{ }^{19} \mathrm{~F}$ NMR $(470.2 \mathrm{MHz}$, $\left.\mathrm{CDCl}_{3}\right):-149.97\left(\mathrm{~s},{ }^{10} \mathrm{BF}_{4}, 4 \mathrm{~F}\right),-150.2\left(\mathrm{~s},{ }^{11} \mathrm{BF}_{4}, 4 \mathrm{~F}\right)$. Anal. Calcd for $\mathrm{C}_{19} \mathrm{H}_{15} \mathrm{BF}_{4} \mathrm{~N}_{5} \mathrm{O}_{3}$ Re: $\mathrm{C}, 35.90 ; \mathrm{H}, 2.38 ; \mathrm{N}, 11.02$. Found: C, 35.62; H, $2.11 ; \mathrm{N}, 10.77$.

fac- $\left[\operatorname{Re}(\mathrm{CO})_{3}(\mathrm{pzH})_{2}(\mathrm{OTf})\right], 5 a$. Silver triflate $(0.084 \mathrm{~g}, 0.33 \mathrm{mmol})$ was added to a solution of $3 \mathrm{a}(0.146 \mathrm{~g}, 0.3 \mathrm{mmol})$ in THF $(15 \mathrm{~mL})$, and the mixture was stirred for $1 \mathrm{~h}$ at room temperature in the absence of light. The reaction mixture was filtered, and hexane was added to the filtrate. The solution was concentrated and cooled to $-20^{\circ} \mathrm{C}$, giving a colorless 
microcrystalline solid, which was decanted, washed with hexane $(3 \times 3$ $\mathrm{mL}$ approximately), and dried in vacuo, yielding $0.145 \mathrm{~g}$ (87\%). IR $\left(\mathrm{THF}, \mathrm{cm}^{-1}\right): 2037 \mathrm{vs}, 1932 \mathrm{vs}, 1905 \mathrm{vs}$. IR $\left(\mathrm{KBr}, \mathrm{cm}^{-1}\right): 3291 \mathrm{~s}, 3270 \mathrm{~s}$ 2036 vs, 1930 vs, 1917 vs, 1654 w, 1560 w, 1540 w, 1491 w, 1412 w, 1364 w, $1314 \mathrm{~s}, 1236 \mathrm{~s}, 1212 \mathrm{~s}, 1191 \mathrm{~m}, 1139 \mathrm{~m}, 1070 \mathrm{w}, 1057 \mathrm{~m}, 1031 \mathrm{~m}, 952$ w, 912 w, 863 w, 777 m, 659 w, 633 m, 606 w, 573 w, 537 w. ${ }^{1}$ H NMR $\left(399.8 \mathrm{MHz}^{\mathrm{CDCl}}{ }_{3}\right): 6.45\left(\mathrm{~s}, \mathrm{H}^{4} \mathrm{pzH}, 1 \mathrm{H}\right), 7.58\left(\mathrm{~s}, H^{3,5} \mathrm{pzH}, 1 \mathrm{H}\right)$, $7.71\left(\mathrm{~s}, H^{5,3} \mathrm{pzH}, 1 \mathrm{H}\right), 11,42(\mathrm{~s}, \mathrm{NH}, 1 \mathrm{H}) .{ }^{13} \mathrm{C}\left\{{ }^{1} \mathrm{H}\right\} \mathrm{NMR}(100.5 \mathrm{MHz}$, $\left.\mathrm{CDCl}_{3}\right): 107.8\left(\mathrm{~s}, \mathrm{C}^{4} \mathrm{pzH}\right), 119.1\left(\mathrm{~s}, \mathrm{CF}_{3} \mathrm{SO}_{3}\right), 131.5\left(\mathrm{~s}, \mathrm{C}^{5,3} \mathrm{pzH}\right), 143.1$ (s, $\left.\mathrm{C}^{3,5} \mathrm{pzH}\right), 192.3$ (s, $\left.1 \mathrm{CO}\right), 193.0$ (s, $\left.2 \mathrm{CO}\right) .{ }^{19} \mathrm{~F}$ NMR $(376.2 \mathrm{MHz}$, $\left.\mathrm{CDCl}_{3}\right)$ : $-75.5\left(\mathrm{~s}, \mathrm{CF}_{3} \mathrm{SO}_{3}\right)$. Anal. Calcd for $\mathrm{C}_{10} \mathrm{H}_{8} \mathrm{~F}_{3} \mathrm{~N}_{4} \mathrm{O}_{6} \mathrm{ReS}$ : C, 21.58; H, 1.45; N, 10.07. Found: C, 21.77; H, 1.36 ; N, 9.90 .

fac- $\left[\operatorname{Re}(\mathrm{CO})_{3}(d m p z H)_{2}(\mathrm{OTf})\right], 5 b$. Silver triflate $(0.056 \mathrm{~g}, 0.22 \mathrm{mmol})$ was added to a solution of $3 \mathrm{~b}(0.108 \mathrm{~g}, 0.2 \mathrm{mmol})$ in THF $(15 \mathrm{~mL})$, and the mixture was stirred for $2 \mathrm{~h}$ at room temperature in the absence of light. Working up as for 5 a gave $0.103 \mathrm{~g}(84 \%)$ of $\mathbf{5 b}$ as a colorless solid. IR (THF, $\left.\mathrm{cm}^{-1}\right): 2034 \mathrm{~s}, 1928$ vs, 1901 vs. IR $\left(\mathrm{KBr}, \mathrm{cm}^{-1}\right): 3446 \mathrm{~m}$, 3349 m, 3288 m, 2036 vs, 1923 vs, 1917 vs, 1654 w, 1636 w, 1578 w, 1419 w, 1379 w, 1316 m, 1294 m, 1261 m, 1233 m, 1205 m, 1186 m, 1053 w, 1026 m, 819 w, 800 w, 661 w, 636 m, 518 w, 458 w, 419 w. ${ }^{1} \mathrm{H}$ NMR (399.8 MHz, $\left.\mathrm{CDCl}_{3}\right): 2.11\left(\mathrm{~s}, \mathrm{C}^{3} \mathrm{H}_{3} \mathrm{dmpzH}, 6 \mathrm{H}\right), 2.21\left(\mathrm{~s}, \mathrm{C}^{5} \mathrm{H}_{3}\right.$ dmpzH, $6 \mathrm{H}), 5.93\left(\mathrm{~s}, \mathrm{H}^{4} \mathrm{dmpzH}, 2 \mathrm{H}\right), 10.63$ (s, NH, 2 H) ${ }^{13} \mathrm{C}\left\{{ }^{1} \mathrm{H}\right\}$ NMR (100.5 MHz, $\left.\mathrm{CDCl}_{3}\right): 10.9\left(\mathrm{~s}, \mathrm{C}^{5} \mathrm{H}_{3} \mathrm{dmpzH}\right), 14.5\left(\mathrm{~s}, \mathrm{C}^{3} \mathrm{H}_{3}\right.$ dmpzH), 106.7 (s, $\mathrm{C}^{4} \mathrm{H}$ dmpzH), $119.2\left(\mathrm{q}, \mathrm{J}=318.5 \mathrm{~Hz}, \mathrm{CF}_{3} \mathrm{SO}_{3}^{-}\right)$, 143.2 (s, $\left.\mathrm{CCH}_{3} \mathrm{dmpzH}\right), 153.7$ (s, $\left.\mathrm{CCH}_{3} \mathrm{dmpzH}\right), 193.4$ (s, CO), 193.5 (s, $2 \mathrm{CO}) .{ }^{19} \mathrm{~F}$ NMR $\left(376.2 \mathrm{MHz}, \mathrm{CDCl}_{3}\right):-75.6\left(\mathrm{~s}, \mathrm{CF}_{3} \mathrm{SO}_{3}\right)$. Anal. Calcd for $\mathrm{C}_{14} \mathrm{H}_{16} \mathrm{~F}_{3} \mathrm{~N}_{4} \mathrm{O}_{6} \mathrm{ReS}$ : C, 27.49; H, 2.64; N, 9.16. Found: $\mathrm{C}$ $27.24 ; \mathrm{H}, 2.36 ; \mathrm{N}, 8.99$.

fac- $\left[\operatorname{Re}(\mathrm{CO})_{3}(\mathrm{indzH})_{2}(\mathrm{OTf})\right], 5 \mathrm{c}$. Silver triflate $(0.056 \mathrm{~g}, 0.22 \mathrm{mmol})$ was added to a solution of $3 \mathrm{c}(0.117 \mathrm{~g}, 0.2 \mathrm{mmol})$ in THF $(15 \mathrm{~mL})$, and the mixture was stirred for $2 \mathrm{~h}$ at room temperature in the absence of light. Working up as for 5 a gave $0.123 \mathrm{~g}(94 \%)$ of $5 \mathrm{c}$ as a colorless solid. IR (THF, cm $\left.{ }^{-1}\right): 2038$ vs, 1937 vs, 1910 vs. IR $\left(\mathrm{KBr}, \mathrm{cm}^{-1}\right): 3415 \mathrm{~m}$, $3134 \mathrm{~m}, 3055 \mathrm{~m}, 2974 \mathrm{~m}, 2880 \mathrm{~m}, 2036$ vs, 1924 vs, 1906 vs, $1630 \mathrm{~m}$, $1516 \mathrm{w}, 1360 \mathrm{~m}, 1338 \mathrm{~m}, 1234 \mathrm{~s}, 1199 \mathrm{~s}, 1174 \mathrm{~s}, 1150 \mathrm{~m}, 1084 \mathrm{w}, 1050 \mathrm{~m}$, 1014 s, 886 w, 839 w, $751 \mathrm{~m}, 658$ w, $631 \mathrm{~m}, 572$ w, 526 w, 482 w, 433 w. ${ }^{1} \mathrm{HNMR}\left(399.8 \mathrm{MHz}, \mathrm{CDCl}_{3}\right): 7.26\left(\mathrm{~m}, H^{6}\right.$ indzH $\left.2 \mathrm{H}\right), 7.51-7.53(\mathrm{~m}$, $H^{5}$ and $H^{7}$ indzH, $\left.4 \mathrm{H}\right), 7.71$ (d, $J=8.5 \mathrm{~Hz}, H^{4}$ indzH, $\left.2 \mathrm{H}\right), 8.15\left(\mathrm{~s}, H^{3}\right.$ indzH, $2 \mathrm{H}), 11.39$ (s, NH indzH, $2 \mathrm{H}) .{ }^{13} \mathrm{C}\left\{{ }^{1} \mathrm{H}\right\}$ NMR $(100.5 \mathrm{MHz}$, $\left.\mathrm{CDCl}_{3}\right): 110.5\left(\mathrm{~s}, \mathrm{C}^{7}\right.$ indzH), $119.1\left(\mathrm{q}, \mathrm{J}=314.0 \mathrm{~Hz}, \mathrm{CF}_{3} \mathrm{SO}_{3}^{-}\right), 120.1$ (s, $\mathrm{C}^{4}$ indzH), 122.6 (s, $\mathrm{C}^{3 \mathrm{a}}$ indzH), $123.2\left(\mathrm{~s}, \mathrm{C}^{6}\right.$ indzH), $129.9\left(\mathrm{~s}, \mathrm{C}^{5}\right.$ indzH), 138.8 (s, $\mathrm{C}^{3}$ indzH), 140.6 (s, $\mathrm{C}^{7 \mathrm{a}}$ indzH), 192.4 (br, $\left.1 \mathrm{CO}\right)$, 192.9 (br, $2 \mathrm{CO}) .{ }^{19} \mathrm{~F}$ NMR (376.2 $\left.\mathrm{MHz}, \mathrm{CDCl}_{3}\right):-75.4\left(\mathrm{~s}, \mathrm{CF}_{3} \mathrm{SO}_{3}\right)$ Anal. Calcd for $\mathrm{C}_{18} \mathrm{H}_{12} \mathrm{~F}_{3} \mathrm{~N}_{4} \mathrm{O}_{6} \mathrm{ReS}$ : C, 32.98; H, 1.84; N, 8.55. Found: C, 32.68; H, 1.76; N, 8.49.

fac- $\left[\operatorname{Re}(\mathrm{CO})_{3}(\right.$ indzH $)\left(\mathrm{NH}=\mathrm{C}(\mathrm{Me})\right.$ indz- $\left.\left.^{2} \mathrm{~N}, \mathrm{~N}\right)\right] \mathrm{OTf}, 6 \mathrm{c}-\mathrm{OTf} \mathrm{f}^{18}$ A solution of $5 \mathrm{c}$-OTf $(0.197 \mathrm{~g}, 0.3 \mathrm{mmol})$ in $\mathrm{MeCN}(15 \mathrm{~mL})$ was stirred for $10 \mathrm{~h}$ at room temperature. Volatiles were removed in vacuo to give a yellow solid, which was recrystallized from THF/hexane at $-20{ }^{\circ} \mathrm{C}$, giving a yellow microcrystalline solid, which was decanted, washed with hexane $(3 \times 3 \mathrm{~mL}$ approximately), and dried in vacuo, yielding $0.186 \mathrm{~g}$ (89\%). IR (THF, $\mathrm{cm}^{-1}$ ): 2035 vs, 1939 vs, 1924 vs. IR $\left(\mathrm{KBr}, \mathrm{cm}^{-1}\right)$ : $3434 \mathrm{~m}, 3125 \mathrm{~m}, 2976 \mathrm{~m}, 2874 \mathrm{w}, 2031$ vs, 1916 vs br, $1631 \mathrm{~m}, 1514 \mathrm{w}$, $1480 \mathrm{~m}, 1463 \mathrm{w}, 1425 \mathrm{~m}, 1356 \mathrm{~m}, 1281 \mathrm{w}, 1194 \mathrm{w}, 1117 \mathrm{~s}, 1086 \mathrm{~s}, 1044$ m, 915 w, 884 w, 845 w, 795 w, 753 m, 624 m, 535 w, 521 w, $475 w .{ }^{1} \mathrm{H}$ $\operatorname{NMR}\left(399.8 \mathrm{MHz}, \mathrm{Me}_{2} \mathrm{CO}-d_{6}\right): 3.32\left(\mathrm{~s}, \mathrm{NH}=\mathrm{CCH}_{3}, 3 \mathrm{H}\right), 7.19(\mathrm{t}, J=$ $7.5 \mathrm{~Hz}, H^{5}$ indzH, $\left.1 \mathrm{H}\right), 7.47\left(\mathrm{t}, J=7.5 \mathrm{~Hz}, H^{6}\right.$ indzH, $\left.1 \mathrm{H}\right), 7.55(\mathrm{~d}, J=$ $8.5 \mathrm{~Hz}, H^{7}$ indzH, $\left.1 \mathrm{H}\right), 7.59\left(\mathrm{t}, J=7.5 \mathrm{~Hz}, H^{5}\right.$ indz, $\left.1 \mathrm{H}\right), 7.71(\mathrm{~d}, J=8.5$ $\mathrm{Hz}, H^{4}$ indzH, $\left.1 \mathrm{H}\right), 7.82\left(\mathrm{t}, J=8.0, H^{6}\right.$ indz $\left.1 \mathrm{H}\right), 8.11\left(\mathrm{~d}, J=9.0 \mathrm{~Hz}, H^{7}\right.$ indz, $1 \mathrm{H}), 8.14\left(\mathrm{~d}, J=9.0 \mathrm{~Hz}, H^{4}\right.$ indz, $\left.1 \mathrm{H}\right), 8.36\left(\mathrm{~s}, H^{3}\right.$ indzH, $\left.1 \mathrm{H}\right)$, $9.47\left(\mathrm{~s}, \mathrm{H}^{3}\right.$ indz, $\left.1 \mathrm{H}\right), 10.86\left(\mathrm{~s}, \mathrm{NH}=\mathrm{CCH}_{3}, 1 \mathrm{H}\right), 12.81(\mathrm{~s}, \mathrm{NH}$ ind $\mathrm{H}, 1$ H). ${ }^{13} \mathrm{C}\left\{{ }^{1} \mathrm{H}\right\}$ NMR (100.5 MHz, Me $\left.2 \mathrm{CO}-d_{6}\right): 21.6\left(\mathrm{~s}, \mathrm{NH}=\mathrm{CCH}_{3}\right)$, $111.2\left(\mathrm{~s}, \mathrm{C}^{7}\right.$ indzH), 113.7 (s, $C^{7}$ indz), 121.8 (s, $C^{4}$ indzH), 123.5 (s, $C^{5}$ indzH), $124.4\left(\mathrm{~s}, \mathrm{C}^{4}\right.$ indz), $126.6\left(\mathrm{~s}, \mathrm{C}^{5}\right.$ indz), $127.2\left(\mathrm{C}^{3 \mathrm{a}}\right.$, the other $C^{3 \mathrm{a}}$ was not observed), $130.3\left(\mathrm{~s}, \mathrm{C}^{6}\right.$ indzH), $133.4\left(\mathrm{~s}, \mathrm{C}^{3}\right.$ indzH), $140.6\left(C^{7 \mathrm{a}}\right)$, $142.1\left(C^{7 \mathrm{a}}\right), 148.0\left(\mathrm{~s}, \mathrm{C}^{3} \mathrm{indz}\right), 168.3\left(\mathrm{~s}, \mathrm{NH}=\mathrm{CCH}_{3}\right), 191.6(\mathrm{~s}, \mathrm{CO})$ 195.2 (s, CO), 195.4 (s, CO). ${ }^{19} \mathrm{~F}$ NMR (376.2 MHz, Me 2 CO- $\left.d_{6}\right)$ : -73.7 (s, $\mathrm{CF}_{3} \mathrm{SO}_{3}$ ). Anal. Calcd for $\mathrm{C}_{20} \mathrm{H}_{15} \mathrm{~F}_{3} \mathrm{~N}_{5} \mathrm{O}_{6} \mathrm{ReS}$ : C, 34.43; $\mathrm{H}$, 2.17; N, 10.04. Found: C, 34.79; H, 2.29; N, 9.86. fac- $\left[\operatorname{Re}(\mathrm{CO})_{3}(\mathrm{NCMe})\left(\mathrm{NH}=\mathrm{C}(\mathrm{Me})\right.\right.$ indz- $\left.\left.\kappa^{2} \mathrm{~N}, \mathrm{~N}\right)\right] \mathrm{OTf}$, 7c-OTf. Silver triflate $(0.085 \mathrm{~g}, 0.33 \mathrm{mmol})$ was added to a solution of $2 \mathrm{c}(0.152 \mathrm{mg}$, $0.30 \mathrm{mmol})$ in $\mathrm{MeCN}(30 \mathrm{~mL})$. The mixture was refluxed for $2 \mathrm{~h}$ in the absence of light. The reaction mixture was then filtered and dried in vacuo. The yellow residue was crystallized in acetone/hexane at $-20^{\circ} \mathrm{C}$, giving a yellow microcrystalline solid, which was decanted, washed with hexane $(3 \times 3 \mathrm{~mL}$ approximately), and dried in vacuo, yielding $0.158 \mathrm{~g}$ (85\%). IR (THF, $\left.\mathrm{cm}^{-1}\right)$ : 2035 vs, 1939 vs, 1924 vs. IR $\left(\mathrm{KBr}, \mathrm{cm}^{-1}\right)$ : $3194 \mathrm{w}, 2027 \mathrm{vs}, 1902$ vs br, $1638 \mathrm{~m}, 1512 \mathrm{w}, 1484 \mathrm{w}, 1424 \mathrm{~m}, 1355 \mathrm{~m}$, $1276 \mathrm{~s}, 1253 \mathrm{~s}, 1222 \mathrm{~s}, 1149 \mathrm{~s}, 1091 \mathrm{w}, 1030 \mathrm{w}, 876 \mathrm{w}, 800 \mathrm{w}, 758 \mathrm{~s}, 668 \mathrm{w}$, $637 \mathrm{~s}, 572 \mathrm{w}, 517 \mathrm{~m}, 485 \mathrm{~m}, 431 \mathrm{w} .{ }^{1} \mathrm{H}$ NMR $\left(376.2 \mathrm{MHz}, \mathrm{Me}_{2} \mathrm{CO}-d_{6}\right)$ : $2.38\left(\mathrm{~s}, \mathrm{NCCH}_{3}, 3 \mathrm{H}\right), 3.30\left(\mathrm{~s}, \mathrm{NH}=\mathrm{CCH}_{3}, 3 \mathrm{H}\right), 7.64\left(\mathrm{t}, J=8.0 \mathrm{~Hz}, \mathrm{H}^{6}\right.$ indz, $1 \mathrm{H}), 7.91\left(\mathrm{t}, J=8.0 \mathrm{~Hz}, H^{5}\right.$ indz, $\left.1 \mathrm{H}\right), 8.17\left(\mathrm{~d}, J=8.0 \mathrm{~Hz}, H^{7}\right.$ indz, $1 \mathrm{H}), 8.22\left(\mathrm{~d}, J=9.0 \mathrm{~Hz}, H^{4}\right.$ indz, $\left.1 \mathrm{H}\right), 9.29\left(\mathrm{~s}, H^{3}\right.$ indz, $\left.1 \mathrm{H}\right), 10.87(\mathrm{~s}$, br, $\mathrm{NH}, 1 \mathrm{H}) .{ }^{13} \mathrm{C}\left\{{ }^{1} \mathrm{H}\right\}$ NMR $\left(125.7 \mathrm{MHz}, \mathrm{Me}_{2} \mathrm{CO}-d_{6}\right): 3.2(\mathrm{~s}$, $\left.\mathrm{NCCH}_{3}\right), 21.4\left(\mathrm{~s}, \mathrm{NH}=\mathrm{CCH}_{3}\right), 113.7\left(\mathrm{~s}, \mathrm{C}^{4}\right.$ indz $), 123.41\left(\mathrm{~s}, \mathrm{C}^{7}\right.$ indz $)$, 126.5 (s, $C^{6}$ indz), $127.2\left(\mathrm{~s}, \mathrm{C}^{3 a}\right.$ indz), $133.4\left(\mathrm{~s}, \mathrm{C}^{5}\right.$ indz), $140.5\left(\mathrm{~s}, \mathrm{C}^{7 a}\right.$ indz), $147.4\left(\mathrm{~s}, \mathrm{C}^{3}\right.$ indz), $167.8\left(\mathrm{~s}, \mathrm{NCCH}_{3}\right), 190.2(\mathrm{~s}, \mathrm{CO}), 194.1(\mathrm{~s}, 2$ CO). ${ }^{19} \mathrm{~F} \mathrm{NMR}\left(470.2 \mathrm{MHz}, \mathrm{Me}_{2} \mathrm{CO}-d_{6}\right):-73.69\left(\mathrm{~s}, \mathrm{CF}_{3} \mathrm{SO}_{3}\right)$. Anal. Calcd for $\mathrm{C}_{15} \mathrm{H}_{12} \mathrm{~F}_{3} \mathrm{~N}_{4} \mathrm{O}_{6} \mathrm{ReS}$ : C, 29.03; H, 1.95; N, 9.03. Found: C, 28.74; H, 1.71; N, 8.88 .

Kinetic Studies. Reactions were monitored by ${ }^{1} \mathrm{H}$ NMR using 0.05 $\mathrm{M}$ solutions prepared under $\mathrm{Ar}$ atmosphere. Pure $\mathrm{NaBF}_{4}, \mathrm{NaClO}_{4}$, and $\mathrm{NaOTf}$ were prepared by adding $\mathrm{NaOH}$ solutions to the corresponding acid solutions until $\mathrm{pH}=7$ (measured with a $\mathrm{pH}$ meter) and drying to dryness. Studies with excess of $\mathrm{NaOH}(\mathrm{aq})$ were carried out by mixing $0.025 \mathrm{M}$ solutions of the complex and a recently prepared $0.02 \mathrm{M}$ aqueous solution of $\mathrm{NaOH}$. The NMR probe temperature was calibrated using an ethylene glycol standard before and after the experiment.

Crystal Structure Determination for Compounds 2c, 3b, 3c, $4 \mathrm{a}-\mathrm{ClO}_{4}, 5 \mathrm{~b}$-OTf, $5 \mathrm{~b}-\mathrm{ClO}_{4}$, and $7 \mathrm{c}-\mathrm{ClO}_{4}$. Crystals were grown by slow diffusion of hexane into concentrated solutions of the complexes in chloroform (for $3 \mathbf{b}, 3 \mathbf{c}, 4 \mathrm{a}-\mathrm{ClO}_{4}, \mathbf{5 b}$-OTf) or acetone (for $2 \mathrm{c}, 7 \mathrm{c}-\mathrm{ClO}_{4}$ ) at $-20^{\circ} \mathrm{C}$. Relevant crystallographic details can be found in the CIF. For all complexes except $2 c$, a crystal was attached to a glass fiber and transferred to a Bruker AXS SMART 1000 diffractometer with graphite monochromatized Mo K $\alpha$ X-radiation and a CCD area detector. Raw frame data were integrated with the SAINT program. ${ }^{19}$ The structure was solved by direct methods with SHELXTL. ${ }^{20}$ A semiempirical absorption correction was applied with the program SADABS. ${ }^{21}$ All non-hydrogen atoms were refined anisotropically. Hydrogen atoms were set in calculated positions and refined as riding atoms, with a common thermal parameter. All calculations and graphics were made with SHELXTL. Distances and angles of hydrogen bonds were calculated with PARST ${ }^{22}$ (normalized values). ${ }^{23}$ For $2 \mathrm{c}$, crystal structure determination was accomplished on an Oxford Diffraction Xcalibur S diffractometer: data collection, CrysAlis CCD; ${ }^{24}$ cell refinement, CrysAlis RED; ${ }^{24}$ data reduction, CrysAlis RED; absorption correction, multiscan. ${ }^{24}$ Crystal structure determinations were effected at $-100{ }^{\circ} \mathrm{C}$ (Mo K $\alpha$ radiation, $\alpha=0.71073 \AA$ ). The structure was solved by applying direct and Fourier methods using SHELXS97 and SHELXL-97. ${ }^{20}$ All nonhydrogen atoms were refined anisotropically. Hydrogen atoms were placed in geometrically calculated positions, and each was assigned a fixed isotropic displacement parameter based on a riding model.

\section{ASSOCIATED CONTENT}

\section{S Supporting Information}

$\mathrm{X}$-ray crystallographic data for compounds $2 \mathrm{c}, 3 \mathbf{b}, 3 \mathbf{c}, 4 \mathrm{a}-\mathrm{ClO}_{4}$, 5b-OTf, $5 \mathbf{b}-\mathrm{ClO}_{4}$, and $7 \mathrm{c}-\mathrm{ClO}_{4}$ in CIF format; figures of the crystal structures of $f a c-\left[\operatorname{ReBr}(\mathrm{CO})_{3}(\mathrm{dmpzH})_{2}\right], \quad 3 \mathbf{b}, \quad[\mathrm{Re}-$ $\left.(\mathrm{CO})_{3}(\mathrm{dmpzH})_{2}\left(\mathrm{OClO}_{3}\right)\right]$, $\mathbf{5 b}-\mathrm{ClO}_{4}$, representations and tables of kinetic experiments. This material is available free of charge via the Internet at http://pubs.acs.org. 


\section{AUTHOR INFORMATION}

\section{Corresponding Author}

*Phone: 34983 184620. Fax: 34983 423013.E-mail: fervilla@qi. uva.es.

\section{Notes}

The authors declare no competing financial interest.

\section{ACKNOWLEDGMENTS}

The authors thank the Spanish Ministerio de Ciencia e Innovación (CTQ2009-12111) and the Junta de Castilla y León (VA070A08 and GR Excelencia 125) for financial support. M.A. thanks the MEC (FPI Program) and P. G.-I. the UVa for their grants.

\section{REFERENCES}

(1) (a) Kukushkin, V. Y.; Pombeiro, A. J. L. Inorg. Chim. Acta 2005 358, 1-21. (b) Pombeiro, A. J. L.; Kukushkin, V. Y. In Comprehensive Coordination Chemistry, 2nd ed.; Lever, A. B. P., Ed.; Elsevier: London, 2004; Vol. 1, pp 639-660. (c) Kukushkin, V. Y.; Pombeiro, A. J. L. Chem. Rev. 2002, 102, 1771-1802. (d) Michelin, R. A.; Mozzon, M.; Bertani, R. Coord. Chem. Rev. 1996, 147, 299-338.

(2) (a) Hsieh, C.-C.; Lee, C.-J.; Horng, Y.-C. Organometallics 2009, 28 , 4923-4928. (b) Khripun, A. V.; Kukushkin, V. Y.; Selivanov, S. I. Haukka, M.; Pombeiro, A. J. L. Inorg. Chem. 2006, 45, 5073-5083. (c) Govidaswamy, P.; Mozharivskyj, Y. A.; Kollipara, M. R. J. Organomet. Chem. 2004, 689, 3265-3274. (d) Kollipara, M. R; Sarkhel, P.; Chakraborty, S.; Lalrempuia, R. J. Coord. Chem. 2003, 56, 1085-1091. (e) Carmona, D.; Ferrer, J.; Lahoz, F. J.; Oro, L. A.; Lamata, M. P. Organometallics 1996, 15, 5175-5178. (f) López, J.; Santos, A.; Romero, A.; Echavarren, A. M. J. Organomet. Chem. 1993, 443, 221-228. (g) Cinellu, M. A.; Stoccoro, S.; Minghetti, G.; Bandini, A. L.; Banditelli, G.; Bovio, B. J. Organomet. Chem. 1989, 372, 311-325. (h) Albers, M. O.; Francesca, S.; Crosby, A.; Liles, D. C.; Robinson, D. J.; Shaver, A.; Singleton, E. Organometallics 1987, 6, 2014-2017. (i) Gracey, G. D. Rettig, S. T.; Storr, A.; Trotter, J. Can. J. Chem. 1987, 65, 2469-2477.

(j) Romero, A.; Vegas, A.; Santos, A. J. Organomet. Chem. 1986, 310, C8-C10. (k) Jones, C. J.; McCleverty, J. A.; Rothin, A. S. J. Chem. Soc,, Dalton Trans. 1986, 109-111.

(3) (a) Arroyo, M.; Gómez-Iglesias, P.; Martín-Alvarez, J. M.; Alvarez, C. M.; Miguel, D.; Villafañe, F. Inorg. Chem. 2012, 51, 6070-6080 (b) Antón, N.; Arroyo, M.; Gómez-Iglesias, P.; Miguel, D.; Villafañe, F. J. Organomet. Chem. 2008, 693, 3074-3080. (c) Arroyo, M.; Miguel, D.; Villafañe, F.; Nieto, S.; Pérez, J.; Riera, L. Inorg. Chem. 2006, 45, 70187026. (d) Arroyo, M.; López-Sanvicente, A.; Miguel, D.; Villafañe, F. Eur. J. Inorg. Chem. 2005, 4430-4437.

(4) Reviews: (a) Pettinari, C.; Pettinari, R. Coord. Chem. Rev. 2005, 249, 663-691. (b) R. Mukherjee, R. Coord. Chem. Rev. 2000, 203, 151218. (c) Constable, E. C.; Steel, P. J. Coord. Chem. Rev. 1989, 93, 205223. Some recent references: (d) Newton, G. N.; Mitsumoto, K.; Wei, R.-J.; Iijima, F.; Shiga, T.; Nishikawa, H.; Oshio, H. Angew. Chem., Int. Ed 2014, 53, 2941-2944. (e) Hamann, J. N.; Tuczek, F. Chem. Commun 2014, 50, 2298-2300. (f) Vuong, K. Q.; Wong, C. M.; Bhadbhade, M.; Messerle, B. A. Dalton Trans. 2014, 43, 7540-7553. (g) Amarante, T. R. Neves, P.; Paz, F. A. A.; Valente, A. A.; Pillinger, M.; Gonçalves, I. S. Dalton Trans. 2014, 43, 6059-6069. (h) Yu, X.-Y.; Deng, L.; Zheng, B. Zeng, B.-R.; Yi, P.; Xu, X. Dalton Trans. 2014, 43, 1524-1533. (i) Qu, X.; Liu, Y.; Si, Y.; Wu, X.; Wu, Z. Dalton Trans. 2014, 43, 1246-1260. (j) Bassanetti, I.; Twist, C. P.; Kim, M.-G.; Seyam, A. M.; Bazzi, H. S. Wang, Q.J.; Chung, Y.-W.; Marchió, L.; Delferro, M.; Marks, T. J. Inorg. Chem. 2014, 53, 4629-4638. (k) Varzatskii, O. A.; Penkova, L. V.; Kats, S. V.; Dolganov, A. V.; Vologzhanina, A. V.; Pavlov, A. A.; Novikov, V. V.; Bogomyakov, A. S.; Nemykin, V. N.; Voloshin, Y. Z. Inorg. Chem 2014, 53, 3062-3071. (1) Amarante, T. R.; Neves, P.; Gomes, A. C.; Nolasco, M. M.; Ribeiro-Claro, P.; Coelho, A. C.; Valente, A. A.; Paz, F. A. A.; Smeets, S.; McCusker, L. B.; Pillinger, M.; Gonçalves, I. S. Inorg. Chem. 2014, 53, 2652-2665. (m) Turega, S.; Cullen, W.; Whitehead, M.; Hunter, C. A.; Ward, M. D. J. Am. Chem. Soc. 2014, 136, 8475-8483. (n) Huang, C.-Y.; Kuan, K.-Y.; Liu, Y.-H.; Peng, S.-M.; Liu, S.-T. Organometallics 2014, 33, 2831-2836. (o) Muller, K.; Sun, Y.; Heimermann, A.; Menges, F.; Niedner-Schatteburg, G.; van Wüllen, C.; Thiel, W. R. Chem.-Eur. J. 2013, 19, 7825-7834. (p) Ferrer, I.; Rich, J.; Fontrodona, X.; Rodríguez, M.; Romero, I. Dalton Trans. 2013, 42, 13461-13469. (q) Ojwach, S. O.; Okemwa, T. T.; Attandoh, N. W.; Omondi, B. Dalton Trans. 2013, 42, 10735-10745. (r) Milek, M. Heinemann, F. W.; Khusniyarov, M. M. Inorg. Chem. 2013, 52, 1158511592. (s) Shavaleev, N. M.; Monti, F.; Scopelliti, R.; Baschieri, A. Sambri, L.; Armaroli, N.; Grätzel, M.; Nazeeruddin, M. K. Organometallics 2013, 32, 460-467.

(5) Reisner, E.; Arion, V. B.; Rufiska, A.; Chiorescu, I.; Schmid, W. F.; Keppler, B. K. Dalton Trans. 2005, 2355-2364.

(6) (a) Díez, J.; Falagán, S.; Gamasa, P.; Gimeno, J. Polyhedron 1988, 7, 37-42. (b) García, M. P.; Esteruelas, M. A.; Martín, M.; Oro, L. A. J. Organomet. Chem. 1994, 467, 151-159. (c) Denisova, T. O.; Nefedov, S. E. Mendeleev Commun. 2003, 13, 161-162. (d) Zheng, L.-L.; Leng, J.-D.; Liu, W.-T.; Zhang, W.-X.; Lu, J.-X.; Tong, M.-L. Eur. J. Inorg. Chem. 2008, 4616-4624. (e) Martín, M.; Horváth, H.; Sola, E.; Kathó, A.; Joó, F. Organometallics 2009, 28, 561-566.

(7) Ardizzoia, G. A.; LaMonica, G.; Maspero, A.; Moret, M.; Masciocchi, N. Eur. J. Inorg. Chem. 1998, 1503-1512.

(8) Synthesis and characterization of $3 \mathbf{b}$ was described in ref 7 , but the cystal structure was not reported.

(9) (a) Jeffrey, G. A. An Introduction to Hydrogen Bonding; Oxford University Press: New York, 1997; Chapter 2. (b) Steiner, T. Angew. Chem., Int. Ed. 2002, 41, 48-76.

(10) la could not be isolated pure (ref $3 \mathrm{c}$ ).

(11) (a) Reimann, R. H.; Singleton, E. J. Chem. Soc., Dalton Trans. 1974, 808-813. (b) Edwards, D. A.; Marshalsea, J. J. Organomet. Chem. $1977,131,73-91$.

(12) These complexes could not be isolated. For the pzH complex, its logical precursors is complex 1a, which could not be isolated pure (ref 3c). The dmpzH complex could be detected and identified in solution IR (THF, $\left.\mathrm{cm}^{-1}\right): 2045$ vs, 1939 vs br. ${ }^{1} \mathrm{H}$ NMR $\left(\mathrm{Me}_{2} \mathrm{CO}-d_{6}\right): 2.35\left(\mathrm{~s}, \mathrm{C}^{5} \mathrm{H}_{3}\right.$ dmpzH, $3 \mathrm{H}), 2.43\left(\mathrm{~s}, \mathrm{C}^{3} \mathrm{CH}_{3} \mathrm{dmpzH}, 3 \mathrm{H}\right), 2.65(\mathrm{~s}, \mathrm{NCCH} 3,6 \mathrm{H}), 6.19$ $\left(\mathrm{s}, \mathrm{H}^{4} \mathrm{dmpzH}, 1 \mathrm{H}\right), 11.73(\mathrm{br}, \mathrm{NH}$ dmpzH, $1 \mathrm{H})$. All attempts to obtain the indzH complex were unsuccessful and gave the inserted product $7 \mathrm{c}$ because removal of bromido by a silver salt needs a long time or mild heating, conditions where the coupling process occurs.

(13) Formation of $\mathbf{3}$ from $\mathbf{1}$ should occur with concomitant formation of $\left[\operatorname{ReBr}(\mathrm{CO})_{3}(\mathrm{NCMe})_{2}\right]$, but this complex or other nitrile complexes which might also be present in solution such as $\left[\mathrm{Re}(\mathrm{CO})_{3}(\mathrm{NCMe})_{3}\right]^{+}$ cannot be detected by ${ }^{1} \mathrm{H}$ NMR in $\mathrm{CD}_{3} \mathrm{CN}$ due to rapid exchange of the $\mathrm{MeCN}$ ligands with the solvent at temperatures higher than $40^{\circ} \mathrm{C}$.

(14) (a) Catalán, J.; Claramunt, R. M.; Elguero, J.; Laynez, J.; Menéndez, M.; Anvia, F.; Quian, J. H.; Taagepera, M.; Taft, R. W. J. Am. Chem. Soc. 1988, 110, 4105-4111. (b) Elguero, J.; Yranzo, G. I.; Laynez, J.; Jiménez, P.; Menéndez, M.; Catalán, J.; de Paz, J. L. G.; Anvia, F.; Taft, R. W. J. Org. Chem. 1991, 56, 3942-3947.

(15) (a) Raamat, E.; Kaupmees, K.; Ovsjannikov, G.; Trummal, A.; Kütt, A.; Saame, J.; Koppel, I.; Kaljurand, I.; Lipping, L.; Rodima, T.; Pihl, V.; Koppel, I. A.; Leito, I. J. Phys. Org. Chem. 2013, 26, 162-170. (b) Kütt, A.; Rodima, T.; Saame, J.; Raamat, E.; Mäemets, V.; Kaljurand, I.; Koppel, I. A.; Garlyauskayte, R. Y.; Yagupolskii, Y. L.; Yagupolskii, L. M.; Bernhardt, E.; Willner, H.; Leito, I. J. Org. Chem. 2011, 76, 391-395. (c) Koppel, I. A.; Burk, P.; Koppel, I.; Leito, I.; Sonoda, T.; Mishima, M. J. Am. Chem. Soc. 2000, 122, 5114-5124.

(16) Perrin, D. D.; Armarego, W. L. F. Purification of Laboratory Chemicals, 3rd ed.; Pergamon Press: Oxford, 1988.

(17) Farona, M. F.; Kraus, K. F. Inorg. Chem. 1970, 9, 1700-1704.

(18) Alternative synthesis of $6 \mathrm{c}-\mathrm{BF}_{4}: 0.028 \mathrm{~mL}$ of a $\mathrm{NaOH}$ aqueous solution $(0.018 \mathrm{M}, 0.0005 \mathrm{mmol})$ was added to a solution of $4 \mathrm{c}-\mathrm{BF}_{4}$ $(0.070 \mathrm{~g}, 0.10 \mathrm{mmol})$ in $\mathrm{CH}_{3} \mathrm{CN}(10 \mathrm{~mL})$. After stirring for $15 \mathrm{~min}$ at room temperature, the volatiles were removed in vacuo and the yellow residue was crystallized from acetone/hexane at $-20^{\circ} \mathrm{C}$, yielding $61 \mathrm{mg}$ (96\% of $\left.6 \mathrm{c}-\mathrm{BF}_{4}\right)$.

(19) SAINT+. SAX area detector integration program, Version 6.02; Bruker AXS, Inc.: Madison, WI, 1999. 
(20) (a) Sheldrick, G. M. SHELXTL, An integrated system for solving, refining, and displaying crystal structures from diffraction data, Version 5.1 Bruker AXS, Inc.: Madison, WI, 1998. (b) Sheldrick, G. M. Acta Crystallogr. 2008, A64, 112-122.

(21) Sheldrick, G. M. SADABS, Empirical Absorption Correction Program; University of Göttingen: Göttingen, Germany, 1997.

(22) (a) Nardelli, M. Comput. Chem. 1983, 7, 95-98. (b) Nardelli, M. J. Appl. Crystallogr. 1995, 28, 659.

(23) (a) Jeffrey, G. A.; Lewis, L. Carbohydr. Res. 1978, 60, 179-182.

(b) Taylor, R; Kennard, O. Acta Crystallogr. 1983, B39, 133-138.

(24) CrysAlis CCD and CrysAlis RED; Oxford Diffraction Ltd.: Yarnton, England, 2008. 


\section{SUPPORTING INFORMATION}

\section{Pyrazolylamidino Ligands from Coupling of Acetonitrile and Pyrazoles: a Systematic Study}

Patricia Gómez-Iglesias, ${ }^{\dagger}$ Marta Arroyo, ${ }^{\dagger}$ Sonia Bajo, ${ }^{\dagger}$ Carsten Strohmann, ${ }^{\ddagger}$ Daniel Miguel, ${ }^{\dagger}$ and Fernando Villafañe ${ }^{\dagger, *}$

† GIR MIOMeT-IU Cinquima-Química Inorgánica, Facultad de Ciencias, Campus Miguel Delibes, Universidad de Valladolid, 47011 Valladolid, Spain.

* Technische Universität Dortmund, Anorganische Chemie, Otto-Hahn-Str. 6, D-44227 Dortmund, Germany. 


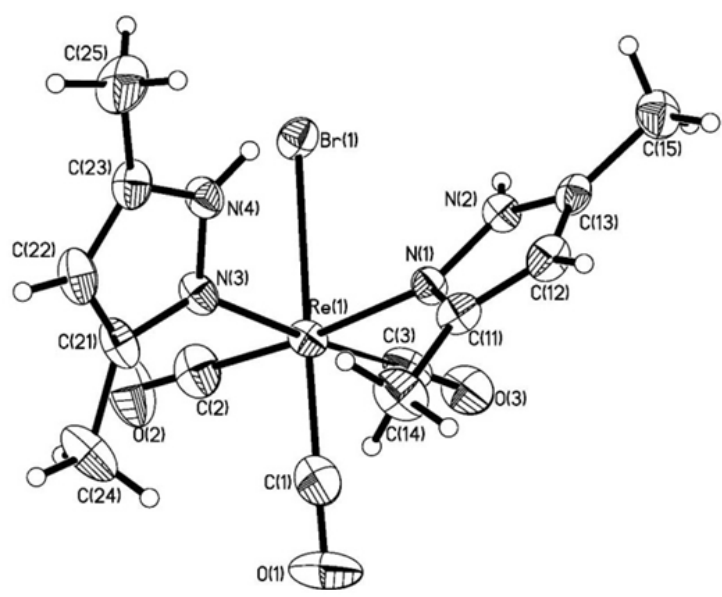

Figure S1. Perspective view of fac- $\left[\operatorname{ReBr}(\mathrm{CO})_{3}(\mathrm{dmpzH})_{2}\right]$, $\mathbf{3}$ b showing the atom numbering. Ellipsoids are drawn at $30 \%$ probability. 

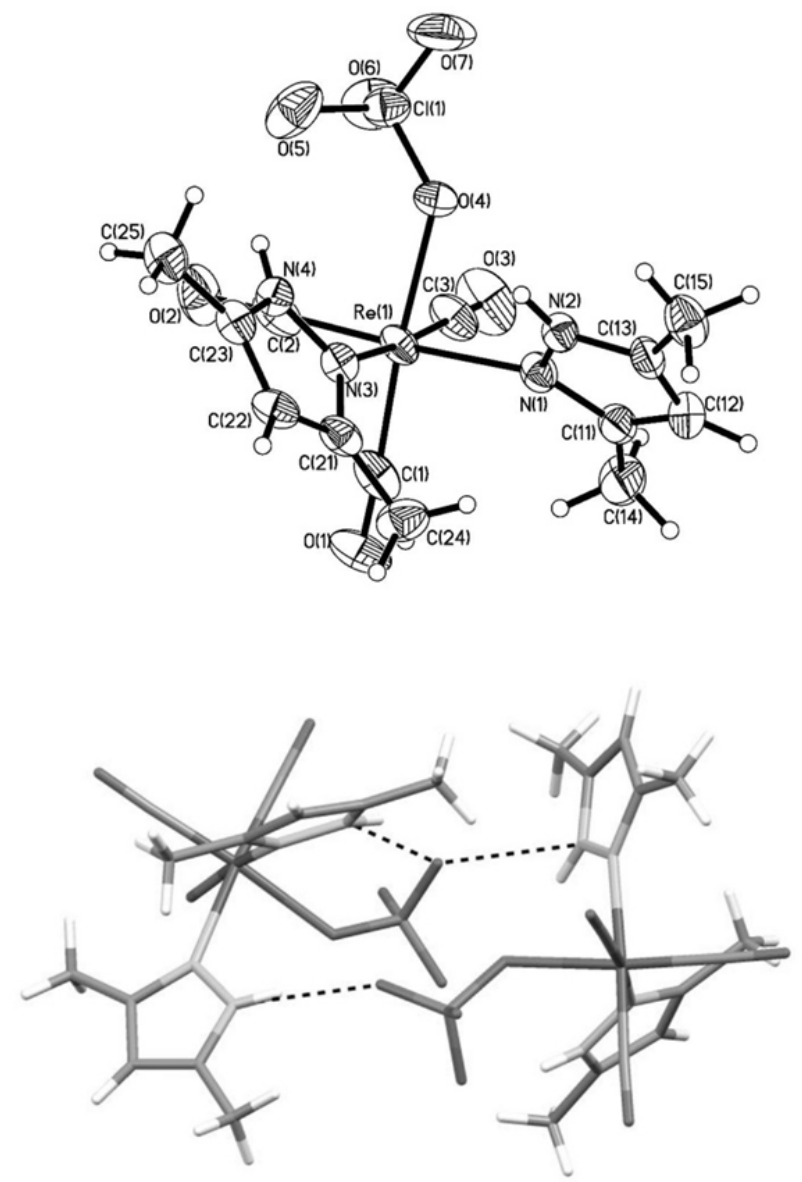

Figure S2. Perspective view of fac- $\left[\operatorname{Re}(\mathrm{CO})_{3}(\mathrm{dmpzH})_{2}\left(\mathrm{OClO}_{3}\right)\right], \mathbf{5} \mathbf{b}-\mathrm{ClO}_{4}$ (above), and hydrogen bonds (below),showing the atom numbering. Ellipsoids are drawn at $30 \%$ probability.

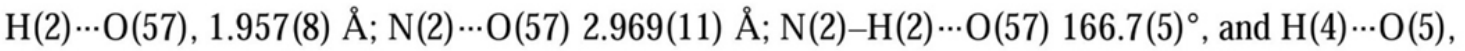
2.009(7) $\AA$; $\mathrm{N}(4) \cdots \mathrm{O}(5) 2.957(9) \AA \AA \mathrm{N}(4)-\mathrm{H}(4) \cdots \mathrm{O}(5) 151.7(5)^{\circ}$ for $\mathbf{5 b}-\mathrm{ClO}_{4}$ 

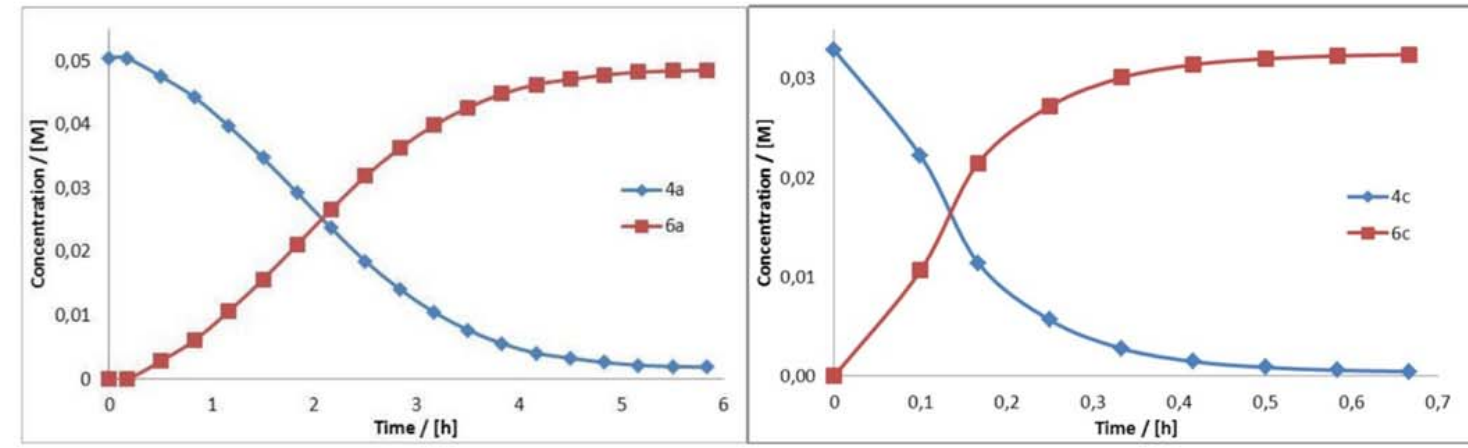

Figure S3. Representation of the observed concentrations of $\mathbf{4}-\mathrm{ClO}_{4}$ and $\mathbf{6}-\mathrm{ClO}_{4}$, when $\mathbf{4}-\mathrm{ClO}_{4}$ are heated in $\mathrm{CD}_{3} \mathrm{CN}$ at $40{ }^{\circ} \mathrm{C}$; for (a) complexes $\mathbf{a}(\mathrm{pzH})$, and (b) complexes $\mathbf{c}$ (indzH).

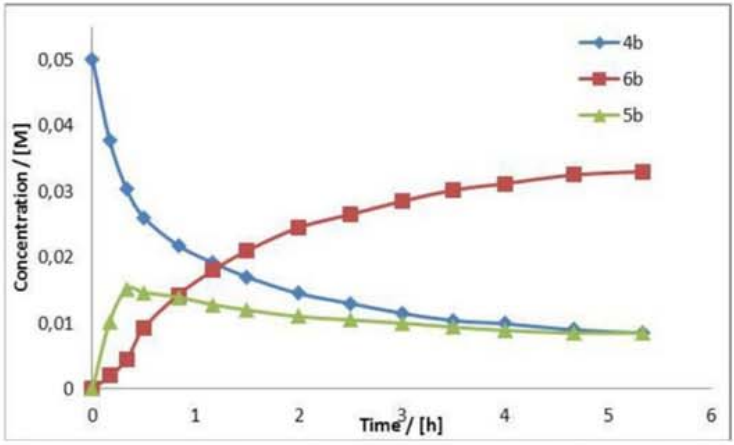

Figure S4. Representation of the observed concentrations of $\mathbf{4 b}$-OTf, $\mathbf{5 b}$ and $\mathbf{6 b}-\mathrm{Otf}$, when $\mathbf{4 b}$-OTf is heated in $\mathrm{CD}_{3} \mathrm{NO}_{2}$ at $80^{\circ} \mathrm{C}$ (above).

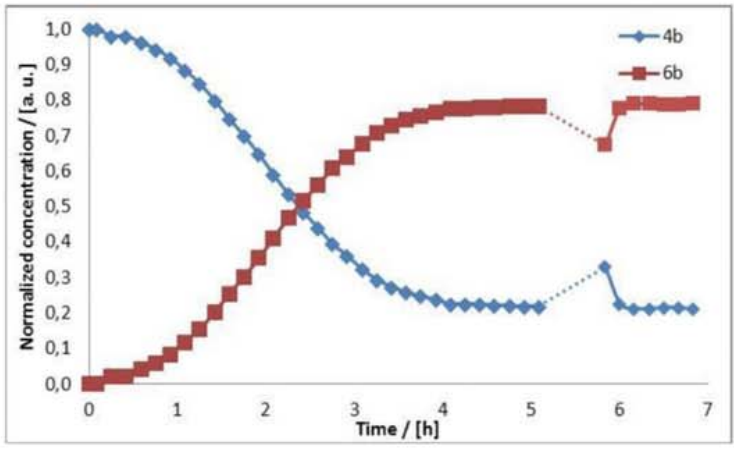

Figure S5. Representation of the observed concentrations of $\mathbf{4 b}$-OTf and $\mathbf{6 b}-\mathrm{OTf}$, when $\mathbf{4 b}$-OTf is heated in $\mathrm{CD}_{3} \mathrm{CN}$ at $40{ }^{\circ} \mathrm{C}$. After $5 \mathrm{~h}, 5 \mathrm{mg}$ of $\mathbf{4 b}$-OTf were added . 


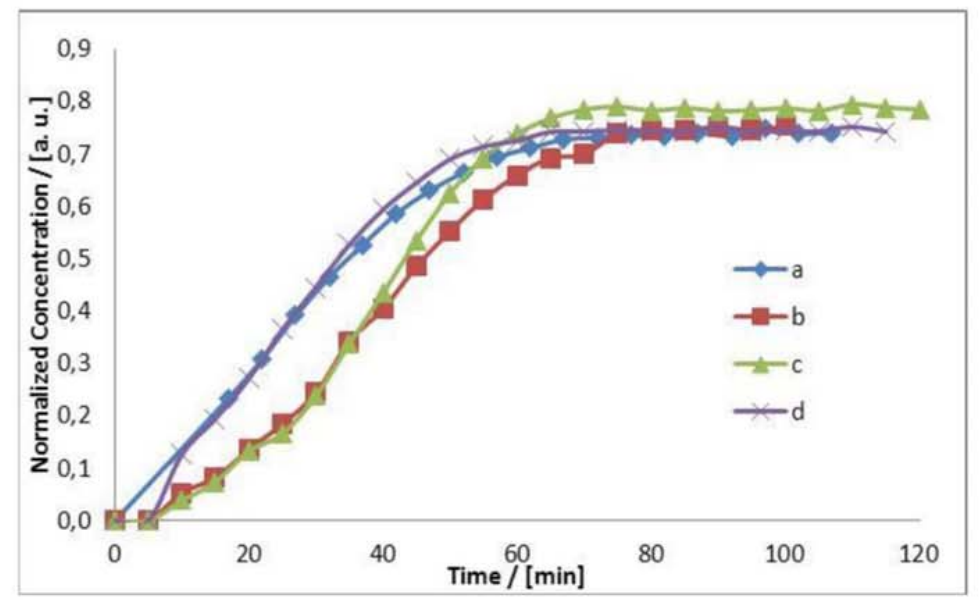

Figure S6. Representation of the observed normalized concentrations of $\mathbf{6 b}$, when $0.5 \mathrm{M} \mathbf{4 b}-\mathrm{BF}_{4}$ is heated in $\mathrm{CD}_{3} \mathrm{CN}$ at $40{ }^{\circ} \mathrm{C}$ (a) without extra anion; (b) with $3 / 1$ excess of $\mathrm{NaClO}_{4}$; (c) with $3 / 1$ excess of NaOTf; (d) with $3 / 1$ excess of $\mathrm{NaBF}_{4}$.

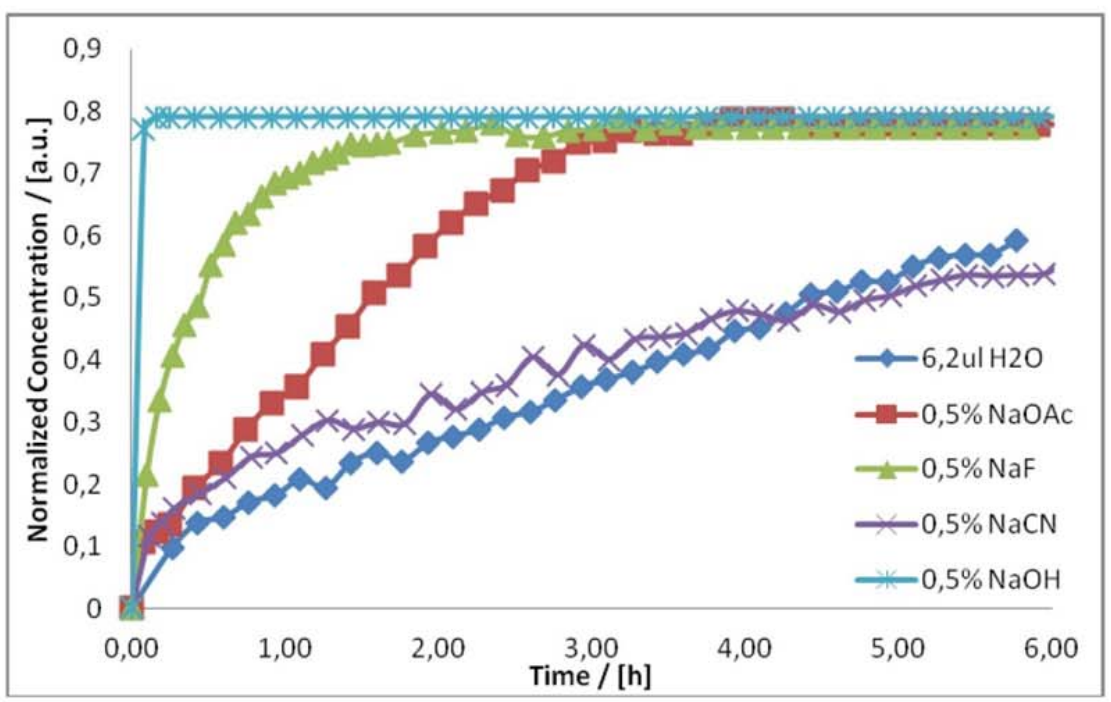

Figure S7. Representation of the observed normalized concentrations of $\mathbf{6 b}-\mathrm{BF}_{4}$ when $0.5 \mathrm{M} \mathbf{4 b}$ $\mathrm{BF}_{4}$ is stirred at r.t. with $6.2 \mu \mathrm{L}$ of $\mathrm{H}_{2} \mathrm{O}$, or with the aqueous solutions indicated. All the reactions are carried out in $\mathrm{CD}_{3} \mathrm{CN}$. 
Table S1. Final ratios and reactions time (from ${ }^{1} \mathrm{H}$ NMR spectra) for the synthesis of $\mathbf{6 c}-\mathrm{BF}_{4}$ and 6b-OTf from $\mathbf{4 c}-\mathrm{BF}_{4}$ and $\mathbf{4 b}$-OTf respectively at different temperatures in $\mathrm{CD}_{3} \mathrm{CN}$.

\begin{tabular}{cccc}
\hline Conversion & Temp. $^{\left({ }^{\circ} \mathbf{C}\right)}$ & Reaction time & Final ratio 6/4 \\
\hline $\mathbf{4 c}-\mathrm{BF}_{4} \rightarrow \mathbf{6 c}-\mathrm{BF}_{4}$ & 20 & $9 \mathrm{~h}$ & $100 / 0$ \\
$\mathbf{4 c}-\mathrm{BF}_{4} \rightarrow \mathbf{6 c}-\mathrm{BF}_{4}$ & 40 & $1 \mathrm{~h}$ & $98 / 2$ \\
& & & \\
$\mathbf{4 b - O T f} \rightarrow \mathbf{6 b}-\mathrm{OTf}^{\dagger}$ & 40 & $6 \mathrm{~h}$ & $79 / 21$ \\
$\mathbf{4 b - O T f} \rightarrow \mathbf{6 b}-\mathrm{OTf}^{\dagger}$ & 60 & $2 \mathrm{~h}$ & $69 / 31$
\end{tabular}

${ }^{\dagger}$ Van't Hoff analysis of these data gave the following results: $\Delta \mathrm{H}^{0}=-23 \mathrm{~kJ} \mathrm{~mol}^{-1} ; \Delta \mathrm{S}^{0}=-62 \mathrm{~J} \mathrm{~K}^{-1}$ $\mathrm{mol}^{-1}$

Table S2. Final ratios and reaction times (from ${ }^{1} \mathrm{H}$ NMR spectra) for the synthesis of $\mathbf{6}$ from $\mathbf{4}$ in $\mathrm{CD}_{3} \mathrm{CN}$ at $40{ }^{\circ} \mathrm{C}$ for each pyrazole.

\begin{tabular}{ccc}
\hline Reaction & Reaction time & Final ratio 6/4 \\
\hline $\mathbf{4 a}-\mathrm{ClO}_{4} \rightarrow \mathbf{6 a}-\mathrm{ClO}_{4}$ & $6 \mathrm{~h}$ & $95 / 5$ \\
$\mathbf{4 b}-\mathrm{OTf} \rightarrow \mathbf{6 b}-\mathrm{OTf}$ & $6 \mathrm{~h}$ & $79 / 21$ \\
$\mathbf{4 c}-\mathrm{BF}_{4} \rightarrow \mathbf{6 c}-\mathrm{BF}_{4}$ & $1 \mathrm{~h}$ & $98 / 2$ \\
\hline
\end{tabular}

Table S3. Final ratios and reaction times (from ${ }^{1} \mathrm{H}$ NMR spectra) for the synthesis of $\mathbf{2}$ from $\mathbf{1}^{*}$ in $\mathrm{CD}_{3} \mathrm{CN}$ at r.t. for each pyrazole in the presence of $1 \%$ of $0.02 \mathrm{M} \mathrm{NaOH}$.

\begin{tabular}{ccc}
\hline Reaction & Reaction time & Final ratio 2/1 \\
\hline $\mathbf{1 b} \rightarrow \mathbf{2 b}$ & $30 \mathrm{~min}$ & $65 / 35$ \\
$\mathbf{1 c} \rightarrow \mathbf{2 c}$ & $10 \mathrm{~min}$ & $98 / 2$
\end{tabular}

* 1a could not be obtained pure (ref. S1).

Ref. S1 The synthesis and characterization of $\mathbf{3 b}$ was described in ref. S2, but the cystal structure was not reported. Ref. S2. Ardizzoia, G. A.; LaMonica, G.; Maspero, A; Moret, M.; Masciocchi, N. Eur. J. Inorg. Chem. 1998, 15031512. 


\section{Artículo 2:}

Luminiscent Rhenium(I) Tricarbonyl Complexes with Pyrazolylamidino Ligands: Photophysical, Electrochemical and Computational Studies 



\title{
Dalton Transactions
}

\section{Luminescent rhenium(।) tricarbonyl complexes with pyrazolylamidino ligands: photophysical, electrochemical, and computational studies $\dagger$}

\author{
Patricia Gómez-Iglesias, ${ }^{a}$ Fabrice Guyon, ${ }^{b}$ Abderrahim Khatyr, ${ }^{b}$ Gilles Ulrich, ${ }^{c}$ \\ Michael Knorr, ${ }^{b}$ Jose Miguel Martín-Alvarez, ${ }^{a}$ Daniel Miguel ${ }^{\mathrm{a}}$ and \\ Fernando Villafañe*a
}

\begin{abstract}
New pyrazolylamidino complexes fac- $\left[\mathrm{ReCl}(\mathrm{CO})_{3}\left(\mathrm{NH}=\mathrm{C}(\mathrm{Me}) \mathrm{pz}^{*}-\mathrm{k}^{2} \mathrm{~N}, \mathrm{~N}\right)\right]\left(\mathrm{pz} z^{*} \mathrm{H}=\right.$ pyrazole, pzH; 3,5-dimethylpyrazole, dmpzH; indazole, indzH) and $f a c-\left[\operatorname{Re} B r(C O)_{3}\left(N H=C(P h) p z^{*}-\kappa^{2} N, N\right)\right]$ are synthesized via base-catalyzed coupling of the appropriate nitrile with pyrazole, or via metathesis by halide abstraction with $\mathrm{AgBF}_{4}$ from a bromido pyrazolylamidino complex and the subsequent addition of $\mathrm{LiCl}$. In order to study both the influence of the substituents present at the pyrazolylamidino ligand, and that of the "sixth" ligand in the complex, photophysical, electrochemical, and computational studies have been carried out on this series and other complexes previously described by us, of the general formula fac-[ReL$\left.(\mathrm{CO})_{3}\left(\mathrm{NH}=\mathrm{C}\left(\mathrm{R}^{\prime}\right) \mathrm{pz}^{*}-\kappa^{2} \mathrm{~N}, \mathrm{~N}\right)\right]^{n+}\left(\mathrm{L}=\mathrm{Cl}, \mathrm{Br} ; \mathrm{R}^{\prime}=\mathrm{Me}, \mathrm{Ph}, n=0\right.$; or $\mathrm{L}=\mathrm{NCMe}, \mathrm{dmpzH}$, indzH, $\left.\mathrm{R}^{\prime}=\mathrm{Me}, n=1\right)$. All complexes exhibit phosphorescent decays from a prevalently ${ }^{3} \mathrm{MLCT}$ excited state with quantum yields $(\Phi)$ in the range between 0.007 and 0.039 , and long lifetimes $(\tau \sim 8-1900 \mathrm{~ns})$. The electrochemical study reveals irreversible reduction for all complexes. The oxidation of the neutral complexes was found to be irreversible due to halido-dissociation, whereas the cationic species display a reversible process implying the Rel/Rell couple. Density functional and time-dependent density functional theory (TD-DFT) calculations provide a reasonable trend for the values of emission energies in line with the experimental photophysical data, supporting the ${ }^{3}$ MLCT based character of the emissions.
\end{abstract}

Accepted 8th September 2015

DOI: $10.1039 / c 5 d t 02793 d$

www.rsc.org/dalton

\section{Introduction}

Since the first report on the photophysical properties of rhenium(I) tricarbonyl diimine complexes 40 years ago, this class of chelate compounds has been intensively studied. ${ }^{1}$

\footnotetext{
${ }^{a}$ GIR MIOMeT-IU Cinquima-Quimica Inorgánica, Facultad de Ciencias, Campus Miguel Delibes, Universidad de Valladolid, 47011 Valladolid, Spain. E-mail:fervilla@qi.uva.es

${ }^{b}$ Institut UTINAM, UMR 6213, Équipe Matériaux et Surfaces Structurés, Université de Franche-Comté, 16 Route de Gray, 25030 Besancon, France

'ICPEES, ECPM, UMR 7515, CNRS-Université Louis Pasteur, 25 rue Becquerel, 67087 Strasbourg, France

$\dagger$ Electronic supplementary information (ESI) available: Figure of the crysta structure of $f a c-\left[\operatorname{ReCl}(\mathrm{CO})_{3}\left(\mathrm{NH}=\mathrm{C}(\mathrm{Me}) \mathrm{dmpz}-\kappa^{2} N, N\right)\right], 2$; normalized emission and absorption spectra recorded in $\mathrm{CH}_{2} \mathrm{Cl}_{2}$ of complexes 2-6, 8, 10-12 at $298 \mathrm{~K}$ cyclic voltammograms of $10 \mathrm{mM} 5$ recorded in $\mathrm{CH}_{2} \mathrm{Cl}_{2}$ solution, and of $8.6 \mathrm{mM}$ $\left[\mathrm{ReBr}(\mathrm{CO})_{3}(\mathrm{dmpzH})_{2}\right]$ recorded in MeCN solution; tables with selected bond distances obtained in the geometry optimization of complex 1 with different func tionals and basis sets, frontier molecular orbital compositions in the grounc and excited states, and calculated excited energies and dominant orbital exci tations from TD-DFT for all the complexes. CCDC 1414405-1414407. For ESI and crystallographic data in CIF or other electronic format see DOI: 10.1039/ c5dt02793d
}

In the meantime, an important number of luminescent fac- $\left[\operatorname{ReX}(\mathrm{CO})_{3}(\mathrm{~N}-\mathrm{N})\right]$ complexes showing rich excited-state properties associated with their long-lived triplet metal-to-ligand charge transfer $\left({ }^{3}\right.$ MLCT) excited state have been widely reported. ${ }^{2,3}$ Their photophysical properties may be adequately tuned by varying the diimine ligand, the "sixth" ligand " $\mathrm{X}$ " (a halide or pseudo-halide for neutral complexes, a neutral ligand for cationic complexes), and the solvent. ${ }^{4}$ These properties have led to the development of diverse applications for this type of compound, ${ }^{5}$ for example as biomolecular agents, ${ }^{6}$ as photocatalysts for the reduction of $\mathrm{CO}_{2},{ }^{7}$ as light-emitting devices, ${ }^{8}$ or as molecular sensors or photoswitches. ${ }^{9}$

A panoply of diimine ligands, usually derived from bipy or phen, may be found in the literature. Nonetheless, finding a straightforward, synthetically accessible way to obtain new $\mathrm{N}, \mathrm{N}$-chelating ligands is one of the remaining challenges in this field. The photophysical properties may be adjusted by choosing the appropriate ligand, but most of the ordinarily used diimine ligands usually require synthetic methods which are often difficult and tiresome. Therefore, the possibility of using "a la carte" and "easy to make" ligands would be very welcome to scientists working in this field. Pyrazolylamidino 


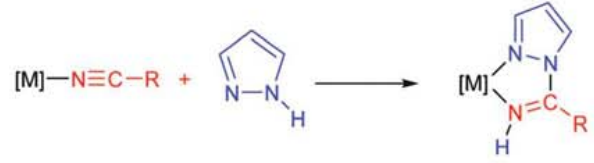

Scheme 1 Coupling reaction between a coordinated nitrile and a pyrazole to obtain a pyrazolylamidino ligand.

ligands fulfill all these requirements, since they can be readily obtained in situ by the coupling reaction of pyrazoles and coordinated nitriles (Scheme 1). Although reports on the synthesis of complexes containing pyrazolylamidino ligands are relatively scarce, ${ }^{10,11}$ a wide panel of pyrazolylamidino complexes can be synthesized by using different nitriles and pyrazoles, providing the opportunity of controlling both the electronic and steric properties of the ligand. We have recently published a systematic study on the mechanism of the metal-mediated coupling of pyrazoles and nitriles. ${ }^{12}$ This reversible intramolecular basecatalysed coupling reaction opens a broad range of synthetic possibilities to obtain new pyrazolylamidino complexes.

Since there are no previous reports dealing with the photophysical studies of pyrazolylamidino complexes, we report herein the first spectroscopic, electrochemical, and computational studies of rhenium(I) tricarbonyl complexes containing pyrazolylamidino ligands.

\section{Results and discussion}

\subsection{Synthesis and characterization}

All the complexes investigated in this study are collected in Table 1. In order to study the influence of the substituents on the pyrazolylamidino ligand and of the "sixth" ligand in a given complex, a panel of complexes was synthesized, some of them previously reported by us. ${ }^{11 c, 12}$ The pyrazolylamidino ligands result from the coupling of pyrazole $(\mathrm{pzH}), 3,5-\mathrm{di}-$ methylpyrazole $(\mathrm{dmpzH})$ or indazole (indzH) (labelled as pz- $\mathrm{R}$ in Table 1) with either acetonitrile or benzonitrile (NCR' in Table 1). In the neutral complexes, chlorido or bromido ligands were used, whereas acetonitrile and pyrazole $(\mathrm{dmpzH}$ or indzH) were coordinated in the cationic complexes ( $\mathrm{L}$ in Table 1). This diversity allows us to discriminate the influence of different stereo-electronic factors on the luminescence and electrochemical properties.

The syntheses and characterization of the species subjected to this study are described first, before discussing their properties. The syntheses of the new pyrazolylamidino complexes are presented in Scheme 2. Complexes 3, 7, and 8 were obtained by the coupling of nitrile with pyrazole, using $\mathrm{NaOH}$ (aq.) as a catalyst, as previously reported by us. ${ }^{12}$ Chlorido complexes 1 and 2 were instead obtained from the previously synthesized bromido pyrazolylamidino complexes by abstracting the bromido ligand with $\mathrm{AgBF}_{4}$ and the subsequent addition of chloride. Alternatively, complexes 1 and 2 can also be obtained by the same manner as complex 3 , that is by coup-
Table 1 Pyrazolylamidino complexes used in this study

\begin{tabular}{|c|c|c|c|c|c|}
\hline \multirow[b]{2}{*}{ Compd. } & \multirow[b]{2}{*}{$n$} & \multicolumn{3}{|c|}{$7^{n+}$} & \multirow[b]{2}{*}{ Ref. } \\
\hline & & $\mathrm{L}$ & $\mathrm{pz}-\mathrm{R}$ & $\mathrm{R}^{\prime}$ & \\
\hline 1 & 0 & $\mathrm{Cl}$ & $\mathrm{pz}$ & $\mathrm{Me}$ & This work \\
\hline 2 & 0 & $\mathrm{Cl}$ & dmpz & $\mathrm{Me}$ & This work \\
\hline 3 & 0 & $\mathrm{Cl}$ & ind $z$ & $\mathrm{Me}$ & This work \\
\hline 4 & 0 & $\mathrm{Br}$ & $\mathrm{pz}$ & $\mathrm{Me}$ & $11 c$ \\
\hline 5 & 0 & $\mathrm{Br}$ & $\mathrm{dmpz}$ & $\mathrm{Me}$ & $11 c$ \\
\hline 6 & 0 & $\mathrm{Br}$ & indz & $\mathrm{Me}$ & 12 \\
\hline 7 & 0 & $\mathrm{Br}$ & dmpz & $\mathrm{Ph}$ & This work \\
\hline 8 & 0 & $\mathrm{Br}$ & indz & $\mathrm{Ph}$ & This work \\
\hline 9 & $1\left(\mathrm{ClO}_{4}{ }^{-}\right.$salt $)$ & NCMe & dmpz & $\mathrm{Me}$ & $11 c$ \\
\hline 10 & $1\left(\mathrm{ClO}_{4}{ }^{-}\right.$salt $)$ & NCMe & ind $z$ & $\mathrm{Me}$ & 12 \\
\hline 11 & $1\left(\mathrm{ClO}_{4}{ }^{-}\right.$salt $)$ & dmpzH & $\mathrm{dmpz}$ & $\mathrm{Me}$ & $11 c$ \\
\hline 12 & $1\left(\mathrm{ClO}_{4}^{-}\right.$salt $)$ & indzH & ind $z$ & $\mathrm{Me}$ & 12 \\
\hline
\end{tabular}
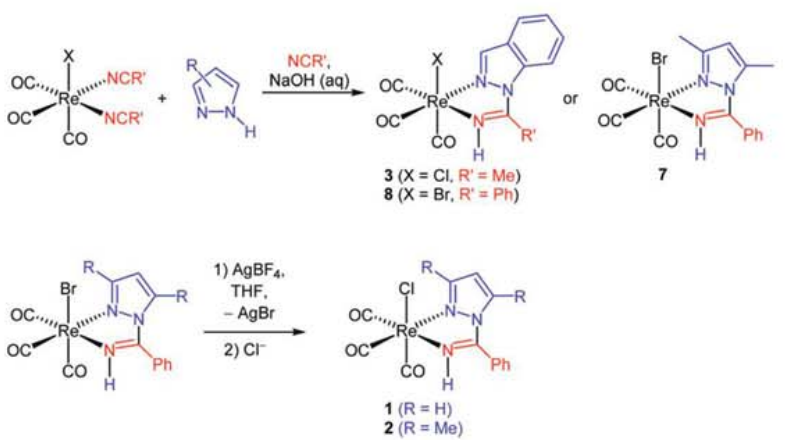

Scheme 2 Syntheses of the new pyrazolylamidino complexes.

ling of the corresponding nitrile with pyrazole. However, when using this latter route the yields are much lower, as these processes usually reach equilibrium between the mixed nitrilepyrazole and the final pyrazolylamidino complexes. ${ }^{12}$ This equilibrium is shifted to the starting mixture for chlorido complexes 1-3, whereas for bromido complexes 4-8 it is driven to the final pyrazolylamidino complexes.

The spectroscopic and analytical data support the proposed geometries and are included in the Experimental section. The hydrogen atoms at the ortho position of the phenyl substituents in benzonitrile-derived complexes $\mathbf{7}$ and $\mathbf{8}$ display broad signals in the ${ }^{1} \mathrm{H}$ NMR spectra at room temperature, probably due to the slowing down of the phenyl group rotation. Spectra recorded at lower temperatures gave the expected pattern (see the Experimental section). Furthermore, complexes 1 (Fig. 1), 2 (Fig. S1 $\dagger$ ), and 7 (Fig. 2) were characterized by single-crystal $\mathrm{X}$-ray diffraction studies. The distances and angles (CCDC 1414405-1414407) are similar to those found in other pyrazolylamidinorhenium complexes. ${ }^{11,12}$ In complexes 2 and 7 , the $\mathrm{N}$-bound hydrogens of the pyrazolylamidino ligands are involved in hydrogen bonding with a chlorido ligand of an 


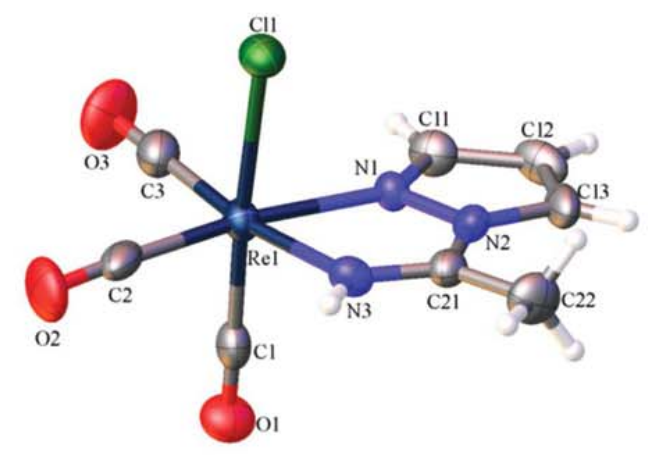

Fig. 1 Perspective view of $\mathrm{fac}-\left[\mathrm{ReCl}(\mathrm{CO})_{3}\left(\mathrm{NH}=\mathrm{C}(\mathrm{Me}) \mathrm{pz}-\kappa^{2} \mathrm{~N}, \mathrm{~N}\right)\right]$ 1 , showing the atom numbering. Thermal ellipsoids are drawn at $50 \%$ probability. Selected bond lengths $(\dot{A})$ and angles $\left({ }^{\circ}\right)$ : N1-Re1 2.164(6), N1-N2 1.365(11), C21-N2 1.399(13), C21-N3 1.289(12), N3-Re1 2.158(8), Cl1-Re1 2.500(2); C1-Re1-Cl1 176.8(2), C1-Re1-N1 89.9(3), C1-Re1N3 95.0(4), C2-Re1-Cl1 95.0(3), C2-Re1-N1 170.7(4), C2-Re1-N3 97.8(4), C3-Re1-Cl1 91.5(4), C3-Re1-N1 99.6(4), C3-Re1-N3 171.4(4), N1-Re1-Cl1 87.0(2), N3-Re1-Cl1 83.3(2), N3-Re1-N1 73.3(3), N2-N1Re1 114.4(5), N1-N2-C21 118.1(7), N3-C21-N2 114.7(8).

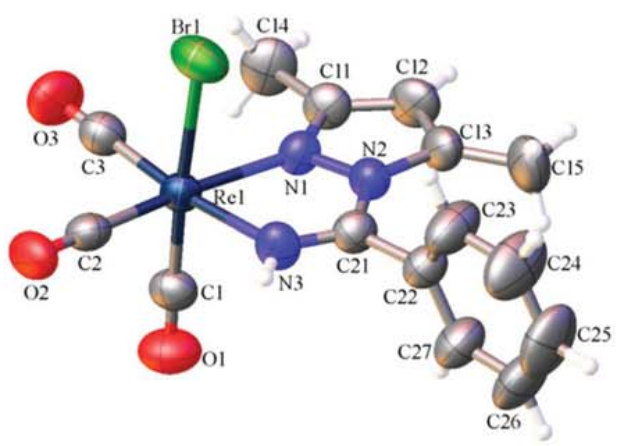

Fig. 2 Perspective view of $f a c-\left[\operatorname{ReBr}(\mathrm{CO})_{3}\left(\mathrm{NH}=\mathrm{C}(\mathrm{Ph}) \mathrm{dmpz}-\kappa^{2} N, N\right)\right]$ 7 . showing the atom numbering. Thermal ellipsoids are drawn at $50 \%$ probability. Selected bond lengths $(\dot{A})$ and angles $\left({ }^{\circ}\right)$ : Re1-N1 2.169(4), N1-N2 1.385(6), N2-C21 1.411(7), N3-C21 1.266(7), Re1-N3 2.130(5), $\operatorname{Re} 1-\mathrm{Br} 1$ 2.6274(7); N1-Re1-Br1 84.02(12), N3-Re1-Br1 84.97(13), N3Re1-N1 72.98(17), C1-Re1-Br1 176.81(19), C1-Re1-N1 93.8(2), C1-Re1N3 92.2(2), C2-Re1-Br1 92.49(17), C2-Re1-N1 169.9(2), C2-Re1-N3 97.3(2), C3-Re1-Br1 91.15(19), C3-Re1-N1 100.9(2), C3-Re1-N3 173.0(2), N2-N1-Re1 114.4(3), N1-N2-C21 116.1(4), N3-C21-N2 115.0(5), C21 N3 Re1 121.3(4).

adjacent molecule, or with the oxygen atom of a THF molecule present in the crystal, respectively. The distances and angles detected $(\mathrm{H}(3) \cdots \mathrm{Cl}(1) 2.279(8) \AA, \mathrm{N}(3) \cdots \mathrm{Cl}(1) 3.267(8) \AA, \mathrm{N}(3)-$ $\mathrm{H}(3) \cdots \mathrm{Cl}(1) 160.2(4)^{\circ}$, for 2 , and $\mathrm{H}(3) \cdots \mathrm{O}(91), 1.815(8) \AA$; $\mathrm{N}(3)$ ‥ $\left.\mathrm{O}(91) 2.837(8) \AA, \mathrm{N}(4)-\mathrm{H}(3) \cdots \mathrm{O}(91) 171.8(4)^{\circ}\right)$ for 7 may be considered respectively as "weak" and "moderate" hydrogen bonds. ${ }^{13}$

\subsection{Photophysical studies}

One main objective of this work was the investigation of the photophysical properties of our family of rhenium(I) tricarb- onyl complexes containing pyrazolylamidino ligands, as there are no previous reports on the photophysical properties of complexes bearing these ligands. The absorption and emission spectral data collected for all complexes are summarized in Table 2. The electronic absorption and emission spectra of complexes 1 to 12 have been measured at $298 \mathrm{~K}$ using $\mathrm{CH}_{2} \mathrm{Cl}_{2}$ as the solvent. Fig. 3 shows representative absorption and emission spectra of the neutral chlorido complex 1 and of the cationic complex 9 , respectively. The absorption spectra of all complexes (see the ESI, Fig. S2 $\dagger$ ) exhibit high-energy transitions with maxima between 230 and $300 \mathrm{~nm}$, and a tail reaching up to $480 \mathrm{~nm}$. The absorption data of the complexes are qualitatively similar to the related $\operatorname{Re}(\mathrm{I})$ compounds already published. ${ }^{2 a, 14}$ Selected examples displaying similar absorption spectra are $f a c-\left[\operatorname{ReX}(\mathrm{CO})_{3}(\mathrm{~N}-\mathrm{N})\right]$ where $\mathrm{X}=\mathrm{Cl}$ or $\mathrm{Br}$, and $\mathrm{N}-\mathrm{N}$ represents a bidentate $\mathrm{N}$-heterocyclic carbene, ${ }^{15}$ or pyridyl-triazole derivatives ${ }^{16}$ possessing imine-type $\mathrm{N}$-donor sites. Therefore it seems justified to interpret the absorption features of our rhenium(I) complexes in an analogous manner. As described below, the results of the computational study also support this assignment. Intense bands due to an intraligand (IL) origin are observed in the UV region at high energy (230-300 nm). The lowest energy absorption bands listed in Table 2 are assigned to a mixture of MLCT Re $\rightarrow \pi^{*}(\mathrm{~L})$, ligandto-ligand charge-transfer (LLCT), and halide-to-ligand chargetransfer (XLCT) transitions. The XLCT character is supported by the fact that the absorption maxima shifts to lower energy upon changing the halide ligands from $\mathrm{Cl}$ to $\mathrm{Br}$, because the oxidation of the metal becomes progressively easier upon decreasing the electronegativity of the halide. The same behaviour was also observed for the series $\left[\operatorname{Re}_{2}(\mu-\mathrm{X})_{2}(\mathrm{CO})_{6}-\right.$ $\{\mu$-(1,2-diazine $)\}]$ when changing the nature of the halide $(\mathrm{X}=$ $\mathrm{Cl}, \mathrm{Br}, \mathrm{I}){ }^{17}$

In order to evaluate the halide influence on the photophysical properties, the series of chlorido complexes (1-3) is compared with their bromido-substituted analogues (4-6). After excitation at $390 \mathrm{~nm}$, the comparison of the emission bands reveals that those of the chlorido complexes 1, 2 and 3 show a slight hypsochromic shift with respect to their bromido counterparts 4, 5 and 6 . As reported by Bertrand et al., ${ }^{16}$ these profiles are typical of the emission from MLCT/XLCT excited states when considering band shapes and the values of the emission wavelengths.

The luminescence quantum yields $\varnothing$ of the pyrazolylamidino complexes were determined using cresyl violet as a luminescence quantum yield standard, ${ }^{18}$ all measurements have been performed in deaerated solvents. The quantum yields of our complexes are relatively weak, independent of the halide or counter ion, and fall in the range reported for other "fac-Re(CO) $)_{3}$ " complexes. ${ }^{15,19}$ Nevertheless, in the case of halide series 1-6, somewhat higher quantum yields are found for the bromido-derivatives 4-6 (Ø $0.017-0.026 \%$ ) compared to those of chlorido-derivatives 1-3 (Ø $0.015-0.022 \%)$. However complexes $\mathbf{4}$ and $\mathbf{5}$ emit at lower excited energy states, thus contradicting trends dictated by the energy gap law (EGL), ${ }^{20}$ the shorter lifetime values for complexes 1, 2, 3 and 6 might 
Table 2 Absorption and emission data of complexes 1 to 12 in $\mathrm{CH}_{2} \mathrm{Cl}_{2}$ at $298 \mathrm{~K}^{\mathrm{a}}$

\begin{tabular}{|c|c|c|c|c|c|c|}
\hline \multirow[b]{2}{*}{ Comp } & \multirow{2}{*}{$\begin{array}{l}\text { Absorption } \\
\lambda \mathrm{nm}\left(\varepsilon \times 10^{-3} \mathrm{M}^{-1} \mathrm{~cm}^{-1}\right)\end{array}$} & \multicolumn{5}{|l|}{ Emission } \\
\hline & & $\begin{array}{l}\lambda_{\text {em }}(\mathrm{nm}) \\
{\left[\lambda_{\text {excit }}=390 \mathrm{~nm}\right]}\end{array}$ & $\begin{array}{l}\emptyset \times 10^{-3} \\
( \pm 8 \%)\end{array}$ & $\tau(\mathrm{ns})$ & $k_{\mathrm{r}} / 10^{4} \mathrm{~s}^{-1}$ & $k_{\mathrm{nr}} / 10^{6} \mathrm{~s}^{-1}$ \\
\hline 1 & $264 \operatorname{sh}(13), 360(7)$ & 570 & 15 & 220 & 6.8 & 4.5 \\
\hline 2 & $232(16.7), 261 \operatorname{sh}(10.9), 352(5)$ & 557 & 22 & 254 & 8.6 & 3.85 \\
\hline 3 & $260(15.1), 304(5), 316(5), 367(6.7)$ & 559 & 18 & 210 & 8.6 & 4.7 \\
\hline 4 & $246(17.1), 267 \operatorname{sh}(15.8), 368(2)$ & 572 & 17 & 890 & 1.9 & 1.1 \\
\hline 5 & $248(17.4), 283(20.2), 356(21.3)$ & 564 & 26 & 430 & 6.0 & 2.3 \\
\hline 6 & $251(20.1), 269 \mathrm{sh}(18.9), 379(3.8)$ & 581 & 21 & 180 & 11.7 & 5.4 \\
\hline 8 & 233 (19.1), 273 (19.4), 310 sh $(4.2), 323$ sh (3.3), 381 (3.7) & 606 & 11 & 35 & 31.4 & 28.3 \\
\hline 9 & $233(19.5), 254(20.2), 324(10.3)$ & 524 & 12 & 17 & 7.1 & 58.1 \\
\hline 10 & $246(21.1), 313(8.4), 340(8.5)$ & 532 & 16 & 8 & 200 & 123 \\
\hline 11 & $260(10.2), 346(16)$ & 536 & 7 & 560 & 1.25 & 1.77 \\
\hline 12 & $254(21.7), 282(24.1), 359$ (13.7) & 544 & 39 & 1900 & 2.1 & 0.5 \\
\hline
\end{tabular}

${ }^{a}$ No reliable spectra could be obtained for 7 due to its instability in $\mathrm{CH}_{2} \mathrm{Cl}_{2}$ solution.
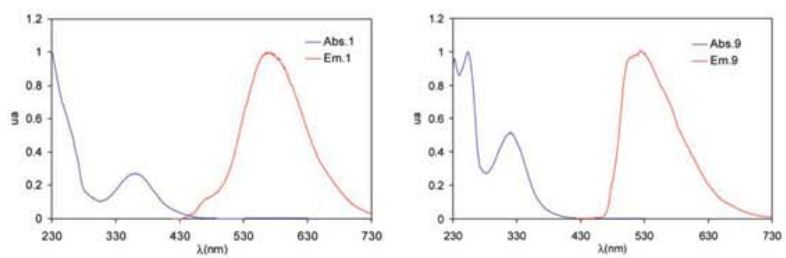

Fig. 3 Emission (red) and absorption (blue) spectra recorded in $\mathrm{CH}_{2} \mathrm{Cl}_{2}$ of complexes 1 (left) and 9 (right) at $298 \mathrm{~K}$.

be caused by competing photochemical pathways triggered upon excitation. Despite a long-lived emission due to the ${ }^{3}$ MLCT transition of pz-complex 4 ( $890 \mathrm{~ns}$ ), with $\tau$ being twice that of the dmpz complex 5 (430 ns), the quantum yields of both compounds are quite close, around $0.02-0.03 \%$.

The following trends are noticed: (i) introduction of electron-donating groups in the pyrazole core causes a weak shift to lower $\lambda_{\text {em }}$. This effect can be observed when comparing pyrazole complexes 1 and 4 with 3,5-dimethylpyrazole complexes 2 and 5, resulting in $\Delta \lambda_{\mathrm{em}} \sim\left[13 \mathrm{~nm} / 409 \mathrm{~cm}^{-1}\right]$ and $\left[8 \mathrm{~nm} / 248 \mathrm{~cm}^{-1}\right.$ ] respectively. (ii) When the "sixth" ligand is replaced from an anionic $\sigma$-donor/ $\pi$-donor ligand (chlorido in complexes 2,3 , and bromido in complexes 5,6 ) by a neutral $\sigma$-donor ligand (acetonitrile in complexes 9, 10) there is an hypsochromic shift in the emission that ranges from $\Delta \lambda_{\mathrm{em}}=$ [33 nm/1130 $\mathrm{cm}^{-1}$ ] when comparing complexes 2 and 9 , to $\Delta \lambda_{\mathrm{em}}=\left[49 \mathrm{~nm} / 1585 \mathrm{~cm}^{-1}\right]$ when comparing complexes 6 and 10. A simultaneous enhancement of the non-radiative constant is observed, which may be induced by the change of the $\sigma$-donor $/ \pi$-donor character of chlorido/bromido by the $\sigma$-donor character of acetonitrile in the complex, thus favouring a nonemissive vibrational de-excitation pathway. This is reflected by a strong drop of the lifetime $\tau$ from 430 to $17 \mathrm{~ns}$. (iii) The replacement of the imine-methyl group in bromido complex 6 by a phenyl group in indz-complex 8 induces a red-shift of the emission with $\Delta \lambda_{\mathrm{em}} \sim\left[25 \mathrm{~nm} / 710 \mathrm{~cm}^{-1}\right]$, concomitant with an enhanced non-radiative constant.
This same effect is also noticed when comparing the emission maxima of complex 6 with those of $12\left(\Delta \lambda_{\mathrm{em}} \sim[17 \mathrm{~nm} /\right.$ $\left.\left.1170 \mathrm{~cm}^{-1}\right]\right)$ and $10\left(\Delta \lambda_{\mathrm{em}} \sim\left[49 \mathrm{~nm} / 1585 \mathrm{~cm}^{-1}\right]\right)$. Note that a considerable diminution of the non-radiative constant, evidenced by a longer emission lifetime, is observed when the indazole ligand in $\mathbf{1 2}$ is replaced by an acetonitrile ligand in 10. A similar long life-time emission at $536 \mathrm{~nm}$ is observed for cationic complex 11, where the Re centre is coordinated by a chelating pyrazolylamidino ligand containing a dmpz fragment, and a N-bound 3,5-dimethylpyrazole ligand. The emitting level can be assigned to the ${ }^{3}$ MLCT transition according to the usual considerations of the position and shape of the emission band for complexes 9 to $\mathbf{1 2}$. This interpretation is consistent with those previously reported for similar carbonyl and diimine ligands coordinated to a $\operatorname{Re}(\mathrm{I}) \mathrm{d}^{6}$ low-spin centre assigned to ${ }^{3} \mathrm{MLCT}$ emitters, ${ }^{21}$ and with the results of the theoretical calculations carried out on this complexes (see below).

In summary, the substitution of chloride in complexes 1-3 by bromide (complexes 4-6) is translated by a small hypsochromic shift. The same behavior is observed when the hydrogens at the 3- and 5-positions of the pyrazole core (in 4) are substituted by two electron-donating methyl groups (in 5). The substitution of the bromido ligand in the dmpz complex 5 by acetonitrile (in 9) gives rise to an increase of the energy of the emitter level by $1354 \mathrm{~cm}^{-1}$. The replacement of the methyl group at the amidino fragment (in 6) by a phenyl group (in 8) induces a red-shift of the emission by $710 \mathrm{~cm}^{-1}$. All the complexes exhibit phosphorescent decays from the ${ }^{3}$ MLCT excited state, and their quantum yields $(\Phi \sim 0.007-0.039)$ correspond to those reported previously for other rhenium $(\mathrm{I})$ tricarbonyl complexes. Their long lifetimes $(\tau \sim 8-1900 \mathrm{~ns})$ are a further proof that the emissions arise from a prevalently ${ }^{3}$ MLCT state.

\subsection{Electrochemical study}

The redox properties of each compound have been investigated by cyclic voltammetry in MeCN solution in the potential region from $-2.30 \mathrm{~V}$ to $1.50 \mathrm{~V}$. Scan rates between 0.025 and 
Table 3 Redox potentials of the pyrazolylamidino complexes

\begin{tabular}{llll}
\hline Compd. & $E_{\text {red }}^{\mathrm{p}}$ & $E_{\text {ox }}^{\mathrm{p}}$ & $E_{\text {ox }}^{1 / 2}$ \\
\hline $\mathbf{1}$ & -2.08 & +0.92 & +1.34 \\
$\mathbf{2}$ & -2.25 & +0.89 & +1.30 \\
$\mathbf{3}$ & & +0.93 & $a$ \\
$\mathbf{4}$ & -2.10 & +0.91 & +1.34 \\
$\mathbf{5}$ & -2.20 & +0.88 & +1.31 \\
$\mathbf{6}$ & -1.47 & +0.91 & +1.32 \\
7 & -1.87 and -2.14 & +0.91 & +1.33 \\
$\mathbf{8}$ & -1.84 & +0.92 & +1.34 \\
$\mathbf{9}$ & -1.96 & & +1.32 \\
$\mathbf{1 0}$ & -1.80 & & +1.34 \\
$\mathbf{1 1}$ & -1.96 & & +1.15 \\
$\mathbf{1 2}$ & -2.04 & & +1.32
\end{tabular}

${ }^{a}$ The low solubility of 3 in MeCN precluded a clear determination of $E_{\mathrm{ox}}^{1 / 2}$ and $E_{\mathrm{red}}^{\mathrm{p}}$.

$2.5 \mathrm{~V} \mathrm{~s}^{-1}$ were examined. Cyclic voltammograms have also been recorded for some samples in $\mathrm{CH}_{2} \mathrm{Cl}_{2}$ in order to probe the influence of a non-coordinating solvent on their redox properties. Table 3 lists the measured redox potentials in MeCN.

All compounds display an irreversible cathodic wave between $-1.80 \mathrm{~V}$ and $-2.25 \mathrm{~V}$. Due to the significant shift of the cathodic peak potential $\left(E_{\mathrm{red}}^{\mathrm{p}}\right)$ when changing the nature of the pyrazolylamidino ligand, a pyrazolylamidino-based reduction is assigned to this wave. Thus, reductions are more favored for indazolylamidino ligands compared to those containing $\mathrm{pz}$ or dmpz groups in the order indz $>\mathrm{pz}>\mathrm{dmpz}$ (Table 3). This is supported by the results of the computational study (see below), since the LUMO, which has mainly an amidino contribution, is more stabilised for amidino ligands containing indz fragments ( 3 and $\mathbf{6}$ ) than for similar pz (1 and 4) or dmpz (2 and 5) derivatives. For the neutral complexes, the irreversibility of the process is attributed to the halide dissociation, as reported for related compounds. ${ }^{22}$ This is corroborated by the observation of an anodic wave at $c a$. $+0.5 \mathrm{~V}$ for the bromido complexes $\mathbf{4 - 8}$, which may result from the oxidation of bromide when the scan starts towards reduction before the oxidation potentials (see curves corresponding to the 2nd and 3rd scans of 5 in Fig. 4).

Neutral complexes (1-8) exhibit two oxidation processes (see Fig. 4 for 5). An irreversible peak is observed, even for a scan rate of $2.5 \mathrm{~V} \mathrm{~s}^{-1}$, at $0.90 \pm 0.02 \mathrm{~V}$, followed by an electrochemically reversible one at $1.32 \pm 0.02 \mathrm{~V}$. In contrast, the cationic species (9-12) display only one quasi-reversible wave in the range 1.15-1.34 V (see Fig. 4 for 9). For compounds 9-11, the ratio of peak currents $\left(i_{\mathrm{pa}} / i_{\mathrm{pc}}\right)$ is equal to 1 at a scan rate of $100 \mathrm{mV} \mathrm{s}^{-1}$, whereas the reversibility is observed only for scan rates above $500 \mathrm{mV} \mathrm{s}^{-1}$ for compound 12. For the bromido complexes 4-8 the oxidation peak at $0.90 \mathrm{~V}$ is coupled in the following scan to a reduction peak at $c a .0 .55 \mathrm{~V}$ (see Fig. 4 for

¥As shown in Table 3, compound 7 displays a second wave at $-2.14 \mathrm{~V}$, whereas a second wave at potential lower than the lower limit recorded (below $-2.5 \mathrm{~V}$ ) may be also perceived for compound $\mathbf{8}$. Therefore, this second wave might be attributed to the presence of a phenyl substituent in the pyrazolylamidino ligand.

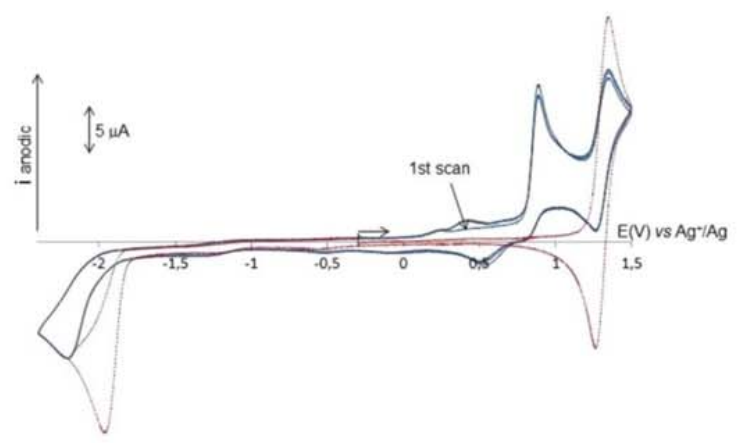

Fig. 4 Cyclic voltammograms recorded in MeCN solutions of $15 \mathrm{mM} 5$ (blue, 3 scans) and $16 \mathrm{mM} 9$ (red, 1 scan). Scan rate: $100 \mathrm{mV} \mathrm{s}^{-1}$. Initial potential: $-0.3 \mathrm{~V}$.

5). Overall, the cyclic voltammograms of the neutral compounds investigated here are comparable to that of fac-[ReCl$\left.(\mathrm{CO})_{3}(\mathrm{dmbipy})\right]\left(\mathrm{dmbipy}=4,4^{\prime}\right.$-dimethyl-2,2'-bipyridyl $){ }^{23}$ In this case the first oxidation was found to produce chlorine and fac- $\left[\mathrm{Re}(\mathrm{MeCN})(\mathrm{CO})_{3}(\mathrm{dmbipy})\right]^{+}$. We propose a similar EC mechanism for pyrazolylamidino halido complexes 1-8 in the first stage (Scheme 3). The potentials $E_{\mathrm{ox}}^{\mathrm{p}}$ are independent of the nature of the ligands (Table 3), and therefore the process is assigned to a metal centred oxidation, leading to the formal 17-electron monocationic species $f a c$ - $\left[\mathrm{Re}^{\mathrm{II}} \mathrm{X}(\mathrm{CO})_{3}\left(\mathrm{NH}=\mathrm{C}\left(\mathrm{R}^{\prime}\right)\right.\right.$ $\left.\left.\mathrm{pz}^{*}-\kappa^{2} N, N\right)\right]^{+}, \boldsymbol{A}$. This is followed by dissociation of the halide with concomitant coordination of a molecule of $\mathrm{MeCN}$ to give the 17-electron cationic species fac- $\left[\mathrm{Re}^{\mathrm{II}}(\mathrm{NCMe})(\mathrm{CO})_{3}(\mathrm{NH}=\mathrm{C}\right.$ $\left.\left.\left(\mathrm{R}^{\prime}\right) \mathrm{pz}^{*}-\kappa^{2} N, N\right)\right]^{+}, \boldsymbol{B}$. This $\mathrm{Re}^{\mathrm{II}}$ adduct is reduced by reaction with halide to give $\mathrm{X}_{2}$ and the 18-electron cation fac$\left[\mathrm{Re}^{\mathrm{I}}(\mathrm{NCMe})(\mathrm{CO})_{3}\left(\mathrm{NH}=\mathrm{C}\left(\mathrm{R}^{\prime}\right) \mathrm{pz}^{*}-\kappa^{2} N, N\right)\right]^{+}, C$, which is electrochemically reversibly oxidized at $1.32 \pm 0.02 \mathrm{~V}$, to give fac$\left[\mathrm{Re}^{\mathrm{II}}(\mathrm{NCMe})(\mathrm{CO})_{3}\left(\mathrm{NH}=\mathrm{C}\left(\mathrm{R}^{\prime}\right) \mathrm{pz}^{*}-\kappa^{2} N, N\right)\right]^{\cdot 2+}, \boldsymbol{D}$ (Scheme 3). The very close half-wave potentials of dmpz complexes 2,5 and 9 on the one hand, and of the indz complexes $\mathbf{6}$ and $\mathbf{1 0}$ on the other hand§ (Table 3 and Fig. 4) support this proposal. Moreover, the wave observed at $1.32 \pm 0.02 \mathrm{~V}$ is irreversible when the cyclic voltammograms of the halido complexes are performed in $\mathrm{CH}_{2} \mathrm{Cl}_{2}$ (Fig. S3 $\dagger$ ), as expected for the oxidation of fac-[Re$\left.(\mathrm{CO})_{3}\left(\mathrm{NH}=\mathrm{C}\left(\mathrm{R}^{\prime}\right) \mathrm{pz}^{*}-\kappa^{2} N, N\right)\right]^{+}$, which would lead to a very unstable 15 electron species. The relatively limited deviation between all the half-wave potentials collected $\left(E_{\mathrm{ox}}^{1 / 2}\right.$ in Table 3$)$ points to an electronic transfer implying the $\operatorname{Re}(\mathrm{I}) / \operatorname{Re}(\mathrm{II})$ couple, as indicated in Scheme 3.

The cathodic wave observed at $0.55 \mathrm{~V}$ for the bromido complexes 4-8 is assigned to the reduction of molecular bromine to bromide, ${ }^{24}$ which reacts with $f a c-\left[\mathrm{Re}^{\mathrm{II}}(\mathrm{NCMe})(\mathrm{CO})_{3}(\mathrm{NH}=\right.$ $\left.\left.\mathrm{C}\left(\mathrm{R}^{\prime}\right) \mathrm{pz}^{*}-\mathrm{\kappa}^{2} N, N\right)\right]^{++}, C$, to regenerate the starting materials (Scheme 3). Thus, a wave due to oxidation of the bromine is

$\S$ Complex 3 should present the same behaviour as 6 or 10 but the $E_{o x}^{1 / 2}$ was not clear in the CV probably due to the low solubility of this compound in MeCN (as indicated in the footnote in Table 3). 


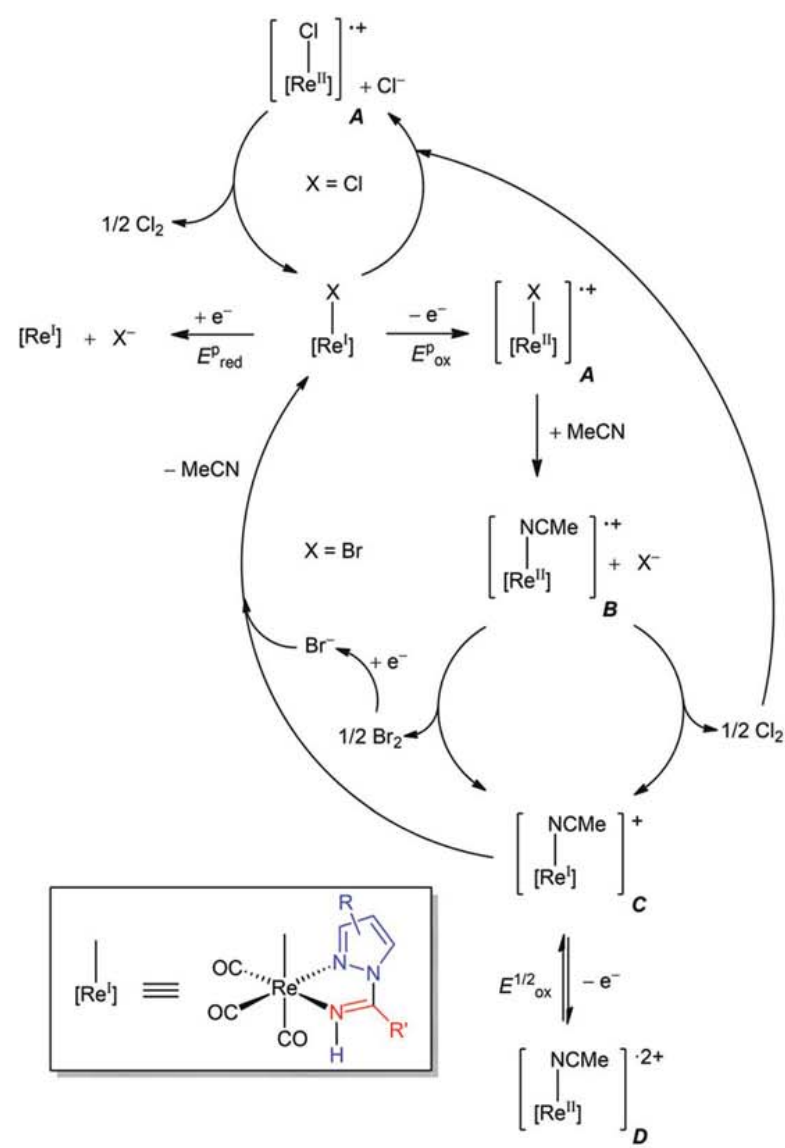

Scheme 3 Electrochemical processes proposed for the pyrazolylamidino complexes.

observed when the scan is cyclized between -0.3 and $+1.5 \mathrm{~V}$ at a scan rate of $100 \mathrm{mV} \mathrm{s}^{-1}$.

In the cyclic voltammograms of the chlorido complexes $1-3$, the reduction of chlorine is not detected. Chlorine is a stronger oxidizing agent than bromine, and therefore should oxidize the starting complexes 1-3 (Scheme 3).

The irreversibility of the oxidation herein observed for the neutral pyrazolylamidino complexes is not a general feature for the neutral rhenium(I) tricarbonyl diimine complexes. For example, $f a c-\left[\operatorname{ReX}(\mathrm{CO})_{3}\left({ }^{t} \mathrm{Bu}-\mathrm{DAB}\right)\right]\left(\mathrm{X}=\mathrm{Cl}\right.$ or $\mathrm{Br} ;{ }^{t} \mathrm{Bu}-\mathrm{DAB}=1,4$ di-tert-butyl-1,4-diazabutadiene) exhibits a reversible oxidation at a potential similar to those listed as $E_{\mathrm{ox}}^{\mathrm{p}}$ in Table $3 .^{25}$ In order to assess the influence of the pyrazolylamidino ligands on the redox properties of these $f a c$ - $\left[\operatorname{ReX}(\mathrm{CO})_{3}(\right.$ diimine $\left.)\right]$ complexes, this study was completed by the characterization of the electrochemical behaviour of $f a c-\left[\operatorname{ReBr}(\mathrm{CO})_{3}(\mathrm{dmpzH})_{2}\right]^{26}$ and $f a c-\left[\operatorname{ReBr}(\mathrm{CO})_{3}(\mathrm{MeCN})(\mathrm{dmpzH})\right]^{11 c}$ complexes. fac-[ReBr$\left.(\mathrm{CO})_{3}(\mathrm{dmpzH})_{2}\right]$ exhibits a reversible wave at $0.93 \mathrm{~V}$ (Fig. S4 $\dagger$ ), whereas for $f a c-\left[\operatorname{ReBr}(\mathrm{CO})_{3}(\mathrm{MeCN})(\mathrm{dmpzH})\right]$ the ratio $i_{\mathrm{pa}} / i_{\mathrm{pc}}$ centred at $0.99 \mathrm{~V}$ is equal to 0.4 at a scan rate of $100 \mathrm{mV} \mathrm{s}^{-1}$. It is noteworthy that in both cases reduction of bromine is not detected in the following scan. Thus, the stabilities of fac-
$\left[\operatorname{Re}^{\mathrm{II}} \mathrm{Br}(\mathrm{CO})_{3}(\mathrm{dmpzH})_{2}\right]^{++}$and $\mathrm{fac}-\left[\mathrm{Re}^{\mathrm{II}} \mathrm{Br}(\mathrm{CO})_{3}(\mathrm{MeCN})(\mathrm{dmpzH})\right]^{++}$ contrast with that of $f a c-\left[\operatorname{Re}^{\mathrm{II}} \mathrm{Br}(\mathrm{CO})_{3}(\text { pyrazolylamidino })\right]^{++}$, which may be interpreted by considering the difference in the lability of the $\mathrm{Re}-\mathrm{Br}$ bond in these compounds.

\subsection{Computational study}

All the complexes were also studied theoretically by means of density functional and time-dependent density functional theory (TD-DFT) calculations. Computational details can be found in the Experimental section, the relevant types of complexes are discussed here, and the complete list of results are included in the ESI. $\dagger$ The ground-state geometry was optimized at the PBE1PBE level (PBE0) with no symmetry restraints for all the complexes and the minimum obtained compares well with the structure obtained by X-ray diffraction when available (see Tables S1 and S2 in the ESI $\dot{\dagger}$ ).

The partial frontier molecular orbital compositions and energy levels of compounds $\mathbf{1}$ and $\mathbf{9}$, as models for neutral (1-8) and cationic (9-12) complexes are listed in Tables 4 and 5 , respectively.

It can be seen that the highest occupied molecular orbitals (HOMOs) have a mixed $\mathrm{Re} / \mathrm{CO} / \mathrm{Cl}$ character with different contributions in the case of the neutral complex $\mathbf{1}$, while for the cationic complex 9 there is also a non-negligible contribution from the pyrazolylamidino ligand. In both cases the LUMO is mainly centred in the amidino ligand.

The calculated absorption energies associated with their oscillator strengths, the main configuration and their assignments, together with the experimental results for complexes $\mathbf{1}$ and 9 are given in Tables 6 and 7, respectively.

For the neutral complex 1, the low lying absorption measured experimentally at $360 \mathrm{~nm}$ can be assigned to the singlet excited state $\mathrm{S}_{2}(366 \mathrm{~nm})$, which consists primarily of the excitation from $\mathrm{HOMO}-1$ with $\mathrm{d}(\mathrm{Re})+\mathrm{p}(\mathrm{Cl})+\pi(\mathrm{CO})$ main

Table 4 Frontier molecular orbital compositions (\%) in the ground state for complex 1 at the PBE1PBE level $(L=$ amidino)

\begin{tabular}{|c|c|c|c|c|c|c|}
\hline \multirow[b]{2}{*}{ Orbital } & \multirow[b]{2}{*}{$E(\mathrm{eV})$} & \multicolumn{4}{|c|}{ Contribution (\%) } & \multirow[b]{2}{*}{ Main bond type } \\
\hline & & $\operatorname{Re}$ & $\mathrm{Cl}$ & $\mathrm{CO}$ & $\mathrm{L}$ & \\
\hline HOMO-4 & -7.76 & 12.29 & 55.89 & 3.97 & 27.85 & $\mathrm{~d}(\mathrm{Re})+\mathrm{p}(\mathrm{Cl})+\pi(\mathrm{L})$ \\
\hline HOMO-3 & -7.66 & 9.84 & 58.90 & 3.35 & 27.91 & $\mathrm{~d}(\mathrm{Re})+\mathrm{p}(\mathrm{Cl})+\pi(\mathrm{L})$ \\
\hline HOMO-2 & -6.98 & 68.90 & 0.53 & 28.57 & 2.00 & $\mathrm{~d}(\mathrm{Re})+\pi(\mathrm{CO})$ \\
\hline HOMO-1 & -6.40 & 46.90 & 25.98 & 20.78 & 6.33 & $\mathrm{~d}(\mathrm{Re})+\mathrm{p}(\mathrm{Cl})+\pi(\mathrm{CO})$ \\
\hline HOMO & -6.32 & 47.08 & 25.77 & 22.84 & 4.32 & $\mathrm{~d}(\mathrm{Re})+\mathrm{p}(\mathrm{Cl})+\pi(\mathrm{CO})$ \\
\hline LUMO & -2.04 & 4.60 & 1.68 & 5.82 & 87.91 & $\pi^{*}(\mathrm{~L})$ \\
\hline LUMO+1 & -0.55 & 29.29 & 1.08 & 65.50 & 4.14 & $\mathrm{p}(\mathrm{Re})+\pi^{*}(\mathrm{CO})$ \\
\hline $\mathrm{LUMO}+2$ & -0.31 & 27.97 & 2.90 & 61.25 & 7.89 & $\mathrm{p}(\mathrm{Re})+\pi^{*}(\mathrm{CO})$ \\
\hline
\end{tabular}


Table 5 Frontier molecular orbital compositions (\%) in the ground state for complex 9 at the PBE1PBE level ( $\mathrm{L}=$ amidino)

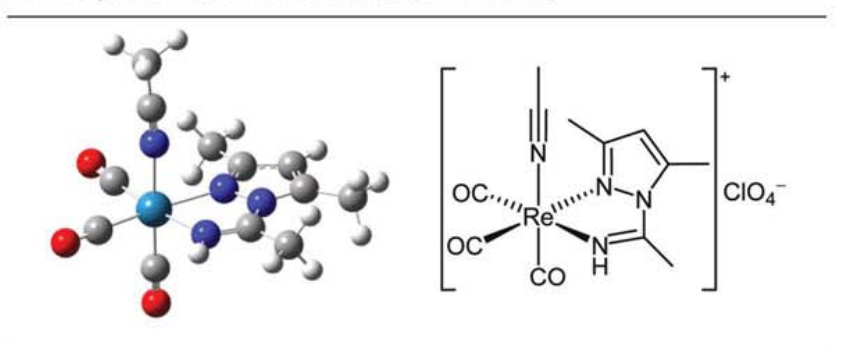

\begin{tabular}{lllllrll}
\hline & \multicolumn{5}{c}{ Contribution (\%) } & \\
\cline { 3 - 6 } Orbital & $E(\mathrm{eV})$ & $\mathrm{Re}$ & $\mathrm{MeCN}$ & $\mathrm{CO}$ & \multicolumn{1}{c}{$\mathrm{L}$} & \multirow{2}{*}{ Main bond type } \\
\hline HOMO-3 & -8.39 & 6.21 & 1.44 & 2.11 & 90.25 & $\pi(\mathrm{L})$ \\
HOMO-2 & -7.5 & 69.58 & 0 & 27.9 & 2.52 & $\mathrm{~d}(\mathrm{Re})+\pi(\mathrm{CO})$ \\
HOMO-1 & -7.17 & 59.02 & 4.74 & 23.04 & 13.21 & $\mathrm{~d}(\mathrm{Re})+\pi(\mathrm{CO})+\pi(\mathrm{L})$ \\
HOMO & -7.11 & 54 & 4.09 & 21.28 & 20.63 & $\mathrm{~d}(\mathrm{Re})+\pi(\mathrm{CO})+\pi(\mathrm{L})$ \\
LUMO & -2.37 & 5.65 & 0.5 & 7.38 & 86.48 & $\pi^{*}(\mathrm{~L})$ \\
LUMO+1 & -1.27 & 26.08 & 18.09 & 51.59 & 4.23 & $\mathrm{p}(\mathrm{Re})+\pi^{*}(\mathrm{CO})+$ \\
LUMO+2 & -0.93 & 19.19 & 25.13 & 51.32 & 4.36 & $\mathrm{p}(\mathrm{Re})+\pi^{*}(\mathrm{CO})+$ \\
& & & & & & $\pi^{*}(\mathrm{MeCN})$
\end{tabular}

bond type to LUMO with $\pi^{*}$ (amidino) main bond type. Thus, this transition has a MLCT/LLCT/XLCT character, consistent with the trends experimentally observed for the absorption maxima shifts, already discussed in the photophysical study section above.

On the other hand, when the halide ligand is replaced by a neutral ligand (acetonitrile or a pyrazole) to obtain a cationic complex, the lowest experimental absorption is blue-shifted (found at $324 \mathrm{~nm}$ in complex 9 with respect to $352 \mathrm{~nm}$ in the chlorido-dmpz neutral complex 2). The calculated singlet excited state $\left(\mathrm{S}_{2}\right.$ also in this case) now consists of two tran-
Table 8 Molecular orbital compositions in the excited states

\begin{tabular}{|c|c|c|c|c|c|c|}
\hline \multirow[b]{2}{*}{ Complex } & \multirow[b]{2}{*}{ Orbital } & \multirow[b]{2}{*}{$\begin{array}{l}\text { Energy } \\
\text { (eV) }\end{array}$} & \multicolumn{4}{|c|}{ Contribution (\%) } \\
\hline & & & $\mathrm{Re}$ & $\begin{array}{l}\text { "Sixth" } \\
\text { ligand }\end{array}$ & $\mathrm{CO}$ & Amidino \\
\hline \multirow[t]{2}{*}{1} & HOMO & -5.87 & 46.33 & 18.86 & 17.50 & 17.31 \\
\hline & LUMO & -2.37 & 5.66 & 2.43 & 8.96 & 82.95 \\
\hline \multirow[t]{2}{*}{9} & HOMO & -6.61 & 47.79 & 3.87 & 18.38 & 29.97 \\
\hline & LUMO & -2.78 & 5.19 & 0.61 & 7.48 & 86.72 \\
\hline
\end{tabular}

sitions, from HOMO-1 and HOMO to LUMO, which contribute almost equally. The composition of HOMO-1 and HOMO orbitals has a significant contribution from the amidino moiety, 13 and $21 \%$ respectively, and therefore, the transition has a less marked charge transfer character than in the case of the neutral complexes (Table 8). The MLCT transition plays an important role in the excitation and, consequently, the absorption intensity of $\mathbf{9}$ is stronger than $\mathbf{1}$, as observed experimentally. Moreover, the weaker $\pi$-donating ability of acetonitrile with respect to the halido ligand, makes the HOMO and HOMO-1 orbitals less energetic, which is consistent with the blue-shift observed in the absorption.

The MLCT character of the low lying absorption transitions for complexes 1 and 9 can be observed in Fig. 5, where the relevant molecular orbitals are depicted for both compounds.

The lowest triplet states $T_{1}$ of all the complexes have been optimized by the UPBE0 method and, from the geometry thus obtained, the TD-DFT method has been applied to calculate their phosphorescence emission. The composition of the HOMO and LUMO orbitals is very similar to those of the singlet ground state, as can be seen by inspection of the values shown in Table 7. Therefore, the character of the emissions is ${ }^{3} \mathrm{MLCT} /{ }^{3} \mathrm{LLCT} /{ }^{3} \mathrm{XLCT}$ for the neutral complexes and ${ }^{3} \mathrm{MLCT} /{ }^{3} \mathrm{LLCT} /{ }^{3} \mathrm{ILCT}$ for the cationic complexes, and the calcu-

Table 6 Calculated excited energies, dominant orbital excitations, and oscillator strength ( $f$ ) from TD-DFT calculations for complex 1

\begin{tabular}{lllllll}
\hline State & Excitation & Coef. & $E_{\text {calc }}(\mathrm{eV})$ & $\lambda_{\text {calc }}(\mathrm{nm})$ & $f$ & $\lambda_{\exp }(\mathrm{nm})$ \\
\hline $\mathrm{S}_{1}$ & HOMO $\rightarrow$ LUMO & 0.70 & 3.21 & 386 & 0.0035 & Character \\
$\mathrm{S}_{2}$ & HOMO-1 $\rightarrow$ LUMO & 0.69 & 3.39 & 366 & 0.0964 & 360 \\
$\mathrm{~S}_{8}$ & HOMO-4 $\rightarrow$ LUMO & 0.64 & 4.76 & 261 & 0.1178 & MLCT/LLCT/XLCT \\
& HOMO-3 $\rightarrow$ LUMO & 0.27 & & & & MLCT/LLCT/XLCT
\end{tabular}

Table 7 Calculated excited energies, dominant orbital excitations, and oscillator strength ( $f$ ) from TD-DFT calculations for complex 9

\begin{tabular}{|c|c|c|c|c|c|c|c|}
\hline State & Excitation & Coef. & $E_{\text {calc }}(\mathrm{eV})$ & $\lambda_{\text {calc }}(\mathrm{nm})$ & $f$ & $\lambda_{\exp }(\mathrm{nm})$ & Character \\
\hline \multirow[t]{2}{*}{$S_{1}$} & HOMO-1 $\rightarrow$ LUMO & 0.46 & \multirow[t]{2}{*}{3.70} & \multirow[t]{2}{*}{355} & \multirow[t]{2}{*}{0.0133} & & \multirow[t]{2}{*}{ MLCT/LLCT/ILCT } \\
\hline & HOMO $\rightarrow$ LUMO & 0.53 & & & & & \\
\hline \multirow[t]{2}{*}{$\mathrm{S}_{2}$} & HOMO-1 $\rightarrow$ LUMO & 0.52 & \multirow[t]{2}{*}{3.86} & \multirow[t]{2}{*}{321} & \multirow[t]{2}{*}{0.1784} & \multirow[t]{2}{*}{324} & \multirow[t]{2}{*}{ MLCT/LLCT/ILCT } \\
\hline & HOMO $\rightarrow$ LUMO & 0.45 & & & & & \\
\hline \multirow[t]{2}{*}{$\mathrm{S}_{8}$} & $\mathrm{HOMO}-2 \rightarrow \mathrm{LUMO}+2$ & 0.40 & \multirow[t]{2}{*}{4.97} & \multirow[t]{2}{*}{250} & \multirow[t]{2}{*}{0.0561} & \multirow[t]{2}{*}{254} & \multirow[t]{2}{*}{ MLCT/LLCT/ILCT/LXCT } \\
\hline & $\mathrm{HOMO} \rightarrow \mathrm{LUMO}+2$ & 0.40 & & & & & \\
\hline $\mathrm{S}_{9}$ & HOMO-3 $\rightarrow$ LUMO & 0.67 & 5.12 & 242 & 0.1457 & 233 & ILCT \\
\hline
\end{tabular}


1

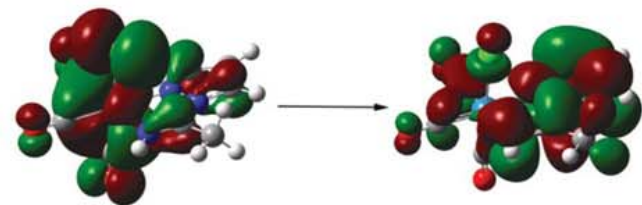

HOMO-1

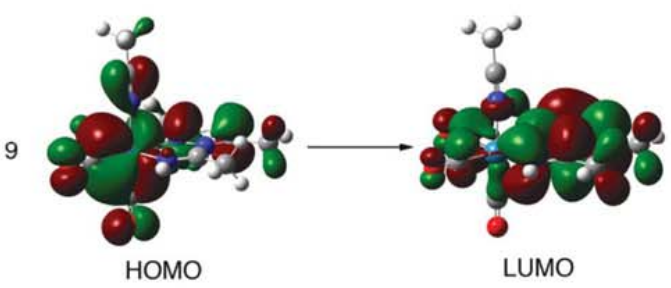

Fig. 5 Single electron transitions for the low lying absorptions of complexes 1 and 9, calculated at the TD-DFT/PBEO level.

lated emission energies and the corresponding transition characters for both types of complexes are shown in Table 9.

Although the TD-DFT computing methods cannot exactly reproduce the experimental values of the emission wavelengths, it can provide reasonable values that follow the same trend. In this respect, the substitution of the halide in the neutral complexes by a weaker $\pi$-donor stabilizes the HOMO, makes the HOMO-LUMO energy gap wider and, as in the absorption transitions, a blue-shift in the wavelength is observed.

\section{Experimental section}

\subsection{General remarks}

All manipulations were performed under a $\mathrm{N}_{2}$ atmosphere following conventional Schlenk techniques. Solvents were purified according to standard procedures. ${ }^{27}$ fac $-\left[\operatorname{ReCl}(\mathrm{CO})_{3^{-}}\right.$ $\left.(\mathrm{NCMe})_{2}\right],{ }^{28} \quad f a c-\left[\operatorname{ReBr}(\mathrm{CO})_{3}(\mathrm{NCMe})_{2}\right]{ }^{19} \quad f a c-\left[\operatorname{ReBr}(\mathrm{CO})_{3}(\mathrm{NH}=\right.$ $\left.\left.\mathrm{C}(\mathrm{Me}) \mathrm{pz}-\kappa^{2} N, N\right)\right],{ }^{11 c}$ fac- $\left[\mathrm{ReBr}(\mathrm{CO})_{3}\left(\mathrm{NH}=\mathrm{C}(\mathrm{Me}) \mathrm{dmpz}-\kappa^{2} N, N\right)\right],{ }^{11 c}$ and $f a c-\left[\operatorname{ReBr}(\mathrm{CO})_{3}\left(\mathrm{NH}=\mathrm{C}(\mathrm{Me})\right.\right.$ indz- $\left.\left.{ }^{2} N, N\right)\right],{ }^{12}$ were obtained as previously described. Table 1 provides references for the preparation and characterization of some of the complexes herein studied. All other reagents were obtained from the usual commercial suppliers, and used as received. Infrared spectra were recorded in a Perkin-Elmer FT-IR spectrum BX apparatus using $0.2 \mathrm{~mm} \mathrm{CaF}_{2}$ cells for solutions or $\mathrm{KBr}$ pellets for solid samples. NMR spectra were recorded in a Varian MR500 instrument at room temperature (r.t.) unless otherwise indicated, and are referred to the internal residual solvent peak for ${ }^{1} \mathrm{H}$ and ${ }^{13} \mathrm{C}\left\{{ }^{1} \mathrm{H}\right\}$ NMR. Assignment of the ${ }^{13} \mathrm{C}\left\{{ }^{1} \mathrm{H}\right\}$ NMR data was supported by $2 \mathrm{D}$ heteronuclear experiments and relative intensities of the resonance signals. Elemental analyses were performed on a Perkin-Elmer 2400B microanalyzer.

\section{2. $f a c-\left[\operatorname{ReCl}(\mathrm{CO})_{3}\left(\mathrm{NH}=\mathrm{C}(\mathrm{Me}) \mathrm{pz}^{2} \mathrm{\kappa}^{2} \mathrm{~N}, N\right)\right], 1$}

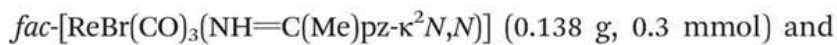
$\mathrm{AgBF}_{4}(0.068 \mathrm{~g}, 0.35 \mathrm{mmol})$ were stirred in THF $(25 \mathrm{~mL})$ for $1 \mathrm{~h}$ at $40{ }^{\circ} \mathrm{C}$. The solvent was removed in vacuo, the complex was extracted with $\mathrm{CH}_{2} \mathrm{Cl}_{2}(40 \mathrm{~mL})$, filtered, and the solvent was removed in vacuo. The pale yellow residue was then dissolved in acetone $(20 \mathrm{~mL})$ and $\mathrm{LiCl}(0.063 \mathrm{~g}, 1.5 \mathrm{mmol})$ was added. The mixture was stirred at r.t. overnight. The solvent was removed in vacuo, and the complex was extracted with THF $(20 \mathrm{~mL})$, filtered, and the yellow residue was crystallized in $\mathrm{THF} /$ hexane at $-20{ }^{\circ} \mathrm{C}$, giving a yellow microcrystalline solid, which was decanted, washed with hexane $(3 \times 3 \mathrm{~mL}$, approximately), and dried in vacuo, yielding $0.111 \mathrm{~g}$ (89\%). IR (THF, $\mathrm{cm}^{-1}$ ): 2021 vs, 1919 vs, 1891 vs. IR $\left(\mathrm{KBr}, \mathrm{cm}^{-1}\right): 3175 \mathrm{~m}$, $3138 \mathrm{~m}, 2025$ vs, 1919 vs, 1893 vs, $1653 \mathrm{~m}, 1560 \mathrm{w}, 1524 \mathrm{w}$, 1431 w, 1409 m, 1398 w, 1376 w, 1328 w, 1241 m, 1129 w, 1073 w, 1053 w, 1043 w, 1000 w, 961 w, 873 w, 775 m, 684 w, 630 w, 562 w, 517 w, 496 w, 472 w. ${ }^{1} \mathrm{H}$ NMR $\left(500 \mathrm{MHz}, \mathrm{Me}_{2} \mathrm{CO}-\right.$ $\left.d_{6}\right): 2.96\left(\mathrm{~s}, \mathrm{CH}_{3}, 3 \mathrm{H}\right), 6.85\left(\mathrm{dd}, J=3.0\right.$ and $\left.2.0 \mathrm{~Hz}, H^{4}, 1 \mathrm{H}\right)$, $8.34\left(\mathrm{~d}, J=2.0 \mathrm{~Hz}, H^{3,5}, 1 \mathrm{H}\right), 8.66\left(\mathrm{~d}, J=3.0 \mathrm{~Hz}, H^{5,3}, 1 \mathrm{H}\right)$, 11.21 (br s, NH, $1 \mathrm{H}$ ). ${ }^{13} \mathrm{C}\left\{{ }^{1} \mathrm{H}\right\}$ NMR (126 MHz, Me $2 \mathrm{CO}-d_{6}$ ): 19.0 (s, $\left.\mathrm{NCCH}_{3}\right), 112.3\left(\mathrm{~s}, C^{4} \mathrm{H} \mathrm{pz}\right), 134.1\left(\mathrm{~s}, C^{5,3} \mathrm{pz}\right), 147.4\left(\mathrm{~s}, C^{3,5}\right.$ $\mathrm{pz}), 164.1\left(\mathrm{~s}, \mathrm{NH}=\mathrm{CCH}_{3}\right), 189.5(\mathrm{~s}, \mathrm{CO}), 197.9(\mathrm{~s}, \mathrm{CO}), 198.1(\mathrm{~s}$, CO). Anal. Calcd for $\mathrm{C}_{8} \mathrm{H}_{7} \mathrm{ClN}_{3} \mathrm{O}_{3} \mathrm{Re} \mathrm{C}, 23.13 ; \mathrm{H}, 1.70 ; \mathrm{N}, 10.12$. Found: C, 23. 40; H, 1.66; N, 9.98.

\section{3. $f a c-\left[\operatorname{ReCl}(\mathrm{CO})_{3}\left(\mathrm{NH}=\mathrm{C}(\mathrm{Me}) \mathrm{dmpz}-\kappa^{2} N, N\right)\right], 2$}

The same procedure as for $\mathbf{1}$, using $f a c-\left[\operatorname{ReBr}(\mathrm{CO})_{3}(\mathrm{NH}=\mathrm{C}(\mathrm{Me})\right.$ dmpz- $\left.\left.\kappa^{2} N, N\right)\right](0.170 \mathrm{~g}, 0.35 \mathrm{mmol})$ as starting material, gave $0.140 \mathrm{~g}(92 \%)$ of 2 as a pale yellow microcrystalline solid. IR (THF, cm ${ }^{-1}$ ): 2018 vs, 1915 vs, 1887 vs. IR $\left(\mathrm{KBr}, \mathrm{cm}^{-1}\right): 3154 \mathrm{~m}$, $3103 \mathrm{~m}, 2017$ vs, 1923 vs, 1896 vs, 1882 vs, 1648 m, 1567 w, $1449 \mathrm{w}, 1407 \mathrm{~m}, 1356 \mathrm{~m}, 1256 \mathrm{~m}, 1131 \mathrm{w}, 1100 \mathrm{w}, 1046 \mathrm{w}$, 895 w, 841 w, 645 w, 627 w, 516 w, 494 w, 478 w. ${ }^{1} \mathrm{H}$ NMR (500 MHz, $\left.\mathrm{Me}_{2} \mathrm{CO}-d_{6}\right): 2.51$ (s, $\left.\mathrm{CH}_{3} \mathrm{dmpz}, 3 \mathrm{H}\right), 2.76\left(\mathrm{~s}, \mathrm{CH}_{3}\right.$ dmpz, $3 \mathrm{H}), 2.97\left(\mathrm{~s}, \mathrm{NH}=\mathrm{CCH}_{3}, 3 \mathrm{H}\right), 6.46\left(\mathrm{~s}, H^{4} \mathrm{dmpz}, 1 \mathrm{H}\right)$, 10.82 (br s, NH, $1 \mathrm{H}$ ). ${ }^{13} \mathrm{C}\left\{{ }^{1} \mathrm{H}\right\}$ NMR (126 MHz, $\left.\mathrm{Me}_{2} \mathrm{CO}-d_{6}\right): 14.3$ (s, $\mathrm{CH}_{3} \mathrm{dmpz}$ ), 16.1 (s, $\mathrm{CH}_{3} \mathrm{dmpz}$ ), 21.5 (s, $\mathrm{N}=\mathrm{CCH}_{3}$ ), 113.8 (s, $C^{4} \mathrm{H} \mathrm{dmpz}$ ), 146.8 (s, $\mathrm{CCH}_{3} \mathrm{dmpz}$ ), 156.5 (s, $\mathrm{CCH}_{3} \mathrm{dmpz}$ ), $165.4\left(\mathrm{~s}, \mathrm{NH}=\mathrm{CCH}_{3}\right), 189.6(\mathrm{~s}, \mathrm{CO}), 198.4(\mathrm{~s}, \mathrm{CO}), 198.9$ (s,

Table 9 Calculated emission energies and dominant orbital emissions from TD-DFT calculations

\begin{tabular}{lllllll}
\hline Complex & State & Transition & Coef. & $E_{\text {calc }}(\mathrm{eV})$ & $\lambda_{\text {calc }}(\mathrm{nm})$ & $\lambda_{\exp }(\mathrm{nm})$ \\
\hline $\mathbf{1}$ & $\mathrm{T}_{1}$ & LUMO $\rightarrow$ HOMO & 0.69 & 1.88 & 659 & 570 \\
9 & $\mathrm{~T}_{1}$ & LUMO $\rightarrow$ HOMO & 0.67 & 2.07 & 599 & 524
\end{tabular}


CO). Anal. Calcd for $\mathrm{C}_{10} \mathrm{H}_{11} \mathrm{ClN}_{3} \mathrm{O}_{3} \mathrm{Re} \mathrm{C}, 27.08 ; \mathrm{H}, 2.50 ; \mathrm{N}, 9.48$. Found: C, 26.91; H, 2.44; N, 9.35.

\section{4. $f a c-\left[\operatorname{ReCl}(\mathrm{CO})_{3}\left(\mathrm{NH}=\mathrm{C}(\mathrm{Me})\right.\right.$ indz- $\left.\left.^{2} N, N\right)\right], 3$}

fac- $\left[\mathrm{ReCl}(\mathrm{CO})_{3}(\mathrm{NCMe})_{2}\right](0.116 \mathrm{~g}, 0.3 \mathrm{mmol})$ and indazole ( $0.035 \mathrm{~g}, 0.3 \mathrm{mmol})$ were stirred in $\mathrm{CH}_{3} \mathrm{CN}(15 \mathrm{~mL})$ for $30 \mathrm{~min}$ at $60{ }^{\circ} \mathrm{C}$, then $0.016 \mathrm{~mL}$ of aqueous $0.02 \mathrm{M} \mathrm{NaOH}$ $(0.003 \mathrm{mmol})$ was added and the solution was stirred for $30 \mathrm{~min}$ at $60{ }^{\circ} \mathrm{C}$. The volatiles were removed in vacuo and the yellow residue was crystallized from acetone/hexane at $-20^{\circ} \mathrm{C}$, giving a yellow microcrystalline solid, which was decanted, washed with hexane $(3 \times 3 \mathrm{~mL}$ approximately), and dried in vacuo, yielding $0.126 \mathrm{~g}(91 \%)$. IR (THF, $\left.\mathrm{cm}^{-1}\right)$ : $2020 \mathrm{vs,} 1920$ vs, 1891 vs. IR ( $\left.\mathrm{KBr}, \mathrm{cm}^{-1}\right): 3178 \mathrm{~m}, 3116 \mathrm{w}, 2021$ vs, 1923 vs, 1885 br vs, 1637 m, 1583 w, 1560 w, 1542 w, 1511 m, 1481 m, $1464 \mathrm{~m}, 1424 \mathrm{~m}, 1354 \mathrm{~m}, 1283 \mathrm{w}, 1214 \mathrm{w}, 1196 \mathrm{~m}, 1089 \mathrm{w}$, 1044 w, 912 w, 874 w, 793 w, 757 m, 649 w, 324 w, 536 w, 519 w, 493 w, 470 w, 420 w. ${ }^{1} \mathrm{H}$ NMR (500 MHz, Me $\left.{ }_{2} \mathrm{CO}-d_{6}\right)$ : $3.27\left(\mathrm{~s}, \mathrm{NH}=\mathrm{CCH}_{3}, 3 \mathrm{H}\right), 7.59\left(\mathrm{t}, J=8 \mathrm{~Hz}, H^{6}\right.$ indz, $\left.1 \mathrm{H}\right), 7.83$ $\left(\mathrm{t}, J=8 \mathrm{~Hz}, H^{5}\right.$ indz, $\left.1 \mathrm{H}\right), 8.12\left(\mathrm{~d}, J=8 \mathrm{~Hz}, H^{7}\right.$ indz, $\left.1 \mathrm{H}\right), 8.18$ (d, $J=8 \mathrm{~Hz}, H^{4}$ indz, $\left.1 \mathrm{H}\right), 9.06\left(\mathrm{~s}, H^{3}\right.$ indz, $\left.1 \mathrm{H}\right), 10.84(\mathrm{br} \mathrm{s}$, $\mathrm{NH}, 1 \mathrm{H}) .{ }^{13} \mathrm{C}\left\{{ }^{1} \mathrm{H}\right\}$ NMR (126 MHz, $\left.\mathrm{Me}_{2} \mathrm{CO}-d_{6}\right): 20.1$ (s, $\left.\mathrm{N}=\mathrm{CCH}_{3}\right), 112.3\left(\mathrm{~s}, C^{4} \mathrm{H}\right.$ indz), $123.0\left(C^{7} \mathrm{H}\right.$ indz), $125.3\left(C^{6} \mathrm{H}\right.$ indz), 126.4 ( $C^{3 \mathrm{a}} \mathrm{H}$ indz), $131.2\left(C^{5} \mathrm{H}\right.$ indz), 139.0 ( $C^{7 \mathrm{a}} \mathrm{H}$ indz), $143.9\left(C^{3} \mathrm{H}\right.$ indz), $163.7\left(\mathrm{~N}=\mathrm{CCH}_{3}\right), C \mathrm{O}$ was not observed due to the low solubility of the compound. Anal. Calcd for $\mathrm{C}_{12} \mathrm{H}_{9} \mathrm{ClN}_{3} \mathrm{O}_{3} \mathrm{Re} \mathrm{C}, 30.97 ; \mathrm{H}, 1.95 ; \mathrm{N}, 9.03$. Found: C, 31.31; $\mathrm{H}, 2.03 ; \mathrm{N}, 8.88$.

\section{5. $f a c-\left[\operatorname{ReBr}(\mathrm{CO})_{3}\left(\mathrm{NH}=\mathrm{C}(\mathrm{Ph}) \mathrm{dmpz}_{-} \kappa^{2} N, N\right)\right], 7$}

fac- $\left[\operatorname{ReBr}(\mathrm{CO})_{3}(\mathrm{NCMe})_{2}\right](0.130 \mathrm{~g}, 0.3 \mathrm{mmol})$ and 3,5-dimethylpyrazole $(0.029 \mathrm{~g}, 0.3 \mathrm{mmol})$ were stirred in benzonitrile $(5 \mathrm{~mL})$ for $5 \mathrm{~min}$ at $80^{\circ} \mathrm{C}$, then $0.053 \mathrm{ml}$ of $0.056 \mathrm{M}$ aqueous $\mathrm{NaOH}(0.003 \mathrm{mmol})$ was added, and the solution was stirred for $20 \mathrm{~min}$ at $80^{\circ} \mathrm{C}$. The solvent was removed in vacuo and the yellow residue was crystallized from acetone/hexane at $-20^{\circ} \mathrm{C}$, giving a yellow microcrystalline solid, which was decanted, washed with hexane $(3 \times 3 \mathrm{~mL}$ approximately), and dried in vacuo, yielding $0.076 \mathrm{~g}$ (46\%). IR (THF, $\left.\mathrm{cm}^{-1}\right): 2020 \mathrm{vs,} 1920$ vs, 1892 vs. IR (KBr, cm ${ }^{-1}$ ): 3119 m, 3059 m, 2974 m, 2870 w, 2020 vs, 1914 vs, 1899 vs, 1638 m, 1598 w, 1569 m, 1474 w, $1445 \mathrm{~m}, 1437 \mathrm{~m}, 1354 \mathrm{~m}, 1284 \mathrm{w}, 1261 \mathrm{w}, 1176 \mathrm{w}, 1120 \mathrm{w}$, 1050 m, 1000 w, 949 w, 919 w, 886 w, 827 m, 803 w, 758 w, $709 \mathrm{~m}, 648 \mathrm{~m}, 635 \mathrm{w}, 526 \mathrm{w}, 496 \mathrm{w}, 478 \mathrm{w} .{ }^{1} \mathrm{H}$ NMR $(500 \mathrm{MHz}$, $\left.\mathrm{Me}_{2} \mathrm{CO}-d_{6}, 298 \mathrm{~K}\right): 1.85$ (s, $\left.\mathrm{CH}_{3} \mathrm{dmpz}, 3 \mathrm{H}\right), 2.58$ (s, $\mathrm{CH}_{3} \mathrm{dmpz}$, $3 \mathrm{H}), 6.47$ (s, C $\left.{ }^{4} H \mathrm{dmpz}, 1 \mathrm{H}\right), 7.54$ (s br, ortho- $\mathrm{C}_{6} H_{5}, 1 \mathrm{H}$ ), 7.66-7.69 (m, meta- $\left.\mathrm{C}_{6} \mathrm{H}_{5}, 2 \mathrm{H}\right), 7.74\left(\mathrm{t}, J=7.5 \mathrm{~Hz}\right.$, para- $\mathrm{C}_{6} \mathrm{H}_{5}$, $1 \mathrm{H}), 7.86$ (s br, ortho- $\left.\mathrm{C}_{6} H_{5}, 1 \mathrm{H}\right), 11.25$ (s br, $\left.\mathrm{NH}, 1 \mathrm{H}\right) .{ }^{1} \mathrm{H}$ NMR $\left(500 \mathrm{MHz}, \mathrm{Me}_{2} \mathrm{CO}-d_{6}, 253 \mathrm{~K}\right): 1.84$ (s, $\left.\mathrm{CH}_{3} \mathrm{dmpz}, 3 \mathrm{H}\right), 2.57$ (s, $\left.\mathrm{CH}_{3} \mathrm{dmpz}, 3 \mathrm{H}\right), 6.51$ (s, C $\left.{ }^{4} H \mathrm{dmpz}, 1 \mathrm{H}\right), 7.52$ (d, $J=9.0 \mathrm{~Hz}$, ortho- $\left.\mathrm{C}_{6} \mathrm{H}_{5}, 1 \mathrm{H}\right), 7.65-7.72\left(\mathrm{~m}\right.$, meta- $\left.\mathrm{C}_{6} H_{5}, 2 \mathrm{H}\right), 7.75(\mathrm{t}, J=$ $7.5 \mathrm{~Hz}$, para- $\left.\mathrm{C}_{6} H_{5}, 1 \mathrm{H}\right), 7.91\left(\mathrm{~d}, J=7.0 \mathrm{~Hz}\right.$, ortho- $\left.\mathrm{C}_{6} H_{5}, 1 \mathrm{H}\right)$, $11.40(\mathrm{~s}, \mathrm{~N} H, 1 \mathrm{H}) \cdot{ }^{13} \mathrm{C}\left\{{ }^{1} \mathrm{H}\right\}$ NMR $\left(126 \mathrm{MHz}, \mathrm{Me}_{2} \mathrm{CO}-d_{6}\right): 14.2(\mathrm{~s}$, $\mathrm{CH}_{3} \mathrm{dmpz}$ ), 16.2 (s, $\mathrm{CH}_{3} \mathrm{dmpz}$ ), 114.2 (s, $C^{4} \mathrm{dmpz}$ ), 129.2 (s, ortho- $C_{6} \mathrm{H}_{5}$ ), 130.1 (s, meta- $\left.C_{6} \mathrm{H}_{5}\right), 130.9$ (s, ipso- $C_{6} \mathrm{H}_{5}$ ), 133.0 (s, para- $\left.C_{6} \mathrm{H}_{5}\right), 147.4$ (s, $\left.\mathrm{CCH}_{3} \mathrm{dmpz}\right), 157.7$ (s, $\left.\mathrm{CCH}_{3} \mathrm{dmpz}\right), 165.9$ $\left(\mathrm{s}, \mathrm{NH}=C\left(\mathrm{C}_{6} \mathrm{H}_{5}\right)\right), 188.9(\mathrm{~s}, \mathrm{CO}), 197.6(\mathrm{~s}, \mathrm{CO}), 198.4(\mathrm{~s}, C \mathrm{O})$. Anal. Calcd for $\mathrm{C}_{15} \mathrm{H}_{13} \mathrm{BrN}_{3} \mathrm{O}_{3}$ Re C, 32.79; $\mathrm{H}, 2.38 ; \mathrm{N}, 7.65$. Found: C, 33.07; H, 2.46; N, 7.77. This complex is rather unstable both in solid and in solution, so the NMR spectra of old samples maintained either in the solid state or in solution gave new unidentified signals. This instability precluded reliable measurement of its photophysical and electrochemical properties.

\section{6. $f a c-\left[\operatorname{ReBr}(\mathrm{CO})_{3}\left(\mathrm{NH}=\mathrm{C}(\mathrm{Ph})\right.\right.$ indz- $\left.\left.^{2} N, N\right)\right], 8$}

The same procedure as for 7 , using indazole $(0.035 \mathrm{~g}$, $0.3 \mathrm{mmol}$ ) as starting material, gave $0.087 \mathrm{~g}(51 \%)$ of 8 as a yellow microcrystalline solid. IR (THF, $\mathrm{cm}^{-1}$ ): 2022 vs, $1925 \mathrm{vs,}$ 1896 vs. IR (KBr, cm ${ }^{-1}$ ): $3448 \mathrm{~m}, 3370 \mathrm{~m}, 2023$ vs, 1930 vs, 1881 vs, 1617 m, 1498 w, 1455 m, 1441 m, 1351 w, 1331 w, $1267 \mathrm{w}, 1107 \mathrm{w}, 1053 \mathrm{w}, 919 \mathrm{w}, 900 \mathrm{w}, 789 \mathrm{w}, 757 \mathrm{~m}, 706 \mathrm{w}$, 644 w, 623 w, 527 w, 493 w, 422 w. ${ }^{1} \mathrm{H}$ NMR $\left(500 \mathrm{MHz}, \mathrm{Me}_{2} \mathrm{CO}-\right.$ $\left.d_{6}, 298 \mathrm{~K}\right): 6.45\left(\mathrm{~d}, J=8.5 \mathrm{~Hz}, \mathrm{C}^{4} H\right.$ indz, $\left.1 \mathrm{H}\right), 7.49-7.50(\mathrm{~m}$, $\mathrm{C}^{5} \mathrm{H}$ and $\mathrm{C}^{6} \mathrm{H}$ indz, $\left.2 \mathrm{H}\right), 7.66\left(\mathrm{~s} \mathrm{br}\right.$, ortho- $\left.\mathrm{C}_{6} \mathrm{H}_{5}, 1 \mathrm{H}\right), 7.78(\mathrm{~m}$, meta $\left.-\mathrm{C}_{6} \mathrm{H}_{5}, 2 \mathrm{H}\right), 7.87\left(\mathrm{t}, J=7.5 \mathrm{~Hz}\right.$, para $\left.-\mathrm{C}_{6} \mathrm{H}_{5}, 1 \mathrm{H}\right), 7.98(\mathrm{~s} \mathrm{br}$, ortho- $\left.\mathrm{C}_{6} H_{5}, 1 \mathrm{H}\right), 8.09\left(\mathrm{~d}, J=8.5 \mathrm{~Hz}, \mathrm{C}^{7} \mathrm{H}\right.$ indz, $\left.1 \mathrm{H}\right), 9.20$ (s, $\mathrm{C}^{3} \mathrm{H}$ indz, $\left.1 \mathrm{H}\right), 11.28$ (s, NH, $\left.1 \mathrm{H}\right) .{ }^{1} \mathrm{H}$ NMR $\left(500 \mathrm{MHz}, \mathrm{Me}_{2} \mathrm{CO}-\right.$ $\left.d_{6}, 253 \mathrm{~K}\right): 6.43\left(\mathrm{~d}, J=8.0 \mathrm{~Hz}, \mathrm{C}^{4} H\right.$ indz, $\left.1 \mathrm{H}\right), 7.51-7.53(\mathrm{~m}$, $\mathrm{C}^{5} \mathrm{H}$ and $\mathrm{C}^{6} \mathrm{H}$ indz, $\left.2 \mathrm{H}\right), 7.64\left(\mathrm{~d}, J=7.5 \mathrm{~Hz}\right.$, ortho $\left.-\mathrm{C}_{6} \mathrm{H}_{5}, 1 \mathrm{H}\right)$, $7.79\left(\mathrm{~m}\right.$, meta- $\left.\mathrm{C}_{6} \mathrm{H}_{5}, 2 \mathrm{H}\right), 7.88\left(\mathrm{t}, J=7.5 \mathrm{~Hz}\right.$, para- $\left.\mathrm{C}_{6} \mathrm{H}_{5}, 1 \mathrm{H}\right)$, $8.03\left(\mathrm{~d}, J=8.0 \mathrm{~Hz}\right.$, ortho- $\left.\mathrm{C}_{6} H_{5}, 1 \mathrm{H}\right), 8.10\left(\mathrm{~d}, J=8.0 \mathrm{~Hz}, \mathrm{C}^{7} \mathrm{H}\right.$ indz, $1 \mathrm{H}), 9.28$ (s, $\mathrm{C}^{3} \mathrm{H}$ indz, $\left.1 \mathrm{H}\right), 11.43$ (s, NH, $\left.1 \mathrm{H}\right) .{ }^{13} \mathrm{C}\left\{{ }^{1} \mathrm{H}\right\}$ NMR (126 MHz, $\left.\mathrm{Me}_{2} \mathrm{CO}-d_{6}\right): 113.6\left(\mathrm{~s}, C^{4} \mathrm{H}\right.$ indz), $124.4\left(\mathrm{~s}, C^{7} \mathrm{H}\right.$ indz), 127.0 (s, $C^{6} \mathrm{H}$ indz), 128.3 (s, $C^{3 \mathrm{a}}$ indz), 130.1 (s, ortho$\left.C_{6} \mathrm{H}_{5}\right), 131.0$ (s, ipso- $\left.C_{6} \mathrm{H}_{5}\right), 131.2\left(\mathrm{~s}\right.$, meta- $\left.C_{6} \mathrm{H}_{5}\right), 132.6\left(\mathrm{~s}, C^{5} \mathrm{H}\right.$ indz), 134.3 (s, para- $\left.C_{6} \mathrm{H}_{5}\right), 141.3\left(\mathrm{~s}, C^{7 \mathrm{a}}\right.$ indz), $146.7\left(\mathrm{~s}, C^{3} \mathrm{H}\right.$ indz), $165.6\left(\mathrm{~s}, \mathrm{NH}=C\left(\mathrm{C}_{6} \mathrm{H}_{5}\right)\right), 189.9(C \mathrm{O}), 198.2(C \mathrm{O}), 198.3$ (CO). Anal. Calcd for $\mathrm{C}_{17} \mathrm{H}_{11} \mathrm{BrN}_{3} \mathrm{O}_{3}$ Re C, 35.73; H, 1.94; N, 7.36. Found: C, 35.92; H, 2.01; N, 7.29.

\subsection{Photophysical experiments}

UV-vis spectra were recorded with a VARIAN-Cary 100 Spectrophotometer and emission spectra were recorded on a JobinYvon FluoroLog 3.2.2 in $\mathrm{CH}_{2} \mathrm{Cl}_{2}$ at room temperature. Luminescence lifetimes were measured on a spectrofluorimeter Edinburgh Instrument Fl-900, using software with timecorrelated single photon mode coupled to a stroboscopic system. The excitation source was a laser diode $(\lambda 320 \mathrm{~nm})$. The instrument response function was determined by using a light-scattering solution (LUDOX).

\subsection{Electrochemical experiments}

Voltammetric analyses were carried out in a standard threeelectrode cell with a Radiometer PGP 201 potentiostat at ambient temperature. The electrolyte consisted of $0.2 \mathrm{M}$ $\mathrm{N}^{n} \mathrm{Bu}_{4} \mathrm{PF}_{6}$ solution in $\mathrm{MeCN}$ or $\mathrm{CH}_{2} \mathrm{Cl}_{2}$. The working electrode was a platinum disk electrode and the auxiliary electrode was a platinum wire. The reference electrode was a silver-silver ion electrode, $\mathrm{Ag} / \mathrm{Ag}^{+}\left(0.1 \mathrm{M} \mathrm{AgClO}_{4}\right.$ in $\left.\mathrm{MeCN}\right)$ separated from the analyzed solution by a sintered glass disk. After each measurement the reference was checked against the ferrocene-ferrici- 
nium couple $(+0.025 \mathrm{~V}$ and $+0.16 \mathrm{~V}$ against this reference electrode in $\mathrm{MeCN}$ and in $\mathrm{CH}_{2} \mathrm{Cl}_{2}$ solution respectively).

\subsection{Computational details}

All calculations have been performed using the Gaussian 09 program package, ${ }^{29}$ in which the PBE1PBE method was applied. This hybrid Hartree-Fock/density functional model is based on the Perdew-Burke-Ernzerhof (PBE) functional, ${ }^{30}$ where the HF/DFT exchange ratio is fixed a priori to $1 / 4$, and was used to optimize the ground and excited state geometries. Geometry optimizations were performed under no symmetry restrictions, using initial coordinates derived from X-ray data of the same complexes when available, and frequency analyses were performed to ensure that a minimum structure with no imaginary frequencies was achieved in each case. On the basis of the optimized ground and excited state geometries, the absorption and emission properties in dichloromethane solution were calculated by TD-DFT ${ }^{31}$ at the PBE1PBE level associated with the PCM method to introduce the solvent effects. ${ }^{32}$ Spin-orbit coupling is not included in the current TD-DFT method, and it influences the excitation energies in which the Re electrons are involved, ${ }^{33}$ whereas it has a negligible effect on the transition character of this complexes. Hence, although TD-DFT cannot exactly estimate the excitation energies, it can still provide a reasonable spectral feature for our investigated complexes. This kind of theoretical approach has been proven to be reliable for transition-metal complex systems. ${ }^{34}$ In the calculations, effective core potentials (ECP) and their associated double- $\zeta$ LANL2DZ basis set were used for the rhenium and bromide atoms, ${ }^{35}$ while the light elements $(\mathrm{O}, \mathrm{N}, \mathrm{C}$, and $\mathrm{H})$ were described with the $6-31+\mathrm{G}(\mathrm{d}, \mathrm{p})$ basis set. ${ }^{36}$ To explain the rationality of the PBE1PBE method and LANL2DZ/6-31+G(d,p) basis set, complex 1 was selected to perform the calculation test with different functionals and basis sets. Table S1 (ESI $\dagger$ ) shows the main bond distances obtained by LANL2DZ/ $6-31+G(d, p)$ basis set with different functionals, the results obtained with PBE1PBE being the most accurate. The calculated results obtained by other larger basis sets including $\mathrm{SDD} / 6-311+\mathrm{G}(\mathrm{d}, \mathrm{p})$ and def2-TZVPP ${ }^{37}$ are shown in Table $\mathrm{S} 2, \dagger$ and no significant improvement in the accuracy is detected, therefore, the LANL2DZ/6-31+G(d,p) basis set was selected to perform the calculations without the computational cost demanded by the larger basis sets. The contribution of every fragment in the molecules studied to the different orbitals involved in the optical transitions was calculated with the AOMix program,${ }^{38}$ and the graphical representation of the orbitals was made with the help of GaussView. ${ }^{39}$

\subsection{Crystal structure determination for compounds 1,2 , and 7}

Crystals were grown by slow diffusion of hexane into concentrated solutions of the complexes in acetone (for 1) or THF (for 2, and 7) at $-20^{\circ} \mathrm{C}$. Relevant crystallographic details can be found in the CIF. $\dagger$ A crystal was attached to a glass fibre and transferred to an Agilent SuperNova diffractometer fitted with an Atlas CCD detector. The crystals were maintained at
293(2) K during data collection. Using Olex $2,{ }^{40}$ the structure was solved for complexes 1 and 7 with the olex2.solve structure solution program, ${ }^{41}$ or with the ShelXT structure solution program for complex $2,{ }^{42}$ and then the structures were refined with the ShelXL refinement package using least squares minimisation. ${ }^{43}$ All non-hydrogen atoms were refined anisotropically. Hydrogen atoms were set in calculated positions and refined as riding atoms, with a common thermal parameter. All graphics were preparedwith Olex2, and distances and angles of hydrogen bonds were calculated with PARST ${ }^{44}$ (normalized values). ${ }^{45}$

\section{Conclusions}

Novel neutral and cationic rhenium(I) pyrazolylamidino complexes have been synthesized and characterized. The main advantage of pyrazolylamidino with respect to other bidentate chelating $\mathrm{N}$-donor ligands is the facile introduction of different substituents starting from the appropriate pyrazole and nitrile. Once coordinated, the pyrazolylamidino ligand is robust enough to allow the substitution of the halide by another halide or by different neutral ligands, so a broad panel of chelate complexes with different substituents are easily obtained. The effect of several substituents on the pyrazolylamidino ligand has been evaluated, as well as the effect of the coordination of chlorido vs. bromido, and their substitution by neutral acetonitrile or pyrazole ligands yielding cationic complexes. All the complexes exhibit phosphorescence decays, their quantum yields and long lifetimes are similar to those of other literature-known rhenium(I) tricarbonyl complexes, and prove that the emission arises from a prevalently ${ }^{3}$ MLCT state. The electrochemical study reveals an irreversible reduction for all the complexes. The oxidation of the neutral complexes was found to be irreversible due to halido dissociation, whereas the cationic species display a reversible process implying the $\mathrm{Re}^{\mathrm{I}} / \mathrm{Re}^{\mathrm{II}}$ couple. Finally, TD-DFT methods provide reasonable values for emission energies, which follow the same trend of experimental values of the emission wavelengths. Therefore, this report provides a new strategy to design new versatile phosphorescent complexes of the rhenium(I)tricarbonyl family, since the targeted chelating $\mathrm{N}$-donor ligand with the appropriate substituents for requested applications may be easily obtained in a one-pot reaction from readily available pyrazole and nitrile ligands.

\section{Acknowledgements}

This research was supported by the Spanish MINECO (Project CTQ2013-41067-P). P. G.-I. thanks the UVa for her grant. The authors in France thank the CNRS for financial support. 


\section{Notes and references}

1 (a) M. Wrighton and D. L. Morse, J. Am. Chem. Soc., 1974, 96, 998-1003; (b) P. Giordano, S. Fredericks, M. S. Wrighton and D. Morse, J. Am. Chem. Soc., 1978, 100, 2257-2259; (c) J. C. Luong, L. Nadjo and M. S. Wrighton, J. Am. Chem. Soc., 1978, 100, 5790-5795.

2 Some reference reviews: (a) A. J. Lees, Chem. Rev., 1987, 87, 711-743; (b) D. J. Stufkens, Comments Inorg. Chem., 1992, 13, 359-385; (c) A. I. Baba, J. R. Shaw, J. A. Simon, R. P. Thummel and R. H. Schmehl, Coord. Chem. Rev., 1998, 171, 43-59; (d) V. W.-W. Yam, Chem. Commun., 2001, 789-796; (e) A. Coleman, C. Brennan, J. G. Vos and M. T. Pryce, Coord. Chem. Rev., 2008, 252, 2585-2595; (f) A. Kumar, S.-S. Sun and A. J. Lees, Top. Organomet. Chem., 2010, 29, 1-35; (g) A. Vlček Jr., Top. Organomet. Chem., 2010, 29, 73-114.

3 Some reference articles: (a) L. A. Worl, R. Duesing, P. Chen, L. D. Ciana and T. J. Meyer, J. Chem. Soc., Dalton Trans., 1991, 849-858; (b) L. Sacksteder, M. Lee, J. N. Demas and B. A. DeGraff, J. Am. Chem. Soc., 1993, 115, 8230-8238; (c) H. Hori, F. P. A. Johnson, K. Koike, K. Takeuchi, T. Ibusuki and O. Ishitani, J. Chem. Soc., Dalton Trans., 1997, 1019-1023; (d) L. Sacksteder, A. P. Zipp, E. A. Brown, J. Streich, J. N. Denas and B. A. DeGraff, Inorg. Chem., 1990, 29, 4335-4340; (e) V. W.-W. Yam, V. C.-Y. Lau and K.-K. Cheung, Organometallics, 1995, 14, 2749-2753; (f) T. A. Oriskovich, P. S. White and H. H. Thorp, Inorg. Chem., 1995, 34, 1629-1631; (g) W. B. Connick, A. J. Di Bilio, M. G. Hill, J. R. Winkler and H. B. Gray, Inorg. Chim. Acta, 1995, 240, 169-173; (h) R. V. Slone, D. I. Yoon, R. M. Calhoun and J. T. Hupp, J. Am. Chem. Soc., 1995, 117, 11813-11814; (i) R. L. Cleary, K. J. Byrom, D. A. Bardwell, J. C. Jeffery, M. D. Ward, G. Calogero, N. Armaroli, L. Flamigni and F. Barigelletti, Inorg. Chem., 1997, 36, 2601-2609; ( $j$ ) S.-S. Sun and A. J. Lees, J. Am. Chem. Soc., 2000, 122, 8956-8967; (k) J. M. Villegas, S. R. Stoyanov, W. Huang and D. P. Rillema, Dalton Trans., 2005, 10421051; (l) J. M. Villegas, S. R. Stoyanov, W. Huang and D. P. Rillema, Inorg. Chem., 2005, 44, 2297-2309; ( $m$ ) C.-C. Ko, W.-M. Kwok, V. W.-W. Yam and D. L. Phillips, Chem. - Eur. J., 2006, 12, 5840-5848; (n) D. V. Partyka, N. Deligonul, M. P. Washington and T. G. Gray, Organometallics, 2009, 28, 5837-5840; (o) M.-J. Li, X. Liu, Y.-Q. Shi, R.-J. Xie, Q.-H. Weia and G.-N. Chen, Dalton Trans., 2012, 41, 10612-10618; (p) D. Chartrand, C. A. Castro Ruiz and G. S. Hanan, Inorg. Chem., 2012, 51, 1273812747; $(q)$ C. B. Anderson, A. B. S. Elliott, C. J. McAdam, K. C. Gordon and J. D. Crowley, Organometallics, 2013, 32, 788-797; (r) N. Saleh, M. Srebro, T. Reynaldo, N. Vanthuyne, L. Toupet, V. Y. Chang, G. Muller, J. A. G. Williams, C. Roussel, J. Autschbach and J. Crassous, Chem. Commun., 2015, 51, 3754-3757.

4 Some reference reviews: (a) K. S. Schanze, D. B. MacQueen, T. A. Perkins and T. A. Cabana, Coord. Chem. Rev., 1993, 122, 63-89; (b) P. Chen and T. J. Meyer, Chem. Rev., 1998,
98, 1439-1477; (c) D. J. Stufkens and A. Vlček Jr., Coord. Chem. Rev., 1998, 177, 127-179; (d) D. R. Striplin and G. A. Crosby, Coord. Chem. Rev., 2001, 211, 163-175.

5 R. A. Kirgan, B. P. Sullivan and D. P. Rillema, Top. Curr. Chem., 2007, 281, 45-100.

6 Some reference reviews: (a) K. K.-W. Lo, W.-K. Hui, C.-K. Chung, K. H.-K. Tsang, T. K.-M. Lee, C.-K. Li, J. S.Y. Lau and D. C.-M. Ng, Coord. Chem. Rev., 2006, 250, 1724-1736; (b) C. Beck, J. Brewer, J. Lee, D. McGraw, B. A. DeGraff and J. N. Demas, Coord. Chem. Rev., 2007, 251, 546-553; (c) V. Fernández-Moreira, F. L. Thorp-Greenwood and M. P. Coogan, Chem. Commun., 2010, 46, 186202; (d) K. K.-W. Lo, M.-W. Louie and K. Y. Zhang, Coord. Chem. Rev., 2010, 254, 2603-2622; (e) K. K.-W. Lo, Top. Organomet. Chem., 2010, 29, 115-158; (f) R. Balasingham, M. P. Coogan and F. L. Thorp-Greenwood, Dalton Trans., 2011, 40, 11663-11674; (g) K.-W. Lo, K. Y. Zhang and S. P.-Y. Li, Eur. J. Inorg. Chem., 2011, 3551-3568; (h) K. K.-W. Lo, A. W.-T. Choi and W. H.-T. Law, Dalton Trans., 2012, 41, 6021-6047.

7 Review: H. Takeda and O. Ishitani, Coord. Chem. Rev., 2010, 254, 346-354.

8 Review: H. Yersin, A. F. Rausch, R. Czerwieniec, T. Hofbeck and T. Fischer, Coord. Chem. Rev., 2011, 255, 2622-2652.

9 Some reference reviews: (a) K. S. Schanze, D. B. MacQueen, T. A. Perkins and L. A. Cabana, Coord. Chem. Rev., 1993, 122, 63-89; (b) A. S. Polo, M. K. Itokazu, K. M. Frin, A. O. de T. Patrocínio and N. Y. M. Iha, Coord. Chem. Rev., 2006, 250, 1669-1680.

10 (a) C.-C. Hsieh, C.-J. Lee and Y.-C. Horng, Organometallics, 2009, 28, 4923-4928; (b) A. V. Khripun, V. Y. Kukushkin, S. I. Selivanov, M. Haukka and A. J. L. Pombeiro, Inorg. Chem., 2006, 45, 5073-5083; (c) E. Reisner, V. B. Arion, A. Rufinsha, I. Chiorescu, W. E. Schmid and D. K. Keppler, Dalton Trans., 2005, 2355-2364; (d) P. Govidaswamy, Y. A. Mozharivskyj and M. R. Kollipara, J. Organomet. Chem., 2004, 689, 3265-3274; (e) M. R. Kollipara, P. Sarkhel, S. Chakraborty and R. Lalrempuia, J. Coord. Chem., 2003, 56, 1085-1091; ( $f$ ) D. Carmona, J. Ferrer, F. J. Lahoz, L. A. Oro and M. P. Lamata, Organometallics, 1996, 15, 5175-5178; (g) J. López, A. Santos, A. Romero and A. M. Echavarren, J. Organomet. Chem., 1993, 443, 221-228; (h) M. A. Cinellu, S. Stoccoro, G. Minghetti, A. L. Bandini, G. Banditelli and B. Bovio, J. Organomet. Chem., 1989, 372, 311-325; (i) M. O. Albers, S. Francesca, A. Crosby, D. C. Liles, D. J. Robinson, A. Shaver and E. Singleton, Organometallics, 1987, 6, 2014-2017; (j) G. D. Gracey, S. T. Rettig, A. Storr and J. Trotter, Can. J. Chem., 1987, 65, 2469-2477; ( k) A. Romero, A. Vegas and A. Santos, J. Organomet. Chem., 1986, 310, C8-C10; (l) C. J. Jones, J. A. McCleverty and A. S. Rothin, J. Chem. Soc., Dalton Trans., 1986, 109-111.

11 (a) M. Arroyo, P. Gómez-Iglesias, J. M. Martín-Alvarez, C. M. Alvarez, D. Miguel and F. Villafañe, Inorg. Chem., 2012, 51, 6070-6080; (b) N. Antón, M. Arroyo, P. GómezIglesias, D. Miguel and F. Villafañe, J. Organomet. Chem., 
2008, 693, 3074-3080; (c) M. Arroyo, D. Miguel, F. Villafañe, S. Nieto, J. Pérez and L. Riera, Inorg. Chem., 2006, 45, 70187026; (d) M. Arroyo, A. López-Sanvicente, D. Miguel and F. Villafañe, Eur. J. Inorg. Chem., 2005, 4430-4437.

12 P. Gómez-Iglesias, M. Arroyo, S. Bajo, C. Strohmann, D. Miguel and F. Villafañe, Inorg. Chem., 2014, 53, 1243712448.

13 (a) G. A. Jeffrey, An Introduction to Hydrogen Bonding, Oxford University Press, New York, 1997, ch. 2; (b) T. Steiner, Angew. Chem., Int. Ed., 2002, 41, 48-76.

14 (a) K. Kalyanasundaram, J. Chem. Soc., Faraday Trans. 2, 1986, 82, 2401-2415; (b) W.-K. Chu, C.-C. Ko, K.-C. Chan, S.-M. Yiu, F.-L. Wong, C.-S. Lee and V. A. L. Roy, Chem. Mater., 2014, 26, 2544-2550.

15 J. G. Vaughan, B. L. Reid, P. J. Wright, S. Ramchandani, B. M. Skelton, P. Raiteri, S. Muzzioli, D. H. Brown, S. Stagni and M. Massi, Inorg. Chem., 2014, 53, 3629-3641.

16 H. C. Bertrand, S. Clède, R. Guillot, F. Lambert and C. Policar, Inorg. Chem., 2014, 53, 6204-6223.

17 D. Donghi, G. D'Alfonso, M.: Mauro, M. Panigati, P. Mercandelli, A. Sironi, P. Mussini and L. D'Alfonso, Inorg. Chem., 2008, 47, 4243-4255.

18 D. Magde, J. H. Brannon, T. L. Cremers and J. Olmsted, J. Phys. Chem., 1979, 83, 696-699.

19 (a) V. W.-W. Yam, B. Li, Y. Yang, B. W.-K. Chu, K. M.-C. Wong and K.-K. Cheung, Eur. J. Inorg. Chem., 2003, 4035-4042; (b) S. Ranjan, S.-Y. Lin, K.-C. Hwang, Y. Chi, W.-L. Ching, C.-S. Liu, Y.-T. Tao, C.-H. Chien, S.-M. Peng and G.-H. Lee, Inorg. Chem., 2003, 42, 12481255; (c) O. S. Wenger, L. M. Henling, M. W. Day, J. R. Winkler and H. B. Gray, Inorg. Chem., 2004, 43, 20432048; (d) H. Tsubaki, A. Sekine, Y. Ohashi, K. Koike, H. Takeda and O. Ishitani, J. Am. Chem. Soc., 2005, 127, 15544-15555; (e) N. J. Lundin, A. G. Blackman, K. C. Gordon and D. L. Officer, Angew. Chem., Int. Ed., 2006, 45, 2582-2584.

20 J. R. Lacowicz, Principles of Fluorescence Spectroscopy, Kluwer, New York, 2nd edn, 1999.

21 (a) P. J. Giordano and M. S. Wrighton, J. Am. Chem. Soc., 1979, 101, 2888-2897; (b) A. Juris, V. S. Campagna, I. Bidd, J.-M. Lehn and R. Ziessel, Inorg. Chem., 1988, 27, 40074011; (c) T. G. Kotch, A. J. Lees, S. J. Fuerniss and K. I. Papathomas, Chem. Mater., 1992, 4, 675-683; (d) A. Vogler and H. Kunkely, Coord. Chem. Rev., 2000, 200-202, 991-1008; (e) T. Doleck, J. Attard, F. R. Fronczek, A. Moskun and R. Isovitsch, Inorg. Chim. Acta, 2009, 362, 3872-3876.

22 See for example: $(a)$ G. J. Stor, F. Hartl, J. W. M. van Outersterp and D. J. Stufkens, Organometallics, 1995, 14, 11151131; (b) B. D. Rossenaar, F. Hartl and D. J. Stufkens, Inorg. Chem., 1996, 35, 6194-6203; (c) A. Klein, C. Vogler and W. Kaim, Organometallics, 1996, 15, 236-244.

23 P. Christensen, A. Hamnett, A. V. G. Muir and J. A. Timney, J. Chem. Soc., Dalton Trans., 1992, 1455-1463.

24 F. Magno, C.-A. Mazzocchin and G. Bontempelli, J. Electroanal. Chem., 1973, 47, 461-468.
25 A. Drozdz, M. Bubrin, J. Fiedler, S. Záliš and W. Kaim, Dalton Trans., 2012, 41, 1013-1019.

26 G. A. Ardizzoia, G. LaMonica, A. Maspero, M. Moret and N. Masciocchi, Eur. J. Inorg. Chem., 1998, 1503-1512.

27 D. D. Perrin and W. L. F. Armarego, Purification of Laboratory Chemicals, Pergamon Press, Oxford, 3rd edn, 1988.

28 M. F. Farona and K. F. Kraus, Inorg. Chem., 1970, 9, 17001704.

29 M. J. Frisch, G. W. Trucks, H. B. Schlegel, G. E. Scuseria, M. A. Robb, J. R. Cheeseman, G. Scalmani, V. Barone, B. Mennucci, G. A. Petersson, H. Nakatsuji, M. Caricato, X. Li, H. P. Hratchian, A. F. Izmaylov, J. Bloino, G. Zheng, J. L. Sonnenberg, M. Hada, M. Ehara, K. Toyota, R. Fukuda, J. Hasegawa, M. Ishida, T. Nakajima, Y. Honda, O. Kitao, H. Nakai, T. Vreven, J. A. Montgomery Jr., J. E. Peralta, F. Ogliaro, M. Bearpark, J. J. Heyd, E. Brothers, K. N. Kudin, V. N. Staroverov, R. Kobayashi, J. Normand, K. Raghavachari, A. Rendell, J. C. Burant, S. S. Iyengar, J. Tomasi, M. Cossi, N. Rega, J. M. Millam, M. Klene, J. E. Knox, J. B. Cross, V. Bakken, C. Adamo, J. Jaramillo, R. Gomperts, R. E. Stratmann, O. Yazyev, A. J. Austin, R. Cammi, C. Pomelli, J. W. Ochterski, R. L. Martin, K. Morokuma, V. G. Zakrzewski, G. A. Voth, P. Salvador, J. J. Dannenberg, S. Dapprich, A. D. Daniels, O. Farkas, J. B. Foresman, J. V. Ortiz, J. Cioslowski and D. J. Fox, Gaussian 09, Revision A.02, Gaussian, Inc., Wallingford CT, 2009.

30 (a) J. P. Perdew, K. Burke and M. Ernzerhof, Phys. Rev. Lett., 1996, 77, 3865-3868; (b) J. P. Perdew, K. Burke and M. Ernzerhof, Phys. Rev. Lett., 1997, 78, 1396; (c) C. Adamo and V. Barone, J. Chem. Phys., 1999, 110, 6158-6170.

31 (a) T. Helgaker and P. Jorgensen, J. Chem. Phys., 1991, 95, 2595-2601; (b) K. L. Bak, P. Jorgensen, T. Helgaker, K. Rund and H. J. A. Jenson, J. Chem. Phys., 1993, 98, 88738887; (c) J. Autschbach, T. Ziegler, S. J. A. Gisbergen and E. J. Baerends, J. Chem. Phys., 2002, 116, 6930-6940.

32 (a) E. Cances, B. Mennucci and J. Tomasi, J. Chem. Phys., 1997, 107, 3032-3041; (b) M. Cossi, V. Barone, B. Mennucci and J. Tomasi, Chem. Phys. Lett., 1998, 286, 253-260; (c) B. Mennucci and J. Tomasi, J. Chem. Phys., 1997, 106, 5151-5158.

33 L.-L. Shi, Y. Liao, L. Zhao, Z.-M. Su, Y.-H. Kan, G.-C. Yang and S. Y. Yang, J. Organomet. Chem., 2007, 692, 5368-5374.

34 (a) S. R. Stoyanov, J. M. Villegas and D. P. Rillema, Inorg. Chem., 2002, 41, 2941-2945; (b) D. Di Censo, S. Fantacci, F. De Angelis, C. Klein, N. Evans, K. Kalyanasundaram, H. J. Bollink, M. Gratzel and M. K. Nazeeruddin, Inorg. Chem., 2008, 47, 980-989; (c) T. H. Kwon, H. S. Cho, M. K. Kim, J. W. Kim, J. J. Kim, K. H. Lee, S. J. Park, I. S. Shin, H. Kim, D. M. Shin, Y. K. Chung and J. I. Hong, Organometallics, 2005, 24, 1578-1585; (d) Q. Zhao, S. Liu, M. Shi, C. Wang, M. Yu, L. Li, F. Li, T. Yi and C. Huang, Inorg. Chem., 2006, 45, 6152-6160; (e) K. Zheng, J. Huang, W. Peng, X. Liu and F. Yun, J. Phys. Chem. A, 2001, 105, 10899-10905; $(f)$ K. Zheng, J. Huang, Y. Shen, D. Kuang and F. Yun, J. Phys. Chem. A, 2001, 105, 7248-7253; 
(g) A. Vlček Jr. and S. Zalis, J. Phys. Chem. A, 2005, 109, 2991-2992.

35 (a) P. J. Hay and W. R. Wadt, J. Chem. Phys., 1985, 82, 270283; (b) P. J. Hay and W. R. Wadt, J. Chem. Phys., 1985, 82, 299-310.

36 (a) A. Gabrielsson, P. Matousek, M. Towrie, F. Hartl, S. Zalis and A. Vlček Jr., J. Phys. Chem. A, 2005, 109, 6147-6153; (b) D. M. Dattelbaum, K. M. Omberg, P. J. Hay, N. L. Gebhart, R. L. Martin, J. R. Schoonover and T. J. Meyer, J. Phys. Chem. A, 2004, 108, 3527-3536; (c) D. M. Dattelbaum, R. L. Martin, J. R. Schoonover and T. J. Meyer, J. Phys. Chem. A, 2004, 108, 3518-3526; (d) N. J. Lundin, P. J. Walsh, S. L. Howell, J. J. McGarvey, A. G. Blackman and K. C. Gordon, Inorg. Chem., 2005, 44, 3551-3560.

37 (a) T. H. Dunning Jr. and P. J. Hay, in Modern Theoretical Chemistry, ed. H. F. Schaefer III, Plenum, New York, 1977, vol. 3, pp. 1-28; (b) U. Wedig, M. Dolg, H. Stoll and H. Preuss, in Quantum Chemistry: The Challenge of Transition Metals and Coordination Chemistry, ed. A. Veillard, Reidel, Dordrecht, 1986, p. 79; (c) F. Weigend and R. Ahlrichs, Phys. Chem. Chem. Phys., 2005, 7, 3297-
3305; (d) D. Andrae, U. Haeussermann, M. Dolg, H. Stoll and H. Preuss, Theor. Chim. Acta, 1990, 77, 123-141.

38 (a) S. I. Gorelsky, AOMix: Program for Molecular Orbital Analysis, version 6.5, University of Ottawa, 2011, http://www. sg-chem.net/; (b) S. I. Gorelsky and A. B. P. Lever, J. Organomet. Chem., 2001, 635, 187-196.

39 R. Dennington, T. Keith and J. Millam, GaussView, Version 5, Semichem Inc., Shawnee Mission KS, 2009.

40 O. V. Dolomanov, L. J. Bourhis, R. J. Gildea, J. A. K. Howard and H. Puschmann, J. Appl. Crystallogr., 2009, 42, 339-341.

41 L. J. Bourhis, O. V. Dolomanov, R. J. Gildea, J. A. K. Howard and H. Puschmann, Acta Crystallogr., Sect. A: Fundam. Crystallogr., 2015, 71, 59-75.

42 G. M. Sheldrick, Acta Crystallogr., Sect. A: Fundam. Crystallogr., 2015, 71, 3-8.

43 G. M. Sheldrick, Acta Crystallogr., Sect. A: Fundam. Crystallogr., 2008, 64, 112-122.

44 (a) M. Nardelli, Comput. Chem., 1983, 7, 95-98; (b) M. Nardelli, J. Appl. Crystallogr., 1995, 28, 659.

45 (a) G. A. Jeffrey and L. Lewis, Carbohydr. Res., 1978, 60, 179-182; (b) R. Taylor and O. Kennard, Acta Crystallogr., Sect. B: Struct. Sci., 1983, 39, 133-138. 


\section{Electronic Supplementary Information}

Luminescent Rhenium(I) Tricarbonyl Complexes with Pyrazolylamidino

Ligands: Photophysical, Electrochemical, and Computational Studies

Patricia Gómez-Iglesias, Fabrice Guyon, Abderrahim Khatyr, Gilles Ulrich, Michael Knorr, Jose

Miguel Martín-Alvarez, Daniel Miguel, and Fernando Villafañe* 


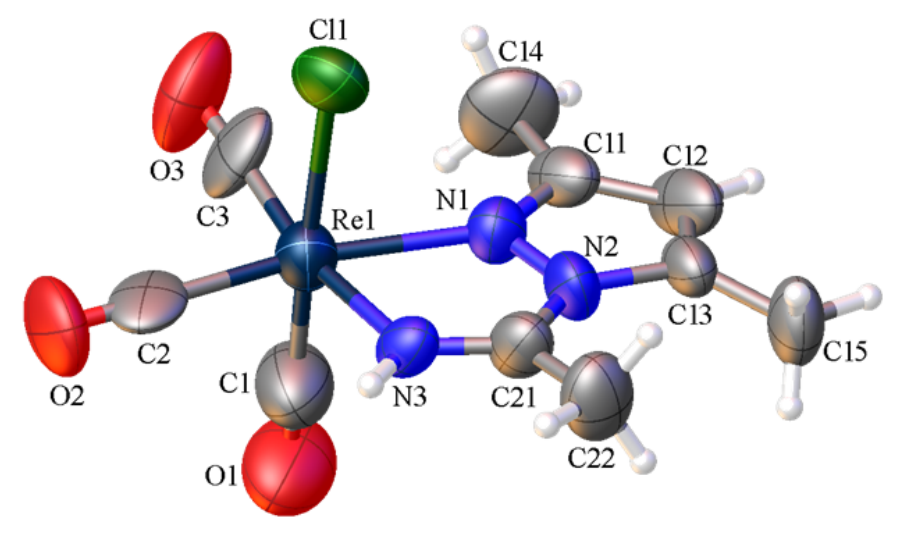

Figure S1. Perspective view of $f a c-\left[\operatorname{ReCl}(\mathrm{CO})_{3}\left(\mathrm{NH}=\mathrm{C}(\mathrm{Me}) \mathrm{dmpz}-\kappa^{2} N, N\right)\right], \mathbf{2}$, showing the atom numbering. Thermal ellipsoids are drawn at 50\% probability. 

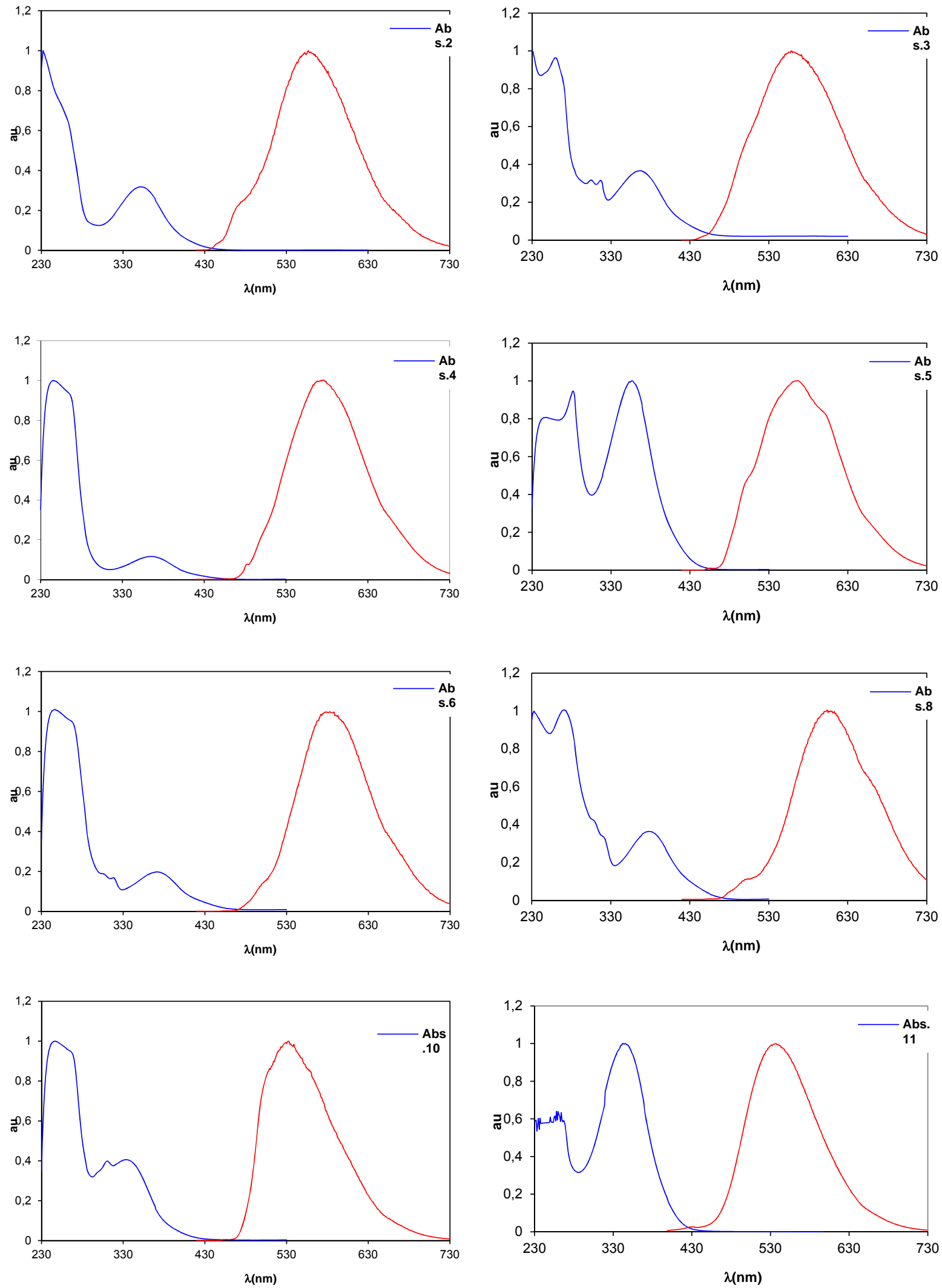


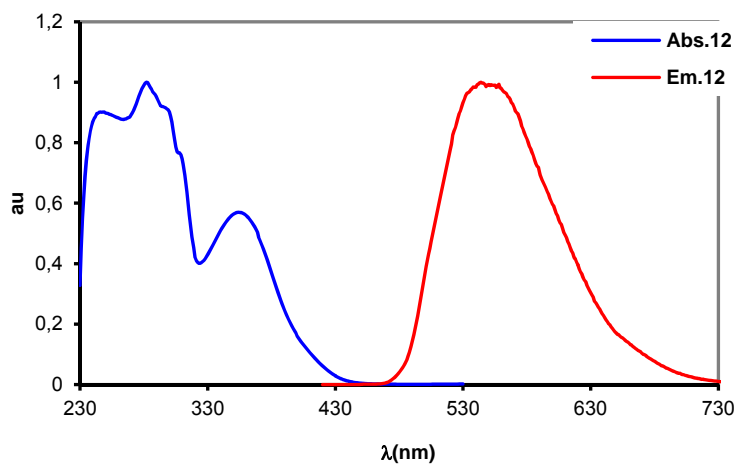

Figure S2. Normalized emission (red) and absorption (blue) spectra recorded in $\mathrm{CH}_{2} \mathrm{Cl}_{2}$ of complexes 2-6, 8, 10-12 at $298 \mathrm{~K}$. As indicated in Table 1, not reliable spectra could be obtained for 7 due to its instability in $\mathrm{CH}_{2} \mathrm{Cl}_{2}$ solution. 


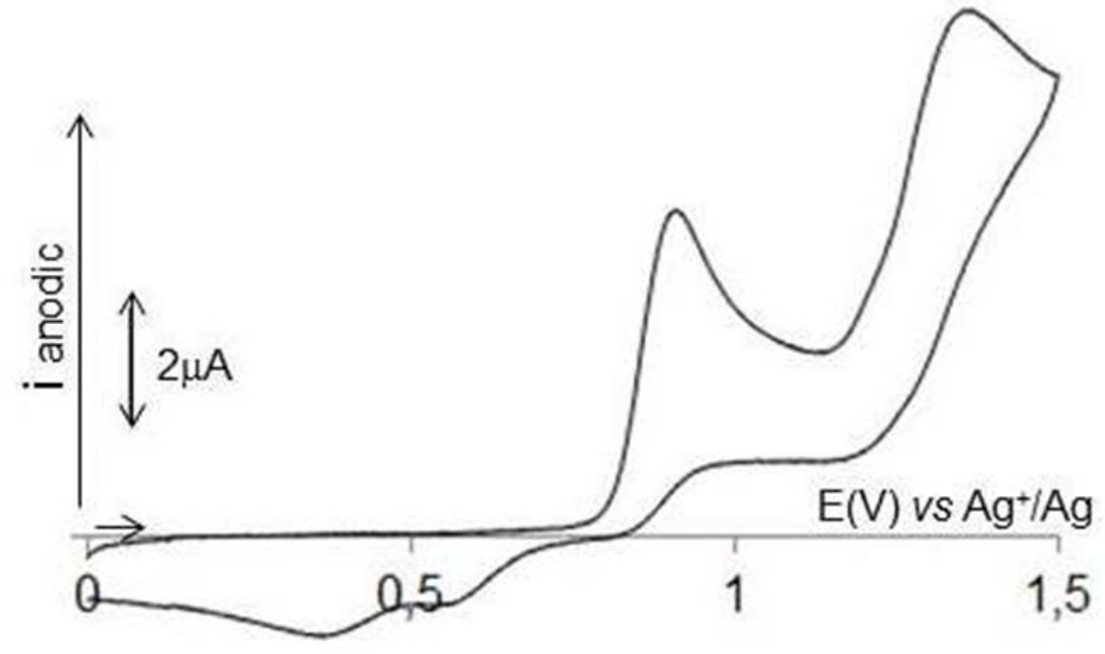

Figure S3. Cyclic voltammogram recorded in $\mathrm{CH}_{2} \mathrm{Cl}_{2}$ solution of $10 \mathrm{mM} \mathrm{5}$. Scan rate: $100 \mathrm{mV} / \mathrm{s}$.

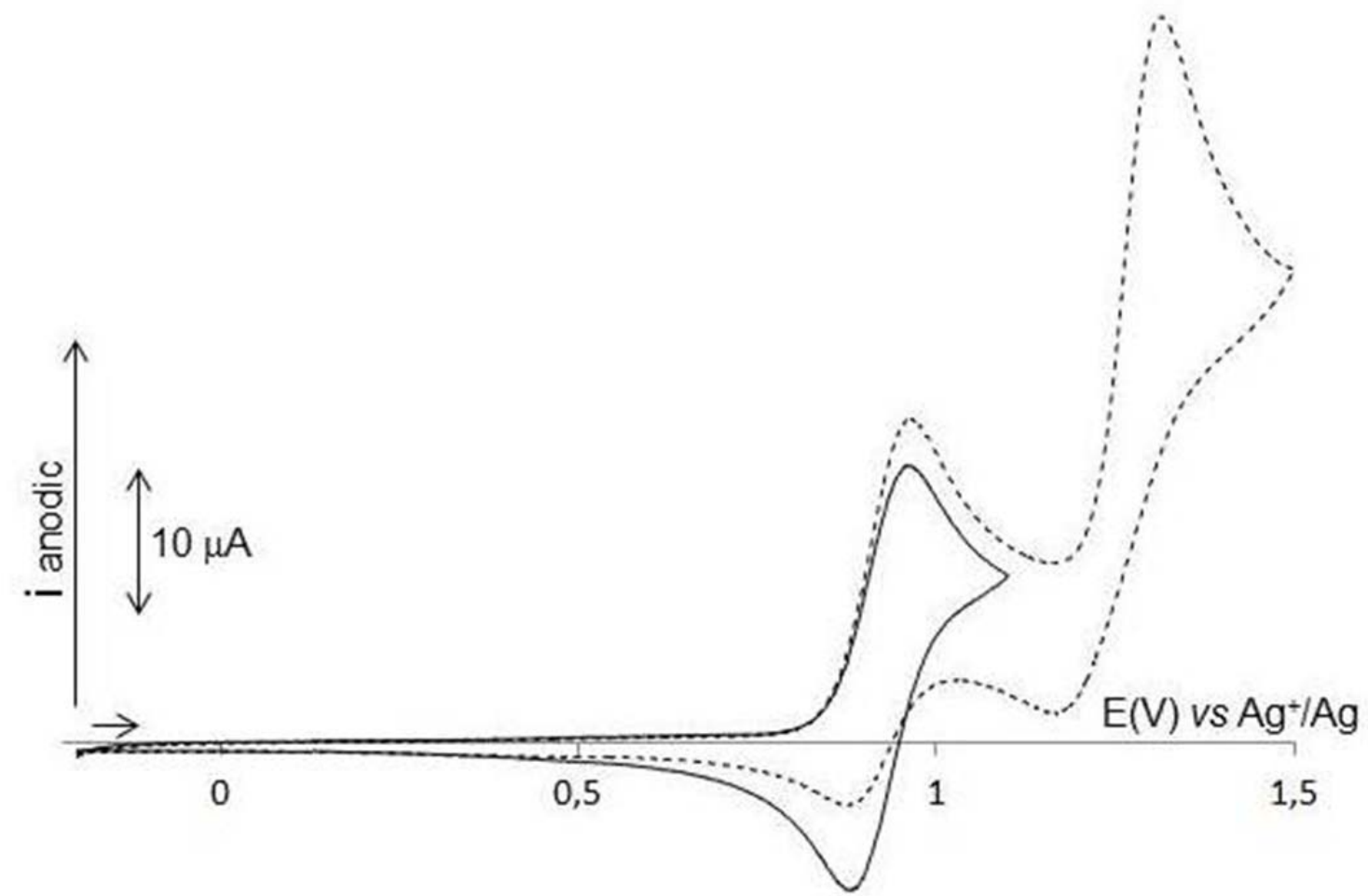

Figure S4. Cyclic voltammogram recorded in $\mathrm{MeCN}$ solution of $8.6 \mathrm{mM} \mathrm{fac-}\left[\operatorname{ReBr}(\mathrm{CO})_{3}(\mathrm{dmpzH})_{2}\right]$. Scan rate: $100 \mathrm{mV} / \mathrm{s}$. 
Table S1. Deviation from the geometry found by X-ray diffraction for selected bond distances of complex 1 calculated with different functionals and using LANL2DZ for the Re atom and $6-31 \mathrm{G}+(\mathrm{d}, \mathrm{p})$ for the rest of the atoms (Calculated distance - experimental distance).

\begin{tabular}{|l|l|l|l|l|l|l|l|}
\hline Functional & Re1-Cl1 & Re1-N3 & Re1-N1 & Re1-C1 & Re1-C2 & Re1-C3 & $\begin{array}{l}\text { Average } \\
\text { deviation }\end{array}$ \\
\hline B3LYP & 0.040 & 0.008 & 0.010 & 0.005 & 0.041 & 0.002 & 0.018 \\
\hline BMK & 0.036 & 0.010 & 0.011 & 0.011 & 0.047 & 0.006 & 0.020 \\
\hline CAM-B3LYP & 0.022 & 0.003 & -0.002 & -0.003 & 0.038 & -0.004 & 0.012 \\
\hline M06 & 0.019 & 0.009 & -0.002 & -0.0002 & 0.038 & -0.005 & 0.012 \\
\hline PBE & 0.019 & -0.013 & -0.008 & 0.003 & 0.034 & -0.005 & 0.014 \\
\hline TPSS & 0.018 & -0.016 & -0.014 & 0.010 & 0.043 & 0.004 & 0.018 \\
\hline WB97XD & 0.026 & 0.012 & 0.002 & -0.010 & 0.032 & -0.011 & 0.016 \\
\hline PBE1PBE & $-0,003$ & -0.018 & -0.021 & -0.008 & 0.030 & -0.011 & 0.015 \\
\hline
\end{tabular}

Table S2. Deviation from the geometry found by X-ray diffraction for selected bond distances of complex 1 calculated with different basis sets and using the PBE1PBE functional (Calculated distance - experimental distance).

\begin{tabular}{|l|l|l|l|l|l|l|l|}
\hline Basis set & Re1-Cl1 & Re1-N3 & Re1-N1 & Re1-C1 & Re1-C2 & Re1-C3 & $\begin{array}{l}\text { Average } \\
\text { deviation }\end{array}$ \\
\hline $\begin{array}{l}\text { LANL2DZ (Re) } \\
\text { 6-31G+(d,p) (rest) }\end{array}$ & -0.003 & -0.018 & -0.021 & -0.008 & 0.030 & -0.011 & 0.015 \\
\hline $\begin{array}{l}\text { LANL2DZ (Re) } \\
\text { 6-311G+(d,p) (rest) }\end{array}$ & 0.010 & -0.021 & -0.024 & -0.009 & 0.031 & -0.010 & 0.018 \\
\hline $\begin{array}{l}\text { SDD (Re) } \\
\text { 6-31G+(d,p) (rest) }\end{array}$ & 0.003 & -0.001 & -0.003 & 0.004 & 0.041 & 0.001 & 0.009 \\
\hline $\begin{array}{l}\text { SDD (Re) } \\
\text { 6-311G+(d,p) (rest) }\end{array}$ & 0.009 & -0.002 & -0.002 & 0.004 & 0.041 & 0.001 & 0.010 \\
\hline \begin{tabular}{l} 
TZVPDD \\
\hline
\end{tabular} & -0.043 & 0.013 & 0.028 & 0.001 & 0.034 & -0.006 & 0.021 \\
\hline
\end{tabular}


Table S3. Frontier Molecular Orbital Compositions (\%) in the Ground State for Complex 1 at the PBE1PBE Level

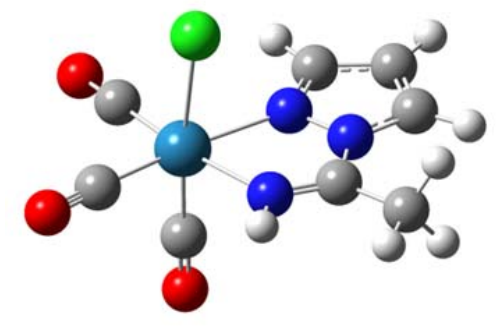<smiles></smiles>

\begin{tabular}{|c|c|c|c|c|c|c|}
\hline & & & Contri & ution (\%) & & \\
\hline Orbital & $\begin{array}{l}\text { Energy } \\
(\mathrm{eV}) \text { : }\end{array}$ & Re: & $\mathrm{Cl}$ & CO: & amidino: & main bond type \\
\hline HOMO-4 & -7.76 & 12.29 & 55.89 & 3.97 & 27.85 & $d(\operatorname{Re})+p(C l)+\pi($ amidino $)$ \\
\hline HOMO-3 & -7.66 & 9.84 & 58.90 & 3.35 & 27.91 & $d(R e)+p(C l)+\pi($ amidino $)$ \\
\hline HOMO-2 & -6.98 & 68.90 & 0.53 & 28.57 & 2.00 & $d(\mathrm{Re})+\pi(\mathrm{CO})$ \\
\hline HOMO-1 & -6.40 & 46.90 & 25.98 & 20.78 & 6.33 & $d(\operatorname{Re})+p(C l)+\pi(C O)$ \\
\hline HOMO & -6.32 & 47.08 & 25.77 & 22.84 & 4.32 & $d(\mathrm{Re})+p(\mathrm{Cl})+\pi(\mathrm{CO})$ \\
\hline LUMO & -2.04 & 4.60 & 1.68 & 5.82 & 87.91 & $\pi^{*}$ (amidino) \\
\hline LUMO+1 & -0.55 & 29.29 & 1.08 & 65.50 & 4.14 & $p(\operatorname{Re})+\pi^{*}(\mathrm{CO})$ \\
\hline LUMO+2 & -0.31 & 27.97 & 2.90 & 61.25 & 7.89 & $\mathrm{p}(\mathrm{Re})+\pi^{*}(\mathrm{CO})$ \\
\hline
\end{tabular}

Table S4. Frontier Molecular Orbital Compositions (\%) in the Ground State for Complex 2 at the PBE1PBE Level
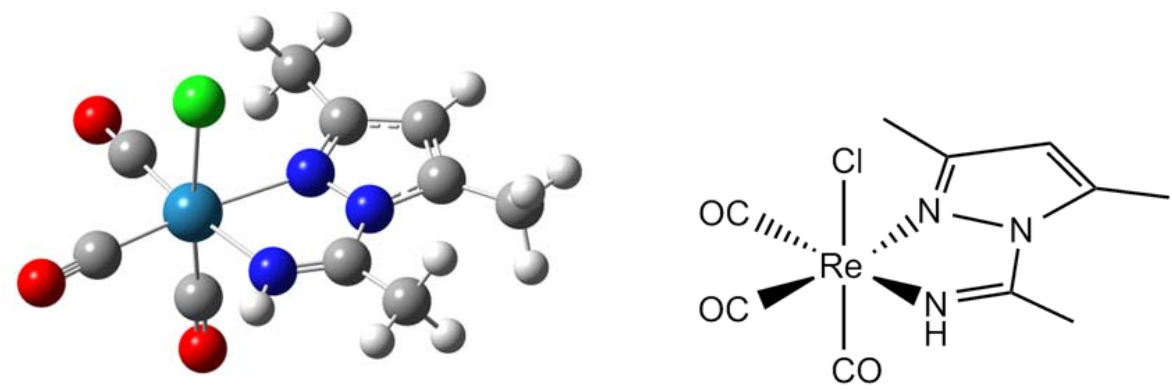

\begin{tabular}{|c|c|c|c|c|c|c|}
\hline \multirow[b]{2}{*}{ Orbital } & \multirow[b]{2}{*}{$\begin{array}{l}\text { Energy } \\
(\mathrm{eV}):\end{array}$} & \multicolumn{4}{|c|}{ Contribution (\%) } & \multirow[b]{2}{*}{ main bond type } \\
\hline & & Re: & $\mathrm{Cl}:$ & CO: & amidino: & \\
\hline HOMO-4 & -7.60 & 6.55 & 45.17 & 2.21 & 46.07 & $\mathrm{p}(\mathrm{Cl})+\pi$ (amidino) \\
\hline HOMO-3 & -7.43 & 5.30 & 54.17 & 1.88 & 38.65 & $\mathrm{p}(\mathrm{Cl})+\pi$ (amidino) \\
\hline HOMO-2 & -6.90 & 67.66 & 0.26 & 28.86 & 3.22 & $d(\operatorname{Re})+\pi(C O)$ \\
\hline HOMO-1 & -6.32 & 46.95 & 22.99 & 20.99 & 9.07 & $d(\operatorname{Re})+p(C l)+\pi(C O)$ \\
\hline HOMO & -6.26 & 47.34 & 24.58 & 22.89 & 5.20 & $d(\operatorname{Re})+p(C l)+\pi(C O)$ \\
\hline LUMO & -1.87 & 5.72 & 1.80 & 6.78 & 85.70 & $\pi^{*}$ (amidino) \\
\hline LUMO+1 & -0.45 & 27.90 & 1.02 & 66.44 & 4.63 & $\mathrm{p}(\mathrm{Re})+\pi^{*}(\mathrm{CO})$ \\
\hline LUMO+2 & -0.25 & 26.72 & 2.72 & 60.20 & 10.36 & $\mathrm{p}(\mathrm{Re})+\pi^{*}(\mathrm{CO})$ \\
\hline
\end{tabular}


Table S5. Frontier Molecular Orbital Compositions (\%) in the Ground State for Complex 3 at the PBE1PBE Level
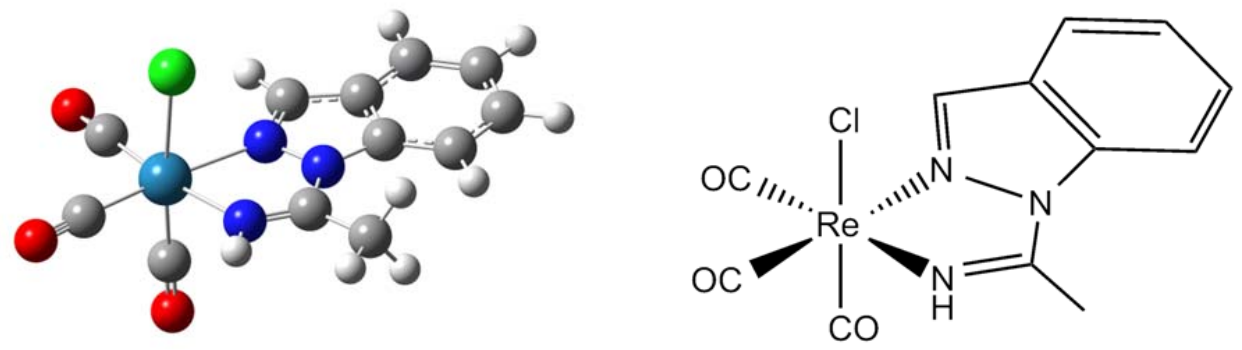

\begin{tabular}{|c|c|c|c|c|c|c|}
\hline & & & & & & \multirow[b]{3}{*}{ main bond type } \\
\hline & \multicolumn{4}{|c|}{ Contribution (\%) } & \\
\hline Orbital & $\begin{array}{l}\text { Energy } \\
(\mathrm{eV}):\end{array}$ & Re: & $\mathrm{Cl}:$ & CO: & amidino: & \\
\hline HOMO-4 & -7.55 & 4.21 & 39.33 & 1.50 & 54.95 & $\mathrm{p}(\mathrm{Cl})+\pi$ (amidino $)$ \\
\hline HOMO-3 & -7.20 & 3.00 & 18.84 & 1.26 & 76.89 & $\mathrm{p}(\mathrm{Cl})+\pi$ (amidino) \\
\hline HOMO-2 & -6.95 & 66.34 & 0.24 & 27.71 & 5.71 & $\mathrm{~d}(\mathrm{Re})+\pi(\mathrm{CO})$ \\
\hline HOMO-1 & -6.36 & 45.98 & 23.72 & 20.47 & 9.83 & $d(\operatorname{Re})+p(C l)+\pi(C O)$ \\
\hline HOMO & -6.29 & 46.34 & 24.92 & 22.16 & 6.58 & $d(\operatorname{Re})+p(C l)+\pi(C O)$ \\
\hline LUMO & -2.12 & 3.97 & 1.58 & 5.25 & 89.20 & $\pi^{*}$ (amidino) \\
\hline LUMO+1 & -0.96 & 0.96 & 0.13 & 2.94 & 95.97 & $\pi^{*}$ (amidino) \\
\hline LUMO+2 & -0.53 & 28.55 & 1.08 & 66.23 & 4.15 & $\mathrm{p}(\mathrm{Re})+\pi^{*}(\mathrm{CO})$ \\
\hline
\end{tabular}

Table S6. Frontier Molecular Orbital Compositions (\%) in the Ground State for Complex 4 at the PBE1PBE Level
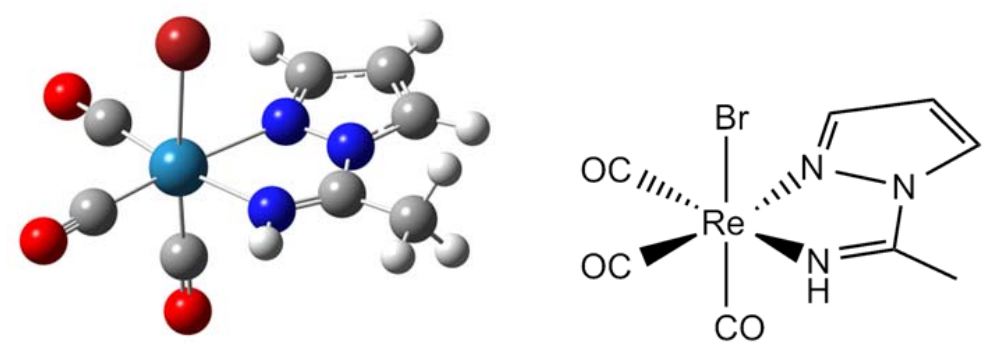

\begin{tabular}{|c|c|c|c|c|c|c|}
\hline \multirow[b]{2}{*}{ Orbital } & \multirow[b]{2}{*}{$\begin{array}{l}\text { Energy } \\
(\mathrm{eV}):\end{array}$} & \multicolumn{4}{|c|}{ Contribution (\%) } & \multirow[b]{2}{*}{ main bond type } \\
\hline & & Re: & $\mathrm{Br}:$ & CO: & amidino: & \\
\hline HOMO-4 & -7.46 & 22.14 & 51.4 & 7.8 & 18.66 & $d(\operatorname{Re})+p(B r)+\pi$ (amidino) \\
\hline HOMO-3 & -7.35 & 17.76 & 54.04 & 6.07 & 22.13 & $d(\operatorname{Re})+p(B r)+\pi$ (amidino) \\
\hline HOMO-2 & -6.99 & 68.7 & 0.52 & 28.53 & 2.26 & $d(\mathrm{Re})+\pi(\mathrm{CO})$ \\
\hline HOMO-1 & -6.34 & 38.37 & 39.86 & 16.81 & 4.95 & $d(\operatorname{Re})+p(B r)+\pi(C O)$ \\
\hline HOMO & -6.28 & 38.97 & 38.68 & 19.04 & 3.3 & $d(\operatorname{Re})+p(B r)+\pi(C O)$ \\
\hline LUMO & -2.05 & 4.4 & 2.48 & 5.83 & 87.29 & $\pi^{*}$ (amidino) \\
\hline LUMO+1 & -0.59 & 30.24 & 1.02 & 64.71 & 4.03 & $\mathrm{p}(\mathrm{Re})+\pi^{*}(\mathrm{CO})$ \\
\hline LUMO+2 & -0.36 & 27.72 & 4.52 & 59.84 & 7.92 & $\mathrm{p}(\mathrm{Re})+\pi^{*}(\mathrm{CO})$ \\
\hline
\end{tabular}

Table S7. Frontier Molecular Orbital Compositions (\%) in the Ground State for Complex 5 at the PBE1PBE Level 

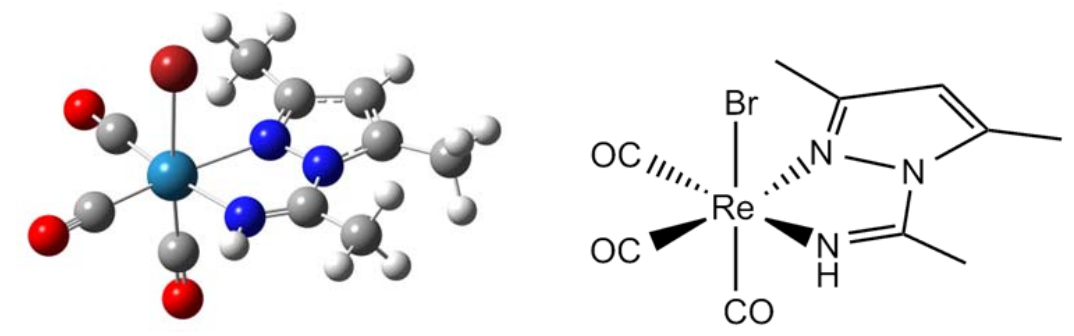

\begin{tabular}{|c|c|c|c|c|c|c|}
\hline \multirow[b]{2}{*}{ Orbital } & \multirow[b]{2}{*}{$\begin{array}{l}\text { Energy } \\
(\mathrm{eV}) \text { : }\end{array}$} & \multicolumn{4}{|c|}{ Contribution (\%) } & \multirow[b]{2}{*}{ main bond type } \\
\hline & & Re: & $\mathrm{Br}:$ & CO: & amidino: & \\
\hline HOMO-4 & -7.34 & 16.88 & 48.95 & 6.14 & 28.02 & $\mathrm{p}(\mathrm{Br})+\pi$ (amidino $)$ \\
\hline HOMO-3 & -7.16 & 14.14 & 52.8 & 4.91 & 28.15 & $\mathrm{p}(\mathrm{Br})+\pi$ (amidino) \\
\hline HOMO-2 & -6.91 & 64.93 & 1.81 & 27.89 & 5.37 & $d(\operatorname{Re})+\pi(C O)$ \\
\hline HOMO-1 & -6.27 & 39.56 & 35.73 & 17.49 & 7.22 & $d(\mathrm{Re})+p(\mathrm{Br})+\pi(\mathrm{CO})$ \\
\hline HOMO & -6.22 & 39.73 & 36.95 & 19.31 & 4.01 & $d(\mathrm{Re})+p(\mathrm{Br})+\pi(\mathrm{CO})$ \\
\hline LUMO & -1.87 & 5.45 & 2.7 & 6.81 & 85.03 & $\pi^{*}$ (amidino) \\
\hline LUMO+1 & -0.49 & 28.91 & 0.98 & 65.55 & 4.56 & $\mathrm{p}(\mathrm{Re})+\pi^{*}(\mathrm{CO})$ \\
\hline LUMO+2 & -0.31 & 26.48 & 4.2 & 58.97 & 10.35 & $\mathrm{p}(\mathrm{Re})+\pi^{*}(\mathrm{CO})$ \\
\hline
\end{tabular}

Table S8. Frontier Molecular Orbital Compositions (\%) in the Ground State for Complex 6 at the PBE1PBE Level
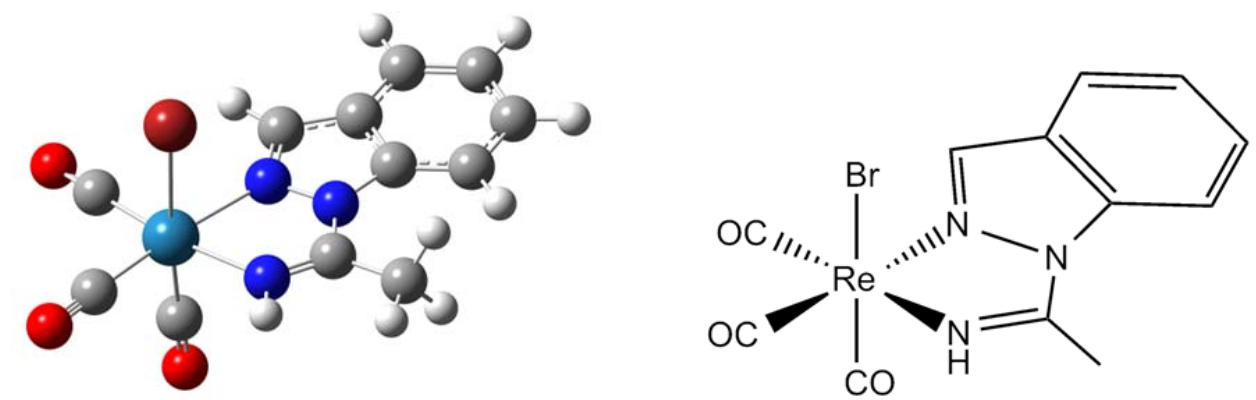

\begin{tabular}{|c|c|c|c|c|c|c|}
\hline & & & Contri & ution (\%) & & \\
\hline Orbital & $\begin{array}{l}\text { Energy } \\
(\mathrm{eV}) \text { : }\end{array}$ & Re: & $\mathrm{Br}:$ & CO: & amidino: & main bond type \\
\hline HOMO-3 & -7.09 & 14.84 & 30.61 & 5.64 & 48.91 & $d(\operatorname{Re})+p(B r)+\pi($ amidino $)$ \\
\hline HOMO-2 & -6.95 & 57.13 & 3.88 & 24.07 & 14.92 & $\mathrm{~d}(\mathrm{Re})+\pi(\mathrm{CO})+\pi($ amidino $)$ \\
\hline HOMO-1 & -6.32 & 38.54 & 36.9 & 17.02 & 7.54 & $d(\operatorname{Re})+p(B r)+\pi(C O)$ \\
\hline HOMO & -6.26 & 38.75 & 37.42 & 18.6 & 5.22 & $d(\operatorname{Re})+p(B r)+\pi(C O)$ \\
\hline LUMO & -2.13 & 3.84 & 2.31 & 5.27 & 88.58 & $\pi^{*}$ (amidino) \\
\hline LUMO+1 & -0.96 & 0.98 & 0.21 & 3.07 & 95.74 & $\pi^{*}$ (amidino) \\
\hline LUMO+2 & -0.57 & 29.53 & 1.02 & 65.4 & 4.06 & $p(\operatorname{Re})+\pi^{*}(\mathrm{CO})$ \\
\hline LUMO+3 & -0.36 & 26.62 & 4.53 & 58.19 & 10.65 & $\mathrm{p}(\mathrm{Re})+\pi^{*}(\mathrm{CO})$ \\
\hline
\end{tabular}

Table S9. Frontier Molecular Orbital Compositions (\%) in the Ground State for Complex 7 at the PBE1PBE Level 

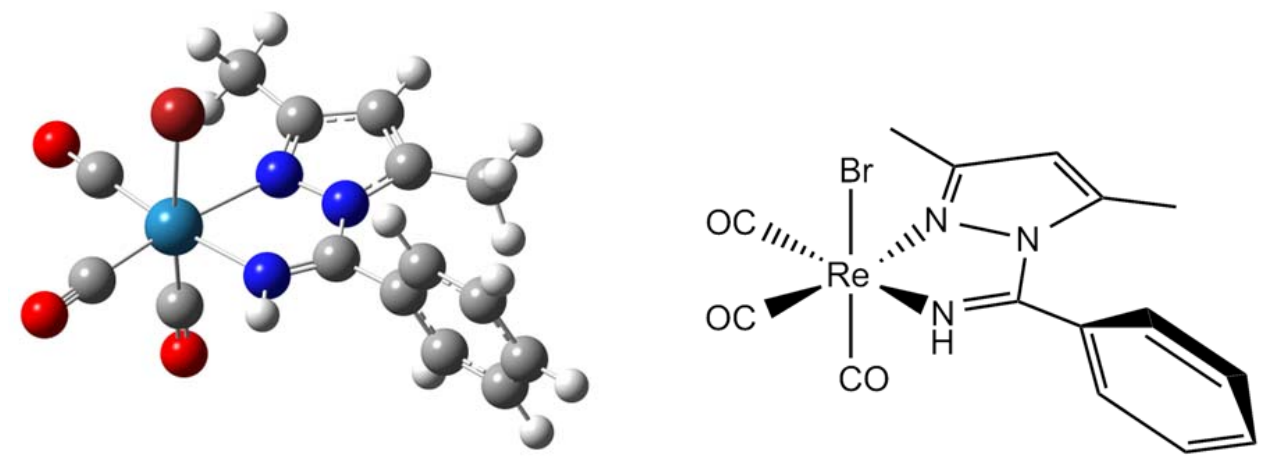

\begin{tabular}{|c|c|c|c|c|c|c|}
\hline & & \multicolumn{4}{|c|}{ Contribution (\%) } & \\
\hline Orbital & $\begin{array}{l}\text { Energy } \\
(\mathrm{eV}) \text { : }\end{array}$ & Re: & $\mathrm{Br}:$ & $\mathrm{CO}:$ & amidino: & main bond type \\
\hline HOMO-6 & -7.82 & 0.9 & 1.62 & 0.45 & 97.03 & $\pi$ (amidino) \\
\hline HOMO-5 & -7.74 & 2.09 & 2.18 & 0.81 & 94.92 & $\pi$ (amidino) \\
\hline HOMO-4 & -7.33 & 15.39 & 45.45 & 5.81 & 33.35 & $\mathrm{~d}(\mathrm{Re})+\mathrm{p}(\mathrm{Br})+\pi($ amidino $)$ \\
\hline HOMO-3 & -7.17 & 13.69 & 52.25 & 4.69 & 29.37 & $d(\operatorname{Re})+p(B r)+\pi($ amidino $)$ \\
\hline HOMO-2 & -6.93 & 65.15 & 1.67 & 27.82 & 5.37 & $\mathrm{~d}(\mathrm{Re})+\pi(\mathrm{CO})$ \\
\hline HOMO-1 & -6.29 & 39.26 & 36.34 & 17.26 & 7.14 & $d(\operatorname{Re})+p(B r)+\pi(C O)$ \\
\hline HOMO & -6.24 & 39.52 & 36.86 & 19.34 & 4.28 & $d(\mathrm{Re})+p(\mathrm{Br})+\pi(\mathrm{CO})$ \\
\hline LUMO & -2.01 & 4.72 & 2.49 & 6.06 & 86.74 & $\pi^{*}$ (amidino) \\
\hline LUMO+1 & -0.84 & 5.83 & 0.46 & 7.79 & 85.92 & $\pi^{*}$ (amidino) \\
\hline LUMO+2 & -0.53 & 1.5 & 0.24 & 3.06 & 95.19 & $\pi^{*}$ (amidino) \\
\hline LUMO+3 & -0.47 & 26.04 & 1.34 & 61.75 & 10.88 & $\mathrm{p}(\mathrm{Re})+\pi^{*}(\mathrm{CO})+\pi^{*}$ (amidino) \\
\hline
\end{tabular}


Table S10. Frontier Molecular Orbital Compositions (\%) in the Ground State for Complex 8 at the PBE1PBE Level
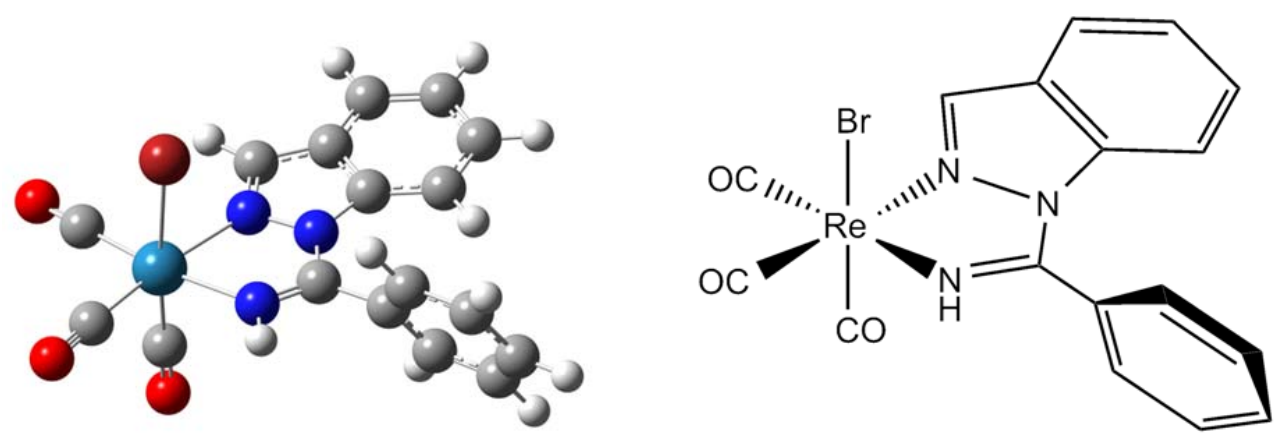

\begin{tabular}{|c|c|c|c|c|c|c|}
\hline & & \multicolumn{4}{|c|}{ Contribution (\%) } & \\
\hline Orbital & $\begin{array}{l}\text { Energy } \\
(\mathrm{eV}):\end{array}$ & Re: & $\mathrm{Br}:$ & CO: & amidino: & main bond type \\
\hline HOMO-5 & -7.55 & 14.5 & 20.43 & 5.43 & 59.65 & $d(\operatorname{Re})+p(B r)+\pi($ amidino $)$ \\
\hline HOMO-4 & -7.35 & 12.98 & 41.12 & 4.69 & 41.2 & $d(\operatorname{Re})+p(B r)+\pi($ amidino $)$ \\
\hline HOMO-3 & -7.07 & 15.01 & 30.52 & 5.73 & 48.74 & $d(\operatorname{Re})+p(B r)+\pi($ amidino $)$ \\
\hline HOMO-2 & -6.97 & 56.7 & 3.83 & 23.8 & 15.68 & $\mathrm{~d}(\mathrm{Re})+\pi(\mathrm{CO})+\pi($ amidino $)$ \\
\hline HOMO-1 & -6.32 & 38.19 & 36.44 & 16.86 & 8.52 & $d(\operatorname{Re})+p(B r)+\pi(C O)$ \\
\hline HOMO & -6.28 & 38.57 & 38.32 & 18.65 & 4.46 & $d(\mathrm{Re})+p(\mathrm{Br})+\pi(\mathrm{CO})$ \\
\hline LUMO & -2.19 & 3.8 & 2.32 & 5.2 & 88.69 & $\pi^{*}$ (amidino) \\
\hline LUMO+1 & -1.24 & 0.48 & 0.04 & 1.85 & 97.63 & $\pi^{*}$ (amidino) \\
\hline LUMO+2 & -0.71 & 13.12 & 0.61 & 23.48 & 62.79 & $\mathrm{p}(\mathrm{Re})+\pi^{*}(\mathrm{CO})+\pi^{*}$ (amidino $)$ \\
\hline
\end{tabular}


Table S11. Frontier Molecular Orbital Compositions (\%) in the Ground State for Complex 9 at the PBE1PBE Level

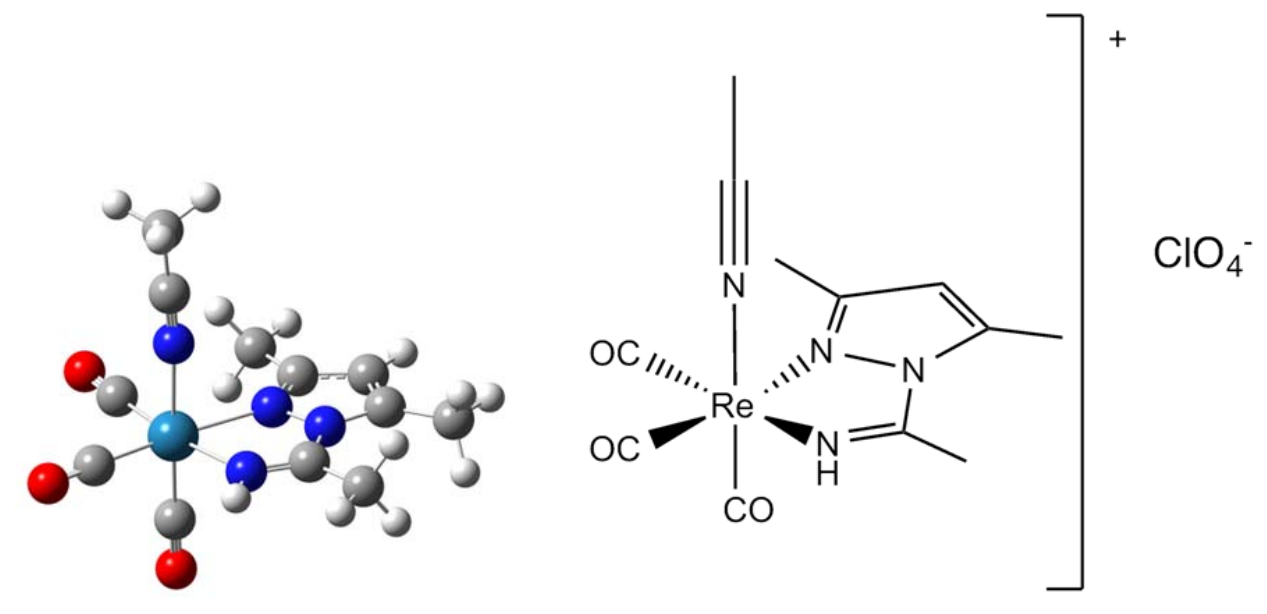

\begin{tabular}{|c|c|c|c|c|c|c|}
\hline & & \multicolumn{4}{|c|}{ Contribution (\%) } & \\
\hline Orbital & $\begin{array}{l}\text { Energy } \\
(\mathrm{eV}):\end{array}$ & Re: & MeCN: & $\mathrm{CO}:$ & amidino: & main bond type \\
\hline HOMO-3 & -8.39 & 6.21 & 1.44 & 2.11 & 90.25 & $\pi$ (amidino) \\
\hline HOMO-2 & -7.5 & 69.58 & 0 & 27.9 & 2.52 & $d(\operatorname{Re})+\pi(C O)$ \\
\hline HOMO-1 & -7.17 & 59.02 & 4.74 & 23.04 & 13.21 & $\mathrm{~d}(\mathrm{Re})+\pi(\mathrm{CO})+\pi($ amidino $)$ \\
\hline HOMO & -7.11 & 54 & 4.09 & 21.28 & 20.63 & $\mathrm{~d}(\mathrm{Re})+\pi(\mathrm{CO})+\pi($ amidino $)$ \\
\hline LUMO & -2.37 & 5.65 & 0.5 & 7.38 & 86.48 & $\pi^{*}$ (amidino) \\
\hline LUMO+1 & -1.27 & 26.08 & 18.09 & 51.59 & 4.23 & $\mathrm{p}(\mathrm{Re})+\pi^{*}(\mathrm{CO})+\pi^{*}(\mathrm{MeCN})$ \\
\hline LUMO+2 & -0.93 & 19.19 & 25.13 & 51.32 & 4.36 & $\mathrm{p}(\mathrm{Re})+\pi^{*}(\mathrm{CO})+\pi^{*}(\mathrm{MeCN})$ \\
\hline
\end{tabular}


Table S12. Frontier Molecular Orbital Compositions (\%) in the Ground State for Complex 10 at the PBE1PBE Level

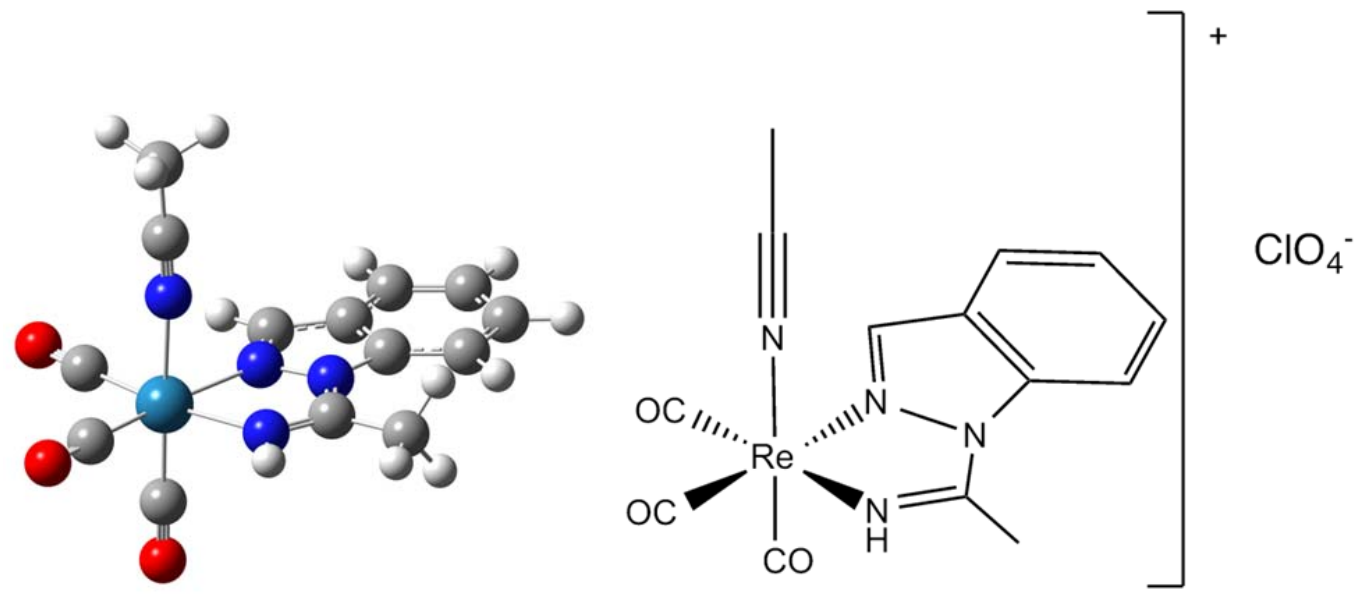

\begin{tabular}{|c|c|c|c|c|c|c|}
\hline & & \multicolumn{4}{|c|}{ Contribution (\%) } & \\
\hline Orbital & $\begin{array}{l}\text { Energy } \\
(\mathrm{eV}):\end{array}$ & Re: & MeCN: & $\mathrm{CO}:$ & amidino: & main bond type \\
\hline HOMO-4 & -8.38 & 10.66 & 2.24 & 3.39 & 83.71 & $\mathrm{~d}(\mathrm{Re})+\pi$ (amidino) \\
\hline HOMO-3 & -7.79 & 15.58 & 1.72 & 5.37 & 77.33 & $\mathrm{~d}(\mathrm{Re})+\pi($ amidino $)$ \\
\hline HOMO-2 & -7.54 & 68.75 & 0.01 & 27.13 & 4.12 & $d(\operatorname{Re})+\pi(C O)$ \\
\hline HOMO-1 & -7.21 & 57.16 & 4.63 & 22.67 & 15.54 & $\mathrm{~d}(\mathrm{Re})+\pi(\mathrm{CO})+\pi($ amidino $)$ \\
\hline HOMO & -7.12 & 45.5 & 3.47 & 17.45 & 33.58 & $\mathrm{~d}(\mathrm{Re})+\pi(\mathrm{CO})+\pi($ amidino $)$ \\
\hline LUMO & -2.6 & 4.23 & 0.45 & 5.9 & 89.42 & $\pi^{*}$ (amidino) \\
\hline LUMO+1 & -1.36 & 10.51 & 6.9 & 20.56 & 62.03 & $\pi^{*}(\mathrm{CO})+\pi *($ amidino $)$ \\
\hline LUMO+2 & -1.31 & 17.45 & 9.94 & 35.79 & 36.82 & $\mathrm{p}(\mathrm{Re})+\pi^{*}(\mathrm{CO})+\pi^{*}$ (amidino) \\
\hline LUMO+3 & -0.97 & 19.45 & 23.74 & 51.89 & 4.91 & $\mathrm{p}(\mathrm{Re})+\pi^{*}(\mathrm{CO})+\pi^{*}(\mathrm{MeCN})$ \\
\hline
\end{tabular}


Table S13. Frontier Molecular Orbital Compositions (\%) in the Ground State for Complex 11 at the PBE1PBE Level
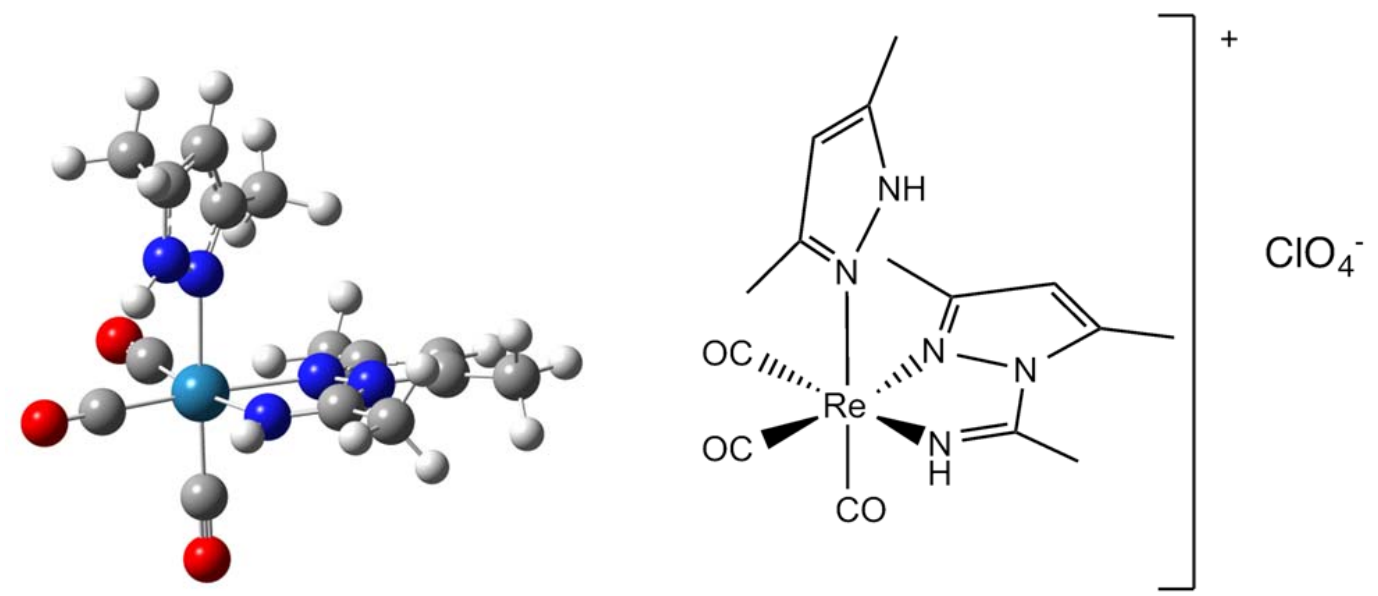

\begin{tabular}{|c|c|c|c|c|c|c|}
\hline & & & Contri & ution (\%) & & \\
\hline Orbital & $\begin{array}{l}\text { Energy } \\
(\mathrm{eV}):\end{array}$ & Re: & dmpz: & CO: & amidino: & main bond type \\
\hline HOMO-4 & -8.10 & 6.49 & 74.87 & 2.42 & 16.22 & $\pi(\mathrm{dmpz})+\pi($ amidino $)$ \\
\hline HOMO-3 & -7.85 & 1.79 & 90.14 & 0.91 & 7.15 & $\pi(\mathrm{dmpz})+\pi($ amidino $)$ \\
\hline HOMO-2 & -7.52 & 68.78 & 0.84 & 28.62 & 1.76 & $d(\mathrm{Re})+\pi(\mathrm{CO})$ \\
\hline HOMO-1 & -7.20 & 59.52 & 0.98 & 24.36 & 15.14 & $\mathrm{~d}(\mathrm{Re})+\pi(\mathrm{CO})+\pi($ amidino $)$ \\
\hline HOMO & -6.88 & 46.28 & 22.68 & 19.57 & 11.48 & $d(\operatorname{Re})+\pi(d m p z)+\pi(C O)$ \\
\hline LUMO & -2.34 & 5.56 & 1.36 & 7.55 & 85.53 & $\pi^{*}$ (amidino) \\
\hline LUMO+1 & -1.14 & 29.03 & 3.64 & 62.59 & 4.74 & $\mathrm{p}(\mathrm{Re})+\pi^{*}(\mathrm{CO})$ \\
\hline LUMO+2 & -0.82 & 18.50 & 17.13 & 56.85 & 7.52 & $\mathrm{p}(\mathrm{Re})+\pi^{*}(\mathrm{dmpz})+\pi^{*}(\mathrm{CO})$ \\
\hline
\end{tabular}


Table S14. Frontier Molecular Orbital Compositions (\%) in the Ground State for Complex 12 at the PBE1PBE Level
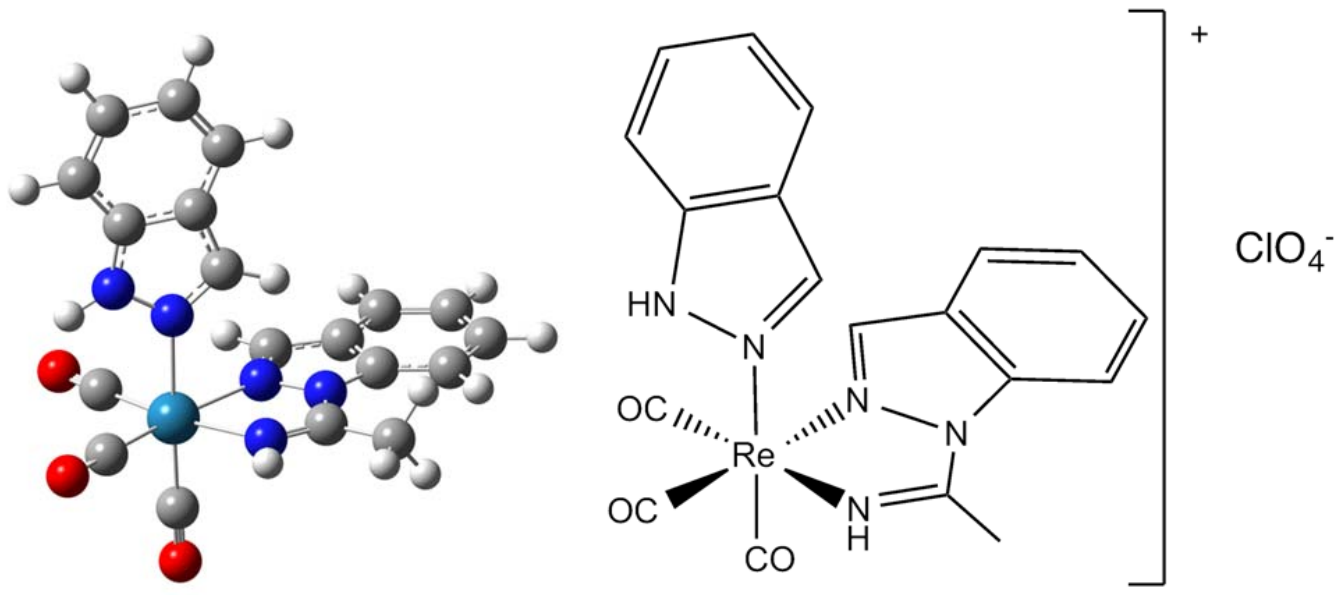

\begin{tabular}{|c|c|c|c|c|c|c|}
\hline & & & Contri & ution (\%) & & \\
\hline Orbital & $\begin{array}{l}\text { Energy } \\
(\mathrm{eV}) \text { : }\end{array}$ & Re: & indz: & CO: & amidino: & main bond type \\
\hline HOMO-2 & -7.22 & 46.02 & 2.75 & 17.87 & 33.35 & $d(\operatorname{Re})+\pi(\mathrm{CO})+\pi($ amidino $)$ \\
\hline HOMO-1 & -7.13 & 4.93 & 91 & 1.56 & 2.51 & $\pi$ (indazol) \\
\hline HOMO & -7 & 42.34 & 30.35 & 18.64 & 8.67 & $\mathrm{~d}(\mathrm{Re})+\pi(\mathrm{CO})+\pi($ indazol $)$ \\
\hline LUMO & -2.67 & 4.47 & 0.86 & 6.17 & 88.49 & $\pi^{*}$ (amidino) \\
\hline LUMO+1 & -1.77 & 6.81 & 79.25 & 12.68 & 1.25 & $\pi^{*}$ (indazol) \\
\hline LUMO+2 & -1.39 & 1.1 & 0.18 & 3.9 & 94.83 & $\pi^{*}$ (amidino) \\
\hline
\end{tabular}


Table S15. Calculated Excited Energies, Dominant Orbital Excitations, and Oscillator Strength $(f)$ from TD-DFT Calculations for Complex 1

\begin{tabular}{|c|l|c|c|c|c|c|l|}
\hline state & excitation & Coef. & $\begin{array}{c}\mathrm{E}_{\text {calc }} \\
(\mathrm{eV})\end{array}$ & $\begin{array}{c}\lambda_{\text {calc }} \\
(\mathrm{nm})\end{array}$ & $f$ & $\begin{array}{c}\lambda_{\exp } \\
(\mathrm{nm})\end{array}$ & Character \\
\hline $\mathrm{S}_{1}$ & HOMO $\rightarrow$ LUMO & 0.70 & 3.21 & 386 & 0.0035 & & $\mathrm{MLCT} / \mathrm{LLCT} / \mathrm{XLCT}$ \\
\hline $\mathrm{S}_{2}$ & HOMO-1 $\rightarrow$ LUMO & 0.69 & 3.39 & 366 & 0.0964 & 360 & $\mathrm{MLCT} / \mathrm{LLCT} / \mathrm{XLCT}$ \\
\hline $\mathrm{S}_{8}$ & HOMO-4 $\rightarrow$ LUMO & 0.64 & 4.76 & 261 & 0.1178 & 264 & $\mathrm{MLCT} / \mathrm{XLCT} / \mathrm{ILCT}$ \\
& HOMO-3 $\rightarrow$ LUMO & 0.27 & & & & & \\
\hline
\end{tabular}

Table S16. Calculated Excited Energies, Dominant Orbital Excitations, and Oscillator Strength $(f)$ from TD-DFT Calculations for Complex 2

\begin{tabular}{|c|l|c|c|c|c|c|l|}
\hline state & excitation & Coef. & $\begin{array}{c}\mathrm{E}_{\text {calc }} \\
(\mathrm{eV})\end{array}$ & $\begin{array}{c}\lambda_{\text {calc }} \\
(\mathrm{nm})\end{array}$ & $f$ & $\begin{array}{c}\lambda_{\text {exp }} \\
(\mathrm{nm})\end{array}$ & Character \\
\hline $\mathrm{S}_{1}$ & HOMO $\rightarrow$ LUMO & 0.69 & 3.33 & 372 & 0.0033 & & $\mathrm{MLCT} / \mathrm{LLCT} / \mathrm{XLCT}$ \\
\hline $\mathrm{S}_{2}$ & HOMO-1 $\rightarrow$ LUMO & 0.69 & 3.49 & 356 & 0.1067 & 352 & $\mathrm{MLCT} / \mathrm{LLCT} / \mathrm{XLCT}$ \\
\hline $\mathrm{S}_{7}$ & HOMO-3 $\rightarrow$ LUMO & 0.67 & 4.62 & 268 & 0.0855 & 261 & $\mathrm{XLCT} / \mathrm{ILCT}$ \\
\hline $\mathrm{S}_{8}$ & HOMO-4 $\rightarrow$ LUMO & 0.67 & 4.76 & 261 & 0.0850 & & $\mathrm{XLCT} / \mathrm{ILCT}$ \\
\hline
\end{tabular}

Table S17. Calculated Excited Energies, Dominant Orbital Excitations, and Oscillator Strength $(f)$ from TD-DFT Calculations for Complex 3

\begin{tabular}{|c|l|c|c|c|c|c|l|}
\hline state & excitation & Coef. & $\begin{array}{c}\mathrm{E}_{\text {calc }} \\
(\mathrm{eV})\end{array}$ & $\begin{array}{c}\lambda_{\text {calc }} \\
(\mathrm{nm})\end{array}$ & $f$ & $\begin{array}{c}\lambda_{\text {exp }} \\
(\mathrm{nm})\end{array}$ & Character \\
\hline $\mathrm{S}_{1}$ & HOMO $\rightarrow$ LUMO & 0.68 & 3.17 & 391 & 0.0031 & & $\mathrm{MLCT} / \mathrm{LLCT} / \mathrm{XLCT}$ \\
\hline $\mathrm{S}_{2}$ & HOMO-1 $\rightarrow$ LUMO & 0.67 & 3.34 & 371 & 0.1680 & 367 & $\mathrm{MLCT} / \mathrm{LLCT} / \mathrm{XLCT}$ \\
\hline $\mathrm{S}_{4}$ & $\mathrm{HOMO}-3 \rightarrow$ LUMO & 0.66 & 4.24 & 292 & 0.1652 & 304 & $\mathrm{XLCT} / \mathrm{ILCT}$ \\
\hline
\end{tabular}

Table S18. Calculated Excited Energies, Dominant Orbital Excitations, and Oscillator Strength $(f)$ from TD-DFT Calculations for Complex 4

\begin{tabular}{|c|l|c|c|c|c|c|l|}
\hline state & excitation & Coef. & $\begin{array}{c}\mathrm{E}_{\text {calc }} \\
(\mathrm{eV})\end{array}$ & $\begin{array}{c}\lambda_{\text {calc }} \\
(\mathrm{nm})\end{array}$ & $f$ & $\begin{array}{c}\lambda_{\text {exp }} \\
(\mathrm{nm})\end{array}$ & Character \\
\hline $\mathrm{S}_{1}$ & HOMO $\rightarrow$ LUMO & 0.69 & 3.18 & 389 & 0.0023 & & $\mathrm{MLCT} / \mathrm{LLCT} / \mathrm{XLCT}$ \\
\hline $\mathrm{S}_{2}$ & HOMO-1 $\rightarrow$ LUMO & 0.69 & 3.32 & 373 & 0.0693 & 368 & $\mathrm{MLCT} / \mathrm{LLCT} / \mathrm{XLCT}$ \\
\hline $\mathrm{S}_{7}$ & HOMO-4 $\rightarrow$ LUMO & 0.58 & 4.46 & 278 & 0.1262 & 267 & $\mathrm{MLCT} / \mathrm{XLCT} / \mathrm{ILCT}$ \\
& HOMO-3 $\rightarrow$ LUMO & 0.33 & & & & & \\
\hline
\end{tabular}


Table S19. Calculated Excited Energies, Dominant Orbital Excitations, and Oscillator Strength $(f)$ from TD-DFT Calculations for Complex $\mathbf{5}$

\begin{tabular}{|c|l|c|c|c|c|c|l|}
\hline state & excitation & Coef. & $\begin{array}{c}\mathrm{E}_{\text {calc }} \\
(\mathrm{eV})\end{array}$ & $\begin{array}{c}\lambda_{\text {calc }} \\
(\mathrm{nm})\end{array}$ & $f$ & $\begin{array}{c}\lambda_{\text {exp }} \\
(\mathrm{nm})\end{array}$ & Character \\
\hline $\mathrm{S}_{1}$ & HOMO $\rightarrow$ LUMO & 0.69 & 3.32 & 374 & 0.0021 & & $\mathrm{MLCT} / \mathrm{LLCT} / \mathrm{XLCT}$ \\
\hline $\mathrm{S}_{2}$ & HOMO-1 $\rightarrow$ LUMO & 0.69 & 3.44 & 361 & 0.0795 & 356 & $\mathrm{MLCT} / \mathrm{LLCT} / \mathrm{XLCT}$ \\
\hline $\mathrm{S}_{4}$ & HOMO-3 $\rightarrow$ LUMO & 0.63 & 4.35 & 285 & 0.0916 & 283 & $\mathrm{LLCT} / \mathrm{ILCT}$ \\
\hline $\mathrm{S}_{7}$ & HOMO-4 $\rightarrow$ LUMO & 0.64 & 4.48 & 277 & 0.0636 & & $\mathrm{LLCT/ILCT}$ \\
\hline $\mathrm{S}_{9}$ & HOMO-1 $\rightarrow$ LUMO+2 & 0.59 & 4.85 & 255 & 0.0340 & 248 & $\mathrm{MLCT} / \mathrm{LLCT} / \mathrm{ILCT}$ \\
\hline
\end{tabular}

Table S20. Calculated Excited Energies, Dominant Orbital Excitations, and Oscillator Strength $(f)$ from TD-DFT Calculations for Complex 6

\begin{tabular}{|c|l|c|c|c|c|c|l|}
\hline state & excitation & Coef. & $\begin{array}{c}\mathrm{E}_{\text {calc }} \\
(\mathrm{eV})\end{array}$ & $\begin{array}{c}\lambda_{\text {calc }} \\
(\mathrm{nm})\end{array}$ & $f$ & $\begin{array}{c}\lambda_{\text {exp }} \\
(\mathrm{nm})\end{array}$ & Character \\
\hline $\mathrm{S}_{1}$ & HOMO $\rightarrow$ LUMO & 0.68 & 3.15 & 393 & 0.0025 & & MLCT/LLCT/XLCT \\
\hline $\mathrm{S}_{2}$ & HOMO-1 $\rightarrow$ LUMO & 0.67 & 3.29 & 377 & 0.1261 & 379 & $\mathrm{MLCT} / \mathrm{LLCT} / \mathrm{XLCT}$ \\
\hline $\mathrm{S}_{4}$ & HOMO-3 $\rightarrow$ LUMO & 0.64 & 4.13 & 300 & 0.2239 & 269 & $\mathrm{MLCT} / \mathrm{XLCT} / \mathrm{ILCT}$ \\
& HOMO-2 $\rightarrow$ LUMO & -0.22 & & & & & \\
\hline $\mathrm{S}_{10}$ & HOMO $\rightarrow$ LUMO+1 & 0.40 & 4.49 & 276 & 0.0818 & 251 & MLCT/LLCT/XLCT \\
& HOMO $\rightarrow$ LUMO+3 & 0.39 & & & & & \\
& HOMO-1 $\rightarrow$ LUMO+1 & -0.30 & & & & & \\
\hline
\end{tabular}

Table S21. Calculated Excited Energies, Dominant Orbital Excitations, and Oscillator Strength $(f)$ from TD-DFT Calculations for Complex 7

\begin{tabular}{|c|c|c|c|c|c|c|c|}
\hline state & excitation & Coef. & $\begin{array}{l}E_{\text {calc }} \\
(\mathrm{eV})\end{array}$ & $\begin{array}{l}\lambda_{\text {calc }} \\
(\mathrm{nm})\end{array}$ & $f$ & $\begin{array}{l}\lambda_{\exp } \\
(\mathrm{nm})\end{array}$ & Character \\
\hline $\mathrm{S}_{1}$ & HOMO $\rightarrow$ LUMO & 0.70 & 3.20 & 387 & 0.0019 & & MLCT/LLCT/XLCT \\
\hline $\mathrm{S}_{2}$ & HOMO-1 $\rightarrow$ LUMO & 0.70 & 3.33 & 372 & 0.0827 & & MLCT/LLCT/XLCT \\
\hline $\mathrm{S}_{4}$ & HOMO-3 $\rightarrow$ LUMO & 0.66 & 4.23 & 293 & 0.0996 & & MLCT/XLCT/ILCT \\
\hline $\mathrm{S}_{5}$ & $\begin{array}{l}\text { HOMO-4 } \rightarrow \text { LUMO } \\
\text { HOMO-1 } \rightarrow \text { LUMO+3 }\end{array}$ & $\begin{array}{l}0.54 \\
0.27\end{array}$ & 4.34 & 286 & 0.0443 & & $\begin{array}{l}\text { MLCT/LLCT/XLCT/ } \\
/ \text { ILCT }\end{array}$ \\
\hline$S_{10}$ & HOMO-6 $\rightarrow$ LUMO & 0.66 & 4.74 & 261 & 0.0462 & & ILCT \\
\hline
\end{tabular}


Table S22. Calculated Excited Energies, Dominant Orbital Excitations, and Oscillator Strength (f) from TD-DFT Calculations for Complex 8

\begin{tabular}{|c|l|c|c|c|c|c|l|}
\hline state & excitation & Coef. & $\begin{array}{c}\mathrm{E}_{\text {calc }} \\
(\mathrm{eV})\end{array}$ & $\begin{array}{c}\lambda_{\text {calc }} \\
(\mathrm{nm})\end{array}$ & $f$ & $\begin{array}{c}\lambda_{\text {exp }} \\
(\mathrm{nm})\end{array}$ & Character \\
\hline $\mathrm{S}_{1}$ & HOMO $\rightarrow$ LUMO & 0.69 & 3.11 & 399 & 0.0026 & & $\mathrm{MLCT} / \mathrm{LLCT} / \mathrm{XLCT}$ \\
\hline $\mathrm{S}_{2}$ & HOMO-1 $\rightarrow$ LUMO & 0.69 & 3.24 & 383 & 0.1225 & 381 & $\mathrm{MLCT} / \mathrm{LLCT} / \mathrm{XLCT}$ \\
\hline $\mathrm{S}_{4}$ & HOMO-3 $\rightarrow$ LUMO & 0.63 & 4.05 & 306 & 0.2035 & 310 & $\mathrm{MLCT} / \mathrm{XLCT} / \mathrm{ILCT}$ \\
\hline $\mathrm{S}_{10}$ & HOMO-5 $\rightarrow$ LUMO & 0.65 & 4.32 & 287 & 0.1437 & 273 & $\mathrm{MLCT} / \mathrm{XLCT} / \mathrm{ILCT}$ \\
\hline
\end{tabular}

Table S23. Calculated Excited Energies, Dominant Orbital Excitations, and Oscillator Strength (f) from TD-DFT Calculations for Complex 9

\begin{tabular}{|c|c|c|c|c|c|c|c|}
\hline state & excitation & Coef. & $\begin{array}{l}E_{\text {calc }} \\
(e V)\end{array}$ & $\begin{array}{l}\lambda_{\text {calc }} \\
(\mathrm{nm})\end{array}$ & $f$ & $\begin{array}{l}\lambda_{\exp } \\
(\mathrm{nm})\end{array}$ & Character \\
\hline $\mathrm{S}_{1}$ & $\begin{array}{l}\text { HOMO-1 } \rightarrow \text { LUMO } \\
\text { HOMO } \rightarrow \text { LUMO }\end{array}$ & $\begin{array}{l}0.46 \\
0.53\end{array}$ & 3.70 & 355 & 0.0133 & & MLCT/LLCT/ILCT \\
\hline $\mathrm{S}_{2}$ & $\begin{array}{l}\text { HOMO-1 } \rightarrow \text { LUMO } \\
\text { HOMO } \rightarrow \text { LUMO }\end{array}$ & $\begin{array}{l}0.52 \\
0.45\end{array}$ & 3.86 & 321 & 0.1784 & 324 & MLCT/LLCT/ILCT \\
\hline $\mathrm{S}_{8}$ & $\begin{array}{l}\text { HOMO-2 } \rightarrow \text { LUMO+2 } \\
\text { HOMO } \rightarrow \text { LUMO+2 }\end{array}$ & $\begin{array}{l}0.40 \\
0.40\end{array}$ & 4.97 & 250 & 0.0561 & 254 & $\begin{array}{l}\text { MLCT/LLCT/ILCT/ } \\
/ \text { LXCT }\end{array}$ \\
\hline$S_{9}$ & HOMO-3 $\rightarrow$ LUMO & 0.67 & 5.12 & 242 & 0.1457 & 233 & ILCT \\
\hline
\end{tabular}

Table S24. Calculated Excited Energies, Dominant Orbital Excitations, and Oscillator Strength $(f)$ from TD-DFT Calculations for Complex 10

\begin{tabular}{|c|l|c|c|c|c|c|l|}
\hline state & excitation & Coef. & $\begin{array}{c}\mathrm{E}_{\text {calc }} \\
(\mathrm{eV})\end{array}$ & $\begin{array}{c}\lambda_{\text {calc }} \\
(\mathrm{nm})\end{array}$ & $f$ & $\begin{array}{c}\lambda_{\text {exp }} \\
(\mathrm{nm})\end{array}$ & Character \\
\hline $\mathrm{S}_{1}$ & HOMO-1 $\rightarrow$ LUMO & 0.62 & 3.59 & 346 & 0.0078 & & MLCT/LLCT/ILCT \\
& HOMO $\rightarrow$ LUMO & 0.32 & & & & & \\
\hline $\mathrm{S}_{2}$ & HOMO-1 $\rightarrow$ LUMO & 0.31 & 3.72 & 333 & 0.3427 & 340 & MLCT/LLCT/ILCT \\
& HOMO $\rightarrow$ LUMO & 0.60 & & & & & \\
\hline $\mathrm{S}_{4}$ & HOMO-3 $\rightarrow$ LUMO & 0.67 & 4.33 & 286 & 0.0975 & & MLCT/ILCT \\
\hline $\mathrm{S}_{10}$ & HOMO-4 $\rightarrow$ LUMO & 0.30 & 4.97 & 250 & 0.0670 & 246 & $\begin{array}{l}\text { MLCT/LLCT/ILCT/ } \\
\text { HOMOCT }\end{array}$ \\
\hline
\end{tabular}


Table S25. Calculated Excited Energies, Dominant Orbital Excitations, and Oscillator Strength $(f)$ from TD-DFT Calculations for Complex 11

\begin{tabular}{|c|l|c|c|c|c|c|l|}
\hline State & excitation & Coef. & $\begin{array}{c}\mathrm{E}_{\text {calc }} \\
(\mathrm{eV})\end{array}$ & $\begin{array}{c}\lambda_{\text {calc }} \\
(\mathrm{nm})\end{array}$ & $f$ & $\begin{array}{c}\lambda_{\exp } \\
(\mathrm{nm})\end{array}$ & Character \\
\hline $\mathrm{S}_{1}$ & HOMO $\rightarrow$ LUMO & 0.70 & 3.64 & 341 & 0.1508 & 346 & $\mathrm{MLCT} / \mathrm{LLCT} / \mathrm{XLCT}$ \\
\hline $\mathrm{S}_{2}$ & HOMO-1 $\rightarrow$ LUMO & 0.70 & 3.77 & 329 & 0.0035 & & $\mathrm{MLCT} / \mathrm{LLCT} / \mathrm{ILCT}$ \\
\hline $\mathrm{S}_{8}$ & HOMO-4 $\rightarrow$ LUMO & 0.61 & 4.85 & 256 & 0.0713 & 260 & $\mathrm{XLCT} / \mathrm{LCT}$ \\
& HOMO-1 $\rightarrow$ LUMO+2 & 0.26 & & & & & \\
\hline $\mathrm{S}_{9}$ & HOMO $\rightarrow$ LUMO+2 & 0.52 & 4.87 & 255 & 0.0727 & & MLCT/LLCT/LXCT \\
& HOMO-1 $\rightarrow$ LUMO+1 & 0.23 & & & & & \\
\hline
\end{tabular}

Table S26. Calculated Excited Energies, Dominant Orbital Excitations, and Oscillator Strength $(f)$ from TD-DFT Calculations for Complex 12

\begin{tabular}{|c|l|c|c|c|c|c|l|}
\hline state & excitation & Coef. & $\begin{array}{c}\mathrm{E}_{\text {calc }} \\
(\mathrm{eV})\end{array}$ & $\begin{array}{c}\lambda_{\text {calc }} \\
(\mathrm{nm})\end{array}$ & $f$ & $\begin{array}{c}\lambda_{\exp } \\
(\mathrm{nm})\end{array}$ & Character \\
\hline $\mathrm{S}_{1}$ & HOMO $\rightarrow$ LUMO & 0.68 & 3.38 & 367 & 0.0053 & & $\mathrm{MLCT} / \mathrm{LLCT} / \mathrm{XLCT}$ \\
\hline $\mathrm{S}_{2}$ & $\mathrm{HOMO}-2 \rightarrow$ LUMO & 0.64 & 3.73 & 332 & 0.3409 & 359 & $\mathrm{MLCT} / \mathrm{LLCT} / \mathrm{ILCT}$ \\
\hline $\mathrm{S}_{6}$ & $\mathrm{HOMO} \rightarrow$ LUMO+1 & 0.56 & 4.25 & 291 & 0.1982 & 282 & $\mathrm{MLCT} / \mathrm{LXCT} / \mathrm{ILCT}$ \\
\hline
\end{tabular}


Table S27. Molecular orbital Compositions in the Excited States.

\begin{tabular}{|c|c|c|c|c|c|c|}
\hline & & & \multicolumn{4}{|c|}{ Contribution (\%) } \\
\hline Complex & Orbital & $\begin{array}{l}\text { Energy } \\
(\mathrm{eV}):\end{array}$ & Re: & $\begin{array}{l}\text { "sixth" } \\
\text { ligand: }\end{array}$ & CO: & amidino: \\
\hline \multirow[t]{2}{*}{1} & HOMO & -5.87 & 46.33 & 18.86 & 17.50 & 17.31 \\
\hline & LUMO & -2.37 & 5.66 & 2.43 & 8.96 & 82.95 \\
\hline \multirow[t]{2}{*}{2} & HOMO & -5.72 & 44.18 & 17.81 & 18.08 & 19.93 \\
\hline & LUMO & -2.24 & 6.12 & 1.97 & 9.17 & 82.74 \\
\hline \multirow[t]{2}{*}{3} & HOMO & -5.76 & 43.27 & 17.96 & 17.58 & 21.18 \\
\hline & LUMO & -2.40 & 5.03 & 2.06 & 8.16 & 84.75 \\
\hline \multirow[t]{2}{*}{4} & HOMO & -5.85 & 42.77 & 25.28 & 16.02 & 15.93 \\
\hline & LUMO & -2.37 & 5.03 & 3.41 & 8.60 & 82.96 \\
\hline \multirow[t]{2}{*}{5} & HOMO & -5.72 & 40.88 & 24.02 & 16.62 & 18.48 \\
\hline & LUMO & -2.24 & 5.49 & 2.86 & 8.88 & 82.77 \\
\hline \multirow[t]{2}{*}{6} & HOMO & -5.76 & 39.84 & 24.25 & 16.03 & 19.88 \\
\hline & LUMO & -2.40 & 4.59 & 2.83 & 7.85 & 84.74 \\
\hline \multirow[t]{2}{*}{7} & HOMO & -5.66 & 39.02 & 24.30 & 17.13 & 19.55 \\
\hline & LUMO & -2.65 & 5.55 & 1.69 & 6.35 & 86.41 \\
\hline \multirow[t]{2}{*}{8} & HOMO & -5.77 & 39.68 & 22.66 & 16.11 & 21.56 \\
\hline & LUMO & -2.65 & 4.86 & 2.04 & 6.43 & 86.67 \\
\hline \multirow[t]{2}{*}{9} & HOMO & -6.61 & 47.79 & 3.87 & 18.38 & 29.97 \\
\hline & LUMO & -2.78 & 5.19 & 0.61 & 7.48 & 86.72 \\
\hline \multirow[t]{2}{*}{10} & HOMO & -6.75 & 41.81 & 3.31 & 15.71 & 39.17 \\
\hline & LUMO & -2.99 & 4.57 & 0.59 & 6.85 & 87.99 \\
\hline \multirow[t]{2}{*}{11} & HOMO & -6.27 & 45.69 & 18.99 & 18.48 & 16.83 \\
\hline & LUMO & -3.07 & 4.44 & 1.92 & 5.38 & 88.26 \\
\hline \multirow[t]{2}{*}{12} & HOMO & -6.60 & 42.39 & 13.71 & 16.14 & 27.76 \\
\hline & LUMO & -3.01 & 4.72 & 1.08 & 7.41 & 86.80 \\
\hline
\end{tabular}


Table S28. Calculated Emission Energies and Dominant Orbital Emissions from TD-DFT Calculations.

\begin{tabular}{|c|c|l|c|c|c|c|l|}
\hline Complex & state & Excitation & Coef. & $\begin{array}{c}\mathrm{E}_{\text {calc }} \\
(\mathrm{eV})\end{array}$ & $\begin{array}{c}\lambda_{\text {calc }} \\
(\mathrm{nm})\end{array}$ & $\begin{array}{c}\lambda_{\text {exp }} \\
(\mathrm{nm})\end{array}$ & Character \\
\hline 1 & $\mathrm{~T}_{1}$ & $\mathrm{HOMO} \rightarrow \mathrm{LUMO}$ & 0.69 & 1.88 & 659 & 570 & ${ }^{3} \mathrm{MLCT} /{ }^{3} \mathrm{LLCT} /{ }^{3} \mathrm{XLCT}$ \\
\hline 2 & $\mathrm{~T}_{1}$ & $\mathrm{HOMO} \rightarrow \mathrm{LUMO}$ & 0.69 & 1.82 & 682 & 557 & ${ }^{3} \mathrm{MLCT} /{ }^{3} \mathrm{LLCT} /{ }^{3} \mathrm{XLCT}$ \\
\hline 3 & $\mathrm{~T}_{1}$ & $\mathrm{HOMO} \rightarrow \mathrm{LUMO}$ & 0.68 & 1.84 & 672 & 559 & ${ }^{3} \mathrm{MLCT} /{ }^{3} \mathrm{LLCT} /{ }^{3} \mathrm{XLCT}$ \\
\hline 4 & $\mathrm{~T}_{1}$ & $\mathrm{HOMO} \rightarrow \mathrm{LUMO}$ & 0.68 & 1.91 & 648 & 572 & ${ }^{3} \mathrm{MLCT} /{ }^{3} \mathrm{LLCT} /{ }^{3} \mathrm{XLCT}$ \\
\hline 5 & $\mathrm{~T}_{1}$ & $\mathrm{HOMO} \rightarrow \mathrm{LUMO}$ & 0.68 & 1.88 & 661 & 564 & ${ }^{3} \mathrm{MLCT} /{ }^{3} \mathrm{LLCT} /{ }^{3} \mathrm{XLCT}$ \\
\hline 6 & $\mathrm{~T}_{1}$ & $\mathrm{HOMO} \rightarrow \mathrm{LUMO}$ & 0.66 & 1.86 & 667 & 581 & ${ }^{3} \mathrm{MLCT} /{ }^{3} \mathrm{LLCT} /{ }^{3} \mathrm{XLCT}$ \\
\hline 7 & $\mathrm{~T}_{1}$ & $\mathrm{HOMO} \rightarrow \mathrm{LUMO}$ & 0.68 & 1.48 & 840 & & ${ }^{3} \mathrm{MLCT} /{ }^{3} \mathrm{LLCT} /{ }^{3} \mathrm{XLCT}$ \\
\hline 8 & $\mathrm{~T}_{1}$ & $\mathrm{HOMO} \rightarrow \mathrm{LUMO}$ & 0.68 & 1.61 & 769 & 606 & ${ }^{3} \mathrm{MLCT} /{ }^{3} \mathrm{LLCT} /{ }^{3} \mathrm{XLCT}$ \\
\hline 9 & $\mathrm{~T}_{1}$ & $\mathrm{HOMO} \rightarrow \mathrm{LUMO}$ & 0.67 & 2.07 & 599 & 524 & ${ }^{3} \mathrm{MLCT} /{ }^{3} \mathrm{LLCT} /{ }^{3} \mathrm{ILCT}$ \\
\hline 10 & $\mathrm{~T}_{1}$ & $\mathrm{HOMO} \rightarrow \mathrm{LUMO}$ & 0.66 & 1.93 & 644 & 532 & ${ }^{3} \mathrm{MLCT} /{ }^{3} \mathrm{LLCT} /{ }^{3} \mathrm{ILCT}$ \\
\hline 11 & $\mathrm{~T}_{1}$ & $\mathrm{HOMO} \rightarrow \mathrm{LUMO}$ & 0.67 & 1.77 & 699 & 536 & ${ }^{3} \mathrm{MLCT} /{ }^{3} \mathrm{LLCT} /{ }^{3} \mathrm{XLCT}$ \\
\hline 12 & $\mathrm{~T}_{1}$ & $\mathrm{HOMO} \rightarrow \mathrm{LUMO}$ & 0.65 & 1.90 & 653 & 544 & ${ }^{3} \mathrm{MLCT} /{ }^{3} \mathrm{LLCT} /{ }^{3} \mathrm{ILCT}$ \\
\hline
\end{tabular}




\section{Artículo 3:}

Incorporating Biomolecules as Amidino Ligands in $\mathrm{Re}(\mathrm{CO})_{3}$ complexes by in situ coupling 



\section{Dalton Transactions}

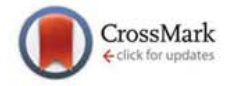

Cite this: DOI: $10.1039 / \mathrm{c} 5 \mathrm{dt} 03221 \mathrm{k}$

Received 20th August 2015 Accepted 11th September 2015

DOI: $10.1039 / \mathrm{c} 5 \mathrm{dt} 03221 \mathrm{k}$

www.rsc.org/dalton

\section{Amidino ligands obtained from the coupling of 1-methylcytosine and nitrile: a new method to incorporate biomolecules into luminescent $\operatorname{Re}(\mathrm{CO})_{3}$ complexes $\dagger$}

\author{
Patricia Gómez-Iglesias, Jose Miguel Martín-Alvarez, Daniel Miguel and \\ Fernando Villafañe*
}

\begin{abstract}
The formation of an amidino chelating ligand from the coupling reaction of 1-methylcytosine and nitrile is a new method herein reported for the incorporation of biologically relevant substrates into rhenium(1) tricarbonyl complexes. The reactions are carried out thermally or are microwave assisted.
\end{abstract}

The use of luminescent rhenium(I) tricarbonyl complexes as labels and probes for biomolecules relies both on their intense and long-lived emission properties and on the activity and binding selectivity of the biomolecules, which are retained in almost all cases. ${ }^{1}$ Therefore, the incorporation of biologically relevant substrates into these complexes is one of the most important challenges for the future in inorganic medicinal chemistry. ${ }^{1,2}$ More recently, IR spectroscopy has been used on these complexes to know about the local environment without the need of labels or staining, allowing one to combine bimodal IR and luminescent probes. This method has been proposed and named as SCoMPI, for "Single Core Multimodal Probe for Imaging", by Policar's group. ${ }^{3}$

Besides direct coordination of the nucleobase to the fac$\operatorname{Re}(\mathrm{CO})_{3}$ fragment, ${ }^{4}$ three main strategies have been developed in order to graft biomolecules to the $f a c-\left[\operatorname{ReX}(\mathrm{CO})_{3}(\mathrm{~N}-\mathrm{N})\right]^{n}$ $(\mathrm{N}-\mathrm{N}=$ diimine chelating ligand; $\mathrm{X}=$ halogen or pseudohalogen, $n=0$; $\mathrm{X}=$ pyridyl type ligand, $n=+1$ ) complexes: ${ }^{5}$ the biomolecule may be attached either to the diimine chelating ligand ${ }^{6}$ or to the pyridyl type ligand; ${ }^{7}$ whereas the third option is attaching the biomolecule in a tripodal nitrogen-donor

GIR MIOMeT-IU Cinquima-Quimica Inorgánica, Facultad de Ciencias, Campus Miguel Delibes, Universidad de Valladolid, 47011 Valladolid, Spain.

E-mail:fervilla@qi.uva.es

$\dagger$ Electronic supplementary information (ESI) available: Synthesis and characterization of the complexes, NBO charges and Wiberg indices for 1a, photophysical data, figure of the crystal structure of $\mathbf{2 a}$, frontier molecular orbital compositions in the ground and excited states, and calculated excited energies and dominant orbital excitations from TD-DFT for 1a and 2a. CCDC 1415524 and 1415525. For ESI and crystallographic data in CIF or other electronic format see DOI: 10.1039/ c5dt03221k ligand on complexes $f a c-\left[\operatorname{Re}(\mathrm{CO})_{3}(\mathrm{~N}-\mathrm{N}-\mathrm{N})\right](\mathrm{N}-\mathrm{N}-\mathrm{N}=$ tripodal nitrogen-donor ligand). ${ }^{8}$

Herein we present a new method to incorporate biomolecules, in this case a nucleobase, into the rhenium(I) tricarbonyl moiety: instead of attaching a biomolecule to a chelating diimine previously coordinated, a new chelating ligand is formed by the reaction of the nucleobase with a coordinated nitrile. This process may be carried out thermally or is microwave assisted.

This reaction is based on the activation of coordinated nitriles by the metal centre, which results in an enhancement of the electrophilicity of the carbon atom, and facilitates the addition of different nucleophiles. ${ }^{9}$ For instance, the addition of amines bearing a proton leads to amidines, of particular interest due to their organic, medicinal, or coordination chemistries. ${ }^{9 c}$ When the amine belongs to a heterocycle containing a donor atom in the appropriate position, the involvement of their electron pair in aromatization makes the resulting chelating amidino ligand significantly interesting. Our previous studies on pyrazole complexes ${ }^{10}$ led us to conclude that the formation of pyrazolylamidino complexes is base-catalysed, ${ }^{10 e}$ and to study their photochemistry ${ }^{10 f}$ or their properties as anion receptors. ${ }^{10 b}$ We envisaged a logical continuation of this previous work by attempting to make a new amidino complex from the reaction of a nucleobase and a rhenium( $\mathrm{I}$ ) tricarbonyl nitrile precursor, since this reaction has not been previously reported for this metallic moiety, as indicated above. In fact, the field of metal ion-induced modifications to nucleobases is practically unexplored, although the coordination of nucleobases to metals has been profusely reported. ${ }^{4}$ The only precedent of metal-mediated transformation coupling reactions with nitriles and nucleobases is the amidino complex $\left[\operatorname{ReCl}_{4}\left\{\mathrm{NH}=\mathrm{C}(\mathrm{Me})\left(\mathrm{Me}_{2} \mathrm{AdH}-\kappa^{2} N, N\right\}\right]\right.$, obtained after the reaction of $N^{6}, N^{6}$-dimethyladenine $\left(\mathrm{Me}_{2} \mathrm{AdH}\right)$ with cis$\left[\operatorname{ReCl}_{4}(\mathrm{NCMe})_{2}\right] .^{11}$ The rest of the processes of this type previously reported included the deprotonation of the nucleobase, affording an anionic chelating amidino ligand in the complexes cis- $\left[\mathrm{L}_{2} \mathrm{Pt}\left\{\mathrm{NH}=\mathrm{CR}\left(\mathrm{MeAd}-\kappa^{2} N, N\right\}\right]^{+}(\mathrm{MeAdH}=\right.$ 9-methyl- 
adenine $)$ or cis- $\left[\mathrm{L}_{2} \mathrm{Pt}\left\{\mathrm{NH}=\mathrm{CR}\left(\mathrm{MeCy}-\kappa^{2} N, N\right\}\right]^{+}\left(\mathrm{L}=\mathrm{PMePh}_{2}\right.\right.$, $\mathrm{PPh}_{3} ; \mathrm{R}=\mathrm{Me}, \mathrm{Ph} ; \mathrm{MeCyH}_{2}=1$-methylcytosine) ${ }^{12}$

The reactions of $f a c-\left[\operatorname{ReBr}(\mathrm{CO})_{3}(\mathrm{NCMe})_{2}\right]^{13}$ with equimolar amounts of $\mathrm{MeCyH}_{2}$ in refluxing $\mathrm{NCR}(\mathrm{R}=\mathrm{Me}, \mathrm{Ph})$ led cleanly to $f a c-\left[\operatorname{ReBr}(\mathrm{CO})_{3}\left\{\mathrm{NH}=\mathrm{C}(\mathrm{R})\left(\mathrm{MeCyH}-\kappa^{2} N, N\right\}\right](\mathrm{R}=\mathrm{Me}, \mathbf{1 a} ; \mathrm{R}=\right.$ $\mathrm{Ph}, \mathbf{1 b}$ ) as yellow microcrystalline solids (Scheme 1). The formation of the amidino chelating ligand by the coupling of 1-methylcytosine and one molecule of acetonitrile is evident in the X-ray crystal structure of 1a, shown in Fig. 1 together with selected distances and angles. Tables with details of the structure determination, and the rest of the spectroscopic data for both complexes in accordance with the geometry deduced by $\mathrm{X}$-ray diffraction can be found in the ESI. $\rightarrow$

As indicated above, there are no previous reports of crystal structures containing amidino ligands derived from the coupling of nitriles and $\mathrm{MeCyH}_{2}$. The chelate six-membered ring

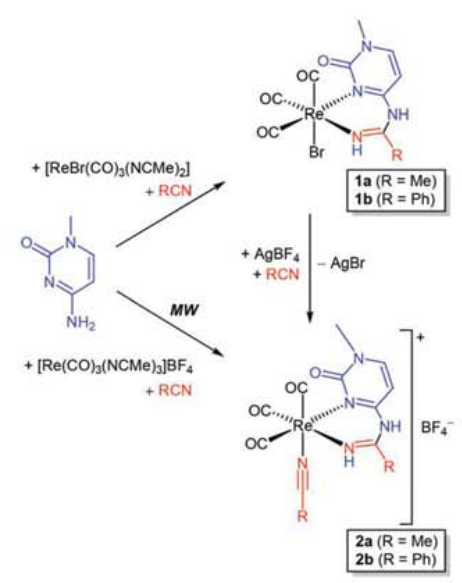

Scheme 1 Syntheses of the amidino complexes from the coupling of $\mathrm{MeCyH}_{2}$ and NCR.

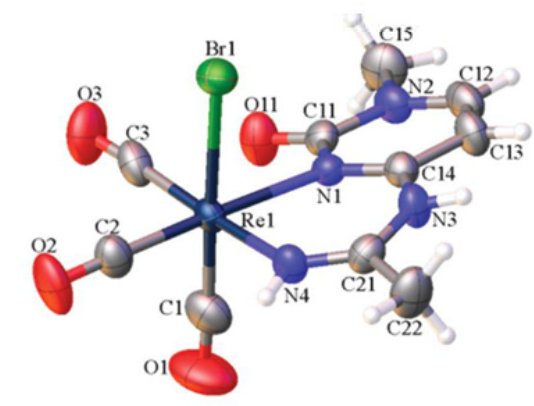

Fig. 1 Perspective view of fac- $\left[\operatorname{ReBr}(\mathrm{CO}){ }_{3}\left\{\mathrm{NH}=\mathrm{C}(\mathrm{Me})\left(\mathrm{MeCyH}-\kappa^{2} N, N\right\}\right]\right.$, $1 \mathrm{a}$, showing the atom numbering. Ellipsoids are drawn at $50 \%$ probability. Selected bond lengths $(\hat{A})$ and angles $\left({ }^{\circ}\right)$ : Re1-N1 2.242(3), N1C14 1.331(5), N3-C14 1.356(5), N3-C21 1.370(5), N4-C21 1.271(5), Re1N4 2.132(3), N1-C11 1.409(5), N2-C11 1.400(4), N2-C12 1.346(5), C12C13 1.322(6), C14-C13 1.417(5); C14-N1-Re1 125.5(2), N1-C14-N3 122.8(3), C14-N3-C21 133.3(3), N4-C21-N3 121.3(4), C21-N4-Re1 132.2(3), N4-Re1-N1 83.28(11). containing the rhenium atom is almost planar, with a very slight distortion towards a boat conformation, where Re1 and $\mathrm{N} 3$ are $0.245(6)$ and $0.065(6) \AA$ above the mean plane formed by N1, C14, C21 and N4. The latter mean plane forms an angle of $6.36(15)^{\circ}$ with the cytosine ring, resulting in a twisted nucleobase ligand. Moreover, the mean plane of the whole nucleobase forms an angle of $12.79(12)^{\circ}$ with the coordination plane defined by the $\mathrm{C} 2, \mathrm{C} 3, \mathrm{~N} 1$, and $\mathrm{N} 4$ atoms. All these distortions seem to be intended to move away the carbonyl group in the methylcytosine fragment from the carbonyl ligand in cis to the nitrogen donor atom of the nucleobase fragment. In fact, the O11-O3 and O11-C3 distances (2.948(4) and 2.591(6) $\AA)$ are well below the sum of the respective van der Waals radii, 3.04 and $3.22 \AA$, respectively. Obviously, the high steric crowding on this side of the molecule brings these two carbonyls apart from each other, and any chemical interaction between them should be discarded. The Re-N distances (2.242(3) and 2.132(3) ̊) are similar to those previously found in pyrazolylamidino complexes, ${ }^{10}$ whereas two different $\mathrm{C}-\mathrm{N}$ distances are found in the chelate six membered ring: those where $\mathrm{C}=\mathrm{N}$ bonds may be proposed (N1-C14 1.331(5) and N4-C21 1.271(5) $\AA)$ are in the expected range for double $\mathrm{C}\left(\mathrm{sp}^{2}\right)=\mathrm{N}\left(\mathrm{sp}^{2}\right)$ bonds, ${ }^{14}$ but the other CN distances (N3-C14 1.356(5) and N3C21 1.370(5) $\AA$ ) are shorter than those expected for a single $\mathrm{C}\left(\mathrm{sp}^{2}\right)-\mathrm{N}\left(\mathrm{sp}^{2}\right)$ bond. ${ }^{14}$ The tricoordinate $\mathrm{N} 3$ atom should be labelled as $\mathrm{sp}^{2}$ since it is planar, which implies that its electron pair should be delocalized. In order to support this, an NBO study was performed on the minimum geometry to calculate the Wiberg indices of the bonds in the coordinated chelating ligand. The results, collected in Fig. $\mathrm{S} 1, \dagger$ support that the bond distances found in the crystal structure have an electronic origin and they are not due to packing effects. Therefore, the best description for this ligand is that depicted in Scheme 1, although resonance forms where the $\mathrm{C}-\mathrm{N} 3$ bonds have a double character also contribute to the resonance hybrid, as expected for the planar geometry of N3. Concerning this point, it should be pointed out that determining the energy of the possible tautomers is essential in biological processes, since those energetically less stable may be active intermediates for many transformations, which affects the mechanism of the processes where the biomolecule is involved. ${ }^{15}$ In fact, both the monodeprotonated cytosine anion and the involvement of cytosine in hydrogen bonds or in coordination with metals have been theoretically evaluated. ${ }^{16}$

The N-bound hydrogen atom of the amidino ligand is involved in a hydrogen bond with the oxygen atom of a $\mathrm{Me}_{2} \mathrm{CO}$ molecule present in the crystal. The distances and angles

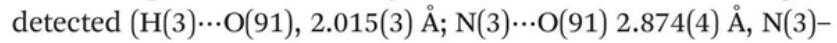
$\left.\mathrm{H}(3) \cdots \mathrm{O}(91) 176.6(3)^{\circ}\right)$ led us to consider this hydrogen bond as "moderate". ${ }^{17}$

The new chelating ligands are robust enough so they remain unchanged when the complexes undergo further reactivity. Thus, the reactions of complexes 1 with $\mathrm{AgBF}_{4}$ in NCR afford the cationic complexes $f a c-\left[\operatorname{Re}(\mathrm{CO})_{3}(\mathrm{NCR})\{\mathrm{NH}=\mathrm{C}(\mathrm{R})\right.$ $\left.\left(\mathrm{MeCyH}-\kappa^{2} N, N\right\}\right] \mathrm{BF}_{4}(\mathrm{R}=\mathrm{Me}, \mathbf{2 a} ; \mathrm{R}=\mathrm{Ph}, \mathbf{2 b})$ after substituting the bromido ligand by NCR (Scheme 1). The crystallographic 
data for 2a may be found in the ESI, $\dagger$ as well as its spectroscopic data. The distances and angles found in the crystal structure of $\mathbf{2 a}$ are very similar to those found for the structure of $1 \mathrm{a}$, discussed above.

These cationic complexes can also be obtained in a one-pot process from $f a c-\left[\operatorname{Re}(\mathrm{CO})_{3}(\mathrm{NCMe})_{3}\right] \mathrm{BF}_{4},{ }^{18}$ 1-methylcytosine, and the nitrile by a microwave assisted reaction, in $10 \mathrm{~min}$ at $180^{\circ} \mathrm{C}$. The yields are slightly lower than those obtained when the reaction is carried out by traditional methods $(76 \% v s$. $92 \%$ for $2 \mathrm{a}, 60 \%$ vs. $83 \%$ for $2 \mathrm{~b}$ ). However, they are clearly higher than those once the yields of the necessary previous steps of 1a and 1 b are considered (global yields 53\% and $46 \%$ respectively, considering that the yields of both parent complexes $f a c-\left[\operatorname{ReBr}(\mathrm{CO})_{3}(\mathrm{NCMe})_{2}\right]$ and $\mathrm{fac}$ - $\left[\mathrm{Re}(\mathrm{CO})_{3}(\mathrm{NCMe})_{3}\right] \mathrm{BF}_{4}$ from $f a c-\left[\operatorname{ReBr}(\mathrm{CO})_{5}\right]$ are higher than $90 \%$ and are therefore almost quantitative). Therefore the microwave assisted reaction is a better synthetic method considering the whole atom economy, since the microwave assisted processes start from fac- $\left[\mathrm{Re}(\mathrm{CO})_{3}(\mathrm{NCMe})_{3}\right] \mathrm{BF}_{4}$. We are not aware of previous reports on the use of microwave to form amidines from nitriles and amines. However, the use of microwaves is not a suitable method to obtain the neutral bromido complexes $\mathbf{1}$, as the yields in this case are much lower than those obtained by refluxing the nitriles.

As indicated above, the interest in these complexes relies on the incorporation of the nucleobase into a luminescent complex. It is well known that $\operatorname{Re}(\mathrm{CO})_{3}$ complexes with chelate $\mathrm{N}$-donor ligands are likely to be phosphorescent. ${ }^{19}$ In this way, we have recently described some similar complexes with pyrazolylamidino ligands, and discussed what changes occur in the emission features when structural modifications are made. ${ }^{10 f}$ Nonetheless, we have measured some photophysical properties of compounds $\mathbf{1 a}$ and $\mathbf{2 a}$, in order to check the luminescent behaviour of these nucleobase complexes. Their absorption spectra (see Fig. S2 and Table S1 in the ESI $\dagger$ ) are very similar to those of pyrazolylamidino $\operatorname{Re}(\mathrm{CO})_{3}$ complexes. ${ }^{10 f}$ Thus, the intense bands observed in the UV region at high energy (250-320 $\mathrm{nm}$ ) have an intraligand (IL) origin, while the lowest energy absorption bands are assigned to a mixture of MLCT Re $\rightarrow \pi^{*}(\mathrm{~L})$, ligand-to-ligand charge-transfer (LLCT), and halide-to-ligand charge-transfer (XLCT) transitions. As expected, the substitution of the anionic $\sigma$-donor $/ \pi$-donor bromido ligand by a neutral $\sigma$-donor acetonitrile ligand led to a hypsochromic shift, in this case of $c a .60 \mathrm{~nm}$ in the low energy absorptions. Emission spectra showed bands in the range $500-580 \mathrm{~nm}$, with quantum yields from 0.009 to $0.013 \%$, values that are in accordance with those found for the pyrazolylamidino complexes.

In order to support the assignment of the low-lying absorption transitions as MLCT, theoretical calculations at the same level of theory as for the pyrazolylamidino complexes discussed above have been carried out for complexes 1a and 2a. These calculations showed that the highest occupied molecular orbitals (HOMOs) have a mixed $\mathrm{Re} / \mathrm{CO} / \mathrm{Br}$ character with different contributions in the case of the neutral complex 1a, while the HOMOs of the cationic complex $2 \mathrm{a}$ have a $\mathrm{Re} / \mathrm{CO}$ character. In both cases the LUMO is mainly centred in the nucleobase ligand, confirming the metal to ligand charge transfer nature of the optical transitions (full details can be found in the ESI + ).

In summary, new luminescent rhenium( $\mathrm{t}$ ) tricarbonyl complexes containing amidino chelating ligands are obtained by the coupling of nitriles and 1-methylcytosine. The formation of new amidino chelating ligands in this system by extending this reaction to couple different nitriles and new nucleobases (besides cytosine, adenine and guanine contain donor atoms in the appropriate position to form new amidino ligands) is to be expected. Neutral and cationic complexes have been synthesized, and the latter may also be obtained in a microwave reactor, which opens the door to the coordination of a wide range of substrates to the system.

The authors wish to acknowledge Dr A. Kathyr (Université de Franche-Comté, France) for photophysical measurements and the Spanish Ministerio de Ciencia e Innovación (CTQ2013-41067-P) for financial support, and P. G.-I. thanks the UVa for her grant.

\section{References}

1 K. K.-W. Lo, K. Y. Zhang and S. P.-Y. Li, Eur. J. Inorg. Chem., 2011, 3551-3568.

2 D.-L. Ma, H.-Z. He, K.-H. Leung, D. S.-H. Chan and C.-H. Leung, Angew. Chem., Int. Ed., 2013, 52, 7666-7682.

3 (a) S. Clède, F. Lambert, C. Sandt, Z. Gueroui, M. Refregiers, M.-A. Plamont, P. Dumas, A. Vessieres and C. Policar, Chem. Commun., 2012, 48, 7729-7731; (b) S. Clède, N. Delsuc, C. Laugel, F. Lambert, C. Sandt, A. Baillet-Guffroy and C. Policar, Chem. Commun., 2015, 51, 2687-2689.

4 (a) T. A. Oriskovich, P. S. White and H. H. Thorp, Inorg. Chem., 1995, 34, 1629-1631. Some leading reviews: (b) P. Amo-Ochoa and F. Zamora, Coord. Chem. Rev., 2014, 276, 34-58; (c) P. J. Bailey and S. Pace, Coord. Chem. Rev., 2001, 214, 91-141; (d) B. Lippert, Coord. Chem. Rev., 2000, 200, 487-516; (e) E. Zangrando, F. Pichierri, L. Randaccio and B. Lippert, Coord. Chem. Rev., 1996, 156, 275-332.

5 S. Clède and C. Policar, Chem. - Eur. J., 2015, 21, 942-958. See references therein for more examples of the methods indicated in the text for grafting biomolecules to the ligands in rhenium(I) tricarbonyl complexes.

6 Some leading references: (a) M.-W. Louie, M. H.-C. Lam and K. K.-W. Lo, Eur. J. Inorg. Chem., 2009, 4265-4273; (b) M. Wolff, L. Muñoz, A. Francois, C. Carrayon, A. Seridi, N. Saffon, C. Picard, B. Machura and E. Benoist, Dalton Trans., 2013, 42, 7019-7031; (c) H. C. Bertrand, S. Clède, R. Guillot, F. Lambert and C. Policar, Inorg. Chem., 2014, 53, 6204-6223.

7 Some leading references: (a) A. J. Amoroso, M. P. Coogan, J. E. Dunne, V. Fernández-Moreira, J. B. Hess, A. J. Hayes, D. Lloyd, C. Millet, S. J. A. Pope and C. Williams, Chem. Commun., 2007, 3066-3068; (b) K. K.-W. Lo, M.-W. Louie, 
K.-S. Sze and J. S.-Y. Lau, Inorg. Chem., 2008, 47, 602-611; (c) M.-W. Louie, H.-W. Liu, M. H.-C. Lam, Y.-W. Lam and K. K.-W. Lo, Chem. - Eur. J., 2011, 17, 8304-8308.

8 Some leading references: (a) K. A. Stephenson, S. R. Banerjee, T. Besanger, O. O. Sogbein, M. K. Levadala, N. McFarlane, J. A. Lemon, D. R. Boreham, K. P. Maresca, J. D. Brennan, J. W. Babich, J. Zubieta and J. F. Valliant, J. Am. Chem. Soc., 2004, 126, 8598-8599; (b) M. D. Bartholomé, A. R. Vortherms, S. Hillier, J. Joyal, J. Babich, R. P. Doyle and J. Zubieta, Dalton Trans., 2011, 40, 6216-6225.

9 (a) V. Y. Kukushkin and A. J. L. Pombeiro, Inorg. Chim. Acta, 2005, 358, 1-21; (b) A. J. L. Pombeiro and V. Y. Kukushkin, in Comprehensive Coordination Chemistry, ed. A. B. P. Lever, Elsevier, London, 2nd edn, 2004, vol 1, pp. 639-660; (c) V. Y. Kukushkin and A. J. L. Pombeiro, Chem. Rev., 2002, 102, 1771-1802; (d) R. A. Michelin, M. Mozzon and R. Bertani, Coord. Chem. Rev., 1996, 147, 299-338.

10 (a) M. Arroyo, A. López-Sanvicente, D. Miguel and F. Villafañe, Eur. J. Inorg. Chem., 2005, 4430-4437; (b) M. Arroyo, D. Miguel, F. Villafañe, S. Nieto, J. Pérez and L. Riera, Inorg. Chem., 2006, 45, 7018-7026; (c) N. Antón, M. Arroyo, P. Gómez-Iglesias, D. Miguel and F. Villafañe, J. Organomet. Chem., 2008, 693, 3074-3080; (d) M. Arroyo, P. Gómez-Iglesias, J. M. Martín-Alvarez, C. M. Alvarez, D. Miguel and F. Villafañe, Inorg. Chem., 2012, 51, 60706080; (e) P. Gómez-Iglesias, M. Arroyo, S. Bajo, C. Strohmann, D. Miguel and F. Villafañe, Inorg. Chem., 2014, 53, 12437-12448; (f) P. Gómez-Iglesias, F. Guyon, A. Khatyr, G. Ulrich, M. Knorr, J. M. Martín-Alvarez,
D. Miguel and F. Villafañe, Dalton Trans., 2015, DOI: 10.1039/C5DT02793D.

11 C. Pearson and A. L. Beauchamp, Inorg. Chem., 1998, 37, 1242-1248.

12 (a) B. Longato, D. Montagner, G. Bandoli and E. Zangrando, Inorg. Chem., 2006, 45, 1805-1814; (b) D. Montagner, A. Venzo, E. Zangrando and B. Longato, Inorg. Chem., 2010, 49, 2103-2110.

13 M. F. Farona and K. F. Kraus, Inorg. Chem., 1970, 9, 17001704.

14 F. H. Allen, O. Kennard, D. G. Watson, L. Brammer, A. G. Orpen and R. Taylor, J. Chem. Soc., Perkin Trans. 2, 1987, S1-S19.

15 E. D. Raczyńska, W. Kosińska, B. Osḿiałowski and R. Gawinecki, Chem. Rev., 2005, 105, 3561-3612.

16 (a) M. A. Esteruelas, J. García-Raboso and M. Oliván, Inorg. Chem., 2012, 51, 9522-9528; (b) C. F. Guerra, P. J. S. Miguel, A. Cebollada, F. M. Bickelhaupt and B. Lippert, Chem. Eur. J., 2014, 20, 9494-9499.

17 (a) G. A. Jeffrey, An Introduction to Hydrogen Bonding, Oxford University Press, New York, 1997, Ch. 2; (b) T. Steiner, Angew. Chem., Int. Ed., 2002, 41, 48-76.

18 V. I. Zdanovitch, N. E. Kolobova, N. I. Vasyukova, Yu. S. Nekrasov, G. A. Panosyan, P. V. Petrovskii and A. Zh. Zhakaeva, J. Organomet. Chem., 1978, 148, 63-71.

19 (a) A. J. Lees, Chem. Rev., 1987, 87, 711-743; (b) K. Kalyanasundaram, J. Chem. Soc., Faraday Trans. 2, 1986, 82, 2401-2415; (c) W.-K. Chu, C.-C. Ko, K.-C. Chan, S.-M. Yiu, F.-L. Wong, C.-S. Lee and V. A. L. Roy, Chem. Mater., 2014, 26, 2544-2550. 


\section{Electronic Supplementary Information}

Amidino ligands from coupling 1-methylcytosine and nitrile: a new method to incorporate biomolecules to luminescent $\operatorname{Re}(\mathrm{CO}) 3$ complexes

Patricia Gómez-Iglesias, Jose Miguel Martín-Alvarez, Daniel Miguel, and Fernando Villafañe ${ }^{*}$ GIR MIOMeT-IU Cinquima-Química Inorgánica, Facultad de Ciencias, Campus Miguel Delibes, Universidad de Valladolid, 47011 Valladolid, Spain. 


\section{Synthesis and characterization of the complexes}

General Remarks. All manipulations were performed under $\mathrm{N}_{2}$ atmosphere following conventional Schlenk techniques. Solvents were purified according to standard laboratory methods. ${ }^{1}$ fac$\left[\operatorname{ReBr}(\mathrm{CO})_{3}(\mathrm{NCMe})_{2}\right],{ }^{2}$ fac- $\left[\operatorname{Re}(\mathrm{CO})_{3}(\mathrm{NCMe})_{3}\right] \mathrm{BF}_{4},{ }^{3}$ and $1-$ methylcytosine ${ }^{4}$ were obtained as previously described. The microwave assisted reactions were carried out in an Anton Paar Monowave 300 apparatus. Infrared spectra were recorded in a Perkin-Elmer FT-IR spectrum BX apparatus using $0.2 \mathrm{~mm} \mathrm{CaF}_{2}$ cells for solutions or in a Perkin-Elmer Frontier spectrometer coupled to a Pike GladiATR-210 accessory for solid samples. NMR spectra were recorded in Varian MR500 instrument at room temperature (r.t.), and are referred to the internal residual solvent peak for ${ }^{1} \mathrm{H}$ and ${ }^{13} \mathrm{C}\left\{{ }^{1} \mathrm{H}\right\}$ NMR. Assignment of the ${ }^{13} \mathrm{C}\left\{{ }^{1} \mathrm{H}\right\}$ NMR data was supported by $2 \mathrm{D}$ HSQC and HMBC experiments and relative intensities of the resonance signals. UV-vis spectra were measured with a VARIAN-Cary 100 or Shimadzu UV-2550 spectrophotometers and emission spectra were recorded on a Jobin-Yvon FluoroLog 3.2.2 or in a Perkin-Elmer LS-55 luminescence spectrometer at room temperature. The luminescence quantum yields $\emptyset$ of the complexes were determined using cresyl violet as a luminescence quantum yield standard. ${ }^{5}$ All measurements were performed in deaerated solvents. Elemental analyses were performed on a Perkin-Elmer 2400B microanalyzer.

fac $-\left[\operatorname{ReBr}(\mathrm{CO})_{3}\left\{\mathbf{N H}=\mathbf{C}(\mathrm{Me})\left(\mathbf{M e C y H}-\boldsymbol{\kappa}^{2} \boldsymbol{N}, \boldsymbol{N}\right)\right\}\right]$, 1a. A solution of $f a c-\left[\operatorname{ReBr}(\mathrm{CO})_{3}(\mathrm{NCMe})_{2}\right]$ $(0.216 \mathrm{~g}, 0.5 \mathrm{mmol})$ and 1-methylcytosine $\left(\mathrm{MeCyH}_{2}, 0.063 \mathrm{~g}, 0.5 \mathrm{mmol}\right)$ in $\mathrm{NCMe}(20 \mathrm{~mL})$ was stirred for $5 \mathrm{~h}$ at reflux. The volatiles were removed in vacuo and the yellow residue was crystallized in acetone/hexane at $-20^{\circ} \mathrm{C}$, giving a yellow microcrystalline solid, which was decanted, washed with hexane ( $3 \times 3 \mathrm{~mL}$ approximately), and dried in vacuo, yielding $0.149 \mathrm{~g}$ (58 \%). IR (THF, cm ${ }^{-1}$ ): 2018 vs, 1912 vs, 1881 vs. IR (neat solid, $\mathrm{cm}^{-1}$ ): $3462 \mathrm{~m}, 3225 \mathrm{~m}, 2027$ vs, 1925 vs, 1902 vs, 1670 m, 1597 m, 1524 w, 1467 m, 1421 m, 1339 m, 1317 m, 1213 m, 1182 w, 1115 w, 1043 w, 806 w, 780 w, 650 w, 632 w, 552 w, 523 w. ${ }^{1} \mathrm{H}$ NMR (499.7 MHz, $\mathrm{CD}_{3} \mathrm{NO}_{2}$ ): 2.41 
(s, $\left.\mathrm{NH}=\mathrm{CCH}_{3}, 3 \mathrm{H}\right), 3.56\left(\mathrm{~s}, \mathrm{CH}_{3} \mathrm{MeCy}, 3 \mathrm{H}\right), 6.21\left(\mathrm{~d}, J=7.0 \mathrm{~Hz}, \mathrm{C}^{5} \mathrm{H} \mathrm{MeCy}, 1 \mathrm{H}\right), 7.86(\mathrm{~d}, J=$ $\left.7.0 \mathrm{~Hz}, \mathrm{C}^{6} \mathrm{HMeCy}, 1 \mathrm{H}\right), 8.73(\mathrm{~s}, \mathrm{~N} H \mathrm{MeCy}, 1 \mathrm{H}), 9.89\left(\mathrm{~s}, \mathrm{~N} H=\mathrm{CCH}_{3}, 1 \mathrm{H}\right) .{ }^{13} \mathrm{C}\left\{{ }^{1} \mathrm{H}\right\} \mathrm{NMR}(125.7$ $\mathrm{MHz}, \mathrm{CD}_{3} \mathrm{NO}_{2}$ ): 24.3 (s, $\left.\mathrm{NH}=\mathrm{CCH}_{3}\right), 40.5$ (s, $\mathrm{NCH}_{3}$ ), 97.1 (s, $\left.C^{6} \mathrm{H} \mathrm{MeCy}\right), 150.9$ (s, $\left.C^{6} \mathrm{H} \mathrm{MeCy}\right)$, 155.7 (s, $\mathrm{CO} \mathrm{MeCy}), 161.6$ (s, NH=CCH3), 162.1 (s, $\left.C^{4} \mathrm{MeCy}\right), 197.1$ (s, $\left.\operatorname{ReCO}\right), 198.0(\mathrm{~s}, \operatorname{Re} C O)$, 198.5 (s, $\mathrm{Re} C \mathrm{C}$ ). Anal. Calcd. for $\mathrm{C}_{10} \mathrm{H}_{10} \mathrm{BrN}_{4} \mathrm{O}_{4} \mathrm{Re}: \mathrm{C}, 23.26 ; \mathrm{H}, 1.95 ; \mathrm{N}, 10.85$. Found: $\mathrm{C}, 22.99$; H, $2.01 ; \mathrm{N}, 10.69$.

fac $-\left[\operatorname{ReBr}(\mathrm{CO})_{3}\left\{\mathrm{NH}=\mathbf{C}(\mathbf{P h})\left(\mathbf{M e C y H}-\boldsymbol{\kappa}^{2} \boldsymbol{N}, \boldsymbol{N}\right)\right\}\right], \mathbf{1 b}$. The same procedure as for $\mathbf{1 a}$, using $\mathrm{NCPh}(7$ $\mathrm{mL}$ ) as solvent, gave $0.158 \mathrm{~g}(55 \%)$ of $\mathbf{1 b}$ as a yellow microcrystalline solid. IR (THF, $\mathrm{cm}^{-1}$ ): 2018 vs, 1913 vs, 1884 vs. IR (neat solid, cm ${ }^{-1}$ ): 3194 w, 2918 m, 2849 m, 2015 vs, 1918 s, 1894 vs, 1867 vs, 1680 m, 1575 m, 1509 m, 1455 m, 1442 m, 1415 m, 1332 m, 1303 w, 1254 m, 1174 w, 1127 w, 1041 m, 1024 w, 874 w, 797 w, 776 w, 697 m, 650 w, 624 w, 607 w, 556 w, 523 m, 481 w, 399 w, 360 w, 303 w. ${ }^{1} \mathrm{H}$ NMR (499.7 MHz, $\mathrm{CD}_{3} \mathrm{NO}_{2}$ ): 3.61 (s, $\left.\mathrm{CH}_{3} \mathrm{MeCy}, 3 \mathrm{H}\right), 6.34$ (d, J= 7.0 $\left.\mathrm{Hz}, \mathrm{C}^{5} \mathrm{HMeCy}, 1 \mathrm{H}\right), 7.6\left(\mathrm{t}, J=7.5 \mathrm{~Hz}\right.$, meta- $\left.\mathrm{C}_{6} \mathrm{H}_{5}, 2 \mathrm{H}\right), 7.69$ (tt, $J=7.5$ and $1.5 \mathrm{~Hz}$, para- $\mathrm{C}_{6} \mathrm{H}_{5}, 1$ H), $7.77\left(\mathrm{~d}, J=7.5 \mathrm{~Hz}\right.$, ortho- $\left.\mathrm{C}_{6} \mathrm{H}_{5}, 2 \mathrm{H}\right), 7.95\left(\mathrm{~d}, J=7.0 \mathrm{~Hz}, \mathrm{C}^{6} H \mathrm{MeCy}, 1 \mathrm{H}\right), 8.89$ (s, NHMeCy, $1 \mathrm{H}), 9.12\left(\mathrm{~s}, \mathrm{~N} H=\mathrm{CCH}_{3}, 1 \mathrm{H}\right) .{ }^{13} \mathrm{C}\left\{{ }^{1} \mathrm{H}\right\} \mathrm{NMR}\left(125.7 \mathrm{MHz}, \mathrm{CD}_{3} \mathrm{NO}_{2}\right): 40.5(\mathrm{~s}, \mathrm{NCH}), 97.5\left(\mathrm{~s}, C^{6} \mathrm{H}\right.$ MeCy), $128.2\left(\mathrm{~s}\right.$, ortho- $\left.\mathrm{C}_{6} \mathrm{H}_{5}\right), 130.7$ (s, meta- $\left.\mathrm{C}_{6} \mathrm{H}_{5}\right), 134.1\left(\mathrm{~s}\right.$, para- $\left.\mathrm{C}_{6} \mathrm{H}_{5}\right), 134.3$ (s, ipso- $\left.\mathrm{C}_{6} \mathrm{H}_{5}\right)$, $151.1\left(\mathrm{~s}, C^{6} \mathrm{H} \mathrm{MeCy}\right), 155.8$ (s, $\left.C \mathrm{O} \mathrm{MeCy}\right), 161.8\left(\mathrm{~s}, \mathrm{~N}=C \mathrm{Ph}_{3}\right), 162.8\left(\mathrm{~s}, C^{4} \mathrm{MeCy}\right), 197.2(\mathrm{~s}$, $\mathrm{Re} C \mathrm{O}$ ), 197.7 (s, $\mathrm{Re} C \mathrm{CO}$ ), 198.4 (s, $\mathrm{Re} C \mathrm{C}$ ). Anal. Calcd. for $\mathrm{C}_{15} \mathrm{H}_{12} \mathrm{BrN}_{4} \mathrm{O}_{4} \mathrm{Re}: \mathrm{C}, 31.14 ; \mathrm{H}, 2.09 ; \mathrm{N}$, 9.69. Found: $30.93 ; \mathrm{H}, 2.28 ; \mathrm{N}, 9.89$.

fac $\left.-[\operatorname{Re}(\mathrm{CO}))_{3}(\mathrm{NCMe})\left\{\mathrm{NH}=\mathrm{C}(\mathrm{Me})\left(\mathrm{MeCyH}_{\mathbf{k}} \boldsymbol{K}^{2} \boldsymbol{N}, \boldsymbol{N}\right)\right\}\right] \mathrm{BF}_{4}, 2 \mathrm{2a}$. Method $A$. A mixture of $\mathbf{1 a}(0.103$ g, $0.2 \mathrm{mmol})$ and $\mathrm{AgBF}_{4}(0.045 \mathrm{~g}, 0.23 \mathrm{mmol})$ in $\mathrm{NCMe}(20 \mathrm{~mL})$ was stirred at $30^{\circ} \mathrm{C}$ for $30 \mathrm{~min}$ with exclusion of light. Then the reaction mixture was filtered, the volatiles were dried in vacuo, and the yellow residue was crystallized in $\mathrm{THF} / \mathrm{Et}_{2} \mathrm{O}$ giving a pale yellow microcrystalline solid, which was decanted, washed with diethyl ether ( $3 \times 3 \mathrm{~mL}$ approximately), and dried in vacuo, 
yielding $0.103 \mathrm{~g}(92 \%)$. Method B. fac- $\left[\operatorname{Re}(\mathrm{CO})_{3}\left(\mathrm{NCMe}_{3}\right] \mathrm{BF}_{4}(0.048 \mathrm{~g}, 0.10 \mathrm{mmol})\right.$, 1-methylcytosine $(0.012 \mathrm{~g}, 0.10 \mathrm{mmol})$, and $\mathrm{NCMe}(2 \mathrm{~mL})$ were placed in a dry $10 \mathrm{~mL}$ glass vessel equipped with a magnetic stirbar. The vessel was sealed with a septum and placed in the microwave apparatus, and heated at $180^{\circ} \mathrm{C}$ during $10 \mathrm{~min}$. The reaction mixture was then cooled to $50^{\circ} \mathrm{C}$, and the contents were transferred into a schlenk flask, and the volatiles were removed in vacuo. Crystallization from THF/Et $2 \mathrm{O}$ yielded $0.044 \mathrm{~g}(76 \%)$ of $\mathbf{2 a}$. IR $\left(\mathrm{THF}, \mathrm{cm}^{-1}\right): 2031 \mathrm{vs,} 1932 \mathrm{vs,}$ 1912 vs. IR (neat solid, cm ${ }^{-1}$ ): 3274 m, 2961 w, 2028 vs, 1949 w, 1899 vs, 1697 m, 1673 m, 1582 m, 1525 w, 1464 w, 1418 w, 1346 w, 1313 m, 1260 w, 1188 w, 1078 vs, 1053 vs, 1004 vs, 878 w, 781 m, 709 w, 649 w, 626 m, 553 w, 536 w, 477 w, 399 w, 375 w. ${ }^{1} \mathrm{H}$ NMR $(499.7 \mathrm{MHz}$, $\left.\mathrm{CD}_{3} \mathrm{NO}_{2}\right): 2.35\left(\mathrm{~s}, \mathrm{NCCH}_{3}, 3 \mathrm{H}\right), 2.46\left(\mathrm{~s}, \mathrm{NH}=\mathrm{CCH}_{3}, 3 \mathrm{H}\right), 3.59\left(\mathrm{~s}, \mathrm{CH}_{3} \mathrm{MeCy}, 3 \mathrm{H}\right), 6.28(\mathrm{~d}, J=$ $\left.7.0 \mathrm{~Hz}, \mathrm{C}^{5} \mathrm{HMeCy}, 1 \mathrm{H}\right), 7.95$ (d, J=7.0 Hz, C ${ }^{6} \mathrm{MeCy}, 1 \mathrm{H}$ ), 8.73 (s, NHMeCy, $1 \mathrm{H}$ ), 9.02 (s, $\left.\mathrm{N} H=\mathrm{CCH}_{3}, 1 \mathrm{H}\right) .{ }^{19} \mathrm{~F}$ NMR $\left(470.2 \mathrm{MHz}, \mathrm{CD}_{3} \mathrm{NO}_{2}\right):-152.87\left(\mathrm{~s},{ }^{10} \mathrm{BF}_{4}, 4 \mathrm{~F}\right),-152.92\left(\mathrm{~s},{ }^{11} \mathrm{BF}_{4}, 4 \mathrm{~F}\right)$. ${ }^{13} \mathrm{C}\left\{{ }^{1} \mathrm{H}\right\} \mathrm{NMR}\left(125.7 \mathrm{MHz}, \mathrm{CD}_{3} \mathrm{NO}_{2}\right): 3.0\left(\mathrm{~s}, \mathrm{NCCH}_{3}\right), 24.1\left(\mathrm{~s}, \mathrm{NH}=\mathrm{CCH}_{3}\right), 40.5\left(\mathrm{~s}, \mathrm{NCH}_{3}\right), 97.1$ (s, $\left.C^{5} \mathrm{H} \mathrm{MeCy}\right), 122.8$ (s, $\left.\mathrm{NCCH}_{3}\right) 151.6$ (s, $\left.C^{6} \mathrm{H} \mathrm{MeCy}\right), 155.9$ (s, $\mathrm{CO} \mathrm{MeCy}$ ), 162.1 (s, $\mathrm{NH}=C \mathrm{CH} 3), 163.6$ (s, $\left.C^{4} \mathrm{MeCy}\right), 194.4$ (s, $\left.\operatorname{Re} C O\right), 195.5$ (s, ReCO), 197.0 (s, ReCO). Anal. Calcd. for $\mathrm{C}_{12} \mathrm{H}_{13} \mathrm{BF}_{4} \mathrm{~N}_{5} \mathrm{O}_{4} \mathrm{Re}: \mathrm{C}, 25.54 ; \mathrm{H}, 2.32 ; \mathrm{N}, 12.41$. Found: $\mathrm{C}, 25.63 ; \mathrm{H}, 2.44 ; \mathrm{N}, 12.15$.

fac $-\left[\operatorname{Re}(\mathbf{C O})_{3}(\mathbf{N C P h})\left\{\mathbf{N H}=\mathbf{C}(\mathbf{P h})\left(\mathbf{M e C y H}_{-} \boldsymbol{\kappa}^{2} \boldsymbol{N}, \boldsymbol{N}\right)\right\}\right] \mathbf{B F}_{4}, \mathbf{2 b}$. Method $A$. A mixture of $\mathbf{1 b}(0.056 \mathrm{~g}$, $0.1 \mathrm{mmol})$ and $\mathrm{AgBF}_{4}(0.023 \mathrm{~g}, 0.12 \mathrm{mmol})$ in $\mathrm{THF}(10 \mathrm{~mL})$ was stirred at $30^{\circ} \mathrm{C}$ for 30 min with exclusion of light. Then the reaction mixture was filtered, the volatiles were dried in vacuo, and the yellow residue was redissolved in $\mathrm{NCPh}(3 \mathrm{~mL})$ and stirred for $30 \mathrm{~min}$. The volatiles were again dried in vacuo, and the yellow residue was crystallized in $\mathrm{THF} / \mathrm{Et}_{2} \mathrm{O}$ giving a pale yellow microcrystalline solid, which was decanted, washed with diethyl ether $(3 \times 3 \mathrm{~mL}$ approximately), and dried in vacuo, yielding $0.057 \mathrm{~g}(83 \%)$. Method B. The same microwave procedure as for $\mathbf{1 b}$, using NCPh (2 mL) as solvent gave $0.041 \mathrm{~g}(60 \%)$ of $\mathbf{2 b}$. IR (THF, cm $\left.{ }^{-1}\right): 2027 \mathrm{vs,} 1920 \mathrm{vs,} 1900$ vs. IR (neat solid, cm ${ }^{-1}$ ): 3293 m, 3262 m, 3196 w, 3112 w, 2027 vs, 1926 m, 1897 vs, 1654 m, 
1567 m, 1506 w, 1492 w, 1454 m, 1447 m, 1406 m, 1338 w, 1302 w, 1243 w, 1131 w, 1054 s, 1025 s, 998 m, 809 w, 796 w, 779 w, 761 m, 699 m, 686 m, 633 m, 562 w, 529 m, 401 w, 363 w. ${ }^{1} \mathrm{H}$ NMR (499.7 MHz, $\mathrm{CD}_{3} \mathrm{NO}_{2}$ ): 3.66 (s, $\left.\mathrm{CH}_{3} \mathrm{MeCy}, 3 \mathrm{H}\right), 6.52$ (d, J=7.5 Hz, C $\left.{ }^{5} H \mathrm{MeCy}, 1 \mathrm{H}\right), 7.58$ (t, $J=7.5$, meta- $\left.\mathrm{C}_{6} \mathrm{H}_{5}, 2 \mathrm{H}\right), 7.62\left(\mathrm{t}, J=7.5 \mathrm{~Hz}\right.$, meta- $\left.\mathrm{C}_{6} \mathrm{H}_{5}, 2 \mathrm{H}\right), 7.73\left(\mathrm{~m}\right.$, para- $\left.\mathrm{C}_{6} \mathrm{H}_{5}, 2 \mathrm{H}\right), 7.81$ (d, $J=7.5 \mathrm{~Hz}$, ortho- $\left.\mathrm{C}_{6} \mathrm{H}_{5}, 2 \mathrm{H}\right), 7.86\left(\mathrm{~d}, J=7.5 \mathrm{~Hz}\right.$, ortho- $\left.\mathrm{C}_{6} \mathrm{H}_{5}, 2 \mathrm{H}\right), 8.06\left(\mathrm{~d}, J=7.5 \mathrm{~Hz}, \mathrm{C}^{6} H\right.$ $\mathrm{MeCy}, 1 \mathrm{H}), 9.20(\mathrm{~s}, \mathrm{NH}, 1 \mathrm{H}), 9.21(\mathrm{~s}, \mathrm{NH}, 1 \mathrm{H}) .{ }^{19} \mathrm{~F}$ NMR $\left(470.2 \mathrm{MHz}, \mathrm{CD}_{3} \mathrm{NO}_{2}\right):-152.87(\mathrm{~s}$, $\left.{ }^{10} \mathrm{BF}_{4}, 4 \mathrm{~F}\right),-152.92\left(\mathrm{~s},{ }^{11} \mathrm{BF}_{4}, 4 \mathrm{~F}\right) .{ }^{13} \mathrm{C}\left\{{ }^{1} \mathrm{H}\right\} \mathrm{NMR}\left(125.7 \mathrm{MHz}, \mathrm{CD}_{3} \mathrm{NO}_{2}\right): 40.6\left(\mathrm{~s}, \mathrm{NCH}_{3}\right), 97.3(\mathrm{~s}$, $\left.C^{5} \mathrm{H}\right), 128.6\left(\mathrm{~s}\right.$, ortho- $\left.\mathrm{C}_{6} \mathrm{H}_{5}\right), 130.6\left(\mathrm{~s}\right.$, ortho- $\left.\mathrm{C}_{6} \mathrm{H}_{5}\right), 130.8\left(\mathrm{~s}\right.$, meta- $\left.\mathrm{C}_{6} \mathrm{H}_{5}\right), 133.5\left(\mathrm{~s}\right.$, meta- $\left.\mathrm{C}_{6} \mathrm{H}_{5}\right)$, 134.7 (s, para- $\left.\mathrm{C}_{6} \mathrm{H}_{5}\right), 136.4$ (s, para- $\left.\mathrm{C}_{6} \mathrm{H}_{5}\right), 152.3$ (s, $\left.C^{6} \mathrm{H} \mathrm{MeCy}\right), 156.0$ (s, CO MeCy), 163.0 (s, $\left.\mathrm{N}=C \mathrm{Ph}_{3}\right), 163.1\left(\mathrm{~s}, C^{4} \mathrm{MeCy}\right), 194.1(\mathrm{~s}, \mathrm{Re} C \mathrm{O}), 195.1(\mathrm{~s}, \mathrm{Re} C \mathrm{O}), 196.9(\mathrm{~s}, \mathrm{Re} C \mathrm{O})$. ipso- $\mathrm{C}_{6} \mathrm{H}_{5}$ and $\mathrm{NCPh}$ not detected. Anal. Calcd. for $\mathrm{C}_{22} \mathrm{H}_{17} \mathrm{BF}_{4} \mathrm{~N}_{5} \mathrm{O}_{4} \mathrm{Re}: \mathrm{C}, 38.38 ; \mathrm{H}, 2.49 ; \mathrm{N}, 10.17$. Found: $\mathrm{C}$, $38.59 ; \mathrm{H}, 2.29 ; \mathrm{N}, 10.37$. 

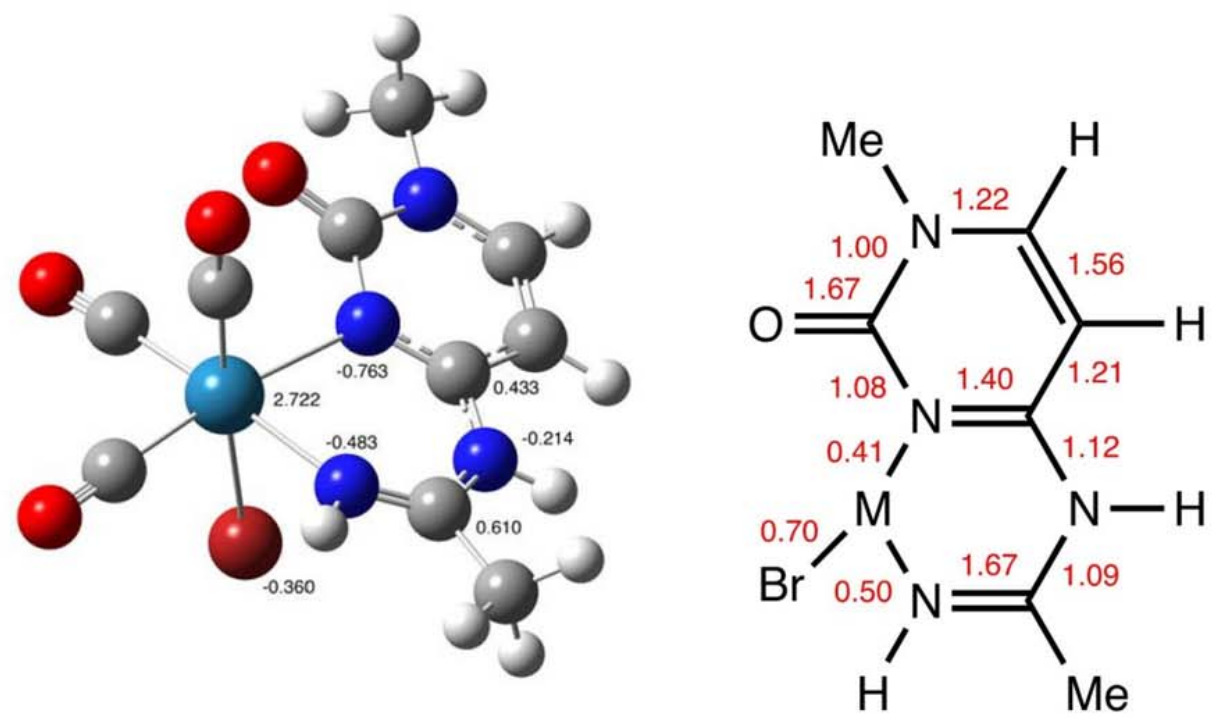

Figure S1. NBO charges and Wiberg indexes found for $\mathbf{1 a}$ 

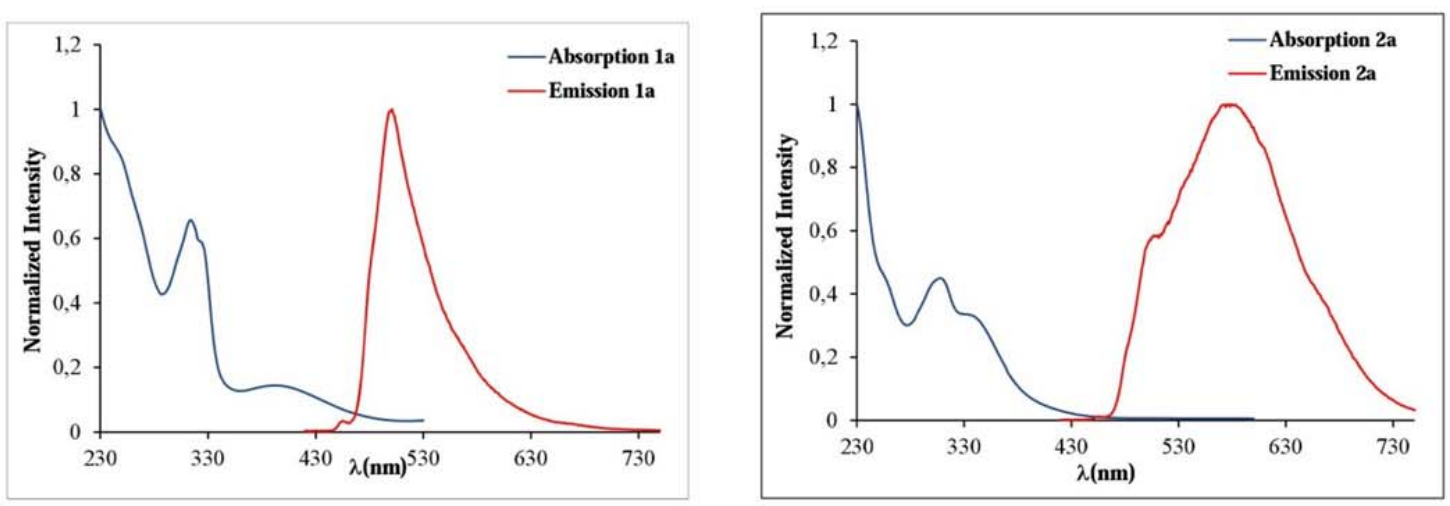

Figure S2. Normalized emission (red) and absorption (blue) spectra recorded in $\mathrm{CH} 2 \mathrm{Cl} 2$ of complexes $\mathbf{1 a}$ and $\mathbf{2 a}$ at $298 \mathrm{~K}$.

Table S1. Photophysical data: ${ }^{(a)}$

\begin{tabular}{|l|c|c|c|}
\hline & Absorption & \multicolumn{2}{|c|}{ Emission } \\
\hline & $\mathrm{CH}_{2} \mathrm{Cl}_{2}{ }^{(\mathrm{b})}$ at $298 \mathrm{~K}$ & $\mathrm{CH}_{2} \mathrm{Cl}_{2}{ }^{(\mathrm{b})}$ at $298 \mathrm{~K}$ & $\boldsymbol{\emptyset}_{\mathrm{L}} \times 10^{-3}$ \\
& $\lambda_{\text {abs }} \mathrm{nm} \varepsilon\left(\mathrm{M}^{-1} \mathrm{~cm}^{-1}\right)$ & $\lambda_{\text {em }}(\mathrm{nm})\left[\lambda_{\text {excit }}=390 \mathrm{~nm}\right]$ & $(\%)$ \\
\hline 1a & $316(16100), 326 \mathrm{sh}(14200), 399(3580)$ & $455 \mathrm{sh}, 501$ & 9 \\
\hline 2a & $259 \mathrm{sh}(16800), 308(17200), 337 \mathrm{sh}(12700)$ & $505 \mathrm{sh}, 576$ & 13 \\
\hline
\end{tabular}

(a) Measurement Conditions: Concentration $=10^{-5} \mathrm{M}$; Excitation: $390 \mathrm{~nm}$; Range: $420-800 \mathrm{~nm}$.

(b) NMR and IR spectra demonstrate that some donor solvents such as MeCN produce partial substitution of the "sixth" ligand $(\mathrm{Br}$ in $\mathbf{1 a}, \mathrm{MeCN}$ in $\mathbf{1 b})$ and therefore the photophysical measurements in these solvents are not reliable. $\mathrm{CH}_{2} \mathrm{Cl}_{2}$ has been chosen because both complexes are stable, even though their solubility is low. 


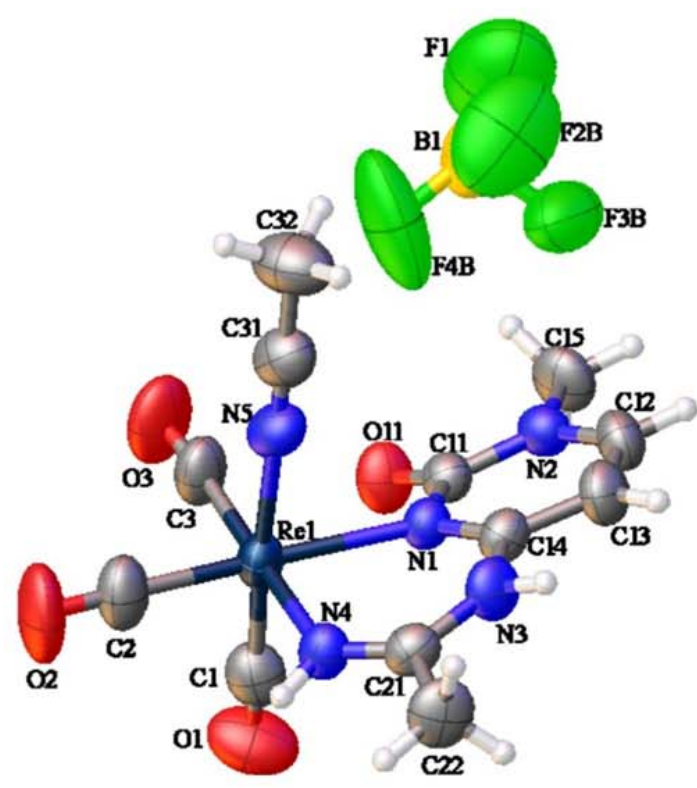

Figure S3. Perspective view of fac- $\left[\mathrm{Re}(\mathrm{CO})_{3}(\mathrm{NCMe})\left\{\mathrm{NH}=\mathrm{C}(\mathrm{Me})\left(\mathrm{MeCyH}-\kappa^{2} N, N\right\}\right] \mathrm{BF}\right.$, , 2a, showing the atom numbering. Ellipsoids are drawn at $50 \%$ probability. Selected bond lengths $(\AA)$ and angles (deg): Re1-N1 2.219(4), N1-C14 1.329 (6) N3-C14 1.379(6), N3-C21 1.379(6), N4-C21 1.255(6), Re1-N4 2.133(4); N1-C11 1.408(6), N2-C11 1.391(6), N2-C12 1.336(6), C12-C13 1.335(7), C14-C13 1.413(7); C14-N1-Re1 124.7(3), N1-C14-N3 122.8(5), C14-N3-C21 131.5(4), N4-C21-N3 122.0(4), C21-N4-Re1 131.1(4), N4-Re1-N1 83.65(14). 


\section{Computational Details.}

All calculations have been performed using the Gaussian 09 program package, ${ }^{6}$ in which the PBE1PBE method was applied. This hybrid Hartree-Fock/ density functional model is based on the Perdew-Burke-Erzenhof (PBE) functional, ${ }^{7}$ where the HF/DFT exchange ratio is fixed a priori to $1 / 4$, and was used to optimize the ground and excited state geometries. Geometry optimizations were performed under no symmetry restrictions, using initial coordinates derived from X-ray data of the same complexes, and frequency analyses were performed to ensure that a minimum structure with no imaginary frequencies was achieved in each case. On the basis of the optimized ground and excited state geometries, the absorption and emission properties in dichloromethane solution were calculated by TD-DFT ${ }^{8}$ at the PBE1PBE level associated with the PCM method to introduce the solvent effects. ${ }^{9}$ Spin-orbital coupling is not included in the current TD-DFT method, and it influences the excitation energies in which the Re electrons are involved, ${ }^{10}$ whereas it has a negligible effect on the transition character of this complexes. Hence, although TD-DFT cannot exactly estimate the excitation energies, it can still provide a reasonable spectral feature for our investigated complexes. This kind of theoretical approach has been proven to be reliable for transition-metal complex systems. ${ }^{11}$ In the calculations, effective core potentials (ECP) and their associated double- $\zeta$ LANL2DZ basis set were used for the rhenium and bromide atoms, ${ }^{12}$ while the light elements $(\mathrm{O}, \mathrm{N}, \mathrm{C}$, and $\mathrm{H})$ were described with the $6-31+\mathrm{G}(\mathrm{d}, \mathrm{p})$ basis. ${ }^{13}$ This level of theory was proved to be adequate in our previous theoretical study of the similar pirazolylamidino complexes. ${ }^{14}$ The contribution of every fragment in the molecules studied to the different orbitals involved in the optical transitions was calculated with the AOMix program, ${ }^{15}$ and the graphical representation of the orbitals was made with the help of GaussView. ${ }^{16}$ Wiberg bond indexes ${ }^{17}$ were calculated with the NBO 5.9 program. ${ }^{18}$

Crystal Structure Determination for Compounds 1a and 2a. Crystals were grown by slow diffusion of hexane into concentrated solutions of the complexes in acetone (for 1a) or THF (for 2a) 
at $-20^{\circ} \mathrm{C}$. Relevant crystallographic details can be found in the CIF. A crystal was attached to a glass fiber and transferred to an Agilent SuperNova diffractometer fitted with an Atlas CCD detector. The crystals were kept at 293(2) K during data collection. Using Olex2, ${ }^{19}$ the structure was solved for complex 1a with the ShelXS structure solution program using direct methods, ${ }^{20}$ and with olex2.solve structure solution program using Charge Flipping for complex $\mathbf{2 a},{ }^{20}$ and then, the structures were refined with the ShelXL refinement package using least squares minimisation. ${ }^{21}$ All non-hydrogen atoms were refined anisotropically. Hydrogen atoms were set in calculated positions and refined as riding atoms, with a common thermal parameter. All graphics were made with Olex2, and distances and angles of hydrogen bonds were calculated with PARST $^{22}$ (normalized values). ${ }^{23}$ 
Table S2. Frontier Molecular Orbital Compositions (\%) in the Ground State for Complex 1a at the PBE1PBE Level
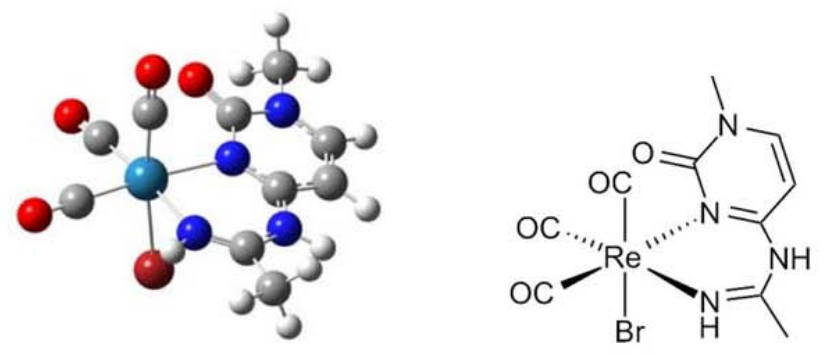

\begin{tabular}{|c|c|c|c|c|c|c|}
\hline & & \multicolumn{4}{|c|}{ Contribution (\%) } & \\
\hline Orbital & $\begin{array}{l}\text { Energy } \\
(\mathrm{eV}) \text { : }\end{array}$ & Re: & $\mathrm{Br}:$ & CO: & nucleob: & main bond type \\
\hline HOMO-3 & -7.27 & 8.10 & 32.61 & 2.57 & 56.73 & $\mathrm{p}(\mathrm{Br})+\pi($ nucleob $)$ \\
\hline HOMO-2 & -6.80 & 64.02 & 7.42 & 24.69 & 3.87 & $d(\operatorname{Re})+\pi(C O)$ \\
\hline HOMO-1 & -6.42 & 44.64 & 32.45 & 19.79 & 3.12 & $d(\operatorname{Re})+p(B r)+\pi(C O)$ \\
\hline HOMO & -6.32 & 48.88 & 24.50 & 19.53 & 7.08 & $d(R e)+p(B r)+\pi(C O)$ \\
\hline LUMO & -2.15 & 0.97 & 0.07 & 2.82 & 96.14 & $\pi^{*}$ (nucleob) \\
\hline LUMO+1 & -0.92 & 27.18 & 4.64 & 21.20 & 46.98 & $\mathrm{p}(\mathrm{Re})+\pi^{*}(\mathrm{CO})+\pi^{*}$ (nucleob) \\
\hline LUMO+2 & -0.54 & 12.37 & 1.49 & 30.90 & 55.24 & $\mathrm{p}(\mathrm{Re})+\pi^{*}(\mathrm{CO})+\pi^{*}$ (nucleob) \\
\hline
\end{tabular}

Table S3. Frontier Molecular Orbital Compositions (\%) in the Ground State for Complex 2a at the PBE1PBE Level
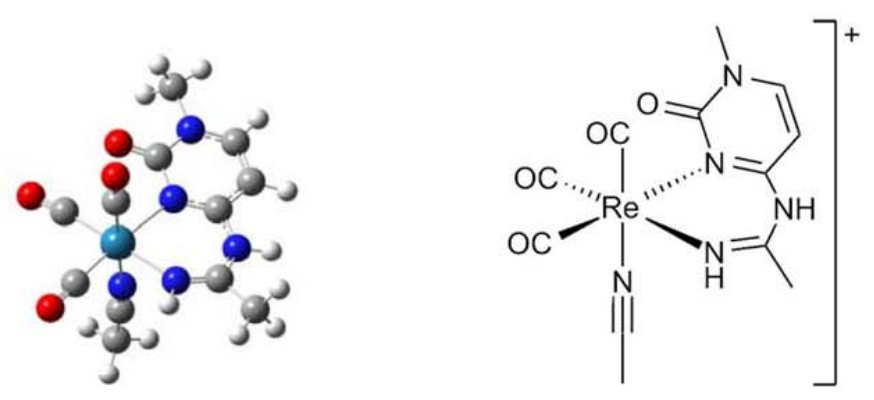

\begin{tabular}{|c|c|c|c|c|c|c|}
\hline \multirow[b]{2}{*}{ Orbital } & \multirow[b]{2}{*}{$\begin{array}{l}\text { Energy } \\
(\mathrm{eV}):\end{array}$} & \multicolumn{4}{|c|}{ Contribution (\%) } & \multirow[b]{2}{*}{ main bond type } \\
\hline & & Re: & NCMe: & CO: & nucleob: & \\
\hline HOMO-3 & -7.89 & 7.56 & 1.11 & 2.42 & 88.91 & $\pi($ nucleob $)$ \\
\hline HOMO-2 & -7.37 & 68.88 & 0.98 & 25.95 & 4.19 & $d(\operatorname{Re})+\pi(C O)$ \\
\hline HOMO-1 & -7.22 & 58.19 & 3.90 & 24.43 & 13.48 & $d(\operatorname{Re})+\pi(C O)$ \\
\hline HOMO & -7.03 & 58.13 & 3.33 & 23.15 & 15.40 & $d(\operatorname{Re})+\pi(C O)$ \\
\hline LUMO & -2.57 & 0.85 & 0.00 & 2.79 & 96.52 & $\pi^{*}$ (nucleob) \\
\hline LUMO+1 & -1.32 & 23.38 & 1.85 & 25.37 & 49.40 & $\mathrm{p}(\mathrm{Re})+\pi^{*}(\mathrm{CO})+\pi^{*}$ (nucleob) \\
\hline LUMO+2 & -1.18 & 33.48 & 22.26 & 43.01 & 1.24 & $\mathrm{p}(\mathrm{Re})+\pi^{*}(\mathrm{NCMe})+\pi^{*}(\mathrm{CO})$ \\
\hline
\end{tabular}


Table S4. Calculated Excited Energies, Dominant Orbital Excitations, and Oscillator Strength $(f)$ from TD-DFT Calculations for Complex 1a

\begin{tabular}{|c|l|c|c|c|c|c|l|}
\hline state & excitation & Coef. & $\begin{array}{c}\mathrm{E}_{\text {calc }} \\
(\mathrm{eV})\end{array}$ & $\begin{array}{c}\lambda_{\text {calc }} \\
(\mathrm{nm})\end{array}$ & $f$ & $\begin{array}{c}\lambda_{\exp } \\
(\mathrm{nm})\end{array}$ & Character \\
\hline $\mathrm{S}_{1}$ & $\begin{array}{l}\text { HOMO } \rightarrow \text { LUMO } \\
\text { HOMO-1 } \rightarrow \text { LUMO }\end{array}$ & 0.66 & 3.23 & 384 & 0.0192 & 399 & MLCT/LLCT/XLCT \\
\hline $\mathrm{S}_{2}$ & $\begin{array}{l}\text { HOMO } \rightarrow \text { LUMO } \\
\text { HOMO-1 } \rightarrow \text { LUMO }\end{array}$ & $\begin{array}{c}-0.25 \\
0.66\end{array}$ & 3.35 & 370 & 0.0426 & & MLCT/LLCT/XLCT \\
\hline $\mathrm{S}_{5}$ & HOMO-3 $\rightarrow$ LUMO & 0.68 & 4.23 & 293 & 0.1858 & 316 & XLCT/ILCT \\
\hline
\end{tabular}

Table S5. Calculated Excited Energies, Dominant Orbital Excitations, and Oscillator Strength $(f)$ from TD-DFT Calculations for Complex 2a

\begin{tabular}{|c|l|c|c|c|c|c|l|}
\hline state & excitation & Coef. & $\begin{array}{c}\mathrm{E}_{\text {calc }} \\
(\mathrm{eV})\end{array}$ & $\begin{array}{c}\lambda_{\text {calc }} \\
(\mathrm{nm})\end{array}$ & $f$ & $\begin{array}{c}\lambda_{\exp } \\
(\mathrm{nm})\end{array}$ & Character \\
\hline $\mathrm{S}_{1}$ & HOMO $\rightarrow$ LUMO & 0.69 & 3.50 & 354 & 0.0203 & 337 & MLCT/LLCT \\
\hline $\mathrm{S}_{2}$ & HOMO-1 $\rightarrow$ LUMO & 0.68 & 3.78 & 328 & 0.1331 & 308 & MLCT/LLCT \\
\hline $\mathrm{S}_{4}$ & HOMO-3 $\rightarrow$ LUMO & -0.35 & 4.39 & 282 & 0.0441 & & MLCT/LLCT/ILCT \\
& HOMO $\rightarrow$ LUMO+1 & -0.35 & & & & & \\
& HOMO $\rightarrow$ LUMO+2 & 0.45 & & & & & \\
\hline $\mathrm{S}_{5}$ & HOMO-3 $\rightarrow$ LUMO & 0.48 & 4.44 & 279 & 0.1103 & 259 & ILCT \\
& HOMO $\rightarrow$ LUMO+2 & 0.44 & & & & & \\
\hline
\end{tabular}

Table S6. Molecular orbital Compositions in the Excited States.

\begin{tabular}{|c|l|r|r|r|r|r|}
\cline { 4 - 7 } \multicolumn{2}{c|}{} & \multicolumn{5}{c|}{ Contribution (\%) } \\
\hline Complex & Orbital & $\begin{array}{l}\text { Energy } \\
(\mathrm{eV}):\end{array}$ & Re: & NCMe: & CO: & nucleob: \\
\hline 1a & HOMO & -6.79 & 30.02 & 15.64 & 11.02 & 43.32 \\
\hline & LUMO & -3.83 & 1.57 & 0.05 & 3.01 & 95.38 \\
\hline & & & & & & \\
\hline 2a & HOMO & -7.48 & 43.04 & 2.10 & 13.80 & 41.06 \\
\hline & LUMO & -4.28 & 14.05 & 0.56 & 4.76 & 80.62 \\
\hline
\end{tabular}


Table S7. Calculated Emission Energies and Dominant Orbital Emissions from TDDFT Calculations.

\begin{tabular}{|c|c|l|c|c|c|c|l|}
\hline Complex & state & Excitation & Coef. & $\begin{array}{c}\mathrm{E}_{\text {calc }} \\
(\mathrm{eV})\end{array}$ & $\begin{array}{c}\lambda_{\text {calc }} \\
(\mathrm{nm})\end{array}$ & $\begin{array}{c}\lambda_{\exp } \\
(\mathrm{nm})\end{array}$ & Character \\
\hline $1 \mathrm{a}$ & $\mathrm{T}_{1}$ & $\mathrm{HOMO} \rightarrow \mathrm{LUMO}$ & 0.94 & 1.71 & 725 & 501 & ${ }^{3} \mathrm{MLCT} /{ }^{3} \mathrm{ILCT} /$ \\
\hline $2 \mathrm{a}$ & $\mathrm{T}_{1}$ & $\mathrm{HOMO} \rightarrow \mathrm{LUMO}$ & 0.86 & 1.63 & 762 & 576 & ${ }^{3} \mathrm{MLCT} /{ }^{3} \mathrm{ILCT} /$ \\
\hline
\end{tabular}

\footnotetext{
${ }^{1}$ D. D. Perrin and W. L. F. Armarego, "Purification of Laboratory Chemicals"; 3rd ed.; Pergamon Press: Oxford, 1988.

${ }^{2}$ M. F. Farona and K. F. Kraus, Inorg. Chem., 1970, 9, 1700-1704.

${ }^{3}$ V. I. Zdanovitch, N. E. Kolobova, N. I. Vasyukova, Yu. S. Nekrasov, G. A. Panosyan, P. V. Petrovskii, and A. Zh.
} Zhakaeva, J. Organomet. Chem., 1978, 148, 63-71.

${ }^{4}$ (a) E. D. Becker, H. T. Miles and R. B. Bradley, J. Am. Chem. Soc., 1965, 87, 5575-5582. (b) A. Papoulis, Y. Al-Abed and R. Bucala, Biochemistry, 1995, 34, 648-655.

${ }^{5}$ D. Magde, J. H. Brannon, T. L. Cremers and J. Olmsted, J. Phys. Chem., 1979, 83, 696-699.

${ }^{6}$ Gaussian 09, Revision A.02, M. J. Frisch, G. W. Trucks, H. B. Schlegel, G. E. Scuseria, M. A. Robb, J. R.

Cheeseman, G. Scalmani, V. Barone, B. Mennucci, G. A. Petersson, H. Nakatsuji, M. Caricato, X. Li, H. P. Hratchian, A. F. Izmaylov, J. Bloino, G. Zheng, J. L. Sonnenberg, M. Hada, M. Ehara, K. Toyota, R. Fukuda, J. Hasegawa, M. Ishida, T. Nakajima, Y. Honda, O. Kitao, H. Nakai, T. Vreven, J. A. Montgomery Jr., J. E. Peralta, F. Ogliaro, M. Bearpark, J. J. Heyd, E. Brothers, K. N. Kudin, V. N. Staroverov, R. Kobayashi, J. Normand, K. Raghavachari, A. Rendell, J. C. Burant, S. S. Iyengar, J. Tomasi, M. Cossi, N. Rega, J. M. Millam, M. Klene, J. E. Knox, J. B. Cross, V. Bakken, C. Adamo, J. Jaramillo, R. Gomperts, R. E. Stratmann, O. Yazyev, A. J. Austin, R. Cammi, C. Pomelli, J. W. Ochterski, R. L. Martin, K. Morokuma, V. G. Zakrzewski, G. A. Voth,P. Salvador, J. J. Dannenberg, S. Dapprich, A. D. Daniels, O. Farkas, J. B. Foresman, J. V. Ortiz, J. Cioslowski and D. J. Fox, Gaussian, Inc., Wallingford CT, 2009.

${ }^{7}$ (a) J. P. Perdew, K. Burke and M. Ernzerhof, Phys. Rev. Lett., 1996, 77, 3865-3868. (b) J. P. Perdew, K. Burke, and M. Ernzerhof, Phys. Rev. Lett., 1997, 78, 1396. (c) C. Adamo and V. Barone, J. Chem. Phys., 1999, 110, 6158-6170.

${ }^{8}$ (a) T. Helgaker and P. Jorgensen, J. Chem. Phys., 1991, 95, 2595-2601. (b) K. L. Bak, P. Jorgensen, T. Helgaker, K. Rund, and H. J. A. Jenson, J. Chem. Phys., 1993, 98, 8873-8887. (c) J. Autschbach, T. Ziegler, S. J. A. Gisbergen and E. J. Baerends, J. Chem. Phys., 2002, 116, 6930-6940.

9 (a) E. Cances, B. Mennucci and J. Tomasi, J. Chem. Phys., 1997, 107, 3032-3041. (b) M. Cossi, V. Barone, B. Mennucci and J. Tomasi, Chem. Phys. Lett. 1998, 286, 253-260. (c) B. Mennucci and J. Tomasi, J. Chem. Phys., 1997, 106, $5151-5158$.

${ }^{10}$ L.-L. Shi, Y. Liao, L. Zhao, Z.-M. Su,Y.-H. Kan, G.-C. Yang and S.Y. Yang, J. Organomet. Chem., 2007, 692, 53685374.

${ }^{11}$ (a) S. R. Stoyanov, J. M. Villegas and D. P. Rillema, Inorg. Chem., 2002, 41, 2941-2945. (b) D. Di Censo, S. Fantacci, F. De Angelis, C. Klein, N. Evans, K. Kalyanasundaram, H. J. Bollink, M. Gratzel and M. K. Nazeeruddin, Inorg. Chem., 2008, 47, 980-989. (c) T. H. Kwon, H. S. Cho, M. K. Kim, J. W. Kim, J. J. Kim, K. H. Lee, S. J. Park, I. S. Shin, H. Kim, D. M. Shin, Y. K. Chung and J. I. Hong, Organometallics, 2005, 24, 1578-1585. (d) Q. Zhao, S. Liu, M. Shi, C. Wang, M. Yu, L. Li, F. Li, T. Yi and C. Huang, Inorg. Chem., 2006, 45, 6152-6160. (e) K. Zheng, J. Huang, W. Peng, X. Liu and F. Yun, J. Phys. Chem. A, 2001, 105, 10899-10905. (f) K. Zheng, J. Huang, Y. Shen, D. Kuang and F. Yun, J. Phys. Chem. A, 2001, 105, 7248-7253. (g) A. Vlček Jr. and S. Zalis, J. Phys. Chem. A, 2005, 109, 29912992.

${ }^{12}$ (a) P. J. Hay and W. R. Wadt, J. Chem. Phys., 1985, 82, 270-283. (b) P. J. Hay and W. R. Wadt, J. Chem. Phys., $1985,82,299-310$.

${ }^{13}$ (a) A. Gabrielsson, P. Matousek, M. Towrie, F. Hartl, S. Zalis and A. Vlček Jr., J. Phys. Chem. A, 2005, 109, 61476153. (b) D. M. Dattelbaum, K. M. Omberg, P. J. Hay, N. L. Gebhart, R. L. Martin, J. R. Schoonover and T. J. Meyer, J. Phys. Chem. A, 2004, 108, 3527-3536. (c) D. M. Dattelbaum, R. L. Martin, J. R. Schoonover and T. J. Meyer, J. Phys. Chem. A, 2004, 108, 3518-3526. (d) N. J. Lundin, P. J. Walsh, S. L. Howell, J. J. McGarvey, A. G. Blackman and K. C. Gordon, Inorg. Chem., 2005, 44, 3551-3560.

${ }^{14}$ P. Gómez-Iglesias, F. Guyon, A. Khatyr, G. Ulrich, M. Knorr, J. M. Martín-Alvarez, D. Miguel and F. Villafañe, submitted to Dalton Trans.

${ }^{15}$ (a) S. I. Gorelsky, AOMix: Program for Molecular Orbital Analysis, http://www.sg-chem.net/, University of Ottawa, version 6.5, 2011. (b) S. I. Gorelsky and A. B. P. Lever, J. Organomet. Chem., 2001, 635, 187-196.

${ }^{16}$ GaussView, Version 5, R. Dennington, T. Keith and J. Millam, Semichem Inc., Shawnee Mission KS, 2009.

${ }^{17}$ K. Wiberg, Tetrahedron 1968, 24, 1083-1096. 
${ }^{18}$ E. D. Glendening, J. K. Badenhoop, A. E. Reed, J. E. Carpenter, J. A. Bohmann, C. M. Morales, F. Weinhold, NBO, 5.9; Theoretical Chemistry Institute, University of Wisconsin: Madison, WI, 2009; http://www.chem.wisc.edu/<nbo5.

${ }^{19}$ O. V. Dolomanov, L. J. Bourhis, R. J. Gildea, J. A. K. Howard and H. Puschmann, J. Appl. Cryst., 2009, 42, 339-341.

${ }^{20}$ L. J. Bourhis, O. V. Dolomanov, R. J. Gildea, J. A. K. Howard and H. Puschmann, Acta Cryst., 2015, A71, 59-75.

${ }^{21}$ G. M. Sheldrick, Acta Cryst., 2008, A64, 112-122.

22 (a) M. Nardelli, Comput. Chem., 1983, 7, 95-98. (b) M. Nardelli, J. Appl. Crystallogr., 1995, 28, 659.

23 (a) G. A. Jeffrey and L. Lewis, Carbohydr. Res., 1978, 60, 179-182. (b) R. Taylor and O. Kennard, Acta Crystallogr., 1983, B39, 133-138. 
8. Doctorado Internacional 



\section{DOCTORADO INTERNACIONAL}

\subsection{Introducción}

Para poder optar al doctorado internacional, en 2011 realicé una estancia de tres meses en la Universidad de Southampton, en el grupo del Prof. Philip A. Gale. Durante este periodo trabajé en la síntesis de pequeñas moléculas que sean capaces de actuar como transportadores iónicos entre membranas lipídicas. Estos compuestos forman parte de un proyecto más amplio que se detalla a continuación.

Las células de los seres vivos están rodeadas de una membrana apolar de fosfolípidos que impide la libre difusión a través de ella de especies cargadas, como son los aniones. De hecho, los aniones son transportados a través de la membrana celular por medio de unas proteínas especializadas, que están embebidas en la membrana celular y que se encargan de mantener la concentración correcta de cada anión dentro de la célula. Sin embargo, en estas proteínas se pueden producir fallos que inhabiliten el transporte de aniones a través de la membrana celular, lo que se ha relacionado con una serie de enfermedades como la fibrosis quística, ${ }^{121}$ la enfermedad de Dent, ${ }^{122}$ algunos tipos del síndrome de Bartter, ${ }^{123,124}$ el síndrome de Pendred ${ }^{125} \mathrm{u}$ otras enfermedades genéticas. ${ }^{126}$ Por esta razón uno de los temas de trabajo de mayor interés que están desarrollando los químicos supramoleculares en los últimos años consiste en la síntesis y desarrollo de moléculas que puedan reemplazar a las proteínas que no funcionan correctamente. Para ello se deben crear receptores de aniones que sean capaces de transportar aniones a través de la membrana de fosfolípidos ${ }^{127}$, que se pueden dividir en dos grandes grupos: canales o transportadores móviles (Figura 19). Los canales son estructuras que crean poros polares en la membrana a través de los cuales los aniones se pueden difundir. Por otro lado, los transportadores móviles son moléculas que se unen al anión en un lado de la membrana, atraviesan la membrana como un complejo y liberan el anión al otro lado de la membrana. Por todo lo explicado anteriormente, la síntesis de moléculas capaces de imitar la funcionalidad de las proteínas transportadoras de cloruros o bicarbonato a través de la membrana podría posibilitar el desarrollo de nuevos tratamientos para este tipo de enfermedades. ${ }^{128-133}$ 


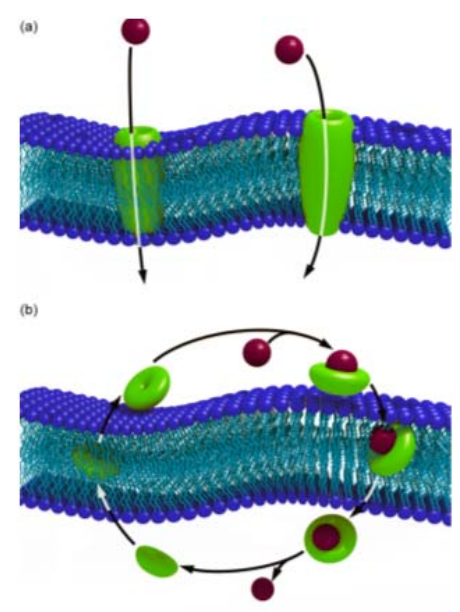

Figura 19. Representación esquemática del transporte aniónico a través de una membrana por medio de (a) un canal y (b) un transportador móvil.

En el momento en el que se produjo la estancia predoctoral, otros grupos habían hecho progresos en el área de diseño de transportadores móviles, pero aún no sé comprendía perfectamente cómo diseñar un receptor aniónico adecuado. En este sentido, los trabajos previos del Prof. Gale en el diseño de receptores aniónicos ${ }^{134}$ les habían permitido desarrollar nuevas series de transportadores móviles a través de membranas para aniones. Estos estudios se limitaban a compuestos relativamente simples, lo que les permitía variar sistemáticamente sus estructuras y propiedades para conseguir una mayor compresión sobre qué propiedades moleculares son necesarias para producir un transportador eficiente. ${ }^{135}$

El trabajo desarrollado durante mi estancia estuvo dividido en dos partes. Una primera parte sintética, en la que debía sintetizar una serie de compuestos derivados del indol que contuviesen los grupos urea y tiourea (Figura 20), así como conseguir una ruta sintética para el 2-butil-5-metil-7-nitro-1H-indol, que es uno de los precursores de estos compuestos. Se pretendía realizar la síntesis de estos compuestos y de sus derivados trifluorometilados para comparar cómo variaba su capacidad transportadora. En la segunda parte estudiaríamos la eficacia de los compuestos sintetizados como transportadores de aniones. El transporte de aniones a través de las membranas lipídicas se puede medir de diferentes maneras, pero el método más comúnmente usado consiste en la preparación de vesículas compuestas por un solo tipo de lípido o de un lípido y colesterol, y aceptarlo como un modelo simple de membrana. Las disoluciones intra- y extravesiculares se preparan de acuerdo a lo que sea necesario para el experimento. 


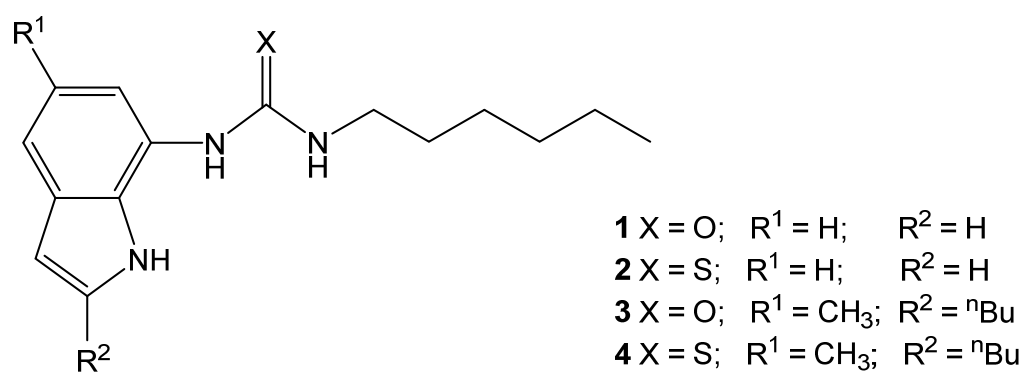

Figura 20. Compuestos sintetizados en Southampton.

\subsection{Discusión de resultados}

\subsubsection{Sintesis de los compuestos}

La síntesis de 2-butil-5-metil-7-nitro-1H-indol se realiza tras la bromación de 3-nitro-4-aminotolueno para obtener 3-bromo-4-amino-5-nitrotolueno. Posteriormente, se arilalquila este compuesto por medio de un acoplamiento de Sonogashira. Por último, se cierra el ciclo mediante una adición del $\mathrm{NH}$ del amino al triple enlace formado anteriormente. El rendimiento total de las etapas de reacción es del 43\% (Esquema 13).

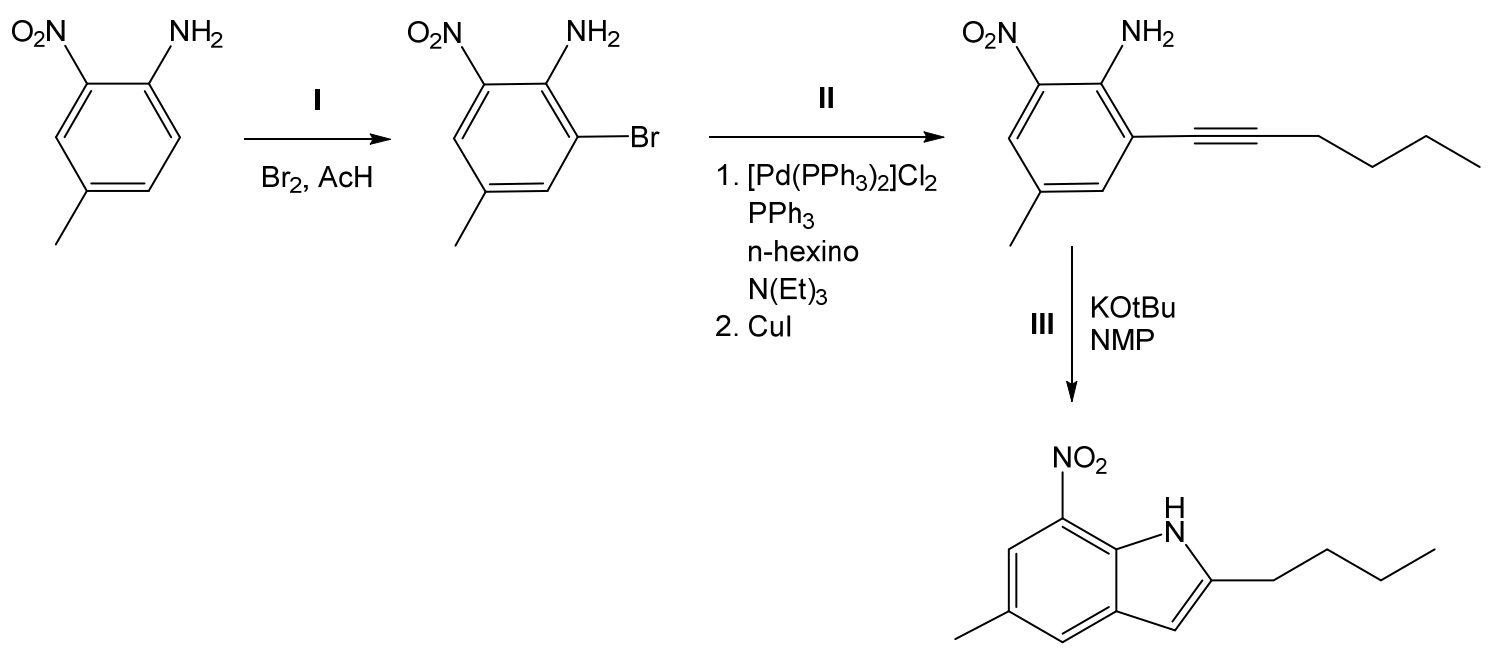

Esquema 13. Síntesis de 2-butil-5-metil-7-nitro-1H-indol.

Los compuestos $\mathbf{1}^{136}$ y $\mathbf{3}$ se sintetizan a partir de 7-nitro- $1 H$-indol y de 2-butil-5-metil-7-nitro-1H-indol respectivamente (Esquema 14). Se parte de la reducción de los 
nitrocompuestos para formar la amina correspondiente. Posteriormente, la amina formada se hace reaccionar con 1,1-carbonildiimidazol para conseguir un intermedio activado, el cual posteriormente es sometido a un acoplamiento con hexilamina para dar lugar a los compuestos buscados, que se obtienen con un rendimiento total del $48 \%$ y el $25 \%$ respectivamente.

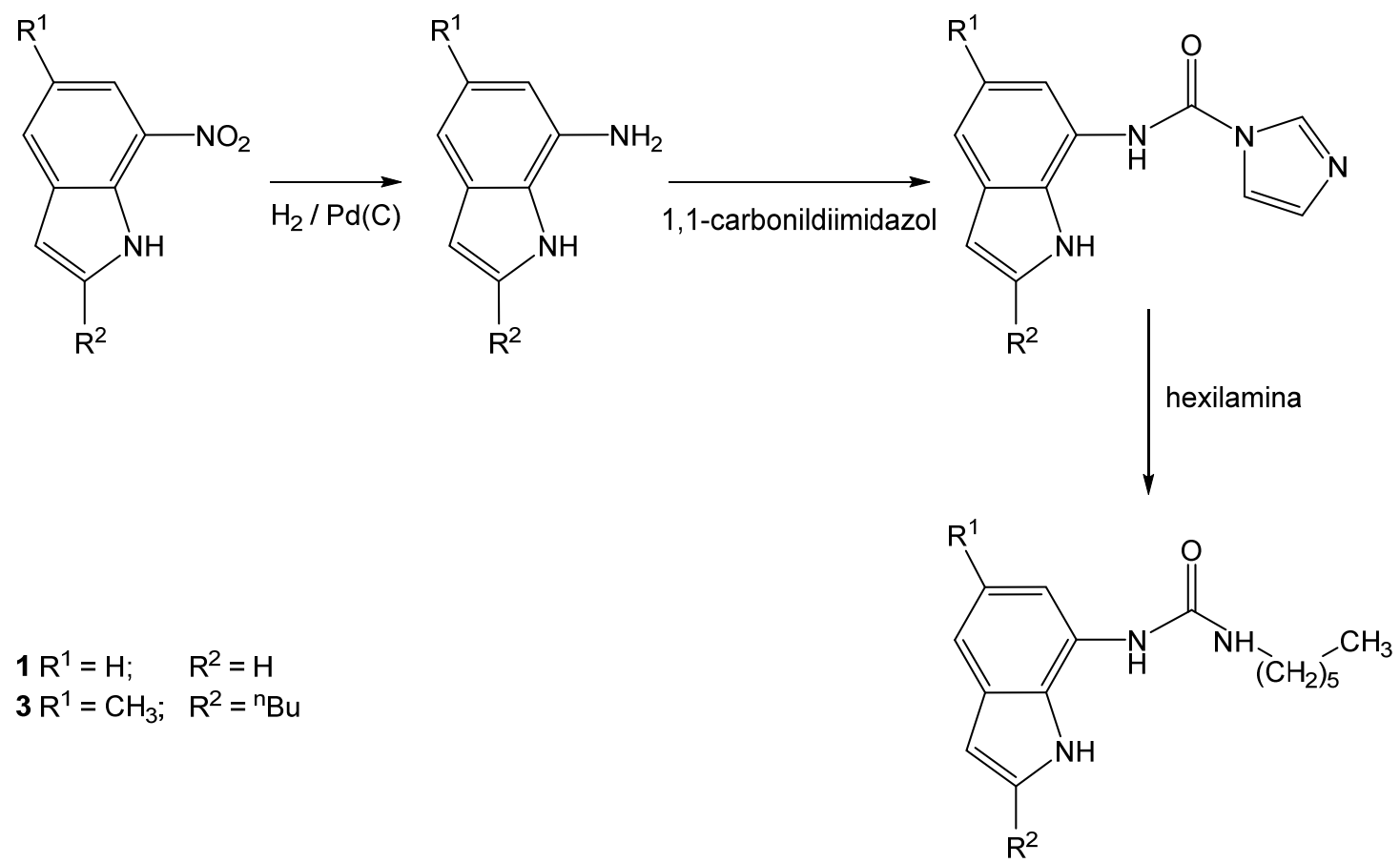

Esquema 14. Síntesis de los derivados de urea.

Las tioureas $\mathbf{2}^{137}$ y $\quad \mathbf{4}$ se sintetizaron a partir del 7-nitro-1H-indol y 2-butil-5-metil-7-nitro-1H-indol respectivamente (Esquema 15). Se realizó la reducción de los nitrocompuestos a la amina correspondiente. Posteriormente se hace reaccionar a las aminas con tiofosgeno para conseguir un intermedio lo suficientemente activo como para que reaccione con la hexilamina y conduzca a los productos buscados con un rendimiento global del $45 \%$ y $36 \%$ respectivamente. 


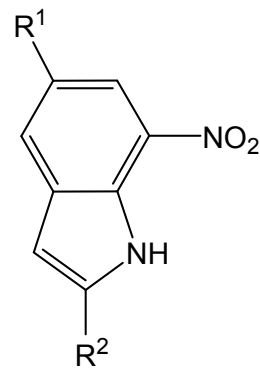

$2 \mathrm{R}^{1}=\mathrm{H} ; \quad \mathrm{R}^{2}=\mathrm{H}$

$4 \mathrm{R}^{1}=\mathrm{CH}_{3} ; \mathrm{R}^{2}={ }^{\mathrm{n}} \mathrm{Bu}$
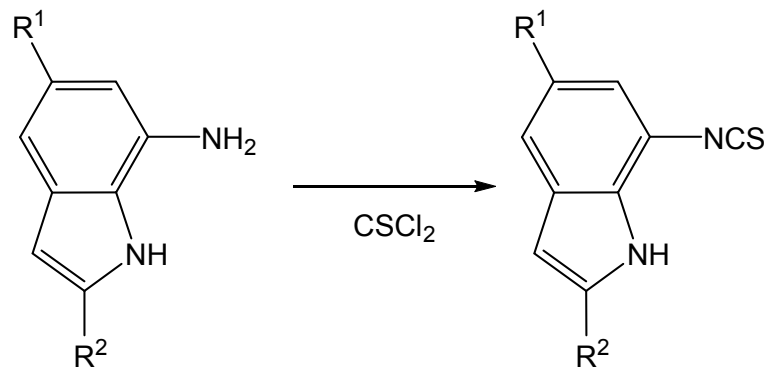

hexilamina
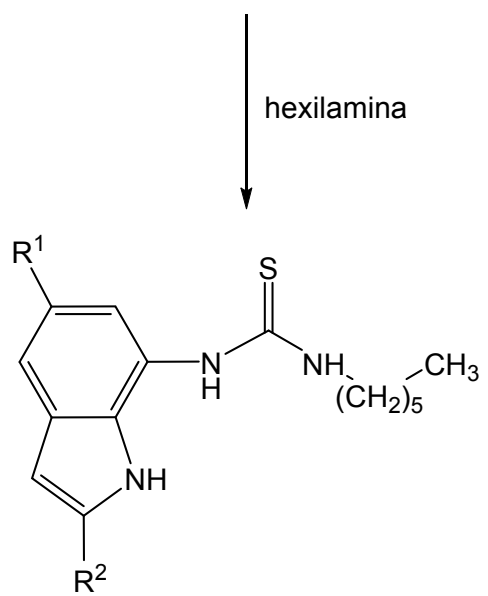

Esquema 15. Síntesis de los derivados de urea.

\subsubsection{Estudios de la capacidad transportadora en vesiculas}

Para evaluar la capacidad transportadora de aniones de nuestros compuestos (1-4), se prepararon una serie de liposomas unilamelares de $200 \mathrm{~nm}$ de diámetro compuestos de 1-palmitol-2-oleoelfosfatidilcolina (POPC). Estos liposomas contienen una disolución de cloruro sódico ( $489 \mathrm{mM}$ con $5 \mathrm{mM}$ de buffer de fosfato a $\mathrm{pH}=7.2$ ) y están suspendidos en un medio formado por una disolución de nitrato sódico $(489 \mathrm{mM}$ con $5 \mathrm{mM}$ de buffer de fosfato a $\mathrm{pH}=7.2) .{ }^{138,139}$ Los compuestos 1-4 (2\% molar con respecto al lípido) se añadieron disueltos en DMSO y el flujo de cloruros resultante fue determinado con un electrodo selectivo de cloruros. A los 5 minutos se añade detergente (octaetilenglicol monododecil éter) para romper las vesículas, usando la última medida para calibrar el electrodo al $100 \%$ de liberación de cloruros. 


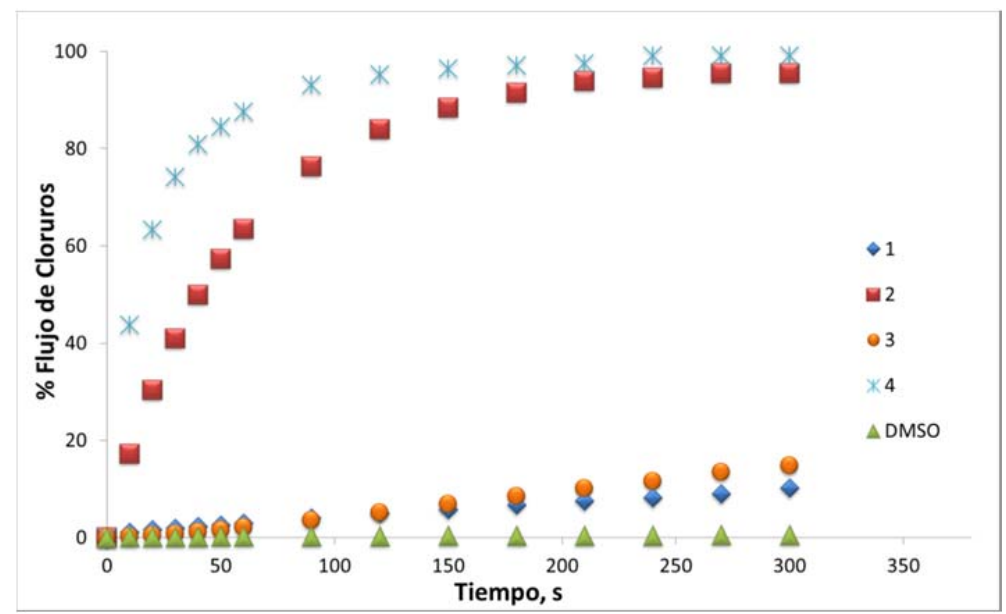

Figura 21. Flujo de cloruros promovido por disoluciones de los compuestos 1 - $\mathbf{4}$ en DMSO al 2 \%. Cada punto representa una media de tres intentos. Se usó DMSO como control.

Los resultados (Figura 21) demuestran que los receptores que contienen grupos tiourea poseen un comportamiento mucho más activo que los derivados análogos de urea. Este hecho ya se había observado con anterioridad y puede deberse a la mayor lipofilia de los grupos tiourea, que haría más favorable el paso del receptor y de su complejo aniónico dentro de la bicapa lipídica. ${ }^{136,140}$

En estas condiciones, el transporte de los aniones a través de la membrana es un proceso pasivo, en el que el balance de cargas a través de la membrana debe mantenerse, ya sea mediante un proceso de simporte (dos moléculas de diferente carga pero que se complementan se mueven a favor de gradiente) o de antiporte (una molécula en el interior de la célula y otra en el exterior de la célula se mueven al mismo tiempo pero en dirección contraria). Por lo tanto, el flujo de cloruros de la Figura 21 podría deberse a un proceso de simporte de $\mathrm{NaCl}$ o $\mathrm{HCl}$, o a un proceso de antiporte $\mathrm{Cl}^{-} / \mathrm{NO}_{3}{ }^{-}$. Aunque los estudios anteriores demostraron que otros transportadores similares funcionan predominantemente bajo un mecanismo de antiporte, ${ }^{135,141}$ decidimos realizar un experimento en el que la disolución interna de $\mathrm{NaCl}$ de la vesícula fuera remplazada por otra disolución interna de $\mathrm{CsCl}$. Al no observarse diferencias en la velocidad de transporte se descartó la posibilidad de un simporte $\mathrm{M}^{+} \mathrm{Cl}^{-}$.

A continuación se midió la capacidad de los compuestos para trabajar en un sistema biológicamente más relevante como es el intercambio cloruro/bicarbonato antiporte (Figura 22). ${ }^{126,142-146}$ Para este experimento las vesículas contienen una disolución de cloruro sódico ( $0.450 \mathrm{mM}$ con $20 \mathrm{mM}$ de buffer de fosfato a $\mathrm{pH}=7.2)$ y se suspenden en una disolución de sulfato sódico (162 mM y $20 \mathrm{mM}$ de buffer de fosfato a $\mathrm{pH}=7.2)$. Los compuestos 1-4 se añaden disueltos en DMSO. El ion sulfato es más difícil de transportar a través de la bicapa 
lipídica que el ión nitrato, a causa de la diferente hidrofilia entre los dos aniones. ${ }^{147} \mathrm{El}$ ion bicarbonato se añade cuando han pasado los dos primeros minutos de reacción, y en este tiempo se observa que no hay flujo de cloruros a través de la membrana. Cuando a los dos minutos se añade el ion bicarbonato, se observa un incremento en el flujo de iones cloruro debido a un mecanismo de antiporte $\mathrm{Cl}^{-} / \mathrm{HCO}_{3}{ }^{-}$. Comparando este experimento con el anterior se observa que la velocidad de intercambio $\mathrm{Cl}^{-} / \mathrm{HCO}_{3}^{-}$es inferior a la $\mathrm{Cl}^{-} / \mathrm{NO}_{3}{ }^{-}$, lo que se debe a que el ión bicarbonato es menos lipófilo que el ion cloruro. ${ }^{147}$

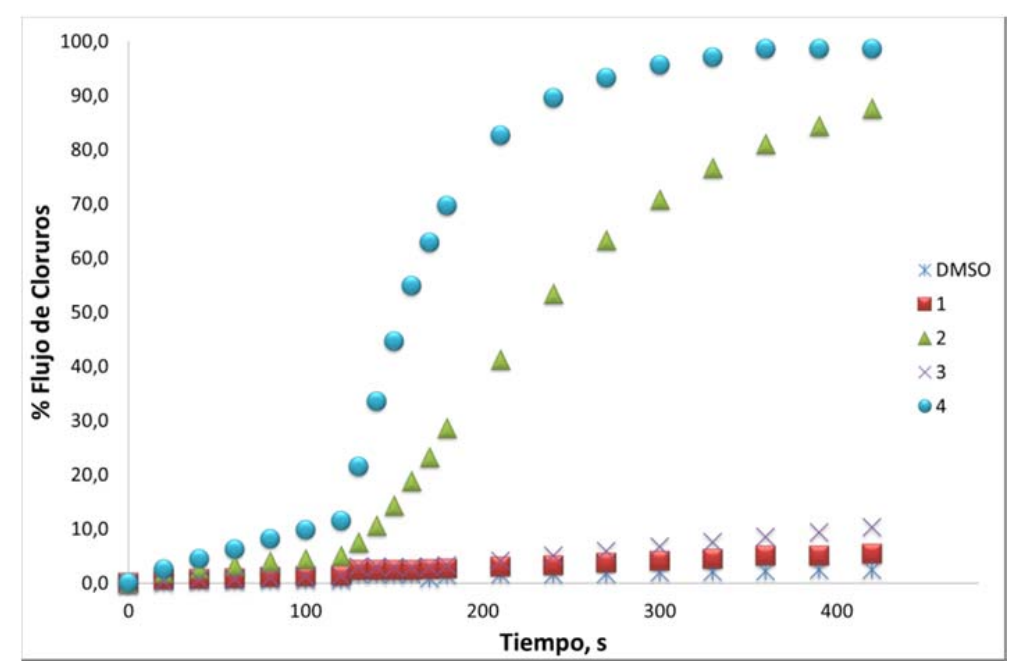

Figura 22. Flujo de cloruros promovido por una disolución de los compuestos 1-4 en DMSO al 2 \%. Cada punto representa una media de tres intentos. Se usó DMSO como control.

Para cuantificar la actividad transportadora de los compuestos 1-4 en los sistemas $\mathrm{Cl}^{-} / \mathrm{NO}_{3}{ }^{-} \mathrm{y} \mathrm{Cl}^{-} / \mathrm{HCO}_{3}{ }^{-}$, y poder establecer una comparación con la de otros sistemas se llevó a cabo un análisis de Hill. ${ }^{148} \mathrm{El}$ análisis de Hill permite determinar el valor $\mathrm{EC}_{50,270}$, que es la concentración de transportador necesaria para transportar el $50 \%$ de los iones cloruro 270 segundos después de la adición del receptor (o de la adición del bicarbonato). Este valor nos permite comparar la capacidad transportadora de los compuestos con otros compuestos análogos y solo pudo ser calculado para los derivados con tiourea (2 y 4) ya que sus análogos de urea presentaban una actividad demasiado baja. Los valores de $\mathrm{EC}_{50,270} \mathrm{y} \log P$ se presentan en la ¡Error! No se encuentra el origen de la referencia.. 
Tabla 4. ${ }^{\text {a }}$ es la concentración (\% molar del transportador con respecto al lípido) necesaria para obtener un flujo del $50 \%$ de los iones cloruro a los $270 \mathrm{~s} .{ }^{\mathrm{b}}$ Coeficiente de Hill. ${ }^{\mathrm{c}}$ no se pudo llevar a cabo el análisis de Hill debido a su baja actividad.

\begin{tabular}{cccccc}
\hline logP & $\begin{array}{c}\mathbf{E C}_{50,270} \\
\left(\mathrm{Cl}^{-} / \mathrm{NO}_{3}^{-}\right)^{\mathbf{a}}\end{array}$ & $\begin{array}{c}\mathbf{n} \\
\left(\mathrm{Cl}^{-} / \mathrm{NO}_{3}^{-}\right)^{\mathbf{b}}\end{array}$ & $\begin{array}{c}\mathbf{E C}_{50,270} \\
\left(\mathrm{Cl}^{-} / \mathrm{HCO}_{3}{ }^{-}\right)^{\mathbf{a}}\end{array}$ & $\begin{array}{c}\mathbf{n} \\
\left(\mathrm{Cl}^{-} / \mathrm{HCO}_{3}^{-}\right)^{\mathbf{b}}\end{array}$ \\
\hline $\mathbf{1}$ & 2.52 & $-{ }^{\mathbf{c}}$ & $-{ }^{\mathbf{c}}$ & $-{ }^{\mathbf{c}}$ & $-{ }^{\mathbf{c}}$ \\
$\mathbf{2}$ & 3.67 & 0.03 & 0.8 & 0.18 & 0.7 \\
$\mathbf{3}$ & 3.96 & $-{ }^{\mathbf{c}}$ & $-{ }^{\mathbf{c}}$ & $-{ }^{\mathbf{c}}$ & $-^{\mathbf{c}}$ \\
$\mathbf{4}$ & 5.10 & 0.01 & 1.4 & 0.04 & 1.4 \\
\hline
\end{tabular}

\subsection{Parte experimental}

\subsubsection{Preparación de las vesículas}

El método general de preparación de las vesículas consta de la evaporación de una disolución de 1-palmitol-2-oleoelfosfatidilcolina (POPC) $(22.32 \mathrm{mg} / \mathrm{mL})$ en cloroformo, para dar un film delgado. Este film se seca a vacío durante $12 \mathrm{~h}$ y se centrifuga para rehidratarlo con la solución interna. Posteriormente esta suspensión de lípidos se somete a nueve ciclos de congelacióndescongelación y a 29 pasos a través de una membrana de $200 \mathrm{~nm}$ de policarbonato, usando un LiposoFast Basic extruder (Avestin, Inc.) para obtener vesículas unilamelares. A continuación se lleva a cabo la diálisis de los liposomas en la disolución externa durante 2 horas. Se prepara una disolución madre de los lípidos diluyéndola con la disolución externa. Las muestras se preparan diluyendo la disolución madre (con la disolución externa) para preparar $5 \mathrm{~mL}$ de una disolución $1 \mathrm{mM}$. El flujo de iones cloruro se determina con un electrodo selectivo de cloruros (Accumet) que ha sido calibrado con muestras patrón. Para iniciar los experimentos se añaden los transportadores disueltos en dimetil sulfóxido (DMSO), de manera que la proporción del compuesto en moles frente al lípido sea $2 \%$. Al final del experimento se añaden $50 \mu 1$ de detergente (octaetilenglicol monododecil éter) para determinar el valor del $100 \%$ de la liberación de los iones cloruro. Los experimentos se repiten por triplicado y en las gráficas se representa la media de los tres ensayos. 


\subsubsection{Sintesis de los compuestos}

2-butil-5-metil-7-nitro-1H-indol. Paso 1. La reacción de bromación de 3-nitro-4-aminotolueno y posterior purificación se lleva a cabo tal y como se describe en la bibliografía, obteniéndose 3-bromo-4-amino-5-nitrotolueno. ${ }^{149}$ Paso 2: Una mezcla de 3-bromo-4-amino-5-nitrotolueno (1.155 g, $5 \mathrm{mmol})$, $\left[\mathrm{PdCl}_{2}\left(\mathrm{PPh}_{3}\right)_{2}\right](0.175 \mathrm{~g}, 0.25 \mathrm{mmol})$, trieltilamina $(1.01 \mathrm{~g}, 7.5 \mathrm{mmol})$, trifenilfosfina $(0.033 \mathrm{mg}, 0.125 \mathrm{mmol})$ y $\mathrm{n}$-hexino $(0.86 \mathrm{~mL}$, $7.5 \mathrm{mmol}$ ) en $20 \mathrm{~mL}$ de tetrahidrofurano se agita durante 20 minutos a temperatura ambiente dando lugar a una disolución amarilla. A continuación se añade yoduro de cobre(I) $(0.012 \mathrm{mg}$, $0.06 \mathrm{mmol}$ ) y la reacción se agita toda la noche bajo $\mathrm{N}_{2}$ a temperatura ambiente. El disolvente se elimina a vacío y el sólido resultante se purifica en una columna de silicagel hexano:diclorometano 2:1. Tras evaporar se obtiene 3-hexino-4-amino-5-nitrotolueno con un rendimiento del $96 \%$ (1.124 g). ${ }^{150}{ }^{1} \mathrm{H}$ RMN (300 MHz, DMSO- $\left.d_{6}\right): 7.79$ (s, aril CH, $1 \mathrm{H}$ ), 7.40 (s, aril $\mathrm{CH}, 1 \mathrm{H}), 6.96(\mathrm{~s}, \mathrm{NH}, 2 \mathrm{H}), 2.52-2.49$ (m, $\left.\mathrm{CH}_{2}, 2 \mathrm{H}\right), 2.17$ (s, $\left.\mathrm{CH}_{3}, 3 \mathrm{H}\right), 1.59-1.49$ (m, $\left.\mathrm{CH}_{2}, 2 \mathrm{H}\right), 1.46-1.36\left(\mathrm{~m}, \mathrm{CH}_{2}, 2 \mathrm{H}\right), 0.90\left(\mathrm{t}, J=7.2 \mathrm{~Hz}, \mathrm{CH}_{3}, 3 \mathrm{H}\right)$. Paso 3: Se disuelve 3-hexino-4-amino-5-nitrotolueno (1.124 g, $4.8 \mathrm{mmol})$ en N-metil-2-pirrolidina $(5 \mathrm{~mL})$ y se añade sobre una disolución de tercbutoxido potásico $(0.730 \mathrm{~g}, 6.5 \mathrm{mmol})$ en $\mathrm{N}$-metil-2-pirrolidina $(20 \mathrm{~mL})$. La disolución vira a morada y la mezcla de reacción se agita $4 \mathrm{~h}$ a temperatura ambiente. A la disolución resultante de color rojo se le añade agua $(5 \mathrm{~mL})$ y acetato de etilo $(50 \mathrm{~mL})$, se lava con una disolución acuosa saturada de $\mathrm{NaCl}$ y se seca con $\mathrm{MgSO}_{4}$. El disolvente se elimina a vacío y se purifica en una columna de silicagel con diclorometano:hexano 7:3. Tras evaporar se obtienen $0.1058 \mathrm{~g}(88 \%)$ de un sólido amarillo, 2-butil-5-metil-7-nitro-1H-indol. ${ }^{151}{ }^{1} \mathrm{H}$ RMN (300 MHz, DMSO- $d_{6}$ ): 11.54 (s, NH, $1 \mathrm{H}$ ), 7.82 (s, $\mathrm{CH}, 1 \mathrm{H}), 7.72(\mathrm{~s}, \mathrm{CH}, 1 \mathrm{H}), 6.34(\mathrm{~s}, \mathrm{CH}, 1 \mathrm{H}), 3.32\left(\mathrm{~s}, \mathrm{CH}_{3}, 3 \mathrm{H}\right), 2.80$ (t, J = $7.5 \mathrm{~Hz}, \mathrm{CH}_{2}, 2$ $\mathrm{H}), 1.73$ - $1.61\left(\mathrm{~m}, \mathrm{CH}_{2}, 2 \mathrm{H}\right), 1.45-1.26\left(\mathrm{~m}, \mathrm{CH}_{2}, 2 \mathrm{H}\right), 0.92\left(\mathrm{t}, J=7.5 \mathrm{~Hz}, \mathrm{CH}_{3}, 3 \mathrm{H}\right)$.

1-Hexyl-3-(1H-indol-7-yl)urea, 1. Se disuelve 7-nitro- $1 H$-indol $(0.175 \mathrm{~g}, 1.08 \mathrm{mmol})$ en metanol $\left(10 \mathrm{~mL}\right.$ ) y se añade $\mathrm{Pd}(\mathrm{C})$ (aprox. $0.05 \mathrm{~g}$ ). El matraz de reacción se llena con $\mathrm{H}_{2}$. La mezcla de reacción se agita durante 90 min a temperatura ambiente. A continuación se filtra la mezcla de reacción para eliminar el catalizador y el disolvente se evapora a vacío, dando lugar a un aceite. Este aceite se disuelve en diclorometano $(50 \mathrm{~mL})$ y se añade 1,1-carbonildiimidazol (0.650 mg, $4 \mathrm{mmol})$, y se agita bajo $\mathrm{N}_{2}$ durante $6 \mathrm{~h}$, formándose un precipitado blanco. E1 precipitado blanco (N-(1H-indol-7-yl)-1H-imidazole-1-carboxamida) se filtra, se disuelve en diclorometano $(50 \mathrm{~mL})$ y se añade hexilamina $(1 \mathrm{~mL}, 7.5 \mathrm{mmol})$. La mezcla de reacción se agita a reflujo durante $16 \mathrm{~h}$. Después la mezcla de reacción se lava con agua $(3 \times 50 \mathrm{~mL})$ y la fracción orgánica se lleva a sequedad y se purifica en columna cristalográfica de silicagel (10\% metanol en diclorometano) para dar lugar a un sólido blanco con un rendimiento del $48 \%(0.124 \mathrm{~g}) .{ }^{1} \mathrm{H}$ RMN (300 MHz, DMSO- $d_{6}$ ): 10.65 (sa, NH, $1 \mathrm{H}$ ), 8.27 (s, NH, $\left.1 \mathrm{H},\right), 7.29$ (t, $J=2.8 \mathrm{~Hz}$, 
$\operatorname{ArCH}, 1 \mathrm{H}), 7.20(\mathrm{~d}, J=8.1 \mathrm{~Hz}, \operatorname{ArCH}, 1 \mathrm{H}), 7.04(\mathrm{~d}, J=7.6 \mathrm{~Hz}, \operatorname{ArCH}, 1 \mathrm{H}), 6.82-6.92(\mathrm{~m}$, $\operatorname{ArCH}, 1 \mathrm{H}), 6.39$ (dd, $J=3.0,2.0 \mathrm{~Hz}, \mathrm{ArCH}, 1 \mathrm{H}), 6.18$ (t, $J=5.6 \mathrm{~Hz}, \mathrm{NH}, 1 \mathrm{H}), 3.06-3.18(\mathrm{~m}$, $\left.\mathrm{CH}_{2}, 2 \mathrm{H}\right), 1.40-1.54\left(\mathrm{~m}, \mathrm{CH}_{2}, 2 \mathrm{H}\right), 1.23-1.37\left(\mathrm{~m}, 3 \mathrm{CH}_{2}, 6 \mathrm{H}\right), 0.87$ (t, J = 7.5 Hz, $\left.\mathrm{CH}_{3}, 3 \mathrm{H}\right)$. ${ }^{13} \mathrm{C}\left\{{ }^{1} \mathrm{H}\right\} \quad \mathrm{RMN}\left(75 \mathrm{MHz}, \mathrm{DMSO}-d_{6}\right): 155.7(\mathrm{CO}), 129.2(\mathrm{ArC}), 127.9(\mathrm{ArC}), 125.0(\operatorname{ArC})$, $124.8(\mathrm{ArCH}), 119.1(\mathrm{ArCH}), 114.6(\mathrm{ArCH}), 111.8(\mathrm{ArCH}), 101.5(\mathrm{ArCH}), 39.4\left(\mathrm{CH}_{2}\right), 31.0$ $\left(\mathrm{CH}_{2}\right), 29.7\left(\mathrm{CH}_{2}\right), 26.1\left(\mathrm{CH}_{2}\right), 22.1\left(\mathrm{CH}_{2}\right), 13.9\left(\mathrm{CH}_{3}\right)$. LRMS (ESI) m/z: $260.2\left([\mathrm{M}+\mathrm{H}]^{+}\right)$, $282.2\left([\mathrm{M}+\mathrm{Na}]^{+}\right), \quad 541.4\left([2 \mathrm{M}+\mathrm{Na}]^{+}\right)$. HRMS (ES) $\mathrm{m} / \mathrm{z}: \quad[\mathrm{M}+\mathrm{Na}]^{+}$calculado 282.1577, encontrado 282.1574. IR (film, $\mathrm{cm}^{-1}$ ): 3410 (f), 3350 (m), 3290 (d), 2950 (d), 2930 (f), 2860 (m), 1630 (f). Punto de fusión: $136^{\circ} \mathrm{C}$.

1-Hexyl-3-(1H-indol-7-yl)tiourea, 2. Se disuelve 7-nitro-1 $H$-indol (0.205 g, $1.260 \mathrm{mmol})$ en metanol $\left(30 \mathrm{~mL}\right.$ ) y se añade $\operatorname{Pd}(\mathrm{C})$ (aprox. $0.05 \mathrm{~g}$ ) llenándose el matraz de reacción con $\mathrm{H}_{2}$. La mezcla de reacción se agita durante $3 \mathrm{~h}$ a temperatura ambiente. A continuación se filtra la mezcla de reacción para separar el catalizador y el disolvente se evapora a vacío, dando lugar a un aceite. Este aceite se disuelve en diclorometano $(40 \mathrm{~mL})$ y se añaden $60 \mathrm{~mL}$ de una disolución acuosa saturada de $\mathrm{NaHCO}_{3}$. Se añade el tiofosgeno y se agita toda la noche a temperatura ambiente. Se lava la disolución, se seca con $\mathrm{MgSO}_{4}$ y se elimina el disolvente a vacío, dando lugar a un aceite naranja. Este aceite se disuelve en diclorometano (50 mL) y se añade hexilamina (0.6 mL, $4.4 \mathrm{mmol})$. La disolución se agita $15 \mathrm{~h}$ bajo $\mathrm{N}_{2}$ a reflujo. Después el disolvente se elimina a vacío y el aceite amarillo resultante se purifica en columna de silicagel (metanol:diclorometano 1:10), tras evaporar se obtienen $0.221 \mathrm{mg}$ (64\%) de un sólido blanco. ${ }^{1} \mathrm{H}$ RMN (300 MHz, DMSO- $d_{6}$ ): 10.89 (s, indol NH, $1 \mathrm{H}$ ), 9.22 (s, tiourea $\mathrm{N} H, 1 \mathrm{H}$ ), 7.51-7.40 (m, Ar CH, 2 H), 7.29 (t, $J=2.5$ Hz, Ar CH, $1 \mathrm{H}), 7.02-6.93$ (m, Ar CH, tiourea NH, $2 \mathrm{H}), 6.46$ (dd, $J=2.0,3.0 \mathrm{~Hz}, \mathrm{Ar} \mathrm{CH}, 1 \mathrm{H}), 3.55-3.40$ (m, $\left.\mathrm{CH}_{2}, 2 \mathrm{H}\right), 1.56-1.46\left(\mathrm{~m}, \mathrm{CH}_{2}, 2 \mathrm{H}\right), 1.32-1.22$ (m, $\mathrm{CH}_{2}, 6 \mathrm{H}$ ), 0.87 (t, $\left.J=6.5 \mathrm{~Hz}, \mathrm{CH}_{3}, 3 \mathrm{H}\right) .{ }^{13} \mathrm{C} \mathrm{RMN}\left(100 \mathrm{MHz}, \mathrm{DMSO}-d_{6}\right): 180.7$ (CS), $131.2(\mathrm{Ar} C), 129.5(\operatorname{Ar} C), 125.6(\mathrm{Ar} C H), 122.9(C), 119.0(\mathrm{Ar} C \mathrm{H}), 118.0(\mathrm{Ar} \mathrm{CH}), 118.0(\mathrm{Ar}$ $\mathrm{CH})$, 101.6 ( $\mathrm{Ar} \mathrm{CH}), 44.3\left(\mathrm{CH}_{2}\right), 31.0\left(\mathrm{CH}_{2}\right), 28.5\left(\mathrm{CH}_{2}\right), 26.0\left(\mathrm{CH}_{2}\right), 22.0\left(\mathrm{CH}_{2}\right), 13.9\left(\mathrm{CH}_{3}\right)$. LRMS (ES $\left.{ }^{-}\right)$m/z: $274.2[\mathrm{M}-\mathrm{H}]^{-}$. HRMS $\left(\mathrm{ES}^{+}\right) \mathrm{m} / \mathrm{z}$ : encontrado $298.1356[\mathrm{M}+\mathrm{Na}]^{+}$, calculado 298.1354. IR (Golden Gate) $v_{\max } / \mathrm{cm}^{-1}: 3380$ (indol $\mathrm{NH}$ tensión), 3330, 3190 (tiourea $\mathrm{NH}$ tensión), 3020, 2920, 2860 (CH tensión). Punto de fusión: $92-94^{\circ} \mathrm{C}$.

1-(2-butil-5-metil-1H-indol-7-il)-3-hexilurea, 3. Se disuelve 2-butil-5-metil-7-nitro-1H-indol $(0.200 \mathrm{~g}, 0.860 \mathrm{mmol})$ en metanol $(10 \mathrm{~mL})$ y se añade $\operatorname{Pd}(\mathrm{C})$ (aprox. $0.05 \mathrm{~g})$. El matraz de reacción se llena con $\mathrm{H}_{2}$ y la mezcla de reacción se agita durante 30 min a temperatura ambiente. A continuación se filtra la mezcla para eliminar el catalizador y el disolvente se evapora a vacío, dando lugar a un sólido blanco. Este solido se disuelve en diclorometano (50 $\mathrm{mL})$, se añade 1,1-carbonildiimidazol $(0.325 \mathrm{mg}, 2 \mathrm{mmol})$ y se agita bajo $\mathrm{N}_{2}$ durante $4 \mathrm{~h}$. A 
continuación la disolución se lava con agua, se seca con $\mathrm{MgSO}_{4}$, y se lleva a vacío. El sólido formado se disuelve en diclorometano $(60 \mathrm{~mL})$ y se añade hexilamina $(1 \mathrm{~mL}, 7.6 \mathrm{mmol})$. Tras agitar a reflujo durante $18 \mathrm{~h}$, la disolución se lleva a sequedad a vacío y se purifica por columna cristalográfica en silicagel (acetonitrilo:diclorometano 5:95) para dar lugar a un sólido blanco, con un rendimiento del $25 \%(0.050 \mathrm{~g}) .{ }^{1} \mathrm{H}$ RMN (400 MHz, DMSO- $\left.d_{6}\right): 10.32$ (s, NH, $\left.1 \mathrm{H}\right)$, 8.07 (s, NH, $1 \mathrm{H}), 6.85$ (s, $\mathrm{ArCH}, 1 \mathrm{H}), 6.83$ (s, $\mathrm{ArCH}, 1 \mathrm{H}), 6.14$ (s, $\mathrm{ArCH}, 1 \mathrm{H}), 6.01$ (s, NH, 1 H), $3.12\left(\mathrm{t}, J=7.0 \mathrm{~Hz}, \mathrm{CH}_{2}, 2 \mathrm{H}\right), 2.69$ (t, $\left.J=7.6 \mathrm{~Hz}, \mathrm{CH}_{2}, 2 \mathrm{H}\right), 2.28\left(\mathrm{~s}, \mathrm{CH}_{3}, 3 \mathrm{H}\right), 1.69-1.59$ (m, $\left.\mathrm{CH}_{2}, 2 \mathrm{H}\right), 1.51-1.42$ (m, $\left.\mathrm{CH}_{2}, 2 \mathrm{H}\right), 1.40-1.24$ (m, $\left.4 \mathrm{CH}_{2}, 8 \mathrm{H}\right), 0.96-0.84\left(\mathrm{~m}, 2 \mathrm{CH}_{3}, 6 \mathrm{H}\right)$. ${ }^{13} \mathrm{C}\left\{{ }^{1} \mathrm{H}\right\} \quad \mathrm{RMN}\left(101 \mathrm{MHz}, \mathrm{DMSO}-d_{6}\right): 155.64(\mathrm{CO}), 139.58(\operatorname{ArC}), 130.01(\operatorname{ArC}), 127.30$ $(\mathrm{ArC}), 125.96(\mathrm{ArC}), 123.83(\mathrm{ArC}), 113.45(\mathrm{ArCH}), 112.60(\mathrm{ArCH}), 98.40(\mathrm{ArCH}), 39.52$ $\left(\mathrm{CH}_{2}\right), 31.05\left(\mathrm{CH}_{2}\right), 31.01\left(\mathrm{CH}_{2}\right), 29.76\left(\mathrm{CH}_{2}\right), 27.31\left(\mathrm{CH}_{2}\right), 26.08\left(\mathrm{CH}_{2}\right), 22.10\left(\mathrm{CH}_{2}\right), 21.83$ $\left(\mathrm{CH}_{2}\right), 21.29\left(\mathrm{CH}_{3}\right), 13.92\left(\mathrm{CH}_{3}\right), 13.71\left(\mathrm{CH}_{3}\right)$. Punto de fusión: $118-120^{\circ} \mathrm{C}$.

1-(2-butil-5-metil-1H-indol-7-il)-3-hexiltiourea, 4. En metanol $(10 \mathrm{~mL})$ se disuelve 2-butil-5-metil-7-nitro-1H-indol (0.150 g, $0.640 \mathrm{mmol})$ y se añade $\operatorname{Pd}(\mathrm{C})$ (aprox. $0.05 \mathrm{~g})$. El matraz de reacción se llena con $\mathrm{H}_{2}$ y la mezcla de reacción se agita durante 30 min a temperatura ambiente. A continuación se filtra para eliminar el catalizador y el disolvente se evapora a vacío, dando lugar a un sólido blanco. Este sólido se disuelve en diclorometano (50 $\mathrm{mL}$ ) y se añaden $100 \mathrm{~mL}$ de una disolución acuosa saturada de $\mathrm{NaHCO}_{3}$. Se añade el tiofosgeno y se agita toda la noche a temperatura ambiente. Se lava la disolución, se seca con $\mathrm{MgSO}_{4}$ y se elimina el disolvente a vacío, formándose un aceite rojo. Este aceite se disuelve en diclorometano $(50 \mathrm{~mL})$ y se añade hexilamina $(1.0 \mathrm{~mL}, 7.6 \mathrm{mmol})$. La disolución se agita durante $16 \mathrm{~h}$ bajo $\mathrm{N}_{2}$ a reflujo. A continuación el disolvente se elimina a vacío y el aceite amarillo resultante se purifica en columna de silicagel (acetonitrilo:diclorometano, 5:95), tras evaporar se obtienen $0.080 \mathrm{mg}(36 \%)$ de un sólido blanco. Punto de fusión: $72-74{ }^{\circ} \mathrm{C}$. 

9. Conclusiones 



\section{CONCLUSIONES}

I. La síntesis de varios complejos en los que el nitrilo y el pirazol están coordinados en cis al fragmento metálico $f a c-" \operatorname{Re}(\mathrm{CO})_{3}$ " ha permitido el estudio de la reacción de acoplamiento de estos ligandos para obtener los correspondientes complejos pirazolilamidino. Este estudio mecanístico se ha realizado a partir de los complejos catiónicos ya que ofrecían una serie de ventajas sobre los neutros. La principal ventaja es que el nitrilo es más electrófilo, lo que se traduce en un descenso de la temperatura necesaria para la reacción y en la mínima formación de subproductos. Todos los datos obtenidos del estudio estos complejos catiónicos indican que el proceso de formación de los complejos pirazolilamidino transcurre a través de un mecanismo intramolecular y reversible.

II. El estudio sistemático de esta reacción, revela que el proceso de inserción esta favorecido cuanto más ácido sea el pirazol y a temperaturas moderadas. Este último factor está en desacuerdo con lo que se creía comúnmente ya que estos complejos generalmente se venían sintetizando calentando a reflujo en el correspondiente nitrilo.

III. El proceso de acoplamiento de nitrilos y pirazoles esta catalizado por bases. En el caso de los complejos neutros se consigue una disminución drástica de la temperatura y del tiempo de reacción cuando la reacción se lleva a cabo usando acetonitrilo como disolvente. En el caso de los complejos catiónicos, aparte de las ventajas señaladas para los complejos neutros, la presencia de base también permite llevar a cabo la reacción en disolventes distintos a nitrilos. Por tanto, esta aportación abrirá nuevas vías para facilitar la síntesis de nuevos complejos con pirazolilamidinos.

IV. Se han sintetizado nuevos complejos con el ligando pirazolilamidino, tanto neutros como catiónicos. La principal ventaja de este ligando sobre otros ligandos bidentados quelato nitrógeno dadores es la facilidad para introducir diferentes sustituyentes en el anillo quelato, pudiendo de esta manera modular las propiedades del compuesto final. Además el ligando pirazolilamidino es lo suficientemente robusto como para permitir la sustitución del halógeno coordinado por otro ligando, ya sea neutro o aniónico, lo que abre la posibilidad de sintetizar complejos con el mismo quelato pero diferentes ligandos de una manera muy sencilla.

V. Se ha evaluado tanto el efecto de diversos sustituyentes en el pirazolilamidino como la variación de la naturaleza del ligando en la "sexta" posición de coordinación sobre las propiedades fotofísicas de los complejos de renio(I). De estos datos se han podido extraer tendencias acerca de la influencia de dichos cambios en los espectros de emisión. Todos los 
complejos son fosforescentes y sus rendimientos cuánticos y tiempos de vida son similares a los de otros compuestos similares descritos en la bibliografía, lo que apoya el hecho de que la emisión se produzca a partir de un estado ${ }^{3}$ MLCT.

VI. En los estudios electroquímicos se puede observar la reducción irreversible de todos complejos, así como la oxidación irreversible de los complejos neutros, que se produce con disociación del halógeno. Los complejos catiónicos muestran además un proceso de oxidación reversible que afecta al metal.

VII. Los estudios fotofísicos y electroquímicos han sido justificados teóricamente a través de cálculos DFT y TD-DFT. Las energías obtenidas teóricamente siguen las mismas tendencias que los obtenidos experimentalmente.

VIII. Se ha conseguido introducir biomoléculas en el fragmento metálico fac$" \operatorname{Re}(\mathrm{CO})_{3}$ " por acoplamiento de nitrilos con 1-metilcitosina. Es previsible que este método se pueda extender a otros nitrilos y otras nucleobases.

IX. Se ha utilizado por primera vez un reactor microondas para la síntesis de complejos amidinos, tanto neutros como catiónicos, lo que abre nuevas vías sintéticas.

X. Por último, durante la estancia en la Universidad de Southampton para optar al título de Doctorado Internacional, se consiguió la síntesis de diversas moléculas capaces de transportar iones a través de una membrana de POPC. 


\subsection{Conclusions}

I. The synthesis of different rhenium(I) tricarbonyl complexes containing both pyrazole and nitrile ligands has allowed us to study the mechanism of the coupling reaction between these two ligands to afford pyrazolylamidino complexes. The study was carried out on cationic complexes because the nitrile is more electrophilic than in neutral complexes, and thus, for the latter higher temperatures are needed, which facilitates formation of different byproducts. All the data obtained starting from pyrazole-nitrile mixed cationic complexes support that the coupling process to give pyrazolylamidino ligands occurs by a reversible intramolecular mechanism.

II. The systematic study carried out on this process revealed that the coupling process is favored: (a) with the acidity of the pyrazole, and (b) at moderate temperatures (and unfavored as the temperature increases), opposite to what was commonly accepted, since pyrazolylamidino complexes had been traditionally synthesized by refluxing or heating pyrazole complexes in nitriles as solvents.

III. The coupling process is base catalyzed, and the reactions to obtain cationic pyrazolylamidino complexes are quantitative, immediate and occurred at room temperature for different solvents when $\leq 1 \%$ of $\mathrm{NaOH}$ (aq) is added to the parent complex solution. Neutral bromido pyrazolylamidino complexes are obtained rapidly and at room temperature when $1 \%$ of $\mathrm{NaOH}(\mathrm{aq})$ is added to the parent complex $\mathrm{CD}_{3} \mathrm{CN}$ solution. These results open a broad range of synthetic possibilities to obtain new pyrazolylamidino complexes in the future.

IV. Novel neutral and cationic rhenium(I) pyrazolylamidino complexes have been synthesized and characterized. The main advantage of pyrazolylamidino with respect to other bidentate chelating N-donor ligands is the facile introduction of different substituents starting from the appropriate pyrazole and nitrile. Once coordinated, the pyrazolylamidino ligand is robust enough to allow the substitution of the halide by another halide or by a different neutral ligand, so a broad panel of chelate complexes with different substituents is easily obtained.

V. The effect of several substituents at the pyrazolylamidino ligand has been evaluated, as well as the effect of the coordination of chlorido $v s$. bromido, and their substitution by neutral acetonitrile or pyrazole ligands yielding cationic complexes. All the complexes exhibit phosphorescence decays, their quantum yields and long lifetimes are similar to those of other literature-known rhenium(I) tricarbonyl complexes, and proof that emission arises from a prevalently ${ }^{3}$ MLCT state. 
VI. The electrochemical study reveals an irreversible reduction for all the complexes studied. The oxidation of the neutral complexes was found to be irreversible due to halido dissociation, whereas the cationic species display a reversible process implying the ReI/ReII couple.

VII. TD-DFT methods provide reasonable values for emission energies for all the complexes studied, which follow the same trend of experimental values of the emission wavelengths.

VIII. New luminescent rhenium(I) tricarbonyl complexes containing amidino chelating ligands are obtained by coupling nitriles and 1-methylcytosine. The formation of new amidino chelating ligands in this system by extending this reaction to couple different nitriles and new nucleobases is to be expected.

IX. Neutral and cationic amidino complexes have been synthesized, the latter may also be obtained in a microwave reactor, which opens the door to the coordination of a wide range of substrates to the system.

X. Finally, during my stay at the University of Southampton, carried out in order to obtain the "International Doctorate", the syntheses of different molecules able to transport ions through a POPC membrane was achieved. 
10. Parte experimental 



\section{METODOLOGIA EMPLEADA}

\subsection{Condiciones generales de reacción}

Las reacciones descritas en la presente memoria han sido realizadas en atmósfera de nitrógeno siguiendo las técnicas convencionales de Schlenk. Se ha evitado en todo momento el contacto de las disoluciones de los compuestos con el aire y la humedad atmosférica, salvo que se indique lo contrario. Los compuestos obtenidos pueden ser inestables en disolución en contacto con la atmósfera, por ello, las operaciones de purificación habituales (filtración, cristalización, etc.) se han llevado a cabo bajo atmosfera de nitrógeno. Las filtraciones se han realizado sobre tierra de diatomeas seca. Los reactivos sólidos se desoxigenaron a vacío antes de ser empleados. Los disolventes se han purificado de acuerdo a los procedimientos convencionales. ${ }^{152}$ Las reacciones que requieren tratamiento térmico se llevaron a cabo en baños de aceite o con dispositivos que permitan que el calentamiento sea homogéneo en toda la superficie del recipiente empleado. Los reactivos se adquirieron de fuentes comerciales y se utilizaron sin purificación previa. Los compuestos de partida han sido sintetizados siguiendo los procedimientos descritos en la bibliografía (Tabla 5).

Tabla 5. Compuestos de partida y su referencia bibliográfica.

\begin{tabular}{cc}
\hline \multicolumn{1}{c}{ Compuesto } & Referencia \\
\hline$f a c-\left[\operatorname{ReBr}(\mathrm{NCMe})_{2}(\mathrm{CO})_{3}\right]$ & 153 \\
$f a c-\left[\operatorname{ReCl}(\mathrm{NCMe})_{2}(\mathrm{CO})_{3}\right]$ & 153 \\
1-Methylcytosine & 154 \\
\hline
\end{tabular}

\subsection{Caracterización}

\subsubsection{Espectroscopia de infrarrojo}

Esta técnica ha sido empleada tanto para el seguimiento de las reacciones que implicasen compuestos organometálicos con ligandos carbonilos en $f a c$ (en disolución) como para la caracterización de los compuestos finales (en estado sólido y disolución). Los espectros se han registrado en un espectrómetro Perkin-Elmer RX I FT-IR para los espectros en disolución o en 
sólido en pastilla de $\mathrm{KBr}$, o en un espectrómetro Perkin-Elmer Frontier equipado con un accesorio Pike GladiATR-210 cuando se ha realizado el espectro directamente sobre el sólido, ambos pertenecientes al área de Química Inorgánica de la Universidad de Valladolid. La posición de las bandas se expresa en $\mathrm{cm}^{-1}$. Los espectros de infrarrojo en disolución se registraron en la zona comprendida entre $2200 \mathrm{~cm}^{-1}$ y $1800 \mathrm{~cm}^{-1}$, donde aparecen las absorciones debidas a las bandas de tensión $\mathrm{C}-\mathrm{O}$ de los carbonilos y para ello se utilizaron ventanas de $\mathrm{CaF}_{2}$ de $0.1 \mathrm{~mm}$ de espesor. Los espectros de infrarrojo en estado sólido se registraron en la zona comprendida entre 4000 y $400 \mathrm{~cm}^{-1}$.

\subsubsection{Espectroscopia de resonancia magnética nuclear}

Los espectros de resonancia magnética nuclear se han registrado en instrumentos Bruker AV400, Varian MR 400, MR 500 o VNMRS 500 pertenecientes al Laboratorio de Técnicas Instrumentales de la Universidad de Valladolid. Los espectros se han realizado a temperatura ambiente a menos que se indique lo contrario, empleando en todos los casos la señal del deuterio para el mantenimiento y ajuste de la homogeneidad del campo magnético. Los valores de los desplazamientos químicos $(\delta)$ se expresan en partes por millón (ppm) siendo valores positivos los que indican desplazamientos a frecuencias más altas o campos más bajos. Las constantes de acoplamiento $(J)$ se expresan en $\mathrm{Hz}$.

Los espectros de ${ }^{13} \mathrm{C}$ se han efectuado con desacoplamiento total del protón, lo que se expresa como ${ }^{13} \mathrm{C}\left\{{ }^{1} \mathrm{H}\right\}$. La asignación de los protones y de los carbonos se ha llevado a cabo mediante la realización de experimentos bidimensionales COSY, HSQC, HMBC, y 1D selective NOESY.

Todos los espectros de ${ }^{1} \mathrm{H}$ y ${ }^{13} \mathrm{C}\left\{{ }^{1} \mathrm{H}\right\}$ RMN están referidos a la señal del TMS.

\subsubsection{Análisis elemental de $C, H y N$.}

Los análisis elementales de $\mathrm{C}, \mathrm{H}$ y $\mathrm{N}$ se han realizados en un microanalizador Perkin Elmer 2400B perteneciente al área de Química Inorgánica de la Universidad de Valladolid. El criterio seguido para considerar los resultados satisfactorios es la admisión de un error absoluto máximo del $0,4 \%$ para los tres elementos. 


\subsubsection{Difracción de Rayos $X$}

Para la determinación estructural por difracción de rayos $\mathrm{X}$, los monocristales se ha utilizado un difractómetro Bruker AXS SMART 1000 o un Oxford Diffraction Super Nova, provistos de detector $\mathrm{CCD}$, usando radiación Mo-Ka monocromada mediante un cristal de grafito, ambos pertenecientes al Laboratorio de Técnicas Instrumentales de la Universidad de Valladolid. Generalmente los cristales se obtuvieron por difusión lenta en hexano de una disolución del complejo en acetona o tetrahidrofurano. Los cristales se midieron a $293 \mathrm{~K}$. Los datos se han integrado con el programa SAINT ${ }^{155}$ o CRISAlisPro. ${ }^{156}$ En general se ha usado una corrección analítica mediante indexación de caras, con el programa CrysAlisPro. Las estructuras fueron resultas con ShelXTL ${ }^{157}$ o con olex2.solve ${ }^{158}$. Los cálculos de parámetros geométricos se han hecho con PARST ${ }^{159,160}$ y los gráficos con OLEX2. La estructura del complejo fac$\left[\operatorname{ReBr}(\mathrm{CO})_{3}\left(\mathrm{NH}=\mathrm{C}(\mathrm{Me})\right.\right.$ indz- $\left.\left.^{2} N, N\right)\right]$ fue resuelta por el Prof. Carsten Strohmann en la Universidad Técnica de Dortmund (Alemania). Se midio en un difractometro Oxford Diffraction Xcalibur S, usando radiación Mo-Ka monocromada a $-100{ }^{\circ} \mathrm{C}$. La reducción de los datos se realizo con CrysAlis y la corrección de la absorción fue multiscan. La estructura fue resuelta usando el SHELXS97 y SHELXL97.

\subsubsection{Experimentos fotofísicos}

Los espectros de UV-Vis se midieron en un espectrómetro VARIAN-Cary 100 y los espectros de emisión en un Jobin-Yvon Fluorong 3.2.2 en diclorometano a temperatura ambiente, ambos equipos pertenecen al instituto UTINAM de la Universidad Franche-Comté (Francia). Los tiempos de vida medio se midieron en un espectofluorímetro Edinburgh FI-900, mediante un software con método de correlación temporal de un único fotón acoplado a un sistema Stroboscopic. La fuente de excitación fue un láser de diodo $(320 \mathrm{~nm})$. El mecanismo de respuesta del equipo se determinó usando una disolución dispersadora de la luz (LUDOX). Este equipo pertenece a la Universidad de Estrasburgo (Francia). Las medidas se llevaron a cabo por Dr. A. Kathyr y Dr. G. Ulrich respectivamente.

\subsubsection{Estudios electroquímicos}

Los análisis voltamperométricos se llevaron a cabo en una celda voltamperométrica estándar de tres electrodos con un potenciador Radiometer PGP 201 a temperatura ambiente. El electrolito 
fue una disolución $0.2 \mathrm{M}^{\mathrm{n}}{ }^{\mathrm{n}} \mathrm{Bu}_{4} \mathrm{PF}_{6}$ en acetonitrilo o diclorometano. El electrodo de trabajo es de disco de platino y el auxiliar de hilo de platino. El electrodo de referencia es $\mathrm{Ag} / \mathrm{Ag}^{+}$. Después de cada medida la referencia se comprobó con la pareja ferroceno-ferricinio $(+0.025 \mathrm{~V}$ $\mathrm{y}+0.16 \mathrm{~V}$ en el electrodo de referencia en disoluciones de acetonitrilo y diclorometano respectivamente). El Dr. F. Guyon realizó las medidas en el instituto UTINAM de la Universidad Franche-Comté (Francia).

\subsubsection{Detalles computacionales}

Todos los cálculos se han realizado con el programa Gaussian $09^{161}$ y se aplicó el método PBE1PBE. Este modelo hibrido Hartree-Fock / funcional de densidad se basa en el funcional Perdew-Burke-Erzenhof (PBE), ${ }^{162-164}$ en el cual la tasa de intercambio HF / DFT se fija a priori en $1 / 4$ y se utilizó para optimizar las geometrías de los estados fundamental y excitado. La optimización de la geometría se realizó sin restricciones de simetría y se usaron como coordenadas iniciales las obtenidas por difracción de Rayos X de los compuestos cuando se pudieron obtener. Un análisis de la frecuencia se llevó a cabo para asegurar que el estado de mínima energía de la estructura se había alcanzado sin frecuencias imaginarias. Las propiedades de emisión y absorción de los complejos se calcularon usando los datos de las geometrías optimizadas. Se calcularon en disolución de diclorometano por medio de TD-DFT ${ }^{165-167}$ al nivel PBE1PBE asociado a un método PCM para incluir los efectos del disolvente. ${ }^{168-170}$ No se ha incluido el acoplamiento espín-orbital en los métodos TD-DFT y esto influye en las energías de excitación en las que los electrones de renio estén implicados, ${ }^{171}$ aunque su efecto sobre el carácter de las transiciones de los complejos no es significativo. Por lo tanto, aunque el TD-DFT no puede calcular exactamente las energías de excitación, puede proporcionar rasgos espectrales razonables para los complejos estudiados. Se ha demostrado que este tipo de aproximación teórica es adecuada para complejos con metales de transición. ${ }^{172-177}$ En los cálculos, se usaron potenciales efectivos de core (ECP) y la base doble- $\zeta$ asociada a LANL2DZ para los átomos de renio y bromo, ${ }^{178,179}$ mientras que los átomos ligeros $(\mathrm{O}, \mathrm{N}, \mathrm{C}$ y H) se describieron con las bases $6-31+\mathrm{G}(\mathrm{d}, \mathrm{p}) .{ }^{180-183}$ Para asegurar que el método era el correcto, un complejo de cada tipo se midió con grupos diferentes de funcionales y bases diferentes. Los resultados obtenidos permiten afirmar que las condiciones elegidas son suficientemente precisas y no es necesario el uso de otras bases o funcionales que requieran más coste computacional. La contribución de cada fragmento de las moléculas estudiadas a los diferentes orbitales moleculares implicados en las transiciones ópticas se calcularon con el programa AOMix. ${ }^{184,185}$ La representación gráfica de los orbitales se realizó con el Gaussview. ${ }^{186}$ Los cálculos teóricos fueron llevados a cabo por el Dr. José M. Martín-Álvarez. 
11. Bibliografía 



\section{BIBLIOGRAFÍA}

1. Boag, N. M. and Kaesz, H. D. In Comprenhensive Organometallic Chemistry I; Abel, E. W., Stone, F. G. A., Wilkinson, G., Eds.; Pergamon: Oxford, 1982; Vol. 4; 161.

2. O'Connor, J. M. In Comprenhesive Organometallic Chemistry II; Abel, E. W., Stone, F. G. A., Wilkinson, G., Eds.; Pergamon: Oxford, 1995; Vol. 6; 167.

3. Braslavsky, S. E., Pure Appl. Chem., 2007, 79, 293-465.

4. Stokes, G. G., Philos. Trans., 1852, 142, 463-562.

5. Perrin, F., Ann. Phys. , 1929, 12, 169-275.

6. Wrighton, M. S.,Ginley, D. S. and Morse, D. L., J. Phys. Chem., 1974, 78, 2229-2233.

7. Luong, J. C.,Nadjo, L. and Wrighton, M. S., J. Am. Chem. Soc., 1978, 100, 5790-5795.

8. Vogler, A. and Kunkely, H., Coord. Chem. Rev., 2000, 200-202, 991-1008.

9. Stufkens, D. J. and Vlček Jr, A., Coord. Chem. Rev., 1998, 177, 127-179.

10. Forster, L. S., Coord. Chem. Rev., 2002, 227, 59-92.

11. Baba, A. I.,Shaw, J. R.,Simon, J. A.,Thummel, R. P. and Schmehl, R. H., Coord. Chem. Rev., 1998, 171, 43-59.

12. Striplin, D. R. and Crosby, G. A., Coord. Chem. Rev., 2001, 211, 163-175.

13. Ward, M. D. and Barigelletti, F., Coord. Chem. Rev., 2001, 216-217, 127-154.

14. Coleman, A.,Brennan, C., Vos, J. G. and Pryce, M. T., Coord. Chem. Rev., 2008, 252, 25852595.

15. Lo, K.-W. In Exploitation of Luminescent Organometallic Rhenium(I) and Iridium(III) Complexes in Biological Studies; Lees, A. J., Ed.; Springer Berlin Heidelberg, 2010; Vol. $29 ; 73-114$.

16. Yersin, H.,Rausch, A. F.,Czerwieniec, R.,Hofbeck, T. and Fischer, T., Coord. Chem. Rev., 2011, 255, 2622-2652.

17. Schanze, K. S.,Brent MacQueen, D.,Perkins, T. A. and Cabana, L. A., Coord. Chem. Rev., 1993, 122, 63-89.

18. Polo, A. S.,Itokazu, M. K.,Frin, K. M.,de Toledo Patrocínio, A. O. and Murakami Iha, N. Y., Coord. Chem. Rev., 2006, 250, 1669-1680.

19. Morais, M.,Paulo, A.,Gano, L.,Santos, I. and Correia, J. D. G., J. Organomet. Chem., 2013, 744, 125-139.

20. Coogan, M. P.,Doyle, R. P.,Valliant, J. F.,Babich, J. W. and Zubieta, J., J. Labelled Compd. Radiopharm., 2014, 57, 255-261.

21. Alberto, R.,Schibli, R.,Abram, U.,Egli, A.,Knapp, F. F. and Schubiger, P. A. In Radiochimica Acta, 1997; Vol. 79; pp 99. 
22. Schibli, R.,La Bella, R.,Alberto, R.,Garcia-Garayoa, E.,Ortner, K.,Abram, U. and Schubiger, P. A., Bioconjugate Chem., 2000, 11, 345-351.

23. R. Dilworth, J. and J. Parrott, S., Chem. Soc. Rev., 1998, 27, 43-55.

24. Lo, K. K.-W., Acc. Chem. Res., 2015.

25. Baggaley, E.,Weinstein, J. A. and Williams, J. A. G., Coord. Chem. Rev., 2012, 256, 17621785.

26. Zhao, Q.,Huang, C. and Li, F., Chem. Soc. Rev., 2011, 40, 2508-2524.

27. Lo, K. K.-W. and Tsang, K. H.-K., Organometallics, 2004, 23, 3062-3070.

28. Dyer, J.,Blau, W. J.,Coates, C. G.,Creely, C. M.,Gavey, J. D.,George, M. W.,Grills, D. C.,Hudson, S.,Kelly, J. M.,Matousek, P.,McGarvey, J. J.,McMaster, J.,Parker, A. W.,Towrie, M. and Weinstein, J. A., Photochem. Photobiol. Sci., 2003, 2, 542-554.

29. Joshi, T. and Gasser, G., Synlett, 2015, 26, 275-284.

30. Li, H. and Liao, J. C., Energy Environ. Sci., 2013, 6, 2892-2899.

31. Darensbourg, D. J., Inorg. Chem., 2010, 49, 10765-10780.

32. Wang, W.,Wang, S.,Ma, X. and Gong, J., Chem. Soc. Rev., 2011, 40, 3703-3727.

33. Sahara, G. and Ishitani, O., Inorg. Chem., 2015, 54, 5096-5104.

34. Grice, K. A. and Kubiak, C. P. In Chapter Five - Recent Studies of Rhenium and Manganese Bipyridine Carbonyl Catalysts for the Electrochemical Reduction of CO2; Michele, A., Rudi van, E., Eds.; Academic Press, 2014; Vol. Volume 66; 163-188.

35. Luong, J. C.,Faltynek, R. A. and Wrighton, M. S., J. Am. Chem. Soc., 1980, 102, 78927900.

36. Ward, M. D., Nat. Chem., 2010, 2, 610-611.

37. Blake, A. J.,Champness, N. R.,Easun, T. L.,Allan, D. R.,Nowell, H.,George, M. W.,Jia, J. and Sun, X.-Z., Nature Chem., 2010, 2, 688-694.

38. Bignozzi, C. A.,Argazzi, R.,Chiorboli, C.,Roffia, S. and Scandola, F., Coord. Chem. Rev., 1991, 111, 261-266.

39. Sun, S.-S. and Lees, A. J., Organometallics, 2002, 21, 39-49.

40. Keefe, M. H.,Benkstein, K. D. and Hupp, J. T., Coord. Chem. Rev., 2000, 205, 201-228.

41. Beer, P. D. and Hayes, E. J., Coord. Chem. Rev., 2003, 240, 167-189.

42. Thanasekaran, P.,Lee, C.-C. and Lu, K.-L., Acc. Chem. Res., 2012, 45, 1403-1418.

43. Thanasekaran, P.,Liao, R.-T.,Liu, Y.-H.,Rajendran, T.,Rajagopal, S. and Lu, K.-L., Coord. Chem. Rev., 2005, 249, 1085-1110.

44. Hupp, J. In Rhenium-Linked Multiporphyrin Assemblies:Synthesis and Properties; Alessio, E., Ed.; Springer Berlin Heidelberg, 2006; Vol. 121; 145-165.

45. Mines, G. A.,Tzeng, B.-C.,Stevenson, K. J.,Li, J. and Hupp, J. T., Angew. Chem. Int. Ed., 2002, 41, 154-157.

46. Gerhard, C., Ann. Chem., 1868, 108. 
47. Raczynska, E. D. G., R., Trends Org. Chem., 1998, 7, 85 - 93.

48. Dilling, W. L., Chem. Rev., 1969, 69, 845-877.

49. Barker, J. and Kilner, M., Coord. Chem. Rev., 1994, 133, 219-300.

50. Greenhill, J. V. and Lue, P. In 5 Amidines and Guanidines in Medicinal Chemistry; Ellis, G. P., Luscombe, D. K., Eds.; Elsevier, 1993; Vol. Volume 30; 203-326.

51. Richter, P. H. W., I.; Schleuder, H.; Keckeis, A., Pharmazie, 1993, 48, 163.

52. Dunn, P. J. In 5.19 - Amidines and N-Substituted Amidines; Taylor, A. R. K. J. K., Ed.; Elsevier: Oxford, 2005; 655-699.

53. Boyd, G. V., The Chemistry of Amidines and Imidates; Wiley: Chechester, 1991; Vol. 2.

54. Gridnev, I. D. and Gridneva, N. A., Usp. Khim. (Russ. Chem. Rev.), 1995, 64, 1091.

55. Karlsson, S. and Hogberg, H.-E., Org. Prep. Proced. Int., 2001, 33, 103.

56. Raimondi, L. and Benaglia, M., Eur. J. Org. Chem., 2001, 1033.

57. Arroyo, M.,Gómez-Iglesias, P.,Martín-Alvarez, J. M.,Alvarez, C. M.,Miguel, D. and Villafañe, F., Inorg. Chem., 2012, 51, 6070-6080.

58. Alvarez, C. M.,Garcia-Escudero, L. A.,Garcia-Rodriguez, R. and Miguel, D., Dalton Trans., 2013, 42, 2556-2561.

59. Alvarez, C. M.,Garcia-Escudero, L. A.,Garcia-Rodriguez, R. and Miguel, D., Chem. Commun., 2012, 48, 7209-7211.

60. Álvarez, C. M.,García-Rodríguez, R.,Martín-Alvarez, J. M.,Miguel, D. and Turiel, J. A., Inorg. Chem., 2012, 51, 3938-3940.

61. Álvarez, C. M.,García-Rodríguez, R. and Miguel, D., Inorg. Chem., 2012, 51, 2984-2996.

62. Alvarez, C. M.,Garcia-Rodriguez, R.,Martin-Alvarez, J. M. and Miguel, D., Dalton Trans., 2010, 39, 1201-1203.

63. Arroyo, M.,García-de-Prada, M. T.,García-Martín, C.,García-Pacios, V.,García-Rodríguez, R.,Gómez-Iglesias, P.,Lorenzo, F.,Martín-Moreno, I.,Miguel, D. and Villafañe, F., $J$. Organomet. Chem., 2009, 694, 3190-3199.

64. Alvarez, C. M.,García-Rodríguez, R. and Miguel, D., J. Organomet. Chem., 2007, 692, $5717-5726$.

65. Alvarez, C. M.,Garcia-Rodriguez, R. and Miguel, D., Dalton Trans., 2007, 3546-3554.

66. Garcia-Rodriguez, R. and Miguel, D., Dalton Trans., 2006, 1218-1225.

67. Arroyo, M.,Gomez-Iglesias, P.,Anton, N.,Garcia-Rodriguez, R.,Alegria, E. C. B. A.,Pombeiro, A. J. L.,Miguel, D. and Villafane, F., Dalton Trans., 2014, 43, 4009-4020.

68. Alvarez, C. M.,Alvarez-Miguel, L.,Garcia-Rodriguez, R. and Miguel, D., Dalton Trans., 2012, 41, 7041-7046.

69. Antón, N.,Arroyo, M.,Gómez-Iglesias, P.,Miguel, D. and Villafañe, F., J. Organomet. Chem., 2008, 693, 3074-3080. 
70. Arroyo, M., Ligandos bidentados derivados del pirazol con metales de los grupos 6 y 7; Universidad de Valladolid, 2007.

71. Mukherjee, R., Coord. Chem. Rev., 2000, 203, 151-218.

72. Kaes, C.,Katz, A. and Hosseini, M. W., Chem. Rev., 2000, 100, 3553-3590.

73. Desiraju, G. R., J. Chem. Soc., Dalton Trans., 2000, 3745-3751.

74. Braga, D., J. Chem. Soc., Dalton Trans., 2000, 3705-3713.

75. Shriver, D. F. K., R. D.; Adams R. D., The Chemistry of Metal Cluster Complexes, 1990.

76. Jones, C. J.,McCleverty, J. A. and Rothin, A. S., J. Chem. Soc., Dalton Trans., 1986, 109111.

77. Romero, A.,Vegas, A. and Santos, A., J. Organomet. Chem., 1986, 310, C8-C10.

78. López, J.,Santos, A.,Romero, A. and Echavarren, A. M., J. Organomet. Chem., 1993, 443, 221-228.

79. Gracey, G. D.,Rettig, S. J.,Storr, A. and Trotter, J., Can. J. Chem., 1987, 65, 2469-2477.

80. Guo, S.-L.,Wagner, M. and Bolte, M., Acta Crystallogr. E, 2001, 57, m428-m430.

81. Hillhouse, G. L.,Goeden, G. V. and Haymore, B. L., Inorg. Chem., 1982, 21, 2064-2071.

82. Lorenzo Cartón, F.; Valladolid, U. d., Ed.

83. Villafañe, F., Coord. Chem. Rev., 2014, 281, 86-99.

84. Arroyo, M.,López-Sanvicente, Á.,Miguel, D. and Villafañe, F., European Journal of Inorganic Chemistry, 2005, 2005, 4430-4437.

85. Arroyo, M.,Miguel, D.,Villafañe, F.,Nieto, S.,Pérez, J. and Riera, L., Inorg. Chem., 2006, 45, 7018-7026.

86. Kollipara, M. R.,Sarkhel, P.,Chakraborty, S. and Lalrempuia, R., J. Coord. Chem., 2003, $56,1085-1091$

87. Govindaswamy, P.,Mozharivskyj, Y. A. and Kollipara, M. R., J. Organomet. Chem., 2004, 689, 3265-3274.

88. Reisner, E.,Arion, V. B.,Rufinska, A.,Chiorescu, I.,Schmid, W. F. and Keppler, B. K., Dalton Trans., 2005, 2355-2364.

89. Kukushkin, V. Y. and Pombeiro, A. J. L., Chem. Rev., 2002, 102, 1771-1802.

90. Liu, X. and Chen, W., Dalton Trans., 2012, 41, 599-608.

91. Carmona, D.,Ferrer, J.,Lahoz, F. J.,Oro, L. A. and Lamata, M. P., Organometallics, 1996, $15,5175-5178$.

92. Hsieh, C.-C.,Lee, C.-J. and Horng, Y.-C., Organometallics, 2009, 28, 4923-4928.

93. Cinellu, M. A.,Stoccoro, S.,Minghetti, G.,Bandini, A. L.,Banditelli, G. and Bovio, B., J. Organomet. Chem., 1989, 372, 311-325.

94. Khripun, A. V.,Kukushkin, V. Y.,Selivanov, S. I.,Haukka, M. and Pombeiro, A. J. L., Inorg. Chem., 2006, 45, 5073-5083. 
95. Hvastijová, M.,Kohout, J.,Klimčíková, J. and Köhler, H., J. Coord. Chem., 1987, 15, 409411.

96. Kozisek, J.,Hvastijova, M.,Kohout, J.,Mrozinski, J. and Kohler, H., J. Chem. Soc., Dalton Trans., 1991, 1773-1778.

97. Mandal, G. C. S., Prashanta; Poddar, Raj K.; Bermejo, E.; Sevillano, P.; Castineiras, Alfonso, Indian Journal of Chemistry, 2001, 40, 630-632.

98. Albers, M. O.,Crosby, S. F. A.,Liles, D. C.,Robinson, D. J.,Shaver, A. and Singleton, E., Organometallics, 1987, 6, 2014-2017.

99. Uguagliati, P.,Belluco, U.,Michelin, R. A. and Guerriero, P., Inorg. Chim. Acta, 1984, 81, 61-67.

100. Amodio, C. A. and B. Nolan, K., Inorg. Chim. Acta, 1986, 113, 27-30.

101. Amo-Ochoa, P. and Zamora, F., Coord. Chem. Rev., 2014, 276, 34-58.

102. Bailey, P. J. and Pace, S., Coord. Chem. Rev., 2001, 214, 91-141.

103. Lippert, B., Coord. Chem. Rev., 2000, 200-202, 487-516.

104. Zangrando, E.,Pichierri, F.,Randaccio, L. and Lippert, B., Coord. Chem. Rev., 1996, 156, 275-332.

105. Louie, M.-W.,Ho-Chuen Lam, M. and Kam-Wing Lo, K., European Journal of Inorganic Chemistry, 2009, 2009, 4265-4273.

106. Wolff, M.,Munoz, L.,Francois, A.,Carrayon, C.,Seridi, A.,Saffon, N.,Picard, C.,Machura, B. and Benoist, E., Dalton Trans., 2013, 42, 7019-7031.

107. Bertrand, H. C.,Clède, S.,Guillot, R.,Lambert, F. and Policar, C., Inorg. Chem., 2014, 53, 6204-6223.

108. Lo, K. K.-W.,Louie, M.-W.,Sze, K.-S. and Lau, J. S.-Y., Inorg. Chem., 2008, 47, 602-611.

109. Louie, M.-W.,Liu, H.-W.,Lam, M. H.-C.,Lam, Y.-W. and Lo, K. K.-W., Chem. Eur. J., 2011, 17, 8304-8308.

110. Amoroso, A. J.,Coogan, M. P.,Dunne, J. E.,Fernandez-Moreira, V.,Hess, J. B.,Hayes, A. J.,Lloyd, D.,Millet, C.,Pope, S. J. A. and Williams, C., Chem. Commun., 2007, 3066-3068.

111. Stephenson, K. A.,Banerjee, S. R.,Besanger, T.,Sogbein, O. O.,Levadala, M. K.,McFarlane, N.,Lemon, J. A.,Boreham, D. R.,Maresca, K. P.,Brennan, J. D.,Babich, J. W.,Zubieta, J. and Valliant, J. F., J. Am. Chem. Soc., 2004, 126, 8598-8599.

112. Bartholoma, M. D.,Vortherms, A. R.,Hillier, S.,Joyal, J.,Babich, J.,Doyle, R. P. and Zubieta, J., Dalton Trans., 2011, 40, 6216-6225.

113. Pearson, C. and Beauchamp, A. L., Inorg. Chem., 1998, 37, 1242-1248.

114. Reimann, R. H. and Singleton, E., J. Chem. Soc., Dalton Trans., 1974, 808-813.

115. Edwards, D. A. and Marshalsea, J., J. Organomet. Chem., 1977, 131, 73-91.

116. Catalan, J.,Claramunt, R. M.,Elguero, J.,Laynez, J.,Menendez, M.,Anvia, F.,Quian, J. H.,Taagepera, M. and Taft, R. W., J. Am. Chem. Soc., 1988, 110, 4105-4111. 
117. Elguero, J.,Yranzo, G. I.,Laynez, J.,Jimenez, P.,Menendez, M.,Catalan, J.,De Paz, J. L. G.,Anvia, F. and Taft, R. W., J. Org. Chem., 1991, 56, 3942-3947.

118. Lees, A. J., Chem. Rev., 1987, 87, 711-743.

119. Kalyanasundaram, K., J. Chem. Soc., Faraday Trans. 2, 1986, 82, 2401-2415.

120. Chu, W.-K.,Ko, C.-C.,Chan, K.-C.,Yiu, S.-M.,Wong, F.-L.,Lee, C.-S. and Roy, V. A. L., Chem. Mater., 2014, 26, 2544-2550.

121. Welsh, M. J. S. A. E., Cell, 1993, 73, $1251-1254$.

122. Lloyd, S. E.,Pearce, S. H. S.,Fisher, S. E.,Steinmeyer, K.,Schwappach, B.,Scheinman, S. J.,Harding, B.,Bolino, A.,Devoto, M.,Goodyer, P.,Rigden, S. P. A.,Wrong, O.,Jentsch, T. J.,Craig, I. W. and Thakker, R. V., Nature, 1996, 379, 445-449.

123. Simon, D. B.,Bindra, R. S.,Mansfield, T. A.,Nelson-Williams, C.,Mendonca, E.,Stone, R.,Schurman, S.,Nayir, A.,Alpay, H.,Bakkaloglu, A.,Rodriguez-Soriano, J.,Morales, J. M.,Sanjad, S. A.,Taylor, C. M.,Pilz, D.,Brem, A.,Trachtman, H.,Griswold, W.,Richard, G. A.,John, E. and Lifton, R. P., Nat. Genet., 1997, 17, 171-178.

124. Simon, D. B.,Karet, F. E.,Hamdan, J. M.,Pietro, A. D.,Sanjad, S. A. and Lifton, R. P., Nat. Genet., 1996, 13, 183-188.

125. Scott, D. A.,Wang, R.,Kreman, T. M.,Sheffield, V. C. and Karniski, L. P., Nat. Genet., 1999, 21, 440-443.

126. Ashcroft, F. M., Academic Press: San Diego and London, 2000.

127. Busschaert, N.,Caltagirone, C.,Van Rossom, W. and Gale, P. A., Chem. Rev., 2015.

128. Davis, J. T.,Okunola, O. and Quesada, R., Chem. Soc. Rev., 2010, 39, 3843-3862.

129. Davis, A. P.,Sheppard, D. N. and Smith, B. D., Chem. Soc. Rev., 2007, 36, 348-357.

130. Fyles, T. M., Chem. Soc. Rev., 2007, 36, 335-347.

131. Matile, S.,Vargas Jentzsch, A.,Montenegro, J. and Fin, A., Chem. Soc. Rev., 2011, 40, 2453-2474.

132. Haynes, C. J. E. and Gale, P. A., Chem. Commun., 2011, 47, 8203-8209.

133. Gokel, G. W. and Barkey, N., New J. Chem., 2009, 33, 947-963.

134. Gale, P. A., Acc. Chem. Res., 2006, 39, 465-475.

135. Gale, P. A., Acc. Chem. Res., 2011, 44, 216-226.

136. Haynes, C. J. E.,Moore, S. J.,Hiscock, J. R.,Marques, I.,Costa, P. J.,Felix, V. and Gale, P. A., Chem. Sci., 2012, 3, 1436-1444.

137. Moore, S. J.,Wenzel, M.,Light, M. E.,Morley, R.,Bradberry, S. J.,Gomez-Iglesias, P.,SotoCerrato, V.,Perez-Tomas, R. and Gale, P. A., Chem. Sci., 2012, 3, 2501-2509.

138. Koulov, A. V.,Lambert, T. N.,Shukla, R.,Jain, M.,Boon, J. M.,Smith, B. D.,Li, H.,Sheppard, D. N.,Joos, J.-B.,Clare, J. P. and Davis, A. P., Angew. Chem. Int. Ed., 2003, 42, 4931-4933.

139. Smith, B. D. and Lambert, T. N., Chem. Commun., 2003, 2261-2268. 
140. Busschaert, N.,Gale, P. A.,Haynes, C. J. E.,Light, M. E.,Moore, S. J.,Tong, C. C.,Davis, J. T. and Harrell, J. W. A., Chem. Commun., 2010, 46, 6252-6254.

141. Wenzel, M.,Light, M. E.,Davis, A. P. and Gale, P. A., Chem. Commun., 2011, 47, 76417643.

142. Davis, J. T.,Gale, P. A.,Okunola, O. A.,Prados, P.,Iglesias-Sánchez, J. C.,Torroba, T. and Quesada, R., Nat. Chem., 2009, 1, 138-144.

143. Rousselle, A. V. and Heymann, D., Bone, 30, 533-540.

144. Cleland, W. W.,Andrews, T. J.,Gutteridge, S.,Hartman, F. C. and Lorimer, G. H., Chem. Rev., 1998, 98, 549-562.

145. Bok, D.,Galbraith, G.,Lopez, I.,Woodruff, M.,Nusinowitz, S.,BeltrandelRio, H.,Huang, W.,Zhao, S.,Geske, R.,Montgomery, C.,Van Sligtenhorst, I.,Friddle, C.,Platt, K.,Sparks, M. J.,Pushkin, A.,Abuladze, N.,Ishiyama, A.,Dukkipati, R.,Liu, W. and Kurtz, I., Nat. Genet., 2003, 34, 313-319.

146. Vaughan-Jones, R. D.,Spitzer, K. W. and Swietach, P., J. M. Cell. Cardiol., 46, 318-331.

147. Marcus, Y., J. Chem. Soc., Faraday Trans., 1991, 87, 2995-2999.

148. Bhosale, S. and Matile, S., Chirality, 2006, 18, 849-856.

149. Carlin, R. B. and Foltz, G. E., J. Am. Chem. Soc., 1956, 78, 1992-1997.

150. Thorand, S. and Krause, N., J. Org. Chem., 1998, 63, 8551-8553.

151. Rodriguez, A. L.,Koradin, C.,Dohle, W. and Knochel, P., Angew. Chem. Int. Ed., 2000, $39,2488-2490$.

152. Perrin, D. D. A. W. L. F., Purification of Laboratory Chemicals; 3rd ed.; Pergamon Press: Oxford, 1988.

153. Farona, M. F. and Kraus, K. F., Inorg. Chem., 1970, 9, 1700-1704.

154. Papoulis, A.,Al-Abed, Y. and Bucala, R., Biochemistry, 1995, 34, 648-655.

155. SAINT+. SAX programa de integración del detector de área. Versión 6.02. Bruker AXS, I. M., WI, 1999.

156. CrysAlisPro, Software de recolección e integración de datos. Oxford Diffraction Ltd., 2009.

157. Sheldrick, G. M., Acta Cryst., 2008, A64, 112. SHELXTL, An integrated system for solving, refining, and displaying crystal structures from diffraction data. Version 5.1. Bruker AXS, Inc. Madison, WI, 1998.

158. Bourhis, L. J., Dolomanov, O. V., Gildea, R. J., Howard, J. A. K., Puschmann, H., Acta Cryst., 2015, A71, 59-75.

159. Nardelli, M., Comput. Chem., 1983, 7, 95.

160. Nardelli, M., J. Appl. Crystallogr., 1995, 28, 659.

161. Gaussian 09, R. A., M. J. Frisch, G. W. Trucks, H. B. Schlegel, G. E. Scuseria, M. A. Robb, J. R. Cheeseman, G. Scalmani, V. Barone, B. Mennucci, G. A. Petersson, H. 
Nakatsuji, M. Caricato, X. Li, H. P. Hratchian, A. F. Izmaylov, J. Bloino, G. Zheng, J. L. Sonnenberg, M. Hada, M. Ehara, K. Toyota, R. Fukuda, J. Hasegawa, M. Ishida, T. Nakajima, Y. Honda, O. Kitao, H. Nakai, T. Vreven, J. A. Montgomery Jr., J. E. Peralta, F. Ogliaro, M. Bearpark, J. J. Heyd, E. Brothers, K. N. Kudin, V. N. Staroverov, R. Kobayashi, J. Normand, K. Raghavachari, A. Rendell, J. C. Burant, S. S. Iyengar, J. Tomasi, M. Cossi, N. Rega, J. M. Millam, M. Klene, J. E. Knox, J. B. Cross, V. Bakken, C. Adamo, J. Jaramillo, R. Gomperts, R. E. Stratmann, O. Yazyev, A. J. Austin, R. Cammi, C. Pomelli, J. W. Ochterski, R. L. Martin, K. Morokuma, V. G. Zakrzewski, G. A. Voth,P. Salvador, J. J. Dannenberg, S. Dapprich, A. D. Daniels, O. Farkas, J. B. Foresman, J. V. Ortiz, J. Cioslowski and D. J. Fox, Gaussian, Inc., Wallingford CT, 2009.

162. Perdew, J. P.,Burke, K. and Ernzerhof, M., Phys. Rev. Lett., 1996, 77, 3865-3868.

163. Perdew, J. P.,Burke, K. and Ernzerhof, M., Phys. Rev. Lett., 1997, 78, 1396.

164. Adamo, C. and Barone, V., J. Chem. Phys., 1999, 110, 6158-6170.

165. Helgaker, T. and Jorgensen, P., J. Chem. Phys., 1991, 95, 2595-2601.

166. Bak, K. L.,Jorgensen, P.,Helgaker, T.,Rund, K. and Jenson, H. J. A., J. Chem. Phys., 1993, 98, 8873-8887.

167. Autschbach, J.,Ziegler, T.,Gisbergen, S. J. A. and Baerends, E. J., J. Chem. Phys., 2002, 116, 6930-6940.

168. Cances, E.,Mennucci, B. and Tomasi, J., J. Chem. Phys., 1997, 107, 3032-3041.

169. Cossi, M.,Barone, V.,Mennucci, B. and Tomasi, J., Chem. Phys. Lett., 1998, 286, 253-260.

170. Mennucci, B. and Tomasi, J., J. Chem. Phys., 1997, 106, 5151-5158.

171. Shi, L.-L.,Liao, Y.,Zhao, L.,Su, Z.-M.,Kan, Y.-H.,Yang, G.-C. and Yang, S. Y., J. Organomet. Chem., 2007, 692, 5368-5374.

172. Stoyanov, S. R.,Villegas, J. M. and Rillema, D. P., Inorg. Chem., 2002, 41, 2941-2945.

173. Censo, D. D.,Fantacci, S.,Angelis, F. D.,Klein, C.,Evans, N.,Kalyanasundaram, K.,Bollink, H. J.,Gratzel, M. and Nazeeruddin, M. K., Inorg. Chem., 2008, 47, 980-989.

174. Kwon, T. H.,Cho, H. S.,Kim, M. K.,Kim, J. W.,Kim, J. J.,Lee, K. H.,Park, S. J.,Shin, I. S.,Kim, H.,Shin, D. M.,Chung, Y. K. and Hong, J. I., Organometallics, 2005, 24, 15781585.

175. Zhao, Q.,Liu, S.,Shi, M.,Wang, C.,Yu, M.,Li, L.,Li, F.,Yi, T. and Huang, C., Inorg. Chem., 2006, 45, 6152-6160.

176. Zheng, K.,Huang, J.,Shen, Y.,Kuang, D. and Yun, F., J. Phys. Chem. A, 2001, 105, 72487253.

177. Jr., A. V. and Zalis, S., J. Phys. Chem. A, 2005, 109, 2991-2992.

178. Hay, P. J. and Wadt, W. R., J. Chem. Phys., 1985, 82, 270-283.

179. Hay, P. J. and Wadt, W. R., J. Chem. Phys., 1985, 82, 299-310. 
180. Gabrielsson, A.,Matousek, P.,Towrie, M.,Hartl, F.,Zalis, S. and Jr., A. V., J. Phys. Chem. A, 2005, 109, 6147-6153.

181. Dattelbaum, D. M.,Omberg, K. M.,Hay, P. J.,Gebhart, N. L.,Martin, R. L.,Schoonover, J. R. and Meyer, T. J., J. Phys. Chem. A, 2004, 108, 3527-3536.

182. Dattelbaum, D. M.,Martin, R. L.,Schoonover, J. R. and Meyer, T. J., J. Phys. Chem. A, 2004, 108, 3518-3526.

183. Lundin, N. J.,Walsh, P. J.,Howell, S. L.,McGarvey, J. J.,Blackman, A. G. and Gordon, K. C., Inorg. Chem., 2005, 44, 3551-3560.

184. Gorelsky, S. I., AOMix: Program for Molecular Orbital Analysis, http://www.sgchem.net, University of Ottawa, version 6.5, 2011.

185. Gorelsky, S. I. and Lever, A. B. P., J. Organomet. Chem., 2001, 635, 187-196.

186. GaussView, Version 5, R. Dennington, T. Keith and J. Millam, Semichem Inc., Shawnee Mission KS, 2009. 

Anexo I 



\title{
Chemical Science
}

Cite this: Chem. Sci., 2012, 3, 2501

www.rsc.org/chemicalscience

EDGE ARTICLE

\section{Towards "drug-like" indole-based transmembrane anion transporters $\dagger$}

\author{
Stephen J. Moore, ${ }^{a}$ Marco Wenzel,,${ }^{a}$ Mark E. Light, ${ }^{a}$ Rebeka Morley, ${ }^{a}$ Samuel J. Bradberry,${ }^{a}$ Patricia Gómez- \\ Iglesias, ${ }^{a b}$ Vanessa Soto-Cerrato, ${ }^{c}$ Ricardo Pérez-Tomás ${ }^{c}$ and Philip A. Gale ${ }^{* a}$
}

Received 1st May 2012, Accepted 31st May 2012

DOI: $10.1039 / \mathrm{c} 2 \mathrm{sc20551 \textrm {c }}$

A series of mono-ureas and mono-thioureas, some incorporating a trifluoromethyl group, have been synthesised and their ability to facilitate ion transport assessed using a combination of ion selective electrode and fluorescence techniques. Chloride/nitrate and chloride/bicarbonate antiport and $\mathrm{HCl}$ symport processes were examined using phospholipid vesicles as a model system. In general, the trifluoromethyl functionalised receptors showed greater transport activity than unfluorinated analogous systems, corresponding with increased $c \log P$. The most active transporter facilitated chloride efflux from phospholipid vesicles at receptor to lipid ratios as low as $1: 20000$. In addition, in vitro fluorescence and viability assays indicated that the most potent anion transporters induced apoptosis in human cancer cell lines.

\section{Introduction}

Biological membranes function as semi-permeable hydrophobic barriers, separating cellular contents from their surroundings. Consequently the transmembrane transport of ionic species requires facilitation by membrane spanning transporter proteins. ${ }^{1}$ Faulty chloride transport proteins are linked to a number of diseases including Bartter's Syndrome, cystic fibrosis and Dent's disease. $^{2}$ In patients with cystic fibrosis, bicarbonate transport through the CFTR channels in epithelial cell membranes is also reduced and this has been linked by Quinton to the production of sticky mucus in the lungs of these patients. ${ }^{3}$ By synthesising molecules capable of restoring the functionality of impaired chloride and bicarbonate transporter proteins, it may be possible to develop new treatments for these types of disease. ${ }^{4}$

The design of molecules capable of functioning as membrane resident mobile carriers for anionic species is of particular interest to our group and others. ${ }^{5}$ A rare example of a class of

${ }^{a}$ Chemistry, University of Southampton, Southampton, SO17 1BJ, U.K. E-mail: philip.gale@soton.ac.uk; Tel: +(023)80593332

${ }^{b} I U$ CINQUIMA/Química Inorgánica, Faciltad de Ciencias, Universidad de Valladolid, 47005 Valladolid, Spain

'Department of Pathology and Experimental Therapeutics, Cancer Cell Biology Research Group, University of Barcelona, Barcelona, Spain

$\dagger$ Electronic supplementary information (ESI) available: Synthesis and characterisation of receptors, fitplots of the ${ }^{1} \mathrm{H}$ NMR titrations with various anions in DMSO- $d_{6} / 0.5 \%$ water, X-ray structure determination, experimental, vesicle assay methods, Hill plots, U-tube experiments, cell viability assays, acridine orange staining assays, Hoechst 33342 staining assays. CCDC reference numbers 879843-879845. For ESI and crystallographic data in CIF or other electronic format see DOI: $10.1039 / \mathrm{c} 2 \mathrm{sc} 20551 \mathrm{c}$

$\ddagger$ Present address: Fraunhofer Institute for Ceramic Technologies and Systems, IKTS, Dresden, Thick-Film Technology, Photovoltaics, Winterbergstraße 28, 01277 Dresden, Germany. natural products capable of facilitating transmembrane anion transport are the prodigiosins, a naturally occurring family of tripyrrolic anionophores capable of facilitating both symport and antiport processes. ${ }^{6}$ The $\mathrm{H}^{+} / \mathrm{Cl}^{-}$symport and $\mathrm{Cl}^{-} / \mathrm{HCO}_{3}{ }^{-}$ antiport properties of this family of molecules have been linked to their biological activity as anticancer agents. ${ }^{7}$ Transport of $\mathrm{HCl}$ from acidic compartments within cells by these compounds results in acidification of the cytoplasm within the cell. This is an early event in apoptosis; the prodigiosins have been shown to trigger apoptosis in cancer cells. ${ }^{8}$

Indole (as tryptophan) is found in the anion binding sites of the nitrate-binding protein $\mathrm{NrtA},{ }^{9}$ the bicarbonate-binding protein $\mathrm{CmpA},{ }^{10}$ and the sulfate-binding protein. ${ }^{11}$ Inspired by nature, synthetic indole containing receptors have been used for anion complexation and transport. ${ }^{12}$ In a recent study, we demonstrated that iso-pentyl functionalised indolylthioureas are potent anion antiporters, ${ }^{13}$ and when used in conjunction with a suitable chloride carrier, can facilitate bicarbonate uniport. ${ }^{14}$

Transporters for use in biological systems should ideally facilitate high ion fluxes at low carrier concentrations and have suitable absorption, distribution, metabolism, excretion, and toxicity (ADMET) characteristics. One strategy to optimise the drug-like properties of a mobile carrier is to use isosteres for potentially toxic moieties. We have previously shown that cyanoguanidines can replace the thiourea group ${ }^{15}$ in a simple phenylthiourea. ${ }^{16}$ An alternative strategy is to fluorinate the mobile carrier. Fluorinated drug molecules often display lower toxicity and higher metabolic stability than their unfluorinated analogues. ${ }^{17}$ Aromatic fluorination can increase both lipophilicity and hydrogen-bond acidity, enhancing membrane partitioning and leading to stronger anion-receptor interactions. Fluorination has been used in this way to enhance the transport properties of cholapods ${ }^{18}$ and calix[4]pyrroles. ${ }^{19}$ Our studies on 
structurally simple transmembrane anion transporters led to the development of tris-urea and tris-thiourea systems based upon tris(2-aminoethyl)amine (tren) scaffolds. ${ }^{20}$ In this latter case, fluorination of the tripodal transporters led to compounds that displayed in vitro activity, inducing apoptosis in human cancer cells. ${ }^{21}$ There are a number of rules of thumb, such as Lipinski's rule of five, that define ranges for various molecular parameters including molecular mass, numbers of atoms, numbers of hydrogen bond donors and acceptors and hydrophobicity in order to maximise the chances of compounds having acceptable absorption, distribution, metabolism and excretion properties. ${ }^{22}$ Our previous generation of fluorinated tren systems had molecular masses outside the acceptable range and the most active compounds had lipophilicities that were also too high (see $\mathrm{ESI} \dagger){ }^{21}$ In order to reduce the mass and lipophilicity of our transport motifs we decided to produce fluorinated derivatives of transporters based upon single urea and thiourea groups.

In this paper we report the transmembrane transport properties of indolylurea/thiourea compounds 1-8 and the structurally related ureas/thioureas 9-12. The anion transport properties of compounds 1 and 10 have been studied previously, ${ }^{23,16}$ whilst compound 5 has been used as a carbamate complexation agent. ${ }^{24}$ The anion binding properties of this series of compounds were analysed in the solution and in some cases in the solid state. The anion transport properties of these compounds were studied using a combination of ion selective electrode assays and fluorescence techniques in phospholipid vesicles and in vitro. The trifluoromethyl bearing compounds display higher anion transport activity than the unfluorinated analogues. This is presumably due to a combination of increased lipophilicity and improved anion affinity. The most active transporters exhibit anticancer properties.

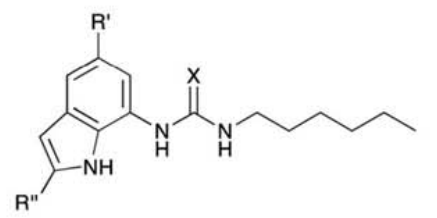

$1 \mathrm{X}=\mathrm{O}, \mathrm{R}^{\prime}=\mathrm{H}, \mathrm{R}^{\prime \prime}=\mathrm{H}$

$2 \mathrm{X}=\mathrm{S}, \mathrm{R}^{\prime}=\mathrm{H}, \mathrm{R}^{\prime \prime}=\mathrm{H}$

$3 \mathrm{X}=\mathrm{O}, \mathrm{R}^{\prime}=\mathrm{CF}_{3}, \mathrm{R}^{\prime \prime}={ }^{\mathrm{n}} \mathrm{Bu}$

$4 \mathrm{X}=\mathrm{S}, \mathrm{R}^{\prime}=\mathrm{CF}_{3}, \mathrm{R}^{\prime \prime}={ }^{\mathrm{n}} \mathrm{Bu}$<smiles>[R]c1ccc(NC([X])Nc2cccc3cc[nH]c23)cc1</smiles>

$5 \mathrm{X}=\mathrm{O}, \mathrm{R}=\mathrm{H}$

$6 \mathrm{X}=\mathrm{S}, \mathrm{R}=\mathrm{H}$

$7 \mathrm{X}=\mathrm{O}, \mathrm{R}=\mathrm{CF}_{3}$

$8 \mathrm{X}=\mathrm{S}, \mathrm{R}=\mathrm{CF}_{3}$<smiles>[R]c1ccc(NC([X])NCCCCCC)cc1</smiles>

$9 \mathrm{X}=\mathrm{O}, \mathrm{R}=\mathrm{H}$

$10 \mathrm{X}=\mathrm{S}, \mathrm{R}=\mathrm{H}$

$11 \mathrm{X}=\mathrm{O}, \mathrm{R}=\mathrm{CF}_{3}$

$12 \mathrm{X}=\mathrm{S}, \mathrm{R}=\mathrm{CF}_{3}$

\section{Results and discussion}

\section{Synthesis}

We have previously reported the synthesis of compounds $1,{ }^{23} 5,{ }^{24}$ and $10 .{ }^{16}$ Compound 2 was synthesised in $64 \%$ yield from 7-nitroindole, using our previously published method for generating thioureas. ${ }^{13}$ Compounds $\mathbf{3}$ and $\mathbf{4}$ were derived from 2butyl-7-nitro-5-(trifluoromethyl)- $1 H$-indole ${ }^{25}$ and synthesised in
$60 \%$ and $47 \%$ yields respectively. ${ }^{13}$ Compounds 6,7 and 8 were prepared from 7-nitroindole. Hydrogenation in methanol with $\mathrm{Pd} / \mathrm{C}$ catalyst, followed by reaction with 4-(trifluoromethyl) phenylisocyanate in dichloromethane afforded compound 7 in $51 \%$ yield, whilst reaction with the corresponding isothiocyanate gave compounds $\mathbf{6}$ and 8 , each in $20 \%$ yield. Compounds $9,{ }^{26} 11$ and 12 were obtained by reaction of hexylamine with the corresponding isocyanate or isothiocyanate in dichloromethane in $98 \%, 69 \%$ and $47 \%$ yields respectively. Further synthetic details and characterisation of the compounds are described in the supporting information. $\dagger$

\section{Anion binding in solution}

The ability of compounds 1-12 to bind anions in solution was investigated using ' $\mathrm{H}$ NMR titration techniques in DMSO- $d_{6}$ / $0.5 \%$ water (with the anions added either as tetrabutylammonium (TBA) or tetraethylammonium (TEA) salts). The binding studies were performed for anions relevant to both biological systems and our transmembrane transport assays. Where possible the change in chemical shift of the most upfield urea/ thiourea NH signal was fitted to a $1: 1$ binding model using WinEQNMR2 software. ${ }^{27} \mathrm{~A}$ summary of the results is presented in Table 1. Previously reported stability constants are included for comparison. ${ }^{16,23}$ Fitted NMR titration curves and Job plots can be found in the supporting information. $\dagger$

Compounds 1-12 were found to exhibit strong 1: 1 binding with tetraethylammonium bicarbonate, moderate $1: 1$ interactions with tetrabutylammonium chloride and no significant interaction with tetrabutylammonium nitrate. ${ }^{13}$ Peak broadening of the urea NH signal was observed with the basic bicarbonate anion for compounds $\mathbf{4}$ and 12. Compounds $\mathbf{6}$ and $\mathbf{8}$ exhibited thiourea $\mathrm{NH}$ peak broadening upon addition of tetraethylammonium bicarbonate and the resulting sigmoidal binding curves did not fit the available models. Although Job plot

Table 1 Stability constants $K_{\mathrm{a}}\left(\mathrm{M}^{-1}\right)$ for compounds 1-12 with chloride and nitrate (added as tetrabutylammonium salts) and bicarbonate (added as the tetraethylammonium salt) in DMSO- $d_{6} / 0.5 \%$ water at $298 \mathrm{~K}^{a}$

\begin{tabular}{lrll}
\hline & Chloride & Bicarbonate & Nitrate \\
\hline $\mathbf{1}$ & $64^{b}$ & 2330 & $c$ \\
$\mathbf{2}$ & 17 & 414 & $c$ \\
$\mathbf{3}$ & 154 & $>10^{4}$ & $c$ \\
$\mathbf{4}$ & 40 & $2150^{d}$ & $c$ \\
$\mathbf{5}$ & 95 & 3860 & $c$ \\
$\mathbf{6}$ & 25 & $e$ & $c$ \\
$\mathbf{7}$ & 101 & $4050(19 \%$ error $)$ & $c$ \\
$\mathbf{8}$ & 26 & 121 & $c$ \\
$\mathbf{9}$ & 16 & 262 & $c$ \\
$\mathbf{1 0}$ & 14 & 329 & $c$ \\
$\mathbf{1 1}$ & 23 & $931^{f}$ & $c$ \\
$\mathbf{1 2}$ & 26 & & $c$
\end{tabular}

${ }^{a}$ All errors $<15 \%$ unless stated otherwise. Data fitted to a $1: 1$ binding model. Binding constant obtained by following most upfield NH unless stated otherwise. ${ }^{b}$ Binding constant obtained by following downfield urea NH due to peak overlap. ${ }^{c}$ No significant interaction observed. ${ }^{d}$ Binding constant obtained by following indole $\mathrm{NH}$ due to broadening of urea NH signals. ${ }^{e}$ Sigmoidal curve could not be fitted to a suitable binding model. ${ }^{f}$ Binding constant obtained by following aromatic $\mathrm{CH}$ due to significant broadening of thiourea NHs. 
analysis suggests $1: 1$ binding in both instances, the observed binding curve is perhaps indicative of more complex solution phase behaviour..$^{21,28}$

Thioureas are more acidic than analogous ureas and consequently may be expected to display higher stability constants with anionic guests. ${ }^{29}$ For the structurally simple ureas and thioureas 9-12 this trend was observed, but for indolyl compounds 1-8 this trend was reversed, as we have observed previously. ${ }^{13}$ The incorporation of electron-withdrawing trifluoromethyl substituents onto the transporter scaffold was found to increase receptor affinity for both chloride and bicarbonate, presumably due to the increased acidity of the hydrogen bonding $\mathrm{NH}$ groups. ${ }^{17}$

\section{Solid-state analysis}

The solid-state behaviour of compounds $\mathbf{3}, \mathbf{6}$ and $\mathbf{1 1}$ was examined using single-crystal X-ray diffraction (Fig. 1). Tables of

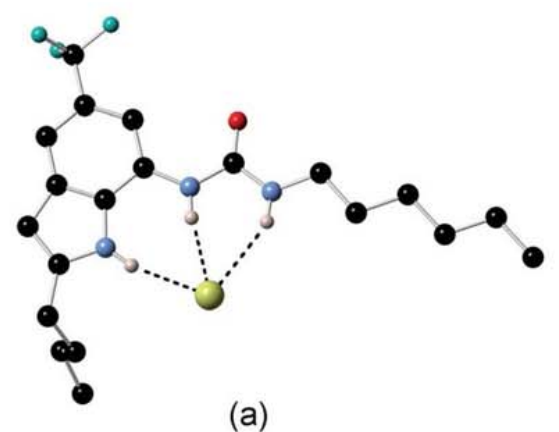

(a)

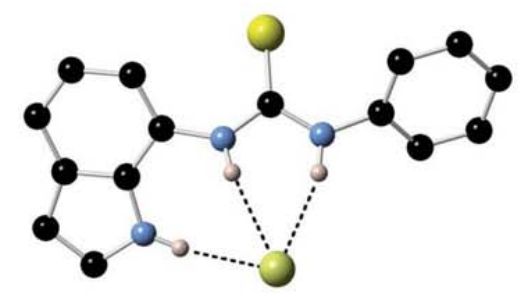

(b)

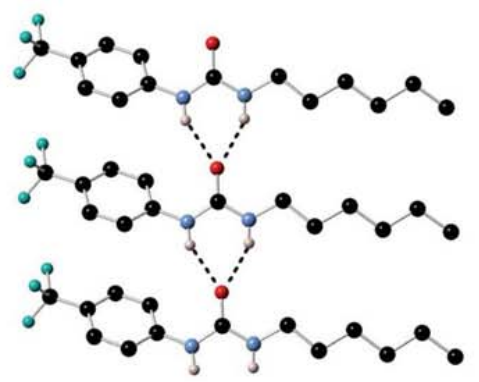

(c)

Fig. 1 X-Ray crystal structures of the chloride complex of 3 (a), the chloride complex of $\mathbf{6}$ (b) and 11 (c). Non-acidic hydrogen atoms and counter cations have been omitted for clarity. hydrogen bonds, data collection and refinement details, and thermal ellipsoid plots can be found for each structure in the supporting information. $\dagger$

Crystal structures were obtained for complexes of $\mathbf{3} \S$ with tetrabutylammonium chloride by slow evaporation of a solution of the receptor in DMSO with warming in the presence of excess tetrabutylammonium chloride and $\mathbf{6} \Phi$ by slow evaporation of the mixture diethyl ether/dichloromethane/isopropanol solution of the receptor in the presence of the same salt. Compound $\mathbf{3}$ forms three $\mathrm{N}-\mathrm{H}$ hydrogen bonds with the chloride ion $(\mathrm{N}-\mathrm{Cl}$ distances $3.140(5)-3.406(5) \AA, N-H \cdots C l$ angles $\left.151.2-170.1^{\circ}\right)$. Thiourea 6 similarly forms three $\mathrm{N}-\mathrm{H}$ hydrogen bonds with the chloride ion (N-Cl distances 3.181(2)-3.235(2) $\AA$, N-H $\cdots \mathrm{Cl}$ angles 141.6$160.1^{\circ}$ ) with the thiourea group twisted with respect to the indole functionality. A crystal structure was also obtained for free receptor $11 \|$ by slow evaporation of a warmed DMSO solution of the receptor. The structure of compound $\mathbf{1 1}$ shows characteristic intermolecular hydrogen bonding between the urea $\mathrm{NHs}$ and adjacent urea oxygen atoms ( $\mathrm{N}-\mathrm{O}$ distances 2.923(3) and $2.936(3) \AA, \mathrm{N}-\mathrm{H} \cdots \mathrm{O}$ angles 146.9 and $\left.150.3^{\circ}\right){ }^{30}$

\section{Transport studies}

We assessed the ability of compounds 1-12 to transport ions across phospholipid bilayers using a combination of ion selective electrode and fluorescence techniques. In a typical assay unilamellar, 1-palmitoyl-2-oleoylphosphatidyl-choline (POPC) vesicles (200 nm diameter) were prepared containing sodium chloride ( $489 \mathrm{mM}$ with $5 \mathrm{mM}$ phosphate buffer at $\mathrm{pH} 7.2$ ) and suspended in a solution of sodium nitrate $(489 \mathrm{mM}$ with $5 \mathrm{mM}$ phosphate buffer at $\mathrm{pH}$ 7.2). ${ }^{31}$ Compounds 1-12 were added as solutions in DMSO and the resulting chloride efflux from vesicles monitored using a chloride selective electrode (Accumet). At the end of the experiment detergent (octaethylene glycol monododecyl ether) was added to lyse the vesicles. The final reading was used to calibrate the electrode to $100 \%$ chloride release.

The results (Fig. 2) show in general higher rates of transport by thioureas $v s$. ureas (expect for compounds 5-8 where this order is reversed) and by fluorinated systems vs. non-fluorinated analogues. Under these conditions, the transmembrane transport of ions across the lipid bilayer is a passive process, with charge balance across the membrane maintained by either a symport or an antiport mechanism. ${ }^{4,31}$ The chloride efflux in Fig. 2 could be the consequence of $\mathrm{NaCl}$ or $\mathrm{HCl}$ symport processes or a chloride/ nitrate antiport process. Previous studies have shown that similar carriers operate predominately via an antiport mechanism, ${ }^{13,16}$ and it is likely that the observed chloride efflux is predominantly due to chloride/nitrate exchange. To confirm an antiport transport mechanism in this experiment $\mathrm{NaCl}$ was replaced with $\mathrm{CsCl}$ as the encapsulated chloride salt. No significant change in transport rates was observed, ruling out the possibility of $\mathrm{M}^{+} / \mathrm{Cl}^{-}$ cotransport (see ESI $\dagger$ ).

We also tested the compounds for their ability to mediate the more biologically relevant chloride/bicarbonate antiport process. ${ }^{2,6 d, 32}$ Vesicles containing sodium chloride $(0.450 \mathrm{mM}$ with $20 \mathrm{mM}$ phosphate buffer at $\mathrm{pH}$ 7.2) were suspended in a solution of sodium sulfate ( $162 \mathrm{mM}$ with $20 \mathrm{mM}$ phosphate buffer at $\mathrm{pH}$ 7.2). Compounds 1-12 were added as solutions in DMSO. After two minutes a sodium bicarbonate 'pulse' was added such that 


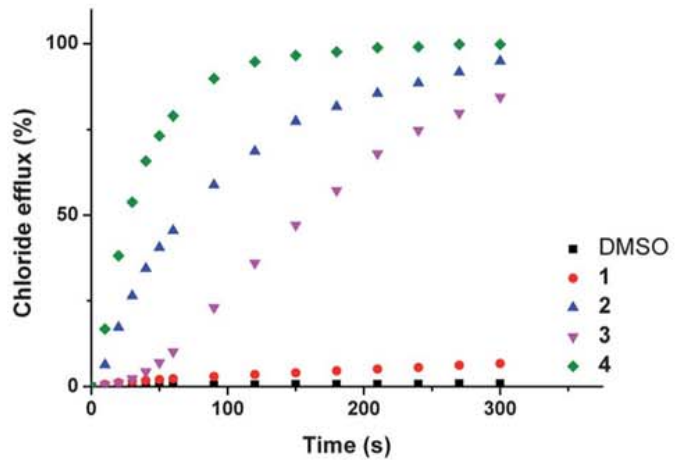

(a)

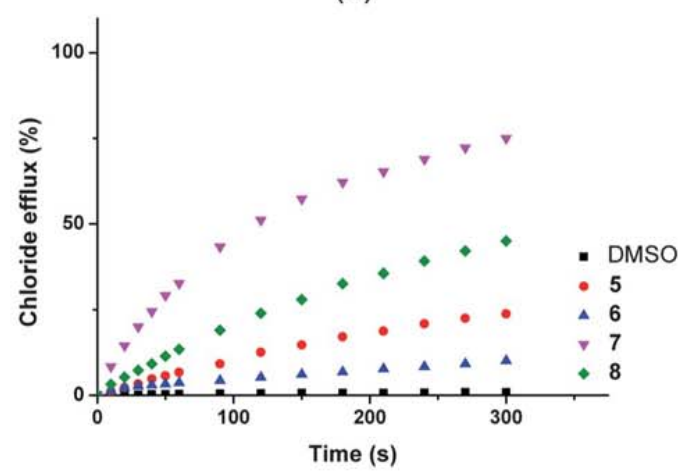

(b)

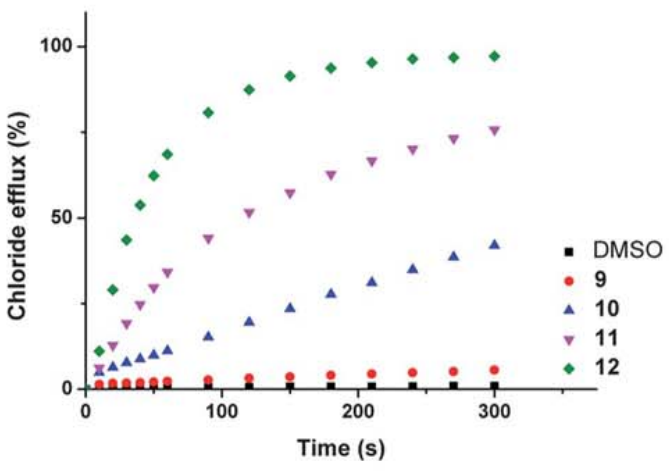

(c)

Fig. 2 Chloride efflux promoted by a DMSO solution of compounds 112 (2 mol\% carrier to lipid) from unilamellar POPC vesicles loaded with $489 \mathrm{mM} \mathrm{NaCl}$ buffered to $\mathrm{pH} 7.2$ with $5 \mathrm{mM}$ sodium phosphate salts. The vesicles were dispersed in $489 \mathrm{mM} \mathrm{NaNO}_{3}$ buffered to $\mathrm{pH} 7.2$ with $5 \mathrm{mM}$ sodium phosphate salts. At the end of the experiment, detergent was added to lyse the vesicles and calibrate the ISE to $100 \%$ chloride efflux. Each point represents an average of three trials. DMSO was used as a control.

the external concentration of bicarbonate was $40 \mathrm{mM}$. Chloride efflux was monitored throughout the experiment using a chloride selective electrode.

As a consequence of the difference in hydrophilicity, the doubly negatively charged sulfate anion is more difficult to transport across lipid bilayers than the nitrate anion. ${ }^{33}$ It follows that for the first two minutes of the bicarbonate pulse assay (i.e. before the pulse) we do not expect chloride transport to occur as the result of an antiport mechanism. Upon addition of the pulse, chloride/bicarbonate exchange becomes possible, and a marked increase in chloride efflux for the majority of the compounds was observed (Fig. 3). Although significant, the rate of bicarbonate transport was less than that observed with nitrate as the external anion. This can be rationalised by the observation that bicarbonate is less lipophilic than nitrate. ${ }^{33}$

For some of the compounds, low levels of chloride efflux were recorded in the two minutes before the chloride pulse in the aforementioned assay. To investigate this effect further, the experiment was repeated without the bicarbonate 'pulse'. Significant chloride efflux ( $>15 \%$ after $420 \mathrm{~s}$ ) was observed only for thiourea compound 4 (see ESI $\dagger$ ). Under the experimental conditions, transport could only be due to $\mathrm{HCl}$ symport or chloride/sulfate antiport (Fig. 4).

To examine the possibility of transmembrane sulfate transport $^{21}$ unilamellar POPC vesicles were prepared containing $100 \mathrm{mM} \mathrm{NaCl}$ and $2 \mathrm{mM}$ lucigenin buffered to $\mathrm{pH} 7.2$ with $20 \mathrm{mM}$ phosphate buffer. These vesicles were suspended in $100 \mathrm{mM} \mathrm{NaCl}$ solution buffered to $\mathrm{pH} 7.2$ with $20 \mathrm{mM}$ phosphate salts. A solution of sodium sulfate was added such that the external concentration of sulfate was $40 \mathrm{mM}$. For compounds 112 no evidence of sulfate transport was observed using this assay (see ESI $\dagger$ ).

To confirm that the chloride efflux observed with compound 4 was therefore the result of $\mathrm{HCl}$ co-transport, a $\mathrm{pH}$ gradient study was performed. ${ }^{34}$ Vesicles containing $450 \mathrm{mM}$ sodium chloride buffered to $\mathrm{pH} 4.0$ with $20 \mathrm{mM}$ citric acid buffer were suspended in a solution of $162 \mathrm{mM}$ sodium sulfate buffered to $\mathrm{pH} 7.2$ with $20 \mathrm{mM}$ sodium phosphate salts. Fig. 4 shows that the rate of chloride transport facilitated by compound $\mathbf{4}$ under gradient conditions is greater than in the absence of a $\mathrm{pH}$ gradient, evidence in favour of a $\mathrm{HCl}$ symport mechanism.

Proton transport was confirmed in an analogous assay, with POPC vesicles loaded with $\mathrm{NaCl}(489 \mathrm{mM})$ and $1 \mathrm{mM} \mathrm{8-}$ hydroxy-1,3,6-pyrenetrisulfonate (HPTS), a $\mathrm{pH}$ sensitive dye. ${ }^{35}$ These vesicles were suspended in a solution of $\mathrm{Na}_{2} \mathrm{SO}_{4}$ and the HPTS fluorescence measured upon addition of a DMSO solution of compound 4. An increase in intravesicular $\mathrm{pH}$ was observed, corresponding to deacidification of the vesicles via either $\mathrm{H}^{+} / \mathrm{Cl}^{-}$ co-transport or an equivalent $\mathrm{Cl}^{-} / \mathrm{OH}^{-}$antiport pathway (see ESI†े).

Transmembrane ion transport is typically facilitated by a mobile carrier mechanism, ${ }^{4}$ a relay mechanism,${ }^{36}$ or channel formation. ${ }^{4}$ Addition of cholesterol, to increase bilayer viscosity, is one method to test for mobile carrier activity, ${ }^{37}$ however results using this method were inconclusive. We have observed previously that structurally related compounds have been shown to operate via a mobile carrier mechanism ${ }^{13,16}$ and it is understood that cholesterol can alter properties other than membrane viscosity, ${ }^{38}$ hence U-tube assays were used to examine the transport mechanism. ${ }^{21}$ The membrane is modelled by a bulk organic phase separating two aqueous phases. For solubility reasons nitrobenzene was used as the organic phase. The source phase was loaded with sodium chloride ( $489 \mathrm{mM}$ buffered to $\mathrm{pH}$ 7.2 with $5 \mathrm{mM}$ sodium phosphate salts) and the receiving phase was loaded with sodium nitrate $(489 \mathrm{mM}$ buffered to $\mathrm{pH} 7.2$ with sodium phosphate salts). The carrier $(1 \mathrm{mM})$ was dissolved in a nitrobenzene organic phase and chloride transport into the 


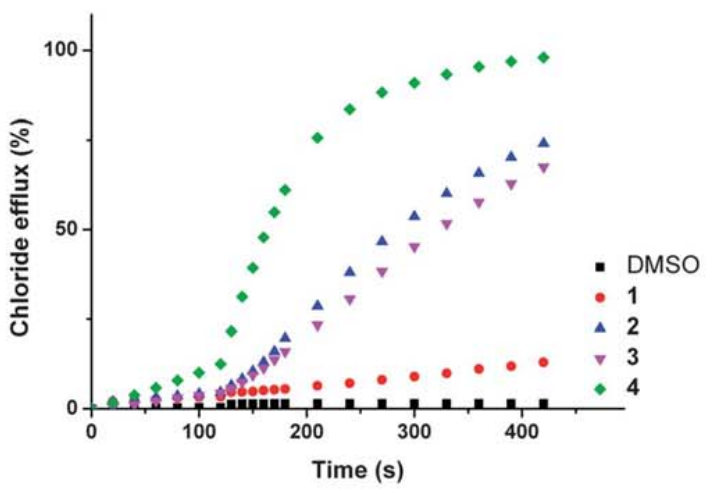

(a)

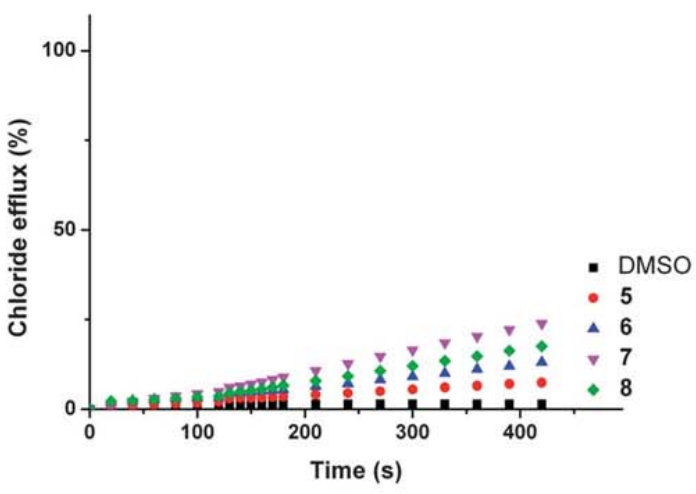

(b)

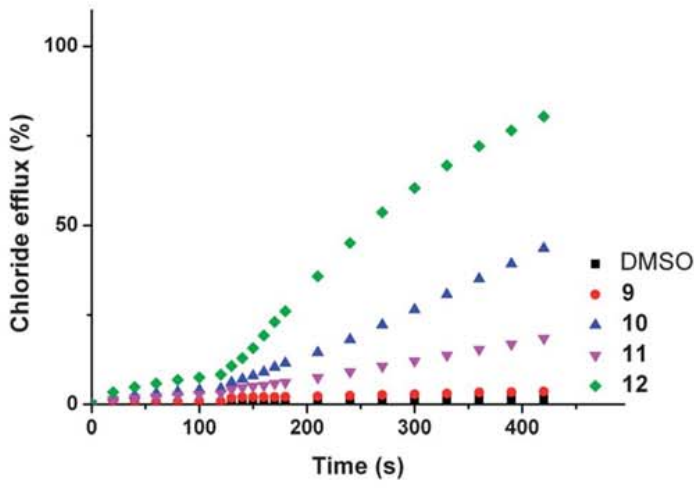

(c)

Fig. 3 Chloride efflux promoted by a DMSO solution of compounds 112 ( $2 \mathrm{~mol} \%$ carrier to lipid) from unilamellar POPC vesicles loaded with $450 \mathrm{mM} \mathrm{NaCl}$ buffered to $\mathrm{pH} 7.2$ with $20 \mathrm{mM}$ sodium phosphate salts. The vesicles were dispersed in $162 \mathrm{mM} \mathrm{Na}_{2} \mathrm{SO}_{4}$ buffered to $\mathrm{pH} 7.2$ with $20 \mathrm{mM}$ sodium phosphate salts. At $t=20 \mathrm{~s}$ a solution of sodium bicarbonate was added such that the external concentration of bicarbonate was $40 \mathrm{mM}$. At the end of the experiment, detergent was added to lyse the vesicles and calibrate the ISE to $100 \%$ chloride efflux. Each point represents an average of three trials. DMSO was used as a control.

receiving phase was monitored using an ion selective electrode. Owing to the separation of the two aqueous phases, transport by a channel mechanism is not possible. ${ }^{39}$ Compounds $2,3,4,7,8$, 11 and 12 were tested by this method and all yielded a higher

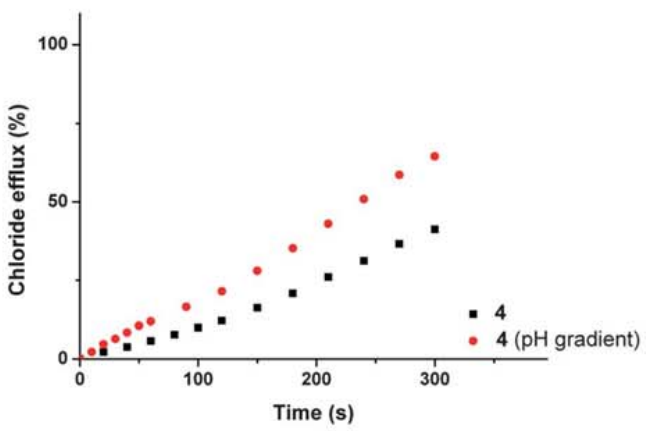

Fig. 4 Chloride efflux promoted by a DMSO solution of compound 4 ( $2 \mathrm{~mol} \%$ carrier to lipid) from unilamellar POPC vesicles loaded with either $450 \mathrm{mM} \mathrm{NaCl}$ buffered to $\mathrm{pH} 7.2$ with $20 \mathrm{mM}$ sodium phosphate salts or $450 \mathrm{mM} \mathrm{NaCl}$ buffered to $\mathrm{pH} 4.0$ with $20 \mathrm{mM}$ sodium citrate salts. The vesicles were dispersed in $162 \mathrm{mM} \mathrm{Na}_{2} \mathrm{SO}_{4}$ buffered to $\mathrm{pH} 7.2$ with $20 \mathrm{mM}$ sodium phosphate salts. At the end of the experiment, detergent was added to lyse the vesicles and calibrate the ISE to $100 \%$ chloride efflux. Each point represents an average of three trials.

concentration of chloride in the receiving phase than in the control (see ESI $\dagger$ ). These results, coupled with low $n$ values by Hill analysis (Table 2) suggest that this series of compounds facilitate ion transport via a mobile carrier mechanism rather than by channel formation.

To quantify the transport activity of compounds 1-12 Hill analyses $^{40}$ for the chloride/nitrate and chloride/bicarbonate antiport assays were performed (see ESI $\dagger$ ). Hill analysis allowed determination of an $\mathrm{EC}_{50,270 \mathrm{~s}}$ value; the concentration of carrier ( $\mathrm{mol} \%$ with respect to lipid) required to afford $50 \%$ chloride efflux $270 \mathrm{~s}$ after addition of the carrier (or after the bicarbonate 'pulse'), enabling us to compare the transport activity of the compounds. These values are summarised in Table 2, together with the Hill co-efficients and the calculated values for $c \log P^{41}$

By examining the data in Table 2 we can see that the trifluoromethyl functionalised receptors are more active than their unfluorinated analogues in the chloride/nitrate and chloride/ bicarbonate assays in all instances. Correspondingly, the $c \log P$ of the trifluoromethyl functionalised compounds is higher than that of their unfluorinated analogues. It is known that introducing a trifluoromethyl group onto an aromatic system increases lipophilicity. ${ }^{17}$ The enhanced membrane partitioning afforded by the addition of the trifluoromethyl moiety, combined with stronger anion binding properties through electron withdrawing effects (Table 1) afford the trifluoromethyl functionalised compounds enhanced ion transport activity. We have observed previously that thiourea transporters are often more active than their analogous ureas owing to differences in lipophilicity. ${ }^{13,20}$ In this series, thioureas are more active than ureas for compounds 1-4 and 9-12, but the reverse is true for compounds 5-8 although it should be noted that this series of compounds is significantly less efficient at anion transport than the other two. For these latter compounds there may be a steric factors to consider, since we observed twisting of the indole moiety in the solid state for compound 6 .

In summary, we have found that the chloride efflux is dependent on the external anion, of the order $\mathrm{NO}_{3}{ }^{-}>\mathrm{HCO}_{3}{ }^{-} \gg$ $\mathrm{SO}_{4}{ }^{2-}$, correlating with the hydrophilicity of the anion. 
Table 2 Overview of transport assays and lipophilicity of compounds 1-12

\begin{tabular}{|c|c|c|c|c|c|}
\hline & $c \log P^{a}$ & $\mathrm{EC}_{50,270 \mathrm{~s}^{b}}\left(\mathrm{Cl}^{-} / \mathrm{NO}_{3}{ }^{-}\right)$ & $n^{c}\left(\mathrm{Cl}^{-} / \mathrm{NO}_{3}^{-}\right)$ & $\mathrm{EC}_{50,270 \mathrm{~s}^{b}}\left(\mathrm{Cl}^{-} / \mathrm{HCO}_{3}^{-}\right)$ & $n^{c}\left(\mathrm{Cl}^{-} / \mathrm{HCO}_{3}{ }^{-}\right)$ \\
\hline 1 & 3.87 & $d$ & $d$ & $d$ & $d$ \\
\hline 2 & 4.03 & 0.029 & 0.8 & 0.18 & 0.7 \\
\hline 3 & 6.23 & 0.47 & 1.3 & 1.2 & 2.0 \\
\hline 4 & 6.40 & ${ }_{d}^{0.016^{e}}$ & ${ }_{d} 7^{e}$ & $\underset{d}{0.081^{e}}$ & ${ }_{d}^{1.5^{e}}$ \\
\hline 5 & 3.81 & & $d$ & & \\
\hline 6 & 3.98 & $d$ & $d$ & d & $d$ \\
\hline 7 & 4.83 & 1.1 & 1.6 & $d$ & $d$ \\
\hline 8 & 5.00 & 2.6 & 1.2 & $d$ & $d$ \\
\hline 9 & 3.39 & & $d$ & $d$ & $d$ \\
\hline 10 & 3.55 & $2.0-3.0^{f}$ & 0.9 & 3.1 & 0.6 \\
\hline 11 & 4.41 & 1.4 & 2.4 & & $d$ \\
\hline 12 & 4.57 & 0.44 & 1.6 & 0.89 & 1.0 \\
\hline
\end{tabular}

${ }^{a} c \log P$ calculated using Fieldview 2.0.2 for Macintosh (Wildman-Crippen model). ${ }^{b} \mathrm{EC}_{50,270 \mathrm{~s}}$ defined as concentration (mol\% carrier with respect to lipid) needed to obtain $50 \%$ efflux after $270 \mathrm{~s} .{ }^{c}$ Hill coefficient. ${ }^{d}$ Accurate Hill analysis could not be performed due to low activity. ${ }^{e}$ Some of the observed activity is from $\mathrm{H}^{+} / \mathrm{Cl}^{-}$co-transport. ${ }^{f}$ Range of values from four experiments. See ESI $\dagger$ for more details.

Compound 4, the most active transporter, facilitated chloride transport at carrier to lipid ratios as low as $1: 20000$. Evidence for compound $\mathbf{4}$ acting as an $\mathrm{HCl}$ symport agent was also observed. This compound has a molecular mass of 399.52 and contains three hydrogen bond donor groups. The $c \log P$ for the most active transporter was 6.40 . Although this is outside the range specified by Lipinski, it may be that for compounds designed as transmembrane transporters a higher $\log P$ will ensure the system remains in the cell membrane. ${ }^{22}$

\section{Cell based assays}

Modulation of intracellular $\mathrm{pH}\left(\mathrm{pH}_{\mathrm{i}}\right)$ has been proposed as a new strategy for cancer treatment. ${ }^{42}$ The anion transport activity of our receptors thus encouraged us to investigate their potential as cytotoxic agents in cancerous cell lines through the evaluation of cell viability, intracellular $\mathrm{pH}$ changes and apoptotic bodies' formation (for experimental details see ESI $\dagger$ ).

The in vitro cytotoxic activity of receptors 1-12 was assessed on several cancer cell lines of diverse origin; including human small-cell lung carcinoma (SCLC) GLC4, human melanoma A375, human colon adenocarcinoma SW480, and human oral adenosquamos carcinoma CAL27 cell lines. Initially, a singlepoint screening at $10 \mu \mathrm{M}$ was performed using the cell viability MTT assay in order to evaluate cytotoxic effects after receptor exposure (48 h). As observed in Fig. 5, receptors 3, 4, 7, 11, and 12 showed significant cytotoxicity, especially in GLC4 and A375 cells, while no significant effect was observed after treatment with the other receptors at the same dose and time.

Dose-response curve experiments were performed and $\mathrm{IC}_{50}$ values (Inhibitory Concentration of $50 \%$ of cell population) were calculated for cytotoxic compounds in the most sensitive cancerous cell lines and also in a non-cancerous human MCF10A mammary epithelial cell line (Table 3). These results corroborate the potency of these cytotoxic receptors, showing $\mathrm{IC}_{50}$ values around $10 \mu \mathrm{M}$ in GLC-4 cells. Interestingly, we observe a significant reduction in cytotoxicity in MCF10A compared to cancerous cells, suggesting some cytotoxic specificity of these receptors towards cancerous cells.

We have shown that fluorinated compounds exhibit higher anion affinity in solution, and have improved anion transport properties in comparison to their unfluorinated analogues. All of the significantly active compounds contain a trifluoromethyl substituent, and the one inactive fluorinated compound, 8 , showed the lowest transport activity in the ISE assays.

The $\mathrm{pH}_{\mathrm{i}}$ is important for many cellular processes, including control of the cell cycle, proliferation and cell death. It is regulated by several $\mathrm{pH}_{\mathrm{i}}$ homeostatic mechanisms, the most relevant are $\mathrm{Na}^{+} / \mathrm{H}^{+}$cotransport, $\mathrm{Cl}^{-} / \mathrm{HCO}_{3}{ }^{-}$antiport, $\mathrm{Na}^{+} / \mathrm{HCO}_{3}{ }^{-}$ symport and $\mathrm{H}^{+}$-translocation by ATPases. ${ }^{43}$ Since our receptors showed anion transport activity in the vesicle assays, we sought to determine whether they could show transport activity inside cells, contributing to their cytotoxicity. The in vitro ionophoric activity of the cytotoxic compounds was studied in A375 melanoma cells using vital staining with acridine orange (AO). This cell-permeable dye shows an orange fluorescence emission when it is protonated and accumulated in cellular acidic compartments. Conversely, AO exhibits green fluorescence when it is at higher $\mathrm{pH}$ in the cytosol. ${ }^{44}$ Cells in basal conditions were stained with $\mathrm{AO}$ and showed typical granular orange fluorescence, corresponding to cellular acidic compartments such as lysosomes (Fig. 6a and b). After cell exposure to cytotoxic compounds 3, 4,

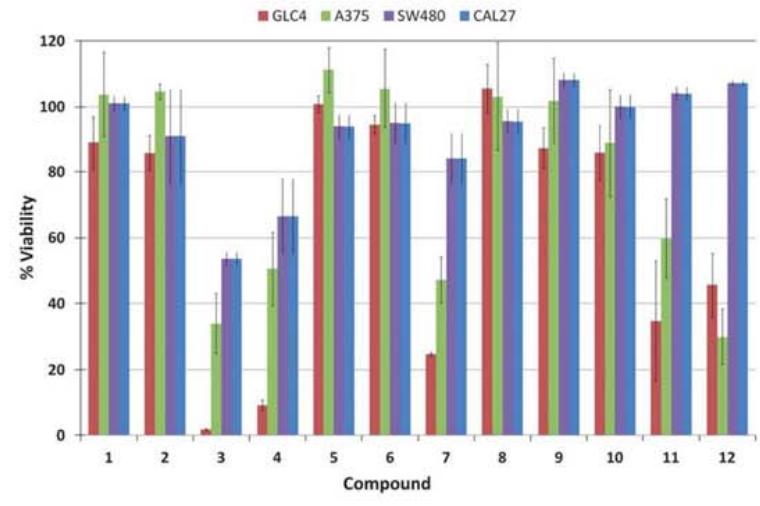

Fig. 5 Cell viability after $48 \mathrm{~h}$ of compound treatment measured by MTT assay. Single-point screening of compounds 1-12 $(10 \mu \mathrm{M})$ on a collection of different cancer cell lines, from left to right, GLC4, A375, SW480 and CAL27. 
View Online

Table $3 \mathrm{IC}_{50}$ values $(\mu \mathrm{M})$ of cytotoxic compounds $3,4,7,11$ and 12 on GLC4, A375 cancerous cell lines and MCF10A non-cancerous cell line

\begin{tabular}{lllc}
\hline & GLC4 & A375 & MCF10A \\
\hline $\mathbf{3}$ & $6.0 \pm 1.1$ & $17.4 \pm 5.5$ & $>70$ \\
$\mathbf{4}$ & $6.3 \pm 0.5$ & $14.3 \pm 0.1$ & $>40$ \\
$\mathbf{7}$ & $9.7 \pm 1.7$ & $22.9 \pm 2.6$ & $>200$ \\
$\mathbf{1 1}$ & $16.8 \pm 0.4$ & $13.7 \pm 2.0$ & $>200$ \\
$\mathbf{1 2}$ & $14.9 \pm 0.1$ & $21.1 \pm 0.8$ & $>30$ \\
\hline
\end{tabular}

7,11 , and 12, orange fluorescence completely disappeared in all cases (c, d, e, f and g; respectively). This indicates the increase of $\mathrm{pH}$ in the acidic organelles through the acidification of the cytoplasm. On the other hand, the non-cytotoxic compound $\mathbf{5}$ was evaluated and we observed that exposure to this receptor did
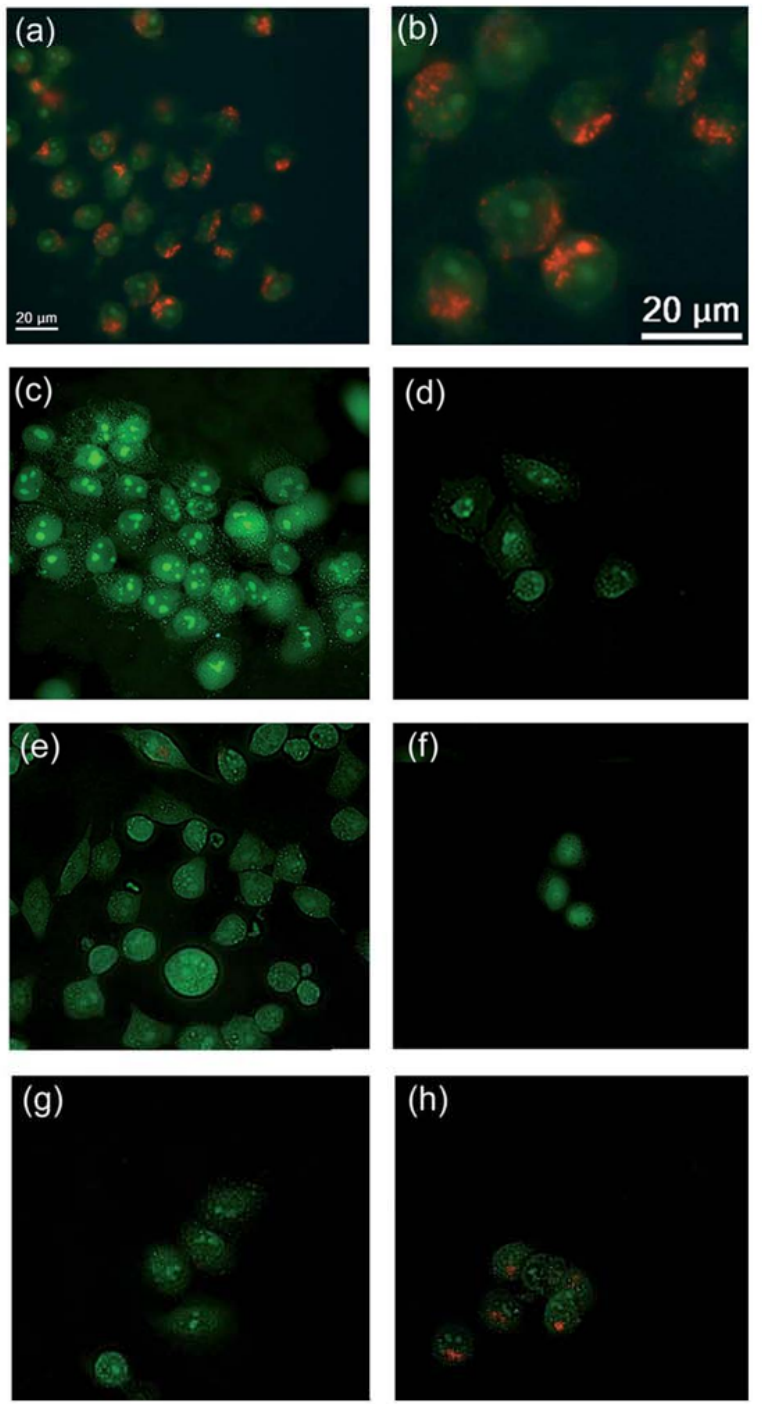

Fig. 6 Acridine Orange staining of melanoma A375 cells after $1 \mathrm{~h}$ exposure to different compounds $(10 \mu \mathrm{M})$ : (a, b) untreated cells, (c) compound 3, (d) compound 4, (e) compound 7, (f) compound 11, (g) compound 12, (h) compound $\mathbf{5}$. Cells with cytoplasmic granular orange fluorescence $(\mathrm{a}, \mathrm{b}, \mathrm{h})$; cells with complete disappearance of cytoplasmic orange fluorescence $(\mathrm{c}-\mathrm{g})$. not alter the $\mathrm{pH}_{\mathrm{i}}$, as the acidic organelles still showed orange fluorescence (h). It has been reported that a sufficiently large reduction in $\mathrm{pH}_{\mathrm{i}}$ alters the normal function of the cell, inducing cell damage may be sufficient to provoke cancer cell death. ${ }^{45}$ In fact, several molecules with cytotoxic properties, such as prodiginines, ${ }^{46}$ tambjamines ${ }^{47}$ and tripodal transmembrane anion transporters, ${ }^{21}$ are able to lower $\mathrm{pH}_{\mathrm{i}}$ presumably through either $\mathrm{HCl}$ cotransport or $\mathrm{Cl}^{-} / \mathrm{HCO}_{3}{ }^{-}$antiport across cell membranes thus favouring apoptosis.

All of the compounds that facilitated a decrease in the $\mathrm{pH}$ of acidic organelles in the $\mathrm{AO}$ assay are potent chloride/nitrate antiport agents. Compounds $\mathbf{3 , 4}$ and $\mathbf{1 2}$ show good activity as chloride/bicarbonate antiport agents and compound 4 can facilitate $\mathrm{HCl}$ co-transport. The biological activity of these compounds may result from the transport of $\mathrm{HCl}$ or basic bicarbonate, but equally could be the consequence of ion transport processes coupled to the uniport of chloride. We have previously reported that antiport agents can facilitate chloride uniport when linked to a complementary transport process. ${ }^{14,48}$

Finally, to better characterize the cellular influence of these receptors, the type of cell death induced by the compounds was analysed. Apoptosis is programmed cell death that controls removal of damaged cells without inducing inflammation in an organism. ${ }^{49}$ This feature differentiates this process from other types of cell death that cause inflammation, an undesirable effect in patient treatment. Moreover, apoptosis has been reported to be induced after changes in $\mathrm{pH}_{\mathrm{i}}{ }^{50}$ This type of cell death can be identified by the provoked changes in nuclear morphology including nuclear condensation, fragmentation and the formation of apoptotic bodies. All these nuclear alterations can be analysed by Hoechst 33342 staining, a fluorescent nuclear dye. Cells exposed to cytotoxic compounds were stained to evaluate whether the cell death triggered by these receptors was apoptosis. In Fig. 7 we can observe non-treated A375 cells with the typical rounded nuclei morphology (a) and cells treated with cytotoxic compounds $3,4,7,11$, and 12 showing nuclear condensation and apoptotic bodies' formation (b, c, d, e, f, respectively). These results confirm that the type of cell death induced by these compounds is apoptosis.
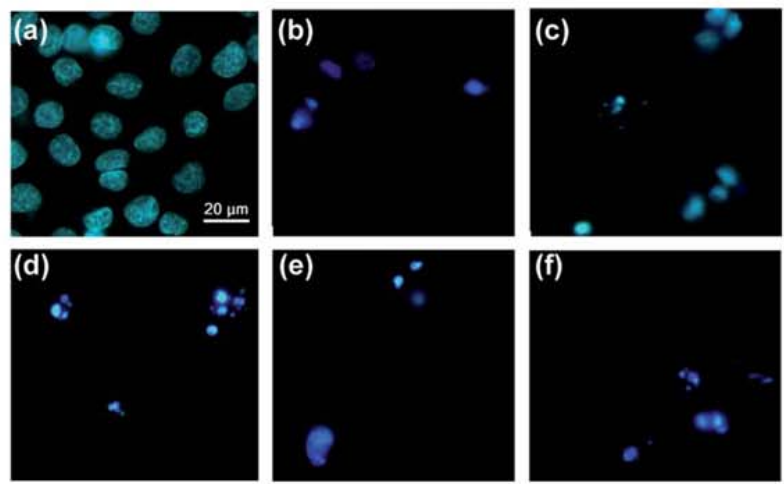

Fig. 7 Hoechst 33342 staining of A375 cells after $48 \mathrm{~h}$ exposure to different receptors $(10 \mu \mathrm{M})$ : (a) untreated cells, (b) compound 3, (c) compound 4, (d) compound 7, (e) compound 11, (f) compound 12. Cells with typical nuclear morphology (a), cells with nuclear condensation and apoptotic bodies (b-f). 
In summary, these results support the hypothesis that the cytotoxic effect caused in cancerous cells by these receptors is due to apoptosis and this process may be induced by sustained changes in the internal $\mathrm{pH}$ regulation as a result of the anion transport activity of these receptors. Further experiments are required in order to confirm the mechanism of deacidification.

\section{Conclusions}

We have shown that the fluorination of a series of structurally simple urea and thiourea compounds yields a significant increase in the transmembrane ion transport activity, and can promote new mechanistic pathways (namely $\mathrm{HCl}$ symport, as observed with compound 4). The trifluoromethyl group increased the anion affinity and the lipophilicity of the receptors, producing transporters capable of functioning as anticancer agents in vitro. Fluorination is proving to be a general strategy in the development of more active anion transport agents. ${ }^{51}$ The systems reported in this paper are significantly smaller and more 'druglike' than our previous generation of biologically active transmembrane anion transporters ${ }^{21}$ and yet retain their transport properties and biological activity. We believe this is a significant step towards more biologically compatible synthetic transmembrane transport systems.

\section{Acknowledgements}

PAG thanks the EPSRC for a PhD studentship (SJM) and postdoctoral fellowship (MW). We thank the EPSRC for access to the crystallographic facilities at the University of Southampton. ${ }^{52}$ This work was supported by a research grant from the Spanish government and the European Union (FIS-PI10/00338).

\section{Notes and references}

\$ Crystal data for the chloride complex of 3: $\mathrm{C}_{36} \mathrm{H}_{64} \mathrm{ClF}_{3} \mathrm{~N}_{4} \mathrm{O}, M=$ 661.36, monoclinic, $a=17.0415(6) \AA, b=14.5286(8) \mathrm{A}, c=17.7209(10)$ $\AA, \beta=116.023(2)^{\circ}, V=3942.7(3) \AA^{3}, T=120(2) \mathrm{K}, P 2_{1} / c, Z=4,31420$ reflections measured, 6931 unique $\left(R_{\text {int }}=0.1506\right), R_{1}=0.1167\left[F^{2}>\right.$ $\left.2 \sigma\left(F^{2}\right)\right], R_{1}=0.2056$ (all data). All hydrogen atoms were placed in idealised positions and refined using a riding model.

- Crystal data for chloride complex of 6: $\mathrm{C}_{31} \mathrm{H}_{49} \mathrm{ClN}_{4} \mathrm{~S}, M=545.25$, monoclinic, $a=10.0881(4) \mathrm{A}, b=9.5939(2) \mathrm{A}, c=17.0202(7) \mathrm{A}, \beta=$ $104.8840(10)^{\circ}, V=1592.02(10) \AA^{3}, T=120(2) \mathrm{K}, P c, Z=2,17355$ reflections measured, 5499 unique $\left(R_{\text {int }}=0.0520\right), R_{1}=0.0374\left[F^{2}>\right.$ $\left.2 \sigma\left(F^{2}\right)\right], R_{1}=0.0443$ (all data). All hydrogen atoms were placed in idealised positions and refined using a riding model.

$\|$ Crystal data for free receptor 11: $\mathrm{C}_{14} \mathrm{H}_{19} \mathrm{~F}_{3} \mathrm{~N}_{2} \mathrm{O}, M=288.31$, monoclinic, $a=19.510(13) \mathrm{A}, b=4.657(3) \mathrm{A}, c=16.320(11) \mathrm{A}, \beta=$ 107.506(16) ${ }^{\circ}, V=1414.0(16) \AA^{3}, T=100(2) \mathrm{K}, P 21 / c, Z=4,6403$ reflections measured, 2496 unique $\left(R_{\text {int }}=0.0621\right), R_{1}=0.0702\left[F^{2}>\right.$ $\left.2 \sigma\left(F^{2}\right)\right], R_{1}=0.1039$ (all data). All hydrogen atoms were placed in idealised positions and refined using a riding model.

1 E. D. Korn, Science, 1966, 153, 1491-1498; J. M. Diamond and E. M. Wright, Annu. Rev. Physiol., 1969, 31, 581-646.

2 (a) F. M. Ashcroft, Ion Channels and Disease, 2000, Academic Press, San Diego; (b) D. N. Sheppard, D. P. Rich, L. S. Ostedgaard, R. J. Gregory, A. E. Smith and M. J. Welsh, Nature, 1993, 362, $160-164$.

3 E. Cordat and J. R. Casey, Biochem. J., 2009, 417, 423-439; P. M. Quinton, Lancet, 2008, 372, 415-417; M. A. Garcia, N. Yang and P. M. Quinton, J. Clin. Invest., 2009, 119, 2613-2622.

4 (a) J. T. Davis, O. Okunola and R. Quesada, Chem. Soc. Rev., 2010, 39, 3843-3862; (b) C. J. E. Haynes and P. A. Gale, Chem. Commun., 2011, 47, 8203-8209; (c) A. P. Davis, D. N. Sheppard and B. D. Smith,
Chem. Soc. Rev., 2007, 36, 348-357; (d) T. M. Fyles, Chem. Soc. Rev., 2007, 36, 335-347; (e) S. Matile, A. V. Jentzsch, J. Montenegro and A. Fin, Chem. Soc. Rev., 2011, 40, 2453-2474; $(f)$ G. W. Gokel and N. Barkey, New J. Chem., 2009, 33, 947-963.

5 (a) P. A. Gale, Acc. Chem. Res., 2011, 44, 216-226; (b) P. R. Brotherhood and A. P. Davis, Chem. Soc. Rev., 2010, 39, 3633-3647

6 (a) A. Fürstner, Angew. Chem., Int. Ed., 2003, 42, 3582-3603; (b) J. L. Seganish and J. T. Davis, Chem Commun., 2005, 5781-5783; (c) H. Konno, H. Matsuya, M. Okamoto, T. Sato, Y. Tanaka, K. Yokoyama, T. Kataoka, K. Nagai, H. H. Wasserman and S. Ohkuma, J. Biochem., 1998, 124, 547-556; (d) J. T. Davis, P. A. Gale, O. A. Okunola, P. Prados, J. C. Iglesias-Sánchez, T. Torroba and R. Quesada, Nat. Chem., 2009, 1, 138-144.

7 (a) T. Sato, H. Konno, Y. Tanaka, T. Kataoka, K. Nagai, H. H. Wasserman and S. Ohkuma, J. Biol. Chem., 1998, 273, 21455-21462; (b) J. L. Sessler, L. R. Eller, W.-S. Cho, S. Nicolaou, A. Aguilar, J. T. Lee, V. M. Lynch and D. J. Magda, Angew. Chem., Int. Ed., 2005, 44, 5989-5992.

8 (a) N. Altan, Y. Chen, M. Schindler and S. M. Simon, J. Exp. Med., 1998, 187, 1583-1598; (b) Y. Chen, M. Schindler and S. M. Simon, J. Biol. Chem., 1999, 274, 18364-18373; (c) S. Matsuyama, J. Llopis, Q. L. Deveraux, R. Y. Tsien and J. C. Reed, Nat. Cell Biol., 2000, 2, 318-325.

9 N. M. Koropatkin, H. B. Pakrasi and T. J. Smith, Proc. Natl. Acad. Sci. U. S. A., 2006, 103, 9820-9825.

10 N. M. Koropatkin, D. W. Koppenaal, H. B. Pakrasi and T. J. Smith, J. Biol. Chem., 2007, 282, 2606-2614.

11 J. J. He and F. A. Quiocho, Science, 1991, 251, 1479-1481.

12 (a) P. A. Gale, Chem. Commun., 2008, 4525-4540; (b) P. A. Gale, J. R. Hiscock, S. J. Moore, C. Caltagirone, M. B. Hursthouse and M. E. Light, Chem.-Asian J., 2010, 5, 555-561; (c) P. A. Gale, J. R. Hiscock, C. Z. Jie, M. B. Hursthouse and M. E. Light, Chem. Sci., 2010, 1, 215-220; (d) C. Caltagirone, P. A. Gale, J. R. Hiscock, M. B. Hursthouse, M. E. Light and G. J. Tizzard, Supramol. Chem., 2009, 21, 125-130; (e) C. Caltagirone, J. R. Hiscock, M. B. Hursthouse, M. E. Light and P. A. Gale, Chem.-Eur. J., 2008, 14, 10236-10243; $(f)$ G. W. Bates, Triyanti, M. E. Light, M. Albrecht and P. A. Gale, J. Org. Chem., 2007, 72, 8921-8927.

13 N. J. Andrews, C. J. E. Haynes, M. E. Light, S. J. Moore, C. C. Tong, J. T. Davis, W. A. Harrell, Jr and P. A. Gale, Chem. Sci., 2011, 2, 256260.

14 S. J. Moore, M. G. Fisher, M. Yano, C. C. Tong and P. A. Gale, Dalton Trans., 2011, 40, 12017-12020.

15 (a) P. B. Smith and C. Crespi, Biochem. Pharmacol., 2002, 63, 19411948; (b) R. C. A. Onderwater, J. N. M. Commandeur, E. J. Groot, A. Sitters, W. M. P. B. Menge and N. P. E. Vermeulen, Toxicology, 1998, 125, 117-129; (c) S. A. Svarovsky, R. H. Simoyi and S. V. Makarov, J. Phys. Chem. B, 2001, 105, 12634-12643.

16 M. Wenzel, M. E. Light, A. P. Davis and P. A. Gale, Chem. Commun., 2011, 47, 7641-7643.

17 (a) S. Purser, P. R. Moore, S. Swallow and V. Gouverneur, Chem. Soc. Rev., 2008, 37, 320-330; (b) B. E. Smart, J. Fluorine Chem., 2001, 109, 3-11; (c) W. K. Hagmann, J. Med. Chem., 2008, 51, 4359-4369; (d) J. H-Böhm, D. Banner, S. Bendels, M. Kamsy, B. Kuhn, K. Müller, U. Obst-Sander and M. Stahl, ChemBioChem, 2004, 5, 637-643; (e) P. Shah and A. D. Westwell, J. Enzyme Inhib. Med. Chem., 2007, 22, 527-540.

18 B. A. McNally, A. V. Koulov, T. N. Lambert, B. D. Smith, J.-B. Joos, A. L. Sisson, J. P. Clare, V. Sgarlata, L. W. Judd, G. Megro and A. P. Davis, Chem.-Eur. J., 2008, 14, 9599-9606.

19 P. A. Gale, C. C. Tong, C. J. E. Haynes, O. Adeosun, D. E. Gross, E. Karnas, E. M. Sedenberg, R. Quesada and J. L. Sessler, J. Am. Chem. Soc., 2010, 132, 3240-3241.

20 N. Busschaert, P. A. Gale, C. J. E. Haynes, M. E. Light, S. J. Moore, C. C. Tong, J. T. Davis and W. A. Harrell, Jr, Chem. Commun., 2010, 46, 6252-6254.

21 N. Busschaert, M. Wenzel, M. E. Light, P. Iglesias-Hernández, R. Pérez-Tomás and P. A. Gale, J. Am. Chem. Soc., 2011, 133, 14136-14148.

22 C. A. Lipinski, F. Lombardo, B. W. Dominy and P. J. Feeney, $A d v$. Drug Delivery Rev., 1997, 23, 3-25; A. K. Ghose, V. N. Viswanadhan and J. J. Wendoloski, J. Comb. Chem., 1999, 1, $55-68$. 
23 C. J. E. Haynes, S. J. Moore, J. R. Hiscock, I. Marques, P. J. Costa, V. Félix and P. A. Gale, Chem. Sci., 2012, 3, 1436-1444.

24 (a) P. R. Edwards, J. R. Hiscock and P. A. Gale, Tetrahedron Lett., 2009, 50, 4922-4924; (b) P. R. Edwards, J. R. Hiscock, P. A. Gale and M. E. Light, Org. Biomol. Chem., 2010, 8, 100-106.

25 (a) A. L. Rodriguez, C. Koradin, W. Dohle and P. Knochel, Angew. Chem., Int. Ed., 2000, 39, 2488-2490; (b) C. Koradin, W. Dohle, A. L. Rodriguez, B. Schmid and P. Knochel, Tetrahedron, 2003, 59, 1571-1587.

26 (a) F. Shi, Y. Deng, T. SiMa and H. Yang, Tetrahedron Lett., 2001, 42, 2161-2163; (b) F. Shi, Q. Zhang, Y. Gu and Y. Deng, Adv. Synth. Catal., 2005, 347, 225-230; (c) P. Adams, U.S. Patent No. $3,161,676,1964$.

27 M. J. Hynes, J. Chem. Soc., Dalton Trans., 1993, 311-312.

28 A. Barnard, S. J. Dickson, M. J. Paterson, A. M. Todd and J. W. Steed, Org. Biomol. Chem., 2009, 7, 1554-1561.

29 (a) F. G. Bordwell, Acc. Chem. Res., 1988, 21, 456-463; (b) D. E. Gómez, L. Fabbrizzi, M. Licchelli and E. Monzani, Org. Biomol. Chem., 2005, 3, 1495-1500.

30 J. W. Steed, Chem. Soc. Rev, 2010, 39, 3686-3699.

31 (a) B. D. Smith and T. N. Lambert, Chem. Commun., 2003, 22612268; (b) A. V. Koulov, T. N. Lambert, R. Shukla, M. Jain, J. M. Boon, B. D Smith, H. Li, D. N. Sheppard, B. J-Joos, J. P. Clare and A. P. Davis, Angew. Chem., Int. Ed., 2003, 42, 49314933.

32 (a) W. W. Cleland, T. J. Andrews, S. Gutteridge, F. C. Hartman and G. H. Lorimer, Chem Rev., 1998, 98, 549-561; (b) A.-V. Rousselle and D. Heymann, Bone, 2002, 30, 533-540; (c) D. Bok, G. Galbraith, I. Lopez, M. Woodruff, S. Nusinowitz, H. BeltrandelRio, W. Huang, S. Zhao, R. Geske, C. Montgomery, I. Van Sligtenhorst, C. Friddle, K. Platt, M. J. Sparks, A. Pushkin, N. Abuladze, A. Ishiyama, R. Dukkipati, W. Liu and I. Kurtz, Nat. Genet., 2003, 34, 313-319; (d) R. D. Vaughan-Jones, K. W. Spitzer and P. Swietach, J. Mol. Cell. Cardiol., 2009, 46, 318-331.

33 Y. Marcus, J. Chem. Soc., Faraday Trans., 1991, 87, 2995-2999.

34 P. A. Gale, J. Garric, M. E. Light, B. A. McNally and B. D. Smith, Chem Commun, 2007, 1736-1738.

35 N. R. Clement and J. M. Gould, Biochemistry, 1981, 20, 1534-1538.
36 B. A. McNally, E. J. O'Neil, A. Nguyen and B. D. Smith, J. Am. Chem. Soc., 2008, 130, 17274-17275.

37 C. Kirby, J. Clarke and G. Gregoriadis, Biochem. J., 1980, 186, 591598

38 (a) H. Ohvo-Rekilä, B. Ramstedt, P. Leppimäki and J. P. Slotte, Prog. Lipid Res., 2002, 41, 66-97; (b) M. E. Weber, P. H. Schlesinger and G. W. Gokel, J. Am. Chem. Soc., 2005, 127, 636-642; (c) T. StarkePeterkovic, N. Turner, M. F. Vitha, M. P. Waller, D. E. Hibbs and R. J. Clarke, Biophys. J., 2006, 90, 4060-4070; (d) J. A. Urbina, S. Pekerar, H. Le, J. Patterson, B. Montez and E. Oldfield, Biochim. Biophys. Acta, Biomembr., 1995, 1238, 163-176.

39 O. Murillo, I. Suzuki, E. Abel, C. L. Murray, E. S. Meadows, T. Jin and G. W. Gokel, J. Am. Chem. Soc., 1997, 119, 5540-5549.

40 (a) A. V. Hill, Biochem. J., 1913, 7, 471-480; (b) S. Bhosale and S. Matile, Chirality, 2006, 18, 849-856.

41 (a) S. A. Wildman and G. M. Crippen, J. Chem. Inf. Comput. Sci., 1999, 39, 863-873; (b) Fieldview Version 2.0.2, Cresset, 2011

42 M. F. McCarty and J. Whitaker, Altern. Med. Rev., 2010, 15, 264 272.

43 I. H. Madshus, Biochem. J., 1988, 250, 1-8.

44 A. C. Allison and M. R. Young, Lysosomes in Biology and Pathology, Vol. 2., 1969, North-Holland Publishing Co., Amsterdam.

45 M. Yamagate and I. F. Tannock, Br. J. Cancer, 1996, 73, 1328 1334.

46 R. Pérez-Tomás, B. Montaner, E. Llagostera and V. Soto-Cerrato, Biochem. Pharmacol., 2003, 66, 1447-1452.

47 P. I. Hernández, D. Moreno, A. A. Javier, T. Torroba, R. PérezTomás and R. Quesada, Chem. Commun., 2012, 48, 1556-1558.

48 S. J. Moore, M. G. Fisher, M. Yano, C. C. Tong and P. A. Gale, Chem. Commun., 2011, 47, 689-691.

49 J. F. Kerr, A. H. Wyllie and A. R. Currie, Br. J. Cancer, 1972, 26, 239-257.

50 A. De Milito, E. Lessi, M. Logozzi, F. Lozupone, M. Spada, M. L. Marino, C. Federici, M. Perdicchio, P. Matarrese, L. Lugini, A. Nilsson and S. Fais, Cancer Res., 2007, 67, 5408-5417.

51 S. Bahmanjah, N. Zhang and J. T. Davis, Chem. Commun., 2012, 48, $4432-4434$

52 S. J. Coles and P. A. Gale, Chem. Sci., 2012, 3, 683-689. 

Anexo II 



\title{
Manganese cationic pyrazolylamidino complexes
}

\author{
Noelia Antón, Marta Arroyo, Patricia Gómez-Iglesias, Daniel Miguel, Fernando Villafañe* \\ IU CINQUIMA/Química Inorgánica, Facultad de Ciencias, Universidad de Valladolid, 47005 Valladolid, Spain
}

\section{A R T I C L E I N F O}

\section{Article history:}

Received 29 April 2008

Received in revised form 19 June 2008

Accepted 19 June 2008

Available online 26 June 2008

\section{Keywords:}

Pyrazolylamidino

Manganese

Hydrogen bonds

Cation-anion interactions

\begin{abstract}
A B S T R A C T
The reactions of $f a c-\left[\mathrm{MnBr}(\mathrm{CO})_{3}\left(\mathrm{NH}=\mathrm{C}\left(\mathrm{CH}_{3}\right) \mathrm{pz}-\kappa^{2} N, N\right)\right]\left(\mathrm{pz}{ }^{*}=\mathrm{pz}, \mathrm{dmpz} ; \mathrm{pzH}=\right.$ pyrazole; dmpzH = 3,5dimethylpyrazole) with wet $\mathrm{AgBF}_{4}$ in a $1: 1$ ratio lead to the cationic pyrazolylamidino complexes fac$\left[\mathrm{Mn}\left(\mathrm{OH}_{2}\right)(\mathrm{CO})_{3}\left(\mathrm{NH}=\mathrm{C}\left(\mathrm{CH}_{3}\right) \mathrm{pz}^{*}-\kappa^{2} N, N\right)\right] \mathrm{BF}_{4}$. The aquo ligand is readily substituted by 2,6-xylylisocyanide $(\mathrm{CNXyl})$ to give fac-[Mn $\left.(\mathrm{CNXyl})(\mathrm{CO})_{3}\left(\mathrm{NH}=\mathrm{C}\left(\mathrm{CH}_{3}\right) \mathrm{pz}^{*}-\kappa^{2} \mathrm{~N}, N\right)\right] \mathrm{BF}_{4}$. The pyrazole complexes fac$\left[\mathrm{Mn}\left(\mathrm{pz}{ }^{\circ} \mathrm{H}\right)(\mathrm{CO})_{3}\left(\mathrm{NH}=\mathrm{C}\left(\mathrm{CH}_{3}\right) \mathrm{pz}^{*}-\kappa^{2} \mathrm{~N}, \mathrm{~N}\right)\right] \mathrm{BF}_{4}$ are obtained by treating fac- $\left[\mathrm{MnBr}(\mathrm{CO})_{3}(\mathrm{NCMe})_{2}\right]$ with $\mathrm{AgBF}_{4}$ and then with pyrazole ( $\mathrm{pzH}$ or dmpzH), in a 1:1:2 ratio. A similar reaction using 1:1:1 ratio and $\mathrm{AgClO}_{4}$ leads to the acetonitrile complexes fac-[Mn(NCMe)(CO)$\left.)_{3}\left(\mathrm{NH}=\mathrm{C}\left(\mathrm{CH}_{3}\right) \mathrm{pz} z^{*}-\kappa^{2} N, N\right)\right] \mathrm{ClO}_{4}$. The X-ray structures of the complexes show moderate hydrogen bonds interactions between the $\mathrm{N}$-bond hydrogen of the pyrazolylamidino ligand and the anion. In the aquo complex, one of the hydrogens of the coordinated water molecule is also involved in a hydrogen bond.
\end{abstract}

(c) 2008 Elsevier B.V. All rights reserved.

\section{Introduction}

The interest of pyrazolylamidine ligands is based on several features: (a) the different properties of the two donor atoms and the electron delocalization within the ligand makes them potentially interesting for electron transfer processes and related physical properties; (b) the pyrazolylamidino ligands are synthesized in situ (Scheme 1), thus using different nitriles and pyrazoles allows the opportunity of controlling both the electronic and steric properties of the metal complexes; (c) the $\mathrm{NH}$ group might be deprotonated, giving rise to further reactivity. However, there are not many examples of pyrazolylamidino complexes [1], even though the amidino has been described as a promising ligand [2].

We have recently reported manganese and rhenium pyrazolylamidino neutral complexes [3]. An enhancement on the acidity of the $\mathrm{H}$ atom in the amidino unit should be expected for pyrazolylamidino cationic complexes. In fact, we have reported several cationic rhenium complexes, which show activity as anion receptors [3b]. Herein, we report the synthesis and structural characterization of manganese pyrazolylamidino cationic complexes.

\section{Results and discussion}

\subsection{Syntheses of the complexes}

The reactions affording to the complexes herein described are collected in Scheme 2.

\footnotetext{
* Corresponding author. Tel.: +34 983 184620; fax: +34 983423013. E-mail address: fervilla@qi.uva.es (F. Villafañe).
}

The complexes fac- $\left[\mathrm{MnBr}(\mathrm{CO})_{3}\left(\mathrm{NH}=\mathrm{C}\left(\mathrm{CH}_{3}\right) \mathrm{pz}-\kappa^{2} N, N\right)\right]$ or $\mathrm{fac}$ $\left[\mathrm{MnBr}(\mathrm{CO})_{3}\left(\mathrm{NH}=\mathrm{C}\left(\mathrm{CH}_{3}\right) \mathrm{dmpz}-\kappa^{2} \mathrm{~N}, \mathrm{~N}\right)\right]$ (pzH or 3,5-dimethylpyrazole, dmpzH) [3a] react with wet $\mathrm{AgBF}_{4}$ in a 1:1 ratio in thf at room temperature, leading to the cationic pyrazolylamidino aquocomplexes $f a c-\left[\mathrm{Mn}\left(\mathrm{OH}_{2}\right)(\mathrm{CO})_{3}\left(\mathrm{NH}=\mathrm{C}\left(\mathrm{CH}_{3}\right) \mathrm{pz}-\kappa^{2} N, N\right)\right] \mathrm{BF}_{4}(\mathbf{1 a})$ or $f a c-$ $\left[\mathrm{Mn}\left(\mathrm{OH}_{2}\right)(\mathrm{CO})_{3}\left(\mathrm{NH}=\mathrm{C}\left(\mathrm{CH}_{3}\right) \mathrm{dmpz}-\kappa^{2} N, N\right)\right] \mathrm{BF}_{4}$ (1) b), respectively. The moisture present in the acetone solution of $\mathrm{AgBF}_{4}$ is the source of the aquo ligand. The formation of carbonylmanganese (I) cationic aquocomplexes is well documented in the literature [4].

When solutions of $\mathbf{1 a}$ or $\mathbf{1 b}$ synthesized in situ are treated with the stoichiometric amount of 2,6-xylylisocyanide (CNXyl), the aquo ligand is readily substituted by the isocyanide affording fac- $\left[\mathrm{Mn}(\mathrm{CNXyl})(\mathrm{CO})_{3}\left(\mathrm{NH}=\mathrm{C}\left(\mathrm{CH}_{3}\right) \mathrm{pz}^{2} \kappa^{2} N, N\right)\right] \mathrm{BF}_{4}$ (2a) and fac$\left[\mathrm{Mn}(\mathrm{CNXyl})(\mathrm{CO})_{3}\left(\mathrm{NH}=\mathrm{C}\left(\mathrm{CH}_{3}\right) \mathrm{dmpz}^{2} \kappa^{2} N, N\right)\right] \mathrm{BF}_{4}(\mathbf{2} \mathbf{b})$.

Similar pyrazole complexes fac-[Mn $(\mathrm{pzH})(\mathrm{CO})_{3}\left(\mathrm{NH}=\mathrm{C}\left(\mathrm{CH}_{3}\right) \mathrm{pz}-\right.$ $\left.\left.\kappa^{2} N, N\right)\right] \mathrm{BF}_{4} \quad$ (3a) and $f a c-\left[\mathrm{Mn}(\mathrm{dmpzH})(\mathrm{CO})_{3}\left(\mathrm{NH}=\mathrm{C}\left(\mathrm{CH}_{3}\right) \mathrm{dmpz}-\right.\right.$ $\left.\left.\kappa^{2} N, N\right)\right] B_{4}$ (3b) were obtained in a one pot process from fac-[ $\left.\mathrm{MnBr}(\mathrm{CO})_{3}(\mathrm{NCMe})_{2}\right], \mathrm{AgBF}_{4}$, and pyrazole (pzH or dmpzH), in a $1: 1: 2$ ratio. Therefore, there is no need to isolate the bromopyrazolylamidino complexes, nor the aquo cationic complexes $\mathbf{1}$, which should be intermediates in the whole process.

When similar reactions are carried out using $\mathrm{AgClO}_{4}$ instead of $\mathrm{AgBF}_{4}$ and 1:1:1 ratio, the incoming pyrazole prefers to become a part of the pyrazolylamidino ligand, whereas the remaining coordination site is occupied by an acetonitrile coming from the solvent, affording the complexes fac- $\left[\mathrm{Mn}(\mathrm{NCMe})(\mathrm{CO})_{3}\left(\mathrm{NH}=\mathrm{C}\left(\mathrm{CH}_{3}\right) \mathrm{pz}^{-} \kappa^{2} \mathrm{~N}, N\right)\right] \mathrm{BF}_{4}(\mathbf{4 a})$ and $f a c-\left[\mathrm{Mn}(\mathrm{NCMe})(\mathrm{CO})_{3}\left(\mathrm{NH}=\mathrm{C}\left(\mathrm{CH}_{3}\right) \mathrm{dmpz}-\kappa^{2} N, N\right)\right] \mathrm{BF}_{4}(\mathbf{4 b})$.

\subsection{Solid-state structural characterization}

The structure of the complexes $\mathbf{1 b}, \mathbf{2 a}, \mathbf{3 a}, \mathbf{3 b}$, and $\mathbf{4 a}$ are shown in Figs. 1-4; whereas Tables 1-4 collect relevant distances and 


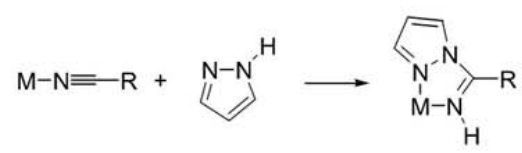

Scheme 1. General method for the synthesis of pyrazolylamidino complexes.

angles. Due to the low quality of the crystal of $\mathbf{2 a}$, the resulting determination is poor (high residuals) and contains an incipent disorder of the $\mathrm{BF}_{4}^{-}$anion which could not be modelled properly. Nevertheless, the structure is included here since it confirms unambiguously the connectivity of the molecule.

The structural data of all the structures herein described are very similar to those of pyrazolylamidino ligands found in other pyrazolylamidino complexes previously reported [1], and also similar to other structures of halotricarbonylmanganese(I) complexes containing a bidentate $\mathrm{N}$-donor ligand in the literature [5].

The anion and the cationic complex are linked by hydrogen bonds. Table 5 collects the strongest interactions detected. All of them may be considered as "moderate" [6]. In all the cases the hydrogen involved is the $\mathrm{N}$-bond hydrogen of the pyrazolylamidino ligand, whereas in $\mathbf{1 b}$, one of the hydrogens of the coordinated water molecule is also involved.

\subsection{Characterization in solution}

The IR spectra of all the complexes show three bands in the C-O stretching region in solution, as expected for a fac-tricarbonyl geometry. The frequencies are higher than those previously reported for the parent neutral bromo complexes fac- $\left[\mathrm{MnBr}(\mathrm{CO})_{3}(\mathrm{NH}=\right.$ $\left.\left.\mathrm{C}\left(\mathrm{CH}_{3}\right) \mathrm{pz}-\kappa^{2} N, N\right)\right]$ or $f a c-\left[\mathrm{MnBr}(\mathrm{CO})_{3}\left(\mathrm{NH}=\mathrm{C}\left(\mathrm{CH}_{3}\right) \mathrm{dmpz}-\kappa^{2} N, N\right)\right]$, and also slightly higher for complexes with pzH than those with $\mathrm{dmpzH}$. Both features are to be expected considering the lower electronic density at the metal center in cationic vs. neutral complexes, and the better donor properties of Hdmpz compared to Hpz. The xylylisocyanide in complexes 2 show one band at $c a .2170 \mathrm{~cm}^{-1}$ corresponding to $\mathrm{C}-\mathrm{N}$ stretching.

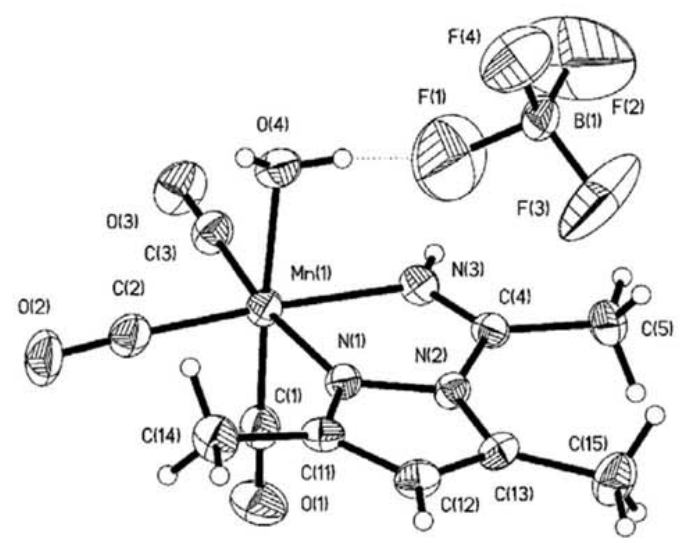

Fig. 1. Perspective view of $f a c-\left[\mathrm{Mn}\left(\mathrm{OH}_{2}\right)(\mathrm{CO})_{3}\left(\mathrm{NH}=\mathrm{C}\left(\mathrm{CH}_{3}\right) \mathrm{dmpz}-\kappa^{2} N, N\right)\right] \mathrm{BF}_{4}(\mathbf{1 b})$ showing the atom numbering.

The ${ }^{1} \mathrm{H}$ and ${ }^{13} \mathrm{C}$ NMR data (see Section 3 ) do not provide important structural information. In the spectra of complexes 3 containing both pyrazole and pirazolylamidino ligands, the signals of the latter give higher chemical shifts. Concerning the amidino fragment, both the ${ }^{1} \mathrm{H}$ and ${ }^{13} \mathrm{C}$ NMR spectra show also higher chemical shifts respect to those reported for coordinated nitrile [7]. The signals of the aquo ligands in $\mathbf{1 a}$ and $\mathbf{1 b}$ in the ${ }^{1} \mathrm{H}$ NMR spectra are sharp singlets, suggesting the absence of exchange process between coordinated water and the solvent [8].

The ${ }^{19} \mathrm{~F}$ NMR spectra of complexes 1-3, display a broad signal around $-150 \mathrm{ppm}$ corresponding to the $\mathrm{BF}_{4}^{-}$group. This anion usually display two singlets, respectively, assigned to ${ }^{11} \mathrm{BF}_{4}^{-}(80 \%)$ and ${ }^{10} \mathrm{BF}_{4}^{-}(20 \%)$. In our case, the broadness of this signal points to a fast scrambling of the fluorine atom(s) involved in the hydrogen bonds with the cation. The broad signal does not sharpens at low temperature, indicating that this scrambling process remains fast even at low temperature. No further studies have been carried out to determine the strength of these interactions in solution, as was<smiles></smiles>

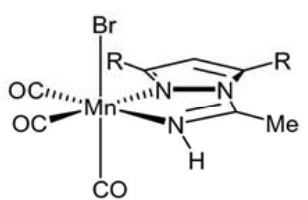<smiles></smiles>
$\mathrm{Me}_{2} \mathrm{CO} / \mathrm{H}_{2} \mathrm{O}$ $\mathrm{R}=\mathrm{H} ; \mathrm{Me}$

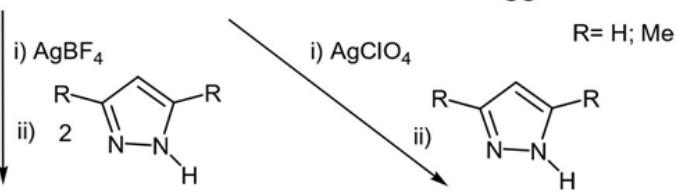

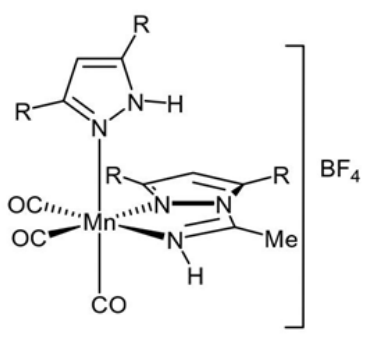

$\mathrm{R}=\mathrm{H}(\mathbf{3 a}) ; \mathrm{Me}(\mathbf{3 b})$

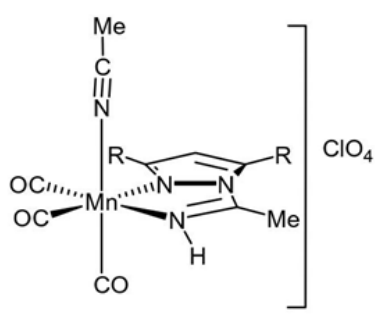

$\mathrm{R}=\mathrm{H}(\mathbf{4 a}) ; \mathrm{Me}(\mathbf{4 b})$

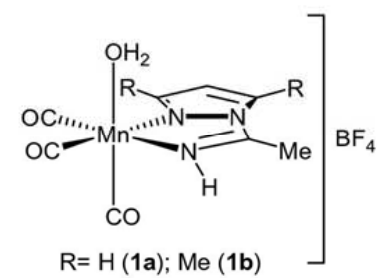
XyINC

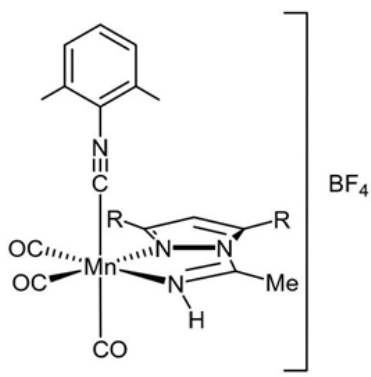

$\mathrm{R}=\mathrm{H}(\mathbf{2 a}) ; \mathrm{Me}(\mathbf{2 b})$

Scheme 2. Syntheses of the complexes. 


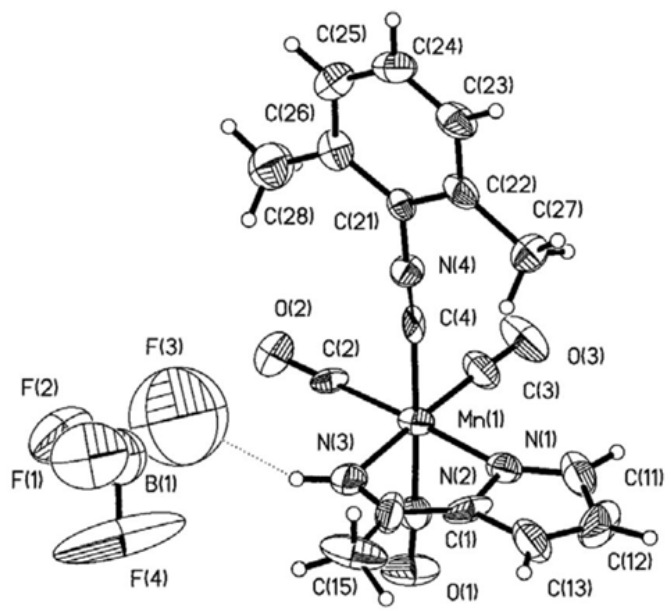

Fig. 2. Perspective view of fac-[Mn(CNXyl) $\left.(\mathrm{CO})_{3}\left(\mathrm{NH}=\mathrm{C}\left(\mathrm{CH}_{3}\right) \mathrm{pz}-\kappa^{2} N, N\right)\right] \mathrm{BF}_{4}$ (2a) showing the atom numbering.
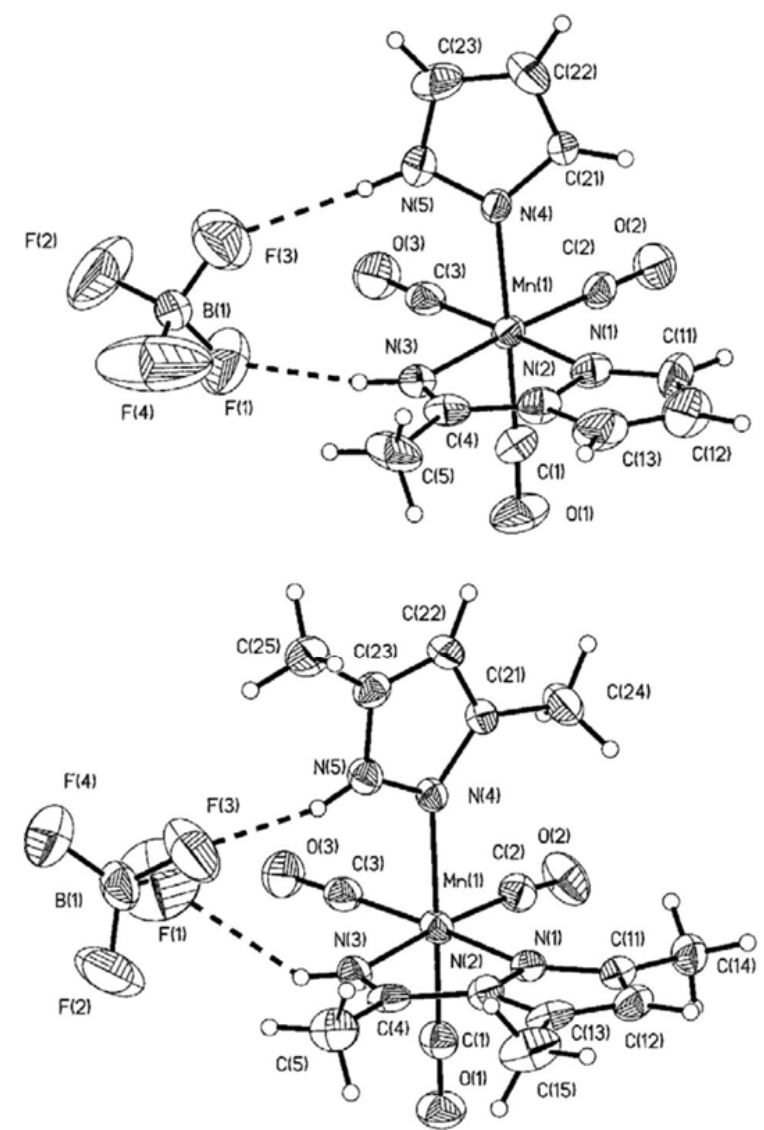

Fig. 3. Perspective views of $f a c-\left[\mathrm{Mn}(\mathrm{pzH})(\mathrm{CO})_{3}\left(\mathrm{NH}=\mathrm{C}\left(\mathrm{CH}_{3}\right) \mathrm{pz}-\kappa^{2} N, N\right)\right] \mathrm{BF}_{4}(3 \mathbf{a})$ and fac- $\left[\mathrm{Mn}(\mathrm{dmpzH})(\mathrm{CO})_{3}\left(\mathrm{NH}=\mathrm{C}\left(\mathrm{CH}_{3}\right) \mathrm{dmpz}-\kappa^{2} N, N\right)\right] \mathrm{BF}_{4}$ (3b) showing the atom numbering.

previously reported for similar pyrazolylamidino rhenium complexes [3b].

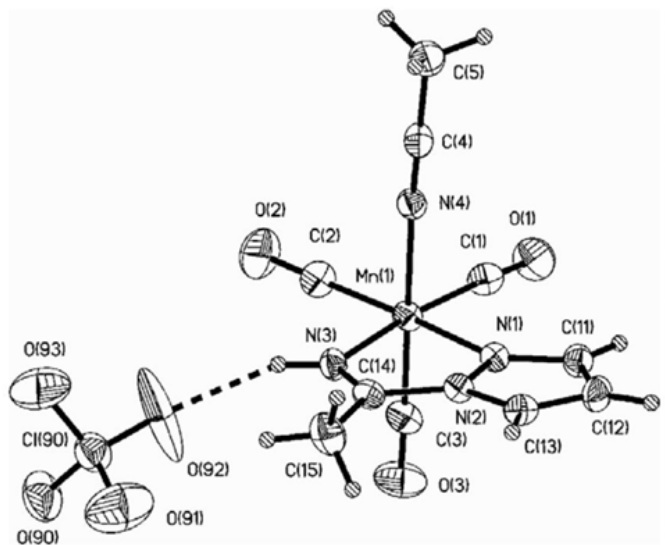

Fig. 4. Perspective view of $f a c-\left[\mathrm{Mn}(\mathrm{NCMe})(\mathrm{CO})_{3}\left(\mathrm{NH}=\mathrm{C}\left(\mathrm{CH}_{3}\right) \mathrm{pz}-\kappa^{2} \mathrm{~N}, N\right)\right] \mathrm{ClO}_{4}$ (4a) showing the atom numbering.

Table 1

Selected distances $(\AA)$ and angles $\left(^{\circ}\right)$ for fac- $\left[\mathrm{Mn}\left(\mathrm{OH}_{2}\right)(\mathrm{CO})_{3}\left(\mathrm{NH}=\mathrm{C}\left(\mathrm{CH}_{3}\right) \mathrm{dmpz}\right.\right.$ $\left.\left.\kappa^{2} N, N\right)\right] B_{4}(\mathbf{1 b})$

\begin{tabular}{ll}
\hline $\mathrm{Mn}(1)-\mathrm{C}(1)$ & $1.796(6)$ \\
$\mathrm{Mn}(1)-\mathrm{C}(2)$ & $1.810(6)$ \\
$\mathrm{Mn}(1)-\mathrm{C}(3)$ & $1.833(6)$ \\
$\mathrm{Mn}(1)-\mathrm{N}(1)$ & $2.048(4)$ \\
$\mathrm{Mn}(1)-\mathrm{N}(3)$ & $2.015(4)$ \\
$\mathrm{Mn}(1)-\mathrm{O}(4)$ & $2.108(5)$ \\
$\mathrm{N}(1)-\mathrm{N}(2)$ & $1.389(5)$ \\
$\mathrm{N}(2)-\mathrm{C}(4)$ & $1.400(6)$ \\
$\mathrm{N}(3)-\mathrm{C}(4)$ & $1.267(6)$ \\
$\mathrm{C}(1)-\mathrm{O}(1)$ & $1.132(7)$ \\
$\mathrm{C}(2)-\mathrm{O}(2)$ & $1.149(6)$ \\
$\mathrm{C}(3)-\mathrm{O}(3)$ & $1.138(6)$ \\
$\mathrm{C}(1)-\mathrm{Mn}(1)-\mathrm{C}(3)$ & $89.6(2)$ \\
$\mathrm{C}(1)-\mathrm{Mn}(1)-\mathrm{C}(2)$ & $88.3(2)$ \\
$\mathrm{C}(3)-\mathrm{Mn}(1)-\mathrm{C}(2)$ & $89.6(2)$ \\
$\mathrm{C}(1)-\mathrm{Mn}(1)-\mathrm{N}(3)$ & $91.5(2)$ \\
$\mathrm{C}(3)-\mathrm{Mn}(1)-\mathrm{N}(3)$ & $95.7(2)$ \\
$\mathrm{C}(2)-\mathrm{Mn}(1)-\mathrm{N}(3)$ & $174.7(2)$ \\
$\mathrm{C}(1)-\mathrm{Mn}(1)-\mathrm{N}(1)$ & $92.6(2)$ \\
$\mathrm{C}(3)-\mathrm{Mn}(1)-\mathrm{N}(1)$ & $171.8(2)$ \\
$\mathrm{C}(2)-\mathrm{Mn}(1)-\mathrm{N}(1)$ & $98.34(19)$ \\
$\mathrm{N}(3)-\mathrm{Mn}(1)-\mathrm{N}(1)$ & $76.40(16)$ \\
$\mathrm{C}(1)-\mathrm{Mn}(1)-\mathrm{O}(4)$ & $177.1(2)$ \\
$\mathrm{C}(3)-\mathrm{Mn}(1)-\mathrm{O}(4)$ & $91.6(2)$ \\
$\mathrm{C}(2)-\mathrm{Mn}(1)-\mathrm{O}(4)$ & $94.4(2)$ \\
$\mathrm{N}(3)-\mathrm{Mn}(1)-\mathrm{O}(4)$ & $85.73(19)$ \\
$\mathrm{N}(1)-\mathrm{Mn}(1)-\mathrm{O}(4)$ & $85.80(16)$ \\
$\mathrm{N}(2)-\mathrm{N}(1)-\mathrm{Mn}(1)$ & $113.3(3)$ \\
$\mathrm{N}(1)-\mathrm{N}(2)-\mathrm{C}(4)$ & $114.4(4)$ \\
$\mathrm{C}(4)-\mathrm{N}(3)-\mathrm{Mn}(1)$ & $119.8(3)$ \\
\hline &
\end{tabular}

\section{Experimental}

\subsection{General remarks}

All manipulations were performed under $\mathrm{N}_{2}$ atmosphere following conventional Schlenk techniques. Filtrations were carried out on dry Celite under $\mathrm{N}_{2}$. Solvents were purified according to standard procedures [9]. $f a c-\left[\mathrm{MnBr}(\mathrm{CO})_{3}\left(\mathrm{NH}=\mathrm{C}\left(\mathrm{CH}_{3}\right) \mathrm{pz}-\kappa^{2} N, N\right)\right]$ and $f a c-\left[\mathrm{MnBr}(\mathrm{CO})_{3}\left(\mathrm{NH}=\mathrm{C}\left(\mathrm{CH}_{3}\right) \mathrm{dmpz}-\kappa^{2} N, N\right)\right]$ were obtained as previously described [3a]. All other reagents were obtained from the usual commercial suppliers, and used as received. CAUTION!: Although no difficulties were experienced with the perchlorate complexes described herein, all perchlorate species should be treated as potentially explosive and handled with care. Infrared spectra were recorded in Perkin-Elmer RX I FT-IR apparatus on $\mathrm{KBr}$ pellets 
Table 2

Selected distances $(\AA)$ and angles $\left(^{\circ}\right)$ for $f a c-\left[\mathrm{Mn}(\mathrm{CNXyl})(\mathrm{CO})_{3}\left(\mathrm{NH}=\mathrm{C}\left(\mathrm{CH}_{3}\right) \mathrm{pz}\right.\right.$ $\left.\left.\kappa^{2} N, N\right)\right] \mathrm{BF}_{4}(\mathbf{2 a})$

\begin{tabular}{ll}
\hline $\mathrm{Mn}(1)-\mathrm{C}(1)$ & $1.846(18)$ \\
$\mathrm{Mn}(1)-\mathrm{C}(2)$ & $1.804(18)$ \\
$\mathrm{Mn}(1)-\mathrm{C}(3)$ & $1.80(2)$ \\
$\mathrm{Mn}(1)-\mathrm{C}(4)$ & $1.972(18)$ \\
$\mathrm{Mn}(1)-\mathrm{N}(1)$ & $1.983(16)$ \\
$\mathrm{Mn}(1)-\mathrm{N}(3)$ & $2.107(17)$ \\
$\mathrm{N}(1)-\mathrm{N}(2)$ & $1.46(2)$ \\
$\mathrm{N}(2)-\mathrm{C}(14)$ & $1.28(2)$ \\
$\mathrm{N}(3)-\mathrm{C}(14)$ & $1.19(3)$ \\
$\mathrm{C}(1)-\mathrm{O}(1)$ & $1.147(17)$ \\
$\mathrm{C}(2)-\mathrm{O}(2)$ & $1.127(17)$ \\
$\mathrm{C}(3)-\mathrm{O}(3)$ & $1.155(19)$ \\
$\mathrm{C}(1)-\mathrm{Mn}(1)-\mathrm{C}(3)$ & $90.6(7)$ \\
$\mathrm{C}(1)-\mathrm{Mn}(1)-\mathrm{C}(2)$ & $90.5(7)$ \\
$\mathrm{C}(3)-\mathrm{Mn}(1)-\mathrm{C}(2)$ & $88.4(8)$ \\
$\mathrm{C}(1)-\mathrm{Mn}(1)-\mathrm{N}(3)$ & $92.2(6)$ \\
$\mathrm{C}(3)-\mathrm{Mn}(1)-\mathrm{N}(3)$ & $174.5(8)$ \\
$\mathrm{C}(2)-\mathrm{Mn}(1)-\mathrm{N}(3)$ & $96.2(7)$ \\
$\mathrm{C}(1)-\mathrm{Mn}(1)-\mathrm{N}(1)$ & $91.1(6)$ \\
$\mathrm{C}(3)-\mathrm{Mn}(1)-\mathrm{N}(1)$ & $96.9(8)$ \\
$\mathrm{C}(2)-\mathrm{Mn}(1)-\mathrm{N}(1)$ & $174.4(7)$ \\
$\mathrm{N}(3)-\mathrm{Mn}(1)-\mathrm{N}(1)$ & $78.3(6)$ \\
$\mathrm{C}(1)-\mathrm{Mn}(1)-\mathrm{C}(4)$ & $177.9(7)$ \\
$\mathrm{C}(3)-\mathrm{Mn}(1)-\mathrm{C}(4)$ & $91.3(7)$ \\
$\mathrm{C}(2)-\mathrm{Mn}(1)-\mathrm{C}(4)$ & $88.6(6)$ \\
$\mathrm{N}(3)-\mathrm{Mn}(1)-\mathrm{C}(4)$ & $86.0(6)$ \\
$\mathrm{N}(1)-\mathrm{Mn}(1)-\mathrm{C}(4)$ & $89.7(5)$ \\
$\mathrm{N}(2)-\mathrm{N}(1)-\mathrm{Mn}(1)$ & $109.0(11)$ \\
$\mathrm{N}(1)-\mathrm{N}(2)-\mathrm{C}(14)$ & $118.2(18)$ \\
$\mathrm{C}(14)-\mathrm{N}(3)-\mathrm{Mn}(1)$ & $113.9(16)$ \\
\hline &
\end{tabular}

Table 3

Selected distances $(\AA)$ and angles $\left(^{\circ}\right)$ for $f a c-\left[\mathrm{Mn}(\mathrm{pzH})(\mathrm{CO})_{3}\left(\mathrm{NH}=\mathrm{C}\left(\mathrm{CH}_{3}\right) \mathrm{pz}-\kappa^{2} N, N\right)\right] \mathrm{BF}{ }_{4}$ (3a) and $f a c-\left[\mathrm{Mn}(\mathrm{dmpzH})(\mathrm{CO})_{3}\left(\mathrm{NH}=\mathrm{C}\left(\mathrm{CH}_{3}\right) \mathrm{dmpz}^{2} \kappa^{2} N, N\right)\right] \mathrm{BF}_{4}(\mathbf{3 b})$

\begin{tabular}{lll}
\hline & $\mathbf{3 a}$ & $\mathbf{3 b}$ \\
\hline $\mathrm{Mn}(1)-\mathrm{C}(1)$ & $1.816(10)$ & $1.805(8)$ \\
$\mathrm{Mn}(1)-\mathrm{C}(2)$ & $1.821(9)$ & $1.803(8)$ \\
$\mathrm{Mn}(1)-\mathrm{C}(3)$ & $1.826(11)$ & $1.811(9)$ \\
$\mathrm{Mn}(1)-\mathrm{N}(1)$ & $2.034(7)$ & $2.053(5)$ \\
$\mathrm{Mn}(1)-\mathrm{N}(3)$ & $2.041(7)$ & $2.013(5)$ \\
$\mathrm{Mn}(1)-\mathrm{N}(4)$ & $2.078(6)$ & $2.117(5)$ \\
$\mathrm{N}(1)-\mathrm{N}(2)$ & $1.409(9)$ & $1.386(6)$ \\
$\mathrm{N}(2)-\mathrm{C}(4)$ & $1.350(11)$ & $1.395(8)$ \\
$\mathrm{N}(3)-\mathrm{C}(4)$ & $1.250(11)$ & $1.270(8)$ \\
$\mathrm{C}(1)-\mathrm{O}(1)$ & $1.129(10)$ & $1.141(7)$ \\
$\mathrm{C}(2)-\mathrm{O}(2)$ & $1.127(9)$ & $1.154(7)$ \\
$\mathrm{C}(3)-\mathrm{O}(3)$ & $1.134(10)$ & $1.136(8)$ \\
$\mathrm{C}(1)-\mathrm{Mn}(1)-\mathrm{C}(3)$ & $88.9(4)$ & $89.2(3)$ \\
$\mathrm{C}(1)-\mathrm{Mn}(1)-\mathrm{C}(2)$ & $89.6(4)$ & $85.9(3)$ \\
$\mathrm{C}(3)-\mathrm{Mn}(1)-\mathrm{C}(2)$ & $88.6(4)$ & $88.4(3)$ \\
$\mathrm{C}(1)-\mathrm{Mn}(1)-\mathrm{N}(3)$ & $91.0(3)$ & $91.6(2)$ \\
$\mathrm{C}(3)-\mathrm{Mn}(1)-\mathrm{N}(3)$ & $97.7(4)$ & $95.3(3)$ \\
$\mathrm{C}(2)-\mathrm{Mn}(1)-\mathrm{N}(3)$ & $173.7(3)$ & $175.5(3)$ \\
$\mathrm{C}(1)-\mathrm{Mn}(1)-\mathrm{N}(1)$ & $92.3(3)$ & $92.9(2)$ \\
$\mathrm{C}(3)-\mathrm{Mn}(1)-\mathrm{N}(1)$ & $175.0(3)$ & $171.4(3)$ \\
$\mathrm{C}(2)-\mathrm{Mn}(1)-\mathrm{N}(1)$ & $96.3(3)$ & $100.0(2)$ \\
$\mathrm{N}(3)-\mathrm{Mn}(1)-\mathrm{N}(1)$ & $77.4(3)$ & $76.3(2)$ \\
$\mathrm{C}(1)-\mathrm{Mn}(1)-\mathrm{N}(4)$ & $177.8(3)$ & $178.9(2)$ \\
$\mathrm{C}(3)-\mathrm{Mn}(1)-\mathrm{N}(4)$ & $91.8(3)$ & $90.3(2)$ \\
$\mathrm{C}(2)-\mathrm{Mn}(1)-\mathrm{N}(4)$ & $92.5(3)$ & $95.1(2)$ \\
$\mathrm{N}(3)-\mathrm{Mn}(1)-\mathrm{N}(4)$ & $86.8(2)$ & $87.47(19)$ \\
$\mathrm{N}(1)-\mathrm{Mn}(1)-\mathrm{N}(4)$ & $86.8(3)$ & $87.44(18)$ \\
$\mathrm{N}(2)-\mathrm{N}(1)-\mathrm{Mn}(1)$ & $110.8(5)$ & $113.3(4)$ \\
$\mathrm{N}(1)-\mathrm{N}(2)-\mathrm{C}(4)$ & $118.2(7)$ & $115.2(5)$ \\
$\mathrm{C}(4)-\mathrm{N}(3)-\mathrm{Mn}(1)$ & $118.6(6)$ & $120.2(5)$ \\
\hline & & \\
& &
\end{tabular}

from 4000 to $400 \mathrm{~cm}^{-1}$. NMR spectra were recorded in Bruker AC300 or ARX-300 instruments in $\left(C_{3}\right)_{2} \mathrm{CO}$, at room temperature unless otherwise stated. NMR spectra are referred to the internal residual solvent peak for ${ }^{1} \mathrm{H}$ and ${ }^{13} \mathrm{C}\left\{{ }^{1} \mathrm{H}\right\}$ NMR. Assignment of the
Table 4

Selected distances $(\AA)$ and angles $\left(^{\circ}\right)$ for fac-[Mn $(\mathrm{NCMe})(\mathrm{CO})_{3}\left(\mathrm{NH}=\mathrm{C}\left(\mathrm{CH}_{3}\right) \mathrm{pz}\right.$ $\left.\left.\kappa^{2} \mathrm{~N}, \mathrm{~N}\right)\right] \mathrm{ClO}_{4}(\mathbf{4 a})$

\begin{tabular}{ll}
\hline $\mathrm{Mn}(1)-\mathrm{C}(1)$ & \\
$\mathrm{Mn}(1)-\mathrm{C}(2)$ & $1.798(6)$ \\
$\mathrm{Mn}(1)-\mathrm{C}(3)$ & $1.806(5)$ \\
$\mathrm{Mn}(1)-\mathrm{N}(1)$ & $1.799(6)$ \\
$\mathrm{Mn}(1)-\mathrm{N}(3)$ & $2.017(4)$ \\
$\mathrm{Mn}(1)-\mathrm{N}(4)$ & $2.029(4)$ \\
$\mathrm{N}(1)-\mathrm{N}(2)$ & $2.016(4)$ \\
$\mathrm{N}(2)-\mathrm{C}(4)$ & $1.364(4)$ \\
$\mathrm{N}(3)-\mathrm{C}(4)$ & $1.401(5)$ \\
$\mathrm{C}(1)-\mathrm{O}(1)$ & $1.259(5)$ \\
$\mathrm{C}(2)-\mathrm{O}(2)$ & $1.136(6)$ \\
$\mathrm{C}(3)-\mathrm{O}(3)$ & $1.133(5)$ \\
$\mathrm{C}(1)-\mathrm{Mn}(1)-\mathrm{C}(3)$ & $1.151(6)$ \\
$\mathrm{C}(1)-\mathrm{Mn}(1)-\mathrm{C}(2)$ & $89.5(2)$ \\
$\mathrm{C}(3)-\mathrm{Mn}(1)-\mathrm{C}(2)$ & $88.6(2)$ \\
$\mathrm{C}(1)-\mathrm{Mn}(1)-\mathrm{N}(3)$ & $92.9(2)$ \\
$\mathrm{C}(3)-\mathrm{Mn}(1)-\mathrm{N}(3)$ & $90.97(18)$ \\
$\mathrm{C}(2)-\mathrm{Mn}(1)-\mathrm{N}(3)$ & $94.74(19)$ \\
$\mathrm{C}(1)-\mathrm{Mn}(1)-\mathrm{N}(1)$ & $172.37(18)$ \\
$\mathrm{C}(3)-\mathrm{Mn}(1)-\mathrm{N}(1)$ & $93.83(19)$ \\
$\mathrm{C}(2)-\mathrm{Mn}(1)-\mathrm{N}(1)$ & $170.98(18)$ \\
$\mathrm{N}(3)-\mathrm{Mn}(1)-\mathrm{N}(1)$ & $95.57(18)$ \\
$\mathrm{C}(1)-\mathrm{Mn}(1)-\mathrm{N}(4)$ & $76.85(14)$ \\
$\mathrm{C}(3)-\mathrm{Mn}(1)-\mathrm{N}(4)$ & $178.94(19)$ \\
$\mathrm{C}(2)-\mathrm{Mn}(1)-\mathrm{N}(4)$ & $91.3(2)$ \\
$\mathrm{N}(3)-\mathrm{Mn}(1)-\mathrm{N}(4)$ & $92.02(19)$ \\
$\mathrm{N}(1)-\mathrm{Mn}(1)-\mathrm{N}(4)$ & $88.31(15)$ \\
$\mathrm{N}(2)-\mathrm{N}(1)-\mathrm{Mn}(1)$ & $85.25(14)$ \\
$\mathrm{N}(1)-\mathrm{N}(2)-\mathrm{C}(4)$ & $113.5(3)$ \\
$\mathrm{C}(4)-\mathrm{N}(3)-\mathrm{Mn}(1)$ & $116.7(3)$ \\
\hline & $119.4(3)$ \\
\hline &
\end{tabular}

Table 5

Hydrogen bonds detected in the crystal structures of $\mathbf{1 b}, \mathbf{2 a}, \mathbf{3 a}, \mathbf{3 b}$, and $\mathbf{4 a}$

\begin{tabular}{ccc}
\hline 1b & $\mathrm{H}(4 \mathrm{~B}) \cdots(1) 1.908 \AA$ & $\mathrm{O}(4) \cdots \mathrm{F}(1) 2.686 \AA$ \\
1b & $\mathrm{H}(3) \cdots \mathrm{F}(4) 2.230 \AA^{\mathrm{a}}$ & $\mathrm{N}(3) \cdots \mathrm{F}(4) 2.995 \AA^{\mathrm{a}}$ \\
2a & $\mathrm{H}(3) \cdots \mathrm{F}(3) 2.227 \AA$ & $\mathrm{N}(3) \cdots \mathrm{F}(3) 3.003 \AA$ \\
3a & $\mathrm{H}(3) \cdots \mathrm{F}(1) 2.233 \AA$ & $\mathrm{N}(3) \cdots \mathrm{F}(1) 3.063 \AA$ \\
3a & $\mathrm{H}(5) \cdots \mathrm{F}(3) 2.257 \AA$ & $\mathrm{N}(5) \cdots \mathrm{F}(3) 3.085 \AA$ \\
3b & $\mathrm{H}(3) \cdots \mathrm{F}(1) 2.448 \AA$ & $\mathrm{N}(3) \cdots \mathrm{F}(1) 3.169 \AA$ \\
3b & $\mathrm{H}(5) \cdots \mathrm{F}(3) 2.104 \AA$ & $\mathrm{N}(5) \cdots \mathrm{F}(3) 2.898 \AA$ \\
4a & $\mathrm{H}(3) \cdots \mathrm{O}(92) 2.127 \AA$ & $\mathrm{N}(3) \cdots \mathrm{O}(92) 2.917 \AA$ \\
\hline \multicolumn{2}{c}{ a } &
\end{tabular}
This interaction is not displaye
anion not depicted in the figure.

${ }^{13} \mathrm{C}\left\{{ }^{1} \mathrm{H}\right\}$ NMR data was supported by DEPT experiments and relative intensities of the resonance signals. Elemental analyses were performed on a Perkin-Elmer 2400B microanalyzer.

\section{2. $f a c-\left[\mathrm{Mn}\left(\mathrm{OH}_{2}\right)(\mathrm{CO})_{3}\left(\mathrm{NH}=\mathrm{C}\left(\mathrm{CH}_{3}\right) p z-\kappa^{2} \mathrm{~N}, \mathrm{~N}\right)\right] \mathrm{BF} \mathrm{F}_{4}(\mathbf{1 a})$}

To a solution of $f a c-\left[\mathrm{MnBr}(\mathrm{CO})_{3}\left(\mathrm{NH}=\mathrm{C}\left(\mathrm{CH}_{3}\right) \mathrm{pz}-\kappa^{2} N, N\right)\right]$, $(0.131 \mathrm{~g}, 0.4 \mathrm{mmol})$ in thf $(10 \mathrm{~mL})$, a $0.1 \mathrm{M}$ solution of $\mathrm{AgBF}_{4}$ in wet acetone $(4 \mathrm{~mL}, 0.4 \mathrm{mmol})$ was added. The mixture was stirred at room temperature excluded from the sunlight for $30 \mathrm{~min}$, and the volatiles were removed in vacuo and the yellow residue was extracted with thf (ca. $20 \mathrm{~mL}$ ) and filtered. Hexane was added (ca. $10 \mathrm{~mL}$ ) and the solution was concentrated and cooled to $-20^{\circ} \mathrm{C}$, giving a yellow microcrystalline solid, which was decanted, washed with hexane ( $3 \times 3 \mathrm{~mL}$ approximately), and dried in vacuo, yielding $0.102 \mathrm{~g}$ (72\%) of 1a. IR (thf, $\mathrm{cm}^{-1}$ ): $2044 \mathrm{vs}, 1948 \mathrm{vs,}, 1936$ vs. IR ( $\left.\mathrm{KBr}, \mathrm{cm}^{-1}\right)$ : $3444 \mathrm{~m}, 3153 \mathrm{w}, 2054 \mathrm{~s}, 1957 \mathrm{vs,} 1940$ vs br, $1657 \mathrm{~m}, 1537 \mathrm{w}, 1465 \mathrm{w}, 1408 \mathrm{~s}, 1336 \mathrm{w}, 1250 \mathrm{w}, 1133 \mathrm{~s}, 1046$ s, $1002 \mathrm{~s}, 768 \mathrm{w}, 631 \mathrm{~m}, 514$ w. ${ }^{1} \mathrm{H}$ NMR $\left(\mathrm{Me}_{2} \mathrm{CO}-d_{6}\right): 2.90$ (s, $\left.\mathrm{N}=\mathrm{C}\left(\mathrm{CH}_{3}\right), 3 \mathrm{H}\right), 4.76\left(\mathrm{~s}, \mathrm{OH}_{2}, 2 \mathrm{H}\right), 6.92\left(\mathrm{~s}, \mathrm{H}^{4} \mathrm{pz}, 1 \mathrm{H}\right), 8.63$ (br s, $\left.H^{3} \mathrm{pz}, 1 \mathrm{H}\right), 8.73\left(\mathrm{br} \mathrm{s}, H^{5} \mathrm{pz}, 1 \mathrm{H}\right), 10.97(\mathrm{br}, H \mathrm{~N}, 1 \mathrm{H}) .{ }^{13} \mathrm{C}\left\{{ }^{1} \mathrm{H}\right\}$ $\operatorname{NMR}\left(\mathrm{Me}_{2} \mathrm{CO}-d_{6}\right): 18.8\left(\mathrm{~s}, \mathrm{HN}=\mathrm{C}\left(\mathrm{CH}_{3}\right)\right), 113.0\left(\mathrm{~s}, \mathrm{C}^{4} \mathrm{pz}\right), 135.0(\mathrm{~s}$, 
$\left.\mathrm{C}^{3,5} \mathrm{pz}\right), 149.6\left(\mathrm{~s}, \mathrm{C}^{5,3} \mathrm{pz}\right), 166.3\left(\mathrm{~s}, \mathrm{HN}=\mathrm{C}\left(\mathrm{CH}_{3}\right)\right), 219.1(\mathrm{~s}, \mathrm{CO}), 220.1$ (s, CO), $221.6(\mathrm{~s}, \mathrm{CO}) .{ }^{19} \mathrm{~F}$ NMR $\left(\mathrm{Me}_{2} \mathrm{CO}-d_{6}\right):-148.1\left(\mathrm{br},{ }^{10} \mathrm{BF}_{4}, 4 \mathrm{~F}\right.$ and ${ }^{11} \mathrm{BF}_{4}, 4 \mathrm{~F}$ ). Anal. Calc. for $\mathrm{C}_{8} \mathrm{H}_{9} \mathrm{BF}_{4} \mathrm{MnN}_{3} \mathrm{O}_{4}: \mathrm{C}, 27.23 ; \mathrm{H}, 2.57$; $\mathrm{N}, 11.91$. Found: C, 26.89; H, 2.36; N, 11.69\%.

\section{3. $\mathrm{fac}-\left[\mathrm{Mn}\left(\mathrm{OH}_{2}\right)(\mathrm{CO})_{3}\left(\mathrm{NH}=\mathrm{C}\left(\mathrm{CH}_{3}\right) \mathrm{dmpz}-\kappa^{2} \mathrm{~N}, \mathrm{~N}\right)\right] \mathrm{BF}_{4}(\mathbf{1 b})$}

To a solution of $f a c-\left[\mathrm{MnBr}(\mathrm{CO})_{3}\left(\mathrm{NH}=\mathrm{C}\left(\mathrm{CH}_{3}\right) \mathrm{dmpz}-\kappa^{2} N, N\right)\right]$, $(0.036 \mathrm{~g}, 0.1 \mathrm{mmol})$ in thf $(10 \mathrm{~mL})$, a $0.17 \mathrm{M}$ solution of $\mathrm{AgBF}_{4}$ in wet acetone $(0.60 \mathrm{~mL}, 0.1 \mathrm{mmol})$ was added. The mixture was stirred at room temperature excluded from the sunlight for $30 \mathrm{~min}$, and the volatiles were removed in vacuo. The yellow residue was extracted with $\mathrm{CH}_{2} \mathrm{Cl}_{2}$ (ca. $20 \mathrm{~mL}$ ) and filtered. Hexane was added (ca. $10 \mathrm{~mL}$ ) and the solution was concentrated and cooled to $-20^{\circ} \mathrm{C}$, giving a yellow microcrystalline solid, which was decanted, washed with hexane $(3 \times 3 \mathrm{~mL}$ approximately), and dried in vacuo, yielding $0.097 \mathrm{~g}$ (51\%) of 1b. IR (thf, $\mathrm{cm}^{-1}$ ): $2040 \mathrm{vs,} 1940 \mathrm{vs,} 1934$ vs. IR $\left(\mathrm{KBr}, \mathrm{cm}^{-1}\right)$ : $3448 \mathrm{~m}, 3327 \mathrm{~m}, 2048$ vs, 1956 vs, 1924 vs, 1647 m, 1575 w, 1453 w, 1416 m, 1356 w, 1251 w, 1100 s, 1048 s, 829 w, 639 w, 514 w. ${ }^{1} \mathrm{H}$ NMR $\left(\mathrm{Me}_{2} \mathrm{CO}-d_{6}\right): 2.69$ (s, $\left.\mathrm{CH}_{3} \mathrm{dmpz}, 3 \mathrm{H}\right), 2.71$ (s, $\left.\mathrm{CH}_{3} \mathrm{dmpz}, 3 \mathrm{H}\right), 2.98$ (s, $\left.\mathrm{N}=\mathrm{C}\left(\mathrm{CH}_{3}\right), 3 \mathrm{H}\right), 4.72\left(\mathrm{~s}, \mathrm{OH}_{2}, 2 \mathrm{H}\right), 6.57$ (s, $\left.H^{4} \mathrm{dmpz}, 1 \mathrm{H}\right), 10.80(\mathrm{br}, H \mathrm{~N}, 1 \mathrm{H}) \cdot{ }^{13} \mathrm{C}\left\{{ }^{1} \mathrm{H}\right\} \mathrm{NMR}\left(\mathrm{Me}_{2} \mathrm{CO}-d_{6}\right): 14.1(\mathrm{~s}$ $\left.\mathrm{CH}_{3} \mathrm{dmpz}\right), 15.3\left(\mathrm{~s}, \mathrm{CH}_{3} \mathrm{dmpz}\right), 21.4\left(\mathrm{~s}, \mathrm{HN}=\mathrm{C}\left(\mathrm{CH}_{3}\right)\right), 115.1\left(\mathrm{~s}, \mathrm{C}^{4}\right.$ dmpz), $147.4\left(\mathrm{~s}, \mathrm{C}^{3,5} \mathrm{dmpz}\right), 159.2\left(\mathrm{~s}, \mathrm{C}^{5,3} \mathrm{dmpz}\right), 167.7$ (s, $\left.\mathrm{HN}=\mathrm{C}\left(\mathrm{CH}_{3}\right)\right), 219.9(\mathrm{~s}, \mathrm{CO}), 220.7(\mathrm{~s}, \mathrm{CO}), 221.2(\mathrm{~s}, \mathrm{CO}) \cdot{ }^{19} \mathrm{~F}$ NMR $\left(\mathrm{Me}_{2} \mathrm{CO}-d_{6}\right):-148.1\left(\mathrm{br},{ }^{10} \mathrm{BF}_{4}, 4 \mathrm{~F}\right.$ and $\left.{ }^{11} \mathrm{BF}_{4}, 4 \mathrm{~F}\right)$. Anal. Calc. for $\mathrm{C}_{10} \mathrm{H}_{13} \mathrm{BF}_{4} \mathrm{MnN}_{3} \mathrm{O}_{4}$ : C, 31.53; $\mathrm{H}, 3.40 ; \mathrm{N}, 11.03$. Found: C, 31.84; $\mathrm{H}, 3.10 ; \mathrm{N}, 10.91 \%$.

\section{4. $\mathrm{fac}-\left[\mathrm{Mn}(\mathrm{CNXyl})(\mathrm{CO})_{3}\left(\mathrm{NH}=\mathrm{C}\left(\mathrm{CH}_{3}\right) p z-\kappa^{2} \mathrm{~N}, \mathrm{~N}\right)\right] \mathrm{BF}_{4}(\mathbf{2 a})$}

A recently prepared solution of 1a (starting from $0.098 \mathrm{~g}$, $0.3 \mathrm{mmol}$ of $\left.f a c-\left[\mathrm{MnBr}(\mathrm{CO})_{3}\left(\mathrm{NH}=\mathrm{C}\left(\mathrm{CH}_{3}\right) \mathrm{pz}-\kappa^{2} N, N\right)\right]\right)$ in thf $(10 \mathrm{~mL})$ was synthesized as described above. After filtering to remove AgBr, CNXyl (0.039 g, $0.3 \mathrm{mmol}$ ) was added and the solution was stirred at room temperature for $5 \mathrm{~h}$. Hexane was added (ca. $10 \mathrm{~mL}$ ) and the solution was concentrated and cooled to $-20^{\circ} \mathrm{C}$, giving a pale yellow microcrystalline solid, which was decanted, washed with hexane $(3 \times 3 \mathrm{~mL}$ approximately), and dried in vacuo, yielding $0.098 \mathrm{~g}(70 \%)$ of $2 \mathrm{a}$. IR (thf, $\mathrm{cm}^{-1}$ ): $2171 \mathrm{w}, 2048 \mathrm{vs}, 1985 \mathrm{~s}$, 1955 vs. IR ( $\left.\mathrm{KBr}, \mathrm{cm}^{-1}\right)$ : 3311 w, $2172 \mathrm{~m}, 2045$ vs, 1979 s, 1951 s, $1654 \mathrm{~m}, 1083 \mathrm{~s}, 786 \mathrm{w}, 628 \mathrm{w} .{ }^{1} \mathrm{H}$ NMR $\left(\mathrm{Me}_{2} \mathrm{CO}-d_{6}\right): 2.24(\mathrm{~s}$, $\left.\mathrm{CNC}_{6} \mathrm{H}_{3}\left(\mathrm{CH}_{3}\right)_{2}, 6 \mathrm{H}\right), 2.93\left(\mathrm{~s}, \mathrm{~N}=\mathrm{C}\left(\mathrm{CH}_{3}\right), 3 \mathrm{H}\right), 6.98\left(\mathrm{~s}, \mathrm{H}^{4} \mathrm{pz}, 1 \mathrm{H}\right)$, 7.20 and $7.28\left(\mathrm{AB}_{2}\right.$ system, $\left.\mathrm{CNC}_{6} \mathrm{H}_{3}\left(\mathrm{CH}_{3}\right)_{2}, 3 \mathrm{H}\right), 8.57$ (d, $\left.J=1.2 \mathrm{~Hz}, H^{3} \mathrm{pz}, 1 \mathrm{H}\right), 8.85\left(\mathrm{~d}, J=3.1 \mathrm{~Hz}, H^{5} \mathrm{pz}, 1 \mathrm{H}\right), 10.73(\mathrm{br}, H \mathrm{~N}$, $1 \mathrm{H}) .{ }^{13} \mathrm{C}\left\{{ }^{1} \mathrm{H}\right\}$ NMR $\left(\mathrm{Me}_{2} \mathrm{CO}-d_{6}\right): 18.2\left(\mathrm{~s}, \mathrm{CNC}_{6} \mathrm{H}_{3}\left(\mathrm{CH}_{3}\right)_{2}\right), 18.9(\mathrm{~s}$, $\left.\mathrm{HN}=\mathrm{C}\left(\mathrm{CH}_{3}\right)\right), 113.5\left(\mathrm{~s}, \mathrm{C}^{4} \mathrm{dmpz}\right), 127.1$ (s, $\left.\mathrm{C}_{\text {ipso }} \mathrm{CNC}_{6} \mathrm{H}_{3}\left(\mathrm{CH}_{3}\right)_{2}\right)$, 128.9 (s, meta- $\left.\mathrm{CNC}_{6} \mathrm{H}_{3}\left(\mathrm{CH}_{3}\right)_{2}\right), 130.7$ (s, para- $\mathrm{CNC}_{6} \mathrm{H}_{3}\left(\mathrm{CH}_{3}\right)_{2}$ ), 135.1 (s, $\left.\mathrm{C}^{3.5} \mathrm{pz}\right), 136.1$ (s, ortho- $\left.\mathrm{CNC}_{6} \mathrm{H}_{3}\left(\mathrm{CH}_{3}\right)_{2}\right), 150.2\left(\mathrm{~s}, \mathrm{C}^{5,3} \mathrm{pz}\right)$, $164.6\left(\mathrm{~s}, \mathrm{HN}=\mathrm{C}\left(\mathrm{CH}_{3}\right)\right), 206.5(\mathrm{~s}, \mathrm{CNXyl}), 218.7$ (br s, CO). ${ }^{19} \mathrm{~F}$ NMR $\left(\mathrm{Me}_{2} \mathrm{CO}-\mathrm{d}_{6}\right):-148.8\left(\mathrm{br},{ }^{10} \mathrm{BF}_{4}, 4 \mathrm{~F}\right.$ and $\left.{ }^{11} \mathrm{BF}_{4}, 4 \mathrm{~F}\right)$. Anal. Calc. for $\mathrm{C}_{17} \mathrm{H}_{16} \mathrm{BF}_{4} \mathrm{MnN}_{4} \mathrm{O}_{3}$ : C, 43.81; H, 3.46; N, 12.02. Found: C, 43.52; $\mathrm{H}, 3.31 ; \mathrm{N}, 11.85 \%$. X-ray diffraction: high values for residuals $R_{\text {int }}$, $R$ and $w R_{2}$ are obtained due to the low quality of the crystal.

\section{5. $f a c-\left[\mathrm{Mn}(\mathrm{CNXyl})(\mathrm{CO})_{3}\left(\mathrm{NH}=\mathrm{C}\left(\mathrm{CH}_{3}\right) d m p z-\kappa^{2} \mathrm{~N}, \mathrm{~N}\right)\right] \mathrm{BF}_{4}(\mathbf{2} \boldsymbol{b})$}

A recently prepared solution of $\mathbf{1 b}$ (starting from $0.071 \mathrm{~g}$, $0.2 \mathrm{mmol}$ of $\left.f a c-\left[\mathrm{MnBr}(\mathrm{CO})_{3}\left(\mathrm{NH}=\mathrm{C}\left(\mathrm{CH}_{3}\right) \mathrm{dmpz}-\kappa^{2} N, N\right)\right]\right)$ in thf $(10 \mathrm{~mL})$ was synthesized as described above. After filtering to remove AgBr, CNXyl $(0.026 \mathrm{~g}, 0.2 \mathrm{mmol})$ was added and the solution was stirred at room temperature for $5 \mathrm{~h}$. Work-up as for $\mathbf{2 a}$ gave $0.088 \mathrm{~g}(90 \%)$ of $\mathbf{2 b}$ as a pale yellow microcrystalline solid. IR (thf, $\mathrm{cm}^{-1}$ ): 2169 w, 2046 vs, 1983 s, 1948 s. IR $\left(\mathrm{KBr}, \mathrm{cm}^{-1}\right)$ : $3338 \mathrm{~m}, 3318$ w, 2179 s, 2045 vs, 1982 vs, 1946 vs, 1655 m, 1575 m, 1478 m, 1452 s, 1412 s, 1355 m, 1246 w, 1073 vs, 786 m, $674 \mathrm{~m}, 636$ s. ${ }^{1} \mathrm{H}$ NMR $\left(\mathrm{Me}_{2} \mathrm{CO}-d_{6}\right): 2.27$ (s, $\mathrm{CNC}_{6} \mathrm{H}_{3}\left(\mathrm{CH}_{3}\right)_{2}, 6$ $\mathrm{H}), 2.66\left(\mathrm{~s}, \mathrm{CH}_{3} \mathrm{dmpz}, 3 \mathrm{H}\right), 2.73\left(\mathrm{~s}, \mathrm{CH}_{3} \mathrm{dmpz}, 3 \mathrm{H}\right), 2.99(\mathrm{~s}$, $\left.\mathrm{N}=\mathrm{C}\left(\mathrm{CH}_{3}\right), 3 \mathrm{H}\right), 6.61\left(\mathrm{~s}, \mathrm{H}^{4} \mathrm{dmpz}, 1 \mathrm{H}\right), 7.23$ and $7.31\left(\mathrm{AB}_{2}\right.$ system, $\left.\mathrm{CNC}_{6} \mathrm{H}_{3}\left(\mathrm{CH}_{3}\right)_{2}, 3 \mathrm{H}\right), 10.48(\mathrm{br}, H \mathrm{~N}, 1 \mathrm{H}) .{ }^{13} \mathrm{C}\left\{{ }^{1} \mathrm{H}\right\}$ NMR $\left(\mathrm{Me}_{2} \mathrm{CO}-d_{6}\right)$ : 14.2 (s, $\left.\mathrm{CH}_{3} \mathrm{dmpz}\right), 15.4$ (s, $\left.\mathrm{CH}_{3} \mathrm{dmpz}\right), 18.2\left(\mathrm{~s}, \mathrm{CNC}_{6} \mathrm{H}_{3}\left(\mathrm{CH}_{3}\right)_{2}\right)$, $21.5\left(\mathrm{~s}, \mathrm{HN}=\mathrm{C}\left(\mathrm{CH}_{3}\right)\right), 115.4\left(\mathrm{~s}, \mathrm{C}^{4} \mathrm{dmpz}\right), 128.9$ (s, meta$\left.\mathrm{CNC}_{6} \mathrm{H}_{3}\left(\mathrm{CH}_{3}\right)_{2}\right), 129.2$ (s, para- $\left.\mathrm{CNC}_{6} \mathrm{H}_{3}\left(\mathrm{CH}_{3}\right)_{2}\right), 130.7$ (s, C ipso $\left.\mathrm{CNC}_{6} \mathrm{H}_{3}\left(\mathrm{CH}_{3}\right)_{2}\right), 136.1$ (s, ortho- $\left.\mathrm{CNC}_{6} \mathrm{H}_{3}\left(\mathrm{CH}_{3}\right)_{2}\right), 147.9\left(\mathrm{~s}, \mathrm{C}^{3.5} \mathrm{dmpz}\right.$ ), 159.6 (s, $\mathrm{C}^{5,3} \mathrm{dmpz}$ ), 166.3 (s, $\left.\mathrm{HN}=\mathrm{C}\left(\mathrm{CH}_{3}\right)\right), \mathrm{CNXyl}$ and $\mathrm{CO}$ not observed. ${ }^{19} \mathrm{~F}$ NMR $\left(\mathrm{Me}_{2} \mathrm{CO}-d_{6}\right):-150.2\left(\mathrm{br},{ }^{10} \mathrm{BF}_{4}, 4 \mathrm{~F}\right.$ and $\left.{ }^{11} \mathrm{BF}_{4}, 4 \mathrm{~F}\right)$. Anal. Calc. for $\mathrm{C}_{19} \mathrm{H}_{20} \mathrm{BF}_{4} \mathrm{MnN}_{4} \mathrm{O}_{3}$ : C, 46.18; $\mathrm{H}, 4.08 ; \mathrm{N}, 11.34$. Found: $\mathrm{C}, 45.93 ; \mathrm{H}, 3.98 ; \mathrm{N}, 11.02 \%$.

\section{6. $f a c-\left[\mathrm{Mn}(\mathrm{pzH})(\mathrm{CO})_{3}\left(\mathrm{NH}=\mathrm{C}\left(\mathrm{CH}_{3}\right) p z-\kappa^{2} \mathrm{~N}, \mathrm{~N}\right)\right] \mathrm{BF}_{4}(\mathbf{3 a})$}

A solution of $\left[\mathrm{MnBr}(\mathrm{CO})_{5}\right](0.083 \mathrm{~g}, 0.3 \mathrm{mmol})$ in $\mathrm{CH}_{3} \mathrm{CN}(10 \mathrm{~mL})$ was maintained at $60{ }^{\circ} \mathrm{C}$ for $30 \mathrm{~min}$. Then a $0.1 \mathrm{M}$ solution of $\mathrm{AgBF}_{4}$ in wet acetone $(3.3 \mathrm{~mL}, 0.33 \mathrm{mmol})$ was added, and the mixture was stirred at $40^{\circ} \mathrm{C}$ excluded from the sunlight for $1 \mathrm{~h}$. Then pzH $(0.041 \mathrm{~g}, 0.6 \mathrm{mmol})$ was added and the mixture was refluxed during $18 \mathrm{~h}$. Work-up as for $\mathbf{1 b}$ gave $0.053(44 \%)$ of $\mathbf{3 a}$ as yellow crystals. IR (thf, $\left.\mathrm{cm}^{-1}\right): 2043 \mathrm{vs,} 1951 \mathrm{~s}, 1940 \mathrm{vs}$. IR $\left(\mathrm{KBr}, \mathrm{cm}^{-1}\right): 3336 \mathrm{~s}$, $3141 \mathrm{~m}, 2042$ vs, 1956 vs, 1929 vs, 1655 s, 1535 m, 1464 m, 1406 s, $1242 \mathrm{~m}, 1118 \mathrm{~m}, 1084 \mathrm{~s}, 1052 \mathrm{~s}, 760 \mathrm{~s}, 633 \mathrm{~m} .{ }^{1} \mathrm{H}$ NMR $\left(\mathrm{Me}_{2} \mathrm{CO}-d_{6}\right)$ : $2.94\left(\mathrm{~s}, \mathrm{~N}=\mathrm{C}\left(\mathrm{CH}_{3}\right), 3 \mathrm{H}\right), 6.42\left(\mathrm{~d}, J=1.9 \mathrm{~Hz}, \mathrm{H}^{4} \mathrm{pzH}, 1 \mathrm{H}\right), 6.95$ (pst, $J=2.5 \mathrm{~Hz}, H^{4} \mathrm{pz}, 1 \mathrm{H}$ ), 7.57 (pst, $J=1.9 \mathrm{~Hz}, H^{3}$ pzH, $1 \mathrm{H}$ ), 7.90 (d, $\left.J=1.9 \mathrm{~Hz}, H^{5} \mathrm{pzH}, 1 \mathrm{H}\right), 8.70\left(\mathrm{~d}, J=1.9 \mathrm{~Hz}, H^{3} \mathrm{pz}, 1 \mathrm{H}\right), 8.73(\mathrm{~d}$, $\left.J=2.5 \mathrm{~Hz}, H^{5} \mathrm{pz}, 1 \mathrm{H}\right), 10.93\left(\mathrm{br}, \mathrm{HN}=\mathrm{C}\left(\mathrm{CH}_{3}\right), 1 \mathrm{H}\right), 12.44(\mathrm{br}, \mathrm{HN}$ pzH, $1 \mathrm{H}) .{ }^{13} \mathrm{C}\left\{{ }^{1} \mathrm{H}\right\}$ NMR $\left(\mathrm{Me}_{2} \mathrm{CO}-d_{6}\right): 19.0\left(\mathrm{~s}, \mathrm{HN}=\mathrm{C}\left(\mathrm{CH}_{3}\right)\right), 108.0$ (s, $\left.C^{4} \mathrm{pzH}\right), 113.3$ (s, $\left.C^{4} \mathrm{pz}\right), 133.8$ (s, $\left.C^{3.5} \mathrm{pzH}\right), 135.0\left(\mathrm{~s}, C^{3.5} \mathrm{pz}\right)$, $144.1\left(\mathrm{~s}, \mathrm{C}^{5,3} \mathrm{pzH}\right), 149.9\left(\mathrm{~s}, \mathrm{C}^{5,3} \mathrm{pz}\right), 165.7(\mathrm{~s}, \mathrm{HN}=\mathrm{C}(\mathrm{CH} 3)), 219.6$ (br s, CO). ${ }^{19} \mathrm{~F}$ NMR $\left(\mathrm{Me}_{2} \mathrm{CO}-d_{6}\right):-148.1\left(\mathrm{br},{ }^{10} \mathrm{BF}_{4}, 4 \mathrm{~F}\right.$ and ${ }^{11} \mathrm{BF}_{4}$, 4F). Anal. Calc. for $\mathrm{C}_{11} \mathrm{H}_{11} \mathrm{BF}_{4} \mathrm{MnN}_{5} \mathrm{O}_{3}$ : C, 32.79; $\mathrm{H}, 2.75 ; \mathrm{N}, 17.38$. Found: C, 33.02; $\mathrm{H}, 2.43 ; \mathrm{N}, 17.09 \%$.

\section{7. $f a c-\left[\mathrm{Mn}(\mathrm{dmpzH})(\mathrm{CO})_{3}\left(\mathrm{NH}=\mathrm{C}\left(\mathrm{CH}_{3}\right) \mathrm{dmpz}-\kappa^{2} \mathrm{~N}, \mathrm{~N}\right)\right] \mathrm{BF}_{4}(\mathbf{3} \boldsymbol{b})$}

A solution of $\left[\mathrm{MnBr}(\mathrm{CO})_{5}\right](0.083 \mathrm{~g}, 0.3 \mathrm{mmol})$ in $\mathrm{CH}_{3} \mathrm{CN}(10 \mathrm{~mL})$ was maintained at $60{ }^{\circ} \mathrm{C}$ for $30 \mathrm{~min}$. Then a $0.1 \mathrm{M}$ solution of $\mathrm{AgBF}_{4}$ in wet acetone $(3.3 \mathrm{~mL}, 0.33 \mathrm{mmol})$ was added, and the mixture was stirred at $40^{\circ} \mathrm{C}$ excluded from the sunlight for $1 \mathrm{~h}$. Then dmpzH $(0.041 \mathrm{~g}, 0.6 \mathrm{mmol})$ was added and the mixture was refluxed during $18 \mathrm{~h}$. Work-up as for $\mathbf{1 b}$ gave 0.069 (50\%) of $\mathbf{3 b}$ as yellow crystals. IR (thf, $\mathrm{cm}^{-1}$ ): $2039 \mathrm{~s}, 1949 \mathrm{~s}, 1931$ vs. IR (KBr, $\mathrm{cm}^{-1}$ ): $3402 \mathrm{~m}, 3352 \mathrm{~m}, 2036$ vs, 1942 vs, 1926 vs, $1642 \mathrm{~m}$, $1577 \mathrm{~m}, 1419 \mathrm{~s}, 1101 \mathrm{~s}, 1044 \mathrm{~s}, 812 \mathrm{~m}, 645 \mathrm{w}, 522 \mathrm{w} .{ }^{1} \mathrm{H}$ NMR $\left(\mathrm{Me}_{2} \mathrm{CO}-d_{6}\right): 2.18$ (s, $\left.\mathrm{CH}_{3} \mathrm{dmpzH}, 3 \mathrm{H}\right), 2.23$ (s, $\left.\mathrm{CH}_{3} \mathrm{dmpzH}, 3 \mathrm{H}\right)$, $2.65\left(\mathrm{~s}, \mathrm{CH}_{3} \mathrm{dmpz}, 3 \mathrm{H}\right), 2.74\left(\mathrm{~s}, \mathrm{CH}_{3} \mathrm{dmpz}, 3 \mathrm{H}\right), 2.92\left(\mathrm{~s}, \mathrm{~N}=\mathrm{C}\left(\mathrm{CH}_{3}\right)\right.$, $3 \mathrm{H}), 5.97$ (s, $\left.H^{4} \mathrm{dmpzH}, 1 \mathrm{H}\right), 6.55$ (s, $\left.H^{4} \mathrm{dmpz}, 1 \mathrm{H}\right), 10.41$ (br, $\left.\mathrm{HN}=\mathrm{C}\left(\mathrm{CH}_{3}\right), 1 \mathrm{H}\right), 10.93(\mathrm{br}, \mathrm{HN}$ dmpzH, $1 \mathrm{H}) .{ }^{13} \mathrm{C}\left\{{ }^{1} \mathrm{H}\right\} \quad \mathrm{NMR}$ $\left(\mathrm{Me}_{2} \mathrm{CO}-\mathrm{d}_{6}\right): 10.5$ (s, $\left.\mathrm{CH}_{3} \mathrm{dmpzH}\right), 14.2$ (s, $\mathrm{CH}_{3} \mathrm{dmpz}$ ), 14.5 (s, $\left.\mathrm{CH}_{3} \mathrm{dmpzH}\right), 15.8\left(\mathrm{~s}, \mathrm{CH}_{3} \mathrm{dmpz}\right), 21.5\left(\mathrm{~s}, \mathrm{HN}=\mathrm{C}\left(\mathrm{CH}_{3}\right)\right), 108.1$ (s, $C^{4}$ dmpzH), 115.2 (s, $\left.C^{4} \mathrm{dmpz}\right), 144.5$ (s, $\left.C^{3.5} \mathrm{dmpzH}\right), 148.3$ (s, $\left.C^{3,5} \mathrm{dmpz}\right), 154.3$ (s, $\left.\mathrm{C}^{5,3} \mathrm{dmpzH}\right), 160.0\left(\mathrm{~s}, \mathrm{C}^{5,3} \mathrm{dmpz}\right), 167.5$ $\left(\mathrm{s}, \mathrm{HN}=\mathrm{C}\left(\mathrm{CH}_{3}\right)\right), 220.1$ (br s, $\left.\mathrm{CO}\right) .{ }^{19} \mathrm{~F}$ NMR $\left(\mathrm{Me}_{2} \mathrm{CO}-d_{6}\right):-148.0$ (br, ${ }^{10} \mathrm{BF}_{4}, 4 \mathrm{~F}$ and $\left.{ }^{11} \mathrm{BF}_{4}, 4 \mathrm{~F}\right)$. Anal. Calc. for $\mathrm{C}_{15} \mathrm{H}_{19} \mathrm{BF}_{4} \mathrm{MnN}_{5} \mathrm{O}_{3}$ : $\mathrm{C}$, $39.24 ; \mathrm{H}, 4.17$; N, 15.25 . Found: C, 39.24; H, 3.89; N, $14.93 \%$.

\section{8. $\mathrm{fac}-\left[\mathrm{Mn}(\mathrm{NCMe})(\mathrm{CO})_{3}\left(\mathrm{NH}=\mathrm{C}\left(\mathrm{CH}_{3}\right) p z-\kappa^{2} \mathrm{~N}, \mathrm{~N}\right)\right] \mathrm{ClO}_{4}$ (4a)}

A solution of $\left[\mathrm{MnBr}(\mathrm{CO})_{5}\right](0.137 \mathrm{~g}, 0.5 \mathrm{mmol})$ in $\mathrm{CH}_{3} \mathrm{CN}(20 \mathrm{~mL})$ was maintained at $60^{\circ} \mathrm{C}$ for $30 \mathrm{~min}$. Then $\mathrm{AgClO}_{4}(0.114 \mathrm{~g}$, $0.55 \mathrm{mmol}$ ) was added, and the mixture was stirred at $60^{\circ} \mathrm{C}$ excluded from the sunlight for $1 \mathrm{~h}$. Then pzH $(0.034 \mathrm{~g}, 0.5 \mathrm{mmol})$ was added and the mixture was refluxed during $18 \mathrm{~h}$. Work-up as for $\mathbf{1 b}$ gave $0.115 \mathrm{~g}(59 \%)$ of $\mathbf{4 a}$ as yellow crystals. IR (thf, 
Table 6

Crystal data and refinement details for $\mathbf{1 a}, \mathbf{2 a}, \mathbf{3 a}, \mathbf{3 b}$, and $\mathbf{4 a}$

\begin{tabular}{|c|c|c|c|c|c|}
\hline & 1b & $2 \mathbf{a}$ & 3a & $\mathbf{3 b}$ & $4 a$ \\
\hline Formula & $\mathrm{C}_{10} \mathrm{H}_{13} \mathrm{BF}_{4} \mathrm{MnN}_{3} \mathrm{O}_{4}$ & $\mathrm{C}_{17} \mathrm{H}_{16} \mathrm{BF}_{4} \mathrm{MnN}_{4} \mathrm{O}_{3}$ & $\mathrm{C}_{22} \mathrm{H}_{22} \mathrm{~B}_{2} \mathrm{~F}_{8} \mathrm{Mn}_{2} \mathrm{~N}_{10} \mathrm{O}_{6}$ & $\mathrm{C}_{15} \mathrm{H}_{19} \mathrm{BF}_{4} \mathrm{MnN}_{5} \mathrm{O}_{3}$ & $\mathrm{C}_{10} \mathrm{H}_{10} \mathrm{ClMnN}_{4} \mathrm{O}_{7}$ \\
\hline Formula weight & 380.98 & 466.09 & 806.00 & 459.10 & 388.61 \\
\hline Crystal system & Monoclinic & Triclinic & Orthorhombic & Monoclinic & Monoclinic \\
\hline Space group & $P 2(1) / n$ & $P 1$ & $P 2(1) 2(1) 2(1)$ & $P 2(1) / c$ & $P 2(1) / n$ \\
\hline$a(\AA)$ & $8.336(5)$ & $7.824(8)$ & $12.807(3)$ & $13.238(3)$ & $6.725(3)$ \\
\hline$b(\AA)$ & $9.223(5)$ & $8.664(9)$ & $15.698(4)$ & $11.694(2)$ & $14.457(7)$ \\
\hline$c(\hat{A})$ & $20.929(11)$ & $15.884(16)$ & $16.442(4)$ & $13.667(3)$ & $16.453(8)$ \\
\hline$\alpha\left({ }^{\circ}\right)$ & 90 & 99.992(13). & 90 & 90 & 90 \\
\hline$\beta\left({ }^{\circ}\right)$ & $99.417(9)$ & $96.31(2)$ & 90 & $106.809(4)$ & $101.364(11)$ \\
\hline$\gamma\left({ }^{\circ}\right)$ & 90 & 91.93(2). & 90 & 90 & 90 \\
\hline$V\left(\AA^{3}\right)$ & $1587.3(15)$ & $1052.4(18)$ & $3305.7(13)$ & 2025.2(7) & $1568.2(14)$ \\
\hline Z & 4 & 2 & 4 & 4 & 4 \\
\hline$T(\mathrm{~K})$ & $296(2)$ & 293(2) & $298(2)$ & $298(2)$ & $293(2)$ \\
\hline$D_{\text {calc }}\left(\mathrm{g} \mathrm{cm}^{-3}\right)$ & 1.594 & 1.471 & 1.619 & 1.506 & 1.646 \\
\hline$F(000)$ & 768 & 472 & 1616 & 936 & 784 \\
\hline$\lambda(\operatorname{Mo~K} \alpha)(\AA)$ & 0.71073 & 0.71073 & 0.71073 & 0.71073 & 0.71073 \\
\hline Crystal size $(\mathrm{mm})$; color & $\begin{array}{l}0.43 \times 0.14 \times 0.09 \\
\text { yellow }\end{array}$ & $\begin{array}{l}0.39 \times 0.12 \times 0.05 ; \text { pale } \\
\text { yellow }\end{array}$ & $\begin{array}{l}0.22 \times 0.14 \times 0.09 \\
\text { yellow }\end{array}$ & $\begin{array}{l}0.27 \times 0.08 \times 0.03 \\
\text { yellow }\end{array}$ & $\begin{array}{l}0.21 \times 0.06 \times 0.03 \\
\text { yellow }\end{array}$ \\
\hline$\mu\left(\mathrm{mm}^{-1}\right)$ & 0.893 & 0.687 & 0.862 & 0.714 & 1.052 \\
\hline Scan range $\left(^{\circ}\right)$ & $1.97 \leqslant \theta \leqslant 23.32$ & $1.31 \leqslant \theta \leqslant 23.16$ & $1.79 \leqslant \theta \leqslant 23.30$ & $1.61 \leqslant \theta \leqslant 23.31$ & $1.89 \leqslant \theta \leqslant 23.30$ \\
\hline Absorption correction & SADABS & SADABS & SADABS & SADABS & SADABS \\
\hline $\begin{array}{l}\text { Corr. factors (maximum, } \\
\text { minimum) }\end{array}$ & $1.000000,0.825580$ & $1.000000,0.12755$ & $1.000000,0.723207$ & $1.000000,0.510039$ & $1.000000,0.746960$ \\
\hline Number of measured reflection & 6877 & 4337 & 21570 & 12937 & 6862 \\
\hline $\begin{array}{l}\text { Number of independent reflection } \\
{\left[R_{\text {int }}\right]}\end{array}$ & $2295[0.0246]$ & $2837[0.2655]$ & $4768[0.1300]$ & $2913[0.1016]$ & $2254[0.0444]$ \\
\hline$I \geqslant 2 \sigma(I)$ & 1856 & 1234 & 3404 & 1638 & 2254 \\
\hline Goodness-of-fit (GOF) of $F^{2}$ & 1.086 & 1.223 & 1.027 & 1.002 & 0.985 \\
\hline Number of parameters & 223 & 250 & 453 & 267 & 210 \\
\hline Residuals $R, w R_{2}$ & $0.0583,0.1709$ & $0.1487,0.4259$ & $0.0692,0.1785$ & $0.0661,0.2019$ & $0.0430,0.1175$ \\
\hline
\end{tabular}

$\mathrm{cm}^{-1}$ ): $2042 \mathrm{~s}, 1947 \mathrm{~s}, 1932$ vs. IR $\left(\mathrm{KBr}, \mathrm{cm}^{-1}\right): 3276 \mathrm{w}, 2051 \mathrm{~s}$, 1978 s, 1951 vs, 1664 w, 1410 m, 1090 s, 776 w, 624 w. ${ }^{1} \mathrm{H}$ NMR $\left(\mathrm{Me}_{2} \mathrm{CO}-d_{6}\right): 2.29\left(\mathrm{~s}, \mathrm{NCCH}_{3}, 3 \mathrm{H}\right), 2.95\left(\mathrm{~s}, \mathrm{~N}=\mathrm{C}\left(\mathrm{CH}_{3}\right), 3 \mathrm{H}\right), 6.94$ (s, $\left.H^{4} \mathrm{pz}, 1 \mathrm{H}\right), 8.53\left(\mathrm{~s}, H^{3} \mathrm{pz}, 1 \mathrm{H}\right), 8.77\left(\mathrm{~s}, H^{5} \mathrm{pz}, 1 \mathrm{H}\right), 10.87(\mathrm{br}$, $\mathrm{HN}, 1 \mathrm{H}) .{ }^{13} \mathrm{C}\left\{{ }^{1} \mathrm{H}\right\}$ NMR $\left(\mathrm{Me}_{2} \mathrm{CO}-d_{6}\right): 3.2\left(\mathrm{~s}, \mathrm{NCCH}_{3}\right), 19.1(\mathrm{~s}$, $\left.\left.\mathrm{HN}=\mathrm{C}\left(\mathrm{CH}_{3}\right)\right), 113.1\left(\mathrm{~s}, \mathrm{C}^{4} \mathrm{pz}\right), 127.8\left(\mathrm{~s}, \mathrm{NCCH}_{3}\right)\right), 135.1\left(\mathrm{~s}, \mathrm{C}^{3,5} \mathrm{pz}\right)$, $149.5\left(\mathrm{~s}, \mathrm{C}^{5,3} \mathrm{pz}\right), 165.5\left(\mathrm{~s}, \mathrm{HN}=\mathrm{C}\left(\mathrm{CH}_{3}\right)\right), \mathrm{CO}$ not observed. Anal. Calc. for $\mathrm{C}_{10} \mathrm{H}_{10} \mathrm{ClMnN}_{4} \mathrm{O}_{7}: \mathrm{C}, 30.91 ; \mathrm{H}, 2.59 ; \mathrm{N}, 14.42$. Found: $\mathrm{C}$, $30.98 ; \mathrm{H}, 2.33 ; \mathrm{N}, 14.39 \%$.

\section{9. fac- $\left[\mathrm{Mn}(\mathrm{NCMe})(\mathrm{CO})_{3}\left(\mathrm{NH}=\mathrm{C}\left(\mathrm{CH}_{3}\right) \mathrm{dmpz}-\kappa^{2} \mathrm{~N}, \mathrm{~N}\right)\right] \mathrm{ClO}_{4}$ (4b)}

A solution of $\left[\mathrm{MnBr}(\mathrm{CO})_{5}\right](0.137 \mathrm{~g}, 0.5 \mathrm{mmol})$ in $\mathrm{CH}_{3} \mathrm{CN}(20 \mathrm{~mL})$ was maintained at $60^{\circ} \mathrm{C}$ for $30 \mathrm{~min}$. Then $\mathrm{AgClO}_{4}(0.114 \mathrm{~g}$, $0.55 \mathrm{mmol}$ ) was added, and the mixture was stirred at $60^{\circ} \mathrm{C}$ excluded from the sunlight for $1 \mathrm{~h}$. Then dmpzH $(0.048 \mathrm{~g}, 0.5 \mathrm{mmol})$ was added and the mixture was refluxed during $18 \mathrm{~h}$. Work-up as for $\mathbf{1 b}$ gave $0.125 \mathrm{~g} \mathrm{(60 \% )}$ of $\mathbf{4 b}$ as yellow crystals. IR (thf, $\mathrm{cm}^{-1}$ ): 2039 vs, 1940 vs, 1932 vs. IR (KBr, cm $\left.{ }^{-1}\right): 3301 \mathrm{~m}, 2047$ vs, 1965 vs, 1953 vs, 1940 vs, $1647 \mathrm{~m}, 1575 \mathrm{~m}, 1456 \mathrm{~m}, 1416 \mathrm{~m}, 1358 \mathrm{~m}$, $1245 \mathrm{w}, 1092 \mathrm{~s}, 624 \mathrm{~m} .{ }^{1} \mathrm{H}$ NMR $\left(\mathrm{Me}_{2} \mathrm{CO}-d_{6}\right): 2.30\left(\mathrm{~s}, \mathrm{NCCH}_{3}, 3 \mathrm{H}\right)$, 2.63 (s, $\left.\mathrm{CH}_{3} \mathrm{dmpz}, 3 \mathrm{H}\right), 2.70$ (s, $\left.\mathrm{CH}_{3} \mathrm{dmpz}, 3 \mathrm{H}\right), 2.98$ (s, $\mathrm{N}=\mathrm{C}\left(\mathrm{CH}_{3}\right)$, $3 \mathrm{H}), 6.54\left(\mathrm{~s}, H^{4} \mathrm{dmpz}, 1 \mathrm{H}\right), 10.78(\mathrm{br}, H \mathrm{~N}, 1 \mathrm{H}) .{ }^{13} \mathrm{C}\left\{{ }^{1} \mathrm{H}\right\} \mathrm{NMR}$ $\left(\mathrm{Me}_{2} \mathrm{CO}-d_{6}\right): 3.2$ (s, $\left.\mathrm{NCCH}_{3}\right), 14.2$ (s, $\mathrm{CH}_{3} \mathrm{dmpz}$ ), 15.2 (s, $\mathrm{CH}_{3} \mathrm{dmpz}$ ), $21.6\left(\mathrm{~s}, \mathrm{HN}=\mathrm{C}\left(\mathrm{CH}_{3}\right)\right), 115.1$ (s, $\left.\mathrm{C}^{4} \mathrm{dmpz}\right), 127.5\left(\mathrm{~s}, \mathrm{NCCH}_{3}\right), 147.6$ (s,

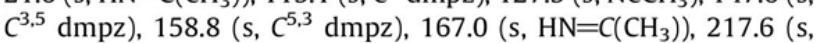
CO), 219.8 (s, CO). Anal. Calc. for $\mathrm{C}_{12} \mathrm{H}_{14} \mathrm{ClMnN}_{4} \mathrm{O}_{7}$ : C, 34.59; $\mathrm{H}$, 3.39; N, 13.45. Found: C, 34.24; H, 3.34; N, 13.36\%.

\subsection{X-ray crystallographic study of $\mathbf{1 b}, \mathbf{2 a}, \mathbf{3 a}, \mathbf{3 b}$ and $\mathbf{4 a}$}

Crystals were grown by slow diffusion of hexane into concentrated solutions of the complexes in $\mathrm{CH}_{2} \mathrm{Cl}_{2}$ at $-20^{\circ} \mathrm{C}$. Relevant crystallographic details are given in Table 6 . A crystal was attached to a glass fiber and transferred to a Bruker AXS SMART 1000 dif- fractometer with graphite monochromatized Mo $\mathrm{K} \alpha \mathrm{X}$-radiation and a CCD area detector. A hemisphere of the reciprocal space was collected up to $2 \theta=48.6^{\circ}$. Raw frame data were integrated with the sAINT program [10]. The structure was solved by direct methods with SHELXTL [11]. A semi-empirical absorption correction was applied with the program SADABS [12]. All non-hydrogen atoms were refined anisotropically except for the low quality structure of 2a, in which some atoms had to be refined isotropically to avoid non-positive-definite ellipsoids. Hydrogen atoms were set in calculated positions and refined as riding atoms, with a common thermal parameter. All calculations and graphics were made with SHELXTL.

\section{Supplementary data}

CCDC $685546,685547,685548,685549$ and 685550 contain the supplementary crystallographic data for $\mathbf{1 a}, \mathbf{2 a}, \mathbf{3 a}, \mathbf{3 b}$ and $\mathbf{4 a}$. These data can be obtained free of charge from The Cambridge Crystallographic Data Centre via www.ccdc.cam.ac.uk/data_request/cif.

\section{Acknowledgments}

The authors thank the Spanish Ministerio de Educación y Ciencia (CTQ2006-08924) and the Junta de Castilla y León (VA012C05) for financial support. M.A. thanks the MEC (Program FPI) for a grant.

\section{References}

[1] (a) A.V. Khripun, V.Y. Kukushkin, S.I. Selivanov, M. Auca, A.J.L. Pombeiro, Inorg. Chem. 45 (2006) 5073-5083;

(b) P. Govidaswamy, Y.A. Mozharivskyj, M.R. Kollipara, J. Organomet. Chem. 689 (2004) 3265-3274:

(c) M.R. Kollipara, P. Sarkhel, S. Chakraborty, R. Lalrempuia, J. Coord. Chem. 56 (2003) 1085-1091; 
(d) D. Carmona, J. Ferrer, F.J. Lahoz, L.A. Oro, M.P. Lamata, Organometallics 15 (1996) 5175-5178:

(e) J. López, A. Santos, A. Romero, A.M. Echavarren, J. Organomet. Chem. 443 (1993) 221-228

(f) M.A. Cinellu, S. Stoccoro, G. Minghetti, A.L. Bandini, G. Banditelli, B. Bovio, J. Organomet. Chem. 372 (1989) 311-325;

(g) G.D. Gracey, S.T. Rettig, A. Storr, J. Trotter, Can. J. Chem. 65 (1987) 24692477;

(h) A. Romero, A. Vegas, A. Santos, J. Organomet. Chem. 310 (1986) C8-C10;

(i) C.J. Jones, J.A. McCleverty, A.S. Rothin, J. Chem. Soc., Dalton Trans. (1986 109-111.

[2] J. Baker, M. Kilner, Coord. Chem. Rev. 133 (1994) 219-300.

[3] (a) M. Arroyo, A. López-Sanvicente, D. Miguel, F. Villafañe, Eur. J. Inorg. Chem. (2005) 4430-4437:

(b) M. Arroyo, D. Miguel, F. Villafañe, S. Nieto, J. Pérez, L. Riera, Inorg. Chem. 45 (2006) 7018-7026

[4] U. Prinz, U. Koelle, S. Ulrich, A.E. Merbach, O. Maas, K. Hegetschweiler, Inorg Chem. 43 (2004) 2387-2391. and references therein.

[5] (a) E. Horn, M.R. Snow, E.R.T. Tiekink, Acta Crystallogr. Sect. C: Cryst. Struct. Commun. 43 (1987) 792-794

(b) G. Schmidt, H. Paulus, R. van Eldik, H. Elias, Inorg. Chem. 27 (1988) 3211-

3214

(c) G.J. Stor, D.J. Stufkens, P. Vernooijs, E.J. Baerends, J. Fraanje, K. Goubitz Inorg. Chem. 34 (1995) 1588-1594.
[6] (a) G.A. Jeffrey, An Introduction to Hydrogen Bonding, Oxford University Press, New York, 1997 (Chapter 2)

(b) T. Steiner, Angew. Chem., Int. Ed. 41 (2002) 48-76.

[7] See for example: (a) R.H. Reimann, E. Singleton, J. Chem. Soc., Dalton Trans. (1974) 808-813;

(b) E.M. Armstrong, P.K. Baker, M.G.B. Drew, Organometallics 7 (1988) 319325 ;

(c) D. Fraccarollo, R. Bertani, M. Mozzon, U. Belluco, R.A. Michelin, Inorg. Chim. Acta 201 (1992) 15-22:

(d) S. Thomas, C.G. Young, E.R.T. Tiekink, Organometallics 17 (1998) 182-189; (e) E. Hevia, J. Pérez, V. Riera, D. Miguel, S. Kassel, A. Rheingold, Inorg. Chem. 41 (2002) 4673-4679.

[8] The singlets do not broaden at low temperature, what points to the absence of acetone-water exchange, as a fast exchange process at low temperature should not be expected.

[9] D.D. Perrin, W.L.F. Armarego, Purification of Laboratory Chemicals, third ed., Pergamon Press, Oxford, 1988.

[10] SAINT+. SAX Area Detector Integration Program. Version 6.02. Bruker AXS Inc. Madison, WI, 1999.

[11] G.M. Sheldrick; SHExTh, An Integrated System for Solving. Refining, and Displaying Crystal Structures from Diffraction Data. Version 5.1. Bruker AXS Inc., Madison, WI, 1998.

[12] G.M. Sheldrick, SADABS, Empirical Absorption Correction Program, University of Göttingen, Göttingen, Germany, 1997. 

Anexo III 



\title{
fac-Acetato-bis(pyrazole) complexes: A systematic study on intra- and intermolecular hydrogen bonds
}

\author{
Marta Arroyo, M. Teresa García-de-Prada, Carolina García-Martín, Vanesa García-Pacios, \\ Raúl García-Rodríguez, Patricia Gómez-Iglesias, Fernando Lorenzo, \\ Isaac Martín-Moreno ${ }^{1}$, Daniel Miguel, Fernando Villafañe *
}

IU CINQUIMA/Química Inorgánica, Facultad de Ciencias, Universidad de Valladolid, 47005 Valladolid, Spain

\section{A R T I C L E I N F O}

\section{Article history:}

Received 6 May 2009

Accepted 7 May 2009

Available online 15 May 2009

\section{Keywords:}

Hydrogen bonds

Pyrazole

Carboxylate ligands

Molybdenum

Group 7 metals

\begin{abstract}
A B S T R A C T
Acetato-bis(pyrazole) complexes [ $\mathrm{Mo}\left(\eta^{3}\right.$-methallyl $\left.)\left(\mathrm{O}_{2} \mathrm{CMe}\right)(\mathrm{CO})_{2}(\mathrm{pz} \cdot \mathrm{H})_{2}\right]$, (methallyl $=\mathrm{CH}_{2} \mathrm{C}\left(\mathrm{CH}_{3}\right) \mathrm{CH}_{2}$ ) and fac- $\left[\mathrm{M}\left(\mathrm{O}_{2} \mathrm{CMe}\right)(\mathrm{CO})_{3}\left(\mathrm{pz}^{*} \mathrm{H}\right)_{2}\right],\left(\mathrm{pz}{ }^{*} \mathrm{H}=\right.$ pyrazole or 3,5-dimethylpyrazole, dmpzH; $\left.\mathrm{M}=\mathrm{Mn}, \mathrm{Re}\right)$ are obtained from $\left[\mathrm{Mo}\left(\eta^{3}\right.\right.$-methallyl $\left.) \mathrm{Cl}(\mathrm{CO})_{2}(\mathrm{NCMe})_{2}\right]$ or $f a c-\left[\mathrm{MBr}(\mathrm{CO})_{3}(\mathrm{NCMe})_{2}\right][\mathrm{M}=\mathrm{Mn}$ (synthesized in situ), Re], 2 equiv. of pyrazole, and 1 equiv. of sodium acetate for Mo complexes, or silver acetate for $\mathrm{Mn}$ or Re complexes. The chlorido-complexes [ $\mathrm{Mo}\left(\eta^{3}\right.$-methallyl $\left.) \mathrm{Cl}(\mathrm{CO})_{2} \mathrm{~L}_{2}\right](\mathrm{L}=\mathrm{pzH}, \mathrm{dmpzH})$, obtained from the same starting material by substitution of $\mathrm{MeCN}$ by pzH or $\mathrm{dmpzH}$, are also described. The crystal structures of the fac-acetato-bis(dimethylpyrazole) complexes present the same pattern of intramolecular hydrogen bonds between the acetate and the dimetylpyrazole ligands, whereas the crystal structures of the fac-acetato-bis(pyrazole) complexes show different hydrogen bonds patterns, with intermolecular interactions. NMR data indicate that these interactions are not maintained in solution.
\end{abstract}

(c) 2009 Elsevier B.V. All rights reserved.

\section{Introduction}

One of the main features of pyrazole complexes is the involvement of the N-bound hydrogen of pyrazole in intra- or intermolecular hydrogen bonds. Their crystal structures rarely show intermolecular hydrogen-bonded chains or oligomers [1,2], and frequently exhibit intramolecular hydrogen-bonds, or hydrogenbonding to solvent molecules or counterions. In fact, cationic pyrazole complexes have been recently used as anion receptors in solution [3].

The presence in the same complex of pyrazoles and other ligands able to behave as hydrogen bond acceptor allows a systematic study of which factors determine the formation of interand/or intramolecular interactions. This is one of the big challenges of chemistry, that is, the understanding and control of the organization of molecules [4]. Hydrogen bonded organic aggregates have so far been object of main attention, but the presence of metals in supramolecular systems is attracting increasing interest, as they may show redox [5], optical [6], magnetic [7], adsorption [8], or catalytical [9] properties. We considered that complexes containing the fac-"MX $\left(\mathrm{pz}^{*} \mathrm{H}\right)_{2}$ " $\left(\mathrm{X}=\right.$ halogen, $\mathrm{pz}{ }^{*} \mathrm{H}=$ any pyrazole $)$ moiety [10] could be good precursors to start this study, if the halogen is replaced by another ligand able to establish hydrogen bonding

\footnotetext{
* Corresponding author. Tel.: +34 983 184620; fax: +34 983323013.

E-mail address: fervilla@qi.uva.es (F. Villafañe).

1 Deceased.
}

interactions with the hydrogens of pyrazoles. The fac geometry of these complexes, caused by the relative donor-accepting properties of the ligands, allows this study, as no other geometric factors are involved. The acetate was chosen to play this role, since the oxygens may act as hydrogen acceptors, and this interaction may determine the coordination behavior of the acetate, as has been recently demonstrated [11].

\section{Results and discussion}

\subsection{Synthesis of the complexes}

The complexes herein described were obtained by the reactions depicted in Scheme 1.

Chlorido-bis(pyrazole) complexes $\left[\mathrm{Mo}\left(\eta^{3}\right.\right.$-methallyl $) \mathrm{Cl}(\mathrm{CO})_{2^{-}}$ $\left.(\mathrm{pzH})_{2}\right](\mathbf{1 a})$ and $\left[\mathrm{Mo}\left(\eta^{3}\right.\right.$-methallyl $\left.) \mathrm{Cl}(\mathrm{CO})_{2}(\mathrm{dmpzH})_{2}\right](\mathbf{1 b})$ were obtained by treating $\left[\mathrm{Mo}\left(\eta^{3}\right.\right.$-methallyl $\left.) \mathrm{Cl}(\mathrm{CO})_{2}(\mathrm{NCMe})_{2}\right]$ with 2 equiv. of pzH or dmpzH in $\mathrm{CH}_{2} \mathrm{Cl}_{2}$ at room temperature (Scheme 1) [12].

The molybdenum complexes $\left[\mathrm{Mo}\left(\eta^{3}\right.\right.$-methallyl $)\left(\mathrm{O}_{2} \mathrm{CMe}\right)(\mathrm{CO})_{2^{-}}$ $\left.(\mathrm{pzH})_{2}\right](\mathbf{2 a})$ and $\left[\mathrm{Mo}\left(\eta^{3}\right.\right.$-methallyl $\left.)\left(\mathrm{O}_{2} \mathrm{CMe}\right)(\mathrm{CO})_{2}(\mathrm{dmpzH})_{2}\right](\mathbf{2 b})$ were obtained from $\left[\mathrm{Mo}\left(\eta^{3}\right.\right.$-methallyl $\left.) \mathrm{Cl}(\mathrm{CO})_{2}(\mathrm{NCMe})_{2}\right], 2$ equiv. of the pyrazole and sodium acetate (Scheme 1). The reactions occur readily at room temperature in THF. Obviously, $\mathbf{1} \mathbf{a}$ or $\mathbf{1 b}$ may be considered as intermediates in the self-assembly method, as has been demonstrated in a separated experiment for 1a, which was also ob- 

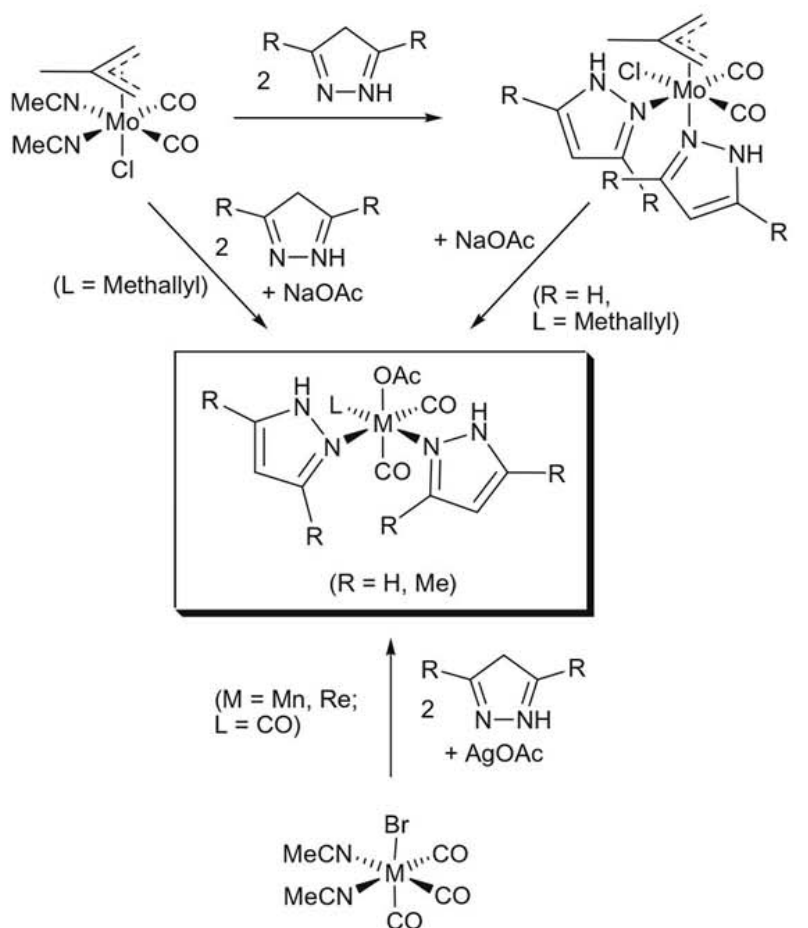

Scheme 1. Syntheses of chlorido and acetato complexes.

tained from the addition of 2 equiv. of pyrazole to [ $\mathrm{Mo}\left(\eta^{3}\right.$-methallyl $) \mathrm{Cl}(\mathrm{CO})_{2}(\mathrm{NCMe})_{2}$ ] (Scheme 1 ).

The manganese and rhenium complexes fac- $\left[\mathrm{M}\left(\mathrm{O}_{2} \mathrm{CCH}_{3}\right)-\right.$ $\left.(\mathrm{CO})_{3}(\mathrm{pzH})_{2}\right] \quad(\mathrm{M}=\mathrm{Mn}, \quad 3 \mathrm{a} ; \mathrm{M}=\mathrm{Re}, \mathbf{4 a})$ and $\mathrm{fac}-\left[\mathrm{M}\left(\mathrm{O}_{2} \mathrm{CCH}_{3}\right)-\right.$ $(\mathrm{CO})_{3}(\mathrm{dmpzH})_{2}$ ] $(\mathrm{M}=\mathrm{Mn}, \mathbf{3 b} ; \mathrm{M}=\mathrm{Re}, \mathbf{4 b})$ were obtained by a similar method but using AgOAc instead of NaOAc as halogen extractor.

\subsection{Solid-state structural characterization}

The structures of $\mathbf{1 a}$ and $\mathbf{1 b}$ [13] are shown in Fig. 1, and Table 1 collects relevant distances and angles.

The molybdenum atoms are pseudo-octahedrally coordinated, assuming that the methallyl group occupies one site. The terminal carbon atoms of the methallyl groups point towards the carbonyl groups, as has been demonstrated to be the most energetically favorable arrangement [14]. The distances and angles are very similar to those found in the previously reported structures of pyrazolemolybdenum(II) complexes with different halogen or allyl groups [10b,15]. One of the pyrazole ligands is coordinated trans to the methallyl group in all these structures, as opposite to what is usually found in complexes of the type $\left[\mathrm{MoX}\left(\eta^{3}\right.\right.$-allyl $\left.)(\mathrm{CO})_{2} \mathrm{~L}_{2}\right](\mathrm{X}=$ halide or pseudo halide, $\mathrm{L}_{2}=$ nitrogen donor ligand), where the nitrogen donor ligands are trans to the carbonyls [16].

The $\mathrm{N}$-bound hydrogens are involved in intramolecular hydrogen bonds with the chlorine atom $[\mathrm{H}(2) \cdots \mathrm{Cl}(1) 2.351 \AA$ and $\mathrm{H}(4) \cdots \mathrm{Cl}(1) 2.257 \AA$ for $\mathbf{1 a}$ and 2.034 and 2.018 for 1b]. These, and the corresponding $\mathrm{N} \cdots \mathrm{Cl}$ distances $[3.119 \AA$ and $3.041 \AA$ for $\mathbf{1 a}$, and 2.681 and 2.649 , respectively, for $\mathbf{1 b}$ ], and $\mathrm{N}-\mathrm{H} \cdots \mathrm{Cl}$ angles $\left[130^{\circ}\right.$ and $132^{\circ}$ for $\mathbf{1 a}, 118^{\circ}$ and $117^{\circ}$ for $\mathbf{1 b}$ ] confirm the presence of a hydrogen bond which may be considered between "weak" and "moderate" for 1a, or "moderate" for $\mathbf{1 b}[17,18]$. The structures of $\mathbf{2 a}$ and $\mathbf{2 b}$ are shown, respectively, in Figs. 2 and 3, whereas relevant distances and angles are collected in Table 2 [19]. Both structures present the usual pseudooctahedral geometry of
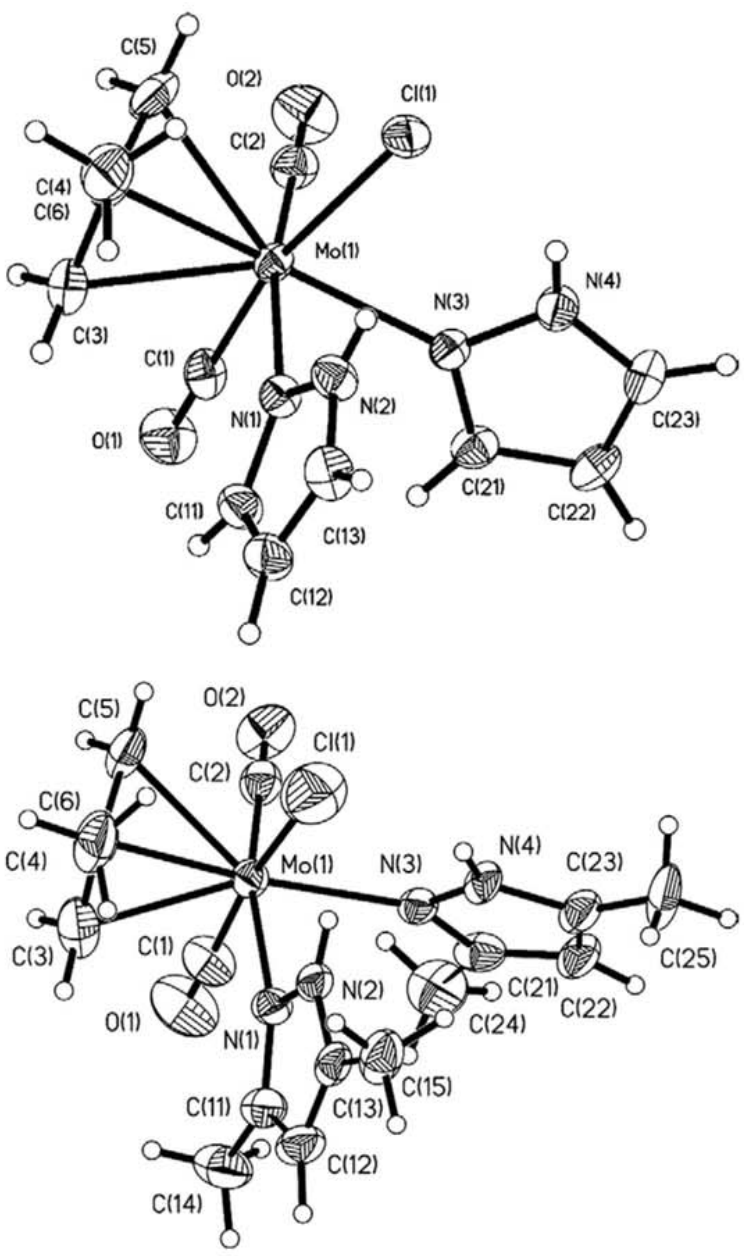

Fig. 1. Perspective views of $\left[\mathrm{Mo}\left(\eta^{3}\right.\right.$-methallyl $\left.) \mathrm{Cl}(\mathrm{CO})_{2}(\mathrm{pzH})_{2}\right]$, 1a (above), and $\left[\mathrm{Mo}\left(\eta^{3}\right.\right.$-methallyl $\left.) \mathrm{Cl}(\mathrm{CO})_{2}(\mathrm{dmpzH})_{2}\right], \mathbf{1 b}$ (below), showing the atom numbering.

Table 1

Selected distances $(\AA \AA)$ and angles (deg.) for $\left[\mathrm{Mo}\left(\eta^{3}\right.\right.$-methallyl $\left.) \mathrm{Cl}(\mathrm{CO})_{2}(\mathrm{pzH})_{2}\right], \mathbf{1 a}$, and $\left[\mathrm{Mo}\left(\eta^{3}\right.\right.$-methallyl $\left.) \mathrm{Cl}(\mathrm{CO})_{2}(\mathrm{dmpzH})_{2}\right], \mathbf{1 b}$

\begin{tabular}{lll}
\hline & $\mathbf{1 a}$ & $\mathbf{1 b}$ \\
\hline $\mathrm{Mo}(1)-\mathrm{C}(1)$ & $1.943(3)$ & $1.93(2)$ \\
$\mathrm{Mo}(1)-\mathrm{C}(2)$ & $1.943(3)$ & $1.943(19)$ \\
$\mathrm{Mo}(1)-\mathrm{N}(1)$ & $2.254(2)$ & $2.281(13)$ \\
$\mathrm{Mo}(1)-\mathrm{N}(3)$ & $2.246(2)$ & $2.232(12)$ \\
$\mathrm{Mo}(1)-\mathrm{Cl}(1)$ & $2.5788(8)$ & $2.156(8)$ \\
$\mathrm{Mo}(1)-\mathrm{C}(4)$ & $2.237(3)$ & $2.220(16)$ \\
$\mathrm{Mo}(1)-\mathrm{C}(3)$ & $2.345(3)$ & $2.326(18)$ \\
$\mathrm{Mo}(1)-\mathrm{C}(5)$ & $2.311(3)$ & $2.303(16)$ \\
$\mathrm{C}(2)-\mathrm{Mo}(1)-\mathrm{C}(1)$ & $81.99(12)$ & $77.4(7)$ \\
$\mathrm{C}(2)-\mathrm{Mo}(1)-\mathrm{N}(1)$ & $168.36(11)$ & $166.6(6)$ \\
$\mathrm{C}(1)-\mathrm{Mo}(1)-\mathrm{N}(1)$ & $94.54(10)$ & $99.0(7)$ \\
$\mathrm{C}(2)-\mathrm{Mo}(1)-\mathrm{N}(3)$ & $88.66(11)$ & $86.8(6)$ \\
$\mathrm{C}(1)-\mathrm{Mo}(1)-\mathrm{N}(3)$ & $86.68(10)$ & $95.2(7)$ \\
$\mathrm{N}(1)-\mathrm{Mo}(1)-\mathrm{N}(3)$ & $80.03(8)$ & $80.6(4)$ \\
$\mathrm{C}(2)-\mathrm{Mo}(1)-\mathrm{Cl}(1)$ & $97.03(9)$ & $102.9(5)$ \\
$\mathrm{C}(1)-\mathrm{Mo}(1)-\mathrm{Cl}(1)$ & $167.98(9)$ & $173.3(6)$ \\
$\mathrm{N}(1)-\mathrm{Mo}(1)-\mathrm{Cl}(1)$ & $84.05(6)$ & $79.1(4)$ \\
$\mathrm{N}(3)-\mathrm{Mo}(1)-\mathrm{Cl}(1)$ & $81.31(6)$ & $78.2(4)$
\end{tabular}

( $\eta^{3}$-methallyl)molybdenum complexes, with the open face of the allyl moiety oriented over the carbonyls. As evidenced by Table 2 , the distances and angles are very similar in both complexes, and 

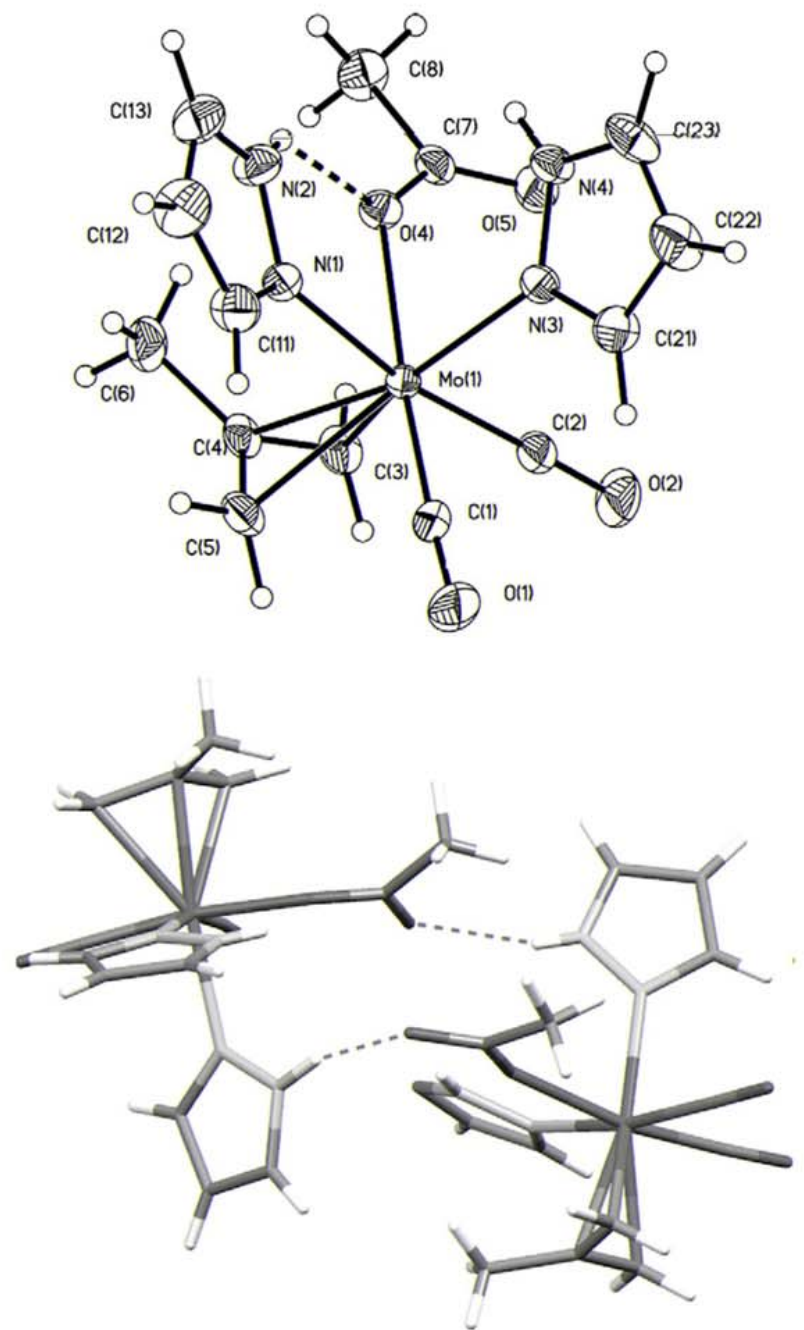

Fig. 2. Perspective view showing the atom numbering (above), and intermolecular hydrogen bonds (below) of $\left[\mathrm{Mo}\left(\eta^{3}-\right.\right.$ methallyl $\left.)\left(\mathrm{O}_{2} \mathrm{CMe}\right)(\mathrm{CO})_{2}(\mathrm{pzH})_{2}\right], 2 \mathrm{a}$ (below), showing the atom numbering.

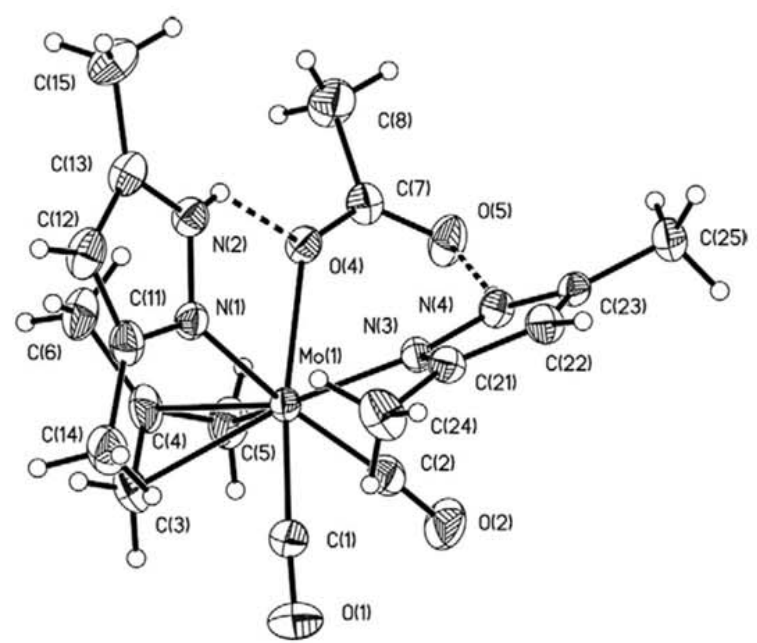

Fig. 3. Perspective view of $\left[\mathrm{Mo}\left(\eta^{3}\right.\right.$-methallyl $\left.)\left(\mathrm{O}_{2} \mathrm{CMe}\right)(\mathrm{CO})_{2}(\mathrm{dmpzH})_{2}\right], \mathbf{2 b}$, showing the atom numbering.
Table 2

Selected distances $(\hat{A})$ and angles (deg.) for $\left[\mathrm{Mo}\left(\eta^{3}\right.\right.$-methallyl $\left.)\left(\mathrm{O}_{2} \mathrm{CMe}\right)(\mathrm{CO})_{2}(\mathrm{pzH})_{2}\right]$, 2a, and $\left[\mathrm{Mo}\left(\eta^{3}-\right.\right.$ methallyl $\left.)\left(\mathrm{O}_{2} \mathrm{CMe}\right)(\mathrm{CO})_{2}(\mathrm{dmpzH})_{2}\right], \mathbf{2 b}$.

\begin{tabular}{lll}
\hline & $\mathbf{2 a}$ & $\mathbf{2 b}$ \\
\hline $\mathrm{Mo}(1)-\mathrm{C}(1)$ & $1.924(4)$ & $1.937(4)$ \\
$\mathrm{Mo}(1)-\mathrm{C}(2)$ & $1.946(4)$ & $1.953(4)$ \\
$\mathrm{Mo}(1)-\mathrm{N}(1)$ & $2.271(3)$ & $2.283(3)$ \\
$\mathrm{Mo}(1)-\mathrm{N}(3)$ & $2.229(3)$ & $2.259(3)$ \\
$\mathrm{Mo}(1)-\mathrm{O}(4)$ & $2.175(3)$ & $2.223(3)$ \\
$\mathrm{Mo}(1)-\mathrm{C}(4)$ & $2.239(4)$ & $2.232(3)$ \\
$\mathrm{Mo}(1)-\mathrm{C}(3)$ & $2.313(4)$ & $2.331(3)$ \\
$\mathrm{Mo}(1)-\mathrm{C}(5)$ & $2.327(4)$ & $2.317(4)$ \\
$\mathrm{C}(2)-\mathrm{Mo}(1)-\mathrm{C}(1)$ & $79.51(18)$ & $78.24(16)$ \\
$\mathrm{C}(2)-\mathrm{Mo}(1)-\mathrm{N}(1)$ & $166.29(15)$ & $169.14(12)$ \\
$\mathrm{C}(1)-\mathrm{Mo}(1)-\mathrm{N}(1)$ & $98.20(15)$ & $98.85(13)$ \\
$\mathrm{C}(2)-\mathrm{Mo}(1)-\mathrm{N}(3)$ & $86.52(15)$ & $87.02(13)$ \\
$\mathrm{C}(1)-\mathrm{Mo}(1)-\mathrm{N}(3)$ & $89.10(15)$ & $89.96(13)$ \\
$\mathrm{N}(1)-\mathrm{Mo}(1)-\mathrm{N}(3)$ & $79.90(11)$ & $82.49(11)$ \\
$\mathrm{C}(2)-\mathrm{Mo}(1)-\mathrm{O}(4)$ & $103.24(15)$ & $101.29(12)$ \\
$\mathrm{C}(1)-\mathrm{Mo}(1)-\mathrm{O}(4)$ & $171.79(15)$ & $170.03(12)$ \\
$\mathrm{N}(1)-\mathrm{Mo}(1)-\mathrm{O}(4)$ & $77.27(11)$ & $79.74(9)$ \\
$\mathrm{N}(3)-\mathrm{Mo}(1)-\mathrm{O}(4)$ & $83.39(11)$ & $80.06(9)$ \\
\hline
\end{tabular}

similar to those described above for $\mathbf{1 a}$ and $\mathbf{1 b}$ or for the previously reported structures of bis(pyrazole)halodicarbonylmolybdenum(II) complexes $[10 \mathrm{~b}, 15]$. As occur in these structures, one of the pyrazole ligands is coordinated trans to the allyl group.

Two intramolecular hydrogen bonds are detected in $\mathbf{2 b}$ (Fig. 3): between the coordinated oxygen of the acetate and the $\mathrm{N}$-bound hydrogen of one of the dmpzH ligands $[\mathrm{H}(2) \cdots \mathrm{O}(4) 1.961 \AA$ A $]$, and between the uncoordinated oxygen of the acetate and the $\mathrm{N}$-bound hydrogen of the second dmpzH $[\mathrm{H}(4) \cdots \mathrm{O}(5) 1.787 \AA$ ] . These and the corresponding $\mathrm{N} \cdots \mathrm{O}$ distances $(2.696$ and $2.789 \AA$, respectively) and $\mathrm{N}-\mathrm{H} \cdots \mathrm{O}$ angles $\left(126^{\circ}\right.$ and $163^{\circ}$, respectively) confirm the presence of a hydrogen bond which may be considered as "moderate" [17]. This pattern (Fig. 4) is observed in all the complexes containing dmpzH and acetate described herein. However, only one intramolecular hydrogen bond is detected for $\mathbf{2 a}$ (Fig. 2 above): that between the coordinated oxygen of the acetate and the $\mathrm{N}$-bound hydrogen of one of the pzH ligands $[\mathrm{H}(2) \cdots \mathrm{O}(4)$ 1.908 , with distances $\mathrm{N}(2) \cdots \mathrm{O}(4) \quad 2.670$, and $\mathrm{N}-\mathrm{H} \cdots \mathrm{O}$ angle $\left.128^{\circ}\right]$. The $\mathrm{N}$-bound hydrogen of the second $\mathrm{pzH}$ is involved in a moderate intermolecular hydrogen bond with the uncoordinated oxygen of the acetate of a second molecule, giving rise to the dimer depicted in Fig. 2 (below) $[\mathrm{H}(4) \cdots \mathrm{O}(55)$ 1.750, $\mathrm{H}(54) \cdots \mathrm{O}(5)$ $1.806 \AA$, with distances $\mathrm{N}(4) \cdots \mathrm{O}(55) 2.745, \mathrm{~N}(54) \cdots \mathrm{O}(5) 2.793 \AA$, and $\mathrm{N}-\mathrm{H} \cdots \mathrm{O}$ angles $161^{\circ}$ and $159^{\circ}$, respectively]. Both intra- and intermolecular values correspond again to "moderate" hydrogen bonds [17].

The relative orientation of the pyrazole ligands differs in each complex: dmpzH ligands are tilted in the same direction in $\mathbf{2 b}$ (46(1) $)^{\circ}$ for the dmpzH involved in the intramolecular bond with the uncoordinated oxygen of the acetate, and $12(1)^{\circ}$ for the other

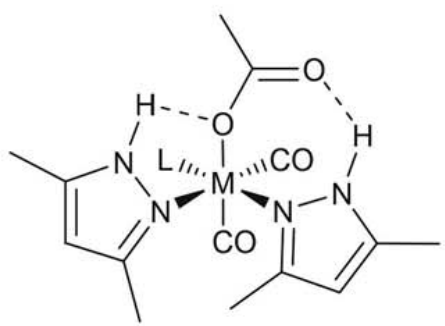

Fig. 4. Hydrogen bond pattern observed in the crystal structures of the complexes containing dmpzH and acetate $\left[\mathrm{L}=\left(\eta^{3}\right.\right.$-methallyl), $M=M o(2 \mathbf{b}) ; \mathrm{L}=\mathrm{CO}, \mathrm{M}=\mathrm{Mn}$ (3b), $\operatorname{Re}(\mathbf{4 b})]$. 
dmpzH), whereas pzH ligands in $\mathbf{2 a}$ are symmetrically tilted respect to the plane perpendicular to that containing the metal and the nitrogen donor atoms $\left(-14(1)^{\circ}\right.$ and $7(1)^{\circ}$, respectively). Therefore, the intra- or intermolecular nature of the hydrogen bond seems to determine the orientation of the pyrazole ligand involved in it. Steric factors might also influentiate this feature, as the structures of complexes containing two dmpzH coordinated cis usually show higher distortions than those with pzH [10]. In fact, the deviations shown by the pzH ligands in the chlorido-complexes are clearly lower: $10(1)^{\circ}$ and $-1(1)^{\circ}$ for $\mathbf{1 a}$, and $10(1)^{\circ}$ and $-5(1)^{\circ}$ for 1b. The structures of the manganese and rhenium complexes $3 a$, $\mathbf{3 b}, \mathbf{4 a}$, and $\mathbf{4 b}$ were also determined by X-ray diffraction, and the results are shown in Figs. 5 (3a), 6 (4a), and 7 (3b and $\mathbf{4 b}$ ). Distances and angles in these structures (those relevant are collected in Table 3) are similar to those found in previously reported structures of pyrazolemanganese $(\mathrm{I})$ and -rhenium(I) complexes, which are scarce, and show a slightly distorted octahedral geometry $[10 a, 10 c, 20]$. These distortions are evidenced by the slight deviation from the ideal angles shown by the ligands coordinated trans or cis (see Table 3).

The intramolecular hydrogen bonds detected the complexes with dmpzH $\mathbf{3 b}$ and $\mathbf{4 b}$ (Fig. 7) follow the same pattern than those described above for $\mathbf{2 b}$ (depicted in Fig. 4): the coordinated oxygen of the acetate is hydrogen-bonded to the $\mathrm{N}$-bound hydrogen of one of the dmpzH ligands $[\mathrm{H}(2) \cdots \mathrm{O}(4) 2.381 \AA$ for $\mathbf{3 b}$ and $2.334 \AA$ for 4b, with $\mathrm{N} \cdots \mathrm{O}$ distances $2.794 \hat{\AA}$ and $2.803 \hat{\AA}$, and $\mathrm{N}-\mathrm{H} \cdots \mathrm{O}$ angles $103^{\circ}$ and $106^{\circ}$, respectivelyl, and the uncoordinated oxygen of the acetate is hydrogen-bonded the $\mathrm{N}$-bound hydrogen of the second dmpzH $[\mathrm{H}(4) \cdots \mathrm{O}(5) 1.925 \AA$ for $\mathbf{3 b}$ and $1.796 \AA$ for $\mathbf{4 b}$, with $\mathrm{N} \cdots \mathrm{O}$ distances $2.716 \AA$ and 2.717 , and $\mathrm{N}-\mathrm{H} \cdots \mathrm{O}$ angles $164^{\circ}$ and $147^{\circ}$, respectively]. These distances confirm the presence of a hydrogen bond which may be considered between "weak" and "moderate" [17].

Whereas one intra- and other intermolecular hydrogen bond were detected for $\mathbf{2 a}$ (Fig. 2), only intermolecular bonds are found in 3a: both N-bound hydrogens of each molecule are hydrogenbonded to the uncoordinated oxygen of an adjacent molecule, forming a chain structure (Fig. 5). The distances indicate that these hydrogen bonds may be considered as "moderate" [17]: 2.095 Å for $\mathrm{H}(2) \cdots \mathrm{O}(5)$ and $1.953 \AA$ for $\mathrm{H}(4) \cdots \mathrm{O}(5)$, being $3.055 \AA$ for $\mathrm{N}(2) \cdots \mathrm{O}(5)$ and $2.910 \AA$ for $\mathrm{N}(4) \cdots \mathrm{O}(5)$, with $\mathrm{N}-\mathrm{H} \cdots \mathrm{O}$ angles $154^{\circ}$ and $153^{\circ}$, respectively.

A different pattern from those found in the structures of $\mathbf{2 a}$ and 3a is detected in 4a: in this case, the uncoordinated oxygen of the acetate is involved in two hydrogen bonds, one intramolecular with one of the pyrazoles $[\mathrm{H}(4) \cdots \mathrm{O}(5) 1.880 \AA$, N (4) $\cdots \mathrm{O}(5)$ $2.765 \AA$, and $\mathrm{N}-\mathrm{H} \cdots \mathrm{O} 142^{\circ}$ ], and another intermolecular with the pyrazole of other molecule not involved in intramolecular hydrogen bonding $[\mathrm{H}(2) \cdots \mathrm{O}(5) 1.702 \AA$, and $\mathrm{N}(2) \cdots \mathrm{O}(5) 2.720 \AA$, and $\mathrm{N}-\mathrm{H} \cdots \mathrm{O} 169^{\circ}$ ] (Fig. 6). These distances point to hydrogen bonds which may be considered as "moderate" [17].

The pyrazole ligands in the structures of $\mathbf{3 a}, \mathbf{3 b}, \mathbf{4 a}$, and $\mathbf{4 b}$ are tilted around the Mo-N bonds. In these structures each pair of pyrazole ligands is orientated in the same direction respect to the plane perpendicular to that containing the metal and the nitrogen donor atoms, being the averaged angles $25(1)^{\circ}$ and $23(1)^{\circ}$ for $\mathbf{3 a}$, $43(1)^{\circ}$ and $38(1)^{\circ}$ for $3 \mathbf{b}, 50(1)^{\circ}$ and $44(1)^{\circ}$ for $4 \mathbf{a}$, and $31(1)^{\circ}$ and $50(1)^{\circ}$ for $4 \mathbf{b}$. It should be noted that these angles are rather similar in the three structures, as opposite to what is observed in those of $\mathbf{2 a}$ and $\mathbf{2 b}$ (see above).
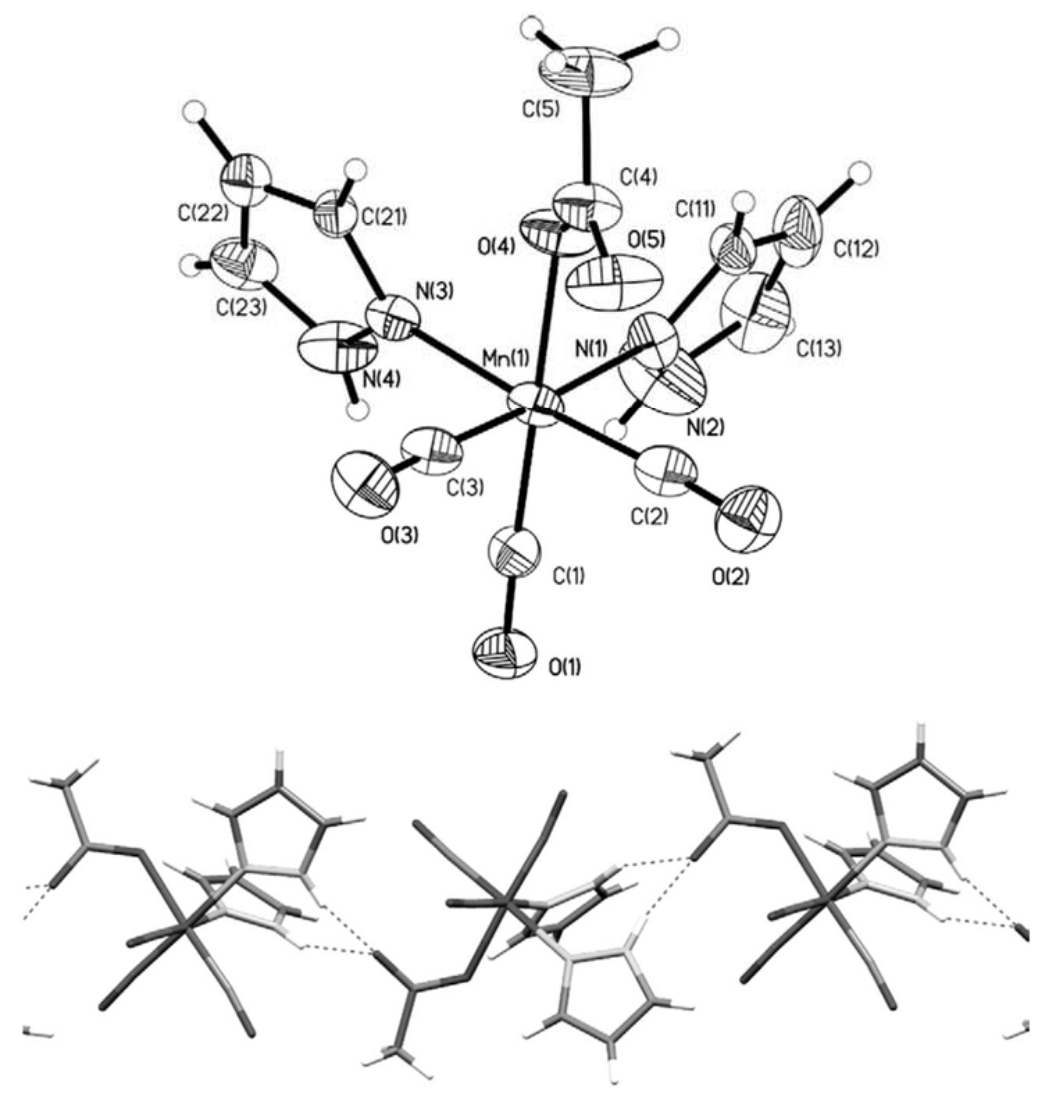

Fig. 5. Perspective view showing the atom numbering (above), and hydrogen bonds (below) of $f a c-\left[\mathrm{Mn}\left(\mathrm{O}_{2} \mathrm{CMe}\right)(\mathrm{CO})_{3}(\mathrm{pzH})_{2}\right], 3 a$. 

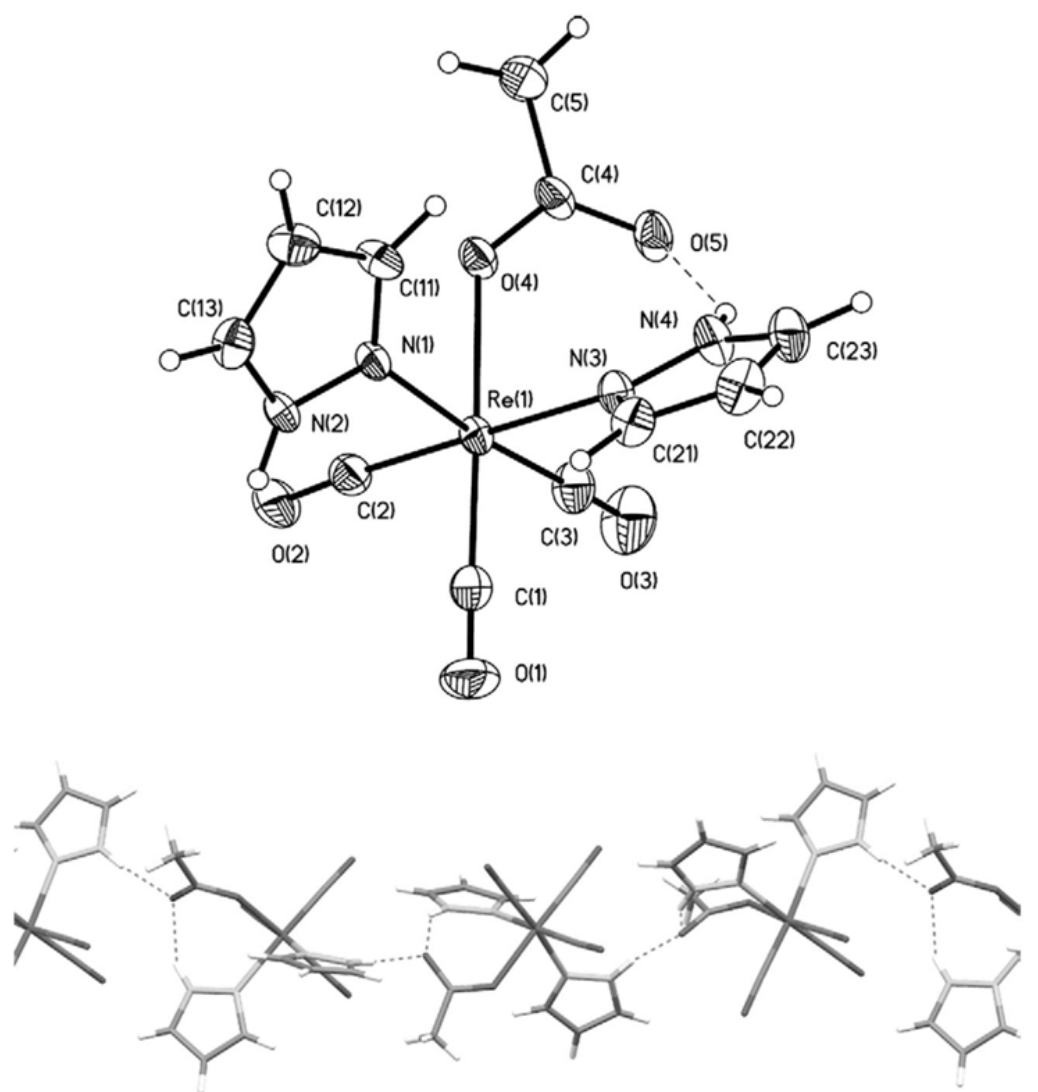

Fig. 6. Perspective view showing the atom numbering (above), and hydrogen bonds (below) of $f a c-\left[\operatorname{Re}\left(\mathrm{O}_{2} \mathrm{CMe}\right)(\mathrm{CO})_{3}(\mathrm{pzH})_{2}\right], 4 a$.

\subsection{Characterization in solution}

The IR spectra of all the complexes show two bands in the C-O stretching region in solution for the molybdenum complexes and three for the manganese and rhenium complexes, as expected for their respective cis-dicarbonyl and fac-tricarbonyl geometries. The frequencies are higher for complexes with $\mathrm{pzH}$ than those with $\mathrm{dmpzH}$, and for manganese than for rhenium complexes. Both features are to be expected considering the higher electronic density of the third row vs. first row transition metal series, and the better donor properties of dmpzH compared to $\mathrm{pzH}$ [21].

As indicated above, complexes of the type $\left[\mathrm{Mo}\left(\eta^{3}\right.\right.$ $\left.\left.\mathrm{CH}_{2} \mathrm{C}(\mathrm{R}) \mathrm{HCH}_{2}\right) \mathrm{X}(\mathrm{CO})_{2} \mathrm{~L}_{2}\right][\mathrm{R}=\mathrm{H}$ (allyl), Me (methallyl); $\mathrm{X}=$ halide or pseudo halide; $\mathrm{L}_{2}=$ two monodentate ligands or a bidentate ligand] may be considered as pseudo-octahedral if the $\eta^{3}$-allyl ligand is considered as occupying one coordination position. Considering only the most favorable arrangement, where the terminal atoms of the allyl group are oriented over the carbonyl groups [14], there are two possible geometries for these complexes: $\mathbf{S}$ or symmetric, where the pyrazoles are coordinated in the equatorial positions, trans to the carbonyls; and $\mathbf{A}$ or asymmetric, where one of the pyrazoles is coordinated trans to the allyl group, in the axial position (Fig. 8).

Molybdenum complexes 1a, 1b, 2a, and $\mathbf{2 b}$ show a dymanic behavior in solution similar to that observed for similar bromidocomplexes with allyl instead of methallyl, which has been previously detailed $[10 \mathrm{~b}]$. Although they crystallize as the asymmetric isomer $\mathbf{A}$ (Figs. 1 and 8), their ${ }^{1} \mathrm{H}$ and ${ }^{13} \mathrm{C}$ NMR spectra at room temperature show the equivalence of both methylenes of the methallyl group, and both pyrazoles, what points to the symmetric isomer $\mathbf{S}$.
The broadness of some signals suggests a slow exchange process in solution below the coalescence. Complexes $\left[\mathrm{Mo}\left(\eta^{3}\right.\right.$ $\left.\mathrm{CH}_{2} \mathrm{C}(\mathrm{R}) \mathrm{HCH}_{2}\right) \mathrm{X}(\mathrm{CO})_{2} \mathrm{~L}_{2}$ ] usually display a non-dissociative trigonal twist process in which there is an intramolecular rotation of the $\mathrm{XL}_{2}$ triangular face [22], which would lead to the equilibrium between the symmetric $\mathbf{S}$ and both enantiomers of the asymmetric A. Therefore, if this exchange process is fast enough, a symmetric average spectrum should be observed. As previously described [10b], other dynamic processes in solution detected for this type of complexes, such as the $\eta^{3}-\eta^{1}-\eta^{3}$ rearrangement of the allyl [23], or the "pivoted double switch" process [24], may be discarded.

The trigonal twist process observed for $\mathbf{1 a}$ and $\mathbf{1 b}$ is faster than those observed for the similar complexes [ $\mathrm{Mo}\left(\eta^{3}\right.$-allyl $\left.) \mathrm{Br}(\mathrm{CO})_{2} \mathrm{~L}_{2}\right]$ ( $\mathrm{L}=\mathrm{pzH}, \mathrm{dmpzH})$, which ${ }^{1} \mathrm{H}$ NMR spectra at the same field show averaged symmetric only at higher temperatures [10b]. The lower activation energy of methallyl respect to allyl complexes in the system $\left[\mathrm{Mo}\left(\eta^{3}-\mathrm{CH}_{2} \mathrm{C}(\mathrm{R}) \mathrm{HCH}_{2}\right) \mathrm{X}(\mathrm{CO})_{2} \mathrm{~L}_{2}\right]$ has been already reported [25].

The broadness observed at room temperature for the $\mathrm{NH}$ protons might be due to a rapid prototropic exchange involving the pyrrolic proton, which is common in pyrazole complexes [26] The assignment of the hydrogens or methyl groups in positions 3 and 5 is difficult when they display singlets, since their chemical shift seems to be affected by different factors, which are difficult to evaluate: whether the hydrogen (or methyl) group at position 3 resonates at higher field than 5 or viceversa may vary in the same family of complexes [27], or even depending on the solvent used [28]. When the complexes are fluxional the broader signals (those coalescing at higher temperatures) have been assigned to the 

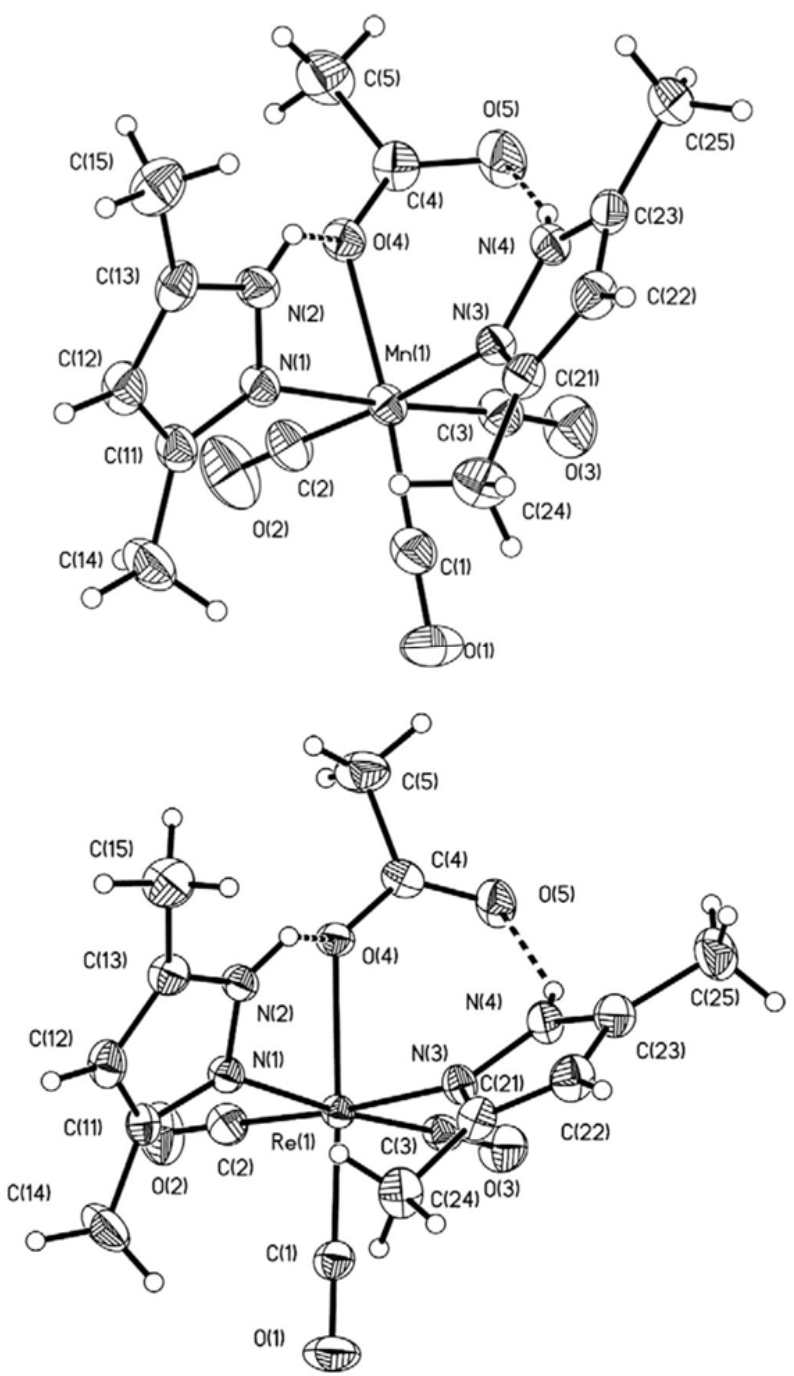

Fig. 7. Perspective views of $f a c-\left[\mathrm{Mn}\left(\mathrm{O}_{2} \mathrm{CMe}\right)(\mathrm{CO})_{3}(\mathrm{dmpzH})_{2}\right], \mathbf{3 b}$ (above), and fac$\left[\operatorname{Re}\left(\mathrm{O}_{2} \mathrm{CMe}\right)(\mathrm{CO})_{3}(\mathrm{dmpzH})_{2}\right], \mathbf{4 b}$ (below), showing the atom numbering.

group ( $\mathrm{H}$ or $\mathrm{Me}$ ) at position 3 , as they are closer to the unequivalence source than those at position 5 , which point to the outside of the complex. However, the assignment proposed for the rest of complexes in Section 4 may be considered as tentative.

The ${ }^{1} \mathrm{H}$ NMR spectrum of 3a displays broad signals for the methyl of the acetate and for some pyrazole signals. When the spectrum is carried out at $223 \mathrm{~K}$, no substantial sharpening is detected, probably because of the nuclear quadrupole moment of manganese. The ${ }^{1} \mathrm{H}$ NMR spectrum of $\mathbf{3 a}$ at room temperature with an excess of sodium acetate shows only one singlet for the methyl groups of coordinated and free acetate, suggesting a process involving dissociation of the acetate ligand. The electrical conductivities of the acetato complexes in acetone solution are typical of non-electrolyte complexes, what point to very low dissociation degree.

The $\mathrm{NH}$ protons of the acetate complexes resonate at lower field (ca. $1 \mathrm{ppm})$ than those of similar halocomplexes $\left[\mathrm{Mo}\left(\eta^{3}\right.\right.$-methallyl $\left.) \mathrm{Cl}(\mathrm{CO})_{2} \mathrm{~L}_{2}\right]$ (2), fac-[MnBr(CO) $\left.{ }_{3} \mathrm{~L}_{2}\right]$ [10a], or fac-[ $\left.\operatorname{ReBr}(\mathrm{CO})_{3} \mathrm{~L}_{2}\right]$ [10c]; $(\mathrm{L}=\mathrm{pzH}$. dmpzH), and this chemical shift is independent from the concentration. The last feature may be interpreted considering either (a) all the hydrogen bond interactions detected in
Table 3

Selected distances $(\AA)$ and angles $\left(^{\circ}\right)$ for fac- $\left[\mathrm{Mn}\left(\mathrm{O}_{2} \mathrm{CMe}\right)(\mathrm{CO})_{3}(\mathrm{pzH})_{2}\right], 3 \mathbf{a}$, fac$\left[\mathrm{Mn}\left(\mathrm{O}_{2} \mathrm{CMe}\right)(\mathrm{CO})_{3}(\mathrm{dmpzH})_{2}\right], 3 \mathbf{b}$, fac- $\left[\operatorname{Re}\left(\mathrm{O}_{2} \mathrm{CMe}\right)(\mathrm{CO})_{3}(\mathrm{pzH})_{2}\right], 4 \mathbf{a}$, and $f a c-\left[\operatorname{Re}\left(\mathrm{O}_{2} \mathrm{C}-\right.\right.$ $\left.\mathrm{Me})(\mathrm{CO})_{3}(\mathrm{dmpzH})_{2}\right], \mathbf{4 b}$.

\begin{tabular}{lllll}
\hline & 3a $(\mathrm{M}=\mathrm{Mn})$ & $\mathbf{3 b}(\mathrm{M}=\mathrm{Mn})$ & $\mathbf{4 a}(\mathrm{M}=\mathrm{Re})$ & $\mathbf{4 b}(\mathrm{M}=\mathrm{Re})$ \\
\hline $\mathrm{M}(1)-\mathrm{C}(1)$ & $1.781(5)$ & $1.786(3)$ & $1.894(5)$ & $1.878(9)$ \\
$\mathrm{M}(1)-\mathrm{C}(2)$ & $1.796(6)$ & $1.792(3)$ & $1.908(5)$ & $1.918(9)$ \\
$\mathrm{M}(1)-\mathrm{C}(3)$ & $1.793(5)$ & $1.802(3)$ & $1.926(5)$ & $1.917(8)$ \\
$\mathrm{M}(1)-\mathrm{N}(1)$ & $2.069(4)$ & $2.070(2)$ & $2.178(3)$ & $2.182(6)$ \\
$\mathrm{M}(1)-\mathrm{N}(3)$ & $2.069(4)$ & $2.0792(19)$ & $2.189(4)$ & $2.195(6)$ \\
$\mathrm{M}(1)-\mathrm{O}(4)$ & $2.024(3)$ & $2.0530(16)$ & $2.156(3)$ & $2.164(5)$ \\
$\mathrm{C}(1)-\mathrm{M}(1)-\mathrm{C}(2)$ & $87.4(2)$ & $89.30(12)$ & $87.4(2)$ & $87.6(4)$ \\
$\mathrm{C}(1)-\mathrm{M}(1)-\mathrm{C}(3)$ & $89.3(2)$ & $87.02(12)$ & $88.1(2)$ & $86.7(3)$ \\
$\mathrm{C}(2)-\mathrm{M}(1)-\mathrm{C}(3)$ & $91.1(2)$ & $89.10(11)$ & $87.0(2)$ & $89.5(4)$ \\
$\mathrm{C}(1)-\mathrm{M}(1)-\mathrm{O}(4)$ & $177.05(17)$ & $175.35(10)$ & $174.95(17$ & $177.3(3)$ \\
$\mathrm{C}(2)-\mathrm{M}(1)-\mathrm{O}(4)$ & $94.68(19)$ & $86.66(10)$ & $94.95(16)$ & $91.5(3)$ \\
$\mathrm{C}(3)-\mathrm{M}(1)-\mathrm{O}(4)$ & $92.75(17)$ & $95.22(9)$ & $96.47(18)$ & $95.9(3)$ \\
$\mathrm{N}(1)-\mathrm{M}(1)-\mathrm{O}(4)$ & $84.42(15)$ & $82.13(7)$ & $78.88(12)$ & $80.0(2)$ \\
$\mathrm{N}(3)-\mathrm{M}(1)-\mathrm{O}(4)$ & $82.40(14)$ & $89.07(7)$ & $86.02(13)$ & $84.5(2)$ \\
$\mathrm{C}(1)-\mathrm{M}(1)-\mathrm{N}(1)$ & $93.50(18)$ & $95.77(10)$ & $96.44(17)$ & $97.5(3)$ \\
$\mathrm{C}(2)-\mathrm{M}(1)-\mathrm{N}(1)$ & $90.18(19)$ & $92.82(10)$ & $95.46(16)$ & $93.4(3)$ \\
$\mathrm{C}(3)-\mathrm{M}(1)-\mathrm{N}(1)$ & $176.97(19)$ & $176.63(10)$ & $174.91(18)$ & $175.0(3)$ \\
$\mathrm{O}(4)-\mathrm{M}(1)-\mathrm{N}(1)$ & $84.42(15)$ & $82.13(7)$ & $78.88(12)$ & $80.0(2)$ \\
$\mathrm{C}(2)-\mathrm{M}(1)-\mathrm{N}(3)$ & $176.15(18)$ & $175.65(10)$ & $177.81(16)$ & $175.6(3)$ \\
$\mathrm{C}(1)-\mathrm{M}(1)-\mathrm{N}(3)$ & $95.43(18)$ & $94.93(10)$ & $91.52(19)$ & $96.3(3)$ \\
$\mathrm{C}(3)-\mathrm{M}(1)-\mathrm{N}(3)$ & $91.52(19)$ & $92.08(10)$ & $94.89(18)$ & $92.9(3)$ \\
$\mathrm{O}(4)-\mathrm{M}(1)-\mathrm{N}(3)$ & $82.40(14)$ & $89.07(7)$ & $86.02(13)$ & $84.5(2)$ \\
$\mathrm{N}(1)-\mathrm{M}(1)-\mathrm{N}(3)$ & $87.05(13)$ & $85.81(7)$ & $82.79(13)$ & $84.0(2)$ \\
\hline
\end{tabular}

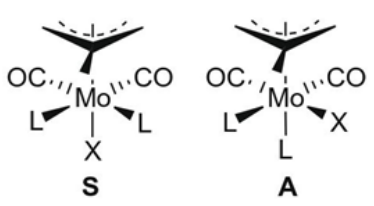

Fig. 8. Two possible geometries for complexes $\left[\mathrm{Mo}\left(\eta^{3}-\mathrm{CH}_{2} \mathrm{C}(\mathrm{R}) \mathrm{HCH}_{2}\right) \mathrm{X}(\mathrm{CO})_{2} \mathrm{~L}_{2}\right]$.

the solid state structures are not maintained in solution, or (b) all the hydrogen bond interactions are intramolecular. As the solid state structures of the acetato-bis(pyrazole) complexes show intermolecular interactions, option (b) should be discarded.

\section{Conclusions}

The crystal structures of the complexes herein described containing one acetato and two dimetylpyrazole ligands in a fac geometry show the same pattern: intramolecular hydrogen bonds are detected between the $\mathrm{N}$-bound hydrogen of one of the dmpz H ligands with the coordinated oxygen of the acetate, and between the N-bound hydrogen of the second $\mathrm{dmpzH}$ with the uncoordinated oxygen of the acetate. When similar complexes with $\mathrm{pzH}$ are obtained, their crystal structures do not show the same pattern, since intermolecular hydrogen bonds are detected. These arrangements of the three monodentate ligands observed in the solid state do not persist in solution, as indicate NMR data.

\section{Experimental}

\subsection{General Remarks}

All manipulations were performed under $\mathrm{N}_{2}$ atmosphere following conventional Schlenk techniques. Filtrations were carried out on dry Celite under $\mathrm{N}_{2}$. Solvents were purified according to standard procedures [29]. $\left[\mathrm{Mo}\left(\eta^{3}\right.\right.$-methallyl $\left.) \mathrm{Cl}(\mathrm{CO})_{2}(\mathrm{NCMe})_{2}\right]$ [30], fac-[ $\left.\mathrm{MnBr}(\mathrm{CO})_{3}(\mathrm{NCMe})_{2}\right][10 \mathrm{a}]$, and $\mathrm{fac}-\left[\operatorname{ReBr}(\mathrm{CO})_{3}(\mathrm{NCMe})_{2}\right]$ [31] were obtained as previously described. All other reagents 
were obtained from the usual commercial suppliers, and used as received. Infrared spectra were recorded in a Perkin-Elmer RX I FT-IR apparatus using $0.2 \mathrm{~mm} \mathrm{CaF}_{2}$ cells for solutions or on $\mathrm{KBr}$ pellets for solid samples. NMR spectra were recorded in Bruker AC300 or ARX-300 instruments in $\mathrm{CDCl}_{3}$ at room temperature unless otherwise stated. NMR spectra are referred to the internal residual solvent peak for ${ }^{1} \mathrm{H}$ and ${ }^{13} \mathrm{C}\left\{{ }^{1} \mathrm{H}\right\}$ NMR. Assignment of the ${ }^{13} \mathrm{C}\left\{{ }^{1} \mathrm{H}\right\}$ NMR data was supported by DEPT experiments and relative intensities of the resonance signals. Electrical conductivity measurements were carried out at r.t. with a Crison 522 conductivimeter on ca. $5 \times 10^{-4} \mathrm{M}$ solutions; the range of molar conductivity for $1 / 1$ electrolytes is $100-160 \mathrm{~S} \mathrm{~cm}^{2} \mathrm{~mol}^{-1}$ in acetone solutions [32]. Elemental analyses were performed on a Perkin-Elmer 2400B microanalyzer.

\section{2. $\left[\mathrm{Mo}\left(\eta^{3}\right.\right.$-methallyl $\left.) \mathrm{Cl}(\mathrm{CO})_{2}(\mathrm{pzH})_{2}\right](\mathbf{1 a})$}

[Mo $\left(\eta^{3}\right.$-methallyl $\left.) \mathrm{Cl}(\mathrm{CO})_{2}(\mathrm{NCMe})_{2}\right] \quad(0.160 \mathrm{~g}, 0.5 \mathrm{mmol})$ was added to a solution of pzH $(0.068 \mathrm{~g}, 1.0 \mathrm{mmol})$ in $\mathrm{CH}_{2} \mathrm{Cl}_{2}(20 \mathrm{~mL})$. The solution was stirred at r.t. for $5 \mathrm{~min}$ and hexane was added (ca. $20 \mathrm{~mL}$ ). Concentration of the solution in vacuo and cooling to $-20^{\circ} \mathrm{C}$ gave a yellow microcrystalline solid, which was decanted, washed with hexane ( $3 \times 3 \mathrm{~mL}$ approximately), and dried in vacuo, yielding $0.172 \mathrm{~g}(91 \%)$. IR (THF, $\mathrm{cm}^{-1}$ ): $1942 \mathrm{vs,} 1845 \mathrm{~s}$. IR (KBr, $\mathrm{cm}^{-1}$ ): $3311 \mathrm{~s}, 3269 \mathrm{~s}, 3115 \mathrm{w}, 1925 \mathrm{~s}, 1815 \mathrm{~s}, 1473 \mathrm{~m}, 1404 \mathrm{w}$ $1350 \mathrm{~m}, 1260 \mathrm{w}, 1130 \mathrm{~m}, 1049 \mathrm{~s}, 1030 \mathrm{~m}, 788 \mathrm{~m}, 764 \mathrm{~s}, 734 \mathrm{w}$ 606 w. ${ }^{1} \mathrm{H}$ NMR (r.t.): 1.37 (s, $H^{\text {anti }}$ methallyl, $\left.2 \mathrm{H}\right), 1.92\left(\mathrm{~s}, \mathrm{CH}_{3}\right.$ methallyl, $3 \mathrm{H}$ ), 3.25 (br, $H^{\text {syn }}$ methallyl, $\left.2 \mathrm{H}\right), 6.32\left(\mathrm{br}, \mathrm{H}^{4} \mathrm{pzH}\right.$, $2 \mathrm{H}), 7.40\left(\mathrm{~s}, H^{5} \mathrm{pzH}, 2 \mathrm{H}\right), 7.92\left(\mathrm{br}, H^{3} \mathrm{pzH}, 2 \mathrm{H}\right), 11.86(\mathrm{br}, \mathrm{NH}$ $2 \mathrm{H}) .{ }^{1} \mathrm{H}$ NMR $(223 \mathrm{~K}): 1.27$ (s, $H^{\text {anti }}$ methallyl, $\left.1 \mathrm{H}\right), 1.39$ (s, $H^{\text {anti }}$ methallyl, $1 \mathrm{H}), 1.86\left(\mathrm{~s}, \mathrm{CH}_{3}\right.$ methallyl, $\left.3 \mathrm{H}\right), 3.00\left(\mathrm{~s}, H^{\text {syn }}\right.$ methallyl, $1 \mathrm{H}), 3.43\left(\mathrm{~s}, H^{\text {syn }}\right.$ methallyl, $\left.1 \mathrm{H}\right), 6.25\left(\mathrm{~s}, H^{4} \mathrm{pzH}, 1 \mathrm{H}\right), 6.40\left(\mathrm{~s}, H^{4}\right.$ pzH, $1 \mathrm{H}), 7.40\left(\mathrm{~s}, H^{5} \mathrm{pzH}, 2 \mathrm{H}\right), 7.56\left(\mathrm{~s}, H^{3} \mathrm{pzH}, 1 \mathrm{H}\right), 8.26\left(\mathrm{~s}, H^{3}\right.$ pzH, 1H), 11.78 (s, NH, 2H). ${ }^{13} \mathrm{C}\left\{{ }^{1} \mathrm{H}\right\}$ NMR: 20.0 (s, $\mathrm{CH}_{3}$ methallyl), $58.8\left(\mathrm{~s}, \mathrm{CH}_{2}\right.$ methallyl), $83.0\left(\mathrm{~s}, \mathrm{CH}_{3} \mathrm{C}\left(\mathrm{CH}_{2}\right)_{2}\right), 107.0\left(\mathrm{~s}, \mathrm{C}^{4} \mathrm{pzH}\right)$, 128.8 (s, $C^{5}$ pzH), 143.0 (s, $C^{3}$ pzH), 225.4 (br, CO). Anal. Calcd. for $\mathrm{C}_{14} \mathrm{H}_{15} \mathrm{ClMoN}_{4} \mathrm{O}_{2}: \mathrm{C}, 38.06 ; \mathrm{H}, 3.99 ; \mathrm{N}, 14.79$. Found: $\mathrm{C}, 38.32$; $\mathrm{H}, 3.70 ; \mathrm{N}, 14.83 \%$.

\section{3. $\left[\mathrm{Mo}\left(\eta^{3}\right.\right.$-methallyl $\left.) \mathrm{Cl}(\mathrm{CO})_{2}(\mathrm{dmpzH})_{2}\right](\mathbf{1} \boldsymbol{b})$}

$\left[\mathrm{Mo}\left(\eta^{3}\right.\right.$-methallyl $\left.) \mathrm{Cl}(\mathrm{CO})_{2}(\mathrm{NCMe})_{2}\right] \quad(0.160 \mathrm{~g}, \quad 0.5 \mathrm{mmol})$ was added to a solution of dmpzH $(0.096 \mathrm{~g}, 1.0 \mathrm{mmol})$ in $\mathrm{CH}_{2} \mathrm{Cl}_{2}$ $(20 \mathrm{~mL})$. The solution was stirred at r.t. for $5 \mathrm{~min}$, the volatiles were removed in vacuo, and the yellow residue was extracted with $\mathrm{Et}_{2} \mathrm{O}$ (ca. $20 \mathrm{~mL}$ ) and filtered. Hexane was added (ca. $20 \mathrm{~mL}$ ) and the solution was concentrated and cooled to $-20^{\circ} \mathrm{C}$, giving a yelloworange microcrystalline solid, which was decanted, washed with hexane $(3 \times 3 \mathrm{~mL}$ approximately), and dried in vacuo, yielding $0.103 \mathrm{~g} \mathrm{(49 \% )}$. IR (THF, cm $\left.{ }^{-1}\right): 1941 \mathrm{vs,} 1842 \mathrm{~s}$. IR $\left(\mathrm{KBr}, \mathrm{cm}^{-1}\right)$ : 3314 m, 3271 m, 1933 s, 1837 s, 1572 m, 1420 w, 1372 w, 1284 w, $1159 \mathrm{w}, 1020 \mathrm{w}, 790 \mathrm{w} .{ }^{1} \mathrm{H}$ NMR (r.t.): 1.31 (s, $H^{\text {anti }}$ methallyl, $2 \mathrm{H}), 2.06$ (s, $\mathrm{CH}_{3}$ methallyl, 3H), 2.13 (s, $\left.\mathrm{CH}_{3} \mathrm{dmpzH}, 6 \mathrm{H}\right), 2.43$ (br, $\mathrm{CH}_{3}$ dmpzH, $6 \mathrm{H}$ ), 3.35 (br, $H^{\text {syn }}$ methallyl, $\left.2 \mathrm{H}\right), 5.83$ (br, $H^{4}$ dmpzH, 2H), 10.98 (br, NH, 1H), 11.41 (br, NH, 1H). ${ }^{1} \mathrm{H}$ NMR $(233 \mathrm{~K}): 1.21\left(\mathrm{~s}, H^{\text {anti }}\right.$ methallyl, $\left.1 \mathrm{H}\right), 1.37\left(\mathrm{~s}, H^{\text {anti }}\right.$ methallyl, $\left.1 \mathrm{H}\right)$, 2.04 (s, $\mathrm{CH}_{3}$ methallyl, 3H), 2.05 (s, $\mathrm{CH}_{3}$ dmpzH, 3H), 2.21 (s, $\mathrm{CH}_{3}$ dmpzH, 3H), 2.23 (s, $\left.\mathrm{CH}_{3} \mathrm{dmpzH}, 3 \mathrm{H}\right), 2.80$ (s, $\left.\mathrm{CH}_{3} \mathrm{dmpzH}, 3 \mathrm{H}\right)$, $2.87\left(\mathrm{~d}, J=3.5 \mathrm{~Hz}, H^{\text {syn }}\right.$ methallyl, $\left.1 \mathrm{H}\right), 3.44\left(\mathrm{~d}, J=4.0 \mathrm{~Hz}, H^{\text {syn }}\right.$ methallyl, 1H), $5.78\left(\mathrm{~s}, H^{4} \mathrm{dmpzH}, 1 \mathrm{H}\right), 5.87\left(\mathrm{~s}, H^{4} \mathrm{dmpzH}, 1 \mathrm{H}\right)$, $10.56(\mathrm{~s}, \mathrm{NH}, 1 \mathrm{H}), 11.32(\mathrm{~s}, \mathrm{NH}, 1 \mathrm{H}) .{ }^{13} \mathrm{C}\left\{{ }^{1} \mathrm{H}\right\}$ NMR: $10.7\left(\mathrm{~s}, \mathrm{C}^{5} \mathrm{H}_{3}\right.$ dmpzH), 15.0 (br, $\mathrm{C}^{3} \mathrm{H}_{3}$ dmpzH), 20.4 (s, $\mathrm{CH}_{3}$ methallyl), 52.3 (br, $\mathrm{CH}_{2}$ methallyl), 61.5 (br, $\mathrm{CH}_{2}$ methallyl), $84.9\left(\mathrm{~s}, \mathrm{CH}_{3} \mathrm{C}\left(\mathrm{CH}_{2}\right)_{2}\right)$, 106.6 (s, $C^{4}$ dmpzH), 139.7 (s, $C^{5}$ pzH), 152.0 (br, $C^{3}$ dmpzH), 153.8 (br, $\mathrm{C}^{3} \mathrm{dmpzH}$ ), 225.0 (br, CO). Anal. Calcd. for $\mathrm{C}_{16} \mathrm{H}_{23} \mathrm{ClMo}-$ $\mathrm{N}_{4} \mathrm{O}_{2}$ : C, 44.20; H, 5.33; $\mathrm{N}, 12.88$. Found: C, 44.51; H, 5.02; $\mathrm{N}$,
$13.06 \%$. Crystals of $\mathbf{1 b} \cdot 0.5\left(\mathrm{dmpzH} \mathrm{H}_{2}\right) \mathrm{BF}_{4}$ were unexpectedly obtained after the reaction of $\left[\mathrm{Mo}\left(\eta^{3}\right.\right.$-methallyl $\left.) \mathrm{Cl}(\mathrm{CO})_{2}(\mathrm{NCMe})_{2}\right]$ with $\mathrm{TlBF}_{4}$ and 3-fold excess of dmpzH in $\mathrm{CH}_{2} \mathrm{Cl}_{2}$.

\section{4. $\left[\mathrm{Mo}\left(\eta^{3}\right.\right.$-methallyl $\left.)\left(\mathrm{O}_{2} \mathrm{CCH}_{3}\right)(\mathrm{CO})_{2}(\mathrm{pzH})_{2}\right](\mathbf{2 a})$}

\subsubsection{Method $A$}

$\mathrm{NaOAc} 3 \mathrm{H}_{2} \mathrm{O}(0.204 \mathrm{~g}, 1.5 \mathrm{mmol})$ and $\mathrm{pzH}(0.068 \mathrm{~g}, 1.0 \mathrm{mmol})$ were added to a solution of $\left[\mathrm{Mo}\left(\eta^{3}\right.\right.$-methallyl $\left.) \mathrm{Cl}(\mathrm{CO})_{2}(\mathrm{NCMe})_{2}\right]$ $(0.162 \mathrm{~g}, 0.5 \mathrm{mmol})$ in THF $(20 \mathrm{~mL})$. The mixture was stirred at r.t. for $3 \mathrm{~h}$. The volatiles were removed in vacuo and the orange residue was extracted with $\mathrm{CH}_{2} \mathrm{Cl}_{2}$ (ca. $30 \mathrm{ml}$ ) and filtered. Hexane was added (ca. $20 \mathrm{~mL}$ ) and the solution was concentrated and cooled to $-20^{\circ} \mathrm{C}$, giving a orange microcrystalline solid, which was decanted, washed with hexane $(3 \times 3 \mathrm{~mL}$ approximately), and dried in vacuo, yielding $0.101 \mathrm{~g}$ (51\%) of $\mathbf{2 a}$.

\subsubsection{Method $B$}

$\mathrm{NaOAc} 3 \mathrm{H}_{2} \mathrm{O}(0.030 \mathrm{~g}, 0.22 \mathrm{mmol})$ were added to a solution of 1a $(0.075 \mathrm{~g}, 0.2 \mathrm{mmol})$ in THF $(10 \mathrm{~mL})$. The mixture was stirred at r.t. for $3 \mathrm{~h}$. Work-up as for Method A gave $0.045 \mathrm{~g}(56 \%)$ of 2a. IR (THF, $\left.\mathrm{cm}^{-1}\right)$ : $1944 \mathrm{vs}, 1847$ s. IR $\left(\mathrm{KBr}, \mathrm{cm}^{-1}\right): 3255 \mathrm{~m}, 3144 \mathrm{w}$, 2961 w, 2919 w, 1946 s, 1930 s, 1831 vs, 1612 s, 1527 m, 1474 m, $1394 \mathrm{~s}, 1332 \mathrm{~m}, 1254 \mathrm{w}, 1139 \mathrm{~m}, 1048 \mathrm{~m}, 1025 \mathrm{w}, 941 \mathrm{w}$, 900 w, 773 m, 660 w, 635 w, 609 w, 501 w. ${ }^{1} \mathrm{H}$ NMR (r.t.): 1.37 $\left(\mathrm{s}, H^{\text {anti }}\right.$ methallyl, $\left.2 \mathrm{H}\right), 1.71\left(\mathrm{~s}, \mathrm{CH}_{3}\right.$ methallyl, 3H), 2.11 (s, acetate, $3 \mathrm{H}), 3.11\left(\mathrm{~s}, H^{\mathrm{syn}}\right.$ methallyl, $\left.2 \mathrm{H}\right), 6.30\left(\mathrm{~s}, H^{4} \mathrm{pzH}, 2 \mathrm{H}\right), 7.46\left(\mathrm{~s}, H^{5,3}\right.$ pzH, 2H), 7.75 (s, $H^{3.5}$ pzH, 2H), 13.09 (br, NH, 2H). ${ }^{1} \mathrm{H}$ NMR $(213 \mathrm{~K}): 1.11\left(\mathrm{~s}, H^{\text {anti }}\right.$ methallyl, $\left.1 \mathrm{H}\right), 1.16\left(\mathrm{~s}, H^{\text {anti }}\right.$ methallyl, $\left.1 \mathrm{H}\right)$, $1.64\left(\mathrm{~s}, \mathrm{CH}_{3}\right.$ methallyl, $\left.3 \mathrm{H}\right), 1.90\left(\mathrm{~s}, \mathrm{CH}_{3}\right.$ acetate, $\left.3 \mathrm{H}\right), 2.67\left(\mathrm{~s}, H^{\text {syn }}\right.$ methallyl, $1 \mathrm{H}), 3.24\left(\mathrm{~s}, H^{\mathrm{syn}}\right.$ methallyl, $\left.1 \mathrm{H}\right), 6.37\left(\mathrm{~s}, H^{4} \mathrm{pzH}, 1 \mathrm{H}\right)$, $6.48\left(\mathrm{~s}, H^{4} \mathrm{pzH}, 1 \mathrm{H}\right), 7.63\left(\mathrm{~s}, H^{5} \mathrm{pzH}, 1 \mathrm{H}\right), 7.69\left(\mathrm{~s}, H^{5} \mathrm{pzH}, 1 \mathrm{H}\right)$, $7.96\left(\mathrm{~s}, H^{3} \mathrm{pzH}, 1 \mathrm{H}\right), 8.01\left(\mathrm{~s}, H^{3} \mathrm{pzH}, 1 \mathrm{H}\right), 11.81(\mathrm{br}, \mathrm{NH}, 1 \mathrm{H})$, 14.95 (br, $\mathrm{NH}, 1 \mathrm{H}) \cdot{ }^{13} \mathrm{C}\left\{{ }^{1} \mathrm{H}\right\}$ NMR: $19.2\left(\mathrm{~s}, \mathrm{CH}_{3}\right.$ methallyl), 25.6 (s,

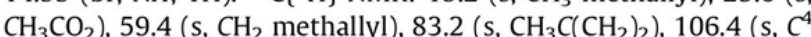
$\mathrm{pzH}), 129.6$ (s, $\left.\mathrm{C}^{5,3} \mathrm{pzH}\right), 144.8$ (s, $\left.\mathrm{C}^{3.5} \mathrm{pzH}\right), 182,1\left(\mathrm{~s}, \mathrm{CH}_{3} \mathrm{CO}_{2}\right), \mathrm{CO}$ not observed. Anal. Calcd. for $\mathrm{C}_{14} \mathrm{H}_{18} \mathrm{MoN}_{4} \mathrm{O}_{4}$ : C, 41.80; H, 4.51; $\mathrm{N}, 13.93$. Found: C, $42.17 ; \mathrm{H}, 4.34 ; \mathrm{N}, 14.16 \%$.

\section{5. $\left[\mathrm{Mo}\left(\eta^{3}\right.\right.$-methallyl $\left.)\left(\mathrm{O}_{2} \mathrm{CCH}_{3}\right)(\mathrm{CO})_{2}(\mathrm{dmpzH})_{2}\right](\mathbf{2 b})$}

$\mathrm{NaOAc} 3 \mathrm{H}_{2} \mathrm{O}(0.122 \mathrm{~g}, 0.9 \mathrm{mmol})$ and $\mathrm{dmpzH}(0.058 \mathrm{~g}$, $0.6 \mathrm{mmol})$ were added to a solution of $\left[\mathrm{Mo}\left(\eta^{3}\right.\right.$-methallyl $\left.) \mathrm{Cl}(\mathrm{CO})_{2}(\mathrm{NCMe})_{2}\right](0.097 \mathrm{~g}, 0.3 \mathrm{mmol})$ in THF $(15 \mathrm{~mL})$. The mixture was stirred at r.t. for $2 \mathrm{~h}$. Work-up as for $2 \mathrm{a}$ gave $0.075 \mathrm{~g}$ (55\%) of $\mathbf{2 b}$ as a yellow microcrystalline solid. IR (THF, $\mathrm{cm}^{-1}$ ): 1943 vs, 1846 s. IR (KBr, cm $\left.{ }^{-1}\right): 3265$ m, 3143 w, 3102 w, 3049 w, 2990 w, 2949 w, 2862w, 1935 vs, 1851 vs, 1588 s, 1569 s, 1492 w, 1474 w, 1394 s, 1335 m, 1306 w, 1272 m, 1160 w, 1042 w, $1028 \mathrm{~m}, 786 \mathrm{~m}, 741 \mathrm{w}, 658 \mathrm{w}, 633$ w. ${ }^{1} \mathrm{H}$ NMR (r.t.): 1.26 (s, $H^{\text {anti }}$ methallyl, $2 \mathrm{H}), 1.68\left(\mathrm{~s}, \mathrm{CH}_{3}\right.$ methallyl, $\left.3 \mathrm{H}\right), 2.09\left(\mathrm{~s}, \mathrm{CH}_{3}\right.$ acetate, $\left.3 \mathrm{H}\right)$, $2.19\left(\mathrm{~s}, \mathrm{CH}_{3} \mathrm{dmpzH}, 6 \mathrm{H}\right), 2.32\left(\mathrm{~s}, \mathrm{CH}_{3} \mathrm{dmpzH}, 6 \mathrm{H}\right), 3.01\left(\mathrm{~s}, H^{\mathrm{syn}}\right.$ methallyl, 2H), $5.82\left(\mathrm{~s}, \mathrm{H}^{4} \mathrm{dmpzH}, 2 \mathrm{H}\right), 12.02(\mathrm{br}, \mathrm{NH}, 2 \mathrm{H}) .{ }^{1} \mathrm{H}$ NMR $(233 \mathrm{~K}): 1.23\left(\mathrm{~s}, H^{\text {anti }}\right.$ methallyl, $\left.1 \mathrm{H}\right), 1.27\left(\mathrm{~s}, H^{\text {anti }}\right.$ methallyl, $1 \mathrm{H}), 1.57\left(\mathrm{~s}, \mathrm{CH}_{3}\right.$ methallyl, 3H), $1.99\left(\mathrm{~s}, \mathrm{CH}_{3}\right.$ acetate, $\left.3 \mathrm{H}\right), 2.13$ (s, $\mathrm{CH}_{3}$ dmpzH, 6H), $2.26\left(\mathrm{~s}, \mathrm{CH}_{3} \mathrm{dmpzH}, 3 \mathrm{H}\right), 2.53\left(\mathrm{~s}, \mathrm{CH}_{3} \mathrm{dmpzH}\right.$, $3 \mathrm{H}), 2.80\left(\mathrm{~s}, H^{\text {syn }}\right.$ methallyl, $\left.1 \mathrm{H}\right), 3.08\left(\mathrm{~s}, H^{\text {syn }}\right.$ methallyl, $\left.1 \mathrm{H}\right), 5.77$ (s, $H^{4}$ dmpzH, 1H), $5.86\left(\mathrm{~s}, H^{4}\right.$ dmpzH, 1H), $11.13(\mathrm{~s}, \mathrm{NH}, 1 \mathrm{H})$, $13.37(\mathrm{~s}, \mathrm{NH}, 1 \mathrm{H}),{ }^{13} \mathrm{C}\left\{{ }^{1} \mathrm{H}\right\}$ NMR: $10.9\left(\mathrm{~s}, \mathrm{CH}_{3} \mathrm{dmpzH}\right), 14.5(\mathrm{~s}$, $\mathrm{CH}_{3}$ dmpzH), 19.2 (s, $\mathrm{CH}_{3}$ methallyl), 25.9 (s, $\mathrm{CH}_{3} \mathrm{CO}_{2}$ ), 59.6 (br, $\mathrm{CH}_{2}$ methallyl), $84.3\left(\mathrm{~s}, \mathrm{CH}_{3} \mathrm{C}\left(\mathrm{CH}_{2}\right)_{2}\right), 106.1$ (s, $\left.\mathrm{C}^{4} \mathrm{dmpzH}\right), 140.2$ (s, $\left.\mathrm{C}^{5,3} \mathrm{dmpzH}\right), 151.2\left(\mathrm{~s}, \mathrm{C}^{3,5} \mathrm{dmpzH}\right), 180.9\left(\mathrm{~s}, \mathrm{CH}_{3} \mathrm{CO}_{2}\right), \mathrm{CO}$ not observed. Anal. Calcd. for $\mathrm{C}_{18} \mathrm{H}_{26} \mathrm{MoN}_{4} \mathrm{O}_{4}$ : C, 47.17; $\mathrm{H}, 5.72 ; \mathrm{N}, 12.23$. Found: C, 46.92; H, 5.42; N, 12.00\%. 


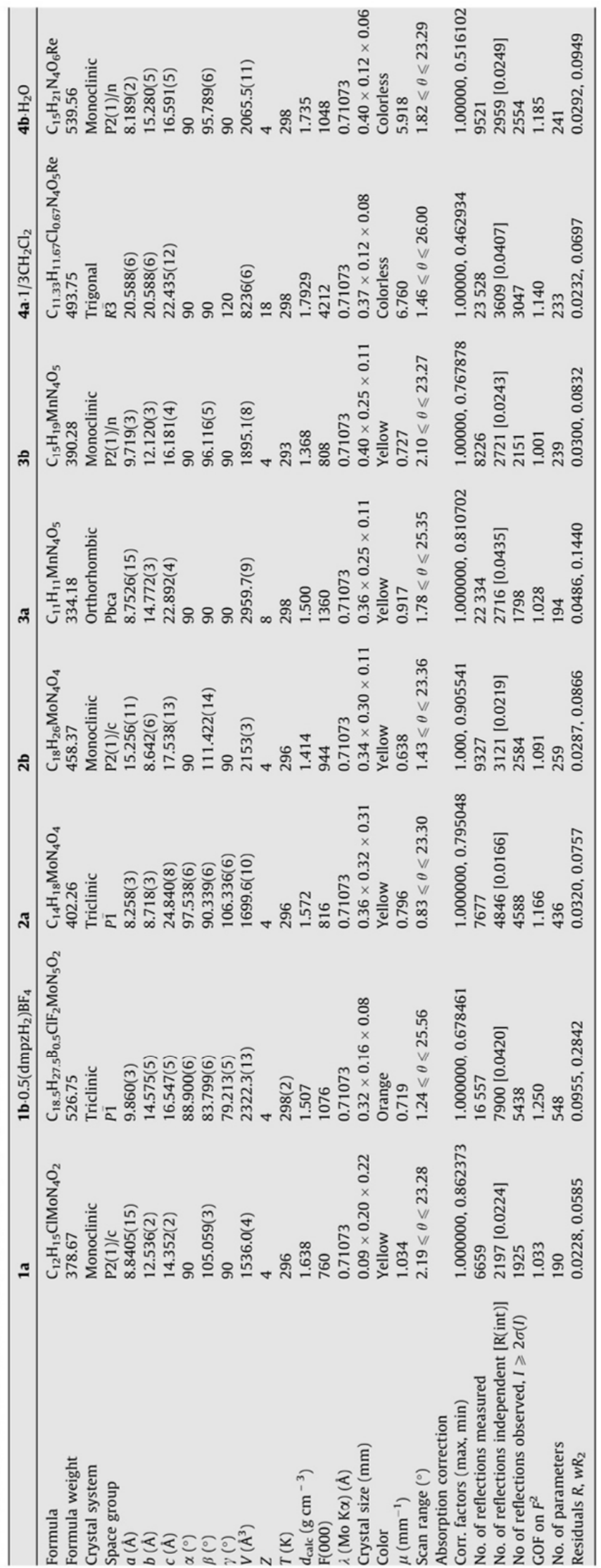




\section{6. $\mathrm{fac}-\left[\mathrm{Mn}\left(\mathrm{O}_{2} \mathrm{CCH}_{3}\right)(\mathrm{CO})_{3}(\mathrm{pzH})_{2}\right](3 \boldsymbol{a})$}

To a recently prepared solution of $f a c-\left[\mathrm{MnBr}(\mathrm{CO})_{3}(\mathrm{NCMe})_{2}\right]$ (obtained from $0.082 \mathrm{~g}$ of $\left.\left[\mathrm{MnBr}(\mathrm{CO})_{5}\right], 0.3 \mathrm{mmol}\right)$ in THF $(15 \mathrm{~mL})$, AgOAc $(0.055 \mathrm{~g}, 0.33 \mathrm{mmol})$ and then $\mathrm{pzH}(0.042 \mathrm{~g}, 0.6 \mathrm{mmol})$ were added. The solution was stirred for $5 \mathrm{~min}$. Work-up as for 2a gave $0.075 \mathrm{~g}$ (75\%) of $\mathbf{3 a}$ as a yellow microcrystalline solid. IR (THF, $\left.\mathrm{cm}^{-1}\right)$ : 2033 vs 1938 vs, 1912 vs. IR $\left(\mathrm{KBr}, \mathrm{cm}^{-1}\right): 3344 \mathrm{w}$, $3158 \mathrm{w}, 2026$ vs, 1918 vs br, $1608 \mathrm{~m}, 1534 \mathrm{~m}, 1471 \mathrm{~m}, 1387 \mathrm{~m}$, 1355 w, 1335 m, 1261 m, 1163 w, 1134 m, 1059 m, 1048 m, 942 w, 910 w, 864 w, 759 m, 698 w, 664 w, 634 w, 599 w, 521 w. ${ }^{1} \mathrm{H}$ NMR: 2.24 (br, acetate, $3 \mathrm{H}), 6.37\left(\mathrm{~s}, H^{4} \mathrm{pzH}, 2 \mathrm{H}\right), 7.59\left(\mathrm{br}, H^{3}\right.$ pzH, 2H), $7.63\left(\mathrm{~s}, \mathrm{H}^{5} \mathrm{pzH}, 2 \mathrm{H}\right), 13.04(\mathrm{br}, \mathrm{NH}, 2 \mathrm{H}) .{ }^{13} \mathrm{C}\left\{{ }^{1} \mathrm{H}\right\}$ NMR [( $\left.\left.\mathrm{CD}_{3}\right)_{2} \mathrm{CO}\right][33]: 28.1\left(\mathrm{~s}, \mathrm{CH}_{3} \mathrm{CO}_{2}\right), 108.4\left(\mathrm{~s}, \mathrm{C}^{4} \mathrm{pzH}\right), 132.7\left(\mathrm{~s}, \mathrm{C}^{5.3}\right.$ pzH), 143.7 (s, $\left.\mathrm{C}^{3,5} \mathrm{pzH}\right), 170.0\left(\mathrm{~s}, \mathrm{CH}_{3} \mathrm{CO}_{2}\right), 222.2$ (s, 1CO), 223.3 (s, 2CO). Conduct. $\Lambda_{\mathrm{M}}\left(\mathrm{Me}_{2} \mathrm{CO}\right): 2 \mathrm{~S} \mathrm{~cm}^{2} \mathrm{~mol}^{-1}$. Anal. Calcd. for $\mathrm{C}_{11} \mathrm{H}_{11} \mathrm{MnN}_{4} \mathrm{O}_{5}$ : C, 39.54; H, 3.32; N, 16.77. Found: C, 39.21; $\mathrm{H}$ $2.97 ; \mathrm{N}, 17.07 \%$.

\section{7. fac- $\left[\mathrm{Mn}\left(\mathrm{O}_{2} \mathrm{CCH}_{3}\right)(\mathrm{CO})_{3}(\mathrm{dmpzH})_{2}\right](\mathbf{3 b})$}

To a recently prepared solution of $f a c-\left[\mathrm{MnBr}(\mathrm{CO})_{3}(\mathrm{NCMe})_{2}\right]$ (obtained from $0.137 \mathrm{~g}$ of $\left.\left[\mathrm{MnBr}(\mathrm{CO})_{5}\right], 0.5 \mathrm{mmol}\right)$ in THF $(20 \mathrm{~mL})$, AgOAc $(0.091 \mathrm{~g}, 0.55 \mathrm{mmol})$ and then dmpzH $(0.097 \mathrm{~g}, 1.0 \mathrm{mmol})$ were added. The solution was stirred for $45 \mathrm{~min}$. Work-up as for 2a gave $0.152 \mathrm{~g}(78 \%)$ of $\mathbf{3 b}$ as a yellow microcrystalline solid. IR (THF, $\left.\mathrm{cm}^{-1}\right)$ : 2030 vs, 1934 vs, 1906 vs. IR $\left(\mathrm{KBr}, \mathrm{cm}^{-1}\right): 3313 \mathrm{w}$, 3271 w, 2930 w, 2029 vs, 1934 vs, 1898 vs, 1571 s, 1543 w, 1400 s, 1289 m, 1142 w, 1043 w, 806 m, 688 w, 662 w, 632 w, 518 w. ${ }^{1} \mathrm{H}$ NMR: 2.13 (s, $\left.\mathrm{CH}_{3} \mathrm{dmpzH}, 6 \mathrm{H}\right), 2.17$ (s, $\mathrm{CH}_{3}$ acetate, $3 \mathrm{H}), 2.23$ (s, $\left.\mathrm{CH}_{3} \mathrm{dmpzH}, 6 \mathrm{H}\right), 5.84\left(\mathrm{~s}, \mathrm{H}^{4} \mathrm{dmpzH}, 2 \mathrm{H}\right), 12.02(\mathrm{br}$, $\mathrm{NH}, 2 \mathrm{H}) .{ }^{13} \mathrm{C}\left\{{ }^{1} \mathrm{H}\right\}$ NMR: $11.5\left(\mathrm{~s},{ }^{5} \mathrm{CH}_{3} \mathrm{dmpzH}\right), 13.9\left(\mathrm{~s},{ }^{3} \mathrm{CH}_{3} \mathrm{dmpzH}\right)$ 26.0 (br, $\mathrm{CH}_{3} \mathrm{CO}_{2}$ ), 106.9 (s, $\mathrm{C}^{4} \mathrm{dmpzH}$ ), 141.0 (s, $\mathrm{C}^{5,3} \mathrm{dmpzH}$ ), 153.1 (s, $\left.\mathrm{C}^{3.5} \mathrm{dmpzH}\right), 184.5\left(\mathrm{br}, \mathrm{CH}_{3} \mathrm{CO}_{2}\right), 219.7$ (s, 2CO), 223.1 (s, 1CO). Conduct. $\Lambda_{\mathrm{M}} \quad\left(\mathrm{Me}_{2} \mathrm{CO}\right): 0 \mathrm{~S} \mathrm{~cm}^{2} \mathrm{~mol}^{-1}$. Anal. Calcd. for $\mathrm{C}_{15} \mathrm{H}_{19} \mathrm{MnN}_{4} \mathrm{O}_{5}$ : C, 46.16; $\mathrm{H}, 4.90 ; \mathrm{N}, 14.36$. Found: $\mathrm{C}, 45.81 ; \mathrm{H}$, $4.63 ; \mathrm{N}, 14.04 \%$.

\section{8. $f a c-\left[\operatorname{Re}\left(\mathrm{O}_{2} \mathrm{CCH}_{3}\right)(\mathrm{CO})_{3}(\mathrm{pzH})_{2}\right](4 \boldsymbol{a})$}

To a solution of $f a c-\left[\operatorname{ReBr}(\mathrm{CO})_{3}(\mathrm{NCMe})_{2}\right](0.127 \mathrm{~g}, 0.3 \mathrm{mmol})$ in $\mathrm{Me}_{2} \mathrm{CO}(10 \mathrm{~mL}), \mathrm{AgOAc}(0.055 \mathrm{~g}, 0.33 \mathrm{mmol})$ and then $\mathrm{pzH}$ $(0.042 \mathrm{~g}, 0.6 \mathrm{mmol})$ were added. The solution was stirred for $30 \mathrm{~min}$. Work-up as for $\mathbf{2 a}$ gave $0.115 \mathrm{~g}(84 \%)$ of $\mathbf{4 a}$ as a colorless microcrystalline solid. IR (THF, $\mathrm{cm}^{-1}$ ): 2024 vs, 1914 vs, 1894 vs. IR $\left(\mathrm{KBr}, \mathrm{cm}^{-1}\right)$ : 3145 w, 2989 w, 2875 w, 2027 vs, 1903 vs br, 1570 s, 1528 s, 1482 s, 1404 s, 1353 s, 1272 m, 1164 m, 1142 s, 1064 s, 1051 s, 1020 w, 951 w, 912 w, 882 w, 880 w, 807 m, 766 s, $672 \mathrm{~m}, 659 \mathrm{w}, 635 \mathrm{w}, 608 \mathrm{~m}, 531 \mathrm{~m}, 488 \mathrm{~m}$. ${ }^{1} \mathrm{H}$ NMR: 2.18 (s, acetate, $3 \mathrm{H}), 6.35\left(\mathrm{~s}, \mathrm{H}^{4} \mathrm{pzH}, 2 \mathrm{H}\right), 7.58\left(\mathrm{~s}, H^{3,5} \mathrm{pzH}, 2 \mathrm{H}\right), 7.62\left(\mathrm{~s}, H^{5,3}\right.$ pzH, 2H), 12.94 (br, NH, $2 \mathrm{H}) \cdot{ }^{13} \mathrm{C}\left\{{ }^{1} \mathrm{H}\right\}$ NMR $\left[\left(\mathrm{CD}_{3}\right)_{2} \mathrm{CO}\right]::^{43} 23.9$ (s, $\left.\mathrm{CH}_{3} \mathrm{CO}_{2}\right), 107.6\left(\mathrm{~s}, \mathrm{C}^{4} \mathrm{pzH}\right), 131.9\left(\mathrm{~s}, \mathrm{C}^{5,3} \mathrm{pzH}\right), 143.0\left(\mathrm{~s}, \mathrm{C}^{3,5} \mathrm{pzH}\right)$, 180.8 (s, $\mathrm{CH}_{3} \mathrm{CO}_{2}$ ), 196.9 (2CO), 206.1 (partially overlapped with the acetone signal, $\mathrm{CO})$. Conduct. $\Lambda_{\mathrm{M}}\left(\mathrm{Me}_{2} \mathrm{CO}\right): 2 \mathrm{~S} \mathrm{~cm}^{2} \mathrm{~mol}^{-1}$. Anal. Calcd. for $\mathrm{C}_{11} \mathrm{H}_{11} \mathrm{~N}_{4} \mathrm{O}_{5}$ Re: C, 28.39; $\mathrm{H}, 2.38$; N, 12.04. Found: C, 28.73; H, 2.67; N, 11.72\%.

\section{9. $f a c-\left[\operatorname{Re}\left(\mathrm{O}_{2} \mathrm{CCH}_{3}\right)(\mathrm{CO})_{3}(\mathrm{dmpzH})_{2}\right](\mathbf{4} \boldsymbol{b})$}

To a solution of $f a c-\left[\operatorname{ReBr}(\mathrm{CO})_{3}(\mathrm{NCMe})_{2}\right](0.216 \mathrm{~g}, 0.5 \mathrm{mmol})$ in $\mathrm{Me}_{2} \mathrm{CO}(20 \mathrm{~mL}), \mathrm{AgOAc}(0.092 \mathrm{~g}, 0.55 \mathrm{mmol})$ and then dmpzH $(0.097 \mathrm{~g}, 1.0 \mathrm{mmol})$ were added. The solution was stirred for $40 \mathrm{~min}$. Work-up as for $\mathbf{2 a}$ gave $0.239 \mathrm{~g}(92 \%)$ of $\mathbf{4 b}$ as a colorless microcrystalline solid. IR (THF, $\mathrm{cm}^{-1}$ ): 2021 vs, 1911 vs, 1886 vs. IR $\left(\mathrm{KBr}, \mathrm{cm}^{-1}\right)$ : 3398 s, 2929 w, 2017 vs, 1897 vs br, 1576 m, 1395 m, 1337 m, 1309 w, 1824 w, 1176 w, 1152 w, 1101 w,
1048 m, 1027 m, 882 w, 800 w, 664 m, 503 w. ${ }^{1}$ H NMR: 2.12 (s, $\mathrm{CH}_{3}$ acetate, $\left.3 \mathrm{H}\right), 2.14\left(\mathrm{~s}, \mathrm{CH}_{3} \mathrm{dmpzH}, 6 \mathrm{H}\right), 2.25\left(\mathrm{~s}, \mathrm{CH}_{3} \mathrm{dmpzH}\right.$, $6 \mathrm{H}), 5.87$ (s, $\left.\mathrm{H}^{4} \mathrm{dmpzH}, 2 \mathrm{H}\right), 12.02$ (br, $\left.\mathrm{NH}, 2 \mathrm{H}\right) .{ }^{13} \mathrm{C}\left\{{ }^{1} \mathrm{H}\right\}$ NMR: $11.1\left(\mathrm{~s},{ }^{5} \mathrm{CH}_{3} \mathrm{dmpzH}\right), 14.2$ (s, $\left.{ }^{3} \mathrm{CH}_{3} \mathrm{dmpzH}\right), 24.2\left(\mathrm{~s}, \mathrm{CH}_{3} \mathrm{CO}_{2}\right)$, 106.1 (s, $C^{4} \mathrm{dmpzH}$ ), 141.2 (s, $\left.\mathrm{C}^{5.3} \mathrm{dmpzH}\right), 152.6$ (s, $\mathrm{C}^{3.5} \mathrm{dmpzH}$ ), $181.6\left(\mathrm{~s}, \mathrm{CH}_{3} \mathrm{CO}_{2}\right), 195.3(\mathrm{~s}, 2 \mathrm{CO}), 195.8$ (s, $\left.1 \mathrm{CO}\right)$. Conduct. $\Lambda_{\mathrm{M}}$ $\left(\mathrm{Me}_{2} \mathrm{CO}\right): 0 \mathrm{~S} \mathrm{~cm}^{2} \mathrm{~mol}^{-1}$. Anal. Calcd. for $\mathrm{C}_{15} \mathrm{H}_{19} \mathrm{~N}_{4} \mathrm{O}_{5} \mathrm{Re}$ : C, 34.54; $\mathrm{H}, 3.67$; N, 10.74. Found: C, 34.34; $\mathrm{H}, 3.31 ; \mathrm{N}, 10.47 \%$.

\subsection{Crystal structure determination for compounds $\mathbf{1 a}, \mathbf{1 b}, \mathbf{2 a}, \mathbf{2 b}$, $3 a, 3 b, 4 a$, and $4 b$}

Crystals were grown by slow diffusion of hexane into concentrated solutions of the complexes in $\mathrm{CH}_{2} \mathrm{Cl}_{2}$ at $-20^{\circ} \mathrm{C}$. Relevant crystallographic details are given in Table 4 . A crystal was attached to a glass fiber and transferred to a Bruker AXS SMART 1000 diffractometer with graphite monochromatized Mo $\mathrm{K} \alpha \mathrm{X}$-radiation and a CCD area detector. Raw frame data were integrated with the sAINT program [34]. The structure was solved by direct methods ith SHELXTL [35]. A semi-empirical absorption correction was applied with the program SADABS [36]. All non-hydrogen atoms were refined anisotropically. Hydrogen atoms were set in calculated positions and refined as riding atoms, with a common thermal parameter. All calculations and graphics were made with SHELXTL. For $\mathbf{4 a}$ several peaks were found in the proximity of the trigonal axis. After several attempts, they were modelled as two disordered molecules of dichloromethane with the carbon atoms lying in the trigonal axis, they were refined as rigid groups with occupancy factors of one-sixth each. Distances and angles of hydrogen bonds were calculated with PARST [37] (normalized values) [38].

\section{Supplementary material}

CCDC 716936, 716937, 716938, 716939, 716940, 716941, 716942 and 716943 contain the supplementary crystallographic data for this paper. These data can be obtained free of charge from The Cambridge Crystallographic Data Centre via www.ccdc.cam.ac.uk/data_request/cif.

\section{Acknowledgments}

The authors thank the Spanish Ministerio de Educación y Ciencia (CTQ2006-08924) and the Junta de Castilla y León (VA070A08) for financial support. M.A. and R.G.-R. thank the MEC (Program FPI) for a grant. We also thank Dr. Celedonio Alvarez for helpful discussions.

\section{References}

[1] Some examples of chains: (a) R. Graziani, U. Casellato, R. Ettorre, G. Plazzogna, J. Chem. Soc., Dalton Trans. (1982) 805-808;

(b) J.D. Crane, O.D. Fox, E. Sinn, J. Chem. Soc., Dalton Trans. (1999) 1461-1465: (c) K. Sakai, Y. Tomita, T. Ue, K. Goshima, M. Ohminato, T. Tsubomura, K Matsumoto, K. Ohmura, K. Kawakami, Inorg. Chim. Acta 297 (2000) 64-71; (d) A. Chadghan, J. Pons, A. Caubet, J. Casabó, J. Ros, A. Alvarez-Larena, J.F. Piniella, Polyhedron 19 (2000) 855-862.

[2] Some examples of dimers: (a) M.A. Cinellu, S. Stoccoro, G. Minghetti, A.L Bandini, G. Banditelli, B. Bovio, J. Organomet. Chem. 372 (1989) 311-325; (b) M. Munakata, L.P. Wu, M. Yamamoto, T. Kuroda-Sowa, M. Maekawa, S. Kawata, S. Kitagawa, J. Chem. Soc. Dalton Trans. (1995) 4099-4106: (c) G.A. Ardizzoia, G. La Monica, S. Cenini, M. Moret, N. Masciocchi, J. Chem (c) G.A. Ardizzoia, G. La Monica, S. Cenini,

Soc., Dalton Trans. (1996) 1351-1357;
(d) I.A. Guzei, C.H. Winter, Inorg. Chem. 36 (1997) 4415-4420;

(e) S.M. Couchman, J.C. Jeffery, M.D. Ward, Polyhedron 18 (1999) 2633-2640.

[3] (a) S. Nieto, J. Pérez, L. Riera, V. Riera, D. Miguel, J.A. Golen, A.L. Rheingold Inorg. Chem. 46 (2007) 3407-3418;

(b) S. Nieto, J. Pérez, L. Riera, V. Riera, D. Miguel, Chem. Eur. J. 12 (2006) 22442251;

(c) S. Nieto, J. Pérez, V. Riera, D. Miguel, C. Alvarez, Chem. Commun. (2005) 546-548; 
(d) S.L. Renard, C.A. Kilner, J. Fisher, M.A. Halcrow, J. Chem. Soc., Dalton Trans. (2002) 4206-4212;

(e) X. Liu, C.A. Kilner, M.A. Halcrow, Chem. Commun. (2002) 704-705; (f) D.L. Reger, Y. Ding, A.L. Rheingold, R.L. Ostrander, Inorg. Chem. 33 (1994) 4226-4230;

(g) A. Looney, G. Parkin, A.L. Rheingold, Inorg. Chem. 30 (1991) 3099-3101.

[4] (a) D. Braga, J. Chem. Soc., Dalton Trans. (2000) 3705-3713:

(b) G.R. Desiraju, J. Chem. Soc., Dalton Trans. (2000) 3745-3751.

[5] See for example: (a) M. Tadokoro, T. Inoue, S. Tamaki, K. Fujii, K. Isogai, H. Nakazawa, S. Takeda, K. Isobe, N. Koga, A. Ichimura, K. Nakasuji, Angew. Chem., Int. Ed. 46 (2007) 5938-5942;

(b) S. Shibahara, H. Kitagawa, Y. Ozawa, K. Toriumi, T. Kubo, K. Nakasuji, Inorg. Chem. 46 (2007) 1162-1170.

[6] (a) S. Derossi, H. Adams, M.D. Ward, Dalton Trans, (2007) 33-36:

(b) V. Coué, R. Dessapt, M. Bujoli-Doeuff, M. Evain, S. Jobic, Inorg. Chem. 46 (2007) 2824-2835;

(c) O. Sato, Acc. Chem. Res. 36 (2003) 692-700;

(d) E.H.A. Beckers, P.A. van Hal, A.P.H.J. Schenning, A. El-ghayoury, E. Peeters, M.T. Rispens, J.C. Hummelen, E.W. Meijer, R.A.J. Janssen, J. Mater. Chem. 12 (2002) 2054-2060.

[7] C. Desplanches, E. Ruiz, S. Alvarez, Chem. Commun. (2002) 2614-2615.

[8] (a) S. Kitagawa, K. Uemura, Chem. Soc. Rev, 34 (2005) 109-119;

(b) S. Kitagawa, R. Kytaura, S. Noro, Angew. Chem., Int. Ed. 43 (2004)2334-2375;

(c) F. Zhang, M.C. Jennings, R.J. Puddephatt, Chem. Commun. (2007) 1496-1498;

(d) M. Du, X.-J. Yiang, X.-J. Zhao, Inorg. Chem. 46 (2007) 3984-3995;

(e) N.L. Rosi, J. Kim, M. Eddaoudi, B. Chen, M. O'Keefe, O.M. Yaghi, J. Am. Chem. Soc. 127 (2005) 1504-1518.

[9] See for example: (a) D.B. Grotjahn, Chem. Eur. J. 11 (2005) 7146-7153;

(b) K. Abdur-Raschid, R. Abbel, A. Hadzovic, A.J. Lough, R.H. Morris, Inorg. Chem. 44 (2005) 2483-2492:

(c) W.K. Fung, X. Huang, M.L. Man, S.M. Ng. M.Y. Hung, Z. Lin, C.P. Lau, J. Am. Chem. Soc. 125 (2003) 11539-11544.

[10] (a) M. Arroyo, A. López-Sanvicente, D. Miguel, F. Villafañe, Eur. J. Inorg. Chem. (2005) 4430-4437:

(b) P. Paredes, D. Miguel, F. Villafañe, Eur. J. Inorg. Chem. (2003) 995-1004;

(c) G.A. Ardizzoia, G. LaMonica, A. Maspero, M. Moret, N. Masciocchi, Eur. J. Inorg. Chem. (1998) 1503-1512.

[11] (a) E. Szajna-Fuller, B.M. Chambers, A.M. Arif, L.M. Berreau, Inorg. Chem. 46 (2007) 5486-5498;

(b) E. Szajna, A.M. Arif, L.M. Berreau, J. Am. Chem. Soc. 127 (2005) 1718617187.

[12] The synthesis of the allyl complex similar to $\mathbf{1 b}$ has been recently described by a different method, but no complete spectroscopic or structural characterization was given (Ref. [3a])

[13] 1b crystallized as $\mathbf{1 b} \cdot 0.5\left(\mathrm{dmpzH}_{2}\right) \mathrm{BF}_{4}$ (see Section 4), and contains two crystallographically independent but chemically equivalent molecules, their distances and angles being very similar. Fig. 1 and Table 1 collect one of them. distances and angles being very similar. Fig. 1 and Table 1 collect one of them.
Complete Tables for the two molecules can be found in the CIF. Due to the low Complete Tables for the two molecules can be found in the CIF. Due to the low
quality of the crystal, the resulting determination is poor (high residuals). quality of the crystal, the resulting determination is poor (high residuals).
Nevertheless, the structure is included here since it confirms unambiguously the connectivity of the molecule.

[14] M.D. Curtis, O. Eisenstein, Organometallics 3 (1984) 887-895.

[15] F.A. Cotton, R.L. Luck, Acta Crystallogr., Sect. C 46 (1990) 138-140.

[16] (a) R. Davis, L.A.P Kane-Maguire, in: G. Wilkinson, F.G.A. Stone, E.W. Abel (Eds.), Comprehensive Organometallic Chemistry, vol. 8, Pergamon, Oxford, UK, 1982, pp. 1156-1159;

(b) M.W. Whiteley, in: E.W. Abel, F.G.A. Stone, G. Wilkinson (Eds.), Comprehensive Organometallic Chemistry II, vol. 12, Pergamon, Oxford, UK, 1995, pp. 337-338.

[17] (a) G.A. Jeffrey, An Introduction to Hydrogen Bonding, Oxford University Press, New York, 1997 (Chapter 2):

(b) T. Steiner, Angew. Chem., Int. Ed. 41 (2002) 48-76.
[18] 1b crystallized out incorporating one-half of the ionic pair $\left(\mathrm{dmpz \textrm {H } _ { 2 }}\right) \mathrm{BF}_{4}$ per molecule of $\mathbf{1 b}$. The pyrazolium ion is involved in strong hydrogen bonds with

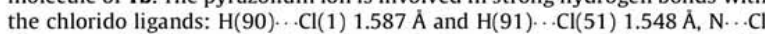
distances $2.598 \AA$ and $2.573 \AA$, and $\mathrm{N}-\mathrm{H} \cdots \mathrm{Cl}$ angles $166^{\circ}$ and $173^{\circ}$. respectively.

[19] For 2a, two crystallographically independent but chemically equivalent molecules were found in the asymmetric unit, with their distances and angles being very similar. Fig. 2 and Table 2 collect one of them. Complete tables for the two molecules can be found in the CIF.

[20] (a) N.I. Pyshnograeva, V.N. Setkina, V.G. Andrianov, Y.T. Struchkov, D.N. Kursanov, J. Organomet. Chem. 186 (1980) 331-338

(b) S.U. Son, K.H. Park, Y.K. Chung, Organometallics 19 (2000) 5241-5243;

(c) W.-Y. Wong, W.-K. Wong, C. Sun, W.-T. Wong. J. Organomet. Chem. 612 (2000) $160-171$.

[21] However, the solid state $\mathrm{C}-\mathrm{O}$ frequencies of 1a state are slightly lower than those of $\mathbf{1 b}$ (see Section 2). This feature was also observed for the complexes $\left[\mathrm{Mo}\left(\eta^{3}\right.\right.$-allyl $\left.) \mathrm{Br}(\mathrm{CO})_{2} \mathrm{~L}_{2}\right](\mathrm{L}=\mathrm{pzH}, \mathrm{dmpzH})$, and could be explained considering either lattice effects, and/or weak intermolecular hydrogen bonds involving the $\mathrm{NH}$ atoms and the oxygens of the carbonyls (Ref. [10b]).

[22] J.W. Faller, D.A. Haitko, R.D. Adams, D.F. Chodosh, J. Am. Chem. Soc. 101 (1979) 865-876.

[23] (a) S.K. Chowdhury, M. Nandi, V.S. Joshi, A. Sarkar, Organometallics 16 (1997) 1806-1809;

(b) D.S. Frohnapfel, P.S. White, J.L. Templeton, H. Rüegger, P.S. Pregosin, Organometallics 16 (1997) 3737-3750

(c) K.-B. Shiu, C.-J. Chang, Y. Wang, M.-C. Cheng, J. Organomet. Chem. 406 (1991) 363-369.

[24] P. Espinet, R. Hernando, G. Iturbe, F. Villafañe, G.A. Orpen, I. Pascual, Eur. J. Inorg. Chem. (2000) 1031-1038.

[25] D.R. van Staveren, E. Bill, E. Bothe, M. Bühl, T. Weyhermüller, N. Metzler-Nolte, Chem. Eur. J. 8 (2002) 1649-1662.

[26] (a) D. Carmona, J. Ferrer, J.M. Arilla, J. Reyes, F.J. Lahoz, S. Elipe, F.J. Modrego, L.A. Oro, Organometallics 19 (2000) 798-808;

(b) D. Röttger, G. Erker, M. Grehl, R. Fröhlich, Organometallics 13 (1994) 3897-3902;

(c) D. Carmona, J. Ferrer, L.A. Oro, M.C. Apreda, C. Foces-Foces, F.H. Cano, J. Elguero, M.L. Jimeno, J. Chem. Soc., Dalton Trans. (1990) 1463-1476;

(d) D. Carmona, L.A. Oro, M.P. Lamata, J. Elguero, M.C. Apreda, C. Foces-Foces, (d) D. Carmona, L.A. Oro, M.P. Lamata, J. Elguero, M.C. Apreda, C.

[27] R. Contreras, M. Valderrama, E.M. Orellana, D. Boys, D. Carmona, L.A. Oro, M.P. Lamata, J. Ferrer, J. Organomet. Chem. 606 (2000) 197-202.

[28] T. Beringhelli, G. D’Alfonso, M. Panigati, F. Porta, P. Mercandelli, M. Moret, A. Sironi, Organometallics 17 (1998) 3282-3292.

[29] D.D. Perrin, W.L.F Armarego, Purification of Laboratory Chemicals, 3rd ed., Pergamon Press, Oxford, 1988.

[30] H. Tom Dieck, H. Friedel, J. Organomet. Chem. 14 (1968) 375-385.

[31] M.F. Farona, K.F. Kraus, Inorg. Chem. 9 (1970) 1700-1704.

[32] W. Geary, Coord. Chem. Rev. 7 (1971) 81-122.

[33] No signals from the acetate group are detected in the ${ }^{13} \mathrm{C}$ NMR spectrum in $\mathrm{CDCl}_{3}$ due to their extreme broadness.

[34] SAINT+. SAX Area Detector Integration Program. Version 6.02, Bruker AXS Inc., Madison, WI, 1999

[35] G.M. Sheldrick, SHELXT, An Integrated System for Solving, Refining, and Displaying Crystal Structures from Diffraction Data, Version 5.1. Bruker AXS Inc., Madison, WI, 1998.

[36] G.M. Sheldrick, SADABS, Empirical Absorption Correction Program, University of Göttingen, Göttingen, Germany, 1997.

[37] M. Nardelli, Comp. Chem. 7 (1983) 95-98; M. Nardelli, J. Appl. Cryst. 28 (1995) 659.

[38] (a) G.A. Jeffrey, L. Lewis, Carbohydr. Res. 60 (1978) 179-182;

(b) R. Taylor, O. Kennard, Acta Crystallogr. B39 (1983) 133-138. 
Anexo IV 

Inorganic Chemistry

\section{Coordination versus Coupling of Dicyanamide in Molybdenum and Manganese Pyrazole Complexes}

Marta Arroyo, Patricia Gómez-Iglesias, Jose Miguel Martín-Alvarez, Celedonio M. Alvarez, Daniel Miguel, and Fernando Villafañe*

IU CINQUIMA/Química Inorgánica, Facultad de Ciencias, Universidad de Valladolid, 47005 Valladolid, Spain

Supporting Information

ABSTRACT: The reactions of cis-[ $\mathrm{MoCl}\left(\eta^{3}\right.$-methallyl $\left.)(\mathrm{CO})_{2}(\mathrm{NCMe})_{2}\right]$ (methallyl $\left.=\mathrm{CH}_{2} \mathrm{C}\left(\mathrm{CH}_{3}\right) \mathrm{CH}_{2}\right)$ with $\mathrm{Na}(\mathrm{NCNCN})$ and $\mathrm{pz} * \mathrm{H}(\mathrm{pzH}$, pyrazole, or dmpzH, 3,5-dimethylpyrazole) lead to cis-[Mo $\left(\eta^{3}\right.$-methallyl $)(\mathrm{CO})_{2}\left(\mathrm{pz}^{*} \mathrm{H}\right)$ $\left.\left(\mu-N C N C N-\kappa^{2} N, N\right)\right]_{2}(p z H, 1 \mathbf{1 a} ; \operatorname{dmpzH}, \mathbf{1 b})$, where dicyanamide is coordinated as bridging ligand. Similar reactions with fac- $[\mathrm{MnBr}-$ $\left.(\mathrm{CO})_{3}(\mathrm{NCMe})_{2}\right]$ lead to the pyrazolylamidino complexes fac- $[\mathrm{Mn}(\mathrm{pz} * \mathrm{H})$ $\left.(\mathrm{CO})_{3}\left(\mathrm{NH}=\mathrm{C}\left(\mathrm{pz}^{*}\right) \mathrm{NCN}-\kappa^{2} \mathrm{~N}, N\right)\right](\mathrm{pzH}, 2 \mathrm{a} ; \mathrm{dmpzH}, 2 \mathbf{b})$, resulting from the coupling of pyrazol with one of the $\mathrm{CN}$ bonds of dicyanamide. The second $\mathrm{CN}$ bond of dicyanamide in $\mathbf{2 a}$ undergoes a second coupling with pyrazole after addition of 1 equiv of $f a c-\left[\mathrm{MnBr}(\mathrm{CO})_{3}(\mathrm{pzH})_{2}\right]$, yielding the dinuclear doubly coupled complex $\left[\left\{f a c-\mathrm{Mn}(\mathrm{pzH})(\mathrm{CO})_{3}\right\}_{2}(\mu-\mathrm{NH}=\mathrm{C}(\mathrm{pz}) \mathrm{NC}(\mathrm{pz})\right.$

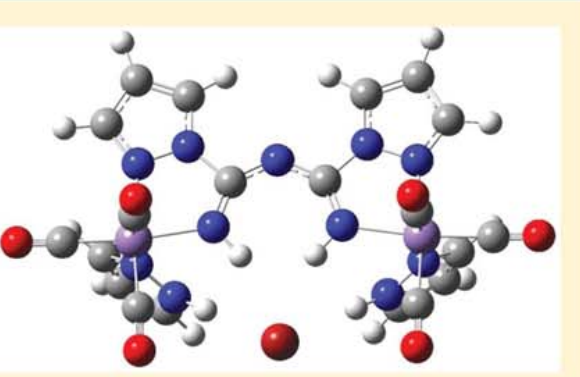

$\left.\left.=N H-\kappa^{4} N, N, N, N\right)\right] \mathrm{Br}(3)$. The crystal structure of 3 reveals the presence of two isomers, cis or trans, depending on whether the terminal pyrazoles are coordinated at the same or at different sides of the approximate plane defined by the bridging bisamidine ligand. Only the cis isomer is detected in the crystal structure of the perchlorate salt of the same bimetallic cation (4), obtained by metathesis with $\mathrm{AgClO}_{4}$. All the $\mathrm{N}$-bound hydrogen atoms of the cations in $\mathbf{3}$ or $\mathbf{4}$ are involved in hydrogen bonds. Some of the $\mathrm{C}-\mathrm{N}$ bonds of the pyrazolylamidino ligand have a character intermediate between single and double, and theoretical studies were carried out on $\mathbf{2} \mathrm{a}$ and $\mathbf{3}$ to confirm its electronic origin and discard packing effects. Calculations also show the essential role of bromide in the planarity of the tetradentate ligand in the bimetallic complex 3.

\section{INTRODUCTION}

We have recently described new pyrazolylamidino complexes obtained from the reactions of pyrazoles and nitriles in the presence of manganese- and rhenium(I) metal centers. ${ }^{1}$ There are not many examples of this reaction, ${ }^{1,2}$ even though pyrazolylamidino ligands present several interesting features: (a) they are synthesized in situ by an addition of the $\mathrm{N}-\mathrm{H}$ bond of the pyrazole across the nitrile $\mathrm{C}-\mathrm{N}$ triple bond (Scheme 1); ${ }^{3}$ thus, using different nitriles and pyrazoles may give rise to new bidentate chelating ligands of distinct electronic and steric properties; (b) the $\mathrm{NH}$ group may give rise to further reactivity, as it may be involved in noncovalent interactions or may be deprotonated; (c) the different properties of the two donor atoms and the electron delocalization within the ligand makes them potentially interesting for electron transfer

Scheme 1. General Method for the Synthesis of Pyrazolylamidino Complexes

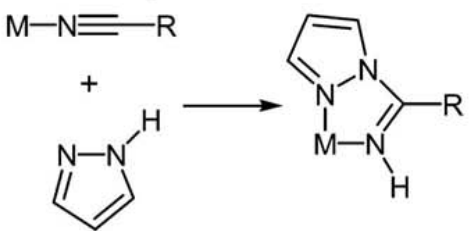

processes and related physical properties. The mechanism of this reaction remains unclear, although it is generally assumed to be a intramolecular nucleophilic attack of the pyrazole to the nitrile, ${ }^{2 f, k}$ intermolecular paths have been also proposed, depending on the electronic configuration of the metal center. $^{2 b}$

Considering the possibility of using different precursors, we decided to extend this study to sodium dicyanamide, which contains two $\mathrm{CN}$ bonds capable of undergoing nucleophilic addition by pyrazoles. In fact, the coupling of pyrazoles and pseudohalides such as dicyanamide, tricyanomethanide, or nitrosodicyanomethanide to form new chelating ligands have already been described for different transition metals. ${ }^{4}$ In our case, the behavior of the dicyanamide/pyrazole system depends on the metallic substrate used.

\section{RESULTS AND DISCUSSION}

Molybdenum Complexes. The reactions of $c i s-\left[\mathrm{MoCl}\left(\eta^{3}\right.\right.$ methallyl $\left.)(\mathrm{CO})_{2}(\mathrm{NCMe})_{2}\right]$ with $\mathrm{Na}(\mathrm{NCNCN})$ and $\mathrm{pzH}$ or $\mathrm{dmpzH}$ in a $1 / 1 / 1$ ratio in tetrahydrofuran (thf) at $60^{\circ} \mathrm{C}$ for 1 $\mathrm{h}$ lead to cis-[Mo $\left(\eta^{3}\right.$-methallyl $)(\mathrm{CO})_{2}(\mathrm{pzH})(\mu-N C N C N-$ $\left.\left.\kappa^{2} N, N\right)\right]_{2}(\mathbf{1 a})$, or cis-[Mo $\left(\eta^{3}\right.$-methallyl $)(\mathrm{CO})_{2}(\mathrm{dmpzH})(\mu$ $\left.\left.\mathrm{NCNCN}-\kappa^{2} \mathrm{~N}, \mathrm{~N}\right)\right]_{2}(\mathbf{l b})$, as yellow solids (Scheme 2). The

Received: December 6, 2011

Published: May 15, 2012 
Scheme 2. Syntheses of Complex 1

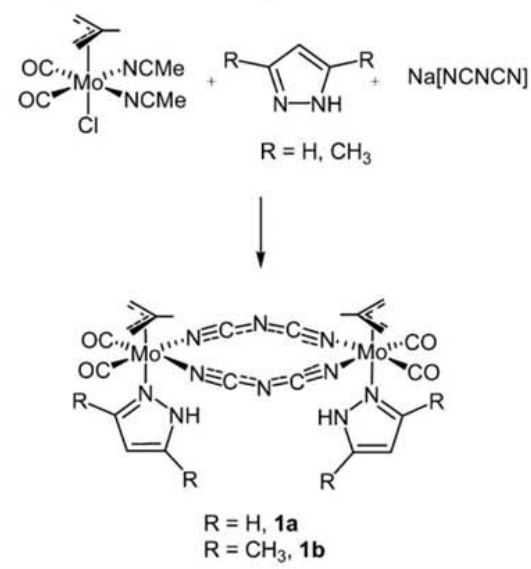

same products are obtained when excess of pyrazole is used. Pyrazolylamidino complexes were never detected even when more drastic reaction conditions were used. This can not be considered surprising, since no pyrazolylamidino products could be isolated when cis-[ $\operatorname{MoCl}\left(\eta^{3}\right.$-methallyl $)$ $\left.(\mathrm{CO})_{2}(\mathrm{NCMe})_{2}\right]$ was treated with pyrazoles in acetonitrile. These results contrast with the report of the only pyrazolylamidino molybdenum complex reported so far, fac-

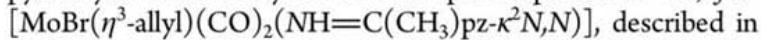
1987 after the reaction of $f a c-\left[\mathrm{Mo}(\mathrm{CO})_{3}(\mathrm{NCMe})_{3}\right]$ with $\mathrm{Na}\left[\mathrm{Me}_{2} \mathrm{Ga}(\mathrm{pz})\left(\mathrm{OC}_{6} \mathrm{H}_{4} \mathrm{NH}_{2}\right)\right]$ and allylbromide. ${ }^{2 \mathrm{j}}$

Compound $\mathbf{1 b}$ could be crystallografically characterized (Figure 1 and Table 1$){ }^{5}$ The resulting determination is poor

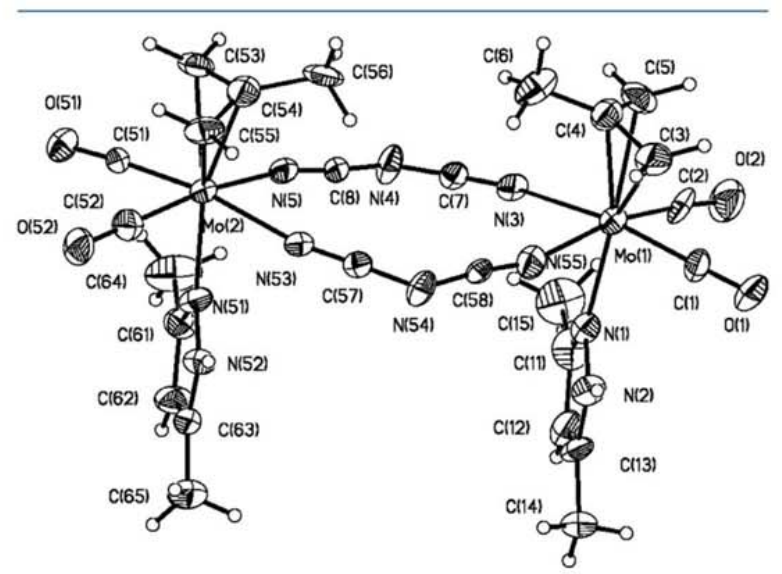

Figure 1. Perspective view of cis-[Mo $\left(\eta^{3}\right.$-methallyl $)(\mathrm{CO})_{2}(\mathrm{dmpzH})$ $\left(\mu\right.$-NCNCN-$\left.\left.\kappa^{2} N, N\right)\right]_{2}(\mathbf{l b})$, showing the atom numbering. Ellipsoids are drawn at $30 \%$ probability.

(high residuals) because of the low quality of the crystal, but the structure is included here since it confirms unambiguously the connectivity of the molecule. Both molybdenum atoms are pseudo-octahedrally coordinated, assuming that the methallyl group occupies one site. The terminal carbon atoms of the methallyl group are oriented over the carbonyl groups, as has been demonstrated to be the most energetically favorable arrangement. ${ }^{6}$ The complex is a quasi-symmetric dimer where two dicyanamides bridge two "cis- $\mathrm{Mo}\left(\eta^{3}\right.$-methallyl $)$ $(\mathrm{CO})_{2}(\mathrm{dmpzH})$ " fragments, with the methallyl and dimethyl-
Table 1. Selected Distances $(\AA)$ and Angles (deg.) for cis$\left[\mathrm{Mo}\left(\eta^{3} \text {-methallyl }\right)(\mathrm{CO})_{2}(\mathrm{dmpzH})\left(\boldsymbol{\mu}-\mathrm{NCNCN}-\kappa^{2} N, N\right)\right]_{2}$ $(\mathbf{l b})^{5}$

$\begin{array}{ll}\mathrm{Mo}(1)-\mathrm{C}(1) & 2.03(3) \\ \mathrm{Mo}(1)-\mathrm{C}(2) & 1.99(3) \\ \mathrm{Mo}(1)-\mathrm{N}(1) & 2.29(2) \\ \mathrm{Mo}(1)-\mathrm{N}(3) & 2.19(2) \\ \mathrm{Mo}(1)-\mathrm{N}(55) & 2.34(2) \\ \mathrm{C}(1)-\mathrm{Mo}(1)-\mathrm{C}(2) & 79.7(11) \\ \mathrm{C}(1)-\mathrm{Mo}(1)-\mathrm{N}(3) & 169.6(9) \\ \mathrm{C}(2)-\mathrm{Mo}(1)-\mathrm{N}(3) & 99.3(9) \\ \mathrm{C}(1)-\mathrm{Mo}(1)-\mathrm{N}(1) & 86.1(9) \\ \mathrm{C}(2)-\mathrm{Mo}(1)-\mathrm{N}(1) & 86.8(10) \\ \mathrm{N}(3)-\mathrm{Mo}(1)-\mathrm{N}(1) & 83.5(8) \\ \mathrm{C}(1)-\mathrm{Mo}(1)-\mathrm{N}(55) & 98.1(10) \\ \mathrm{C}(2)-\mathrm{Mo}(1)-\mathrm{N}(55) & 166.3(10) \\ \mathrm{N}(1)-\mathrm{Mo}(1)-\mathrm{N}(55) & 79.6(7) \\ \mathrm{N}(3)-\mathrm{Mo}(1)-\mathrm{N}(55) & 80.3(7)\end{array}$

pyrazole coordinated respectively trans. Only one of the two possible diastereomers is detected in the structure: that with both methallyl (or both pyrazoles) at the same side of the approximate plane formed by the bridging dicyanamides and the metal centers. A wide range of bimetallic complexes with bridging dicyanamide are known, ${ }^{7}$ although we have not been able to find any precedent containing molybdenum.

The NMR spectra of $\mathbf{1 a}$ and $\mathbf{1 b}$ are not informative (see Experimental Section). Both are very scarcely soluble, and their spectra in $\mathrm{Me}_{2} \mathrm{CO}-d^{6}$ or thf- $d^{8}$ display mixtures which can not be identified. In an attempt to brake these processes in solution, the NMR spectra were recorded immediately after dissolving the solids at low temperature, but mixtures of the complexes were also obtained. There are several reasons to explain the origin of the species detected in the NMR spectra. The isomer found in the solid structure may be described as cis, but the presence of a trans isomer in solution can not be discarded. On the other hand, allyldicarbonylmolybdenum(II) complexes usually display a nondissociative trigonal twist process in which there is an intramolecular rotation of the $\mathrm{XL}_{2}$ triangular face, ${ }^{8}$ which would afford new sets of signals if it were slow enough. Finally, the well-known lability of the metal-nitrile bonds (Mo-NCNCN bonds in $\mathbf{1 a}$ and $\mathbf{1 b}$ ), would lead to decoordination of dicyanamide and eventually to the decomposition of the complex, and in fact the solutions became brown in a few minutes.

The IR spectra of $\mathbf{1 a}$ and $\mathbf{1 b}$ show two bands in the $\mathrm{C}-\mathrm{O}$ stretching region in solution, as expected for their cis-dicarbonyl geometry. The frequencies are slightly higher for the complex with $\mathrm{pzH}$ than those with $\mathrm{dmpzH}$, as could be predicted considering the better donor properties of $\mathrm{dmpzH}$ compared to pzH.

Manganese Mononuclear Complexes. The reactions of fac- $\left[\mathrm{MnBr}(\mathrm{CO})_{3}(\mathrm{NCMe})_{2}\right]$ with $\mathrm{Na}(\mathrm{NCNCN})$ and $\mathrm{pzH}$ or $\mathrm{dmpzH}$ in a $1 / 1 / 2$ ratio in thf at $60^{\circ} \mathrm{C}$ for $6 \mathrm{~h}$ lead to fac$\left[\mathrm{Mn}(\mathrm{pzH})(\mathrm{CO})_{3}\left(\mathrm{NH}=\mathrm{C}(\mathrm{pz}) \mathrm{NCN}-\kappa^{2} N, N\right)\right](2 \mathrm{a})$, or fac$\left[\mathrm{Mn}(\mathrm{dmpzH})(\mathrm{CO})_{3}\left(\mathrm{NH}=\mathrm{C}(\mathrm{dmpz}) \mathrm{NCN}-\kappa^{2} N, N\right)\right](2 \mathbf{b})$, as yellow solids (Scheme 3, path "a"). The same products, although in lower yields, are obtained when 1 equiv of the pyrazole is used.

The IR spectra of $\mathbf{2} \mathbf{a}$ and $\mathbf{2} \mathbf{b}$ show three bands in the $\mathrm{C}-\mathrm{O}$ stretching region in solution, as expected for their factricarbonyl geometry. As described above for the molybdenum 
Scheme 3. Syntheses of Complexes 2 and 3<smiles>[R]c1cc([R])[nH]n1</smiles>

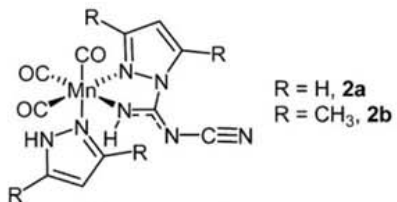
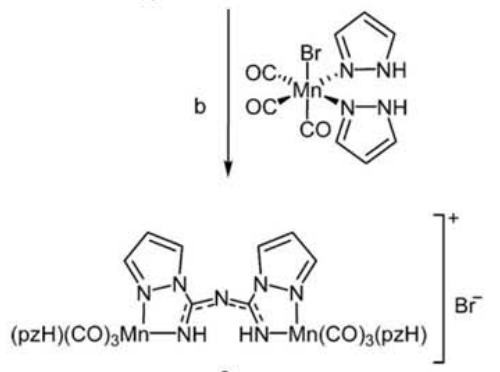

3

complexes, the frequencies are slightly higher for the complex with $\mathrm{pzH}$ than those with $\mathrm{dmpzH}$, as could be predicted considering the better donor properties of $\mathrm{dmpzH}$ compared to $\mathrm{pzH}$.

The NMR data (see Experimental Section) of the new complexes do not provide important structural information, except for a previously observed feature in complexes containing both pyrazole and pirazolylamidino ligands, which is the higher chemical shifts of the latter compared to coordinated pyrazoles, ${ }^{1 \mathrm{c}}$ or to the values previously reported for coordinated nitrile. ${ }^{9}$ The characterization in solution of $\mathbf{2 b}$ was difficult because of its low stability and low solubility in solution. The low stability generated ${ }^{1} \mathrm{H}$ NMR spectra always containing more signals than those expected, because of the formation of different byproducts which could not be identified (vide infra). Both complexes, $\mathbf{2} \mathbf{a}$ and $\mathbf{2} \mathbf{b}$, could be crystallographically characterized (Figure 2 and Table 2).

Both structures confirm the coordination of a pyrazolylamidino ligand resulting from the addition of the $\mathrm{N}-\mathrm{H}$ bond of the pyrazole across one of the $\mathrm{CN}$ triple bonds in dicyanamide. As far as we know, these are the first pyrazolylamidino complexes crystallographically characterized that are derived from the coupling of dicyanamide.

The structural data are essentially the same in both complexes, and very similar to those found in previously reported structures of halotricarbonylmanganese(I) complexes containing a bidentate $\mathrm{N}$-donor ligand. ${ }^{10}$ The distances and angles found in the pyrazolylamidino ligands are also similar to those found in pyrazolylamidino complexes obtained from monodentate nitriles. ${ }^{1,2}$

The N-bound hydrogens are involved in intramolecular hydrogen bonds with the free nitrogen atom in the dicyanamide of an adjacent molecule $[\mathrm{H}(3) \cdots \mathrm{N}(7) 2.75 \AA$ and $\mathrm{H}(5) \cdots \mathrm{N}(7)$ $1.99 \AA$ for $2 \mathrm{a} ; \mathrm{H}(3) \cdots \mathrm{N}(7) 2.46 \AA$ and $\mathrm{H}(5) \cdots \mathrm{N}(7) 2.08 \AA$ for 2b]. These and the corresponding $\mathrm{N} \cdots \mathrm{N}$ distances (3.313 and $2.845 \AA$ for $2 \mathrm{a}$, and 3.146 and $2.936 \AA$ for $\mathbf{2 b}$, respectively) and
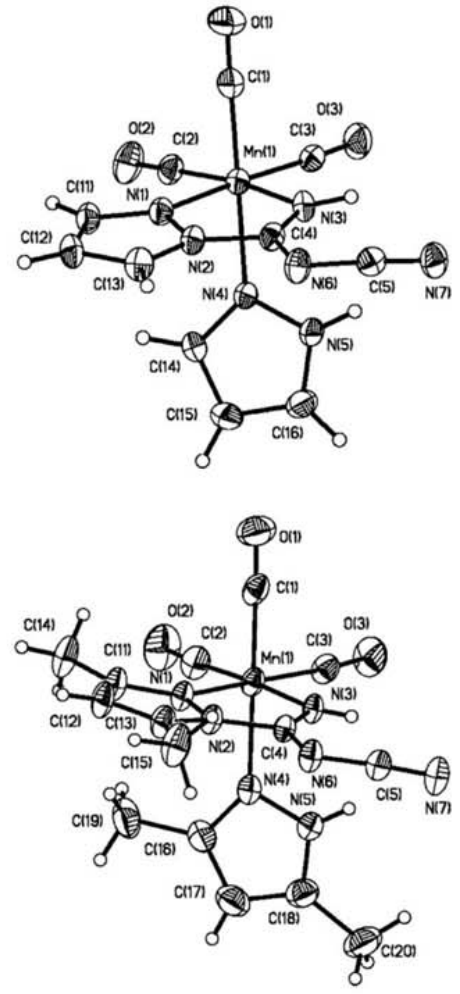

Figure 2. Perspective view of $f a c-\left[\mathrm{Mn}(\mathrm{pzH})(\mathrm{CO})_{3}(\mathrm{NH}=\mathrm{C}(\mathrm{pz})\right.$ $\left.\left.\mathrm{NCN}-\kappa^{2} N, N\right)\right]$ (2a) (above), and fac-[Mn $(\mathrm{dmpzH})(\mathrm{CO})_{3}(\mathrm{NH}=$ $\left.\left.\mathrm{C}(\mathrm{dmpz}) \mathrm{NCN}-\kappa^{2} \mathrm{~N}, N\right)\right](\mathbf{2 b})$ (below), showing the atom numbering. Ellipsoids are drawn at $30 \%$ probability.

$\mathrm{N}-\mathrm{H} \cdots \mathrm{N}$ angles $\left(125\right.$ and $178^{\circ}$ for $2 \mathrm{a}$, and 137 and $174^{\circ}$ for $\mathbf{2 b}$, respectively) confirm the presence of a hydrogen bond which may be considered between "weak" and "moderate". ${ }^{11}$

Two resonance forms may be drawn for the new pyrazolylamidino ligand derived from dicyanamide, depending on which nitrogen atom is bearing the negative charge (Scheme 4). In resonance form $A$, the negative charge is located on the nitrogen donor atom; therefore, it is the expected for a traditional anionic ligand. In form $\mathrm{B}$, the negative charge is placed on the central nitrogen atom of dicyanamide, thus giving rise to a zwitterionic complex. The $\mathrm{N}(3)-\mathrm{C}(4)$ and $\mathrm{C}(4)-$ $\mathrm{N}(6)$ distances in the crystal structures (Table 2) are very similar [1.286(4) vs $1.332(4)$ for $2 a$, and $1.296(4)$ vs $1.342(4)$ for $\mathbf{2 b}$ ] and seem to point to a resonance hybrid where both resonance forms contribute similarly. However, the similarity of that bond distances may have been caused either by electronic or by packing effects, and therefore a theoretical study was carried out on $\mathbf{2 a}$ to determine the origin of that feature. Starting from the crystallographic coordinates, the geometry was optimized using density functional theory (DFT) methods (see Experimental Section) reaching a minimum with bond distances and angles that compare well with the experimental ones (Figure 3 and Table 2). A NBO study was then performed on the minimum geometry to calculate the Wiberg indexes of the two $\mathrm{N}-\mathrm{C}$ bonds, and the results are collected in Table 2 . The Wiberg indexes of the $\mathrm{N}(3)-\mathrm{C}(4)$ and $\mathrm{C}(4)-\mathrm{N}(6)$ bonds are 1.40 and 1.42 , respectively, indicating that both bonds have a bond order intermediate between single and double. Therefore, the similarity in the values of those bond distances 
Table 2. Selected Distances $(\AA)$ and Angles (deg.) for fac$\left[\mathrm{Mn}(\mathrm{pzH})(\mathrm{CO})_{3}\left(\mathrm{NH}=\mathrm{C}(\mathrm{pz}) \mathrm{NCN}-\kappa^{2} N, N\right)\right](2 \mathrm{a})$, and $f a c-$ $\left[\mathrm{Mn}(\mathrm{dmpzH})(\mathrm{CO})_{3}\left(\mathrm{NH}=\mathrm{C}(\mathrm{dmpz}) \mathrm{NCN}-\kappa^{2} \mathrm{~N}, \mathrm{~N}\right)\right](2 \mathrm{~b})$, DFT-Optimized Distances $(\AA)$ and Angles (deg.) for 2a and Wiberg Bond Indexes for Selected Distances

\begin{tabular}{|c|c|c|c|c|}
\hline & $2 a$ & $2 b$ & $\begin{array}{c}2 \mathrm{a} \\
\text { (calcd) }\end{array}$ & $\begin{array}{c}\text { Wiberg } \\
\text { index }\end{array}$ \\
\hline $\mathrm{Mn}(1)-\mathrm{C}(1)$ & $1.795(4)$ & $1.815(5)$ & 1.817 & 0.91 \\
\hline $\operatorname{Mn}(1)-C(2)$ & $1.803(4)$ & $1.816(4)$ & 1.811 & 0.93 \\
\hline $\operatorname{Mn}(1)-C(3)$ & $1.798(4)$ & $1.822(4)$ & 1.819 & 0.90 \\
\hline $\operatorname{Mn}(1)-N(1)$ & $2.026(2)$ & $2.063(3)$ & 2.066 & \\
\hline $\operatorname{Mn}(1)-N(3)$ & $2.041(2)$ & $2.028(3)$ & 2.069 & \\
\hline $\mathrm{Mn}(1)-\mathrm{N}(4)$ & $2.070(2)$ & $2.115(3)$ & 2.124 & \\
\hline $\mathrm{C}(4)-\mathrm{N}(3)$ & $1.286(4)$ & $1.296(4)$ & 1.328 & 1.40 \\
\hline$C(4)-N(6)$ & $1.332(4)$ & $1.342(4)$ & 1.316 & 1.42 \\
\hline $\mathrm{N}(2)-\mathrm{C}(4)$ & $1.419(4)$ & $1.426(4)$ & 1.422 & 0.95 \\
\hline$C(1)-M n(1)-C(3)$ & $88.41(14)$ & $88.50(17)$ & 92.04 & \\
\hline$C(1)-M n(1)-C(2)$ & $90.06(15)$ & $88.8(2)$ & 92.34 & \\
\hline$C(3)-M n(1)-C(2)$ & $89.61(13)$ & $87.77(17)$ & 93.28 & \\
\hline$C(1)-M n(1)-N(3)$ & $94.24(13)$ & $94.04(16)$ & 90.19 & \\
\hline$C(3)-M n(1)-N(3)$ & $97.50(12)$ & $94.92(14)$ & 94.77 & \\
\hline$C(2)-M n(1)-N(3)$ & $171.78(12)$ & $176.12(16)$ & 171.47 & \\
\hline $\mathrm{C}(1)-\mathrm{Mn}(1)-\mathrm{N}(1)$ & $92.89(13)$ & $89.88(15)$ & 91.40 & \\
\hline$C(3)-M n(1)-N(1)$ & $175.00(11)$ & $171.38(14)$ & 171.15 & \\
\hline$C(2)-M n(1)-N(1)$ & $95.21(11)$ & $100.67(14)$ & 94.72 & \\
\hline$N(3)-M n(1)-N(1)$ & $77.60(9)$ & $76.75(11)$ & 77.07 & \\
\hline$C(1)-M n(1)-N(4)$ & $178.76(13)$ & $179.06(15)$ & 176.66 & \\
\hline$C(3)-M n(1)-N(4)$ & $92.63(12)$ & $92.16(15)$ & 89.28 & \\
\hline$C(2)-M n(1)-N(4)$ & $90.62(11)$ & $91.87(17)$ & 90.65 & \\
\hline $\mathrm{N}(3)-\mathrm{Mn}(1)-\mathrm{N}(4)$ & $84.96(9)$ & $85.24(13)$ & 86.64 & \\
\hline$N(1)-M n(1)-N(4)$ & $86.01(9)$ & $89.37(12)$ & 86.86 & \\
\hline
\end{tabular}

Scheme 4. Resonance Forms Proposed for the New Pyrazolylamidino Ligand Derived from Dicyanamide

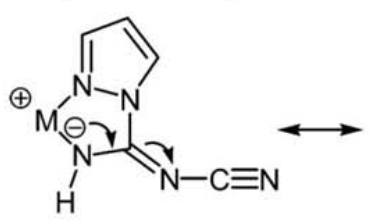

A

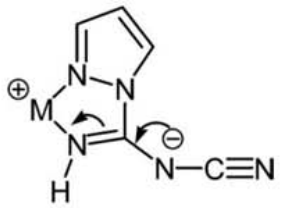

B

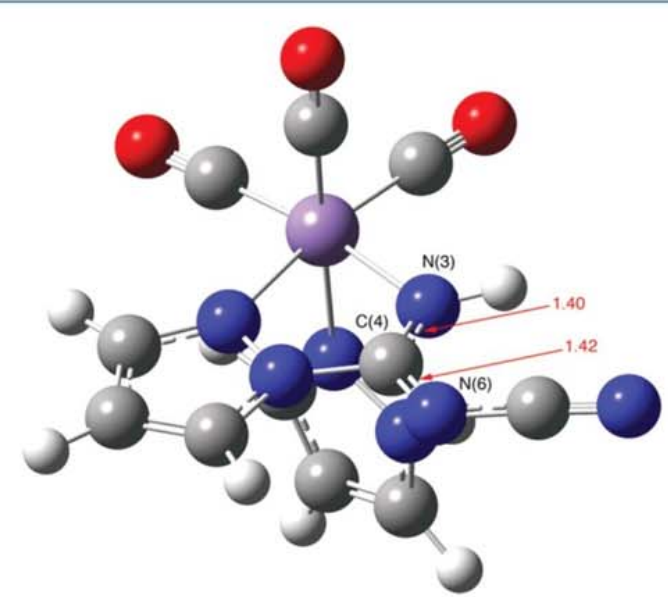

Figure 3. Wiberg indexes of the relevant $\mathrm{C}-\mathrm{N}$ bonds obtained from the theoretical study on 2 a. has an electronic origin and is not due to packing effects. It may be concluded, then, that the best description for this ligand is that depicted in Scheme 3 where the bond order from both $\mathrm{N}-$ $\mathrm{C}$ bonds derived from dicyanamide is 1.5 .

Manganese Binuclear Complexes. When 2a is maintained in solution in the reaction mixture, a new bimetallic complex $\left[\left\{f a c-\mathrm{Mn}(\mathrm{pzH})(\mathrm{CO})_{3}\right\}_{2}(\mu-\mathrm{NH}=\mathrm{C}(\mathrm{pz}) \mathrm{NC}(\mathrm{pz})=\mathrm{NH}-\right.$ $\left.\left.\kappa^{4} N, N, N, N\right)\right] \mathrm{Br}, 3$, is obtained as a mixture of isomers. The formation of this complex may be interpreted considering the process depicted in Scheme 3 (path "b"). The uncoordinated $\mathrm{C} \equiv \mathrm{N}$ present in $2 \mathrm{a}$ may undergo a coupling process with a second pyrazol. This second pyrazol should come from the bis(pyrazol) complex, fac- $\left[\mathrm{MnBr}(\mathrm{CO})_{3}(\mathrm{pzH})_{2}\right]$, which occurs as sideproduct in the coupling reactions to obtain pyrazolylamidino complexes. ${ }^{1}$ Therefore, the presence in solution of both $2 \mathbf{a}$ and $f a c-\left[\mathrm{MnBr}(\mathrm{CO})_{3}(\mathrm{pzH})_{2}\right]$ should give rise to a second coupling process, affording 3 . As indicated above, the mechanism of the coupling reaction is not straighforward, but it is evident that both pyrazole and coordinated nitrile must be in solution to obtain a pyrazolylamidino ligand.

The selective synthesis of $\mathbf{3}$ as a yellow solid was achieved from the reaction of $2 \mathrm{a}$ with the stoichiometric amount of fac$\left[\mathrm{MnBr}(\mathrm{CO})_{3}(\mathrm{pzH})_{2}\right]$ in thf at room temperature for $4 \mathrm{~h}$. The attempts to isolate a similar complex to 3 with dmpzH, starting from $\mathbf{2 b}$, failed. As indicated before, $\mathbf{2} \mathbf{b}$ is unstable in solution, and its ${ }^{1} \mathrm{H}$ NMR spectra show always minor unidentified signals, which could be due to a complex similar to 3 , but containing $\mathrm{dmzH}$ instead of $\mathrm{pzH}$. However, all the attempts to isolate or to synthesize this compound selectively failed.

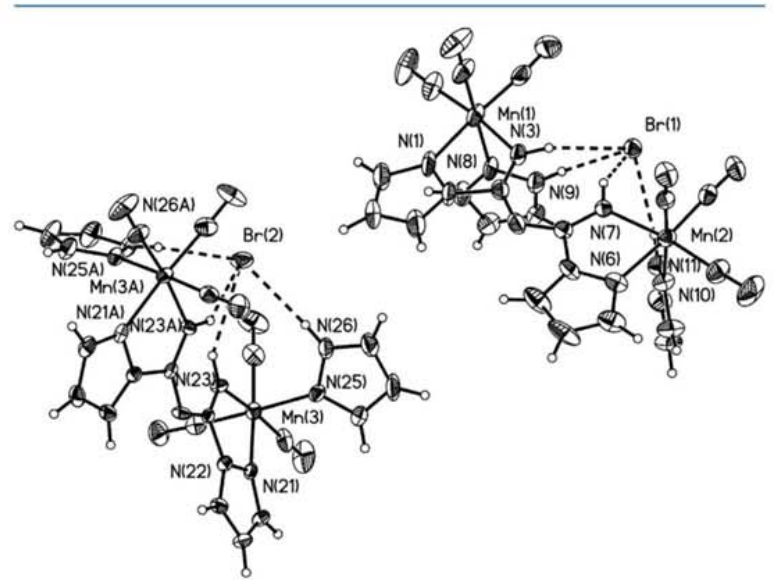

Figure 4. Perspective view of $\left[\left\{f a c-\mathrm{Mn}(\mathrm{pzH})(\mathrm{CO})_{3}\right\}_{2}(\mu-\mathrm{NH}=\right.$ $\left.\left.\mathrm{C}(\mathrm{pz}) \mathrm{NC}(\mathrm{pz})=\mathrm{NH}-\kappa^{4} \mathrm{~N}, N, N, N\right)\right] \mathrm{Br}(3)$ showing the atom numbering. Ellipsoids are drawn at $30 \%$ probability.

The crystal structure of 3 (Figure 4 and Table 3 ) reveals the presence of two isomers, depending on whether both coordinated pyrazols are situated at the same side (cis, right in Figure 4) or at opposite sides (trans, left in Figure 4) of the approximate plane defined by the bridging ligand and the metals. The complex is a dimer constituted by two "fac$\mathrm{Mn}(\mathrm{CO})_{3}(\mathrm{pzH})$ " fragments linked by the new bis(pirazolylamidino) ligand " $\mathrm{NH}=\mathrm{C}(\mathrm{pz}) \mathrm{NC}(\mathrm{pz})=\mathrm{NH}$ $\kappa^{4} N, N, N, N "$, which bridges both metallic fragments. The new pyrazolylamidino ligand comes from the nucleophilic addition of one pyrazole to each $\mathrm{C} \equiv \mathrm{N}$ group of dicyanamide, giving rise 
Table 3. Selected Distances $(\AA)$ and Angles $(\mathrm{deg})$ for $\left[\left\{f a c-\mathrm{Mn}(\mathrm{pzH})(\mathrm{CO})_{3}\right\}_{2}\left(\mu-\mathrm{NH}=\mathrm{C}(\mathrm{pz}) \mathrm{NC}(\mathrm{pz})=\mathrm{NH}-\kappa^{4} N, N, N, N\right)\right] \mathrm{A}(\mathrm{A}=$ $\left.\mathrm{Br}, 3 ; \mathrm{ClO}_{4}, 4\right)^{a}$

\begin{tabular}{|c|c|c|c|c|c|c|c|}
\hline & 3 cis a & 3 cis b & 3 trans & 4 cis a & 4 cis b & cis calcd & trans calcd \\
\hline $\operatorname{Mn}(1)-C(1)$ & $1.791(13)$ & $1.780(12)$ & $1.786(11)$ & $1.77(2)$ & $1.85(2)$ & 1.816 & 1.815 \\
\hline $\mathrm{Mn}(1)-\mathrm{C}(2)$ & $1.779(14)$ & $1.811(12)$ & $1.820(12)$ & $1.73(2)$ & $1.86(2)$ & 1.831 & 1.833 \\
\hline $\mathrm{Mn}(1)-\mathrm{C}(3)$ & $1.814(12)$ & $1.817(12)$ & $1.800(11)$ & $1.70(2)$ & $1.88(3)$ & 1.812 & 1.812 \\
\hline $\operatorname{Mn}(1)-N(1)$ & $2.022(10)$ & $2.015(8)$ & $2.048(7)$ & $2.005(18)$ & $2.022(16)$ & 2.054 & 2.057 \\
\hline $\mathrm{Mn}(1)-\mathrm{N}(3)$ & $2.021(7)$ & $2.042(7)$ & $2.029(6)$ & $2.017(18)$ & $2.054(17)$ & 2.053 & 2.061 \\
\hline $\mathrm{Mn}(1)-\mathrm{N}(8)$ & $2.077(8)$ & $2.091(8)$ & $2.041(7)$ & $2.068(19)$ & $2.062(16)$ & 2.121 & 2.115 \\
\hline $\mathrm{N}(1)-\mathrm{N}(2)$ & $1.344(12)$ & $1.360(11)$ & $1.357(9)$ & $1.42(2)$ & $1.31(2)$ & 1.356 & 1.355 \\
\hline$N(2)-C(14)$ & $1.438(12)$ & $1.406(11)$ & $1.412(10)$ & $1.37(2)$ & $1.49(3)$ & 1.436 & 1.432 \\
\hline$N(3)-C(14)$ & $1.291(12)$ & $1.288(11)$ & $1.283(10)$ & $1.28(2)$ & $1.33(2)$ & 1.300 & 1.301 \\
\hline$N(4)-C(14)$ & $1.336(13)$ & $1.327(11)$ & $1.328(9)$ & $1.30(2)$ & $1.33(2)$ & 1.337 & 1.335 \\
\hline $\mathrm{C}(1)-\mathrm{O}(1)$ & $1.151(13)$ & $1.153(11)$ & $1.141(11)$ & $1.17(3)$ & $1.12(3)$ & 1.153 & 1.153 \\
\hline $\mathrm{C}(2)-\mathrm{O}(2)$ & $1.157(13)$ & $1.132(12)$ & $1.141(12)$ & $1.20(3)$ & $1.09(2)$ & 1.150 & 1.150 \\
\hline $\mathrm{C}(3)-\mathrm{O}(3)$ & $1.136(13)$ & $1.131(12)$ & $1.124(11)$ & $1.19(3)$ & $1.11(3)$ & 1.156 & 1.156 \\
\hline$C(1)-M n(1)-N(8)$ & $177.5(4)$ & $176.4(4)$ & $176.6(3)$ & $176.7(9)$ & $177.4(9)$ & 176.7 & 176.4 \\
\hline$C(2)-M n(1)-N(1)$ & $174.8(4)$ & $174.9(4)$ & $175.0(3)$ & $176.6(9)$ & $173.3(9)$ & 172.9 & 173.9 \\
\hline $\mathrm{C}(3)-\mathrm{Mn}(1)-\mathrm{N}(3)$ & $173.4(5)$ & $172.0(5)$ & $173.1(4)$ & $169.9(8)$ & $173.9(9)$ & 171.1 & 170.9 \\
\hline$C(15)-N(4)-C(14)$ & $123.7(8)$ & & $120.6(9)$ & $123.3(9)$ & & 125.7 & 125.4 \\
\hline
\end{tabular}

${ }^{a}$ The cis isomer does not have a crystallographic symmetry plane and, therefore, the two moieties of the molecule are not equivalent. Here we refer to one of the moieties as "cis a" and to the other moiety as "cis b".

a new tetradentate ligand. It is almost planar, as the dihedral angle formed by its two pirazolylamidino moieties differs $4^{\circ}$ from planarity in the cis diastereomer and $-16^{\circ}$ in the trans diastereomer. As indicated by the different signs, the pirazolylamidino fragments are bent toward the same side in the cis isomer, but to opposite sides in the trans isomer.

A very interesting feature in the structure is the involvement of all the hydrogens bonded to nitrogen atoms in hydrogen bonds with the bromide. The $\mathrm{N} \cdots \mathrm{H}$ and $\mathrm{N} \cdots \mathrm{Br}$ distances are collected in Table 4, and confirm the presence of hydrogen

Table 4. Distances ( $\AA$ ) and Angles (deg.) for the Hydrogen Bonds with Bromide Ion Detected in the Crystal Structure of $\left[\left\{f a c-\mathrm{Mn}(\mathrm{pzH})(\mathrm{CO})_{3}\right\}_{2}(\mu-\mathrm{NH}=\mathrm{C}(\mathrm{pz}) \mathrm{NC}(\mathrm{pz})=\mathrm{NH}-\right.$ $\left.\left.\kappa^{4} N, N, N, N\right)\right] \mathrm{Br}(3)$

\begin{tabular}{|lccc}
\hline \multicolumn{1}{|c}{$\mathrm{N}-\mathrm{H} \cdots \mathrm{Br}$} & $\mathrm{H} \cdots \mathrm{Br}(\AA)$ & $\mathrm{N} \cdots \mathrm{Br}(\AA)$ & $\mathrm{N}-\mathrm{H} \cdots \mathrm{Br}$ (deg.) \\
\hline $\mathrm{N}(3)-\mathrm{H}(3) \cdots \mathrm{Br}(1)$ & 2.606 & 3.513 & 147 \\
$\mathrm{~N}(7)-\mathrm{H}(7) \cdots \mathrm{Br}(1)$ & 2.329 & 3.353 & 173 \\
$\mathrm{~N}(9)-\mathrm{H}(9) \cdots \mathrm{Br}(2)$ & 2.513 & 3.373 & 141 \\
$\mathrm{~N}(12)-\mathrm{H}(12) \cdots \mathrm{Br}(2)$ & 2.311 & 3.334 & 172 \\
$\mathrm{~N}(15)-\mathrm{H}(15) \cdots \mathrm{Br}(2)$ & 2.558 & 3.417 & 141 \\
$\mathrm{~N}(17)-\mathrm{H}(17) \cdots \mathrm{Br}(2)$ & 2.265 & 3.286 & 171 \\
\hline
\end{tabular}

bonds which may be considered as "weak". "To know the role of the anion in the structure, we decided to substitute the bromide by another anion able to form hydrogen bonds, such as perchlorate. Thus, the reaction of 3 with a stoichiometric amount of $\mathrm{AgClO}_{4}$ in thf at room temperature, leads to [ $\{\mathrm{fac}$ $\left.\left.\mathrm{Mn}(\mathrm{pzH})(\mathrm{CO})_{3}\right\}_{2}\left(\mu-N \mathrm{H}=\mathrm{C}(\mathrm{pz}) \mathrm{NC}(\mathrm{pz})=N \mathrm{H}-\kappa^{4} N, N, N, N\right)\right]-$ $\mathrm{ClO}_{4}, 4$.

The crystal structure of 4 is shown in Figure 5, and selected distances and angles are collected in Table $3 .^{12}$ Only the cis diastereomer is detected in the crystal, since the pyrazoles are coordinated at the same side of the approximate plane defined by the bridging ligand and the metals. In this case, the tetradentate ligand is almost planar, since the dihedral angle defined by both pirazolylamidino moieties differs $2^{\circ}$ from

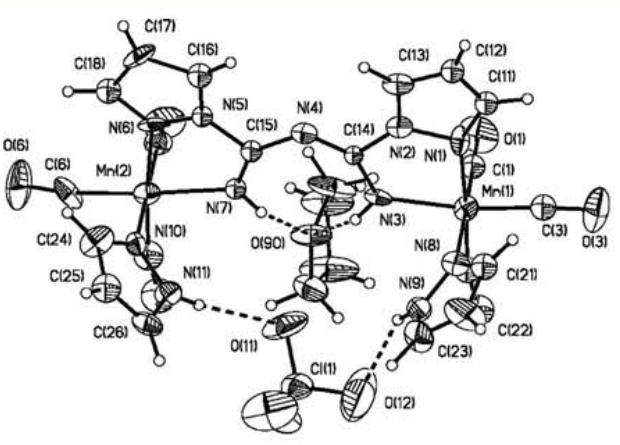

Figure 5. Perspective view of $\left[\left\{\text { fac- } \mathrm{Mn}(\mathrm{pzH})(\mathrm{CO})_{3}\right\}_{2}(\mu-\mathrm{NH}=\right.$ $\left.\left.\mathrm{C}(\mathrm{pz}) \mathrm{NC}(\mathrm{pz})=\mathrm{NH}-\kappa^{4} N, N, N, N\right)\right] \mathrm{ClO}_{4}$ (4) showing the atom numbering. Ellipsoids are drawn at $30 \%$ probability.

planarity, being bent toward the same side, as occurred for the cis isomer in 3 .

As expected, the perchlorate is involved in hydrogen bonds, but only with the hydrogens of the coordinated pyrazols $[\mathrm{H}(11) \cdots \mathrm{O}(11) 1.930 \AA$; and $\mathrm{H}(9) \cdots \mathrm{O}(12) 1.970 \AA$, with $2.930 \AA$ for $\mathrm{N}(11) \cdots \mathrm{O}(11)$, and $2.831 \AA$ for $\mathrm{N}(9) \cdots \mathrm{O}(12)$, being 163 and $139^{\circ}$ the $\mathrm{N}-\mathrm{H} \cdots \mathrm{O}$ angles]. These distances corrrespond to "moderate" hydrogen bonds, ${ }^{11}$ as well as those where the hydrogen atoms of the bis(pyrazolylamidino) ligand derived from dicyanamide are involved, in this case with the oxygen atom of a thf molecule: $\mathrm{H}(3) \cdots \mathrm{O}(90) 2.159$ and $\mathrm{H}(7) \cdots \mathrm{O}(90) 2.025 \AA$; with 3.060 for $\mathrm{N}(3) \cdots \mathrm{O}(90)$, and 2.928 $\AA$ for $\mathrm{N}(7) \cdots \mathrm{O}(90)$, with a value of $145^{\circ}$ for both $\mathrm{N}-\mathrm{H} \cdots \mathrm{O}$ angles.

As for the bidentate ligand derived from the coupling of pyrazole and one $\mathrm{C} \equiv \mathrm{N}$ bond in dicyanamide present in complexes 2, several resonance forms may be drawn for the new bis(pyrazolylamidino) tetradentate ligand present in complexes 3 and 4, depending on which nitrogen atom is bearing the negative charge (Scheme 5). As before, the N(3)$\mathrm{C}(14)$ and $\mathrm{C}(14)-\mathrm{N}(4)$ distances in the crystal structures (Table 3) are very similar but, in this case, the structure 
Scheme 5. Resonance Forms Proposed for the New Tetradentate Bis(pyrazolylamidino) Ligand Derived from Dicyanamide
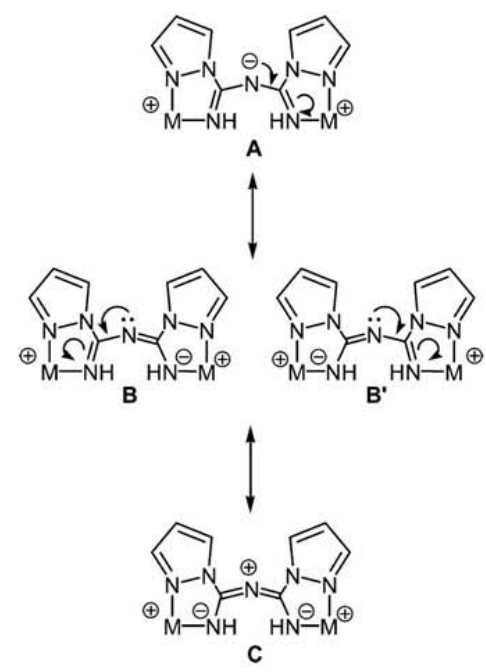

determination of $\mathbf{4}$ is not accurate enough to deduce the predominant resonance form. Thus, a new calculation was set and the same procedure followed for the study of 2a was used to get the Wiberg indexes on the dinuclear complex 3 (for both trans and cis isomers). The results of this study are summarized in Table 5 and Figure 6, which displays the minimized structure

Table 5. Wiberg Bond Indexes of Selected Bonds of cis and trans Isomers of $\left[\left\{f a c-\mathrm{Mn}(\mathrm{pzH})(\mathrm{CO})_{3}\right\}_{2}(\boldsymbol{\mu}-\mathrm{NH}=\right.$ $\left.\left.\mathrm{C}(\mathrm{pz}) \mathrm{NC}(\mathrm{pz})=\mathrm{NH}-\kappa^{4} \mathrm{~N}, \mathrm{~N}, \mathrm{~N}, \mathrm{~N}\right)\right] \mathrm{Br}(3)$

\begin{tabular}{lccccc} 
& \multicolumn{2}{c}{3 cis } & & \multicolumn{2}{c}{3 trans } \\
\cline { 2 - 3 } \cline { 5 - 6 } & $\begin{array}{c}\text { calcd bond } \\
\text { dist. }\end{array}$ & $\begin{array}{c}\text { Wiberg } \\
\text { index }\end{array}$ & & $\begin{array}{c}\text { calcd bond } \\
\text { dist. }\end{array}$ & $\begin{array}{c}\text { Wiberg } \\
\text { index }\end{array}$ \\
$\mathrm{N}(1)-\mathrm{N}(2)$ & 1.356 & 1.16 & & 1.355 & 1.15 \\
$\mathrm{~N}(2)-\mathrm{C}(14)$ & 1.436 & 0.94 & & 1.432 & 0.94 \\
$\mathrm{~N}(3)-\mathrm{C}(14)$ & 1.300 & 1.56 & & 1.301 & 1.56 \\
$\mathrm{~N}(4)-\mathrm{C}(14)$ & 1.337 & 1.28 & & 1.335 & 1.28 \\
\hline
\end{tabular}

and the representative Wiberg indexes. The calculated bond distances compare well with the experimental ones and, as with the study carried out on $2 \mathrm{a}$, the packing effects can be ruled out as the cause of the $\mathrm{C}-\mathrm{N}$ bond distances being intermediate between single and double bonds. The calculated Wiberg indexes of the $\mathrm{N}(3)-\mathrm{C}(14)$ and $\mathrm{C}(14)-\mathrm{N}(4)$ bonds are 1.56 and 1.28 respectively, in agreement with their intermediate character.

A curious feature arising from the theoretical study is that minimization of the bimetallic cis cation alone leads to a structure with the tetradentate bridging ligand twisted, being the dihedral angle defined by both pyrazolylamidino moieties of $38^{\circ}$. The planar structure found in the crystal structure corresponds to a transition state between the two twisted ground structures, as represented in Figure 7, with a calculated activation energy $\Delta E=3.44 \mathrm{kcal} / \mathrm{mol}$. Interestingly, the planar structure corresponding to a minimum of energy is only attained when the bromide anion is included in the calculation (Figure 8). Therefore, all the Wiberg index calculations have
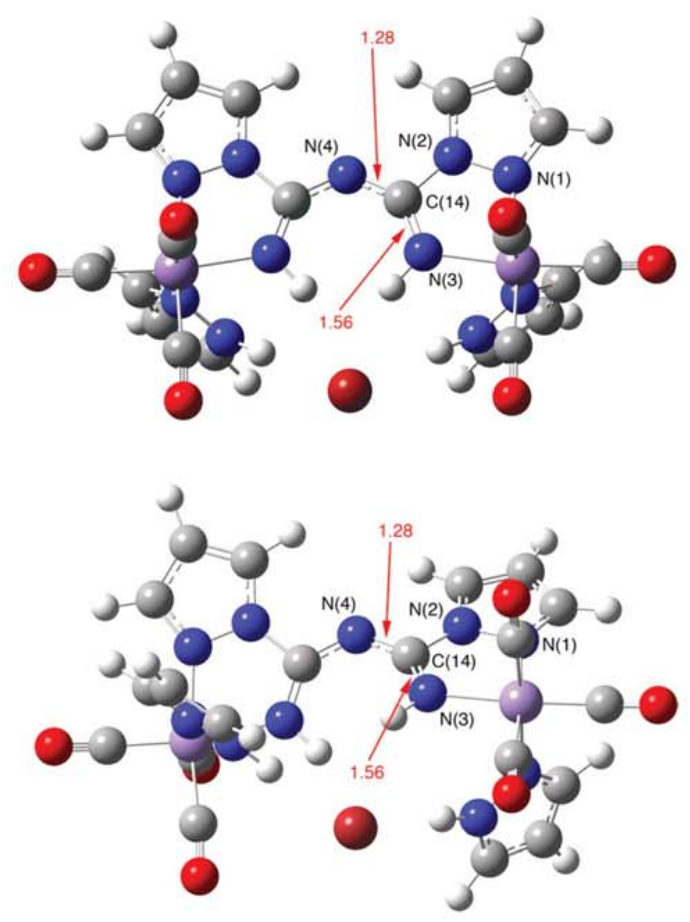

Figure 6. Wiberg bond indexes obtained from the theoretical study of $\left[\left\{\text { fac }-\mathrm{Mn}(\mathrm{pzH})(\mathrm{CO})_{3}\right\}_{2}\left(\mu-N \mathrm{H}=\mathrm{C}(\mathrm{pz}) \mathrm{NC}(\mathrm{pz})=N \mathrm{H}-\kappa^{4} N, N, N, N\right)\right] \mathrm{Br}$ (3), cis isomer above and trans isomer below.

been performed on this ionic pair instead of on the isolated cation.

The NMR data for 3 is rather complicated because of the presence in solution of cis and trans isomers, therefore it will be discussed below, after discussing the NMR spectra of 4, which is simpler since only the cis isomer is present in solution. Table 6 collects ${ }^{1} \mathrm{H}$ NMR data for $\mathbf{4}$ at different temperatures, Scheme 6 displays which protons are involved in the NOEs detected at $183 \mathrm{~K}$, and Figure 9 collects the ${ }^{1} \mathrm{H}$ NMR spectra between 50 and $-90^{\circ} \mathrm{C}$. The data collected in Table 6 clearly show that the pyrazoles are slightly unequivalent in all the range of temperatures registered (except for $\mathrm{H}^{4} \mathrm{pzH}$ at room temperature (r.t.) and above, probably because of accidental degeneration), whereas the protons of both fragments in the bis(pyrazolylamidino) ligand are only unequivalent at low temperature, except for $H^{5} \mathrm{pz}$, which are equivalent in all the range of temperatures registered. The latter feature may be explained considering an equilibrium between enantiomers similar to those detected in the calculations where the tetradentate bis(pyrazolylamidino) ligand is folded. The low energy of the enantiomers exchange indicates that the average situation, corresponding to a planar tetradentate bis(pyrazolylamidino) ligand, must be easily achieved (Figure 7, above). This would explain why the protons in the inner part of the ligand, that is, $H \mathrm{NMn}$ and $\mathrm{H}^{3} \mathrm{pz}$, are those more affected by the process, whereas that external such as $H^{5} \mathrm{pz}$ remains unaffected at different temperatures.

On the other hand, the presence of only the cis isomer in $\mathbf{4}$ is somewhat surprising, as 3 was a mixture of trans and cis. So far we have been unable to find a definitive explanation for this fact. 


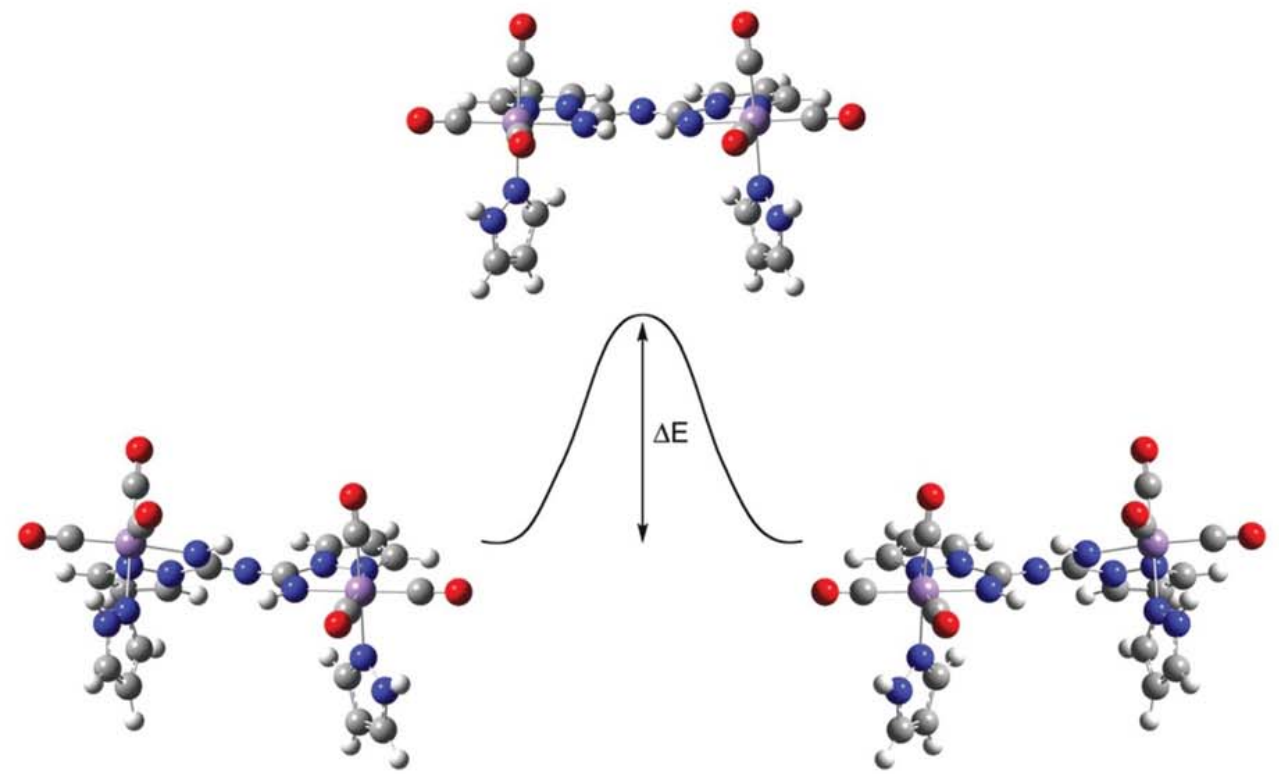

Figure 7. Energetic diagram obtained from the theoretical study on the cation of 3.

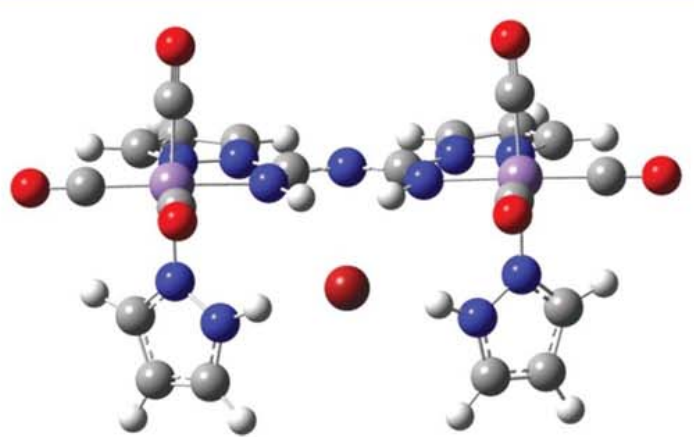

Figure 8. Planar structure obtained from the theoretical study on 3 (including the bromide anion).

The ${ }^{1} \mathrm{H}$ NMR of 3 is rather complicated because of the presence of cis and trans isomers. ${ }^{13}$ The signals of cis isomer are immediately assigned because of their similarity with those of 4 .

The IR spectra of 3 and $\mathbf{4}$ show three bands in the $\mathrm{C}-\mathrm{O}$ stretching region in solution, as expected for fac-tricarbonyl geometries. The frequencies are essentially the same and therefore they do not provide structural information and they are not informative.

Finally, it is interesting to note that dicyanamide does not take part in the process when using rhenium fragments, as the reactions of $f a c-\left[\operatorname{ReBr}(\mathrm{CO})_{3}(\mathrm{NCMe})_{2}\right]$ with $\mathrm{Na}(\mathrm{NCNCN})$ and pyrazole led to the bis(pyrazole) complexes previously described, ${ }^{14}$ probably because of the higher chemical inertness of rhenium.

\section{CONCLUSIONS}

The behavior of the sodium dicyanamide/pyrazole system clearly depends on the metallic substrate used. No pyrazolylamidino complexes are detected when cis-[ $\mathrm{MoCl}\left(\eta^{3}-\right.$ methallyl $\left.)(\mathrm{CO})_{2}(\mathrm{NCMe})_{2}\right]$ is treated with $\mathrm{Na}(\mathrm{NCNCN})$ and $\mathrm{pzH}$ or dmpzH, thus confirming the low tendency of this fragment to give coupling of nitriles and pyrazoles. Instead of coupling, coordination of dicyanamide and pyrazoles occurs giving dicyanamide bridging dimers containing coordinated pyrazole. Stepwise coupling with one $\mathrm{CN}$ bond of dicyanamide or both $\mathrm{CN}$ bonds occur when $f a c-\left[\mathrm{MnBr}(\mathrm{CO})_{3}(\mathrm{NCMe})_{2}\right]$ is used as starting material, giving new pyrazolylamidino chelating ligands coordinated to one metal atom in the first case, or as bridging ligand in a binuclear complex in the second. The X-ray diffraction structure of the new compounds present some $\mathrm{C}-\mathrm{N}$ bonds of the pyrazolylamidino ligands intermediate between single and double. NBO theoretical studies on these complexes allowed to deduce the electronic origin of that feature, and helped to explain the planarity of the tetradentate ligand in the bimetallic complex. The geometry of the bimetallic complex depends on the anion: both cis and trans isomers are present with bromide, whereas only the trans isomer is assembled with perchlorate.

\section{EXPERIMENTAL SECTION}

General Remarks. All manipulations were performed under $\mathrm{N}_{2}$ atmosphere following conventional Schlenk techniques. Filtrations were carried out on dry Celite under $\mathrm{N}_{2}$. Solvents were purified according to standard procedures. ${ }^{15}\left[\mathrm{Mo}\left(\eta^{3}\right.\right.$-Metallyl $) \mathrm{Cl}$ $\left.(\mathrm{CO})_{2}(\mathrm{NCMe})_{2}\right]{ }^{16} f a c-\left[\mathrm{MnBr}(\mathrm{CO})_{3}(\mathrm{NCMe})_{2}\right],{ }^{1 \mathrm{a}}$ and $f a c-[\mathrm{MnBr}-$ $\left.(\mathrm{CO})_{3}(\mathrm{pzH})_{2}\right]^{1 \mathrm{ta}}$ were obtained as previously described. All other reagents were obtained from the usual commercial suppliers, and used as received. Caution! Although no difficulties were experienced with the perchlorate complex described herein, all perchlorate species should be treated as potentially explosive and handled with care. Infrared spectra were recorded in a Perkin-Elmer RX I FT-IR apparatus using $0.2 \mathrm{~mm}$ $\mathrm{CaF}_{2}$ cells for solutions or on $\mathrm{KBr}$ pellets for solid samples. NMR spectra were recorded in Bruker AC-300 or ARX-300 instruments in $\left(\mathrm{CD}_{3}\right)_{2} \mathrm{CO}$ at room temperature unless otherwise stated. NMR spectra are referred to the internal residual solvent peak for ${ }^{1} \mathrm{H}$ and ${ }^{13} \mathrm{C}\left\{{ }^{1} \mathrm{H}\right\}$ NMR. Assignment of the ${ }^{13} \mathrm{C}\left\{{ }^{1} \mathrm{H}\right\}$ NMR data was supported by DEPT experiments and relative intensities of the resonance signals. Elemental analyses were performed on a Perkin-Elmer 2400B microanalyzer

cis-[Mo $\left(\eta^{3} \text {-methallyl) }(\mathrm{CO})_{2}(\mathrm{pzH})\left(\mu-N C N C N-\kappa^{2} N, N\right)\right]_{2}$ (1a). Na$(\mathrm{NCNCN})(0.018 \mathrm{~g}, 0.2 \mathrm{mmol})$ and $\mathrm{pzH}(0.014 \mathrm{~g}, 0.2 \mathrm{mmol})$ were added to a solution of cis-[ $\mathrm{Mo}\left(\eta^{3}\right.$-metallyl $\left.) \mathrm{Cl}(\mathrm{CO})_{2}(\mathrm{NCMe})_{2}\right](0.068$ 


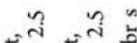

$\approx$

든ำ

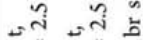

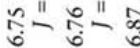

चल चुत्र चुल

$\approx .0$

I

चाल चत्रे चल

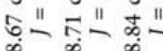

ETh

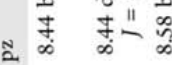

I

攺

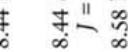

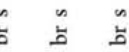

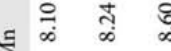

5

再

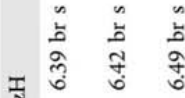

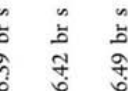

5)

곤

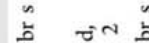

웅

की

足
Scheme 6. NOEs Detected at $183 \mathrm{~K}$ for $4^{a}$

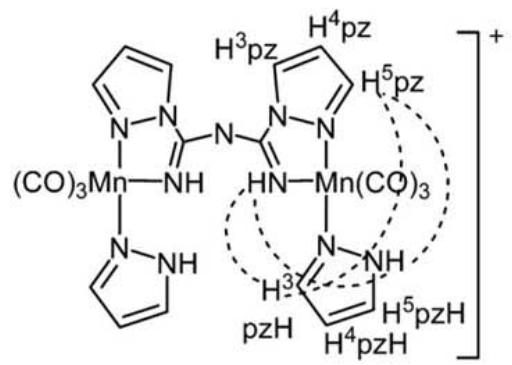

${ }^{a}$ For clarity, only those on one fragment of the molecule are depicted, the same NOEs are detected for the fragment on the left.

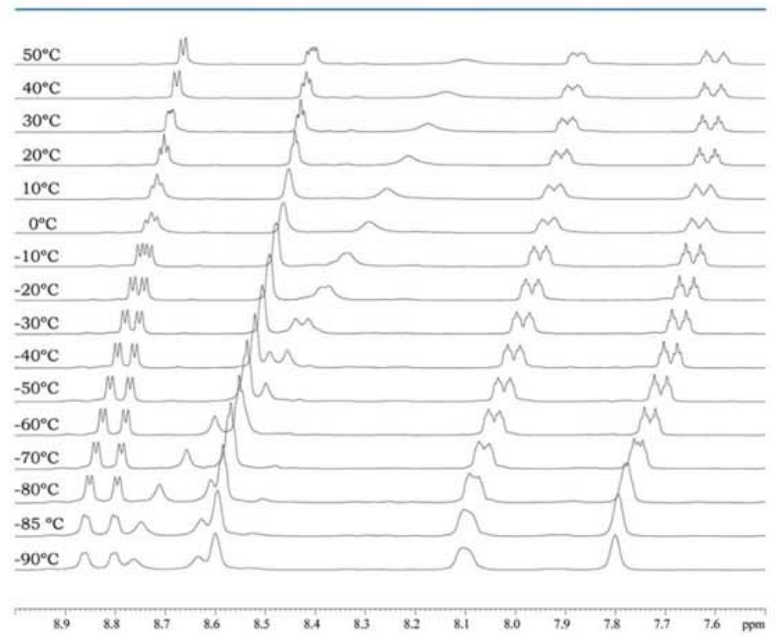

Figure 9. ${ }^{1} \mathrm{H}$ NMR spectra of 4 between 50 and $-90^{\circ} \mathrm{C}$ between 7.5 and $9 \mathrm{ppm}$ showing $H^{3} \mathrm{pz}, H^{5} \mathrm{pz}, H \mathrm{NMn}, H^{5} \mathrm{pzH}, H^{3} \mathrm{pzH}$ (left to right at $\left.50^{\circ} \mathrm{C}\right)$.

$\mathrm{g}, 0.2 \mathrm{mmol})$ in thf $(10 \mathrm{~mL})$. The solution was stirred at $60^{\circ} \mathrm{C}$ for $1 \mathrm{~h}$, and then was filtered and concentrated in vacuo. Addition of hexane (ca. $20 \mathrm{~mL}$ ) and cooling to $-20{ }^{\circ} \mathrm{C}$ gave a yellow microcrystalline solid, which was decanted, washed with hexane $(3 \times 3 \mathrm{~mL}$ approximately), and dried in vacuo, yielding $0.028 \mathrm{~g}$ of 1a (21\%). Decomposition of the solid is observed even under inert atmosphere, which precluded its spectroscopic characterization and suitable $\mathrm{C}, \mathrm{H}, \mathrm{N}$ analysis. IR (thf, cm ${ }^{-1}$ ): $2252 \mathrm{w}, 2202 \mathrm{~s}, 1944$ vs, $1861 \mathrm{~s}$. IR ( $\mathrm{KBr}$, $\mathrm{cm}^{-1}$ ): $3422 \mathrm{w}, 2301 \mathrm{w}, 2251 \mathrm{w}, 2202 \mathrm{~s}, 1936 \mathrm{vs}, 1850$ vs, $1341 \mathrm{~m}$, $1136 \mathrm{w}, 1046 \mathrm{w}, 771 \mathrm{w}, 503 \mathrm{w} .{ }^{1} \mathrm{H}$ NMR: $0.95,1.00,1.16,1.18\left(\mathrm{~s}, H^{\text {anti }}\right.$ methallyl), 2.13 (s, overlapped with the acetone signal, $\mathrm{CH}_{3}$ methallyl), 3.01, 3.02, 3.10, $3.14\left(\mathrm{~s}, H^{\mathrm{syn}}\right.$ methallyl), 6.35, $6.58\left(\mathrm{~s}, H^{4}\right.$ $\mathrm{pzH}), 7.42,7.78,7.90,7.97\left(\mathrm{~s}, H^{3}\right.$ and $\left.H^{5} \mathrm{pzH}\right), 12.37$ (br, NH), the relative intensities of the signals are variable).

cis-[Mo $\left(\eta^{3} \text {-methallyl) }(\mathrm{CO})_{2}(\mathrm{dmpzH})\left(\mu-N C N C N-\kappa^{2} N, N\right)\right]_{2}$ (1b).

$\mathrm{Na}(\mathrm{NCNCN})(0.018 \mathrm{~g}, 0.2 \mathrm{mmol})$ and dmpzH $(0.019 \mathrm{~g}, 0.2$ $\mathrm{mmol})$ were added to a solution of cis-[Mo $\left(\eta^{3}\right.$-methallyl $) \mathrm{Cl}$ $\left.(\mathrm{CO})_{2}(\mathrm{NCMe})_{2}\right](0.068 \mathrm{~g}, 0.2 \mathrm{mmol})$ in thf $(10 \mathrm{~mL})$. The solution was stirred at $60^{\circ} \mathrm{C}$ for $1 \mathrm{~h}$. Workup as for la gave $0.033 \mathrm{~g}(22 \%)$ of $\mathbf{1 b}$ as yellow crystals. Decomposition of the solid is observed even under inert atmosphere, which precluded its spectroscopic characterization and suitable $\mathrm{C}, \mathrm{H} ; \mathrm{N}$ analysis. IR (thf, $\mathrm{cm}^{-1}$ ): $2253 \mathrm{w}, 2202 \mathrm{~s}$, 1942 vs, 1860 s. IR $\left(\mathrm{KBr}, \mathrm{cm}^{-1}\right): 3422 \mathrm{w}, 2184 \mathrm{~m}, 2037 \mathrm{w}, 1937$ vs, $1847 \mathrm{~s}, 1325 \mathrm{~m}, 1046 \mathrm{w}, 886 \mathrm{w}, 670 \mathrm{w} .{ }^{1} \mathrm{H}$ NMR: 0.95, 1.01, 1.10, 1.14 (s, $H^{\text {nti }}$ methallyl), 2.13 (s, overlapped with the acetone signal, $\mathrm{CH}_{3}$ methallyl), 2.16, 2.19, 2.24, 2.28, 2.34, 2.36, 2.41, 2.46, 2.56, 2.59 (s, $\mathrm{CH}_{3}$ dmpzH), 2.82, 3.01, 3.02, 3.05, 3.10 (s, $H^{\text {syn }}$ methallyl), 5.89, 
Table 7. Crystal Data and Refinement Details for $1 b, 2 a, 2 b, 3$, and 4

\begin{tabular}{|c|c|c|c|c|c|}
\hline & $1 \mathrm{~b}$ & $2 a$ & $2 b \cdot$ thf & 3 & 4-thf \\
\hline formula & $\mathrm{C}_{34} \mathrm{H}_{46} \mathrm{Mo}_{2} \mathrm{~N}_{10} \mathrm{O}_{6}$ & $\mathrm{C}_{11} \mathrm{H}_{8} \mathrm{MnN}_{7} \mathrm{O}_{3}$ & $\mathrm{C}_{19} \mathrm{H}_{24} \mathrm{MnN}_{7} \mathrm{O}_{4}$ & $\mathrm{C}_{20} \mathrm{H}_{16} \mathrm{BrMn}_{2} \mathrm{~N}_{11} \mathrm{O}_{6}$ & $\mathrm{C}_{24} \mathrm{H}_{24} \mathrm{ClMn}_{2} \mathrm{~N}_{11} \mathrm{O}_{11}$ \\
\hline fw & 882.69 & 341.18 & 469.39 & 696.23 & 787.87 \\
\hline cryst system & triclinic & monoclinic & triclinic & monoclinic & orthorhombic \\
\hline space group & $P \overline{1}$ & $P 2(1) / n$ & $P \overline{1}$ & $P 2(1) / n$ & Pna2(1) \\
\hline$a, \AA$ & $11.897(4)$ & $7.7764(18)$ & $8.733(7)$ & $16.232(7)$ & $16.046(11)$ \\
\hline$b, \AA$ & $14.105(5)$ & $13.535(3)$ & $10.655(8)$ & $9.622(4)$ & $8.880(6)$ \\
\hline$c, \AA$ & $14.454(5)$ & $13.609(3)$ & $13.642(11)$ & $27.200(9)$ & $23.199(16)$ \\
\hline$\alpha, \operatorname{deg}$ & $67.379(5)$ & 90 & $98.909(13)$ & 90 & 90 \\
\hline$\beta, \operatorname{deg}$ & $85.495(7)$ & $102.601(5)$ & $96.890(13)$ & $97.354(7)$ & 90 \\
\hline$\gamma, \operatorname{deg}$ & $69.564(7)$ & 90 & $107.068(13)$ & 90 & 90 \\
\hline$V, \AA^{3}$ & $2093.6(13)$ & $1397.9(6)$ & $1180.3(16)$ & $4213(3)$ & $3306(4)$ \\
\hline Z & 2 & 4 & 2 & 6 & 4 \\
\hline$T, \mathrm{~K}$ & $293(2)$ & $298(2)$ & $298(2)$ & $293(2)$ & $298(2)$ \\
\hline$d_{\text {calo }} \mathrm{g} \mathrm{cm}^{-3}$ & 1.400 & 1.621 & 1.321 & 1.646 & 1.583 \\
\hline$F(000)$ & 904 & 688 & 488 & 2076 & 1600 \\
\hline$\lambda\left(\mathrm{Mo} \mathrm{K}_{\alpha}\right), \AA$ & 0.71073 & 0.71073 & 0.71073 & 0.71073 & 0.71073 \\
\hline crystal size, mm; color & $\begin{array}{l}0.20 \times 0.06 \\
\text { yellow }\end{array}$ & $\begin{array}{l}0.28 \times 0.16 \times 0.08, \\
\text { yellow }\end{array}$ & $\begin{array}{l}0.36 \times 0.25 \times 0.18 \\
\text { yellow }\end{array}$ & $\begin{array}{l}0.29 \times 0.28 \times 0.16 \\
\text { yellow }\end{array}$ & $\begin{array}{l}0.31 \times 0.24 \\
\text { yellow }\end{array}$ \\
\hline$\mu, \mathrm{mm}^{-1}$ & 0.651 & 0.969 & 0.597 & 2.377 & 0.917 \\
\hline scan range, deg & 1.53 to 23.38 & 2.15 to 23.29 & 1.53 to 28.59 & 1.26 to 23.29 & 1.76 to 24.99 \\
\hline absorption correction & $\begin{array}{l}\text { semiempirical from } \\
\text { equivalents }\end{array}$ & $\begin{array}{l}\text { semiempirical from } \\
\text { equivalents }\end{array}$ & $\begin{array}{l}\text { semiempirical from } \\
\text { equivalents }\end{array}$ & $\begin{array}{l}\text { semiempirical from } \\
\text { equivalents }\end{array}$ & $\begin{array}{l}\text { semiempirical from } \\
\text { equivalents }\end{array}$ \\
\hline corr. factors ( $\max , \min )$ & $1.000000,0.363603$ & $1.000000,0.787786$ & $1.000000,0.368812$ & $1.000000,0.748043$ & $1.000000,0.714322$ \\
\hline no of refl measured & 9429 & 6114 & 11278 & 26351 & 20702 \\
\hline $\begin{array}{l}\text { no of ref independent } \\
[R \text { (int })]\end{array}$ & $5968[0.0988]$ & $2016[0.0258]$ & $5682[0.0397]$ & $6052[0.0735]$ & $5354[0.1021]$ \\
\hline $\begin{array}{l}\text { no of ref observed, } \\
I I \geq 2 \sigma(I)\end{array}$ & 1912 & 1597 & 3926 & 4546 & 3066 \\
\hline GOF on $F^{2}$ & 0.840 & 1.000 & 1.161 & 1.113 & 1.192 \\
\hline no. of parameters & 449 & 199 & 284 & 542 & 384 \\
\hline residuals $\mathrm{R}$, wR2 & $0.0820,0.2188$ & $0.0338,0.0878$ & $0.0608,0.1609$ & $0.0760,0.1760$ & $0.1054,0.2060$ \\
\hline
\end{tabular}

6.00, 6.11, $6.16\left(\mathrm{~s}, \mathrm{H}^{4} \mathrm{pzH}\right), 11.38(\mathrm{br}, \mathrm{NH})$, the relative intensities of the signals are variable).

fac-[Mn $\left.(\mathrm{pz} H)(\mathrm{CO})_{3}\left(\mathrm{NH}=\mathrm{C}(\mathrm{pz}) \mathrm{NCN}-\kappa^{2} N, N\right)\right](2 \mathrm{a}) . \mathrm{Na}(\mathrm{NCNCN})$ $(0.027 \mathrm{~g}, 0.3 \mathrm{mmol})$ and $\mathrm{pzH}(0.041 \mathrm{~g}, 0.6 \mathrm{mmol})$ were added to a solution of $\mathrm{fac}-\left[\mathrm{MnBr}(\mathrm{CO})_{3}(\mathrm{NCMe})_{2}\right]$ (obtained from $0.083 \mathrm{~g}, 0.3$ $\mathrm{mmol}$ of $\left.\left[\mathrm{MnBr}(\mathrm{CO})_{5}\right]\right)^{1 \mathrm{a}}$ in thf $(10 \mathrm{~mL})$. The solution was stirred at $60{ }^{\circ} \mathrm{C}$ for $6 \mathrm{~h}$. Workup as for 1a gave $0.045 \mathrm{~g}(44 \%)$ of $2 \mathrm{a}$ as yellow crystals. IR (thf, cm ${ }^{-1}$ ): $2176 \mathrm{w}, 2159$ vw, 2035 vs, 1939 vs, 1927 vs. IR $\left(\mathrm{KBr}, \mathrm{cm}^{-1}\right): 3342 \mathrm{~s}, 2188 \mathrm{~s}, 2034$ vs, 1942 vs, 1924 vs, $1602 \mathrm{~s}, 1459 \mathrm{~s}$, 1408 s, 1237 m, 1054 m, 772 m, 725 m, 524 m. ${ }^{1}$ H NMR: 6.39 (pst, $\left.=2.5 \mathrm{~Hz}, H^{4} \mathrm{pzH}, 1 \mathrm{H}\right), 6.66$ (pst, $\left.J=2.5 \mathrm{~Hz}, H^{4} \mathrm{pz}, 1 \mathrm{H}\right), 7.65(\mathrm{~d}, J=$ $\left.1.5 \mathrm{~Hz}, H^{3} \mathrm{pzH}, 1 \mathrm{H}\right), 7.89\left(\mathrm{~d}, J=2.0 \mathrm{~Hz}, H^{5} \mathrm{pzH}, 1 \mathrm{H}\right), 8.22(\mathrm{~d}, J=$ $\left.2.5 \mathrm{~Hz}, H^{5} \mathrm{pz}, 1 \mathrm{H}\right), 8.37$ (d, $\left.J=1.5 \mathrm{~Hz}, H^{3} \mathrm{pz}, 1 \mathrm{H}\right), 12.64(\mathrm{br}, H \mathrm{~N}, 1$ H). ${ }^{13} \mathrm{C}\left\{{ }^{1} \mathrm{H}\right\}$ NMR: 107.7 (s, $\left.\mathrm{C}^{4} \mathrm{pzH}\right), 110.8$ (s, $\left.\mathrm{C}^{4} \mathrm{pz}\right), 131.7$ (s, $\mathrm{C}^{3,5}$ $\mathrm{pzH}), 132.9$ (s, $\left.C^{3,5} \mathrm{pz}\right), 143.5\left(\mathrm{~s}, \mathrm{C}^{5,3} \mathrm{pzH}\right), 146.9\left(\mathrm{~s}, \mathrm{C}^{5,3} \mathrm{pz}\right), \mathrm{HN}=\mathrm{C}$, $\mathrm{C} \equiv \mathrm{N}$, and $\mathrm{CO}$ not observed because of the low solubility of the complex. Anal. Calcd. for $\mathrm{C}_{11} \mathrm{H}_{8} \mathrm{MnN}_{7} \mathrm{O}_{3}: \mathrm{C}, 38.73 ; \mathrm{H}, 2.36$; N, 28.74 . Found: C, 38.49; H, 2.11; N, 28.89.

fac-[Mn $\left.(\mathrm{dmpzH})(\mathrm{CO})_{3}\left(\mathrm{NH}=\mathrm{C}(\mathrm{dmpz}) \mathrm{NCN}-\kappa^{2} N, N\right)\right] \quad(2 \mathrm{~b}) . \quad \mathrm{Na}-$ $(\mathrm{NCNCN})(0.027 \mathrm{~g}, 0.3 \mathrm{mmol})$ and dmpzH $(0.058 \mathrm{~g}, 0.6 \mathrm{mmol})$ were added to a solution of $f a c-\left[\mathrm{MnBr}(\mathrm{CO})_{3}(\mathrm{NCMe})_{2}\right]$ (obtained from $0.083 \mathrm{~g}, 0.3 \mathrm{mmol}$ of $\left.\left[\mathrm{MnBr}(\mathrm{CO})_{5}\right]\right)^{1 \mathrm{a}}$ in thf $(10 \mathrm{~mL})$. The solution was stirred at $60{ }^{\circ} \mathrm{C}$ for $6 \mathrm{~h}$. Workup as for 1a gave $0.050 \mathrm{~g}$ (42\%) of $2 \mathrm{~b}$ as yellow crystals. IR (thf, $\mathrm{cm}^{-1}$ ): $2176 \mathrm{w}, 2031 \mathrm{vs,} 1939$ vs, 1919 s. IR $\left(\mathrm{KBr}, \mathrm{cm}^{-1}\right)$ : 3310 m, 3143 w, 2170 s, 2030 vs, 1929 vs, 1911 s, 1613 s, 1429 s, 1283 m, 1238 w, 803 w, 650 w, 523 w. ${ }^{1} \mathrm{H}$ NMR $\left(\mathrm{CD}_{2} \mathrm{Cl}_{2}\right): 2.12\left(\mathrm{~s}, \mathrm{CH}_{3}\right.$ dmpzH, $\left.3 \mathrm{H}\right), 2.28\left(\mathrm{~s}, \mathrm{CH}_{3}\right.$ dmpzH, 3 $\mathrm{H}), 2.54\left(\mathrm{~s}, \mathrm{CH}_{3} \mathrm{dmpz}, 3 \mathrm{H}\right), 2.65\left(\mathrm{~s}, \mathrm{CH}_{3} \mathrm{dmpz}, 3 \mathrm{H}\right), 5.77\left(\mathrm{~s}, \mathrm{H}^{4}\right.$ dmpzH, $1 \mathrm{H}), 6.05\left(\mathrm{~s}, \mathrm{H}^{4} \mathrm{dmpz}, 1 \mathrm{H}\right), 7.11$ (br s, NH, $\left.1 \mathrm{H}\right), 11.88$ (br s, $\mathrm{NH}, 1 \mathrm{H}) \cdot{ }^{13} \mathrm{C}\left\{{ }^{1} \mathrm{H}\right\}$ NMR $\left(\mathrm{CD}_{2} \mathrm{Cl}_{2}\right): 10.9\left(\mathrm{~s}, \mathrm{CH}_{3} \mathrm{dmpzH}\right), 14.3$ (s, $\mathrm{CH}_{3} \mathrm{dmpz}$ ), 14.8 (s, $\left.\mathrm{CH}_{3} \mathrm{dmpzH}\right), 15.4$ (s, $\left.\mathrm{CH}_{3} \mathrm{dmpz}\right), 106.6$ (s, $\mathrm{C}^{4}$ dmpzH), $111.8\left(\mathrm{~s}, \mathrm{C}^{4} \mathrm{dmpz}\right), 142.7$ (s, $\left.\mathrm{C}^{3,5} \mathrm{dmpzH}\right), 146.2\left(\mathrm{~s}, \mathrm{C}^{3,5}\right.$ dmpz), $152.6\left(\mathrm{~s}, C^{5,3} \mathrm{dmpzH}\right), 155.5\left(\mathrm{~s}, \mathrm{C}^{5,3} \mathrm{dmpz}\right), \mathrm{HN}=\mathrm{C}, \mathrm{C} \equiv \mathrm{N}$, and $\mathrm{CO}$ not observed because of the low solubility of the complex. Anal. Calcd. for $\mathrm{C}_{15} \mathrm{H}_{16} \mathrm{MnN}_{7} \mathrm{O}_{3}: \mathrm{C}, 45.35 ; \mathrm{H}, 4.06 ; \mathrm{N}, 24.68$. Found: C, 45.53; H, 3.74; N, 24.35.

$\left[\left\{\text { fac }-\mathrm{Mn}(\mathrm{pz} \mathrm{H})(\mathrm{CO})_{3}\right\}_{2}\left(\mu-N \mathrm{H}=\mathrm{C}(\mathrm{pz}) \mathrm{NC}(\mathrm{pz})=\mathrm{NH}-\kappa^{4} N, N, N, N\right)\right] \mathrm{Br}$ (3). Compound $2 \mathrm{a}(0.017 \mathrm{~g}, 0.05 \mathrm{mmol})$ was added to a solution of fac- $\left[\mathrm{MnBr}(\mathrm{CO})_{3}(\mathrm{pzH})_{2}\right](0.018 \mathrm{~g}, 0.05 \mathrm{mmol})$ in thf $(5 \mathrm{~mL})$, and the solution was stirred at r.t. for $4 \mathrm{~h}$. Hexane was added (ca. $10 \mathrm{~mL}$ ), and the solution was concentrated and cooled to $-20{ }^{\circ} \mathrm{C}$, giving a yelloworange microcrystalline solid, which was decanted, washed with hexane ( $3 \times 3 \mathrm{~mL}$ approximately), and dried in vacuo, yielding $0.026 \mathrm{~g}(75 \%)$. IR (thf, $\mathrm{cm}^{-1}$ ): $2176 \mathrm{w}, 2035$ vs, 1939 vs, $1928 \mathrm{~s}$. IR $\left(\mathrm{KBr}, \mathrm{cm}^{-1}\right): 3115$ m, 2964 m, 2036 vs, 1943 vs, 1919 vs, 1615 m, 1584 s, 1435 m, 1385 m, 1261 m, 1048 w, 1027 w, 808 m, 648 m, 631 w, 561 w, 533 w, 486 w. ${ }^{1} \mathrm{H}$ NMR: 6.31 (br s, $H^{4}$ pzH, $2 \mathrm{H}$ cis), 6.39 (br s, $H^{4}$ pzH, $2 \mathrm{H}$ trans), 6.68 (t, $J=2 \mathrm{~Hz}, H^{4} \mathrm{pz}, 2 \mathrm{H}$ cis), 6.73 (t, $J=2 \mathrm{~Hz}, H^{4} \mathrm{pz}, 2 \mathrm{H}$ trans), 7.65 (br s, $H^{3}$ pzH, $2 \mathrm{H}$ cis), 7.70 (br s, $H^{3}$ pzH, $2 \mathrm{H}$ trans), 7.88 (br s, $H^{5}$ pzH, $2 \mathrm{H}$ cis), 7.96 (br s, $H^{5}$ pzH, $2 \mathrm{H}$ trans), 8.45 (d, J = 2 $\mathrm{Hz}, H^{5} \mathrm{pz}, 2 \mathrm{H}$ cis), 8.49 (d, $J=2 \mathrm{~Hz}, H^{5} \mathrm{pz}, 2 \mathrm{H}$ trans), 8.58 (d, $J=2$ $\mathrm{Hz}, H^{3}$ pz, $2 \mathrm{H}$ trans), 8.64 (d, $J=2 \mathrm{~Hz}, H^{3} \mathrm{pz}, 2 \mathrm{H}$ cis), 9.10 (br s, HNMn, $2 \mathrm{H}$ cis, and $2 \mathrm{H}$ trans), 13.64 (br s, $\mathrm{HN}$ pzH, $2 \mathrm{H}$ cis, and $2 \mathrm{H}$ trans). Ratio cis/trans $=1.4 / 1 .^{11}$ Anal. Calcd. for $\mathrm{C}_{20} \mathrm{H}_{16} \mathrm{BrMn}_{2} \mathrm{~N}_{11} \mathrm{O}_{6}$ : C, 34.50; H, 2.32; N, 22.13. Found: C, 34.80; H, 2.31; N, 21.92.

$\left[\left\{\text { fac-Mn }(\mathrm{pzH})(\mathrm{CO})_{3}\right\}_{2}\left(\mu-N \mathrm{H}=\mathrm{C}(\mathrm{pz}) \mathrm{NC}(\mathrm{pz})=N \mathrm{H}-\kappa^{4} N, N, N, N\right)\right]-$ $\mathrm{ClO}_{4}$ (4). $\mathrm{AgClO}_{4}(0.011 \mathrm{~g}, 0.055 \mathrm{mmol})$ was added to a solution of 3 $(0.035 \mathrm{~g}, 0.050 \mathrm{mmol})$ in thf $(10 \mathrm{~mL})$, and the mixture was stirred at r.t. for $4 \mathrm{~h}$. Workup as for 1a gave $0.032 \mathrm{~g}(82 \%)$ of 4 -thf. IR (thf, $\left.\mathrm{cm}^{-1}\right)$ : $2226 \mathrm{vw}, 2176 \mathrm{w}, 2035$ vs, 1940 vs, $1927 \mathrm{vs} \mathrm{IR}\left(\mathrm{KBr}, \mathrm{cm}^{-1}\right)$ : 3342 m, 2187 s, 2035 vs, 1930 vs, 1925 vs, 1603 s, 1459 m, 1441 m, 1407 m, 1238 w, 1054 w, 772 w, 763 w, 726 w, 689 vw, 643 w, 525 w. ${ }^{1} \mathrm{H}$ NMR: see Table $6 .{ }^{13} \mathrm{C}\left\{{ }^{1} \mathrm{H}\right\}$ NMR: 108.0 (s, $\left.C^{4} \mathrm{Hpz}\right), 111.0\left(\mathrm{~s}, \mathrm{C}^{4}\right.$ pz), 132.9 (s, $\left.C^{3,5} \mathrm{Hpz}\right), 133.3$ (s, $\left.C^{3,5} \mathrm{pz}\right), 143.5$ (s, $\left.C^{5,3} \mathrm{Hpz}\right), 147.5$ $\left(\mathrm{s}, \mathrm{C}^{5,3} \mathrm{pz}\right), 158.0(\mathrm{~s}, \mathrm{HNC}), \mathrm{CO}$ not observed. Anal. Calcd. for 
$\mathrm{C}_{24} \mathrm{H}_{24} \mathrm{ClMn}_{2} \mathrm{~N}_{11} \mathrm{O}_{11}$ (4.thf): C, 36.59; H, 3.07; N, 19.56. Found: C, 36.85; H, 2.88; N, 19.31 .

Computational Details. All computations were carried out using the GAUSSIAN03 package, ${ }^{17}$ in which the hybrid method B3LYP was applied with the Becke three-parameter exchange functional, ${ }^{18}$ and the Lee-Yang-Parr correlation functional. ${ }^{19}$ Effective core potentials (ECP) and their associated double- $\zeta$ LANL2DZ basis set were used for the manganese and bromine atoms, ${ }^{20}$ supplemented by an extra $\mathrm{d}$ polarization function in the case of $\mathrm{Br}^{21}$ The light elements $(\mathrm{O}, \mathrm{N}, \mathrm{C}$, and $\mathrm{H}$ ) were described with the $6-31 \mathrm{G}^{* *}$ basis. $^{22}$ Geometry optimizations were performed under no symmetry restrictions, using initial coordinates derived from X-ray data of the same complexes, and frequency analyses were performed to ensure that a minimum structure with no imaginary frecuencies was achieved in each case. Wiberg bond indexes ${ }^{23}$ were calculated with the NBO 5.9 program. ${ }^{24}$ Crystal Structure Determination for Compounds $1 \mathrm{~b}, 2 \mathrm{a}, 2 \mathrm{~b}$, 3 , and 4. Crystals were grown by slow diffusion of hexane into concentrated solutions of the complexes in thf (for $\mathbf{1 b}, \mathbf{2 b}$, and $\mathbf{4}$ ), or $\mathrm{CH}_{2} \mathrm{Cl}_{2}(2 \mathrm{a}$ and 3$)$ at $-20^{\circ} \mathrm{C}$. Relevant crystallographic details are given in Table 7. A crystal was attached to a glass fiber and transferred to a Bruker AXS SMART 1000 diffractometer with graphite monochromatized $\mathrm{Mo}_{\alpha} \mathrm{X}$-radiation and a $\mathrm{CCD}$ area detector. Raw frame data were integrated with the SAINT program. ${ }^{25}$ The structure was solved by direct methods with SHELXTL. ${ }^{26}$ A semiempirical absorption correction was applied with the program SADABS. ${ }^{27}$ All non-hydrogen atoms were refined anisotropically. Hydrogen atoms were set in calculated positions and refined as riding atoms, with a common thermal parameter. All calculations and graphics were made with SHELXTL. Distances and angles of hydrogen bonds were calculated with PARST ${ }^{28}$ (normalized values). ${ }^{29}$

\section{ASSOCIATED CONTENT}

\section{S Supporting Information}

$\mathrm{X}$-ray crystallographic data for compounds $\mathbf{1 b}, \mathbf{2 a}, \mathbf{2 b}, \mathbf{3}$, (for these also experimental and simulated powder diffraction data) and 4 as a CIF. This material is available free of charge via the Internet at http://pubs.acs.org.

\section{AUTHOR INFORMATION}

\section{Corresponding Author}

*E-mail: fervilla@qi.uva.es. Fax: 34983 423013. Phone: 34983 184620.

\section{Notes}

The authors declare no competing financial interest.

\section{ACKNOWLEDGMENTS}

The authors thank the Spanish Ministerio de Ciencia e Innovación (CTQ2009-12111) and the Junta de Castilla y León (VA070A08 and GR Excelencia 125) for financial support. M.A. and P.G.-I. thank the MEC and the UVa respectively (FPI Programs) for their grants.

\section{REFERENCES}

(1) (a) Arroyo, M.; López-Sanvicente, A.; Miguel, D.; Villafañe, F. Eur. J. Inorg. Chem. 2005, 4430-4437. (b) Arroyo, M.; Miguel, D.; Villafañe, F.; Nieto, S.; Pérez, J.; Riera, L. Inorg. Chem. 2006, 45, 7018-7026. (c) Antón, N.; Arroyo, M.; Gómez-Iglesias, P.; Miguel, D.; Villafañe, F. J. Organomet. Chem. 2008, 693, 3074-3080.

(2) (a) Hsieh, C.-C.; Lee, C.-J.; Horng, Y.-C. Organometallics 2009, 28, 4923-4928. (b) Khripun, A. V.; Kukushkin, V. Y.; Selivanov, S. I.; Haukka, M.; Pombeiro, A. J. L. Inorg. Chem. 2006, 45, 5073-5083. (c) Reisner, E.; Arion, V. B.; Rufinsha, A.; Chiorescu, I.; Schmid, W. E.; Keppler, B. K. Dalton Trans. 2005, 2355-2364. (d) Govidaswamy, P.; Mozharivskyj, Y. A.; Kollipara, M. R. J. Organomet. Chem. 2004, 689, 3265-3274. (e) Kollipara, M. R.; Sarkhel, P.; Chakraborty, S.; Lalrempuia, R. J. Coord. Chem. 2003, 56, 1085-1091. (f) Carmona, D.;
Ferrer, J.; Lahoz, F. J.; Oro, L. A.; Lamata, M. P. Organometallics 1996, 15, 5175-5178. (g) López, J.; Santos, A.; Romero, A.; Echavarren, A. M. J. Organomet. Chem. 1993, 443, 221-228. (h) Cinellu, M. A.; Stoccoro, S.; Minghetti, G.; Bandini, A. L.; Banditelli, G.; Bovio, B. J. Organomet. Chem. 1989, 372, 311-325. (i) Albers, M. O.; Francesca, S.; Crosby, A.; Liles, D. C.; Robinson, D. J.; Shaver, A.; Singleton, E. Organometallics 1987, 6, 2014-2017. (j) Gracey, G. D.; Rettig, S. T.; Storr, A.; Trotter, J. Can. J. Chem. 1987, 65, 2469-2477. (k) Romero, A.; Vegas, A.; Santos, A. J. Organomet. Chem. 1986, 310, C8-C10. (1) Jones, C. J.; McCleverty, J. A.; Rothin, A. S. J. Chem. Soc., Dalton Trans. 1986, 109-111.

(3) For other examples of nucleophilic addition to metal-activated nitriles, see: (a) Pombeiro, A. J. L.; Kukushkin, V. Y. In Comprehensive Coordination Chemistry II; McCleverty, J. A., Meyer, T. J., Lever, A. B. P., Eds.; Elsevier: Oxford, U.K., 2004; Vol. 1, pp 639-660. (b) Kukushkin, V. Y.; Pombeiro, A. J. L. Chem. Rev. 2002, 102, 1771-1802. (c) Michelin, R. A.; Mozzon, M.; Bertani, R. Coord. Chem. Rev. 1996, 147, 299-338.

(4) (a) Review: Hvastijová, M.; Kohout, J.; Buchler, J. W.; Boca, R; Kozısek, J.; Jäger, L. Coord. Chem. Rev. 1998, 175, 17-45. (b) Zheng, L.-L.; Leng, J.-D.; Liu, W.-T.; Zhang, W.-X.; Lu, J.-X.; Tong, M.-L. Eur. J. Inorg. Chem. 2008, 4616-4624. (c) Zheng, L.-L.; Li, H.-X.; Leng, J.D.; Wang, J.; Tong, M.-L. Eur. J. Inorg. Chem. 2008, 213-217. (d) Zheng, L.-L.; Zhang, W.-X.; Qin, L.-J.; Leng, J.-D.; Lu, J.-X.; Tong, M.-L. Inorg. Chem. 2007, 46, 9548-9557. (e) Igashira-Kamiyama, A.; Kajiwara, T.; Konno, T.; Ito, T. Inorg. Chem. 2006, 45, 6460-6466. (f) Tong, M.-L.; Wu, Y.-M.; Tong, Y.-X.; Chen, X.-M.; Chang, H.-C.; Kitagawa, S. Eur. J. Inorg. Chem. 2003, 2385-2388.

(5) The molecule of $\mathbf{l b}$ is formed by two crystallographically equivalent halves because of the presence of a $C_{2}$ perpendicular to the $\mathrm{Mo}_{2}\left(\mu-N C N C N-\kappa^{2} N, N\right)_{2}$ approximate plane. Table 1 collects one of the fragments. Complete tables for the whole molecule can be found in the CIF (see Supporting Information).

(6) Curtis, M. D.; Eisenstein, O. Organometallics 1984, 3, 887-895. (7) See for example: (a) de la Pinta, N.; Martín, S.; Urtiaga, M. K.; Barandika, M. G.; Arriortua, M. I.; Lezama, L.; Madariaga, G.; Cortés, R. Inorg. Chem. 2010, 49, 10445-10454. (b) Ding, B.; Yi, L.; Wang, Y.; Cheng, P.; Liao, D.-Z.; Jiang, Z.-H.; Song, H.-B.; Wang, H.-G. Dalton Trans. 2006, 665-675. (c) Batten, S. R.; Bjernemose, J.; Jensen, P.; Leita, B. A.; Murria, K. S.; Moubaraki, B.; Smith, J. P.; Toftlund, H. Dalton Trans. 2004, 3370-3375. (d) Miyasaka, H.; Nakata, K.; Sugiera, K.; Yamashita, M.; Clérac, R. Angew. Chem., Int. Ed. 2004, 43, 707-711. (e) Jensen, P.; Batten, S. R.; Moubaraki, B.; Murria, K. S. Dalton Trans 2002, 3712-3722. (f) Batten, R; Jensen, P.; Moubaraki, B.; Murria, K. S. Chem. Commun. 2000, 2331-2332.

(8) (a) Faller, J. W.; Haitko, D. A.; Adams, R. D.; Chodosh, D. F. J. Am. Chem. Soc. 1979, 101, 865-876. (b) Paredes, P.; Miguel, D.; Villafañe, F. Eur. J. Inorg. Chem. 2003, 995-1004. (c) Arroyo, M.; García-de-Prada, M. T.; García-Martín, C.; García-Pacios, V.; GarcíaRodríguez, R.; Gómez-Iglesias, P.; Lorenzo, F.; Martín-Moreno, I.; Miguel, D.; Villafañe, F. J. Organomet. Chem. 2009, 694, 3190-3199. (d) Paredes, P.; López-Calzada, A.; Miguel, D.; Villafañe, F. Dalton Trans. 2010, 39, 10099-10104.

(9) See for example: (a) Reimann, R. H.; Singleton, E. J. Chem. Soc,, Dalton Trans. 1974, 808-813. (b) Armstrong, E. M.; Baker, P. K.; Drew, M. G. B. Organometallics 1988, 7, 319-325. (c) Fraccarollo, D.; Bertani, R.; Mozzon, M.; Belluco, U.; Michelin, R. A. Inorg. Chim. Acta 1992, 201, 15-22. (d) Thomas, S.; Young, C. G.; Tiekink, E. R. T. Organometallics 1998, 17, 182-189. (e) Hevia, E.; Pérez, J.; Riera, V.; Miguel, D.; Kassel, S.; Rheingold, A. Inorg. Chem. 2002, 41, 46734679

(10) (a) Stor, G. J.; Stufkens, D. J.; Vernooijs, P.; Baerends, E. J.; Fraanje, J.; Goubitz, K. Inorg. Chem. 1995, 34, 1588-1594. (b) Schmidt, G.; Paulus, H.; van Eldik, R.; Elias, H. Inorg. Chem. 1988, 27, 3211-3214. (c) Horn, E.; Snow, M. R.; Tiekink, E. R. T. Acta Crystallogr., Sect. C: Cryst. Struct. Commun. 1987, 43, 792-794. (11) (a) Jeffrey, G. A. An Introduction to Hydrogen Bonding; Oxford University Press: New York, 1997; Chapter 2. (b) Steiner, T. Angew. Chem., Int. Ed 2002, 41, 48-76. 
(12) Because of the low quality of the crystal, the resulting determination is poor (high residuals). Nevertheless, the structure is included here since it confirms unambiguously the connectivity of the molecule.

(13) The presence of two isomers in solution precluded obtaining a suitable ${ }^{13} \mathrm{C}\left\{{ }^{1} \mathrm{H}\right\}$ NMR spectum of 3 .

(14) Ardizzoia, G. A.; LaMonica, G.; Maspero, A.; Moret, M.; Maschiocchi, N. Eur. J. Inorg. Chem. 1998, 1503-1512.

(15) Perrin, D. D.; Armarego, W. L. F. Purification of Laboratory Chemicals, 3rd ed.; Pergamon Press: Oxford, U.K., 1988.

(16) Tom Dieck, H.; Friedel, H. J. Organomet. Chem. 1968, 14, 375385.

(17) Frisch, M. J.; Trucks, G. W.; Schlegel, H. B.; Scuseria, G. E.; Robb, M. A.; Cheeseman, J. R.; Montgomery, Jr., J. A.; Vreven, T.; Kudin, K. N.; Burant, J. C.; Millam, J. M.; Iyengar, S. S.; Tomasi, J.; Barone, V.; Mennucci, B.; Cossi, M.; Scalmani, G.; Rega, N.; Petersson, G. A.; Nakatsuji, H.; Hada, M.; Ehara, M.; Toyota, K.; Fukuda, R. ; Hasegawa, J.; Ishida, M.; Nakajima, T.; Honda, Y.; Kitao, O.; Nakai, H.; Klene, M.; Li, X.; Knox, J. E.; Hratchian, H. P.; Cross, J. B.; Bakken, V.; Adamo, C.; Jaramillo, J.; Gomperts, R.; Stratmann, R. E.; Yazyev, O.; Austin, A. J.; Cammi, R.; Pomelli, C.; Ochterski, J. W.; Ayala, P. Y.; Morokuma, K.; Voth, G. A.; Salvador, P.; Dannenberg, J. J.; Zakrzewski, V. G.; Dapprich, S. A.; Daniels, D.; Strain, M. C.; Farkas, O.; Malick, D. K.; Rabuck, A. D.; Raghavachari, K.; Foresman, J. B.; Ortiz, J. V.; Cui, Q.; Baboul, A. G.; Clifford, S.; Cioslowski, J.; Stefanov, B. B.; Liu, G.; Liashenko, A.; Piskorz, P.; Komaromi, I.; Martin, R. L.; Fox, D. J.; Keith, T.; Al-Laham, M. A.; Peng, C. Y.; Nanayakkara, A.; Challacombe, M.; Gill, P. M. W.; Johnson, B.; Chen, W.; Wong, M. W.; Gonzalez, C.; Pople, J. A. Gaussian 03, Revision E.01; Gaussian, Inc.: Wallingford, CT, 2004.

(18) Becke, A. D. J. Chem. Phys. 1993, 98, 5648-5652.

(19) Lee, C.; Yang, W.; Parr, R. G. Phys. Rev. B 1988, 37, 785-789.

(20) Hay, P. J.; Wadt, W. R. J. Chem. Phys. 1985, 82, 299-310.

(21) Höllwarth, A.; Böhme, M.; Dapprich, S.; Ehlers, A. W.; Gobbi, A.; Jonas, V.; Köhler, K. F.; Stegman, R; Veldkamp, A.; Frenking, G. Chem. Phys. Lett. 1993, 208, 237-240.

(22) (a) Hariharan, P. C.; Pople, J. A. Theor. Chim. Acta 1973, 28, 213-222. (b) Petersson, G. A.; Al-Laham, M. A. J. Chem. Phys. 1991, 94, 6081-6090. (c) Petersson, G. A.; Bennett, A.; Tensfeldt, T. G.; AlLaham, M. A.; Shirley, W. A.; Mantzaris, J. J. Chem. Phys. 1988, 89, 2193-2218.

(23) Wiberg, K. Tetrahedron 1968, 24, 1083-1096.

(24) Glendening, E. D.; Badenhoop, J. K.; Reed, A. E.; Carpenter, J. E.; Bohmann, J. A.; Morales, C. M.; Weinhold, F. NBO, 5.9; Theoretical Chemistry Institute, University of Wisconsin: Madison, WI, 2009; http://www.chem.wisc.edu/ nbo5.

(25) SAINT+, SAX area detector integration program, Version 6.02; Bruker AXS, Inc.: Madison, WI, 1999.

(26) (a) Sheldrick, G. M. SHELXTL, An integrated system for solving, refining, and displaying crystal structures from diffraction data, Version 5.1; Bruker AXS, Inc.: Madison, WI, 1998. (b) Sheldrick, G. M. Acta Crystallogr. 2008, A64, 112-122.

(27) Sheldrick, G. M. SADABS, Empirical Absorption Correction Program; University of Göttingen: Göttingen, Germany, 1997.

(28) (a) Nardelli, M. Comput. Chem. 1983, 7, 95-98. (b) Nardelli, M. J. Appl. Crystallogr. 1995, 28, 659.

(29) (a) Jeffrey, G. A.; Lewis, L. Carbohydr. Res. 1978, 60, 179-182.

(b) Taylor, R; Kennard, O. Acta Crystallogr. 1983, B39, 133-138. 

Anexo $V$ 

Note

\title{
(Piperidinomethyl)silylmethyl cyclopalladated complexes with amino acidato ligands
}

\author{
José S. Melero ${ }^{a}$, Patricia Gómez-Iglesias ${ }^{\text {a }}$, Daniel Schildbach ${ }^{\mathrm{b}}$, Carsten Strohmann ${ }^{\mathrm{b}, * *}$, \\ Fernando Villafañe ${ }^{\mathrm{a}, *}$ \\ a IU CINQUIMA/Química Inorgánica, Facultad de Ciencias, Universidad de Valladolid, 47005 Valladolid, Spain \\ b TU Dortmund, Otto-Hahn-Str. 6, 44227 Dortmund, Germany
}

\section{A R T I C L E I N F O}

\section{Article history:}

Received 7 March 2012

Received in revised form

25 April 2012

Accepted 8 May 2012

Keywords:

Palladium

Metallacycles

$\alpha$-Amino acids

Hydrogen bonds

\begin{abstract}
A B S T R A C T
The reactions of $\left[\mathrm{Pd}\left\{\mathrm{CH}_{2} \mathrm{SiPh}_{2}\left(\mathrm{CH}_{2} N \mathrm{~N}_{5} \mathrm{H}_{10}\right)-\kappa^{2} \mathrm{C}, \mathrm{N}\right\}(\mu-\mathrm{Cl})\right]_{2}$ with the tetra-n-butylammonium $\mathrm{N}^{\mathrm{n}} \mathrm{Bu}_{4}^{+}$salts of different deprotonated $\alpha$-amino acids (N,N-dimethylglycine, $(S)-(+)$-alanine, $(R)-(-)$-2-phenylglycine, and $(S)-(+)$-valine) lead to the amino acidato complexes $\left[\mathrm{Pd}\left\{\mathrm{CH}_{2} \mathrm{SiPh}_{2}\left(\mathrm{CH}_{2} N \mathrm{C}_{5} \mathrm{H}_{10}\right)-\kappa^{2} C, N\right\}\left\{N R_{2} \mathrm{CH}\left(\mathrm{R}^{\prime}\right)\right.\right.$ $\left.\left.\mathrm{C}(\mathrm{O}) O-\kappa^{2} \mathrm{~N}, \mathrm{O}\right\}\right]\left(\mathrm{R}=\mathrm{Me}, \mathrm{R}^{\prime}=\mathrm{H} ; \mathrm{R}=\mathrm{H} ; \mathrm{R}^{\prime}=\mathrm{Me}, \mathrm{Ph},{ }^{\mathrm{i}} \mathrm{Pr}\right)$, where both nitrogen donor atoms are coordinated trans, as shows the crystal structure of $\left[\mathrm{Pd}\left\{\mathrm{CH}_{2} \mathrm{SiPh}_{2}\left(\mathrm{CH}_{2} \mathrm{NC}_{5} \mathrm{H}_{10}\right)-\kappa^{2} \mathrm{C}, N\right\}\left\{N \mathrm{NH}_{2} \mathrm{CH}\left({ }^{\mathrm{i}} \mathrm{Pr}\right) \mathrm{C}(\mathrm{O}) \mathrm{O}\right.\right.$ $\left.\left.\kappa^{2} N, O\right\}\right]$.
\end{abstract}

(C) 2012 Elsevier B.V. All rights reserved.

\section{Introduction}

The organometallic chemistry of complexes containing $\alpha$-amino carboxylates as ligands embraces two independents fields of interest: organometallics and biomolecules [1]. Considering palladium chemistry, the most important application of $\alpha$-amino acidato ligands is their use as chiral resolving agents to synthesize optically active palladacycles [2]. We considered of interest continuing our studies on the syntheses and reactivity of [diphenyl(piperidinomethyl)silylmethyl]palladium(II) complexes [3] by coordinating $\alpha$-amino acidato ligands. The interest of palladacycles containing a non-donor silicon atom inside the metallacycle lie on the study of their stability, their chemical properties and their structural aspects [4].

\section{Results and discussion}

The complex $\left[\mathrm{Pd}\left\{\mathrm{CH}_{2} \mathrm{SiPh}_{2}\left(\mathrm{CH}_{2} \mathrm{NC}_{5} \mathrm{H}_{10}\right)-\kappa^{2} \mathrm{C}, \mathrm{N}\right\}(\mu-\mathrm{Cl})\right]_{2}(\mathbf{1})$ reacts in THF with the $\mathrm{N}^{\mathrm{n}} \mathrm{Bu}_{4}^{+}$salts [5] of the amino acids (N,N-dimethylglycine, $(S)-(+)$-alanine, $(R)-(-)-2$-phenylglycine, and $(S)$ -

\footnotetext{
* Corresponding author. Fax: +34983 423013

** Corresponding author. Tel.: +49 231755 3807; fax: +49 2317557062.

E-mail addresses: mail@carsten-strohmann.de (C. Strohmann), fervilla@ qi.uva.es (F. Villafañe).
}

(+)-valine) in a $1 / 2 \mathrm{M}$ ratio to give $\left[\mathrm{Pd}\left\{\mathrm{CH}_{2} \mathrm{SiPh}_{2}\left(\mathrm{CH}_{2} \mathrm{NC}_{5} \mathrm{H}_{10}\right)\right.\right.$ $\left.\left.\kappa^{2} C, N\right\}\left\{N R_{2} C H\left(\mathrm{R}^{\prime}\right) \mathrm{C}(\mathrm{O}) O-\kappa^{2} N, O\right\}\right]\left[\mathrm{R}=\mathrm{Me}, \mathrm{R}^{\prime}=\mathrm{H}(2) ; \mathrm{R}=\mathrm{H} ; \mathrm{R}^{\prime}=\mathrm{Me}\right.$ (3), $\left.\operatorname{Ph}(\mathbf{4}),{ }^{\mathrm{i}} \operatorname{Pr}(\mathbf{5})\right]$ (Scheme 1). Complex 5 was subjected to a crystal structure determination by X-ray, shown in Fig. 1.

The palladium coordination environment is close to square planar, where the oxygen donor atom of the carboxylate $\mathrm{O}(1)$ deviates only $0.022 \AA$ from the coordination plane (Rms deviation of fitted atoms $=0.018 \AA$ ). Both the amino acidato ligand and the palladacyle adopt a envelope conformation ( $\mathrm{Rms}$ deviation of fitted atoms $=0.009$ and $0.001 \AA$ ), where the silicon atom is that more deviated $(0.843 \AA)$. The diphenylsilicon moiety and the iso-propyl group are in an anti arrangement, as they are at opposite sides of the coordination square plane. Distances and angles are comparable with those found in closely related compounds, namely those palladacycles containing only $C(\mathrm{sp}[3]), \mathrm{N}$-donor atoms [2o,3b,6].

The $\mathrm{N}$-bound hydrogens in the amino acidate ligand are involved in intermolecular hydrogen bonds with the uncoordinated oxygen atom of the same ligand in a adjacent molecule, forming a chain structure (see Supplementary information). The $\mathrm{O}(2) \cdots \mathrm{H}(2)$ distance (2.790), and the corresponding $\mathrm{N} \cdots \mathrm{O}$ distance $(3.490 \AA)$ and $\mathrm{N}-\mathrm{H} \cdots \mathrm{O}$ angle $\left(126^{\circ}\right)$ confirm the presence of a hydrogen bond which may be considered "weak" [7].

The ${ }^{1} \mathrm{H}$ NMR spectra of the complexes allow to propose the same structure of $\mathbf{5}$ for the rest of complexes synthesized. The spectra of the non chiral complex $\mathbf{2}$ is immediately interpreted, since the methylene $\left(\mathrm{PdCH}_{2} \mathrm{Si}, \mathrm{NCH}_{2} \mathrm{Si}, \mathrm{CH}_{2} \mathrm{CO}_{2}\right)$ and methyl groups give rise 


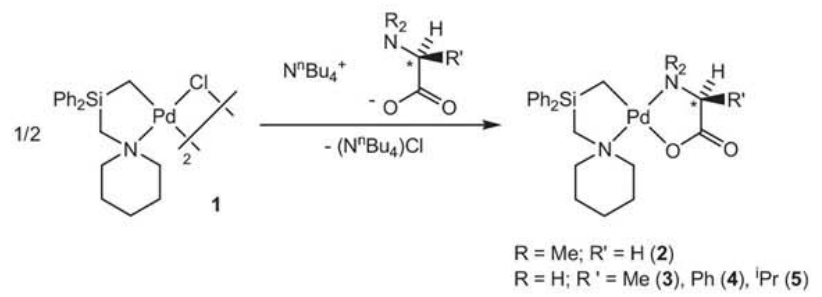

Scheme 1. General synthesis of amino acidato complexes starting from 1.

to singlets, indicating the presence of only one isomer in solution. The ${ }^{1} \mathrm{H}$ NMR spectra of the chiral $\alpha$-amino acidato complexes 3-5 differ clearly from that of $\mathbf{2}$, because the chirality of the $\alpha$ carbon makes inequivalent both sides of the coordination square plane. Therefore, the methylene hydrogens of the metallacycle $\left(\mathrm{PdCH}_{2} \mathrm{Si}\right.$, $\mathrm{NCH}_{2} \mathrm{Si}$ ) and the aminic hydrogens are diastereotopic, although this is not observed in all the cases. In fact, the inequivalence of the methylenic protons is only observed in $\mathrm{CDCl}_{3}$ for $\mathbf{5}\left(\mathrm{R}^{\prime}={ }^{\mathrm{i}} \mathrm{Pr}\right)$ where each methylene gives rise to an $A B$ system. However, a singlet is observed for each methylene group for $\mathbf{3}$ and $\mathbf{4}$ in $\mathrm{CDCl}_{3}$. When the ${ }^{1} \mathrm{H}$ NMR spectra are carried out in $\left(\mathrm{CD}_{3}\right)_{2} \mathrm{CO}$ as solvent, the methylene groups in $\mathbf{4}\left(\mathrm{R}^{\prime}=\mathrm{Ph}\right)$ display an $\mathrm{AB}$ system, but these protons remain equivalent in $3\left(\mathrm{R}^{\prime}=\mathrm{Me}\right)$. Therefore, the inequivalent sequence observed is ${ }^{\mathrm{i}} \operatorname{Pr}(\mathbf{5})>\mathrm{Ph}(\mathbf{4})>\mathrm{Me}(\mathbf{3})$, that is the inequivalence of the methylenic protons is more easily detected when increasing the volume of the group causing this inequivalence between both sides of the coordination square plane. In the later case, for the smallest group, the inequivalence is not observed in $\mathrm{CDCl}_{3}$ nor in $\left(\mathrm{CD}_{3}\right)_{2} \mathrm{CO}$, for 4 it is observed in $\left(\mathrm{CD}_{3}\right)_{2} \mathrm{CO}$ but not observed in $\mathrm{CDCl}_{3}$, whereas in the first case, for the bigger group, the inequivalence is observed in $\mathrm{CDCl}_{3}$. On the other hand, the hydrogens of the $\mathrm{NH}_{2}$ groups are inequivalent for all the complexes, since they are very close to the origin of this inequivalence. As expected, the chain arrangement of the molecules observed in the solid state for $\mathbf{5}$ (Fig. S1) do not persist in solution, as indicated by the NMR data.

The solid IR spectra of all the complexes show two intense absorptions in the $1608-1646 \mathrm{~cm}^{-1}$ and in the $1376-1386 \mathrm{~cm}^{-1}$ regions, which are indicative of the coordination of a monodentate carboxylate ligand [8].

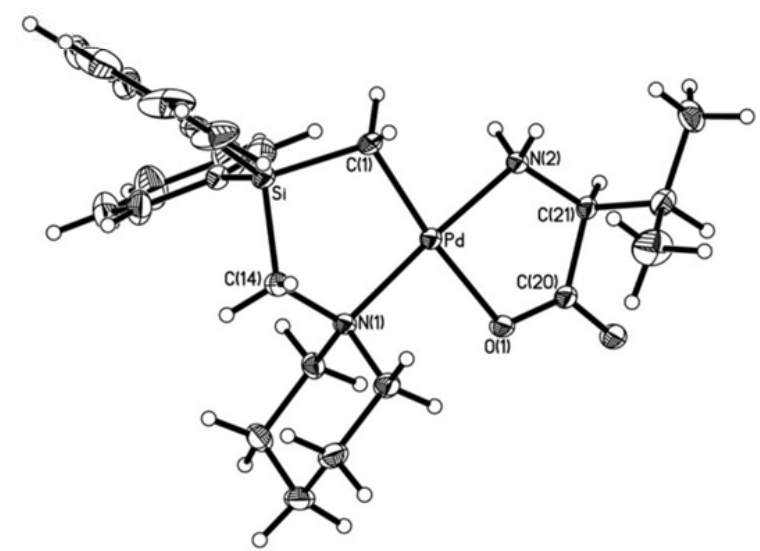

Fig. 1. Molecular structure and numbering scheme of $\left[\mathrm{Pd}\left\{\mathrm{CH}_{2} \mathrm{SiPh}_{2}\left(\mathrm{CH}_{2} \mathrm{NC}_{5} \mathrm{H}_{10}\right)-\right.\right.$ $\left.\left.\kappa^{2} \mathrm{C}, \mathrm{N}\right\}\left\{\mathrm{NH}_{2} \mathrm{CH}\left({ }^{\mathrm{i}} \mathrm{Pr}\right) \mathrm{C}(\mathrm{O}) \mathrm{O}-\kappa^{2} \mathrm{~N}, \mathrm{O}\right\}\right](\mathbf{5})$ in the crystal. The ellipsoids are drawn at $30 \%$ probability. Selected distances $(\AA)$ and angles $\left({ }^{\circ}\right)$ : $\mathrm{Pd}-\mathrm{C}(1) 2.031(3), \mathrm{Si}-\mathrm{C}(1) 1.845(3)$, $\mathrm{Si}-\mathrm{C}(14) 1.885(3), \mathrm{Pd}-\mathrm{N}(1) 2.101(2), \mathrm{Pd}-\mathrm{N}(2)$ 2.024(2), Pd-O(1) 2.117(2), N(2)-Pd$\mathrm{C}(1) 90.62(11), \mathrm{N}(2)-\mathrm{Pd}-\mathrm{N}(1)$ 176.24(9), C(1)-Pd-N(1) 93.14(11), N(2)-Pd-O(1) 82.28(9), C(1)-Pd-O(1) 172.58(11), N(1)-Pd-O(1) 93.96(8), Si-C(1)-Pd 104.00(14).
The coordination of both nitrogen atoms in trans detected in the crystal is in accordance with the antisymbiotic effect of the soft palladium(II) center [9], also defined as transphobia [10]. Thus, the harder atom of the amino acidato ligand (the oxygen donor atom of the carboxylate) is coordinated cis to the harder donor atom of the palladacycle (the nitrogen donor atom of the piperidine).

\section{Experimental}

\subsection{General remarks}

Infrared [KBr pellets, $4000-400 \mathrm{~cm}^{-1}$ ]: Perkin-Elmer $1720 \mathrm{X} .{ }^{1} \mathrm{H}$ NMR [ solvents $\mathrm{CDCl}_{3}$ or $\left(\mathrm{CD}_{3}\right)_{2} \mathrm{CO}$; internal standards $\mathrm{CHCl}_{3}(\delta=7.26)$ and $\mathrm{CHD}_{2} \mathrm{C}(\mathrm{O}) \mathrm{CD}_{3}(\delta=2.04)$; recorded at room temperature]: Bruker AC-300 or ARX-300 (300.13 MHz). -Microanalyses: Perkin-Elmer 2400B microanalyzer, Departamento de Química Inorgánica, Facultad de Ciencias, Valladolid (Spain). -All reactions were carried out under oxygen-free and dried dinitrogen following conventional Schlenk techniques. The solvents were dried according to common procedures. Complex $\mathbf{1}$ was obtained as previously described [5b]. The rest of reactants were obtained from usual commercial suppliers.

\subsection{General method for the preparation of the complexes}

$\mathrm{N}^{\mathrm{n}} \mathrm{Bu}_{4} \mathrm{OH}\left(112 \mu \mathrm{L}, 1.78 \mathrm{M}\right.$ in $\left.\mathrm{H}_{2} \mathrm{O}\right)$ was added to a solution of the $\alpha$-amino acid $(0.2 \mathrm{mmol})$ in $\mathrm{MeOH}(10 \mathrm{~mL})$. The volatiles were removed in vacuo, the white residue was dissolved in THF, and $\mathbf{1}$ $(0.087 \mathrm{~g}, 0.1 \mathrm{mmol})$ was added as a solid. The solution was stirred at room temperature for $5 \mathrm{~h}$ and the solvent was removed in vacuo. The residue was washed with $\mathrm{H}_{2} \mathrm{O}(3 \times 5 \mathrm{~mL})$, vacuum dried, and recrystallized from toluene/hexane at $-20^{\circ} \mathrm{C}$. The solid obtained was washed with hexane $(3 \times 3 \mathrm{~mL})$, and vacuum dried. Colors of the complexes and yields are indicated below.

\section{3. $\left[\mathrm{Pd}\left\{\mathrm{CH}_{2} \mathrm{SiPh}_{2}\left(\mathrm{CH}_{2} \mathrm{NC}_{5} \mathrm{H}_{10}\right)-\mathrm{C}, \mathrm{N}\right\}\left\{\mathrm{NMe}_{2} \mathrm{CH}_{2} \mathrm{C}(\mathrm{O}) \mathrm{O}-\mathrm{N}, \mathrm{O}\right\}\right]$ (2)}

Yellow crystals, $0.063 \mathrm{~g}(66 \%) .{ }^{1} \mathrm{H}$ NMR $\left(\mathrm{CDCl}_{3}\right): \delta 0.70(\mathrm{~s}$, $\left.\mathrm{PdCH}_{2} \mathrm{Si}, 2 \mathrm{H}\right), 1.30\left(\mathrm{~m}, \gamma-\mathrm{NC}_{5} \mathrm{H}_{10}, 1 \mathrm{H}\right), 1.66\left(\mathrm{~m}, \beta\right.$ - and $\gamma-\mathrm{NC}_{5} \mathrm{H}_{10}$, $5 \mathrm{H}), 2.29\left(\mathrm{~m}, \alpha-\mathrm{NC}_{5} \mathrm{H}_{10}, 2 \mathrm{H}\right), 2.50\left(\mathrm{~s}, \mathrm{NCH}_{3}, 6 \mathrm{H}\right), 2.93\left(\mathrm{~s}, \mathrm{CH}_{2} \mathrm{CO}_{2}\right.$, $2 \mathrm{H}), 3.30\left(\mathrm{~s}, \mathrm{NCH}_{2} \mathrm{Si}, 2 \mathrm{H}\right), 3.36\left(\mathrm{~m}, \alpha-\mathrm{NC}_{5} \mathrm{H}_{10}, 2 \mathrm{H}\right), 7.32(\mathrm{~m}, \mathrm{~m}$ - and p- $\left.\mathrm{C}_{6} \mathrm{H}_{5}, 6 \mathrm{H}\right), 7.63\left(\mathrm{~m}, \mathrm{C}_{6} \mathrm{H}_{5}, 4 \mathrm{H}\right) .{ }^{1} \mathrm{H}$ NMR [( $\left.\left(\mathrm{CD}_{3}\right)_{2} \mathrm{CO}\right]: \delta 0.74(\mathrm{~s}$, $\left.\mathrm{PdCH}_{2} \mathrm{Si}, 2 \mathrm{H}\right), 1.45\left(\mathrm{~m}, \gamma-\mathrm{NC}_{5} \mathrm{H}_{10}, 2 \mathrm{H}\right), 1.75\left(\mathrm{~m}, \beta-\mathrm{NC}_{5} \mathrm{H}_{10}, 4 \mathrm{H}\right), 2.41$ (m, $\left.\alpha-\mathrm{NC}_{5} \mathrm{H}_{10}, 2 \mathrm{H}\right), 2.59\left(\mathrm{~s}, \mathrm{NCH}_{3}, 6 \mathrm{H}\right), 3.05\left(\mathrm{~s}, \mathrm{CH}_{2} \mathrm{CO}_{2}, 2 \mathrm{H}\right), 3.25$ (s, $\left.\mathrm{NCH}_{2} \mathrm{Si}, 2 \mathrm{H}\right), 3.35\left(\mathrm{~m}, \alpha-\mathrm{NC}_{5} \mathrm{H}_{10}, 2 \mathrm{H}\right), 7.39\left(\mathrm{~m}, m-\right.$ and $\left.p-\mathrm{C}_{6} \mathrm{H}_{5}, 6 \mathrm{H}\right)$, $7.73\left(\mathrm{~m}, \mathrm{C}_{6} \mathrm{H}_{5}, 4 \mathrm{H}\right)$. IR: $3065 \mathrm{w}(\mathrm{vCH}), 3041 \mathrm{w}(\mathrm{vCH}), 2998 \mathrm{w}(\mathrm{vCH})$, $2961 \mathrm{~m}(v \mathrm{CH}), 2928 \mathrm{~m}(v \mathrm{CH}), 2851 \mathrm{~m}(v \mathrm{CH}), 1646 \mathrm{vs}(v \mathrm{CO}), 1484 \mathrm{w}$, $1467 \mathrm{~m}, 1455 \mathrm{~m}, 1428 \mathrm{~m}, 1415 \mathrm{w}, 1376 \mathrm{~s}$ ( vCO), $1319 \mathrm{w}, 1305 \mathrm{w}, 1271$ w, 1224 w, 1188 w, 1112 s, 1044 w, 980 m, 960 m, 924 m, 876 s, $795 \mathrm{~m}, 763$ s, 729 s, 702 s, 639 w, 579 m, 553 s, 490 s, 437 m, 406 w. Anal. Calcd. for $\mathrm{C}_{23} \mathrm{H}_{32} \mathrm{~N}_{2} \mathrm{O}_{2} \mathrm{PdSi}$ : C, 54.92; $\mathrm{H}, 6.41 ; \mathrm{N}, 5.57$. Found: $\mathrm{C}$, 54.59; $\mathrm{H}, 6.29 ; \mathrm{N}, 5.37$.

\section{4. $\left[\mathrm{Pd}\left\{\mathrm{CH}_{2} \mathrm{SiPh}_{2}\left(\mathrm{CH}_{2} \mathrm{NC}_{5} \mathrm{H}_{10}\right)-\mathrm{C}, \mathrm{N}\right\}\left\{(\mathrm{S})-\mathrm{NH}_{2} \mathrm{CH}(\mathrm{Me}) \mathrm{C}(\mathrm{O}) \mathrm{O}-\mathrm{N}, \mathrm{O}\right\}\right](3)$}

Greenish yellow crystals, $0.016 \mathrm{~g}(16 \%) .{ }^{1} \mathrm{H}$ NMR $\left(\mathrm{CDCl}_{3}\right): \delta 0.49$ (s, $\left.\mathrm{PdCH}_{2} \mathrm{Si}, 2 \mathrm{H}\right), 1.21\left(\mathrm{~m}, \gamma-\mathrm{NC}_{5} \mathrm{H}_{10}, 1 \mathrm{H}\right), 1.50\left(\mathrm{~d}, J=7.0 \mathrm{~Hz}, \mathrm{CH}_{3}\right.$, $3 \mathrm{H}), 1.61\left(\mathrm{~m}, \beta\right.$ - and $\left.\gamma-\mathrm{NC}_{5} \mathrm{H}_{10}, 3 \mathrm{H}\right), 1.92\left(\mathrm{~m}, \beta-\mathrm{NC}_{5} \mathrm{H}_{10}, 2 \mathrm{H}\right), 1.99(\mathrm{~m}$, $\left.\mathrm{NH}_{2}, 1 \mathrm{H}\right), 2.23\left(\mathrm{~m}, \alpha-\mathrm{NC}_{5} \mathrm{H}_{10}, 2 \mathrm{H}\right), 2.80\left(\mathrm{~m}, \mathrm{NH}_{2}, 1 \mathrm{H}\right), 2.99(\mathrm{~s}$, $\left.\mathrm{NCH}_{2} \mathrm{Si}, 2 \mathrm{H}\right), 3.33\left(\mathrm{~m}, \alpha-\mathrm{NC}_{5} \mathrm{H}_{10}, 2 \mathrm{H}\right), 3.61(\mathrm{q}, J=7.0 \mathrm{~Hz}, \mathrm{CH}, 1 \mathrm{H})$, $7.31\left(\mathrm{~m}, \mathrm{~m}\right.$ - and $\left.p-\mathrm{C}_{6} \mathrm{H}_{5}, 6 \mathrm{H}\right), 7.62\left(\mathrm{~m}, 0-\mathrm{C}_{6} \mathrm{H}_{5}, 4 \mathrm{H}\right) .{ }^{1} \mathrm{H}$ NMR $\left[\left(\mathrm{CD}_{3}\right)_{2} \mathrm{CO}\right]: \delta 0.51\left(\mathrm{~s}, \mathrm{PdCH}_{2} \mathrm{Si}, 2 \mathrm{H}\right), 1.38\left(\mathrm{~d}, J=7.0 \mathrm{~Hz}, \mathrm{CH}_{3}, 3 \mathrm{H}\right)$, $1.30-1.80\left(\mathrm{~m}, \beta\right.$ - and $\left.\gamma-\mathrm{NC}_{5} \mathrm{H}_{10}, 6 \mathrm{H}\right), 2.32\left(\mathrm{~m}, \alpha-\mathrm{NC}_{5} \mathrm{H}_{10}, 2 \mathrm{H}\right), 3.03$ $\left(\mathrm{s}, \mathrm{NCH}_{2} \mathrm{Si}, 2 \mathrm{H}\right), 3.27\left(\mathrm{~m}, \alpha-\mathrm{NC}_{5} \mathrm{H}_{10}, 2 \mathrm{H}\right), 3.40(\mathrm{q}, J=7.0 \mathrm{~Hz}, \mathrm{CH}, 1 \mathrm{H})$, $3.46\left(\mathrm{~m}, \mathrm{NH}_{2}, 1 \mathrm{H}\right), 4.26\left(\mathrm{~m}, \mathrm{NH}_{2}, 1 \mathrm{H}\right), 7.35\left(\mathrm{~m}, \mathrm{~m}\right.$ - and $\left.p-\mathrm{C}_{6} \mathrm{H}_{5}, 6 \mathrm{H}\right)$, $7.74\left(\mathrm{~m}, o-\mathrm{C}_{6} \mathrm{H}_{5}, 4 \mathrm{H}\right) . \mathrm{IR}: 3241 \mathrm{w}(\mathrm{vNH}), 3117 \mathrm{w}(v \mathrm{NH}), 2937 \mathrm{~m}$ 
$(v \mathrm{CH}), 2855 \mathrm{w}(v \mathrm{CH}), 1623 \mathrm{~s}(v \mathrm{CO}), 1454 \mathrm{~m}, 1427 \mathrm{~m}, 1386 \mathrm{~s}(v \mathrm{CO})$, 1290 w, 1156 w, 1111 s, 1043 w, 865 w, 799 w, 765 m, 734 m, 701 s, $552 \mathrm{~m}, 503 \mathrm{~m}, 424$ w. Anal. Calcd. for $\mathrm{C}_{22} \mathrm{H}_{28} \mathrm{~N}_{2} \mathrm{O}_{2} \mathrm{PdSi}$ : C, 54.04; $\mathrm{H}$, 6.18; N, 5.73. Found: C, 53.69; H, 5.85; N, 5.41.

\section{5. $\left[\mathrm{Pd}\left\{\mathrm{CH}_{2} \mathrm{SiPh}_{2}\left(\mathrm{CH}_{2} \mathrm{NC}_{5} \mathrm{H}_{10}\right)-\mathrm{C}, \mathrm{N}\right\}\left\{(\mathrm{R})-\mathrm{NH}_{2} \mathrm{CH}(\mathrm{Ph}) \mathrm{C}(\mathrm{O}) \mathrm{O}-\mathrm{N}, \mathrm{O}\right\}\right]$ (4)}

Pale yellow solid, $0.025 \mathrm{~g}$ (23\%). ${ }^{1} \mathrm{H}$ NMR $\left(\mathrm{CDCl}_{3}\right): \delta 0.53(\mathrm{~s}$ $\left.\mathrm{PdCH}_{2} \mathrm{Si}, 2 \mathrm{H}\right), 1.28\left(\mathrm{~m}, \gamma-\mathrm{NC}_{5} \mathrm{H}_{10}, 1 \mathrm{H}\right), 1.64\left(\mathrm{~m}, \beta\right.$ - and $\gamma-\mathrm{NC}_{5} \mathrm{H}_{10}$, $3 \mathrm{H}), 1.93\left(\mathrm{~m}, \beta-\mathrm{NC}_{5} \mathrm{H}_{10}, 2 \mathrm{H}\right), 2.34\left(\mathrm{~m}, \alpha-\mathrm{NC}_{5} \mathrm{H}_{10}, 2 \mathrm{H}\right.$, and $\left.\mathrm{NH}_{2}, 1 \mathrm{H}\right)$, $3.02\left(\mathrm{~s}, \mathrm{NCH}_{2} \mathrm{Si}, 2 \mathrm{H}\right), 3.20\left(\mathrm{~m}, \mathrm{NH}_{2}, 1 \mathrm{H}\right), 3.39\left(\mathrm{~m}, \alpha-\mathrm{NC}_{5} \mathrm{H}_{10}, 2 \mathrm{H}\right)$, $4.56(\mathrm{~m}, \mathrm{CH}, 1 \mathrm{H}), 7.29\left(\mathrm{~m}, \mathrm{~m}\right.$ - and $\left.p-\mathrm{C}_{6} \mathrm{H}_{5}, 9 \mathrm{H}\right), 7.60\left(\mathrm{~m}, \mathrm{o}-\mathrm{C}_{6} \mathrm{H}_{5}, 6 \mathrm{H}\right)$. ${ }^{1} \mathrm{H}$ NMR $\left[\left(\mathrm{CD}_{3}\right)_{2} \mathrm{CO}\right]: \delta 0.64$ and 0.66 (AB system, $J=12.5 \mathrm{~Hz}$, $\left.\mathrm{PdCH}_{2} \mathrm{Si}, 2 \mathrm{H}\right), 1.37\left(\mathrm{~m}, \gamma-\mathrm{NC}_{5} \mathrm{H}_{10}, 1 \mathrm{H}\right), 1.60\left(\mathrm{~m}, \beta\right.$ - and $\gamma-\mathrm{NC}_{5} \mathrm{H}_{10}$ $3 \mathrm{H}), 2.00\left(\mathrm{~m}, \beta-\mathrm{NC}_{5} \mathrm{H}_{10}, 2 \mathrm{H}\right), 2.41\left(\mathrm{~m}, \alpha-\mathrm{NC}_{5} \mathrm{H}_{10}, 2 \mathrm{H}\right), 3.07$ and 3.15 (AB system, $J=14.5 \mathrm{~Hz}, \mathrm{NCH}_{2} \mathrm{Si}, 2 \mathrm{H}$ ), $3.35\left(\mathrm{~m}, \alpha-\mathrm{NC}_{5} \mathrm{H}_{10}, 2 \mathrm{H}\right.$ ), 3.67 $\left(\mathrm{m}, \mathrm{NH}_{2}, 1 \mathrm{H}\right), 4.42(\mathrm{~m}, \mathrm{CH}, 1 \mathrm{H}), 4.77\left(\mathrm{~m}, \mathrm{NH}_{2}, 1 \mathrm{H}\right), 7.34(\mathrm{~m}, \mathrm{~m}$ - and p- $\left.\mathrm{C}_{6} \mathrm{H}_{5}, 9 \mathrm{H}\right), 7.69\left(\mathrm{~m}, \mathrm{o}-\mathrm{C}_{6} \mathrm{H}_{5}, 4 \mathrm{H}\right), 7.81\left(\mathrm{~m}, \mathrm{C}_{6} \mathrm{H}_{5}, 2 \mathrm{H}\right) . \mathrm{IR}: 3326 \mathrm{w}$ $(v \mathrm{NH}), 3045 \mathrm{w}(\mathrm{vCH}), 2918 \mathrm{w}(\mathrm{vCH}), 2883 \mathrm{w}(\mathrm{vCH}), 2854 \mathrm{w}(v \mathrm{CH})$ $2811 \mathrm{w}(v \mathrm{CH}), 1615$ vs (vCO), $1495 \mathrm{w}, 1455 \mathrm{~m}, 1427 \mathrm{~s}, 1380 \mathrm{~s}$ ( $v \mathrm{CO})$, 1305 m, 1262 w, 1229 w, 1104 s, 1040 s, 972 m, 863 w, 800 s, 769 s, 760 s, 736 s, 718 s, 701 s, 498 m. Anal. Calcd. for $\mathrm{C}_{27} \mathrm{H}_{32} \mathrm{~N}_{2} \mathrm{O}_{2}$ PdSi: C, $58.85, \mathrm{H}, 5.85 ; \mathrm{N}, 5.08$. Found: C, 58.52; H, 5.88; N, 4.89 .

\section{6. $\left[\mathrm{Pd}\left\{\mathrm{CH}_{2} \mathrm{SiPh}_{2}\left(\mathrm{CH}_{2} \mathrm{NC}_{5} \mathrm{H}_{10}\right)-\mathrm{C}, \mathrm{N}\right\}\left\{(\mathrm{R})-\mathrm{NH}_{2} \mathrm{CH}\left({ }^{\mathrm{i}} \mathrm{Pr}\right) \mathrm{C}(\mathrm{O}) \mathrm{O}-\mathrm{N}, \mathrm{O}\right\}\right]$ (5)}

Yellow crystals, $0.036 \mathrm{~g}(31 \%) .{ }^{1} \mathrm{H}$ NMR $\left(\mathrm{CDCl}_{3}\right): \delta 0.47$ and 0.50 (AB system, $J=12 \mathrm{~Hz}, \mathrm{PdCH}_{2} \mathrm{Si}, 2 \mathrm{H}$ ), 1.00 (dd, $J=7.0$ and $1.0 \mathrm{~Hz}, \mathrm{CH}_{3}$, $6 \mathrm{H}), 1.22\left(\mathrm{~m}, \gamma-\mathrm{NC}_{5} \mathrm{H}_{10}, 1 \mathrm{H}\right), 1.60\left(\mathrm{~m}, \beta-\right.$ and $\left.\gamma-\mathrm{NC}_{5} \mathrm{H}_{10}, 3 \mathrm{H}\right), 1.90(\mathrm{~m}$, $\left.\beta-\mathrm{NC}_{5} \mathrm{H}_{10}, 2 \mathrm{H}\right), 2.17\left(\mathrm{~m}, \mathrm{NH}_{2}, 1 \mathrm{H}\right), 2.27\left(\mathrm{~m}, \alpha-\mathrm{NC}_{5} \mathrm{H}_{10}, 2 \mathrm{H}\right), 2.45(\mathrm{~m}$, $\left.\mathrm{CHMe}_{2}, 1 \mathrm{H}\right), 2.60\left(\mathrm{~m}, \mathrm{CH}^{\mathrm{i}} \mathrm{Pr}, 1 \mathrm{H}\right), 2.96$ and 3.00 (AB system, $\left.J=14.5 \mathrm{~Hz}, \mathrm{NCH}_{2} \mathrm{Si}, 2 \mathrm{H}\right), 3.32\left(\mathrm{~m}, \alpha-\mathrm{NC}_{5} \mathrm{H}_{10}, 2 \mathrm{H}\right.$, and $\left.\mathrm{NH}_{2}, 1 \mathrm{H}\right), 7.28$ $\left(\mathrm{m}, \mathrm{m}\right.$ - and $\left.p-\mathrm{C}_{6} \mathrm{H}_{5}, 6 \mathrm{H}\right), 7.61\left(\mathrm{~m}, o-\mathrm{C}_{6} \mathrm{H}_{5}, 4 \mathrm{H}\right)$. IR: $3320 \mathrm{~m}(v \mathrm{NH})$, $2932 \mathrm{~s}(\mathrm{vCH}), 1608$ vs $(v \mathrm{CO}), 1485 \mathrm{w}, 1455 \mathrm{~m}, 1427 \mathrm{~s}(v \mathrm{CO}), 1381 \mathrm{~s}$, $1321 \mathrm{w}, 1261 \mathrm{w}, 1162 \mathrm{~m}, 1111 \mathrm{~m}, 1034 \mathrm{~m}, 999 \mathrm{~m}, 971 \mathrm{~m}, 887 \mathrm{w}$ $867 \mathrm{~m}, 839$ w, 807 m, 777 m, 736 s, 700 s, 623 w, 555 w, 495 m, 465 w, 434 w. Anal. Calcd. for $\mathrm{C}_{24} \mathrm{H}_{34} \mathrm{~N}_{2} \mathrm{O}_{2}$ PdSi: C, 55.75, H, 6.63; N, 5.42 . Found: $\mathrm{C}, 55.44 ; \mathrm{H}, 6.31 ; \mathrm{N}, 5.32$.

\subsection{X-ray crystalographic study of 5}

Crystals were grown by slow diffusion of hexane into a concentrated solution of the complexes in toluene at $-20^{\circ} \mathrm{C}$. Relevant crystallographic details are given in Table S2. Measurements were carried out with a Bruker Apex CCD diffractometer; programs used for data collection, cell determination and refinement: Smart V. 5622 (Bruker AXS, 2001), integration: SaintPlus V. 6.02 (Bruker AXS, 1999), empirical absorption correction: Sadabs V. 2.01 (Bruker AXS, 1999). The structure was solved using direct and Fourier methods. Refinement was performed by full-matrix least-squares methods (based on $\mathrm{F}_{\mathrm{o}}$ [2], SHELXL-97). Anisotropic thermal parameters for all non $\mathrm{H}$ atoms were included in the final cycles. the $\mathrm{H}$ atoms were refined on a riding model in their ideal geometric positions. The SHELXS-86 and SHELXL-97 computer programs were used for solving the structure [11].

\section{Acknowledgments}

The authors in Valladolid thank the Spanish Ministerio de Educación y Ciencia (CTQ2009-12111) and the Junta de Castilla y León (GR125 Programa de Grupos de Excelencia de la Junta de
Castilla y León) for financial support. P. G.-I. thanks Universidad de Valladolid MEC for an FPI grant. The authors in Dortmund thank the Deutsche Forschungsgemeinschaft, the Fonds der Chemischen Industrie and Wacker Chemie AG for their support.

\section{Appendix A. Supplementary information}

Supplementary information associated with this article can be found, in the online version, at http://dx.doi.org/10.1016/j. jorganchem.2012.05.014

\section{References}

[1] K. Severin, R. Bergs, W. Beck, Angew. Chem. Int. Ed. 37 (1998) 1634-1654.

[2] Seeforexample: (a) Y. Ding Y. Zhang. Y.Li,S.A. Pullarkat, P.Andrews, P.-H.Leung Eur. J. Inorg. Chem. (2010) 4427-4437;

(b) M. Chiang, Y. Li, D. Krishnan, P. Sumod, K.H. Ng, P.-H. Leung, Eur. J. Inorg. Chem. (2010) 1413-1418;

(c) Y. Ding, M. Chiang, S.A. Pullarkat, Y. Li, P.-H. Leung, Organometallics 28(2009) 4358-4370;

(d) Y. Ding, Y. Li, S.A. Pullarkat, S.L. Yap, P.-H. Leung, Eur. J. Inorg. Chem. (2009) 267-276

(e) Y. Ding, Y. Li, Y. Zhang, S.A. Pullarkat, P.-H. Leung, Eur. J. Inorg. Chem. (2008) 1880-1891:

(f) V.V. Dunina, E.I. Turubanova, M.V. Livantsov, K.A. Lyssenko, Y.K. Grishin, Tetrahedron: Asymmetry 19 (2008) 1519-1522;

(g) J.K.-P. Ng, S. Chen, G.-K. Tan, P.-H. Leung, Eur. J. Inorg. Chem. (2007) 3124-3134;

(h) Y. Li, S. Selvaratnam, J.J. Vittal, P.-H. Leung, Inorg. Chem. 42 (2003) 3229-3236;

(i) F. Levrat, H. Stoeckli-Evans, N. Engel, Tetrahedron: Asymmetry 13 (2002) (i) F. Levrat,

(j) V.V. Dunina, O.N. Gorunova, M.V. Livantsov, Y.K. Grishin, L.G. Kuz'mina,
N.A. N.A. Kataeva, A.V. Churakov, Tetrahedron: Asymmetry 11 (2000) 3967-3984; (k) V.V. Dunina, O.N. Gorunova, L.G. Kuz'mina, M.V. Livantsov, Y.K. Grishin, Tetrahedron: Asymmetry 10 (1999) 3951-3961:

(I) V.V. Dunina, E.D. Razmyslova, L.G. Kuz'mina, A.V. Churakov, M.Y. Rubina, Y.K. Grishin, Tetrahedron: Asymmetry 10 (1999) 3147-3155;

(m) R. Urban, R. Krämer, S. Mihan, K. Polborn, B. Wagner, W. Beck, J. Organomet. Chem. 517 (1996) 191-200;

(n) D.C.R. Hockless, R.C. Mayadunne, S.B. Wild, Tetrahedron: Asymmetry 6 (1995) 3031-3037;

(o) J. Spencer, F. Maassarani, M. Pfeffer, A. DeCian, J. Fischer, Tetrahedron: Asymmetry 5 (1994) $321-324$.

[3] (a) C. Strohmann, B.C. Abele, K. Lehmen, F. Villafañe, L. Sierra, S. Martín-Barrios, D. Schildbach, J. Organomet. Chem. 661 (2002) 149-158;

(b) D. Schildbach, L Sierra, S. Martín-Barrios, K. Lehmen, F. Villafañe, c. Strohmann, Organometallics 23 (2004) 3228-3238.

[4] (a) Y. Fuchita, M. Nakashima, K. Hiraki, M. Kawatani, J. Chem. Soc. Dalton Trans. (1988) 785-789;

(b) C. Eaborn, M.S. Hill, P.B. Hitchcock, J.D. Smith, J. Chem. Soc. Chem. Commun. (2000) 691-692;

(c) K. Itami, T. Kamei, J. Yoshida, J. Am. Chem. Soc. 123 (2001) 8773-8779.

[5] $\mathrm{Bu}_{4} \mathrm{~N}^{+}$salts were used in order to improve the solubility of the amino acidate anion in THF

[6] (a) E.C. Alyea, S.A. Dias, G. Ferguson, A.J. McAlees, R. McCrindle, P.J. Roberts, J. Am. Chem. Soc. 99 (1977) 4985-4989;

(b) A.G. Constable, W.S. McDonald, L.C. Sawkins, B.L. Shaw, J. Chem. Soc. Dalton Trans. (1980) 1992-2000;

(c) J.W. Suggs, K.S. Lee, J. Organomet. Chem. 299 (1986) 297-309; (d) B. Galli, F. Gasparrini, B.E. Mann, L. Maresca, G. Natile, A.M. Manotti-Lanfredi, A. Tiripicchio, J. Chem. Soc. Dalton Trans. (1985) 1155-1161.

[7] (a) G.A. Jeffrey, "An Introduction to Hydrogen Bonding", Oxford University Press, New York, 1997 (Chapter 2):

(b) T. Steiner, Angew. Chem. Int. Ed. 41 (2002) 48-76.

[8] K. Nakamoto, Infrared and Raman Spectra of Inorganic and Coordination Compounds, third ed., John Wiley \& Sons, New York, 1978, p. 310.

[9] R.G. Pearson, Inorg. Chem. 12 (1973) 712-713.

[10] (a) J. Vicente, A. Arcas, D. Bautista, P.G. Jones, Organometallics 16 (1997) 2127-2138;

(b) J. Vicente, J.A. Abad, A.D. Frankland, M.C. Ramírez de Arellano, Chem. Eur. J. 5 (1999) 3066-3075.

[11] (a) G.M. Sheldrick, SHELXS-86, Structure Solving Program for Crystal Structure Determination, University of Göttingen, Göttingen, 1986; (b) G.M. Sheldrick, SHELXL-97, a Computer Program for Refinement of Crystal Structures, University of Göttingen, Göttingen, 1997. 

Anexo VI 



\title{
Bridging Pseudohalides in Palladacycles as a Source of Different Assemblies
}

\author{
Marta Arroyo, ${ }^{[a]}$ Patricia Gómez-Iglesias, ${ }^{[a]}$ José Santos Melero, ${ }^{[a]}$ Daniel Schildbach, ${ }^{[b]}$ \\ Christian Unkelbach, ${ }^{[b]}$ Carsten Strohmann, ${ }^{* \mid b]}$ and Fernando Villafañe*[a]
}

\author{
Keywords: Self-assembly / Bridging ligands / Palladium / Metallacycles / Silanes
}

The reaction of $\left[\mathrm{Pd}\left\{\mathrm{CH}_{2} \mathrm{SiPh}_{2}\left(\mathrm{CH}_{2} \mathrm{NC}_{5} \mathrm{H}_{10}\right)-\kappa^{2} \mathrm{C}, \mathrm{N}\right\}(\mu-\mathrm{Cl})\right]_{2}$ $\left(\mathrm{CH}_{2} \mathrm{NC}_{5} \mathrm{H}_{10}=\right.$ piperidinomethyl) with $\mathrm{KSCN}$ led to the centrosymmetric dimer $\left[\mathrm{Pd}\left\{\mathrm{CH}_{2} \mathrm{SiPh}_{2}\left(\mathrm{CH}_{2} \mathrm{NC}_{5} \mathrm{H}_{10}\right)-\kappa^{2} C_{t} N\right\}(\mu\right.$ $\left.\left.\mathrm{SCN}-\kappa^{1} S, \kappa^{1} N\right)\right]_{2}$, which features side-on bridging thiocyanate ligands. However, the analogous reaction of the chloridobridged starting material with $\mathrm{NaN}_{3}$ yielded the dimer $\left[\mathrm{Pd}\left\{\mathrm{CH}_{2} \mathrm{SiPh}_{2}\left(\mathrm{CH}_{2} \mathrm{NC}_{5} \mathrm{H}_{10}\right)-\kappa^{2} \mathrm{C}, N\right\}\left(\mu-\mathrm{N}_{3}-\kappa^{1} \kappa^{1} N\right)\right]_{2}$, in which the azido ligands exhibit end-on coordination. This complex persists as a mixture of cis and trans isomers in solution. Lastly, the square tetrametallic complex $\left[\mathrm{Pd}\left\{\mathrm{CH}_{2} \mathrm{SiPh}_{2}\left(\mathrm{CH}_{2} \mathrm{NC}_{5} \mathrm{H}_{10}\right)-\kappa^{2} \mathrm{C}, N\right\}\left(\mu-\mathrm{CN}-\kappa^{1} C_{,} \kappa^{1} N\right)\right]_{4}$ was obtained from the reaction between the parent chlorido- bridged complex and $\mathrm{AgCN}$. In solution, this compound forms an equilibrium between the tetra- and trimetallic species. Thermodynamic data (equilibrium constants and free energies in $\mathrm{CDCl}_{3}$ and $\mathrm{C}_{6} \mathrm{D}_{6}$, and enthalpy and entropy in $\mathrm{CDCl}_{3}$ ) were determined and show that the formation of the trimetallic isomer is thermodynamically disfavored $\left[K_{\text {eq }}=\right.$ $(1.93 \pm 0.07) \times 10^{-4} \mathrm{molL}^{-1}$ and $\Delta G_{\mathrm{eq}}=20.83 \pm 0.11 \mathrm{~kJ} \mathrm{~mol}^{-1}$ in $\mathrm{CDCl}_{3}, K_{\text {eq }}=(4.5 \pm 0.2) \times 10^{-5} \mathrm{molL}^{-1}$ and $\Delta G_{\text {eq }}=$ $24.40 \pm 0.14 \mathrm{~kJ} \mathrm{~mol}^{-1}$ in $\mathrm{C}_{6} \mathrm{D}_{6}$ ] and that the variation in the enthalpy and entropy are positive $\left(\Delta H=75 \pm 5 \mathrm{~kJ} \mathrm{~mol}^{-1}\right.$ and $\Delta S=186 \pm 15 \mathrm{~J} \mathrm{~mol}^{-1} \mathrm{~K}^{-1}$ in $\left.\mathrm{CDCl}_{3}\right)$.

\section{Introduction}

In coordination chemistry, pseudohalides are interesting polyatomic ligands due to their ability to induce a variety of structural motifs. They often act as bridging ligands giving rise to different structures that may be discrete moieties, such as dimers, trimers, or tetramers, infinite assemblies, such as monodimensional chains, either ladder or helicoid type, or even two- or three-dimensional cages. The final structure depends both on the electronic and structural requirements of both the pseudohalide and the metal fragment used. The donor atoms and the directionality of the frontier orbital determine the coordination mode of the pseudohalide. ${ }^{[1]}$

Following our studies on the reactivity of (piperidinomethyl)silylmethyl cyclopalladated complexes, ${ }^{[2]}$ we decided to explore the behavior of this soft metallic center with two coordinating sites available in cis geometry towards pseudohalides such as cyanide, thiocyanate, or azide, which present several possible coordination modes and give rise to different assemblies, as described herein.

[a] IU CINQUIMA/Química Inorgánica, Facultad de Ciencias, Universidad de Valladolid,

47005 Valladolid, Spain

Fax: +34-983-423-013

E-mail: fervilla@qi.uva.es

[b] Technische Universität Dortmund, Anorganische Chemie, Otto-Hahn-Straße 6, 44227 Dortmund, Germany

Fax: +49-231-755-7062

E-mail: mail@carsten-strohmann.de

Supporting information for this article is available on the WWW under http://dx.doi.org/10.1002/ejic.201200247.
The presence of a silicon atom in the (piperidinomethyl)silylmethyl cyclopalladated complexes is expected to play a dual role: stabilizing the metallated carbon atom by polarization effects and preventing $\beta$-elimination. The palladacycle is made possible by the presence of a nitrogen donor in the side-arm that can coordinate to the $\mathrm{Pd}^{\mathrm{II}}$ center, thereby forming the five-membered palladacycle. This chelating side-arm is an often employed tool, for example, in activating alkylsilanes towards metallation and in stabilizing the configuration of diastereomerically enriched $\alpha$-lithiated alkylsilanes in the case of chiral amine ligands. ${ }^{[3]}$

\section{Results and Discussion}

Chlorido-bridged dimer $\left[\mathrm{Pd}\left\{\mathrm{CH}_{2} \mathrm{SiPh}_{2}\left(\mathrm{CH}_{2} \mathrm{NC}_{5} \mathrm{H}_{10}\right)\right.\right.$ $\left.\left.\kappa^{2} C, N\right\}(\mu-\mathrm{Cl})\right]_{2}(\mathbf{1})$ served as the starting material for the synthesis of new pseudohalido-bridged complexes. The pseudohalides employed were thiocyanate, azide, and cyanide and were introduced by the reaction of 1 with metal salts of the corresponding pseudohalide (Scheme 1).
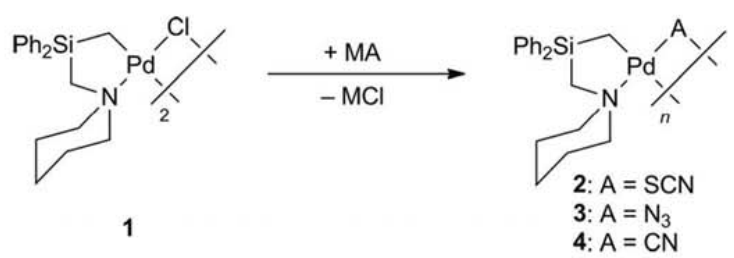

Scheme 1. General synthesis of pseudohalide complexes by starting from 1. 
The reaction of $\mathbf{1}$ with potassium thiocyanate in THF led to a new dimer, $\left[\mathrm{Pd}\left\{\mathrm{CH}_{2} \mathrm{SiPh}_{2}\left(\mathrm{CH}_{2} \mathrm{NC}_{5} \mathrm{H}_{10}\right)-\kappa^{2} C, N\right\}(\mu-\right.$ $\left.\left.\mathrm{SCN}-\kappa^{1} S, \kappa^{1} N\right)\right]_{2}$ (2) in which the pseudohalide acts as bridging ligand. In general, thiocyanate may coordinate in one of the three following modes: Side-on or end-on, and in the later case, with $\mathrm{S}$ or $\mathrm{N}$ as donor (cf. Figure 1). In this case, the IR spectrum of $\mathbf{2}$ immediately suggests a side-on coordination mode as its $\mathrm{CN}$ stretching absorption appears at $2137 \mathrm{~cm}^{-1}$, higher than would be expected for the two end-on coordination modes. ${ }^{[4]}$

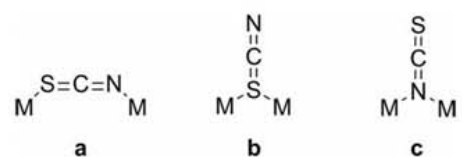

Figure 1. Coordination modes for a bridging thiocyanato ligand.

The molecular structure of $\mathbf{2}$ obtained unambiguously supports this assignment (Figure 2). The compound crystallizes from hexane/dichloromethane with a tetragonal crystal system in the space group $I 4_{1} / a$. The asymmetric unit contains one half of the centrosymmetric dimeric structure.

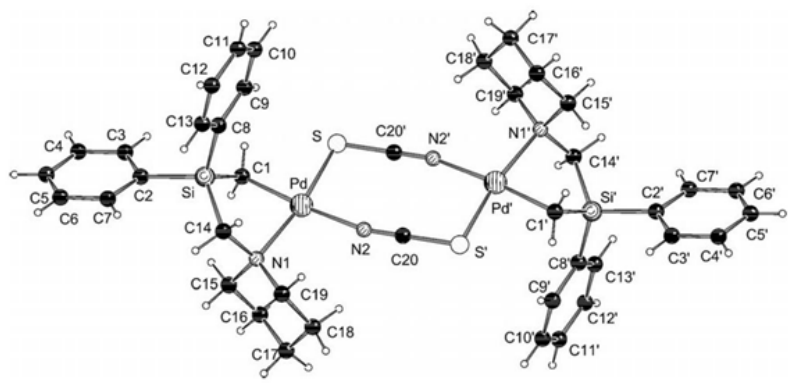

Figure 2. Molecular structure and numbering scheme of compound 2 in the crystal form (SCHAKAL plot). ${ }^{[12]}$ Selected distances $[\AA]$ and angles $\left[{ }^{\circ}\right]$ : $\mathrm{C}(1)-\mathrm{Pd} 2.045(2), \mathrm{C}(1)-\mathrm{Si} 1.849(2), \mathrm{C}(14)-\mathrm{S}$ 1.892(2), C(14)-N(1) 1.497(3), N(1)-Pd 2.1601(17), N(2)-Pd $2.1079(17), \quad \mathrm{Pd}-\mathrm{S} 2.3071(6), \quad \mathrm{S}-\mathrm{C}(20)^{\# 1} \quad 1.669(2), \quad \mathrm{C}(20)-\mathrm{N}(2)$ 1.145(3); Si-C(1)-Pd 99.96(10), C(1)-Si-C(14) 104.05(10), N(1)$\mathrm{C}(14)-\mathrm{Si} 109.59(14), \quad \mathrm{C}(14)-\mathrm{N}(1)-\mathrm{Pd}$ 103.12(12), C(1)-Pd-N(2) 174.78(9), C(1)-Pd-N(1) 86.19(8), N(2)-Pd-N(1) 96.70(6), C(1)$\mathrm{Pd}-\mathrm{S}$ 83.49(7), N(2)-Pd-S 93.62(5), N(1)-Pd-S 169.67(5), N(2)$\mathrm{C}(20)-\mathrm{S}^{\# 1} \quad 179.7(2), \quad \mathrm{C}(20)-\mathrm{N}(2)-\mathrm{Pd} \quad 160.31(16), \quad \mathrm{C}(20)^{\# 1}-\mathrm{S}-\mathrm{Pd}$ 104.34(7). Symmetry operator: ${ }^{\# 1}$ : $-x+1 / 2,-y+3 / 2,-z+1 / 2$.

As the structure of $\mathbf{2}$ is a centrosymmetric dimer, the trans isomer is observed in which both carbon or both nitrogen donor atoms are at opposite sides of the molecule. The thiocyanate groups have a linear geometry $[\mathrm{S}-\mathrm{C}-\mathrm{N}$ $\left.179.7(2)^{\circ}\right]$ and the $\mathrm{S}-\mathrm{C}$ and $\mathrm{C}-\mathrm{N}$ distances are typical of double bonds. ${ }^{[5]}$ The thiocyanato bridging ligands form an eight-membered, nearly planar ring with both palladium centers. The slight distortion from planarity is reflected in the dihedral angle $\mathrm{N}-\mathrm{Pd}-\mathrm{S}-\mathrm{C} 20$ of $8.0(4)^{\circ}$ between the metal atoms and the bridging ligands. This value is similar to those found in other palladium complexes with bridging thiocyanato ligands, such as $11.9(3)^{\circ}$ for $\left[\mathrm{P}\left(\mathrm{CH}_{2} \mathrm{Ph}\right) \mathrm{Ph}_{3}\right]_{2-}$ $\left[\left(\mathrm{C}_{6} \mathrm{~F}_{3} \mathrm{H}_{2}\right)_{2} \mathrm{Pd}(\mu-\mathrm{SCN})(\mu-\mathrm{NCS}) \mathrm{Pd}\left(\mathrm{C}_{6} \mathrm{~F}_{3} \mathrm{H}_{2}\right)_{2}\right]^{[6]}$ or $5.2(4)^{\circ}$ for $\left[\operatorname{Pd}\left(C^{2}, N \text {-dmba }\right)(\mu-\mathrm{SCN})\right]_{2},{ }^{[7]}$ but slightly larger than those found in palladacycles with metallated chiral ferrocenylimines ${ }^{[8]}$ and benzylideneaniline. ${ }^{[9]}$

Each palladium atom is also coordinated by the nitrogen and carbon donor atoms of the $\left[\mathrm{CH}_{2} \mathrm{SiPh}_{2}\left(\mathrm{CH}_{2} \mathrm{NC}_{5} \mathrm{H}_{10}\right)\right]$ moiety, thereby forming the palladacycle. The $\mathrm{Pd}-\mathrm{C}$ distance of $2.045(2) \AA$ is in the range typically found for Pd$\mathrm{C}\left(\mathrm{sp}^{3}\right)$ single bonds. ${ }^{[10]}$

The conformation of the five-membered silapalladacycle may be described as an envelope in which the average dihedral angle of the palladium center with respect to the other four atoms is $36.2(2)^{\circ}$. The presence of palladium and silicon in the five-membered palladacycle results in a short $\mathrm{Pd} \cdots \mathrm{Si}$ distance of 2.985(1) $\AA$, and the $\mathrm{Si}-\mathrm{Cl} 1-\mathrm{Pd}$ angle is $100.0(1)^{\circ}$. These distances and angles in the silapalladacycle are in the range of those previously found. ${ }^{[2]}$

The nitrogen atoms of the bridging thiocyanate and the cyclometallated ligand are coordinated in cis geometry. This is to be expected taking into account the higher trans influence of the carbon donor ligand and of the sulfur donor atom in the bridging thiocyanate compared with the lower trans influence of the two nitrogen donors. This is a result of the antisymbiotic effect of the palladium(II) soft metal center. $^{[11]}$

In solution, only one isomer of $\mathbf{2}$ was detected (see the Exp. Sect.). This suggests that the above geometry is maintained in solution, because any of the end-on modes would give rise to cis and trans geometries. A singlet signal is observed for each methylene group of the palladacycle $\left(\mathrm{PdCH}_{2} \mathrm{Si}\right.$ and $\left.\mathrm{SiCH}_{2} \mathrm{~N}\right)$, which results from the fast dynamic process usually observed in five-membered metallacycles with an envelope conformation in which the $\mathrm{Si}$ and $\mathrm{C}$ atoms move from one side of the plane to the other, making both sides equivalent.

A mixture of isomers was obtained in solution after reaction of the parent chlorido-bridging dimer 1 with sodium azide, which gave $\left[\mathrm{Pd}\left\{\mathrm{CH}_{2} \mathrm{SiPh}_{2}\left(\mathrm{CH}_{2} \mathrm{NC}_{5} \mathrm{H}_{10}\right)-\kappa^{2} C, N\right\}(\mu-\right.$ $\left.\left.\mathrm{N}_{3}-\kappa^{1} \kappa^{1} N\right)\right]_{2}(3)$. Like the thiocyanate, the azido ligand may also coordinate side-on (Figure 3, a) or end-on (Figure 3, b). In contrast to thiocyanate, in this case IR spectroscopy does not allow differentiation between coordination modes as the $\mathrm{N}=\mathrm{N}$ stretching absorptions are very similar. An endon coordination is proposed for $\mathbf{3}$, as occurs in the few reported examples of structures with bridging azides coordinated to palladium(II) ${ }^{[13]}$ Single crystals obtained from 3 confirmed this connectivity; however, the overall quality of the data was insufficient to merit publication. ${ }^{[14]}$

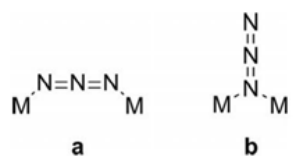

Figure 3. Possible coordination modes for a bridging azido ligand.

Two signal sets are detected in the ${ }^{1} \mathrm{H}$ and ${ }^{13} \mathrm{C}$ NMR spectra of 3, which suggests the presence of two isomers in solution. The most informative signals are those of the methylene groups $\mathrm{PdCH}_{2} \mathrm{Si}$ and $\mathrm{SiCH}_{2} \mathrm{~N}$, which resonate at $\delta \approx 1$ and $3 \mathrm{ppm}$, respectively, in the ${ }^{1} \mathrm{H}$ NMR spectra and 
at $\delta \approx 5$ and $50 \mathrm{ppm}$, respectively, in the ${ }^{13} \mathrm{C}$ NMR spectra. For 3, the two isomers coexist in a ratio of $55: 45$ in $\mathrm{CDCl}_{3}$. When the spectrum was recorded in $\left(\mathrm{CD}_{3}\right)_{2} \mathrm{CO}$, the ratio changed to 60:40 (see the Exp. Sect.). This led to the assignment of the major isomer observed to cis and the minor isomer to trans on the basis of the higher polarity of the cis isomer and acetone relative to the trans form and chloroform. Thus, the two isomers clearly undergo a slow equilibrating process in solution (Scheme 2). However, the trans structure is exclusively observed in the crystal. This observation has also been made for the parent chlorido-bridged complex 1. ${ }^{[2 \mathrm{~b}]}$
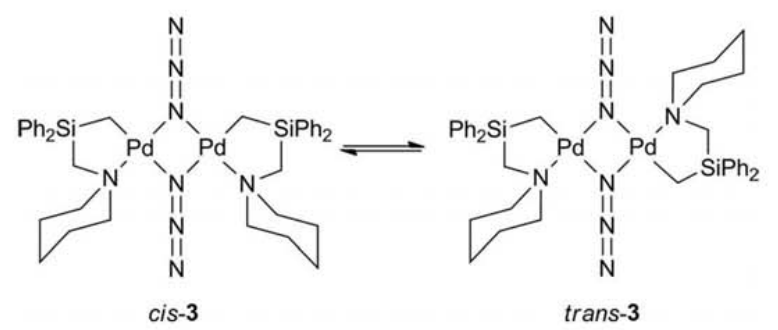

Scheme 2. Isomers of $\mathbf{3}$ detected in solution.

The third pseudohalide studied was cyanide. Whereas azide and thiocyanate coordinate as bridging ligands in dimetallic species with bent geometries, cyanide, given its tendency to form linear bridges, should promote a different mode of assembly. Thus, parent chlorido-bridged dimer $\mathbf{1}$ was treated with equimolar amounts of silver cyanide leading to the precipitation of $\mathrm{AgCl}$ and the formation of the tetrametallic complex $\left[\mathrm{Pd}\left\{\mathrm{CH}_{2} \mathrm{SiPh}_{2}\left(\mathrm{CH}_{2} \mathrm{NC}_{5} \mathrm{H}_{10}\right)\right.\right.$ $\left.\left.\kappa^{2} C, N\right\}\left(\mu-\mathrm{CN}-\kappa^{1} C, \kappa^{1} N\right)\right]_{4}$ (4). The crystals obtained were subjected to crystal structure determination, which gave the structure shown in Figure 4. ${ }^{[13]}$

Complex 4-hexane crystallizes from dichloromethane/ hexane in the monoclinic crystal system. The asymmetric unit contains two independent molecules of the tetrametallacycle 4 and two disordered hexane molecules. Each molecule of $\mathbf{4}$ contains four palladium centers bridged by cyanido ligands. However, the structural determination does not allow differentiation of the carbon and nitrogen atoms of the bridging cyanide. Therefore, the structure was refined by taking into account the antisymbiotic effect of the soft palladium(II) center, ${ }^{[11]}$ which led to the proposal of mutual cis coordination of both carbon donor ligands (i.e., methylene and cyanide- $C$, with higher trans influence) and both nitrogen donor ligands (i.e., piperidyl and cyanide- $N$, with lower trans influence). A cyclometalated (piperidinomethyl)silylmethyl moiety is also coordinated to each palladium center. The bridging cyanides are essentially linear: The Pd$\mathrm{C}-\mathrm{N}$ angles range from $175.5(7)$ to $179.5(8)^{\circ}$, and the $\mathrm{C}-$ $\mathrm{N}-\mathrm{Pd}$ angles are in the range $167.3(6)-178.0(5)^{\circ}$. These angles and the $\mathrm{C}-\mathrm{N}$ distances are similar to those found in other tetranuclear complexes with bridging cyanides. ${ }^{[15]}$ The four palladium atoms are not coplanar, but form a dihedral angle of $27^{\circ}$. With dihedral angles found in similar tetrametallic structures ranging from 0 to $35^{\circ}$, this deviation from planarity is relatively distinct.

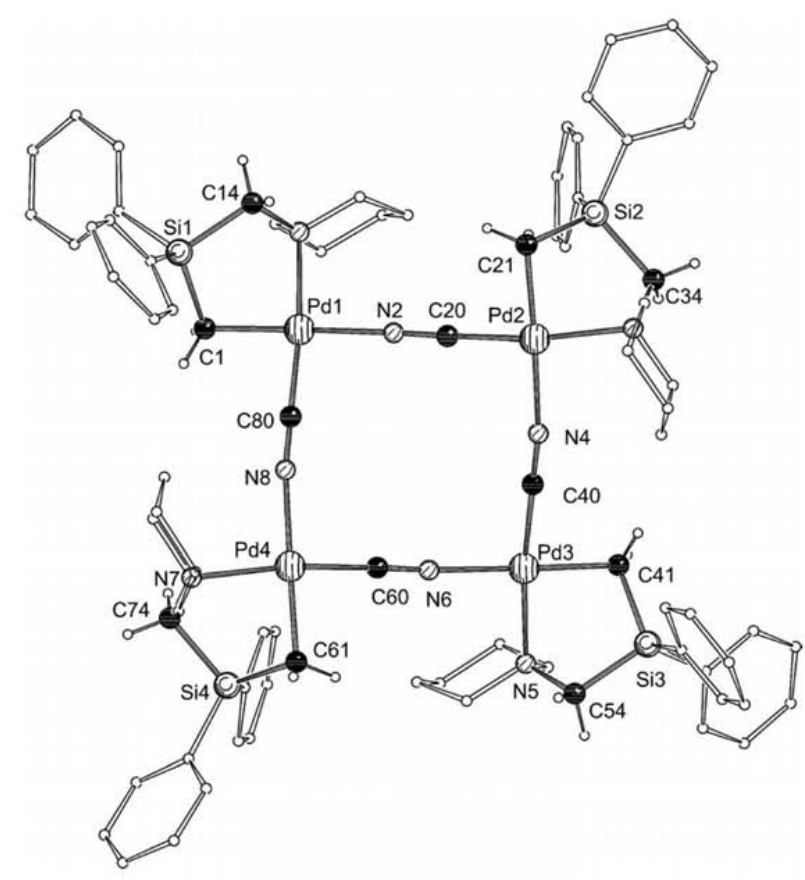

Figure 4. Molecular structure and numbering scheme of compound 4 in the crystal (only one of the two independent molecules in the asymmetric unit is shown, SCHAKAL plot). ${ }^{[12]}$ Peripheral hydrogen atoms outside the palladacycles have been omitted for clarity. Selected distances $[\AA]$ and angles $\left[{ }^{\circ}\right]$ : Pd1-Sil 3.088(2), Pd1-N1 2.178(5), Pd1-N2 2.089(6), Pd1-C1 2.064(8), Pd1-C80 1.928(6), Pd2-Si2 3.051(2), Pd2-N3 2.185(7), Pd2-N4 2.096(5), Pd2-C20 1.9154(7), Pd2-C21 2.0608(6), Pd3-N5 2.1977(5) Pd3-N6 2.0992(6), Pd3-C40 1.936(6), Pd3-C41 2.055(7), Pd4-Si4 3.030(2), Pd4-N7 2.180(6), Pd4-N8 2.093(5), Pd4 C60 1.943(7), Pd4 C61 $2.058(6)$, N2-C20 1.188(10), N4-C40 1.168(8), N6-C60 1.160(9), N8-C80 1.174(8); Pd1-N2-C20 178.2(6), Pd2-N4-C40 170.2(5), Pd3-N6-C60 175.8(6), Pd4-N8-C80 171.1(6), Pd1-Cl-Sil 103.6(4), Pd2-C21-Si2 102.4(3), Pd3-C41-Si3 105.4(4), Pd4-C61Si 4 101.2(3), Pd1-N2-C20 178.2(6), Pd2-N4-C40 170.2(5), Pd3N6-C60 175.8(6), Pd4-N8-C80 171.1(6), Pd2-C20-N2 178.4(6), Pd3-C40-N4 179.4(6), Pd4-C60-N6 178.0(6), Pd1-C80-N8 178.3(6).

The Pd-C distances [2.028(7)-2.061(6) $\AA$ ] are in the range found for $\mathrm{Pd}-\mathrm{C}\left(\mathrm{sp}^{3}\right)$ single bonds. ${ }^{[10]}$ The conformation of the five-membered palladacycles may be described as envelopes: The dihedral angles of the palladium atoms with respect to the other four atoms range from $31.6^{\circ}$ for $\operatorname{Pd}(3)$ to $36.2^{\circ}$ for $\operatorname{Pd}(1)$, as is usually found in these metallacycles. As with compounds $\mathbf{1}$ and $\mathbf{2}$, the distance between the palladium and the silicon atom in the five-membered palladacycles in $\mathbf{4}$ is short; however, the Pd $\cdots \mathrm{Si}$ distances in the tetrametallacycle are slightly longer than those observed in the thiocyanato-bridged dimer $\mathbf{2}$ and range from 3.015(2) to $3.117(2) \AA$. These distances and angles in the silapalladacycles are similar to those previously found..$^{[2]}$

The structure found in the solid is not maintained in solution, as evidenced by the NMR spectra displaying signals from two different species. The signals of the methylene groups $\mathrm{NCH}_{2} \mathrm{Si}$ and $\mathrm{SiCH}_{2} \mathrm{Pd}$ allowed a quantitative analysis of the concentration of each isomer. The two species 
are present in a ratio that depends on the concentration, temperature, and solvent, but one of the isomers is always dominant. To assign unequivocally the signals to each isomer, an NMR sample of $\mathbf{4}$ in frozen $\mathrm{CDCl}_{3}$ was prepared in a liquid-nitrogen bath and then allowed to melt and simultaneously dissolve at $-40^{\circ} \mathrm{C}$ in the NMR probe. The ${ }^{1} \mathrm{H}$ NMR spectrum immediately recorded under these conditions showed only signals from the major isomer, which led to the conclusion that the major isomer in solution is always the tetranuclear complex detected in the crystal structure. The concentration of the minor isomer is higher in diluted solutions and at higher temperatures, and in polar $\mathrm{CDCl}_{3}$ compared with nonpolar $\mathrm{C}_{6} \mathrm{D}_{6}$. On the other hand, the IR spectra only show one $\mathrm{CN}$ stretching absorption in the solid state $\left(2162 \mathrm{~cm}^{-1}\right)$ as well as in $\mathrm{CH}_{2} \mathrm{Cl}_{2}$ $\left(2159 \mathrm{~cm}^{-1}\right)$ and toluene $\left(2164 \mathrm{~cm}^{-1}\right)$ solutions. As IR spectroscopy is a fast technique on the spectroscopic timescale, that is, it differentiates between species present in solution even when they are involved in slow processes in solution, the conclusion is that the $\mathrm{CN}$ stretching absorption is the same for both isomers.

All these data are in accord with the equilibrium proposed in Scheme 3 between the tetrametallic complex detected in the crystal structure and a trimetallic species. This type of equilibria has been found for other tetrametallic complexes, and the factors controlling the tetrametallic/trimetallic equilibria have recently been the target of extensive studies. ${ }^{[16]}$

In our case, the ratio of tetrametallic/trimetallic species in $\mathrm{CDCl}_{3}$ increases with concentration, with values of 80:20 at 0.08 mequiv. $\mathrm{mL}^{-1}$ and $69: 31$ at 0.003 mequiv. $\mathrm{mL}^{-1}$ (see Table 1), which leads to an equilibrium constant, $K_{\text {eq }}$, of $(1.93 \pm 0.07) \times 10^{-4} \mathrm{~mol} \mathrm{~L}^{-1}$ and a free energy, $\Delta G_{\text {eq }}$, of $20.83 \pm 0.11 \mathrm{~kJ} \mathrm{~mol}^{-1}$ (see the Supporting Information) for the equilibrium depicted in Scheme 3.

A study of the concentrations of the isomers as a function of temperature allowed us to determine the values of $\Delta H_{\mathrm{eq}}$ and $\Delta S_{\mathrm{eq}}$ for the equilibrium process (Table 2) from the van't Hoff equation (1).

$\ln K_{\mathrm{eq}}=-\left(\Delta G_{\mathrm{eq}} / R T\right)=-\left(\Delta H_{\mathrm{eq}} / R T\right)+\left(\Delta S_{\mathrm{eq}} / \mathrm{R}\right)$
Table 1. Thermodynamic data for the equilibrium detected in solutions of $\mathbf{4}$ as a function of concentration.

\begin{tabular}{ccc}
\hline Concentration $\left[\mathrm{meq} \mathrm{mL}^{-1}\right]$ & Trimetallic [\%] & Tetrametallic [\%] \\
\hline 0.080 & 20 & 80 \\
0.050 & 22 & 78 \\
0.025 & 25 & 75 \\
0.012 & 28 & 72 \\
0.006 & 30 & 70 \\
0.003 & 31 & 69 \\
\hline
\end{tabular}

Table 2. Thermodynamic data for the equilibrium detected in the solutions of $\mathbf{4}$ as a function of temperature.

\begin{tabular}{cccc}
\hline$T[\mathrm{~K}]$ & Trimetallic [\%] & Tetrametallic [\%] & $K_{\text {eq }}$ \\
\hline 253 & 6 & 94 & $9.86 \times 10^{-7}$ \\
273 & 13 & 87 & $2.74 \times 610^{-5}$ \\
293 & 20 & 80 & $1.98 \times 10^{-4}$ \\
313 & 30 & 70 & $1.49 \times 10^{-3}$ \\
\hline
\end{tabular}

As expected, the enthalpy of the process depicted in Scheme 3 is positive $\left(\Delta H=75 \pm 5 \mathrm{~kJ} \mathrm{~mol}^{-1}\right)$, which reflects the lower strain of the tetrametallic structure, and the entropy is quite large and also positive $\left(186 \pm 15 \mathrm{~J} \mathrm{~mol}^{-1} \mathrm{~K}^{-1}\right)$, which reflects the higher disorder that results from the greater number of particles when trimetallic isomers are formed from tetrametallic isomers.

These thermodynamic values are similar to those obtained for similar equilibria previously reported between tetra- and trimetallic palladium complexes. ${ }^{[16 \mathrm{~d}-16 \mathrm{f}]} \mathrm{An}$ important difference between complex $\mathbf{4}$ and those previously described is that $\mathbf{4}$ is neutral, whereas those reported in the literature are cationic. This might be the cause of their different behavior when the polarity of the solvent changes: for the cationic complexes, the equilibrium is shifted towards the trimetallic isomer as the solvent polarity increases, ${ }^{[16 \mathrm{~d}, 16 \mathrm{f}]}$ whereas for $\mathbf{4}$, the equilibrium constant detected in nonpolar $\mathrm{C}_{6} \mathrm{D}_{6}$ is smaller $\left[K_{\mathrm{eq}}=\right.$ $\left.(4.5 \pm 0.2) \times 10^{-5} \mathrm{~mol} \mathrm{~L}^{-1}\right]$, and thus the free energy is higher $\left(\Delta G_{\mathrm{eq}}=24.40 \pm 0.14 \mathrm{~kJ} \mathrm{~mol}^{-1}\right.$; see the Supporting Information) than in $\mathrm{CDCl}_{3}$ (see above). This feature might be interpreted on the basis that the equilibrium proposed in Scheme 2 should occur through a dissociative mechanism

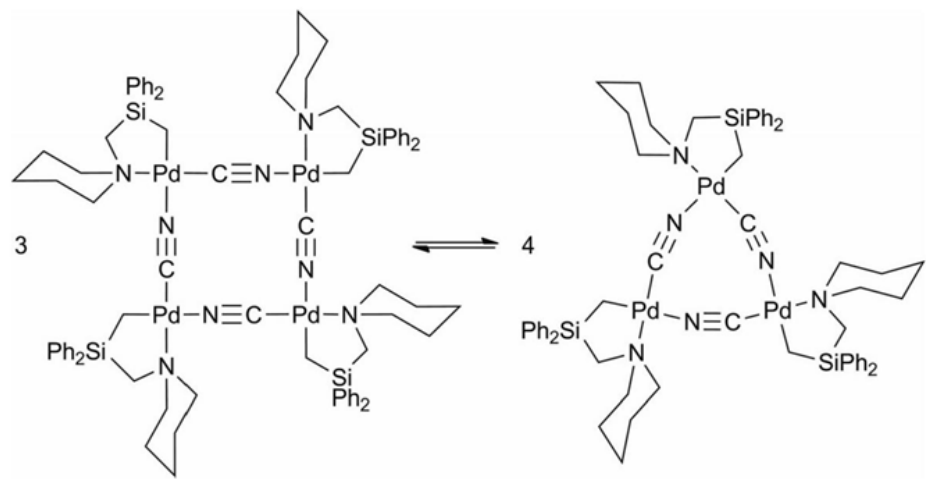

Scheme 3. Isomers detected in solutions of 4. 
due to metal-ligand bond cleavage, and therefore polar solvents should favor this step.

\section{Conclusions}

The coordination of the pseudohalides cyanide, thiocyanate, or azide to a "soft" $\mathrm{Pd}^{\mathrm{II}}$ center with two potential coordinating positions in cis geometry led to different types of assemblies. The bridging azide and thiocyanate give rise to dimetallic species in which the azide is coordinated endon and the thiocyanate is coordinated side-on. In contrast, the linear bridging cyanide gives rise to a square-shaped tetrametallic complex. The latter is in equilibrium with a trimetallic isomer in solution, whereas the bridging azide dimer persists as a mixture of cis and trans isomers in solution. The trimetallic species is always the minor isomer, but its ratio increases with dilution, increasing temperature, and increasing polarity of the solvent used.

\section{Experimental Section}

General: IR ( $\mathrm{KBr}$ pellets, $4000-450 \mathrm{~cm}^{-1}$ ): Perkin-Elmer Spectrum RX I FT-IR spectrometer. ' ${ }^{\mathrm{H}} \mathrm{NMR}$ [solvent $\mathrm{CDCl}_{3}$; internal standard: $\mathrm{CHCl}_{3}(\delta=7.24 \mathrm{ppm})$; recorded at room temperature]: Bruker AC-300 or ARX-300 spectrometer $(300.13 \mathrm{MHz}) .{ }^{13} \mathrm{C}$ NMR [solvent and internal standard: $\mathrm{CDCl}_{3}(\delta=77.00 \mathrm{ppm})$; recorded at room temperature; integrations are indicated per " $\mathrm{CH}_{2} \mathrm{SiPh}_{2}\left(\mathrm{CH}_{2} \mathrm{NC}_{5} \mathrm{H}_{10}\right.$ )" unit]: Bruker ARX-300 spectrometer (75.78 MHz). Assignment of the ${ }^{13} \mathrm{C}$ NMR spectroscopic data is supported by DEPT experiments and the relative intensities of the resonance signals. Microanalyses: Perkin-Elmer 2400B microanalyzer, Área de Química Inorgánica, Facultad de Ciencias, Valladolid (Spain). All reactions were carried out under oxygen-free and dried dinitrogen according to conventional Schlenk techniques. The solvents were dried according to common procedures. Complex 1 was obtained as described previously. ${ }^{[2 b]}$ The other reactants were obtained from the usual commercial suppliers.

$\left[\left.\mathrm{Pd}\left\{\mathrm{CH}_{2} \mathrm{SiPh}_{2}\left(\mathrm{CH}_{2} \mathrm{NC}_{5} \mathrm{H}_{10}\right)-\kappa^{2} C, N\right\}\left(\mu-\mathrm{SCN}-\kappa^{1} S, \kappa^{1} N\right)\right|_{2}(2): \mathrm{A}\right.$ mixture of $1(0.087 \mathrm{~g}, 0.1 \mathrm{mmol})$ and $\mathrm{KSCN}(0.097 \mathrm{~g}, 1.0 \mathrm{mmol})$ in THF $(10 \mathrm{~mL})$ was stirred at $40^{\circ} \mathrm{C}$ for $15 \mathrm{~h}$. The volatiles were removed in vacuo, and the residue was extracted with $\mathrm{CH}_{2} \mathrm{Cl}_{2}$ (ca. $20 \mathrm{~mL}$ ). The yellow solution was filtered, and hexane (ca. $10 \mathrm{~mL}$ ) was added. Concentration in vacuo and cooling to $-20^{\circ} \mathrm{C}$ afforded yellow crystals, which were decanted, washed with hexane $(3 \times$ $3 \mathrm{~mL}$ ), and vacuum-dried to yield $0.052 \mathrm{~g}(57 \%)$ of 2 . IR $(\mathrm{KBr}): \tilde{v}$ $=3066(\mathrm{~m}), 2945(\mathrm{~s}), 2856(\mathrm{~s}), 2808(\mathrm{~m}), 2137$ (vs), 1587 (w), 1567 (w), $1486(\mathrm{w}), 1468(\mathrm{~m}), 1442(\mathrm{~s}), 1426(\mathrm{~m}), 1374(\mathrm{w}), 1298(\mathrm{w})$, $1282(\mathrm{w}), 1261$ (w), 1225 (w), $1175(\mathrm{w}), 1111(\mathrm{~s}), 1039$ (m), 998 (m), $910(\mathrm{w}), 882(\mathrm{w}), 862(\mathrm{~m}), 797(\mathrm{~m}), 765(\mathrm{~s}), 720(\mathrm{~s}), 698(\mathrm{~s}), 575$ (w), $551(\mathrm{~m}), 508$ (s), 491 (s), $461(\mathrm{~m}), 419(\mathrm{w}) \mathrm{cm}^{-1} \cdot{ }^{1} \mathrm{H}$ NMR: $\delta$ $=7.65\left(\mathrm{~m}, 4 \mathrm{H}, \mathrm{C}_{6} \mathrm{H}_{5}\right), 7.38\left(\mathrm{~m}, 6 \mathrm{H}, \mathrm{C}_{6} \mathrm{H}_{5}\right), 3.34\left(\mathrm{~m}, 2 \mathrm{H}, \mathrm{CH}_{2}\right.$ pip), 2.98 (s, $2 \mathrm{H}, \mathrm{NCH}_{2} \mathrm{Si}$ ), 2.36 (m, $2 \mathrm{H}, \mathrm{CH}_{2}$ pip), 1.86 (m, $2 \mathrm{H}$, $\mathrm{CH}_{2}$ pip), 1.66 (m, $3 \mathrm{H}, \mathrm{CH}_{2}$ pip), 1.37 (m, $1 \mathrm{H}, \mathrm{CH}_{2}$ pip), 0.64 (s, $\left.2 \mathrm{H}, \mathrm{SiCH}_{2} \mathrm{Pd}\right) \mathrm{ppm} .{ }^{13} \mathrm{C}\left\{{ }^{1} \mathrm{H}\right\}$ NMR: $\delta=136.5$ (s, $\mathrm{Si}_{6} \mathrm{H}_{5}$ ipso), 134.7 (s, $\mathrm{SiC}_{6} \mathrm{H}_{5}$ ortho), $129.3\left(\mathrm{SiC}_{6} \mathrm{H}_{5}\right.$ para $), 127.9\left(\mathrm{SiC}_{6} \mathrm{H}_{5}\right.$ meta), 126.7 (s, $\mathrm{SCN}$ ), 62.7 (s, $\mathrm{NCH}_{2} \mathrm{CH}_{2} \mathrm{CH}_{2}$ ), 55.0 (s, $\mathrm{NCH}_{2} \mathrm{Si}$ ), 23.1 (s, $\mathrm{NCH}_{2} \mathrm{CH}_{2} \mathrm{CH}_{2}$ ), 22.9 (s, $\mathrm{NCH}_{2} \mathrm{CH}_{2} \mathrm{CH}_{2}$ ), 1.3 (s, $\mathrm{PdCH}_{2} \mathrm{Si}$ ) ppm. $\mathrm{C}_{40} \mathrm{H}_{48} \mathrm{~N}_{4} \mathrm{Pd}_{2} \mathrm{~S}_{2} \mathrm{Si}_{2}$ (917.94): calcd. C 52.34, H 5.27, N 6.10; found C 52.11, H 5.14, N 5.96 .
$\left[\mathrm{Pd}\left\{\mathrm{CH}_{2} \mathrm{SiPh}_{2}\left(\mathrm{CH}_{2} \mathrm{NC}_{5} \mathrm{H}_{10}\right)-\kappa^{2} C, N\right\}\left(\mu-\mathrm{N}_{3}-\boldsymbol{\kappa}^{1} \kappa^{1} N\right)\right]_{2}$ (3): A mixture of $1(0.087 \mathrm{~g}, 0.1 \mathrm{mmol})$ and $\mathrm{NaN}_{3}(0.014 \mathrm{~g}, 0.22 \mathrm{mmol})$ in THF $(10 \mathrm{~mL})$ was stirred at $40^{\circ} \mathrm{C}$ for $15 \mathrm{~h}$. The volatiles were removed in vacuo, and the residue was extracted with toluene (ca. $20 \mathrm{~mL}$ ). The yellow solution was filtered and concentrated in vacuo, and hexane (ca. $10 \mathrm{~mL}$ ) was added. Cooling to $-20^{\circ} \mathrm{C}$ afforded yellow crystals, which were decanted, washed with hexane $(3 \times 3 \mathrm{~mL})$, and vacuum-dried to yield $0.040 \mathrm{~g}(46 \%)$ of 3 . IR $(\mathrm{KBr}): \tilde{v}=3064(\mathrm{w})$, 2943 (w), 2860 (w), 2050 (vs), 1448 (w), 1427 (m), 1357 (w), 1285 (m), $1261(\mathrm{w}), 1234(\mathrm{w}), 1110(\mathrm{~s}), 1029(\mathrm{~m}), 998$ (m), 947 (w), 867 (m), 804 (s), 733 (s), 699 (s), $622(\mathrm{w}), 550(\mathrm{~m}), 504$ (w), 489 (m), 466 (w) $\mathrm{cm}^{-1} .{ }^{1} \mathrm{H}$ NMR: $\delta=7.73$ (m, $4 \mathrm{H}, \mathrm{C}_{6} H_{5}, 2$ isomers), 7.40 ( $\mathrm{m}, 6 \mathrm{H}, \mathrm{C}_{6} H_{5}, 2$ isomers), $3.17\left(\mathrm{~m}, 2 \mathrm{H}, \mathrm{CH}_{2}\right.$ pip, 2 isomers), 3.08 (s, $2 \mathrm{H}, \mathrm{NCH}_{2} \mathrm{Si}, 2$ isomers), $2.50\left(\mathrm{~m}, 2 \mathrm{H}, \mathrm{CH}_{2}\right.$ pip, 2 isomers), $1.77\left(\mathrm{~m}, 5 \mathrm{H}, \mathrm{CH}_{2}\right.$ pip, 2 isomers), $1.44\left(\mathrm{~m}, 1 \mathrm{H}, \mathrm{CH}_{2}\right.$ pip, 2 isomers), 1.25 (s, $2 \mathrm{H}, \mathrm{SiCH}_{2} \mathrm{Pd}$, cis isomer), 1.12 (s, $2 \mathrm{H}, \mathrm{SiCH}_{2} \mathrm{Pd}$ pip, trans isomer) ppm; ratio cis/trans $=55: 45 .{ }^{13} \mathrm{C}\left\{{ }^{1} \mathrm{H}\right\}$ NMR: $\delta=$ 136.3 (s, $\mathrm{Si}_{6} \mathrm{H}_{5}$ ipso, cis isomer), 136.2 ( $\mathrm{s}, \mathrm{Si}_{6} \mathrm{H}_{5}$ ipso, trans isomer), $134.6\left(\mathrm{~s}, \mathrm{SiC}_{6} \mathrm{H}_{5}\right.$ ortho, cis isomer), $134.5\left(\mathrm{~s}, \mathrm{Si}_{6} \mathrm{H}_{5}\right.$ ortho, trans isomer), $129.4\left(\mathrm{SiC}_{6} \mathrm{H}_{5}\right.$ para, 2 isomers), $128.0\left(\mathrm{SiC}_{6} \mathrm{H}_{5}\right.$ meta, trans isomer), $127.9 \quad\left(\mathrm{SiC}_{6} \mathrm{H}_{5}\right.$ meta, cis isomer), 61.6 (s. $\mathrm{NCH}_{2} \mathrm{CH}_{2} \mathrm{CH}_{2}$, cis isomer), 61.4 (s, $\mathrm{NCH}_{2} \mathrm{CH}_{2} \mathrm{CH}_{2}$, trans isomer), 55.5 (s, $\mathrm{NCH}_{2} \mathrm{Si}$, cis isomer), 55.1 (s, $\mathrm{NCH}_{2} \mathrm{Si}$, trans isomer), 22.9 (s, $\mathrm{NCH}_{2} \mathrm{CH}_{2} \mathrm{CH}_{2}, 2$ isomers), 21.8 ( $\mathrm{s}, \mathrm{NCH}_{2} \mathrm{CH}_{2} \mathrm{CH}_{2}$, cis isomer), 21.4 (s, $\mathrm{NCH}_{2} \mathrm{CH}_{2} \mathrm{CH}_{2}$, trans isomer), 6.7 (s, $\mathrm{PdCH}_{2} \mathrm{Si}$, cis isomer), $5.6\left(\mathrm{~s}, \mathrm{PdCH} \mathrm{H}_{2} \mathrm{Si}\right.$, trans isomer) ppm. $\mathrm{C}_{38} \mathrm{H}_{48} \mathrm{~N}_{8} \mathrm{Pd}_{2} \mathrm{Si}_{2}$ (885.82): calcd. C 51.62, H 5.46, N 12.55; found C 51.90, H 5.37, N 12.20.

$\left[\mathrm{Pd}\left\{\mathrm{CH}_{2} \mathrm{SiPh}_{2}\left(\mathrm{CH}_{2} \mathrm{NC}_{5} \mathrm{H}_{10}\right)-\kappa^{2} C, N\right\}\left(\mu-\mathrm{CN}-\kappa^{1} C, \kappa^{1} N\right)\right]_{4}(4): \mathrm{A}$ mixture of $1(0.044 \mathrm{~g}, 0.05 \mathrm{mmol})$ and freshly prepared $\mathrm{AgCN}$ (from $0.019 \mathrm{~g}, 0.11 \mathrm{mmol}$ of $\mathrm{AgNO}_{3}$ and $0.007 \mathrm{~g}, 0.012 \mathrm{mmol}$ of $\mathrm{NaCN}$ ) in THF $(5 \mathrm{~mL})$ was stirred at room temp. for $3 \mathrm{~h}$. Workup as for 3 gave $0.030 \mathrm{~g}(70 \%)$ of $\mathbf{4}$ as colorless crystals. IR $(\mathrm{KBr}): \tilde{v}=3065$ (w), $3046(\mathrm{~m}), 2938(\mathrm{~s}), 2856(\mathrm{~m}), 2813(\mathrm{w}), 2162(\mathrm{~s}), 1451(\mathrm{~m})$, 1427 (s), 1381 (w), 1261 (w), 1109 (s), 1037 (m), 999 (w), 865 (w), $802(\mathrm{~m}), 768(\mathrm{~s}), 735(\mathrm{~s}), 700(\mathrm{vs}), 557(\mathrm{w}), 503(\mathrm{~m}), 488(\mathrm{~m}), 473$ (w), 437 (w) $\mathrm{cm}^{-1} .{ }^{1} \mathrm{H}$ NMR: $\delta=7.66\left(\mathrm{~m}, 4 \mathrm{H}, \mathrm{C}_{6} \mathrm{H}_{5}, 2\right.$ isomers), 7.34 (m, $6 \mathrm{H}, \mathrm{C}_{6} \mathrm{H}_{5}, 2$ isomers), 3.25 ( $\mathrm{m}, 2 \mathrm{H}, \mathrm{CH}_{2}$ pip, 2 isomers), $2.75\left(\mathrm{~s}, 2 \mathrm{H}, \mathrm{NCH}_{2} \mathrm{Si}\right.$, minor isomer), $2.73\left(\mathrm{~s}, 2 \mathrm{H}, \mathrm{NCH}_{2} \mathrm{Si}\right.$, major isomer), $2.05\left(\mathrm{~m}, 2 \mathrm{H}, \mathrm{CH}_{2}\right.$ pip, 2 isomers), $1.65\left(\mathrm{~m}, 2 \mathrm{H}, \mathrm{CH}_{2}\right.$ pip, 2 isomers), $1.34\left(\mathrm{~m}, 3 \mathrm{H}, \mathrm{CH}_{2}\right.$ pip, 2 isomers), $1.05\left(\mathrm{~m}, 1 \mathrm{H}, \mathrm{CH}_{2}\right.$ pip, 2 isomers), 0.76 (s, $2 \mathrm{H}, \mathrm{SiCH}_{2} \mathrm{Pd}$, minor isomer), $0.65(\mathrm{~s}, 2 \mathrm{H}$, $\mathrm{SiCH} \mathrm{H}_{2} \mathrm{Pd}$, major isomer) ppm; ratio major/minor isomers $=80: 20$. ${ }^{13} \mathrm{C}\left\{{ }^{1} \mathrm{H}\right\}$ NMR: $\delta=137.6$ (s, $\mathrm{Si}_{6} \mathrm{H}_{5}$ ipso, minor isomer), 137.4 (s, $\mathrm{Si}_{6} \mathrm{H}_{5}$ ipso, major isomer), 134.9 ( $\mathrm{s}, \mathrm{Si}_{6} \mathrm{H}_{5}$ ortho, major isomer), 134.7 (s, $\mathrm{SiC}_{6} \mathrm{H}_{5}$ ortho, minor isomer), 130.5 (s, $\mathrm{CN}, 2$ isomers), $128.9\left(\mathrm{Si}_{6} \mathrm{H}_{5}\right.$ para, 2 isomers), $127.6\left(\mathrm{SiC}_{6} \mathrm{H}_{5}\right.$ meta, 2 isomers). 61.5 (s, $\mathrm{NCH}_{2} \mathrm{CH}_{2} \mathrm{CH}_{2}$, minor isomer), 60.7 (s, $\mathrm{NCH}_{2} \mathrm{CH}_{2} \mathrm{CH}_{2}$, major isomer), 54.7 (s, $\mathrm{NCH}_{2} \mathrm{Si}$, minor isomer), $53.2\left(\mathrm{~s}, \mathrm{NCH}_{2} \mathrm{Si}\right.$, major isomer), 23.1 (s, $\mathrm{NCH}_{2} \mathrm{CH}_{2} \mathrm{CH}_{2}, 2$ isomers), 22.6 (s, $\mathrm{NCH}_{2} \mathrm{CH}_{2} \mathrm{CH}_{2}, 2$ isomers), -7.6 (s, $\mathrm{PdCH} \mathrm{CH}_{2} \mathrm{Si}, 2$ isomers) ppm. $\mathrm{C}_{80} \mathrm{H}_{96} \mathrm{~N}_{8} \mathrm{Pd}_{4} \mathrm{Si}_{4}$ (1707.64): calcd. C 51.62, H 5.46, N 12.55; found C $51.90, \mathrm{H} 5.37, \mathrm{~N} 12.20$.

X-ray Diffraction Study of 2 and 4: Crystals were grown by slow diffusion of hexane into concentrated solutions of the complexes in $\mathrm{CH}_{2} \mathrm{Cl}_{2}$ at $-20^{\circ} \mathrm{C}$. The crystallographic data were collected with a Stoe IPDS diffractometer and are presented in Table 3. The structures were solved by using direct and Fourier methods: Refinement by full-matrix least-squares methods (based on $F_{\mathrm{o}}{ }^{2}$ ), anisotropic thermal parameters for all non- $\mathrm{H}$ atoms in the final cycles, $\mathrm{H}$ atoms were refined by using a riding model in their ideal geometric positions. SHELXS-86 and SHELXL-97 were used in the structural solutions and refinements. ${ }^{[17]}$ CCDC-870641 (for 2) and -870642 (for 4) contain the detailed crystallographic data for this paper. 
This data may be obtained free of charge from the Cambridge Crystallographic Data Center through www.ccdc.cam.ac.uk/data_ request/cif.

Table 3. Crystal and experimental data for compounds $\mathbf{2}$ and $\mathbf{4}$.

\begin{tabular}{|c|c|c|}
\hline & 2 & 4-hexane \\
\hline $\begin{array}{l}\text { Empirical formula } \\
M\left[\mathrm{gmol}^{-1}\right]\end{array}$ & $\begin{array}{l}\mathrm{C}_{40} \mathrm{H}_{48} \mathrm{~N}_{4} \mathrm{Pd}_{2} \mathrm{~S}_{2} \mathrm{Si}_{2} \\
917.92\end{array}$ & $\begin{array}{l}\mathrm{C}_{86} \mathrm{H}_{110} \mathrm{~N}_{8} \mathrm{Pd}_{4} \mathrm{Si}_{4} \\
1793.78\end{array}$ \\
\hline Crystal system & tetragonal & monoclinic \\
\hline Space group & $I 4_{1} / a$ & $P \overline{1}$ \\
\hline Crystal size $[\mathrm{mm}]$ & $0.20 \times 0.20 \times 0.20$ & $0.20 \times 0.20 \times 0.10$ \\
\hline$a[\AA]$ & $20.3965(9)$ & $15.291(4)$ \\
\hline$b[\AA]$ & $20.3965(9)$ & $23.438(5)$ \\
\hline$c[\AA]$ & $19.4889(13)$ & $25.862(6)$ \\
\hline$\alpha\left[^{\circ}\right]$ & 90 & $73.91(3)$ \\
\hline$\beta\left[^{\circ}\right]$ & 90 & $86.30(4)$ \\
\hline$\gamma\left[^{\circ}\right]$ & 90 & $73.32(3)$ \\
\hline$V\left[\AA^{3}\right]$ & $8107.7(7)$ & $8530(3)$ \\
\hline$Z$ & 8 & 4 \\
\hline$\rho_{\text {calcd. }}\left[\mathrm{g} \mathrm{cm}^{-3}\right]$ & 1.504 & 1.397 \\
\hline$\mu\left[\mathrm{mm}^{-1}\right]$ & 1.083 & 0.933 \\
\hline Refl. measured & 44752 & 57780 \\
\hline Scan range $\left[{ }^{\circ}\right]$ & $1.45<2 \theta<27.00$ & $0.941<2 \theta<25.00$ \\
\hline Unique refl. & 4420 & 28281 \\
\hline Refl. observed $[I>2 \sigma(I)]$ & 3777 & 17531 \\
\hline$R 1, w R 2$ & $0.0261,0.0640$ & $0.0576,0.1499$ \\
\hline
\end{tabular}

Supporting Information (see footnote on the first page of this article): Thermodynamic data for the tetrametallic/trimetallic equilibrium of the $\mathrm{CN}$-bridging complex in $\mathrm{CDCl}_{3}$, and ORTEP plot for molecular structure of $\mathbf{4}$.

\section{Acknowledgments}

The authors in Valladolid thank the Spanish Ministerio de Educación y Ciencia (CTQ2009-12111) and the Junta de Castilla y León (GR125 Programa de Grupos de Excelencia de la Junta de Castilla y León) for financial support. M. A. and P. G.-I. thank the Ministerio de Educación y Ciencia (MEC) and the Universidad de Valladolid (FPI Programs), respectively, for their grants. The authors in Dortmund thank the Deutsche Forschungsgemeinschaft, the Fonds der Chemischen Industrie, and Wacker Chemie AG for their support.

[1] A. N. Golub, H. Kohler, V. V. Skopenko, Chemistry of the Pseudohalides, Elsevier, Amsterdam, 1986.

[2] a) C. Strohmann, B. C. Abele, K. Lehmen, F. Villafañe, L. Sierra, S. Martín-Barrios, J. Organomet. Chem. 2002, 661, 149158 ; b) D. Schildbach, M. Arroyo, K. Lehmen, S. Martín-Barrios, L. Sierra, F. Villafañe, C. Strohmann, Organometallics 2004, 23, 3228-3238.

[3] a) C. Strohmann, K. Lehmen, K. Wild, D. Schildbach, Organometallics 2002, 21, 3079-3081; b) T. H. Chan. P. Pellon, J. Am. Chem. Soc. 1989, 111, 8737-8738; c) G. Fraenkel, J. H. Duncan, K. Martin, J. Wang, J. Am. Chem. Soc. 1999, 121, 1053810544; d) C. Strohmann, D. H. M. Buchold, T. Seibel, K. Wild, D. Schildbach, Eur. J. Inorg. Chem. 2003, 3453-3463; e) C. Unkelbach, B. C. Abele, K. Lehmen, D. Schildbach, B. Waerder, C. Strohmann. Chem. Commun. 2012, 48, 2492-2494.

[4] K. Nakamoto, Infrared and Raman Spectra of Inorganic and Coordination Compounds, 3rd ed., Wiley, 1978, p. 274.
[5] F. H. Allen, O. Kennard, D. G. Watson, L. Brammer, A. G. Orpen, R. Taylor, J. Chem. Soc. Perkin Trans. 2 1987, S1-S19.

[6] G. López, G. García, M. D. Santana, G. Sánchez, J. Ruiz, J. A. Hermoso, A. Vegas, M. Martinez-Ripoll, J. Chem. Soc., Dalton Trans. 1990, 1621-1626.

[7] A. E. Mauro, A. V. G. Netto, A. C. Moro, J. G. Ferreira, R. H de A. Santos, E. T. de Almeida, Anal. Sci.: X-ray Struct. Anal. Online 2009, 25, 65-66.

[8] G. Zhao, Q.-C. Yang, T. C. W. Mak, Organometallics 1999, 18 , 3623-3636.

[9] A. M. Santana, A. V. de G. Netto, E. T. de Almeida, A. E. Mauro, J. Souza, R. H. de A. Santos, Z. Kristallogr. New Cryst. Struct. 2002, 217, 147.

[10] a) P. M. Maitlis, P. Espinet, M. J. H. Rusell in Comprehensive Organometallic Chemistry, vol. 6 (Eds.: G. Wilkinson, F. G. A. Stone, E. W. Abel), Pergamon Press, Oxford, 1982, pp. 333334; b) A. J. Canty in Comprehensive Organometallic Chemistry II, vol. 9 (Eds.: G. Wilkinson, F. G. A. Stone, E. W. Abel), Pergamon Press, Oxford, 1995, pp. 271-272.

[11] R. G. Pearson, Inorg. Chem. 1973, 12, 712 .

[12] E. Keller, SCHAKAL99, University of Freiburg, 1999

[13] a) W. P. Fehlhammer, L. F. Dahl, J. Am. Chem. Soc. 1972, 94. 3370-3377; b) W. Beck, W. P. Fehlhammer, K. Feldl. T. M. Klapötke, G. Kramer, P. Mayer, H. Piotrowski, P. Pollmann, W. Ponikwar, T. Schutt, E. Schuierer, M. Vogt, Z. Anorg. Allg. Chem. 2001, 627, 1751; c) E. T. de Almeida, A. E. Mauro, A. M. Santana, S. R. Ananias, A. V. G. Netto, J. G. Ferreira R. H. A. Santos, Inorg. Chem. Commun. 2007, 10, 1394-1398.

[14] Colorless blocks from hexane/dichloromethane: $\mathrm{C}_{38} \mathrm{H}_{98} \mathrm{~N}_{8} \mathrm{Si}_{2} \mathrm{Pd}_{2}, M=936.25 \mathrm{~g} \mathrm{~mol}^{-1}$, monoclinic, space group $P 2_{1}$ (no. 4), $a=9.7370(15), b=14.5009(22), c=29.0035(4) \AA$ $\beta=99.677(2)^{\circ}, V=4036.89(18) \AA^{3}$.

[15] a) For a review, see: G. N. Newton, M. Nihei, H. Oshio, Eur. J. Inorg. Chem. 2011, 3031-3042; b) W. C. Kalb, Z. Demidowicz. D. M. Speckman, C. Knobler, R. G. Teller, M. F. Hawthorne, Inorg. Chem. 1982, 21, 4027-4036; c) P. Schinnerling, U. Thewalt, J. Organomet. Chem. 1992, 431, 41-45; d) F. Olbrich, J. Kopf, E. Weiss, J. Organomet. Chem. 1993, 456, 293-298; e) S. M. Contakes, T. B. Rauchfuss, Angew. Chem. 2000, 112 , 2060; Angew. Chem. Int. Ed. 2000, 39, 1984-1986; f) A. Galstyan, P. J. S. Miguel, J. Wolf, E. Freisinger, B. Lippert, Eur. J. Inorg. Chem. 2011, 1649-1656.

[16] a) For a review, see: E. Zangrando, M. Casanova, E. Alessio, Chem. Rev. 2008, 108, 4979-5013; b) A. Galstyan, W.-Z. Shen, E. Freisinger, H. Alkam, W. Hiller, P. J. S. Miguel, M. Schürmann, B. Lippert, Chem. Eur. J. 2011, 17, 10771-10780; c) M. Ferrer, A. Pedrosa, L. Rodriguez, O. Rossell, M. Vilaseca, Inorg. Chem. 2010, 49, 9438-9449; d) K. Uehara, K. Kasai, N. Mizuno, Inorg. Chem. 2010, 49, 2008-2015; e) S. Ghosh, P. S Mukherjee, Inorg. Chem. 2009, 48, 2605-2613; f) T. Weilandt, R. W. Troff, H. Saxell, K. Rissanen, C. A. Schalley, Inorg. Chem. 2008, 47, 7588-7598; g) E. Holló-Sitkei, G. Tárkányi, L. Párkányi, T. Megyes, G. Besenyei, Eur. J. Inorg. Chem. 2008 , 1573-1583; h) K. Suzuki, M. Kawano, M. Fujita, Angew. Chem. 2007, 119, 2877; Angew. Chem. Int. Ed. 2007, 46, 2819 2822; i) S. Derossi, M. Casanova, E. Iengo, E. Zangrando, M. Stener, E. Alessio, Inorg. Chem. 2007, 46, 11243-11253; j) M. Ferrer, A. Gutiérrez, M. Mounir, O. Rossell, E. Ruiz, A. Rang, M. Engeser, Inorg. Chem. 2007, 46, 3395-3406; k) K. Uehara, K. Kasai, N. Mizuno, Inorg. Chem. 2007, 46, 2409-2416.

[17] a) G. M. Sheldrick, SHELXS-90, Structure Solving Program for Crystal Structure Determination, University of Göttingen. Göttingen, 1990; b) G. M. Sheldrick, SHELXL-97, A Computer Program for Refinement of Crystal Structures, University of Göttingen, Göttingen, 1997.

Received: March 10, 2012 Published Online: June 1, 2012 
Anexo VII 



\title{
Reactivity of Silyl-Substituted Iron-Platinum Hydride Complexes toward Unsaturated Molecules: 4. Insertion of Fluorinated Aromatic Alkynes into the Platinum-Hydride Bond. Synthesis and Reactivity of Heterobimetallic Dimetallacylopentenone, Dimetallacyclobutene, $\mu$-Vinylidene, and $\mu_{2}-\sigma$-Alkenyl Complexes
}

\author{
Isabelle Jourdain, ${ }^{* \dagger}$ Michael Knorr, ${ }^{* \dagger}$ Carsten Strohmann, ${ }^{\ddagger}$ Christian Unkelbach, ${ }^{\dagger}$ Saúl Rojo, ${ }^{\S}$ \\ Patricia Gómez-Iglesias, $§$ and Fernando Villafañe ${ }^{\S}$ \\ 'Institut UTINAM UMR 6213, Équipe Matériaux et Surfaces Structurés, Université de Franche-Comté, 16 Route de Gray, \\ 25030 Besançon, France \\ ${ }^{*}$ Technische Universität Dortmund, Anorganische Chemie, Otto-Hahn-Straße 6, 44227 Dortmund, Germany \\ ${ }^{\S}$ IU CINQUIMA/Química Inorgánica, Facultad de Ciencias, Campus Miguel Delibes, Universidad de Valladolid, 47011 Valladolid, Spain
}

Supporting Information

\begin{abstract}
Insertion of $p-\mathrm{FC}_{6} \mathrm{H}_{4} \mathrm{C} \equiv \mathrm{CH}, p-\mathrm{CF}_{3} \mathrm{C}_{6} \mathrm{H}_{4} \mathrm{C} \equiv \mathrm{CH}$, and $m-\mathrm{CF}_{3} \mathrm{C}_{6} \mathrm{H}_{4} \mathrm{C} \equiv \mathrm{CH}$ into the $\mathrm{Pt}-\mathrm{H}$ bond of $\left[(\mathrm{OC})_{3} \mathrm{Fe}\left\{\mathrm{Si}(\mathrm{OMe})_{3}\right\}(\mu\right.$-dppm $) \mathrm{Pt}(\mathrm{H})-$ $\left.\left(\mathrm{PPh}_{3}\right)\right](1 \mathrm{a})$ yields first the $\sigma$-alkenyl complexes $\left[(\mathrm{OC})_{3} \mathrm{Fe}\left\{\mu\right.\right.$-Si $\left.(\mathrm{OMe})_{2}(\mathrm{OMe})\right\}(\mu$ dppm) $\left.\mathrm{Pt}\left(\mathrm{ArC}=\mathrm{CH}_{2}\right)\right]\left(2 \mathrm{a}, \mathrm{Ar}=\mathrm{C}_{6} \mathrm{H}_{4} \mathrm{~F}-p ; 2 \mathrm{~d}, \mathrm{C}_{6} \mathrm{H}_{4} \mathrm{CF}_{3}-p ; 2 \mathrm{e}, \mathrm{C}_{6} \mathrm{H}_{4} \mathrm{CF}_{3}-m\right)$, which react in a second step with the liberated $\mathrm{PPh}_{3}$ ligand to afford the structurally characterized $\mu$-vinylidene complexes $\left[(\mathrm{OC})_{3} \mathrm{Fe}(\mu\right.$-dppm $)\left\{\mu\right.$-C $\left.=\mathrm{C}(\mathrm{H}) \mathrm{C}_{6} \mathrm{H}_{4} \mathrm{~F}-p\right\} \mathrm{Pt}$ $\left.\left(\mathrm{PPh}_{3}\right)\right]$ (3a) and $\left[(\mathrm{OC})_{3} \mathrm{Fe}(\mu\right.$-dppm $\left.)\left\{\mu-\mathrm{C}=\mathrm{C}(\mathrm{H}) \mathrm{C}_{6} \mathrm{H}_{4} \mathrm{R}\right\} \mathrm{Pt}\left(\mathrm{PPh}_{3}\right)\right]$ (3d, $\mathrm{R}=$ $\left.p-\mathrm{CF}_{3} ; 3 \mathrm{e}, \mathrm{R}=m-\mathrm{CF}_{3}\right)$. In contrast, treatment of $1 \mathrm{a}$ with $o-\mathrm{FC}_{6} \mathrm{H}_{4} \mathrm{C} \equiv \mathrm{CH}$ produces first $\left[(\mathrm{OC})_{3} \mathrm{Fe}\left\{\mu-\mathrm{Si}(\mathrm{OMe})_{2}(\mathrm{OMe})\right\}(\mu\right.$-dppm $\left.) \mathrm{Pt}\left(o-\mathrm{FC}_{6} \mathrm{H}_{4} \mathrm{C}=\mathrm{CH}_{2}\right)\right]$ (2b), which evolves to the dimetallacyclopentenone complex $\left[(\mathrm{OC})_{2} \mathrm{Fe}(\mu\right.$-dppm $)\{\mu-\mathrm{C}(=$ $\left.\left.\mathrm{O}) \mathrm{C}(\mathrm{H})=\mathrm{C}\left(\mathrm{C}_{6} \mathrm{H}_{4} \mathrm{~F}-0\right)\right\} \mathrm{Pt}\left(\mathrm{PPh}_{3}\right)\right] \quad\left(\mathbf{4 b}^{\prime}\right)$. The latter slowly rearranges to the structurally characterized thermodynamic isomer $\left[(\mathrm{OC})_{2} \mathrm{Fe}(\mu\right.$-dppm $)\{\mu-\mathrm{C}(=\mathrm{O}) \mathrm{C}$ $\left.\left.\left(\mathrm{C}_{6} \mathrm{H}_{4} \mathrm{~F}-\mathrm{o}\right)=\mathrm{C}(\mathrm{H})\right\} \mathrm{Pt}\left(\mathrm{PPh}_{3}\right)\right]$ (4b). Treatment of 1a with 2,4- $\mathrm{F}_{2} \mathrm{C}_{6} \mathrm{H}_{3} \mathrm{C} \equiv \mathrm{CH}$ produces via transient alkenyl complex $2 \mathrm{c}$ an isomeric mixture of $\left[(\mathrm{OC})_{3} \mathrm{Fe}(\mu\right.$-dppm $\left.)\left\{\mu-\mathrm{C}=\mathrm{C}(\mathrm{H}) \mathrm{C}_{6} \mathrm{H}_{3} \mathrm{~F}_{2}-2,4\right\} \mathrm{Pt}\left(\mathrm{PPh}_{3}\right)\right](3 \mathrm{c})$, $\left[(\mathrm{OC})_{2} \mathrm{Fe}(\mu\right.$-dppm $)\left\{\mu\right.$ - $\left.\left.\mathrm{C}(=\mathrm{O}) \mathrm{C}(\mathrm{H})=\mathrm{C}\left(\mathrm{C}_{6} \mathrm{H}_{3} \mathrm{~F}_{2}-2,4\right)\right\} \mathrm{Pt}\left(\mathrm{PPh}_{3}\right)\right] \quad\left(4 \mathrm{c}^{\prime}\right)$, and $\left[(\mathrm{OC})_{2} \mathrm{Fe}(\mu\right.$-dppm $)\left\{\mu-\mathrm{C}(=\mathrm{O}) \mathrm{C}\left(\mathrm{C}_{6} \mathrm{H}_{3} \mathrm{~F}_{2}-2,4\right)=\right.$ $\left.\mathrm{C}(\mathrm{H})\} \mathrm{Pt}\left(\mathrm{PPh}_{3}\right)\right](4 \mathrm{c})$. Alternatively, $4 \mathbf{b}, \mathbf{c}$ and $\left[(\mathrm{OC})_{2} \mathrm{Fe}(\mu\right.$-dppm $\left.)\{\mu-\mathrm{C}(=\mathrm{O}) \mathrm{C}(\mathrm{Ar})=\mathrm{C}(\mathrm{H})\} \mathrm{Pt}\left(\mathrm{PPh}_{3}\right)\right]\left(\mathbf{4 a}, \mathrm{Ar}=\mathrm{C}_{6} \mathrm{H}_{4} \mathrm{~F}-p, 4 \mathrm{~d}\right.$, $\left.\mathrm{Ar}=\mathrm{C}_{6} \mathrm{H}_{4} \mathrm{CF}_{3}-p\right)$ were obtained by reaction of $\left[(\mathrm{OC})_{3} \mathrm{Fe}(\mu\right.$-dppm $\left.)(\mu-\mathrm{C}=\mathrm{O}) \mathrm{Pt}\left(\mathrm{PPh}_{3}\right)\right]$ with the respective terminal alkyne. Upon reaction of 1a, $\left[(\mathrm{OC})_{3} \mathrm{Fe}\left\{\mathrm{Si}(\mathrm{OMe})_{3}\right\}(\mu\right.$-dppa $\left.) \mathrm{Pt}(\mathrm{H})\left(\mathrm{PPh}_{3}\right)\right]$ (1b; dppa = bis(diphenylphosphino)amine), and $\left[(\mathrm{OC})_{3} \mathrm{Fe}\{\mathrm{Si}\right.$ $\left.(\mathrm{OMe})_{3}\right\}\left(\mu\right.$-dppm) $\left.\mathrm{Pt}(\mathrm{H})\left(\mathrm{PMePh}_{2}\right)\right]$ (1c) with $o-\mathrm{F}_{3} \mathrm{CC}_{6} \mathrm{H}_{4} \mathrm{C} \equiv \mathrm{CH}$, the dimetallacyclobutenes $\left[(\mathrm{OC})_{3} \mathrm{Fe}\left(\mu\right.\right.$ - $\left.\mathrm{PPh}_{2} \mathrm{XPPh}_{2}\right)\{\mu$ $\left.\left.\mathrm{C}\left(\mathrm{C}_{6} \mathrm{H}_{4} \mathrm{CF}_{3}-\mathrm{o}\right) \mathrm{C}=\mathrm{C}(\mathrm{H})\right\} \mathrm{Pt}\left(\mathrm{PPh}_{2} \mathrm{R}\right)\right]\left(5 \mathrm{a}, \mathrm{X}=\mathrm{CH}_{2} \mathrm{R}=\mathrm{Ph} ; \mathbf{5 b}, \mathrm{X}=\mathrm{NH}, \mathrm{R}=\mathrm{Ph} ; \mathbf{5 c}, \mathrm{X}=\mathrm{CH}_{2}, \mathrm{R}=\mathrm{Me}\right)$ are formed as the

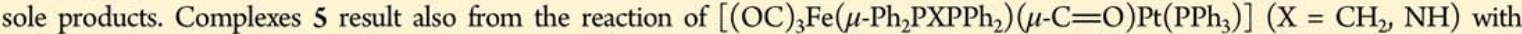
$o$-trifluorophenylacetylene. NMR studies at variable temperatures reveal that dimetallacyclobutenes 5 are in equilibrium with dimetallacyclopentenones $\left[(\mathrm{OC})_{2} \mathrm{Fe}\left(\mu-\mathrm{Ph}_{2} \mathrm{PXPPh}_{2}\right)\left\{\mu\right.\right.$-C(=O)C( $\left.\left.\left.\mathrm{C}_{6} \mathrm{H}_{4} \mathrm{CF}_{3}-o\right)=\mathrm{C}(\mathrm{H})\right\} \mathrm{Pt}\left(\mathrm{PPh}_{2} \mathrm{R}\right)\right]\left(4 \mathrm{e}, \mathrm{X}=\mathrm{CH}_{2}, \mathrm{R}=\mathrm{Ph} ; 4 \mathrm{f}\right.$, $\left.\mathrm{X}=\mathrm{NH}, \mathrm{R}=\mathrm{Ph} ; 4 \mathrm{~g}, \mathrm{X}=\mathrm{CH}_{2}, \mathrm{R}=\mathrm{Me}\right)$. Addition of $\mathrm{HBF}_{4}$ to 5 leads to formation of the $\mathrm{Fe}-\sigma: \mu_{2}$-alkenyl salts $\left[(\mathrm{OC})_{3} \mathrm{Fe}(\mu\right.$ $\left.\left.\mathrm{Ph}_{2} \mathrm{PXPPh}_{2}\right)\left\{\mu-\mathrm{C}\left(\mathrm{C}_{6} \mathrm{H}_{4} \mathrm{CF}_{3}-\sigma\right)=\mathrm{CH}_{2}\right\} \mathrm{Pt}\left(\mathrm{PPh}_{3}\right)\right]\left[\mathrm{BF}_{4}\right]\left(6 \mathrm{a}, \mathrm{X}=\mathrm{CH}_{2} ; 6 \mathbf{b}, \mathrm{X}=\mathrm{NH}\right)$. Protonation of 4 gives the isomeric $\mathrm{Pt}-\sigma: \mu_{2}-$ alkenyl salts $\left[(\mathrm{OC})_{3} \mathrm{Fe}(\mu\right.$-dppm $)\left\{\mu\right.$ - $\left.\left.\mathrm{CH}_{2}=\mathrm{C}(\mathrm{Ar})\right\} \mathrm{Pt}\left(\mathrm{PPh}_{3}\right)\right]\left[\mathrm{BF}_{4}\right]$ (7) together with small amounts of the $\mathrm{Fe}-\sigma: \mu_{2}$-alkenyl salts $\left[(\mathrm{OC})_{3} \mathrm{Fe}(\mu\right.$-dppm $)\left\{\mu\right.$-C $\left.\left.(\mathrm{Ar})=\mathrm{CH}_{2}\right\} \mathrm{Pt}\left(\mathrm{PPh}_{3}\right)\right]\left[\mathrm{BF}_{4}\right]\left(\mathrm{Ar}=p-\mathrm{C}_{6} \mathrm{H}_{4} \mathrm{CF}_{3}, p-\mathrm{C}_{6} \mathrm{H}_{4} \mathrm{~F}, 2,4-\mathrm{C}_{6} \mathrm{H}_{3} \mathrm{~F}_{2}\right)$. Protonation of the vinylidene complexes $\left[(\mathrm{OC})_{3} \mathrm{Fe}(\mu\right.$-dppm $)\{\mu$-C $\left.=\mathrm{C}(\mathrm{H}) \mathrm{Ar}\} \mathrm{Pt}\left(\mathrm{PPh}_{3}\right)\right]\left(3 ; \mathrm{Ar}=p-\mathrm{C}_{6} \mathrm{H}_{4} \mathrm{CF}_{3}, \mathrm{Ph}, p-\mathrm{C}_{6} \mathrm{H}_{4} \mathrm{CH}_{3}\right)$ with $\mathrm{HBF}_{4}$ occurs exclusively at the $\alpha$-position of the vinylidene unit to produce a mixture of the isomeric $\sigma$-alkenyl salts cis-[(OC) ${ }_{3} \mathrm{Fe}(\mu$-dppm $)\{\mu$-C $(\mathrm{H})=$ $\left.\mathrm{C}(\mathrm{H}) \operatorname{Ar}\} \mathrm{Pt}\left(\mathrm{PPh}_{3}\right)\right]\left[\mathrm{BF}_{4}\right]($ 8-cis $)$ and trans- $\left[(\mathrm{OC})_{3} \mathrm{Fe}(\mu\right.$-dppm $\left.)\{\mu-\mathrm{C}(\mathrm{H})=\mathrm{C}(\mathrm{H}) \operatorname{Ar}\} \mathrm{Pt}\left(\mathrm{PPh}_{3}\right)\right]\left[\mathrm{BF}_{4}\right]$ (8-trans).
\end{abstract}

\section{INTRODUCTION}

The insertion of small unsaturated molecules into the $\mathrm{Pt}-\mathrm{H}$ bond of mononuclear $\mathrm{Pt}(\mathrm{II})$ complexes has been studied in detail in connection with their role in hydrogenation, hydrosilylation, hydrocyanation, and polymerization reactions. ${ }^{1}$ With terminal alkynes $\mathrm{RC} \equiv \mathrm{CH}$, square-planar $\sigma$-alkenyl complexes of the type $\mathrm{L}_{n} \mathrm{Pt}\left(\mathrm{CR}=\mathrm{CH}_{2}\right)$ or $\mathrm{L}_{n} \mathrm{Pt}(\mathrm{CH}=\mathrm{CHR})$ are generated. ${ }^{2}$

Received: July 1, 2013

Published: September 23, 2013 
Scheme 1

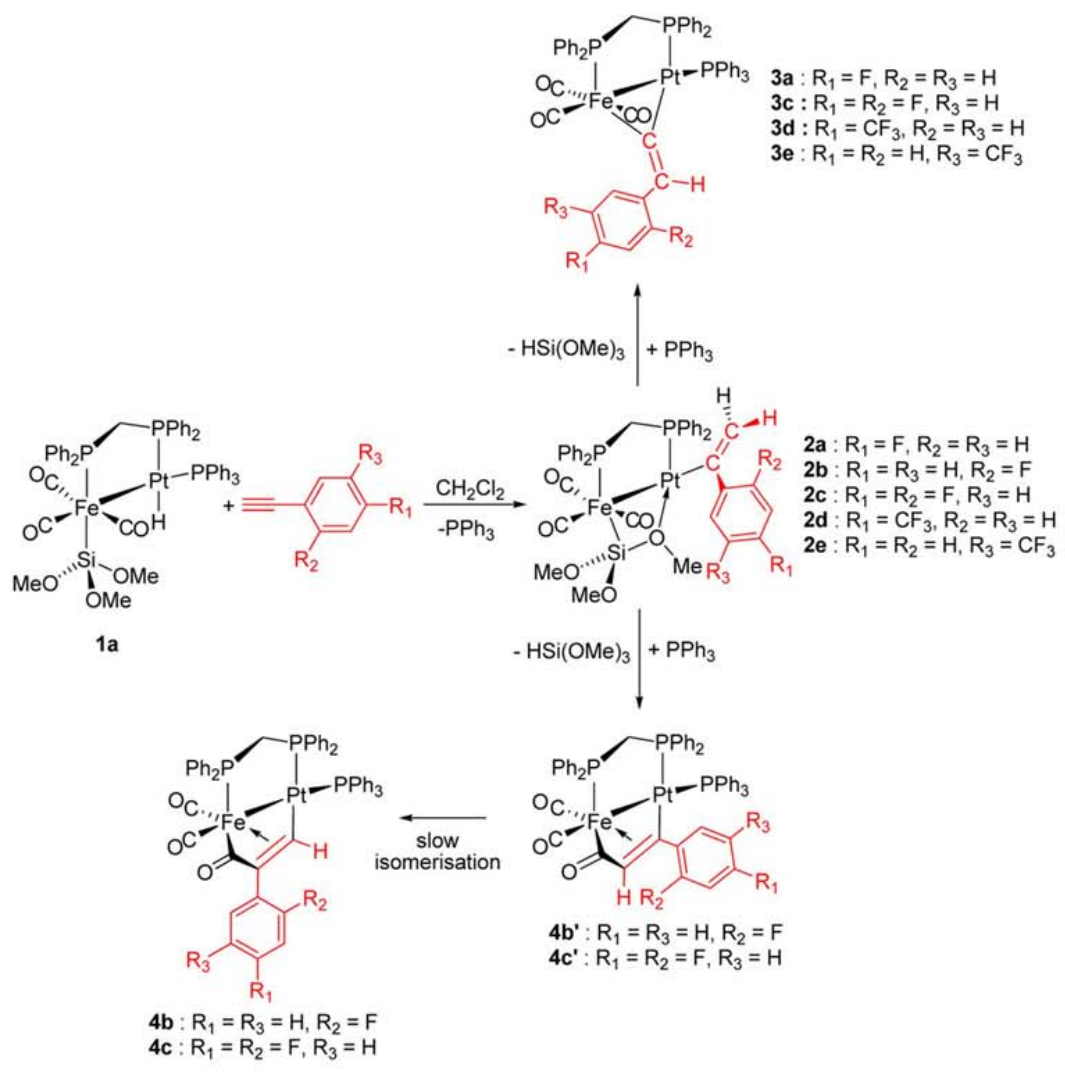

Generally, insertion (also called hydrometalation) occurs through the classical "migratory insertion" mechanism, but in some cases radical pathways have been evidenced. ${ }^{3}$ There have also been some experimental and theoretical studies on the reactivity of homodinuclear platinum complexes bearing terminal or bridging hydride ligand toward alkynes. ${ }^{4}$ Studies on the reactivity of heterobimetallic hydride species are scarce, although the activation of small molecules by heterobimetallic compounds has stimulated much interest due to possible synergic effects exerted by the close proximity of metal centers (with different coordination spheres, oxidation states, ...). ${ }^{5}$ A nice example demonstrating the sometimes diverging reactivity pattern between homobimetallics and related heterobimetallics has been provided by Mays et al., who studied the reactivities of $\left[\mathrm{Mn}_{2}(\mu-\mathrm{H})\left(\mu-\mathrm{PPh}_{2}\right)(\mathrm{CO})_{8}\right]$ and $\left[\left(\eta-\mathrm{C}_{5} \mathrm{H}_{5}\right)(\mathrm{CO})_{2} \mathrm{Mo}(\mu-\mathrm{H})(\mu-\right.$ $\left.\left.\mathrm{PPh}_{2}\right) \mathrm{Mn}(\mathrm{CO})_{4}\right]$ toward propyne: whereas the $\mathrm{Mn}-\mathrm{Mn}$ compound afforded the two isomeric $\mu$-vinyl complexes $\left[\mathrm{Mn}_{2}\left(\mu-\mathrm{PPh}_{2}\right)\left\{\mu-\sigma: \eta^{2}-\mathrm{C}(\mathrm{Me})=\mathrm{CH}_{2}\right\}(\mathrm{CO})_{7}\right]$ and $\left[\mathrm{Mn}_{2}\{\mu-\right.$ $\left.\left.\sigma: \eta^{2}-\mathrm{C}(\mathrm{H})=\mathrm{C}(\mathrm{H}) \mathrm{Me}\right\}\left(\mu-\mathrm{PPh}_{2}\right)(\mathrm{CO})_{7}\right]$ along with the allyl compound $\left[\mathrm{Mn}_{2}\left(\mu-\mathrm{PPh}_{2}\right)\left(\eta^{3}-\mathrm{C}_{3} \mathrm{H}_{5}\right)(\mathrm{CO})_{7}\right]$, the $\mathrm{Mo}-\mathrm{Mn}$ compound yielded as the sole insertion product $\left[\left(\eta-\mathrm{C}_{5} \mathrm{H}_{5}\right)\right.$ $\left.(\mathrm{CO})_{2} \mathrm{Mo}\left(\mu-\mathrm{PPh}_{2}\right) \mathrm{Mn}\left(\eta^{3}-\mathrm{C}_{3} \mathrm{H}_{5}\right)(\mathrm{CO})_{3}\right]^{6 a}$ Another example of alkyne insertion into a heterobimetallic $\mu$-phosphido complex is described for $\left[\operatorname{RuMn}(\mu-\mathrm{H})\left(\mu-\mathrm{PPh}_{2}\right)\left(\eta^{5}-\mathrm{C}_{5} \mathrm{H}_{5}\right)(\mathrm{CO})_{5}\right]$, which produces $\left[\operatorname{RuMn}\left\{\mu-\sigma: \eta^{2}-\mathrm{C}(\mathrm{Ph})=\mathrm{C}(\mathrm{H}) \mathrm{Ph}\right\}\left(\mu-\mathrm{PPh}_{2}\right)\left(\eta^{5}\right.\right.$ $\left.\left.\mathrm{C}_{5} \mathrm{H}_{5}\right)(\mathrm{CO})_{4}\right]{ }^{66}$ Insertion of alkynes occurs also into the $\mathrm{Os}-\mathrm{H}$ and $\mathrm{Mo}-\mathrm{H}$ bonds of $\left[(\mathrm{OC}) \mathrm{Rh}(\mu \text {-dppm })_{2} \mathrm{Os}(\mathrm{H})(\mathrm{CO})_{2}\right]$ and $\left[(\mathrm{OC}) \mathrm{Rh}(\mu \text {-dppm })_{2} \mathrm{Mo}(\mathrm{H})(\mathrm{CO})_{3}\right]$, leading to $\sigma$-alkenyl complexes. $^{7 a-c}$ Furthermore, Cowie's group has investigated the reactivity of $\left[\mathrm{RhMn}(\mathrm{CO})_{4}(\mu-\mathrm{H})(\mathrm{dppm})_{2}\right]\left[\mathrm{BF}_{4}\right]$ toward

DMAD. ${ }^{7 \mathrm{~d}}$ Upon treatment with $\mathrm{RC} \equiv \mathrm{CR}(\mathrm{R}=\mathrm{Ph}, p$-Tol), the hydride complex $\left[\operatorname{RhPt}(\mu-\mathrm{H})(\mu\right.$-CO $)\left(\mathrm{PEt}_{3}\right)_{2}\left(\mathrm{PPh}_{3}\right)\left(\eta^{5}\right.$ $\left.\left.\mathrm{C}_{2} \mathrm{~B}_{9} \mathrm{H}_{11}\right)\right]$ was converted to $[\mathrm{RhPt}\{\sigma-\mathrm{C}(\mathrm{R})=\mathrm{C}(\mathrm{R}) \mathrm{H}\}(\mathrm{CO})$ $\left.\left(\mathrm{PEt}_{3}\right)\left(\mathrm{PPh}_{3}\right)\left(\eta^{5}-\mathrm{C}_{2} \mathrm{~B}_{9} \mathrm{H}_{11}\right)\right]$ bearing a terminal Pt-bound alkenyl group. ${ }^{8}$ Note, however, that addition of alkynes to the unsupported hydride compound $\left[\left(\eta^{5}-\mathrm{Cp}\right)(\mathrm{OC})_{3} \mathrm{Mo}-\mathrm{Pt}(\mathrm{H})\right.$ (dppe)] promotes first hydrogen transfer with concomitant cleavage of the metal-metal bond. ${ }^{9 a}$ Only in the case of terminal alkynes does subsequent addition of $\left[\left(\eta^{5}-\mathrm{Cp}\right)(\mathrm{OC})_{3} \mathrm{Mo}(\mathrm{H})\right]$ across $[(\mathrm{HC} \equiv \mathrm{CR}) \mathrm{Pt}($ dppe $)]$ generate the final alkenyl-bridged system $\left[\left(\eta^{5}-\mathrm{Cp}\right)(\mathrm{OC})_{2} \mathrm{Mo}(\mu-\mathrm{CO})\left(\mu-\mathrm{H}_{2} \mathrm{C}=\mathrm{CR}\right) \mathrm{Pt}(\mathrm{H})\right.$ (dppe) $]{ }^{9 b}$ The dinuclear alkenyl complex $\left[\mathrm{Cp}(\mathrm{CO})_{2} \operatorname{Re}(\mu\right.$ $\left.\mathrm{H}) \mathrm{Pt}\left(\mathrm{PPh}_{3}\right)_{2}\left\{\mathrm{C}\left(\mathrm{CH}_{3}\right)=\mathrm{CHCH}_{3}\right\}\right]$ was proposed as a possible intermediate in the reaction of 2-butyne with the dihydride complex $\left[\mathrm{Cp}(\mathrm{CO})_{2} \operatorname{Re}(\mu-\mathrm{H}) \mathrm{Pt}(\mathrm{H})\left(\mathrm{PPh}_{3}\right)_{2}\right]$ to give $\left[\mathrm{Cp}(\mathrm{CO})_{2^{-}}\right.$ $\mathrm{Re}\left(\right.$ cis- $\left.\left.\mathrm{CH}_{3} \mathrm{CH}=\mathrm{CHCH}_{3}\right)\right]$. ${ }^{9 c}$ Adams has shown that Pt$\left(\mathrm{PBut}_{3}\right)_{2}$-promoted insertion of $\mathrm{PhC} \equiv \mathrm{CH}$ into the $\mathrm{Os}-\mathrm{H}$ bond of $\mathrm{HOs}(\mathrm{CO})_{4} \mathrm{SnPh}_{3}$ occurs via formation of the bimetallic hydride complex $\left[\mathrm{PtOs}(\mathrm{CO})_{4}\left(\mathrm{SnPh}_{3}\right)\left(\mathrm{PBut}_{3}\right)(\mu-\mathrm{H})\right]$, leading to $\left[\mathrm{PtOs}(\mathrm{CO})_{4}\left(\mathrm{SnPh}_{3}\right)\left(\mathrm{PBut}_{3}\right)(\mu-\mathrm{HC}=\mathrm{C}(\mathrm{H}) \mathrm{Ph})\right]$. Quite recently, theoretical investigations on this study have confirmed the cooperative effect between the two metal centers. ${ }^{10}$ Further examples include reactions of alkynes with $\mathrm{Ru}(\mu-\mathrm{H})_{3} \mathrm{Re}$ and $\mathrm{Ru}(\mu-\mathrm{H})_{4}$ Os complexes. ${ }^{11,12}$

In previous works we have shown that the reactivity of the heterobimetallic iron-platinum hydride complexes $\left[(\mathrm{OC})_{3} \mathrm{Fe}-\right.$ $\left\{\mathrm{Si}(\mathrm{OMe})_{3}\right\}(\mu$-dppm $\left.) \mathrm{Pt}(\mathrm{H})\left(\mathrm{PPh}_{3}\right)\right]$ (1a) and $\left[(\mathrm{OC})_{3} \mathrm{Fe}\{\mathrm{Si}-\right.$ $\left.(\mathrm{OMe})_{3}\right\}\left(\mu\right.$-dppa) $\left.\mathrm{Pt}(\mathrm{H})\left(\mathrm{PPh}_{3}\right)\right]$ (1b) toward $\mathrm{RC} \equiv \mathrm{CH}$ depends in a subtle manner on the electronic properties of the alkynes used. In all cases, the insertion reaction of the alkyne in 
Table 1. Selected IR and ${ }^{31} \mathrm{P}\left\{{ }^{1} \mathrm{H}\right\}$ NMR Data

\begin{tabular}{|c|c|c|c|c|c|c|}
\hline \multicolumn{7}{|c|}{$\sigma$-Alkenyl } \\
\hline & & & \multicolumn{4}{|c|}{$\mathrm{NMR}^{e}$} \\
\hline & \multicolumn{2}{|c|}{$\mathrm{IR}^{a} \nu(\mathrm{CO})$} & $\delta\left(\mathrm{P}_{1}\right)$ & $\delta\left(\mathrm{P}_{2}\right)$ & ${ }^{2+3} J_{\mathrm{P}_{1} \mathrm{P}_{2}}$ & ${ }^{1} J_{\mathrm{P}_{2}} \mathrm{Pv}^{2} J_{\mathrm{P}_{1} \mathrm{Pt}}$ \\
\hline $2 \mathrm{a}$ & \multicolumn{2}{|c|}{$1964(s), b 1903(s), 1874(s)$} & $61.3, \mathrm{~d}$ & $6.6, \mathrm{~d}$ & 41 & $5234, \mathrm{ND}$ \\
\hline $2 b$ & \multicolumn{2}{|c|}{$1964(s),{ }^{b} 1904(s), 1869(s)$} & $61.2, \mathrm{~d}$ & $6.8, \mathrm{~d}$ & 40 & $5237, \mathrm{ND}$ \\
\hline $2 \mathrm{c}$ & \multicolumn{2}{|c|}{$1967(\mathrm{~s}){ }^{b} 1907(\mathrm{~s}), 1877(\mathrm{~s})$} & $61.3, \mathrm{~d}$ & $6.8, \mathrm{~d}$ & 42 & 5236,55 \\
\hline $2 d$ & \multicolumn{2}{|c|}{ ND } & $61.2, \mathrm{~d}$ & $6.9, \mathrm{~d}$ & 42 & $5163, \mathrm{ND}$ \\
\hline $2 \mathrm{e}$ & \multicolumn{2}{|l|}{ ND } & $61.6, \mathrm{~d}$ & $7.0, \mathrm{~d}$ & 42 & 5176,56 \\
\hline \multicolumn{7}{|c|}{$\mu$-Vinylidene } \\
\hline & & \multicolumn{5}{|c|}{$\mathrm{NMR}^{e}$} \\
\hline & $\mathrm{IR}^{a} \nu(\mathrm{CO})$ & $\delta\left(\mathrm{P}_{1}\right)$ & $\delta\left(\mathrm{P}_{2}\right)$ & $\delta\left(\mathrm{P}_{3}\right)$ & ${ }^{2+3} J_{P_{1} P_{2}}, J_{P_{1} P_{y},}{ }^{2} J_{P_{2} P_{3}}$ & ${ }^{2} J_{P_{1}}{ }_{P v}{ }^{1} J_{P_{2} P v}{ }^{1} J_{P_{3} P_{t}}$ \\
\hline $3 a$ & $1992(\mathrm{~m}),{ }^{c} 1928(\mathrm{~s}), 1910(\mathrm{~s})$ & $64.3, \mathrm{dd}$ & 43.1, dd & $23.7, \mathrm{dd}$ & $116,13,17$ & $76,2444,3924$ \\
\hline $3 c$ & $1993(\mathrm{~m}), 1930(\mathrm{~s}), 1910(\mathrm{~s})$ & $64.0, \mathrm{dd}$ & $43.2, \mathrm{t}$ & $22.4, \mathrm{dd}$ & $116,15,15$ & $81,2452,4001$ \\
\hline $3 d$ & $1994(\mathrm{~m}), 1931(\mathrm{~s}), 1913(\mathrm{~s})$ & $63.4, \mathrm{dd}$ & $44.0, \mathrm{t}$ & 22.4 , dd & $115,12,15$ & ND, 2474,4011 \\
\hline $3 e$ & $1997(\mathrm{~m}), 1932(\mathrm{~s}), 1925(\mathrm{~s})$ & $63.2, \mathrm{dd}$ & $44.0, \mathrm{t}$ & 22.5 , dd & $115,15,18$ & $80,2480,4004$ \\
\hline \multicolumn{7}{|c|}{ Cyclopentenone } \\
\hline & & \multicolumn{5}{|c|}{$\mathrm{NMR}^{e}$} \\
\hline & $\mathrm{IR}^{a} \nu(\mathrm{CO})$ & $\delta\left(\mathrm{P}_{1}\right)$ & $\delta\left(\mathrm{P}_{2}\right)$ & $\delta\left(\mathrm{P}_{3}\right)$ & ${ }^{2+3} J_{\mathrm{P}_{1} \mathrm{P}_{2}}{ }^{3} J_{\mathrm{P}_{1} \mathrm{P}_{y}},{ }^{2} J_{\mathrm{P}_{2} \mathrm{P}_{3}}$ & ${ }^{2} J_{P_{1}} \mathrm{P} v^{1} J_{\mathrm{P}_{2} \mathrm{Pv}}{ }^{1} J_{\mathrm{P}_{\mathrm{P}} \mathrm{Pt}}$ \\
\hline $4 a$ & $1956(s),{ }^{c} 1909(\mathrm{~s}), 1701(\mathrm{w})$ & $59.4, \mathrm{dd}$ & $7.5, \mathrm{dd}$ & $33.5, \mathrm{dd}$ & $57,36,4$ & $112,2659,3482$ \\
\hline $4 b^{\prime}$ & $1966(s),^{d} 1910(s)$ & $63.4, \mathrm{dd}$ & $8.0, \mathrm{dd}$ & 34.5 , dd & $56,33,8$ & $112,2595,3412$ \\
\hline $4 \mathrm{~b}$ & $1959(\mathrm{~s}),{ }^{c} 1912(\mathrm{~s}), 1701(\mathrm{~m})$ & $60.7, \mathrm{dd}^{f}$ & $6.8, \mathrm{dd}$ & 33.4, dd & $55,35,6$ & $128,2623,3519$ \\
\hline $4 c^{\prime}$ & $1970(\mathrm{~s}), 1914(\mathrm{~s}), 1707(\mathrm{~m})$ & $62.7, \mathrm{dd}$ & $7.5, \mathrm{dd}$ & $33.6, \mathrm{t}$ & $56,34,7$ & $\mathrm{ND}, 2634,3562$ \\
\hline $4 c$ & $1957(\mathrm{~s}), 1911(\mathrm{~s}), 1701(\mathrm{~m})$ & $59.9, \mathrm{dd}^{i}$ & $6.7, \mathrm{~d}$ & $33.3, \mathrm{~d}$ & $55,35, \mathrm{ND}$ & $\mathrm{ND}, 2638,3525$ \\
\hline $4 d$ & $1966(\mathrm{~s}), 1919(\mathrm{~s}), 1696(\mathrm{~m})$ & 59.9 , br dd & $8.6, \mathrm{~d}$ & $34.0, \mathrm{~d}$ & $52,35, \mathrm{ND}$ & $\mathrm{ND}, 2638,3489$ \\
\hline $4 e$ & ND & $59.2, \mathrm{dd}^{h}$ & $7.1, \mathrm{~d}$ & $32.2, \mathrm{~d}$ & $54,33, \mathrm{ND}$ & $\mathrm{ND}, 2642,3470$ \\
\hline $4 f$ & ND & $108.5, \mathrm{dd}^{g}$ & $65.1, \mathrm{~d}$ & $32.4, \mathrm{~d}$ & $54,23, \mathrm{ND}$ & ND, 2912,3428 \\
\hline $4 g$ & ND & $58.6, \mathrm{dd}^{g}$ & $6.4, \mathrm{dd}$ & 31.4 , dd & $54,37,9$ & $\mathrm{ND}, 2627,3468$ \\
\hline $4 h$ & $1968(s), 1916(s), 1704(w)$ & $110.7, \mathrm{dd}$ & $65.3, \mathrm{~d}$ & $34.1, \mathrm{~d}$ & $59,25, \mathrm{ND}$ & ND, 2970,3464 \\
\hline \multicolumn{7}{|c|}{ Cyclobutene } \\
\hline & & \multicolumn{5}{|c|}{$\mathrm{NMR}^{e}$} \\
\hline & $\mathrm{IR}^{a} \nu(\mathrm{CO})$ & $\delta\left(\mathrm{P}_{1}\right)$ & $\delta\left(\mathrm{P}_{2}\right)$ & $\delta\left(\mathrm{P}_{3}\right)$ & ${ }^{2+3} J_{\mathrm{P}_{1} \mathrm{P}_{2}}{ }^{3} J_{\mathrm{P}_{1} \mathrm{P}_{y^{\prime}}}{ }^{2} J_{\mathrm{P}_{2} \mathrm{P}_{3}}$ & ${ }^{2} J_{\mathrm{P}_{1}, \mathrm{P} v}{ }^{1} \mathrm{~J}_{\mathrm{P}_{2} \mathrm{P} v}{ }^{1} \mathrm{~J}_{\mathrm{P}_{3}, \mathrm{P}_{\mathrm{t}}}$ \\
\hline $5 a$ & $1973(\mathrm{~m}), 1915(\mathrm{~s}), 1900(\mathrm{~s})$ & $84.0, \mathrm{~d}^{h}$ & $30.6, d$ & $31.1, \mathrm{~s}$ & $128, \mathrm{ND}, \mathrm{ND}$ & $85,2084,3459$ \\
\hline $5 b$ & $1983(\mathrm{~m}), 1924(\mathrm{~s}), 1908(\mathrm{~s})$ & $128.8, \mathrm{dd}^{g}$ & $83.2, \mathrm{~d}$ & $30.0, \mathrm{~d}$ & $143,9, \mathrm{ND}$ & $89,2313,3444$ \\
\hline $5 c$ & $1973(\mathrm{~m}), 1915(\mathrm{~s}), 1898(\mathrm{~s})$ & $83.6, \mathrm{dd}^{g}$ & $24.6, \mathrm{~d}$ & $10.8, \mathrm{~d}$ & $129,7, \mathrm{ND}$ & $\mathrm{ND}, 2173,3386$ \\
\hline \multicolumn{7}{|c|}{$\sigma, \mu$-Alkenyl } \\
\hline & & \multicolumn{5}{|c|}{$\mathrm{NMR}^{e}$} \\
\hline & $\operatorname{IR}^{a} \nu(\mathrm{CO})$ & $\delta\left(\mathrm{P}_{1}\right)$ & $\delta\left(\mathrm{P}_{2}\right)$ & $\delta\left(\mathrm{P}_{3}\right)$ & ${ }^{2+3} J_{P_{1} P_{2}},{ }^{3} J_{P_{1} P_{y}},{ }^{2} J_{P_{2} P_{3}}$ & ${ }^{2} J_{P_{1}, \mathrm{P} v}{ }^{1} J_{\mathrm{P}_{2} \mathrm{P} v}{ }^{1} J_{\mathrm{P}_{3} \mathrm{Pt}}$ \\
\hline $6 a$ & $2054(\mathrm{~m}), 1992(\mathrm{~s}), 1985(\mathrm{~s})$ & $39.9, \mathrm{dd}$ & $10.9, \mathrm{dd}$ & $30.4, \mathrm{t}$ & $47,10,15$ & $\mathrm{ND}, 3600,3245$ \\
\hline $6 b$ & $2047(\mathrm{~m}), 1990(\mathrm{~s}), 1982(\mathrm{~s})$ & 85.9, dd & $67.8, \mathrm{dd}$ & $30.3, \mathrm{t}$ & $47,10,7$ & $\mathrm{ND}, 4034,3330$ \\
\hline $6 c$ & $\mathrm{ND}$ & $39.0, \mathrm{dd}$ & $11.7, \mathrm{dd}$ & 30.2 , br d & $44,11,15$ & ND \\
\hline $6 d$ & ND & $38.8, \mathrm{br} \mathrm{d}$ & $11.3, \mathrm{br} \mathrm{d}$ & 30.1 , br s & $42,11, \mathrm{ND}$ & $\mathrm{ND}, 3736,3313$ \\
\hline $6 e$ & ND & 38.9, br d & 11.5 , br & $30.3, \mathrm{br}$ & $\mathrm{ND}$ & $\mathrm{ND}, 3757,3282$ \\
\hline $6 f$ & ND & 39.0, br d & 11.8 , br dd & 30.3 , br s & $48,17,12$ & ND \\
\hline $7 a$ & $2031(\mathrm{~s}), 1987(\mathrm{~s}), 1913(\mathrm{~m})$ & $52.1, \mathrm{dd}$ & $7.9, \mathrm{dd}$ & $35.6, \mathrm{dd}$ & $49,27,18$ & $67,2281,3779$ \\
\hline $7 \mathrm{c}$ & $2031(\mathrm{~s}), 1986(\mathrm{~s}), 1906(\mathrm{~m})$ & $51.4, \mathrm{dd}$ & $8.9, \mathrm{dd}$ & $36.0, \mathrm{t}$ & $49,26,19$ & $\mathrm{ND}, 2333,3792$ \\
\hline $7 \mathrm{~d}$ & $2041(\mathrm{~s}), 1990(\mathrm{~s}), 1920(\mathrm{~m})$ & 51.4 , dd & $8.4, \mathrm{dd}$ & 36.4 , dd & $46,26,18$ & $\mathrm{ND}, 2302,3745$ \\
\hline $7 \mathrm{i}$ & $2028(\mathrm{~s}), 1987(\mathrm{~s}), 1916(\mathrm{~m})$ & $51.5, \mathrm{dd}$ & $6.7, \mathrm{dd}$ & $34.9, \mathrm{dd}$ & $49,26,18$ & $61,2275,3774$ \\
\hline 8d-trans & $2043(\mathrm{~s}), 2000(\mathrm{~s}), 1957(\mathrm{~s})$ & $54.4, \mathrm{dd}$ & $8.5, \mathrm{dd}$ & $34.3, \mathrm{t}$ & $39,24,19$ & ND, 2376, 3759 \\
\hline $8 \mathrm{~d}$-cis & ND & $56.8, \mathrm{dd}$ & $9.0, \mathrm{dd}$ & $39.3, \mathrm{t}$ & $42,21,16$ & ND \\
\hline 8f-trans & ND & $56.1, \mathrm{dd}$ & $8.5, \mathrm{dd}$ & 34.7 , dd & $39,24,16$ & $53,2464,3718$ \\
\hline $8 \mathrm{f}$-cis & $2036(\mathrm{~s}){ }^{c} 1979(\mathrm{vs}), 1956(\mathrm{sh})$ & 58.3 , dd & $9.3, \mathrm{dd}$ & 40.0 , dd & $42,21,16$ & $51,2379,3639$ \\
\hline 8g-trans & $2035(\mathrm{~s}){ }^{c} 1979(\mathrm{vs}), 1959(\mathrm{sh})$ & $55.6, \mathrm{dd}$ & $7.6, \mathrm{dd}$ & $34.1, \mathrm{dd}$ & $39,24,17$ & $\mathrm{ND}, 2219,3564$ \\
\hline $8 \mathrm{~g}$-cis & & $57.7, \mathrm{dd}$ & $8.5, \mathrm{dd}$ & $39.1, \mathrm{dd}$ & $43,21,15$ & $\mathrm{ND}, 2381,3635$ \\
\hline
\end{tabular}

${ }^{a}$ IR abbreviations: $\mathrm{s}=$ strong, $\mathrm{m}=$ medium, $\mathrm{sh}=$ shoulder, $\mathrm{vs}=$ very strong, $\mathrm{w}=$ weak. ATR (germanium crystal) unless otherwise indicated. In units of $\mathrm{cm}^{-1}$. ND = not determined. ${ }^{b}$ Dichloromethane solution. ${ }^{c} \mathrm{KBr}$ pellets. ${ }^{d} \mathrm{CDCl}_{3}$ solution. ${ }^{e} \mathrm{NMR}$ abbreviations: $\mathrm{s}=$ singlet, $\mathrm{d}=\mathrm{doublet}, t=$ triplet, $\mathrm{q}=$ quadruplet, $\mathrm{m}=$ multiplet, br $=$ broad. $\mathrm{P}_{1}=\mathrm{P}_{\mathrm{Fedppm}}, \mathrm{P}_{2}=\mathrm{P}_{\mathrm{Ptdppm}}, \mathrm{P}_{3}=\mathrm{PPh}_{3}$. NMR data at $298 \mathrm{~K}$ in $\mathrm{CDCl}_{3}$ unless otherwise indicated. $\delta$ in ppm and $J$ in $\mathrm{Hz} . \mathrm{ND}=$ not determined. ${ }^{f} \mathrm{NMR}$ data at $223 \mathrm{~K} .{ }^{g} \mathrm{NMR}$ data at $233 \mathrm{~K} .{ }^{h} \mathrm{NMR}$ data at $248 \mathrm{~K}$. ${ }^{i} \mathrm{NMR}$ data at $253 \mathrm{~K}$. 
the $\mathrm{Pt}-\mathrm{H}$ bond is stereoselective and leads first to $\sigma$-alkenyl complexes $\left[(\mathrm{OC})_{3} \mathrm{Fe}\left\{\mu\right.\right.$-Si $\left.(\mathrm{OMe})_{2}(\mathrm{OMe})\right\}(\mu$-dppm $) \mathrm{Pt}(\mathrm{RC}=$ $\left.\left.\mathrm{C}(\mathrm{H}) \mathrm{R}^{\prime}\right)\right]\left(\mathrm{R}=\mathrm{Ar}, \mathrm{R}^{\prime}=\mathrm{H} ; \mathrm{R}=\mathrm{CF}_{3}, \mathrm{R}^{\prime}=\mathrm{H} ; \mathrm{R}=\mathrm{R}^{\prime}=\mathrm{CF}_{3}\right.$; $\left.\mathrm{R}={ }^{t} \mathrm{Bu}, \mathrm{R}^{\prime}=\mathrm{H} ; \mathrm{R}=n-\mathrm{C}_{4} \mathrm{H}_{9}, \mathrm{R}^{\prime}=\mathrm{H} ; \mathrm{R}=\left(\mathrm{CH}_{2}\right)_{3} \mathrm{C} \equiv \mathrm{CH}, \mathrm{R}^{\prime}=\mathrm{H}\right)$. In the case of activated alkynes bearing the strongly electron withdrawing $\mathrm{C}(=\mathrm{O}) \mathrm{OMe}$ and $\mathrm{CF}_{3}$ substituents, no further reaction between the $\sigma$-alkenyl complex and the liberated triphenylphosphine was observed. ${ }^{13 a}$ With phenylacetylene and $p$-tolylacetylene, the displaced $\mathrm{PPh}_{3}$ is able to react in a second step with the $\sigma$-alkenyl complex to induce exclusively formation of the $\mu$-vinylidene $\left[(\mathrm{OC})_{3} \mathrm{Fe}\{\mu\right.$-C $=\mathrm{C}(\mathrm{H}) \mathrm{Ar}\}(\mu$-dppm $\left.) \mathrm{Pt}\left(\mathrm{PPh}_{3}\right)\right]$ compounds. ${ }^{13 \mathrm{~b}} \mathrm{~A}$ mixture of $\mu$-vinylidene $\left[(\mathrm{OC}){ }_{3} \mathrm{Fe}\{\mu\right.$-C $=$ $\mathrm{C}(\mathrm{H}) \mathrm{R}\}(\mu$-dppm $\left.) \mathrm{Pt}\left(\mathrm{PPh}_{3}\right)\right]$ and dimetallacyclopentenone complexes $\left[(\mathrm{OC})_{2} \mathrm{Fe}(\mu\right.$-dppm $)\{\mu$-C $\left.(=\mathrm{O}) \mathrm{C}(\mathrm{R}) \mathrm{C}(\mathrm{H})\} \mathrm{Pt}\left(\mathrm{PPh}_{3}\right)\right]$ resulted upon treatment with aliphatic terminal alkynes $\left(\mathrm{R}={ }^{t} \mathrm{Bu}\right.$, $n$ - $\left.\mathrm{C}_{4} \mathrm{H}_{9},\left(\mathrm{CH}_{2}\right)_{3} \mathrm{C} \equiv \mathrm{CH}\right){ }^{13 \mathrm{c}}$ Although isocyanide insertion into the $\mathrm{Pt}-\mathrm{H}$ bond leading to formimidoyl complexes is wellestablished, ${ }^{1 \mathrm{lg}}$ no insertion occurred when 1a was treated with $\mathrm{RN} \equiv \mathrm{C}$. Instead, formal elimination of $\mathrm{HSi}(\mathrm{OMe})_{3}$ leads to the isocyanide-bridged complexes $\left[(\mathrm{OC})_{3} \mathrm{Fe}(\mu\right.$-dppm $)\{\mu$-C $=\mathrm{NR})$ $\left.\operatorname{Pt}\left(\mathrm{PPh}_{3}\right)\right]_{.}^{13 b, 14}$

In order to rationalize the versatile and so far unpredictable reactivity of these iron-platinum hydride complexes 1 , we decided to extend these reactivity studies toward terminal alkynes with electronic properties situated between activated alkynes with strongly electron withdrawing groups and aliphatic alkyne with electron donating alkyl groups. ${ }^{13 a, c}$ We have therefore performed reactions with various aromatic terminal alkynes bearing fluoro-substituents at the ortho, meta, and para positions. Herein we report on the synthesis, dynamic behavior, and structural characterization of the complexes obtained by these hydrometalation reactions. Furthermore, we have undertaken reactivity studies on the resulting $\mu$-vinylidene, dimetallacyclopentenone, and dimetallacyclobutene compounds, which are readily converted to $\mu$ - $\sigma$-alkenyl species upon protonation with $\mathrm{HBF}_{4}$.

\section{RESULTS AND DISCUSSION}

Alkyne Insertion Studies. The reaction of the hydride complex $\left[(\mathrm{OC})_{3} \mathrm{Fe}\left\{\mathrm{Si}(\mathrm{OMe})_{3}\right\}(\mu\right.$-dppm $\left.) \mathrm{Pt}(\mathrm{H})\left(\mathrm{PPh}_{3}\right)\right]$ (1a) with a $\mathrm{CH}_{2} \mathrm{Cl}_{2}$ solution of 3 equiv of $p$-fluoroethynylbenzene yields first the $\sigma$-alkenyl complex $\left[(\mathrm{OC})_{3} \mathrm{Fe}\left\{\mu\right.\right.$-Si $\left.(\mathrm{OMe})_{2}(\mathrm{OMe})\right\}$ $(\mu$-dppm $\left.) \mathrm{Pt}\left(p-\mathrm{FC}_{6} \mathrm{H}_{4} \mathrm{C}=\mathrm{CH}_{2}\right)\right](2 \mathrm{a})$, as evidenced by ${ }^{31} \mathrm{P}$ NMR monitoring of the progress of the reaction. This insertion product $\left(\delta\left({ }^{31} \mathrm{P}\right): 61.3, \mathrm{P}_{\mathrm{Fe}} ; 6.6, \mathrm{P}_{\mathrm{Pt}}\right)$, in which one of the methoxy groups of the $\mathrm{Si}(\mathrm{OMe})_{3}$ ligand forms a hemilabile $\mu$-Si( $\left.\mathrm{OMe}\right)_{2}(\mathrm{OMe})$ interaction with the Pt center, reacts in situ with the liberated $\mathrm{PPh}_{3}$ ligand to give the $\mu$-vinylidene complex $\left[(\mathrm{OC})_{3} \mathrm{Fe}(\mu\right.$-dppm $)\{\mu$ $\left.\left.\mathrm{C}=\mathrm{C}(\mathrm{H}) \mathrm{C}_{6} \mathrm{H}_{4} \mathrm{~F}-\mathrm{p}\right\} \mathrm{Pt}\left(\mathrm{PPh}_{3}\right)\right]$ (3a) according to Scheme 1. The mechanistic aspects and outcome of this transformation are in line with our previous studies on the reactivity of $1 \mathrm{a}$ vis à vis phenylacetylene or $p-\mathrm{CH}_{3} \mathrm{C}_{6} \mathrm{H}_{4} \mathrm{C} \equiv \mathrm{CH}$, leading to the $\mu_{2}$ vinylidenes $\left[(\mathrm{OC})_{3} \mathrm{Fe}(\mu\right.$-dppm $)\{\mu$-C $\left.=\mathrm{C}(\mathrm{H}) \mathrm{Ar}\} \mathrm{Pt}\left(\mathrm{PPh}_{3}\right)\right]$ (3f, $\mathrm{Ar}=\mathrm{Ph} ; 3 \mathrm{~g}, \mathrm{Ar}=p-\mathrm{Tol}) .{ }^{15}$ Spectroscopic data of $3 \mathrm{a}$, which has been isolated in $76 \%$ yield as a yellow air-stable solid, are very reminiscent of those of $\mathbf{3 f}, \mathbf{g}$ and are gathered in Table 1 .

Layering a $\mathrm{CH}_{2} \mathrm{Cl}_{2}$ solution of $3 \mathrm{a}$ with hexane afforded X-raysuitable crystals containing one molecule of solvated $\mathrm{CH}_{2} \mathrm{Cl}_{2}$ alongside $3 \mathrm{a}$ in the asymmetric unit. The overall structure of $3 \mathrm{a}$. $\mathrm{CH}_{2} \mathrm{Cl}_{2}$ (Figure 1) is very similar to that reported for $\left[(\mathrm{OC})_{3} \mathrm{Fe}-\right.$ $(\mu$-dppm $)\{\mu$-C $\left.=\mathrm{C}(\mathrm{H}) \mathrm{Ph}\} \mathrm{Pt}\left(\mathrm{PPh}_{3}\right)\right](3 \mathrm{f}) .{ }^{15} \mathrm{The} \mathrm{Fe}-\mathrm{Pt}$ bond length of 2.5586(12) $\AA$ is almost identical with that of $3 \mathrm{f}$ (2.5586(12) $\AA)$. As in the latter, the vinylidene ligand spans in a symmetric manner the two metal centers, the aryl group being

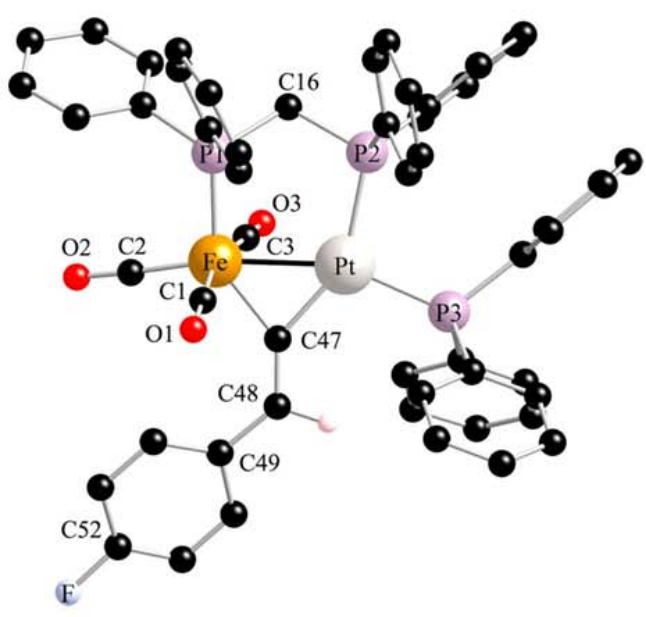

Figure 1. Perspective view of $3 \mathrm{a}$ showing the atom-labeling scheme. Hydrogen atoms apart from $\mathrm{H}(48)$ and the cocrystallized $\mathrm{CH}_{2} \mathrm{Cl}_{2}$ molecule have been omitted for clarity. Selected distances $(\AA)$ and angles (deg): $\mathrm{Fe}-\mathrm{Pt} 2.5586(12), \mathrm{Fe}-\mathrm{P}(1)=2.228(2), \mathrm{Pt}-\mathrm{P}(2)=$ $2.311(2), \mathrm{Pt}-\mathrm{P}(3)=2.264(2), \mathrm{Fe}-\mathrm{C}(1)=1.813(10), \mathrm{Fe}-\mathrm{C}(2)=$ $1.744(9), \mathrm{Fe}-\mathrm{C}(3)=1.827(9), \mathrm{Fe}-\mathrm{C}(47)=1.988(8), \mathrm{Pt}-\mathrm{C}(47)=$ $1.997(7), \mathrm{C}(47)-\mathrm{C}(48)=1.355(12), \mathrm{C}(52)-\mathrm{F}=1.357(11) ; \mathrm{P}(1)-$ $\mathrm{Fe}-\mathrm{Pt}=92.68(7), \mathrm{P}(2)-\mathrm{Pt}-\mathrm{Fe}=99.28(6), \mathrm{P}(3)-\mathrm{Pt}-\mathrm{Fe}=156.27(6)$, $\mathrm{P}(3)-\mathrm{Pt}-\mathrm{P}(2)=103.98(7), \mathrm{Pt}-\mathrm{C}(47)-\mathrm{Fe}=79.9(3), \mathrm{Fe}-\mathrm{C}(47)-$ $\mathrm{C}(48)=141.6(6), \mathrm{C}(48)-\mathrm{C}(47)-\mathrm{Pt}=138.5(6), \mathrm{C}(49)-\mathrm{C}(48)-$ $\mathrm{C}(47)=130.2(7), \mathrm{P}(1)-\mathrm{C}(16)-\mathrm{P}(2)=110.8(4)$.

oriented toward the $\mathrm{Fe}(\mathrm{CO})_{3}$ moiety. The $\mathrm{C}(47)-\mathrm{C}(48)$ double-bond distance $(1.355(12) \AA)$ lies in the usual range found for other $\mu$-arylethenylidene ligands bridging homodinuclear complexes, such as $\left[(\mathrm{OC})_{2} \mathrm{CpMn}\{\mu-\mathrm{C}=\mathrm{C}(\mathrm{H}) \mathrm{Ph}\} \mathrm{MnCp}-\right.$ $\left.(\mathrm{CO})_{2}\right](1.35(2) \AA),{ }^{16}\left[(\mathrm{OC}) \mathrm{Rh}(\mu \text {-dppm })_{2}\{\mu-\mathrm{C}=\mathrm{C}(\mathrm{H}) \mathrm{Ph}\}-\right.$ $\mathrm{Rh}(\mathrm{CO})](1.329(11) \AA),{ }^{17}\left[(\mathrm{OC})\left(\mathrm{PCy}_{3}\right) \mathrm{Rh}\left(\mu-\mathrm{O}_{2} \mathrm{CCH}_{3}\right)\{\mu\right.$ $\left.\mathrm{C}=\mathrm{C}(\mathrm{H}) \mathrm{Ph}\} \operatorname{Rh}\left(\mathrm{PCy}_{3}\right)(\mathrm{CO})\right]\left[\mathrm{BF}_{4}\right](1.318(7) \AA),{ }^{18}$ $\left[\mathrm{Ir}_{2} \mathrm{I}_{2}(\mathrm{CO})_{2}\{\mu-\mathrm{C}=\mathrm{C}(\mathrm{H}) \mathrm{Ph}\}(\mathrm{dppm})_{2}\right](1.35(3) \AA),{ }^{19}$ and $\left.\left[\mathrm{Pt}_{2}(\mathrm{C} \equiv \mathrm{CPh})\{\mu-\mathrm{C}=\mathrm{C}(\mathrm{H}) \mathrm{Ph}\}\left(\mathrm{PEt}_{3}\right)_{4}\right]\left[\mathrm{BF}_{4}\right](1.33(3) \AA)\right)^{20,21}$ Examples of structurally characterized heterobimetallic $\mu$-vinylidene complexes are $\left[\left(\eta^{5}-\mathrm{C}_{5} \mathrm{H}_{5}\right)(\mathrm{CO})(\mu-\mathrm{CO}) \mathrm{Mn}(\mu-\mathrm{C}=\mathrm{C}(\mathrm{H}) \mathrm{Ph}) \mathrm{Pt}\right.$ $\left(\eta^{2}\right.$-dppm) $](1.363(9) \AA),{ }^{22 a}\left[\left(\eta^{5}-\mathrm{C}_{5} \mathrm{H}_{5}\right)(\mathrm{CO})_{2} \operatorname{Re}(\mu\right.$-C $=\mathrm{C}(\mathrm{H})-$ $\left.\mathrm{Ph}) \mathrm{Pt}\left(\mathrm{PPh}_{3}\right)_{2}\right] \quad(1.385(8) \AA),{ }^{22 b}$ and $[\mathrm{TpNi}(\mu-\mathrm{C}=\mathrm{C}(\mathrm{H}) \mathrm{Ph})-$ $\left.\operatorname{RuCp}(\mathrm{CO})_{2}\right]\left(\mathrm{Tp}=\right.$ hydrotris(pyrazolyl)borato) $(1.33(1) \AA) .{ }^{23}$

Surprisingly, the outcome of the reaction between la and $o-\mathrm{FC}_{6} \mathrm{H}_{4} \mathrm{C} \equiv \mathrm{CH}$ under the same reaction conditions was less straightforward. Monitoring the course of the reaction by ${ }^{31} \mathrm{P}$ NMR spectroscopy in an NMR tube revealed after several hours the emergence of the $\sigma$-alkenyl complex $\left[(\mathrm{OC})_{3} \mathrm{Fe}\{\mu\right.$-Si$\left.(\mathrm{OMe})_{2}(\mathrm{OMe})\right\}(\mu$-dppm $\left.) \mathrm{Pt}\left(o-\mathrm{FC}_{6} \mathrm{H}_{4} \mathrm{C}=\mathrm{CH}_{2}\right)\right] \quad(2 \mathbf{b})$ (Scheme 1) with the characteristic two mutually coupled doublets due to the dppm bridge at $\delta 6.8$ and $61.2 \mathrm{ppm}$ along with a broadened signal at $\delta-4.2$ due to dissociated $\mathrm{PPh}_{3}$. Furthermore, resonances corresponding to the dimetallacyclopentenone $\left[(\mathrm{OC})_{2} \mathrm{Fe}(\mu\right.$-dppm $)\left\{\mu\right.$-C $(=\mathrm{O}) \mathrm{C}(\mathrm{H})=\mathrm{C}\left(\mathrm{C}_{6} \mathrm{H}_{4} \mathrm{~F}\right.$ o) $\left.\} \mathrm{Pt}\left(\mathrm{PPh}_{3}\right)\right]$ complex $4 \mathbf{b}^{\prime}$ were identified at $\delta 8.0,34.5$, and $63.4 \mathrm{ppm}$. In line with this observation, the ${ }^{195} \mathrm{Pt}\left\{{ }^{1} \mathrm{H}\right\}$ NMR spectrum displayed a doublet of doublets centered at $\delta-2326$ ppm $\left({ }^{1} J_{\mathrm{PtP}}=5237 \mathrm{~Hz}\right)$ assigned to $2 \mathbf{b}$, along with a doublet of doublets of doublets centered at $\delta-2782 \mathrm{ppm}\left({ }^{2+3} J_{\mathrm{PtP}}=112 \mathrm{~Hz}\right.$; ${ }^{1} J_{\mathrm{PtP}}=2595$ and $3412 \mathrm{~Hz}$ ) due to $4 \mathbf{b}^{\prime}$. After $24 \mathrm{~h}, \mathbf{2} \mathbf{b}$ was completely converted to $4 \mathbf{b}^{\prime}$, whose ${ }^{1} \mathrm{H}$ NMR spectrum revealed a doublet of doublets at $\delta 4.82 \mathrm{ppm}$ with a strong ${ }^{3} \mathrm{~J}_{\mathrm{PtH}}$ coupling of $202 \mathrm{~Hz}$, indicating that the vinylic proton is situated trans to 
Scheme 2

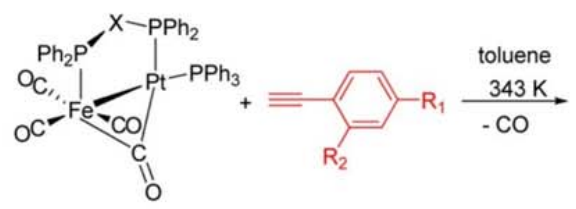
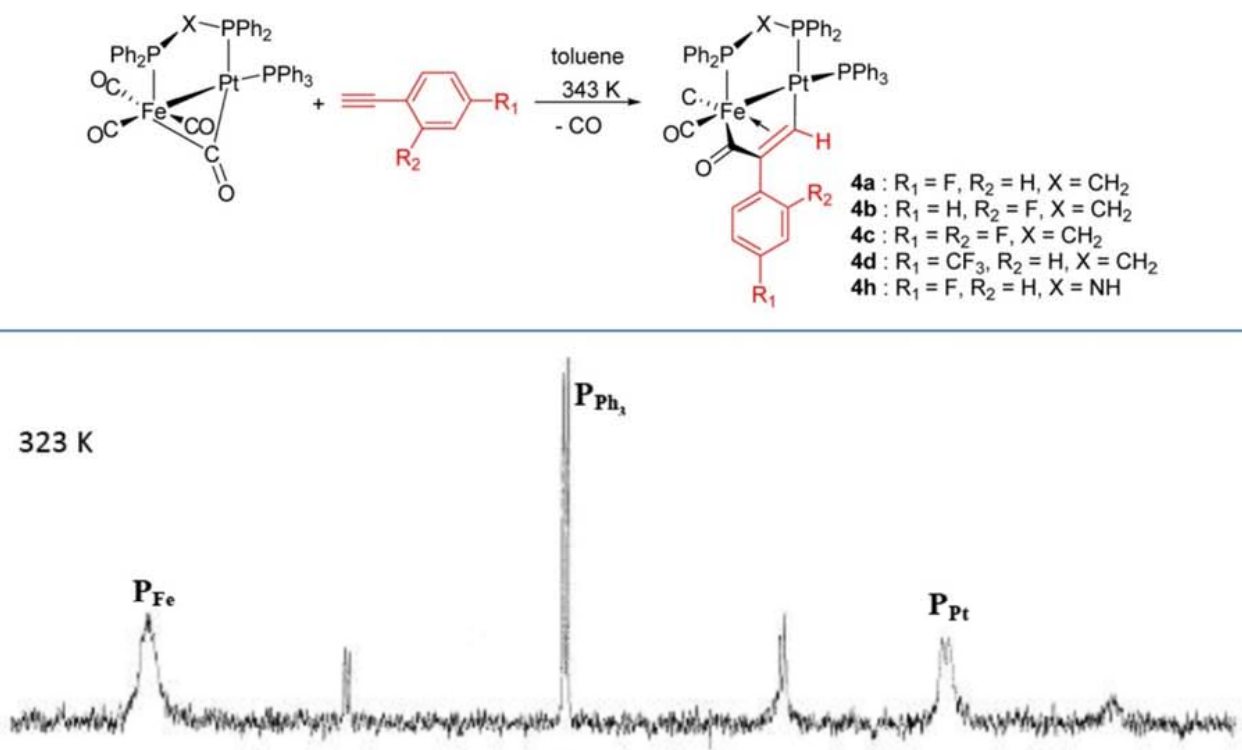

$293 \mathrm{~K}$

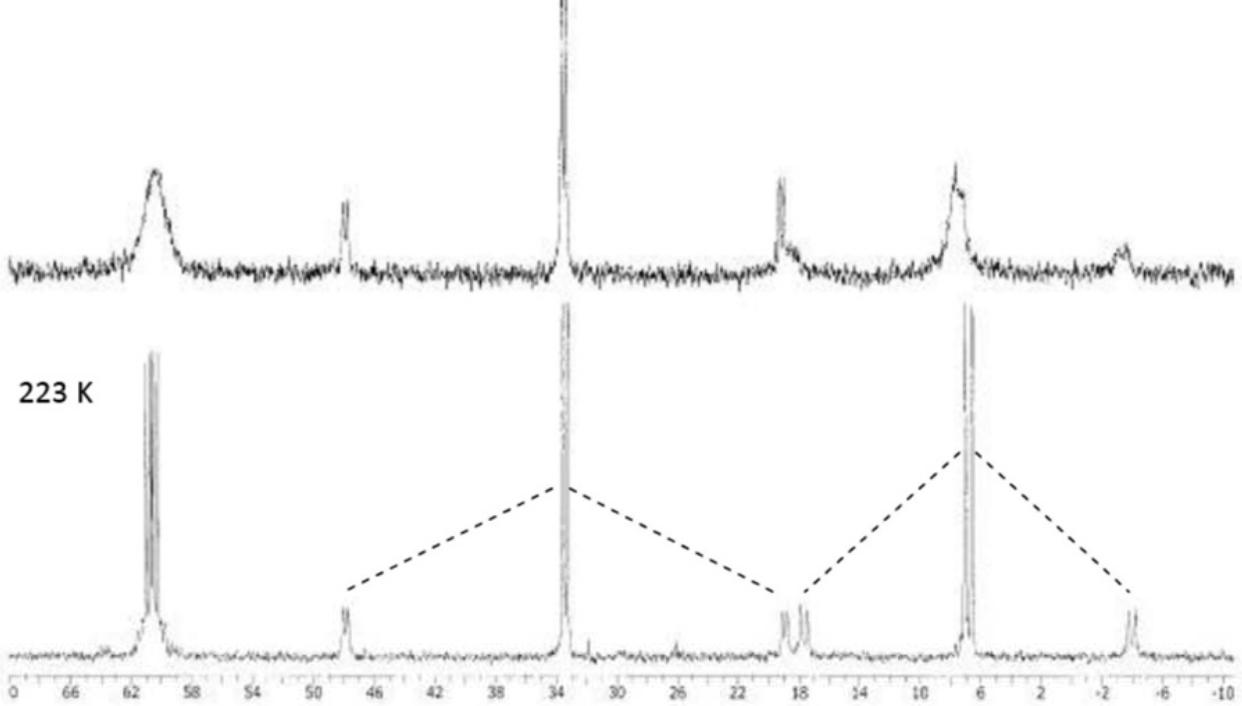

Figure 2. Variable-temperature ${ }^{31} \mathrm{P}\left\{{ }^{1} \mathrm{H}\right\}$ NMR spectra of $4 \mathbf{b}$ in $\mathrm{CDCl}_{3}$.

platinum. After 2 days in solution, progressive isomerization of $\mathbf{4} \mathbf{b}^{\prime}$ to the thermodynamic isomer [(OC) ${ }_{2} \mathrm{Fe}(\mu$-dppm $)\{\mu$-C $(=$ O) $\left.\left.\mathrm{C}\left(\mathrm{C}_{6} \mathrm{H}_{4} \mathrm{~F}-\mathrm{o}\right)=\mathrm{C}(\mathrm{H})\right\} \mathrm{Pt}\left(\mathrm{PPh}_{3}\right)\right]$ (4b) was evidenced in the ${ }^{31} \mathrm{P}$ NMR spectrum. After 4 days at ambient temperature, $4 \mathrm{~b}$ was the dominant species in an approximate ratio of $75: 25$. This second species featured broad signals at $\delta 7.8$ and $60.3 \mathrm{ppm}$, attributed to the iron- and platinum-bound dppm phosphorus atoms, whereas the Pt-bound $\mathrm{PPh}_{3}$ ligand at $\delta 33.5$ gave rise to a well-resolved doublet signal. The same ratio was also encountered in the ${ }^{19} \mathrm{~F}\left\{{ }^{1} \mathrm{H}\right\}$ spectrum, which displayed two broadened singlets at $\delta-110.0$ and $-111.3 \mathrm{ppm}$, respectively. The assignments of the NMR data and structural propositions for $\mathbf{4 b}$ and $\mathbf{4} \mathbf{b}^{\prime}$ are based on a study of Shaw and co-workers, who reacted the $\mu$-carbonyl complex $\left[(\mathrm{OC})_{3} \mathrm{Fe}(\mu\right.$-dppm $)(\mu$-CO $) \mathrm{Pt}$ $\left.\left(\mathrm{PPh}_{3}\right)\right]$ with $\mathrm{ArC} \equiv \mathrm{CH}(\mathrm{Ar}=\mathrm{Ph}, p-\mathrm{Tol}){ }^{24,25}$ In this reaction sequence, the authors observed first formation of the kinetic isomer $\left[(\mathrm{OC})_{2} \mathrm{Fe}(\mu\right.$-dppm $\left.)\{\mu-\mathrm{C}(=\mathrm{O}) \mathrm{C}(\mathrm{H})=\mathrm{C}(\mathrm{Ar})\} \mathrm{Pt}\left(\mathrm{PPh}_{3}\right)\right]$, which evolved to the thermodynamic isomer $\left[(\mathrm{OC})_{2} \mathrm{Fe}(\mu\right.$ dppm $)\{\mu$-C $\left.(=\mathrm{O}) \mathrm{C}(\mathrm{Ar})=\mathrm{C}(\mathrm{H})\} \mathrm{Pt}\left(\mathrm{PPh}_{3}\right)\right]$ during the course of several days.

In order to confirm the hypothesis that $4 b$ constitutes the thermodynamic product in our reaction mixture, we prepared this compound alternatively by treatment of $\left[(\mathrm{OC})_{3} \mathrm{Fe}(\mu\right.$ dppm $)\left(\mu\right.$-CO)Pt $\left.\left(\mathrm{PPh}_{3}\right)\right]$ with a 3 -fold excess of $o-\mathrm{FC}_{6} \mathrm{H}_{4} \mathrm{C} \equiv$ $\mathrm{CH}$ in toluene at $70{ }^{\circ} \mathrm{C}$, according to Scheme 2. Indeed, $\mathbf{4 b}$ was formed as the sole species under these conditions and was isolated as an air-stable orange solid in $85 \%$ yield. In an analogous 
manner, $\left[(\mathrm{OC}){ }_{2} \mathrm{Fe}(\mu\right.$-dppm $)\left\{\mu\right.$-C $\left.(=\mathrm{O}) \mathrm{C}\left(\mathrm{C}_{6} \mathrm{H}_{4} \mathrm{~F}-p\right)=\mathrm{C}(\mathrm{H})\right\}$ $\mathrm{Pt}\left(\mathrm{PPh}_{3}\right)$ ] (4a), which represents an isomeric form of $\mu$-vinylidene complex 3a, was obtained using $p-\mathrm{FC}_{6} \mathrm{H}_{4} \mathrm{C} \equiv \mathrm{CH}$. In both dimetallacyclopentenone complexes, the ketonic $\nu(\mathrm{C}=$ $\mathrm{O})$ vibration of the $\{\mu$ - $\mathrm{C}(=\mathrm{O}) \mathrm{C}(\mathrm{Ar})=\mathrm{C}(\mathrm{H})\}$ moiety, resulting from a $\mathrm{C}-\mathrm{C}$ coupling reaction between a carbonyl ligand and the respective alkyne, gave rise to an IR absorption near $1700 \mathrm{~cm}^{-1}$ (Table 1).

To understand the origin of the line broadness of the ${ }^{31} \mathrm{P}$ NMR resonances of $\mathbf{4 b}$ (see above), we also undertook a variabletemperature study on dissolving some single crystals in $\mathrm{CDCl}_{3}$ (Figure 2). The broad resonances of the dppm phosphorus nuclei sharpen progressively upon cooling. At $223 \mathrm{~K}$, the spectrum features a well-resolved doublet of doublets at $\delta 60.7$ attributed to the Fe-bound dppm phosphorus, a doublet of doublets at $\delta 33.4$ due to the $\mathrm{PPh}_{3}$ ligand, and a third doublet of doublets at $\delta 6.8$ assigned to the Pt-bound dppm phosphorus (Table 1). Upon heating to $323 \mathrm{~K}$, the resonances sharpen but still remain broad.

Since the $p$-fluorine-substituted derivative $4 a$ exhibits sharp resonances in the ${ }^{31} \mathrm{P}\left\{{ }^{1} \mathrm{H}\right\}$ spectrum, one explanation of the line broadness encountered in the case of $4 \mathrm{~b}$ may be a $\mathrm{C}-\mathrm{F} \cdots \mathrm{H}-\mathrm{C}$ interaction between the vinylic hydrogen atom and the fluorine atom situated at the ortho position of the aryl cycle. Indeed, as evidenced by an X-ray diffraction study, the $\mathrm{C}-\mathrm{F} \cdots \mathrm{H}-\mathrm{C}$ contact of $2.187 \AA$ in the solid-state structure of $\mathbf{4 b}$ is rather short (see below). Although "organic" fluorine is considered as a weak hydrogen acceptor, ${ }^{26-29}$ there are some examples of organometallic species featuring $\mathrm{C}-\mathrm{F} \cdots \mathrm{H}-\mathrm{C}$ bonding in solution evidenced by ${ }^{1} \mathrm{H}$ NMR spectroscopy. For example, the dinuclear complex $\left[\mathrm{Ru}_{2}(\mathrm{CO})\left(\mathrm{CF}_{2}=\mathrm{CFCF}_{3}\right)\left(\mu-\mathrm{CH}_{2}\right)(\mu-\mathrm{CO})\left(\eta-\mathrm{C}_{5} \mathrm{H}_{5}\right)_{2}\right]$, which displays in the crystalline state a short intramolecular $\mathrm{C}-\mathrm{F} \cdots \mathrm{H}-\mathrm{C}$ contact of $2.23 \AA$ between the methylene and $\mathrm{CF}_{2}=\mathrm{CFCF}_{3}$ ligand, exhibits a "through space" $J_{\mathrm{HF}}$ coupling of $4.7 \mathrm{~Hz}$ in its ${ }^{1} \mathrm{H}$ NMR spectrum. ${ }^{30,31}$ However, no $J_{\mathrm{HF}}$ coupling could be evidenced for $4 \mathbf{b}$. The doublet of doublets pattern of the vinylic $\mathrm{H}$ atom resonating at $\delta 8.40 \mathrm{ppm}$ is simplified to a singlet flanked by ${ }^{195} \mathrm{Pt}$ satellites upon ${ }^{31} \mathrm{P}$ decoupling, ruling out a visible $J_{\mathrm{HF}}$ coupling.

Crystal Structures of $\left[(\mathrm{OC})_{2} \mathrm{Fe}(\mu-\mathrm{dppm})\left\{\mu-\mathrm{C}(=\mathrm{O}) \mathrm{C}\left(\mathrm{C}_{6} \mathrm{H}_{4} \mathrm{~F}-\right.\right.\right.$ $\left.\mathrm{o})=C(\mathrm{H})\} P t\left(\mathrm{PPh}_{3}\right)\right](4 \mathrm{~b})$ and $\left[(\mathrm{OC})_{2} \mathrm{Fe}(\mu-d p p m)\{\mu-\mathrm{C}(=\mathrm{O}) \mathrm{C}-\right.$ $\left.\left.\left(\mathrm{C}_{6} \mathrm{H}_{4} \mathrm{~F}-\mathrm{p}\right)=\mathrm{C}(\mathrm{H})\right\} \mathrm{Pt}\left(\mathrm{PPh}_{3}\right)\right]$ (4a). X-ray-suitable crystals of $\left[(\mathrm{OC})_{2} \mathrm{Fe}(\mu\right.$-dppm $)\left\{\mu-\mathrm{C}(=\mathrm{O}) \mathrm{C}\left(\mathrm{C}_{6} \mathrm{H}_{4} \mathrm{~F}-o\right)=\mathrm{C}(\mathrm{H})\right\} \mathrm{Pt}-$ $\left.\left(\mathrm{PPh}_{3}\right)\right](4 \mathbf{b})$ were grown by slow diffusion of heptane into a toluene solution. The molecular structure shown in Figure 3 closely resembles that of $\left[(\mathrm{OC})_{2} \mathrm{Fe}(\mu\right.$-dppm $)\{\mu$-C $(=\mathrm{O}) \mathrm{C}$ $\left.(\mathrm{CH}=\mathrm{CH})\} \mathrm{Pt}\left(\mathrm{PPh}_{3}\right)\right]$, confirming the coupling of the alkyne with a carbonyl ligand giving the $\mathrm{C}(\mathrm{H})=\mathrm{C}(\mathrm{Ar})(\mathrm{C}=\mathrm{O})$ moiety $\sigma$-bonded to platinum and $\eta^{3}$-bonded to iron. ${ }^{24}$ The most salient feature is a short $\mathrm{C}-\mathrm{F} \cdots \mathrm{H}(47)-\mathrm{C}$ contact of just $2.187 \AA$ $(\mathrm{F} \cdots \mathrm{C}(47)=2.913 \AA$ ), which falls significantly below the sum of the van der Waals radii $(2.54 \AA))^{32}$

For comparison, we have also grown single crystals of $4 \mathrm{a}$ from toluene/heptane and determined the molecular structure, which is depicted in Figure 4. As expected, the overall structural features are rather comparable with those of $\mathbf{4 b}$. Notably, the $p-\mathrm{C}_{6} \mathrm{H}_{4}$ ring of $4 \mathbf{a}$ adopts the same orientation as the $o-\mathrm{C}_{6} \mathrm{H}_{4}$ ring of $4 \mathbf{b}$, the dihedral angles $\mathrm{C} 54-\mathrm{C} 49-\mathrm{C} 48-\mathrm{C} 47$ being 21.019 and $20.195^{\circ}$, respectively. Therefore, it seems more likely that the orientation of the $o-\mathrm{C}_{6} \mathrm{H}_{4}$ ring is imposed by packing effects rather than by intramolecular hydrogen bonding. There also are no short intermolecular $\mathrm{C}-\mathrm{F} \cdots \mathrm{H}-\mathrm{C}$ contacts below $2.8 \AA$ in the packing diagram of $4 a$. Note that for $p$-fluoroethynylbenzene itself a

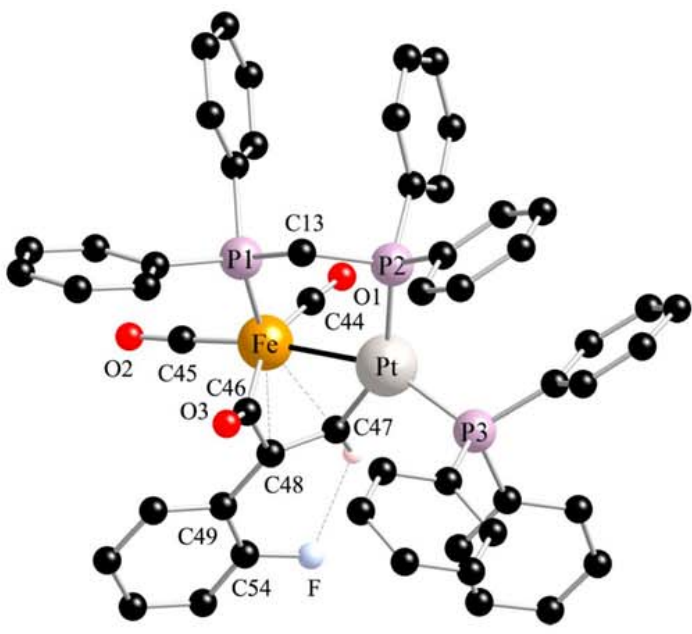

Figure 3. Perspective view of $4 \mathbf{b}$ showing the atom-labeling scheme. Hydrogen atoms apart from $\mathrm{H}(47)$ and the toluene molecule have been omitted for clarity. Selected distances $(\AA)$ and angles (deg): $\mathrm{Fe}-\mathrm{Pt}=$ $2.5865(13), \mathrm{Fe}-\mathrm{P}(1)=2.207(2), \mathrm{Pt}-\mathrm{P}(2)=2.2746(19), \mathrm{Pt}-\mathrm{P}(3)=$ 2.2611(19), $\mathrm{Fe}-\mathrm{C}(44)=1.792(8), \mathrm{Fe}-\mathrm{C}(45)=1.782(9), \mathrm{Fe}-\mathrm{C}(46)=$ $1.927(9), \mathrm{C}(44)-\mathrm{O}(1)=1.151(10), \mathrm{C}(45)-\mathrm{O}(2)=1.141(11)$, $\mathrm{C}(46)-\mathrm{O}(3)=1.202(10), \mathrm{Pt}-\mathrm{C}(47)=2.010(8), \mathrm{C}(47)-\mathrm{C}(48)=$ $1.401(12), \mathrm{C}(46)-\mathrm{C}(48)=1.475(10), \mathrm{C}(54)-\mathrm{F}=1.328(14) ; \mathrm{P}(1)-$ $\mathrm{Fe}-\mathrm{Pt}=92.86(6), \mathrm{P}(2)-\mathrm{Pt}-\mathrm{Fe}=96.64(6), \mathrm{P}(3)-\mathrm{Pt}-\mathrm{Fe}=155.98(6)$, $\mathrm{P}(3)-\mathrm{Pt}-\mathrm{P}(2)=104.03(7), \mathrm{C}(47)-\mathrm{Pt}-\mathrm{Fe}=54.1(2), \mathrm{Fe}-\mathrm{C}(46)-$ $\mathrm{C}(48)=76.2(5), \mathrm{C}(46)-\mathrm{C}(48)-\mathrm{C}(47)=109.5(7), \mathrm{C}(49)-\mathrm{C}(48)-$ $\mathrm{C}(46)=121.3(8), \mathrm{P}(1)-\mathrm{C}(13)-\mathrm{P}(2)=110.1(3)$.

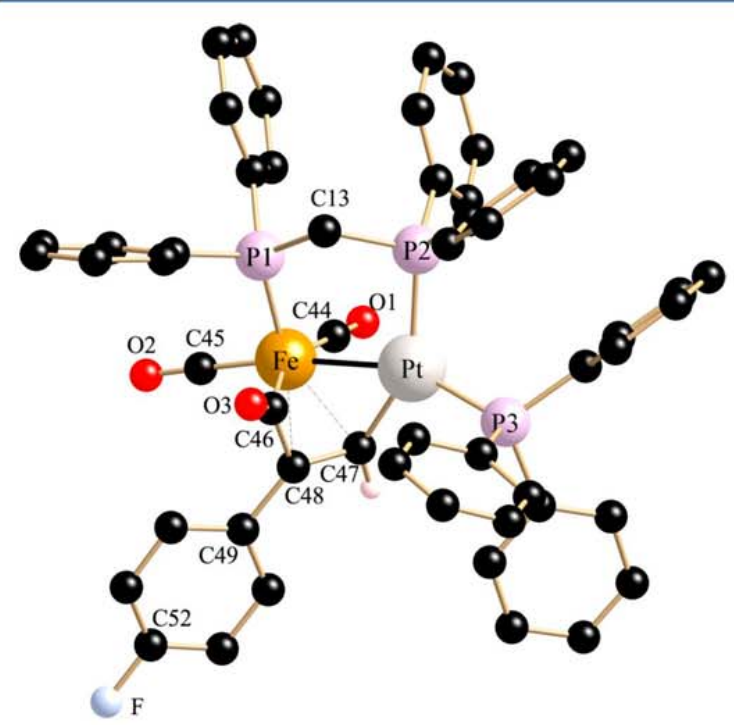

Figure 4. Perspective view of $4 \mathrm{a}$ showing the atom-labeling scheme. Hydrogen atoms apart from $\mathrm{H}(47)$ and the toluene molecule have been omitted for clarity. Selected distances $(\AA)$ and angles (deg): $\mathrm{Fe}-\mathrm{Pt}=$ 2.5821(12), $\mathrm{Fe}-\mathrm{P}(1)=2.207(2), \mathrm{Pt}-\mathrm{P}(2)=2.293(2), \mathrm{Pt}-\mathrm{P}(3)=$ $2.270(2), \mathrm{Fe}-\mathrm{C}(44)=1.765(10), \mathrm{Fe}-\mathrm{C}(45)=1.774(9), \mathrm{Fe}-\mathrm{C}(46)=$ $1.927(8), \mathrm{C}(44)-\mathrm{O}(1)=1.170(11), \mathrm{C}(45)-\mathrm{O}(2)=1.139(11), \mathrm{C}(46)-$ $\mathrm{O}(3)=1.215(11), \mathrm{Pt}-\mathrm{C}(47)=1.981(10), \mathrm{C}(47)-\mathrm{C}(48)=1.401(12)$, $\mathrm{C}(46)-\mathrm{C}(48)=1.459(12), \mathrm{C}(52)-\mathrm{F}=1.361(12) ; \mathrm{P}(1)-\mathrm{Fe}-\mathrm{Pt}=$ 93.68(7), P(2)-Pt-Fe = 96.30(6), P(3)-Pt-Fe = 156.26(6), P(3)-Pt$\mathrm{P}(2)=104.71(8), \mathrm{C}(47)-\mathrm{Pt}-\mathrm{Fe}=54.0(2), \mathrm{C}(46)-\mathrm{Fe}-\mathrm{Pt}=74.3(2)$, $\mathrm{Fe}-\mathrm{C}(46)-\mathrm{C}(48)=77.0(5), \mathrm{C}(46)-\mathrm{C}(48)-\mathrm{C}(47)=108.1(7)$, $\mathrm{C}(49)-\mathrm{C}(48)-\mathrm{C}(46)=121.4(7), \mathrm{P}(1)-\mathrm{C}(13)-\mathrm{P}(2)=111.3(4)$ 
short $\equiv \mathrm{C}-\mathrm{H} \cdots \mathrm{F}$ distance of $2.264 \AA$ has been established in the packing. ${ }^{33}$

In order to study the combined effect of ortho and para substitution on the outcome of the reaction, 1a was also reacted with 2,4- $\mathrm{F}_{2} \mathrm{C}_{6} \mathrm{H}_{3} \mathrm{C} \equiv \mathrm{CH}$ under same reaction conditions. Conducting the reaction in the presence of 3 equiv of 2,4-difluoroethynylbenzene in dichloromethane, allowing contact with air, afforded within several hours the $\sigma$-alkenyl complex $\left[(\mathrm{OC})_{3} \mathrm{Fe}\{\mu\right.$ $\left.\mathrm{Si}(\mathrm{OMe})_{2}(\mathrm{OMe})\right\}(\mu$-dppm $\left.) \mathrm{Pt}\left(2,4-\mathrm{F}_{2} \mathrm{C}_{6} \mathrm{H}_{3} \mathrm{C}=\mathrm{CH}_{2}\right)\right](2 \mathrm{c})$ as the insertion product in almost quantitative spectroscopic yield together with $\mathrm{Ph}_{3} \mathrm{P}=\mathrm{O}$. Running the reaction under an argon atmosphere for 2 days resulted in the formation of a mixture of the isomeric dimetallacyclopentenones $\left[(\mathrm{OC})_{2} \mathrm{Fe}(\mu\right.$-dppm $)\{\mu$ $\left.\left.\mathrm{C}(=\mathrm{O}) \mathrm{C}(\mathrm{H})=\mathrm{C}\left(\mathrm{C}_{6} \mathrm{H}_{3} \mathrm{~F}_{2}\right)\right\} \mathrm{Pt}\left(\mathrm{PPh}_{3}\right)\right]\left(4 \mathrm{c}^{\prime}\right)$ and $\left[(\mathrm{OC})_{2} \mathrm{Fe}(\mu\right.$ dppm $)\left\{\mu\right.$ - $\left.\left.\mathrm{C}(=\mathrm{O}) \mathrm{C}\left(\mathrm{C}_{6} \mathrm{H}_{3} \mathrm{~F}_{2}\right)=\mathrm{C}(\mathrm{H})\right\} \mathrm{Pt}\left(\mathrm{PPh}_{3}\right)\right](4 \mathrm{c})$ and the $\mu$-vinylidene compound $\left[(\mathrm{OC})_{3} \mathrm{Fe}(\mu\right.$-dppm $)\{\mu$-C $=\mathrm{C}(\mathrm{H})$ $\left.\left.\mathrm{C}_{6} \mathrm{H}_{3} \mathrm{~F}_{2}\right\} \mathrm{Pt}\left(\mathrm{PPh}_{3}\right)\right]$ (3c) in a 30:20:50 ratio. The latter compound was separated from the reaction mixture by layering with hexane to give crystals of $3 \mathrm{c}$ suitable for a single-crystal X-ray diffraction study. All metric parameters of $3 c$ are very close to those of 3a. An illustration of the structure along with some selected bond lengths and angles is given in Figure 5. It is worth

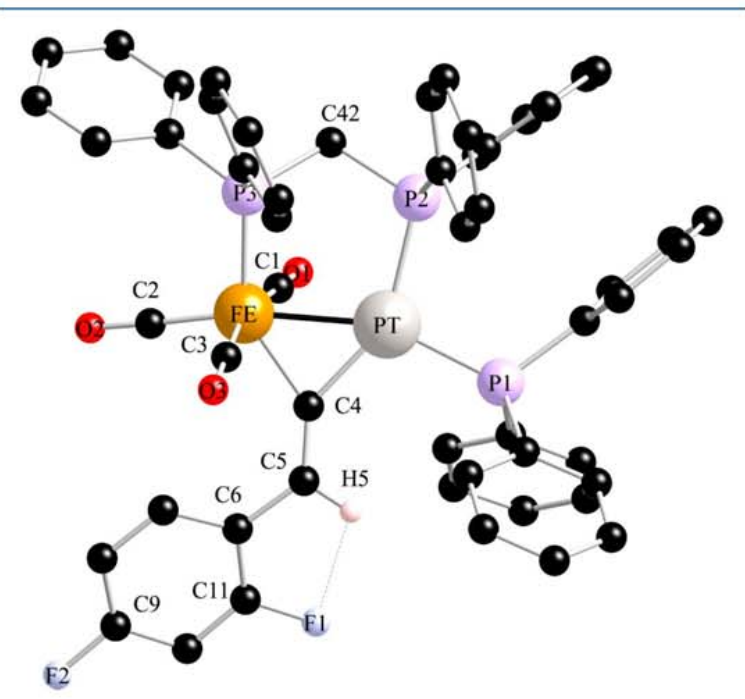

Figure 5. Perspective view of $3 \mathrm{c}$ showing the atom-labeling scheme. Hydrogen atoms apart from $\mathrm{H}(5)$ and the $0.5 \mathrm{C}_{6} \mathrm{H}_{14}$ molecule have been omitted for clarity. Selected distances $(\AA)$ and angles $(\mathrm{deg}): \mathrm{Fe}-\mathrm{Pt}=$ $2.5401(4), \mathrm{Fe}-\mathrm{P}(3)=2.2203(8), \mathrm{Pt}-\mathrm{P}(2)=2.3073(7), \mathrm{Pt}-\mathrm{P}(1)=$ $2.2575(7), \mathrm{Fe}-\mathrm{C}(1)=1.793(3), \mathrm{Fe}-\mathrm{C}(2)=1.761(3), \mathrm{Fe}-\mathrm{C}(3)=$ $1.793(3), \mathrm{Fe}-\mathrm{C}(4)=1.995(3), \mathrm{Pt}-\mathrm{C}(4)=2.010(3), \mathrm{C}(4)-\mathrm{C}(5)=$ $1.322(4), \mathrm{C}(11)-\mathrm{F}(1)=1.356(3), \mathrm{C}(9)-\mathrm{F}(2)=1.358(3) ; \mathrm{P}(3)-\mathrm{Fe}-$ $\mathrm{Pt}=92.88(2), \mathrm{P}(2)-\mathrm{Pt}-\mathrm{Fe}=99.02(2), \mathrm{P}(1)-\mathrm{Pt}-\mathrm{Fe}=156.07(2)$, $\mathrm{P}(1)-\mathrm{Pt}-\mathrm{P}(2)=104.30(3), \mathrm{Pt}-\mathrm{C}(4)-\mathrm{Fe}=78.73(10), \mathrm{Fe}-\mathrm{C}(4)-$ $\mathrm{C}(5)=141.5(2), \mathrm{C}(5)-\mathrm{C}(4)-\mathrm{Pt}=139.7(2), \mathrm{C}(6)-\mathrm{C}(5)-\mathrm{C}(4)=$ $129.6(3), \mathrm{P}(2)-\mathrm{C}(42)-\mathrm{P}(3)=111.18(14)$.

noting that there is a short $\mathrm{C}-\mathrm{F} \cdots \mathrm{H}-\mathrm{C}$ contact of $2.357 \AA$ between $\mathrm{F}(1)$ and $\mathrm{H}(5)$, whose position was freely refined.

To facilitate the spectroscopic assignment of the overlapping resonances in the reaction mixture, the dimetallacyclopentenone complexes $\mathbf{4} \mathbf{c}^{\prime}$ and $\mathbf{4} \mathbf{c}$ were alternatively prepared by treatment of $\left[(\mathrm{OC})_{3} \mathrm{Fe}(\mu\right.$-dppm $)(\mu$-CO $\left.) \mathrm{Pt}\left(\mathrm{PPh}_{3}\right)\right]$ with $2,4-\mathrm{F}_{2} \mathrm{C}_{6} \mathrm{H}_{3} \mathrm{C} \equiv \mathrm{CH}$ in a $1: 2$ ratio. The kinetic isomer $\left[(\mathrm{OC})_{2} \mathrm{Fe}(\mu\right.$-dppm $)\{\mu$-C$\left.\left.(=\mathrm{O}) \mathrm{C}(\mathrm{H})=\mathrm{C}\left(\mathrm{C}_{6} \mathrm{H}_{3} \mathrm{~F}_{2}\right)\right\} \mathrm{Pt}\left(\mathrm{PPh}_{3}\right)\right]\left(4 \mathrm{c}^{\prime}\right)$ was obtained by reaction at ambient temperature in $\mathrm{CH}_{2} \mathrm{Cl}_{2}$ solution and isolated as an orange solid, whereas the thermodynamic product $4 \mathrm{c}$ was obtained by heating the reaction mixture in toluene at $70{ }^{\circ} \mathrm{C}$ for $2 \mathrm{~h}$. The compound was isolated in the form of orange-red crystals after purification by recrystallization from toluene/ heptane. At $298 \mathrm{~K}$ the ${ }^{31} \mathrm{P}\left\{{ }^{1} \mathrm{H}\right\} \mathrm{NMR}$ spectrum of $4 \mathbf{c}^{\prime}$ shows the expected pattern with well-resolved signals similar to those of $4 \mathbf{b}^{\prime}$ (Table 1), but that of $4 \mathrm{c}$ consists of two very broad unstructured resonances at $\delta 61.5\left(\mathrm{P}_{\mathrm{Fe}}\right)$ and $9.1 \mathrm{ppm}\left(\mathrm{P}_{\mathrm{Pt}}\right)$ along with a wellresolved doublet at $\delta 34.1$ attributed to the Pt-bound $\mathrm{PPh}_{3}$ ligand. The broad signals sharpen upon cooling to $273 \mathrm{~K}$, and all resonances become well resolved at $253 \mathrm{~K}$. This dynamic behavior indicates again a possible $\mathrm{C}-\mathrm{F} \cdots \mathrm{H}-\mathrm{C}$ contact of the fluorine atom at the ortho position, as discussed above for $\mathbf{4 b}$. The molecular structure of $\mathbf{4 c}$ has been established by X-ray diffraction and is shown in Figure S1 in the Supporting Information. The overall structure is quite similar to those of $4 \mathbf{a}, \mathbf{b}$. The most salient feature is the presence of a short intramolecular $\mathrm{C}-\mathrm{F}(2) \cdots \mathrm{H}(48)-\mathrm{C}(48)$ contact of only $2.273 \AA(\mathrm{F}(2) \cdots \mathrm{C}(48)=2.908 \AA)$. We also note that the para $\mathrm{C}(52)-\mathrm{F}(1)$ bond is longer than the ortho $\mathrm{C}(54)-$ $\mathrm{F}(2)$ bond (1.362(5) vs $1.321(5) \AA)$.

It is known from the literature that dimetallacyclopentenones can be converted to $\mu$-vinylidene complexes. For instance, Casey et al. have reported a thermal rearrangement at $70^{\circ} \mathrm{C}$ which converts $\left[\mathrm{Cp} *(\mathrm{CO})_{2} \operatorname{Re}\left\{\mu-\eta^{1}: \eta^{3}-\mathrm{CH}=\mathrm{C}\left[\mathrm{C}\left(\mathrm{CH}_{3}\right)=\mathrm{CH}_{2}\right]\right.\right.$ $\left.\mathrm{CO}\} \operatorname{Re}(\mathrm{CO}) \mathrm{Cp}^{*}\right]$ into $\left[\mathrm{Cp} *(\mathrm{CO})_{2} \operatorname{Re}\left\{\mu-\mathrm{C}=\mathrm{CHC}\left(\mathrm{CH}_{3}\right)=\right.\right.$ $\left.\mathrm{CH}_{2}\right\} \operatorname{Re}(\mathrm{CO})_{2} \mathrm{Cp} *{ }^{34}$ A second example is the isomerization of $[\mathrm{CpRu}\{\mu-\mathrm{C}(=\mathrm{O}) \mathrm{C}(\mathrm{Ph})=\mathrm{C}(\mathrm{H})\}(\mu-\mathrm{CO}) \mathrm{Ru}(\mathrm{CO}) \mathrm{Cp}]$ to $[\mathrm{Cp}(\mathrm{OC}) \mathrm{Ru}\{\mu-\mathrm{C}=\mathrm{C}(\mathrm{H}) \mathrm{Ph}\}(\mu-\mathrm{CO}) \mathrm{Ru}(\mathrm{CO}) \mathrm{Cp}]$ in boiling toluene. ${ }^{35 a}$ However, no dimetallacyclopentenone $-\mu$-vinylidene isomerization was evidenced after refluxing a toluene solution of $4 \mathrm{c}$ for $6 \mathrm{~h}$, and only $4 \mathrm{c}$ was recovered. Therefore, the competing formation of $3 \mathrm{c}$ and $4 \mathrm{c}$ observed during the reaction of $1 \mathrm{a}$ with 2,4- $\mathrm{F}_{2} \mathrm{C}_{6} \mathrm{H}_{3} \mathrm{C} \equiv \mathrm{CH}$ must occur at an early stage of the insertion reaction and is not a result of a subsequent isomerization process.

In order to evaluate the impact of a strongly electron withdrawing trifluoromethyl substituent on the outcome of the insertion reaction, hydride complex 1a was also reacted with $p$-(trifluoromethyl)ethynylbenzene in $\mathrm{CH}_{2} \mathrm{Cl}_{2}$ solution. Like the case of $p-\mathrm{FC}_{6} \mathrm{H}_{4} \mathrm{C} \equiv \mathrm{CH}$, insertion of $p-\mathrm{F}_{3} \mathrm{CC}_{6} \mathrm{H}_{4} \mathrm{C} \equiv \mathrm{CH}$ into the $\mathrm{Pt}-\mathrm{H}$ bond produces first the $\sigma$-alkenyl complex $\left[(\mathrm{OC})_{3} \mathrm{Fe}-\right.$ $\left\{\mu\right.$-Si $\left.(\mathrm{OMe})_{2}(\mathrm{OMe})\right\}(\mu$-dppm $\left.) \mathrm{Pt}\left(p-\mathrm{F}_{3} \mathrm{CC}_{6} \mathrm{H}_{4} \mathrm{C}=\mathrm{CH}_{2}\right)\right](\mathbf{2 d})$, which reacts in a second step with the liberated $\mathrm{PPh}_{3}$ ligand to give the $\mu$-vinylidene complex $\left[(\mathrm{OC})_{3} \mathrm{Fe}(\mu\right.$-dppm $)\{\mu$-C $=\mathrm{C}$ (H) $\left.\left.\mathrm{C}_{6} \mathrm{H}_{4} \mathrm{CF}_{3}-p\right\} \mathrm{Pt}\left(\mathrm{PPh}_{3}\right)\right]$ (3d). Spectroscopic examination of the reaction mixture indicates the absence of the dimetallacyclopentenone $\left[(\mathrm{OC})_{2} \mathrm{Fe}(\mu\right.$-dppm $)\left\{\mu\right.$ - $\mathrm{C}(=\mathrm{O}) \mathrm{C}\left(\mathrm{C}_{6} \mathrm{H}_{4} \mathrm{CF}_{3}\right.$ $\left.p)=\mathrm{C}(\mathrm{H})\} \mathrm{Pt}\left(\mathrm{PPh}_{3}\right)\right](4 \mathrm{~d})$. The latter was prepared independently by reaction of $\left[(\mathrm{OC})_{3} \mathrm{Fe}(\mu\right.$-dppm $)\left(\mu\right.$-CO) $\left.\mathrm{Pt}\left(\mathrm{PPh}_{3}\right)\right]$ with $p-\mathrm{F}_{3} \mathrm{CC}_{6} \mathrm{H}_{4} \mathrm{C} \equiv \mathrm{CH}$ in toluene at $70^{\circ} \mathrm{C}$, and its crystal structure was elucidated by an X-ray diffraction study (see Figure S2 in the Supporting Information). In an analogous manner, hydrometalation of $m$-(trifluoromethyl)ethynylbenzene by complex 1a produces first the $\sigma$-alkenyl complex $\left[(\mathrm{OC})_{3} \mathrm{Fe}\{\mu \text {-Si(OMe })_{2}\right.$ $(\mathrm{OMe})\}(\mu$-dppm $\left.) \mathrm{Pt}\left(m-\mathrm{F}_{3} \mathrm{CC}_{6} \mathrm{H}_{4} \mathrm{C}=\mathrm{CH}_{2}\right)\right]$ (2e), which is ultimately converted to the $\mu$-vinylidene complex $\left[(\mathrm{OC})_{3} \mathrm{Fe}(\mu\right.$ dppm) $\left.\left\{\mu-\mathrm{C}=\mathrm{C}(\mathrm{H}) \mathrm{C}_{6} \mathrm{H}_{4} \mathrm{CF}_{3}-m\right\} \mathrm{Pt}\left(\mathrm{PPh}_{3}\right)\right]$ (3e). Both the ${ }^{31} \mathrm{P}$ NMR spectrum and the crystal structure of this yellow compound are shown in the Supporting Information as Figures S3 and S4.

Intrigued by the ortho effect noticed in dimetallacyclopentenone complexes $\mathbf{4 b}$,c, we attempted also hydrometalation of $o$-(trifluoromethyl)ethynylbenzene with 1a. Surprisingly, after a $\mathrm{CH}_{2} \mathrm{Cl}_{2}$ solution of 1a was stirred with $o-\mathrm{F}_{3} \mathrm{CC}_{6} \mathrm{H}_{4} \mathrm{C} \equiv \mathrm{CH}$, 
neither a dimetallacyclopentenone nor a $\mu$-vinylidene compound was detected. Instead, the dimetallacyclobutene complex $\left[(\mathrm{OC})_{3} \mathrm{Fe}(\mu\right.$-dppm $\left.)\left\{\mu-\mathrm{C}\left(\mathrm{C}_{6} \mathrm{H}_{4} \mathrm{CF}_{3}-\mathrm{o}\right)=\mathrm{C}(\mathrm{H})\right\} \mathrm{Pt}\left(\mathrm{PPh}_{3}\right)\right]$ (5a) was isolated in $77 \%$ yield in the form of air-stable orange crystals. The dimetallacyclobutene complex $\left[(\mathrm{OC})_{3} \mathrm{Fe}(\mu\right.$-dppa)$\left.\left\{\mu-\mathrm{C}\left(\mathrm{C}_{6} \mathrm{H}_{4} \mathrm{CF}_{3}-\mathrm{o}\right)=\mathrm{C}(\mathrm{H})\right\} \mathrm{Pt}\left(\mathrm{PPh}_{3}\right)\right]$ (5b) was also formed when reacting $o-\mathrm{F}_{3} \mathrm{CC}_{6} \mathrm{H}_{4} \mathrm{C} \equiv \mathrm{CH}$ with the hydride complex $\left[(\mathrm{OC})_{3} \mathrm{Fe}\left\{\mathrm{Si}(\mathrm{OMe})_{3}\right\}(\mu\right.$-dppa $\left.) \mathrm{Pt}(\mathrm{H})\left(\mathrm{PPh}_{3}\right)\right](\mathbf{l b})$ spanned by the less electron-donating ligand bis(diphenylphosphino)amine. In accordance with the presence of three terminal carbonyls, both complexes display in the ATR-IR spectra three $\nu(\mathrm{CO})$ vibrations (see Table 1), along with a $\mathrm{C}=\mathrm{C}$ absorption at $1599 \mathrm{~cm}^{-1}$. Formation of 5 a was also corroborated by an X-ray diffraction study, confirming the presence of a dimetallacyclobutene framework (Figure 6). A metal-metal bond connects the

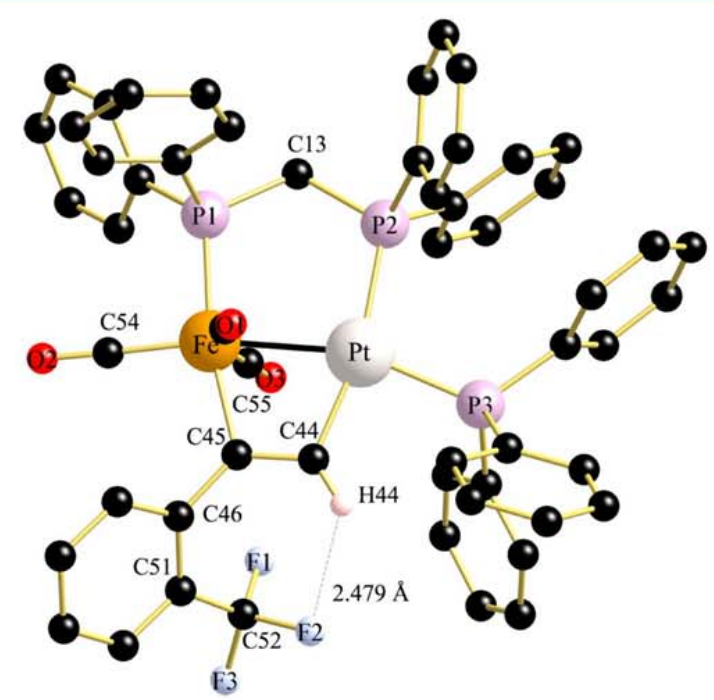

Figure 6. Perspective view of 5a showing the atom-labeling scheme. Hydrogen atoms and the heptane molecule have been omitted for clarity. Selected distances $(\AA)$ and angles $(\mathrm{deg}): \mathrm{Fe}-\mathrm{Pt}=2.6026(5), \mathrm{Fe}-\mathrm{P}(1)=$ $2.2019(11), \mathrm{Pt}-\mathrm{P}(2)=2.3057(10), \mathrm{Pt}-\mathrm{P}(3)=2.2557(10), \mathrm{Fe}-\mathrm{C}(53)=$ $1.782(4), \mathrm{Fe}-\mathrm{C}(54)=1.781(4), \mathrm{Fe}-\mathrm{C}(55)=1.784(4), \mathrm{Fe}-\mathrm{C}(45)=$ $2.049(4), \mathrm{Pt}-\mathrm{C}(44)=2.037(4), \mathrm{C}(44)-\mathrm{C}(45)=1.327(5), \mathrm{C}(52)-$ $\mathrm{F}(1)=1.335(5), \mathrm{C}(52)-\mathrm{F}(2)=1.345(5), \mathrm{C}(52)-\mathrm{F}(3)=1.351(5)$; $\mathrm{P}(1)-\mathrm{Fe}-\mathrm{Pt}=97.10(3), \mathrm{P}(2)-\mathrm{Pt}-\mathrm{Fe}=95.35(3), \mathrm{P}(3)-\mathrm{Pt}-\mathrm{Fe}=$ $160.87(3), \mathrm{P}(3)-\mathrm{Pt}-\mathrm{P}(2)=102.95(3), \mathrm{C}(45)-\mathrm{Pt}-\mathrm{Fe}=72.00(10), \mathrm{Fe}-$ $\mathrm{C}(45)-\mathrm{C}(44)=107.3(3), \mathrm{C}(45)-\mathrm{C}(44)-\mathrm{Pt}=109.0(3), \mathrm{C}(44)-$ $\mathrm{C}(45)-\mathrm{C}(46)=128.5(3), \mathrm{P}(2)-\mathrm{C}(13)-\mathrm{P}(1)=114.51(19)$.

dppm-bridged iron and platinum centers. However, the bond length of $2.6026(15) \AA$ is somewhat longer than the mean distances of $\mu$-vinylidenes $3(2.5494(8) \AA)$ and dimetallacyclopentenones 4 (2.5842(12) $\AA$ ). An elongation of the metal-metal bond has also been noticed for the dimetallacyclobutene $\left[\left\{\left(\eta^{5}\right.\right.\right.$ $\left.\left.\left.\mathrm{C}_{5} \mathrm{H}_{3}\right)_{2}\left(\mathrm{SiMe}_{2}\right)_{2}\right\} \mathrm{Ru}_{2}(\mathrm{CO})_{2}(\mu-\mathrm{CO})\left\{\mu_{2}-\eta^{1}: \eta^{1}-\mathrm{C}(\mathrm{Ph})=\mathrm{C}(\mathrm{H})\right\}\right]$ and its $\mu$-vinylidene isomer. ${ }^{36}$ Note that dinuclear dimetallacyclobutenes bearing a symmetric $M-C(R)=C(R)-M$ moiety are now quite common, but it seems that complexes $\mathbf{S}$ represent the first examples of heterodinuclear complexes spanned by a terminal alkyne. The overall structure may be compared with that of $\left[(\mathrm{OC})_{3} \mathrm{Fe}(\mu\right.$-dppm $\left.)\left(\mu-\mathrm{CF}_{3} \mathrm{C}=\mathrm{CCF}_{3}\right) \mathrm{Pt}(\mathrm{CO})\right]{ }^{13 \mathrm{a}} \mathrm{As}$ in the latter compound, the most salient feature is the spanning of the two metal centers by the $o-\mathrm{F}_{3} \mathrm{CC}_{6} \mathrm{H}_{4} \mathrm{C}=\mathrm{CH}$ moiety in a $\mu-\eta^{1}: \eta^{1}$ mode parallel to the metal-metal axis. The dihedral angle
$\mathrm{Fe}-\mathrm{C}(45)-\mathrm{C}(44)-\mathrm{Pt}$ of the resulting four-membered metallacycle only amounts to $-4.76^{\circ}$. Probably for steric reasons, the plane of the $o-\mathrm{F}_{3} \mathrm{CC}_{6} \mathrm{H}_{4} \mathrm{C}$ moiety is significantly tilted by $50.7^{\circ}$ with respect to the best $\mathrm{Fe}-\mathrm{C}(45)-\mathrm{C}(44)-\mathrm{Pt}$ plane. The $\mathrm{C}=\mathrm{C}$ bond length of the dimetalated alkenyl group $(1.327(5) \AA)$ is comparable with those of $\left[(\mathrm{OC})_{3} \mathrm{Fe}(\mu-\mathrm{dppm})\left(\mu-\mathrm{CF}_{3} \mathrm{C}=\mathrm{CCF}_{3}\right)\right.$ $\mathrm{Pt}(\mathrm{CO})]$ and $\left[(\mathrm{OC})_{3} \mathrm{Fe}(\mu\right.$-dppm $)\left(\mu-\mathrm{CF}_{3} \mathrm{C}=\mathrm{CCF}_{3}\right) \mathrm{Pt}$ (CNxylyl)] (1.319(12) and 1.315(8) $\AA$ ). ${ }^{13 a, 37}$ Also worthy of note is a C-F $\cdots \mathrm{H}-\mathrm{C}$ contact between $\mathrm{F}(2)$ and $\mathrm{H}(44)$ of $2.479 \AA$.

Although in the crystalline state compounds 5 exist exclusively in the dimetallacyclobutene form, ${ }^{31} \mathrm{P}$ NMR monitoring at variable temperature revealed that in solution an unprecedented temperature-dependent equilibrium between $\mathbf{5 a - c}$ and the isomeric dimetallacyclopentenones $4 \mathrm{e}, \mathrm{f}$ exists (Scheme 3 ).

As illustrated in Figure 7, the ${ }^{31} \mathrm{P}\left\{{ }^{1} \mathrm{H}\right\}$ NMR of crystalline 5a dissolved in $\mathrm{CDCl}_{3}$ at $298 \mathrm{~K}$ gives rise to two extremely broadened humps centered at $\delta 78.5$ and $30.2 \mathrm{ppm}$ assigned to the $\mathrm{Fe}$ - and Pt-bound dppm phosphorus nuclei, whereas the resonance of the $\mathrm{PPh}_{3}$ ligand at $\delta 31.2 \mathrm{ppm}$ is sharp and is flanked by the ${ }^{195} \mathrm{Pt}$ satellites with a ${ }^{1} J_{\mathrm{PtP}}$ coupling of $3430 \mathrm{~Hz}$. At $268 \mathrm{~K}$, resonances corresponding to dimetallacyclobutene $5 \mathrm{a}$ sharpen, while a second set of broad signals appears at 59.3, 32.2, and $7.3 \mathrm{ppm}$ which are attributed to the dimetallacyclopentenone complex $\left[(\mathrm{OC})_{2} \mathrm{Fe}(\mu\right.$-dppm $)\left\{\mu\right.$ - $\mathrm{C}(=\mathrm{O}) \mathrm{C}\left(\mathrm{C}_{6} \mathrm{H}_{4} \mathrm{CF}_{3}-o\right)=$ $\left.\mathrm{C}(\mathrm{H})\} \mathrm{Pt}\left(\mathrm{PPh}_{3}\right)\right]$ (4e). At $248 \mathrm{~K}$, well-resolved resonances corresponding to $5 \mathrm{a}$ and $4 \mathrm{e}$ are present. The structural proposition for $4 \mathrm{e}$ bearing the aromatic substituent trans to platinum is supported by comparison of the chemical shifts and coupling constants of $4 \mathrm{e}$ and $\mathbf{4 b}$ at $228 \mathrm{~K}$. Furthermore, this structure is in agreement with a reversible carbon-carbon coupling reaction, implying a carbonyl group and the previously bridging carbon atom bearing the aromatic group. ${ }^{1} \mathrm{H}$ NMR monitoring at variable temperature has also been performed and corroborates the temperature-dependent equilibrium between $5 \mathrm{a}$ and $4 \mathrm{e}$ in the dppm region. At $298 \mathrm{~K}$ a broad hump is centered at $3.72 \mathrm{ppm}$. Upon cooling, this broad resonance disappears, giving rise at $248 \mathrm{~K}$ to two sets of broad signals at $4.75,4.52 \mathrm{ppm}$ and 3.42 , $3.18 \mathrm{ppm}$, consistent with an $\mathrm{AB}$ spin system like that found for the dppm ligand in $4 \mathrm{e}$ and $5 \mathrm{a}$. Attribution of the signals is made by comparison with the resonances observed for dimetallacyclopentenone complexes 4 (see Experimental Section). Moreover, the chemical shift of the dppm resonances observed at 3.42 and $3.18 \mathrm{ppm}$ for $5 \mathrm{a}$ are comparable with that of $\left[(\mathrm{OC})_{3} \mathrm{Fe}(\mu\right.$ dppm $\left.)\left(\mu-\mathrm{CF}_{3} \mathrm{C}=\mathrm{CCF}_{3}\right) \mathrm{Pt}(\mathrm{L})\right](\mathrm{L}=\mathrm{CO}, \mathrm{CNxylyl}){ }^{13 \mathrm{a}}$ The vinylic protons of $5 \mathrm{a}$ and $4 \mathrm{e}$ could not be observed even at low temperature, and we therefore assume that they are obscured by the aryl resonances. The ${ }^{19} \mathrm{~F}\left\{{ }^{1} \mathrm{H}\right\}$ NMR spectrum also exhibits a broad signal at $\delta-58.01$ at $298 \mathrm{~K}$, which splits into two sharp singlets at $\delta-57.5$ (5a) and $-59.2(4 \mathrm{e})$ when the temperature is lowered to $243 \mathrm{~K}$.

Sa,b were also obtained as the sole species by the reaction of $\left[(\mathrm{OC})_{3} \mathrm{Fe}\left(\mu-\mathrm{Ph}_{2} \mathrm{PXPPh}_{2}\right)(\mu\right.$-CO $\left.) \mathrm{Pt}\left(\mathrm{PPh}_{3}\right)\right]$ with $o-\mathrm{F}_{3} \mathrm{CC}_{6} \mathrm{H}_{4} \mathrm{C} \equiv \mathrm{CH}$ in toluene at $70^{\circ} \mathrm{C}$. As dppa is somewhat less electron donating than dppm, in the IR spectrum of $\mathbf{5 b}$ the carbonyl absorptions are shifted to higher values in comparison to those of 5a. Reaction of $\left[(\mathrm{OC})_{3} \mathrm{Fe}(\mu\right.$-dppm $)(\mu$-CO $) \mathrm{Pt}$ $\left.\left(\mathrm{PPh}_{3}\right)\right]$ with $o-\mathrm{F}_{3} \mathrm{CC}_{6} \mathrm{H}_{4} \mathrm{C} \equiv \mathrm{CH}$ was also performed in $\mathrm{CH}_{2} \mathrm{Cl}_{2}$ at room temperature, and $5 \mathrm{a}$ was always isolated as the sole product. In order to slightly enhance the electron-donating propensity and to reduce the cone angle of the $\mathrm{PR}_{3}$ ligand, we also reacted $\left[(\mathrm{OC})_{3} \mathrm{Fe}\left\{\mathrm{Si}(\mathrm{OMe})_{3}\right\}(\mu\right.$-dppm $\left.) \mathrm{Pt}(\mathrm{H})\left(\mathrm{PPh}_{2} \mathrm{Me}\right)\right]$ (1c) ${ }^{13 \mathrm{~b}}$ with $\mathrm{o}-\mathrm{F}_{3} \mathrm{CC}_{6} \mathrm{H}_{4} \mathrm{C} \equiv \mathrm{CH}$. However, these steric/electronic variations had no impact on the outcome of the reaction and only 
Scheme 3
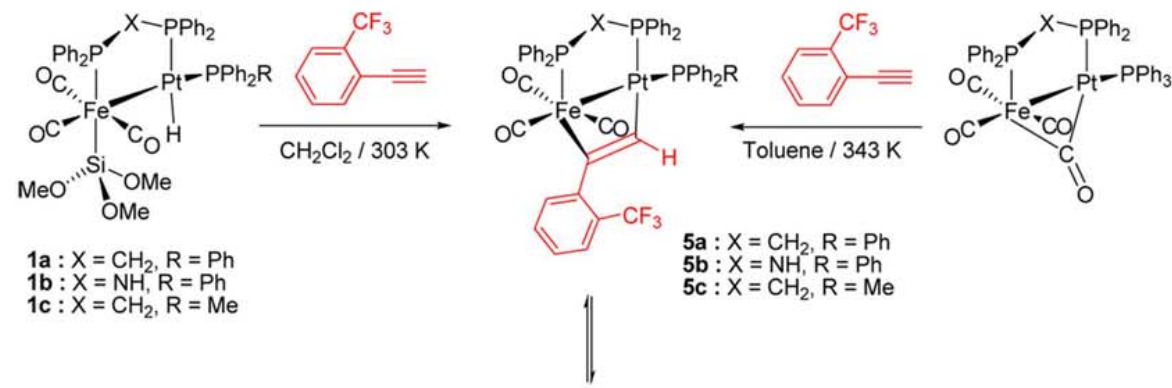

1a: $\mathrm{X}=\mathrm{CH}_{2}, \mathrm{R}=\mathrm{Ph}$

1c: $\mathrm{X}=\mathrm{CH}_{2}, \mathrm{R}=\mathrm{Me}$

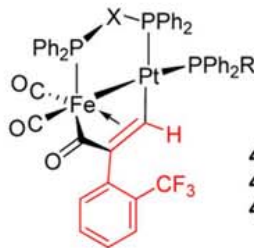

$4 e: X=\mathrm{CH}_{2}, \mathrm{R}=\mathrm{Ph}$

4f: $: X=N H, R=P h$

$4 \mathrm{~g}: \mathrm{X}=\mathrm{CH}_{2}, \mathrm{R}=\mathrm{Me}$

$\left[(\mathrm{OC})_{3} \mathrm{Fe}(\mu\right.$-dppm $)\left\{\mu\right.$-C $\left.\left.\left(\mathrm{C}_{6} \mathrm{H}_{4} \mathrm{CF}_{3}-o\right)=\mathrm{C}(\mathrm{H})\right\} \mathrm{Pt}\left(\mathrm{PPh}_{2} \mathrm{Me}\right)\right]$

(5c) has been detected in an NMR tube experiment.

In the ${ }^{31} \mathrm{P}\left\{{ }^{1} \mathrm{H}\right\}$ NMR spectra of $5 \mathbf{b}, \mathbf{c}$ the resonances of the dppa and dppm phosphorus nuclei are again extremely broadened at ambient temperature. As for $\mathbf{5 a}$, well-resolved spectra were obtained at $233 \mathrm{~K}$. In both cases, a second set of signals attributed to the dimetallacyclopentenones $\mathbf{4 f}, \mathbf{g}$ was observed (Scheme 3 ). This feature is illustrated for $\mathbf{5 b}$ in Figure $\mathrm{S} 5$ of the Supporting Information. Two unresolved signals at $\delta 125.4\left(\mathrm{Fe}_{\mathrm{dppa}}\right)$ and 80.8 $\left(\mathrm{Pt}_{\mathrm{dppa}}\right)$ are present at $318 \mathrm{~K}$, which evolve into broad humps at $298 \mathrm{~K}$. The resonances begin to sharpen at $273 \mathrm{~K}$, and at $253 \mathrm{~K}$ the emergence of a second species is detectable. At $233 \mathrm{~K}$, two sets of well-resolved resonances are present in an approximate 2:1 ratio. The resonance of the $\mathrm{Pt}$-bound $\mathrm{PPh}_{3}$ ligand remains sharp over the entire temperature range, displaying a ${ }^{1} J_{\mathrm{PtP}}$ coupling of $3400 \mathrm{~Hz}$, thus ruling out dissociation or other involvement in the dynamic process. The minor species $4 \mathrm{f}$ features a doublet of doublets at $\delta 108.5\left(\mathrm{Fe}_{\mathrm{dppa}}\right)$ and $65.1\left(\mathrm{Pt}_{\mathrm{dppa}}\right)$ along with a third doublet at $32.4 \mathrm{ppm}$ due to a Pt-bound $\mathrm{PPh}_{3}$ ligand. Since dppa-bridged $\mathrm{Fe}-\mathrm{Pt}$ dimetallacyclopentenones were hitherto unknown, we prepared for comparison $\left[(\mathrm{OC})_{2} \mathrm{Fe}(\mu\right.$-dppa $)\{\mu$ $\left.\left.\mathrm{C}(=\mathrm{O}) \mathrm{C}\left(\mathrm{C}_{6} \mathrm{H}_{4} \mathrm{~F}-\mathrm{p}\right)=\mathrm{C}(\mathrm{H})\right\} \mathrm{Pt}\left(\mathrm{PPh}_{3}\right)\right]$ (4h) according to Scheme 2. Both the chemical shifts and coupling constants of $\mathbf{4 h}$ match well with those of $4 \mathrm{f}$ (Table 1). Therefore, we confidently assign a dimetallacyclopentenone motive to the complex $\left[(\mathrm{OC})_{2} \mathrm{Fe}(\mu\right.$-dppa $)\left\{\mu\right.$ - $\left.\mathrm{C}(=\mathrm{O}) \mathrm{C}\left(\mathrm{C}_{6} \mathrm{H}_{4} \mathrm{CF}_{3}-\mathrm{o}\right)=\mathrm{C}(\mathrm{H})\right\} \mathrm{Pt}-$ $\left.\left(\mathrm{PPh}_{3}\right)\right](4 \mathrm{f})$.

It is known from the literature that thermolysis of the dimetallacyclopentenone $\left[\mathrm{Cp}(\mathrm{OC}) \mathrm{Fe}\left\{\mu-\mathrm{C}(=\mathrm{O}) \mathrm{C}\left(\mathrm{CO}_{2} \mathrm{Me}\right)=\right.\right.$ $\left.\mathrm{C}\left(\mathrm{CO}_{2} \mathrm{Me}\right)\right\}(\mu$-CO $\left.) \mathrm{Fe}(\mathrm{CO}) \mathrm{Cp}\right]$ causes interconversion to the dimetallacyclobutene $\left[\mathrm{Cp}(\mathrm{OC}) \mathrm{Fe}\left\{\mu-\mathrm{C}\left(\mathrm{CO}_{2} \mathrm{Me}\right)=\mathrm{C}\right.\right.$ $\left.\left(\mathrm{CO}_{2} \mathrm{Me}\right)\right\}(\mu-\mathrm{CO}) \mathrm{Fe}(\mathrm{CO}) \mathrm{Cp}$ ] by $\mathrm{CO}$ extrusion. ${ }^{38 \mathrm{a}}$ Puddephatt et al. have shown that $\left[(\mathrm{OC}){ }_{2} \mathrm{Ru}(\mu\right.$-CH$=\mathrm{CH})(\mu \text {-dppm })_{2} \mathrm{Ru}$ $(\mathrm{CO})_{2}$ ] readily inserts $\mathrm{CO}$ to yield the dimetallacyclopentenone $\left[(\mathrm{OC})_{2} \mathrm{Ru}\{\mu-\mathrm{C}(=\mathrm{O}) \mathrm{CH}=\mathrm{CH}\}(\mu \text {-dppm })_{2} \mathrm{Ru}(\mathrm{CO})_{2}\right]$, which loses a carbonyl upon heating in a reversible manner, leading to the dimetallacyclobutene. ${ }^{38,39}$ However, the temperaturedependent equilibrium between $5 \mathrm{a}$ and $4 \mathrm{e}$ constitutes the first example of a dimetallacyclopentenone $\leftrightarrow$ dimetallacyclobutene conversion, implying a reversible carbon-carbon bond formation/ breaking process with low activation barrier. Our NMR studies at variable temperature also allow the conclusion that this phenomenon tolerates a variation of the steric and electronic propensities of P-donor ligands to a certain degree. At present we cannot state with certainty whether this dynamic behavior is exclusively due to the bulkiness of the $o-\mathrm{CF}_{3}$ substituent or whether a combination of steric and electronic parameters of the $o$-trifluoromethyl group accounts for this phenomenon. The fact that a trifluoromethyl group at the para position exerts electron withdrawal comparable to that in the ortho position makes a purely inductive electronic effect less likely. ${ }^{40}$ More experimental work combined with DFT computing is required to fully understand this unprecedented dimetallacyclopentenone $\leftrightarrow$ dimetallacyclobutene interconversion.

Protonation of the Dimetallacyclobutene Complexes $\left[(\mathrm{OC})_{3} \mathrm{Fe}\left(\mu-\mathrm{Ph}_{2} \mathrm{PXPPh}_{2}\right)\left\{\mu-\mathrm{C}\left(\mathrm{C}_{6} \mathrm{H}_{4} \mathrm{CF}_{3}-\mathrm{O}\right)=\mathrm{C}(\mathrm{H})\right\} \mathrm{Pt}\left(\mathrm{PPh}_{3}\right)\right]$. Addition of $\mathrm{HBF}_{4} \cdot \mathrm{Et}_{2} \mathrm{O}$ to a $\mathrm{CH}_{2} \mathrm{Cl}_{2}$ solution of $5 \mathrm{a}$ leads exclusively to the $\mu_{2}-\sigma$-alkenyl salt $\left[(\mathrm{OC})_{3} \mathrm{Fe}(\mu\right.$-dppm $)\{\mu$ $\left.\left.\mathrm{C}\left(\mathrm{C}_{6} \mathrm{H}_{4} \mathrm{CF}_{3}-\mathrm{o}\right)=\mathrm{CH}_{2}\right\} \mathrm{Pt}\left(\mathrm{PPh}_{3}\right)\right]\left[\mathrm{BF}_{4}\right]$ (6a) by protonation at the $\beta$-position (Pt-bound carbon atom) of the bridging alkyne ligand. Site-selective protonation producing $\left[(\mathrm{OC})_{3} \mathrm{Fe}(\mu\right.$-dppa)$\left.\left\{\mu-\mathrm{C}\left(\mathrm{C}_{6} \mathrm{H}_{4} \mathrm{CF}_{3}-o\right)=\mathrm{CH}_{2}\right\} \mathrm{Pt}\left(\mathrm{PPh}_{3}\right)\right]\left[\mathrm{BF}_{4}\right]$ (6b) bearing a Febound $\sigma: \mu_{2}$ alkenyl group occurs also upon reaction of $\mathbf{5 b}$ with an excess of $\mathrm{HBF}_{4} \cdot \mathrm{Et}_{2} \mathrm{O}$ according to Scheme 4 . Note that the reaction of $\left[(\mathrm{OC})_{2} \mathrm{Fe}(\mu\right.$-dppm $)\left\{\mu-\mathrm{C}(=\mathrm{O}) \mathrm{C}\left(\mathrm{C}_{6} \mathrm{H}_{4} \mathrm{Me}-p\right)=\right.$ $\left.\mathrm{C}(\mathrm{H})\} \mathrm{Pt}\left(\mathrm{PPh}_{3}\right)\right]$ with $\mathrm{HBF}_{4} \cdot \mathrm{Et}_{2} \mathrm{O}$ has been reported to produce the "isomeric" vinyl cation $\left[(\mathrm{OC})_{3} \mathrm{Fe}(\mu\right.$-dppm $)\left\{\mu\right.$ - $\mathrm{C}\left(\mathrm{C}_{6} \mathrm{H}_{4} \mathrm{Me}\right.$ $\left.\left.p)=\mathrm{CH}_{2}\right\} \mathrm{Pt}\left(\mathrm{PPh}_{3}\right)\right]\left[\mathrm{BF}_{4}\right]$ bearing a Pt-bound $\sigma: \mu_{2}$ alkenyl group (see below). ${ }^{24}$

In comparison to the three $\nu(\mathrm{CO})$ vibrations of $5 \mathrm{a}$, those of $6 a$ are markedly shifted to higher wavenumbers and appear at $2054(\mathrm{~m}), 1992(\mathrm{~s})$, and 1985 (s) $\mathrm{cm}^{-1}$. The ${ }^{31} \mathrm{P}\left\{{ }^{1} \mathrm{H}\right\}$ NMR spectrum of 6a displays two well-resolved doublets of doublets at $\delta 39.9\left(\mathrm{P}_{\mathrm{Fe}}\right)$ and $10.9\left(\mathrm{P}_{\mathrm{Pt}}\right)$ attributed to the dppm ligand. The Pt-bound triphenylphosphine appears as a triplet at $\delta 30.4$. The magnitude of the ${ }^{1} J_{\text {PtPdppm }}$ coupling constant of $3600 \mathrm{~Hz}$ is also noteworthy, whereas in the isomeric Pt-bound $\sigma: \mu_{2}$ alkenyl compounds 7 and 8 (see below and Table 1) this ${ }^{1} J_{\mathrm{PtPdppm}}$ coupling lies typically in the $2300-2400 \mathrm{~Hz}$ range. ${ }^{24} \mathrm{~A}$ sharp singlet at $\delta-54.3 \mathrm{ppm}$ in the ${ }^{19} \mathrm{~F}\left\{{ }^{1} \mathrm{H}\right\}$ NMR spectrum is attributed to the $\mathrm{CF}_{3}$ group; the tetrafluoroborate counterion gives rise to a considerably broadened resonance at $-152.5 \mathrm{ppm}$. In the ${ }^{1} \mathrm{H}$ NMR spectrum, the two geminal hydrogen atoms of 


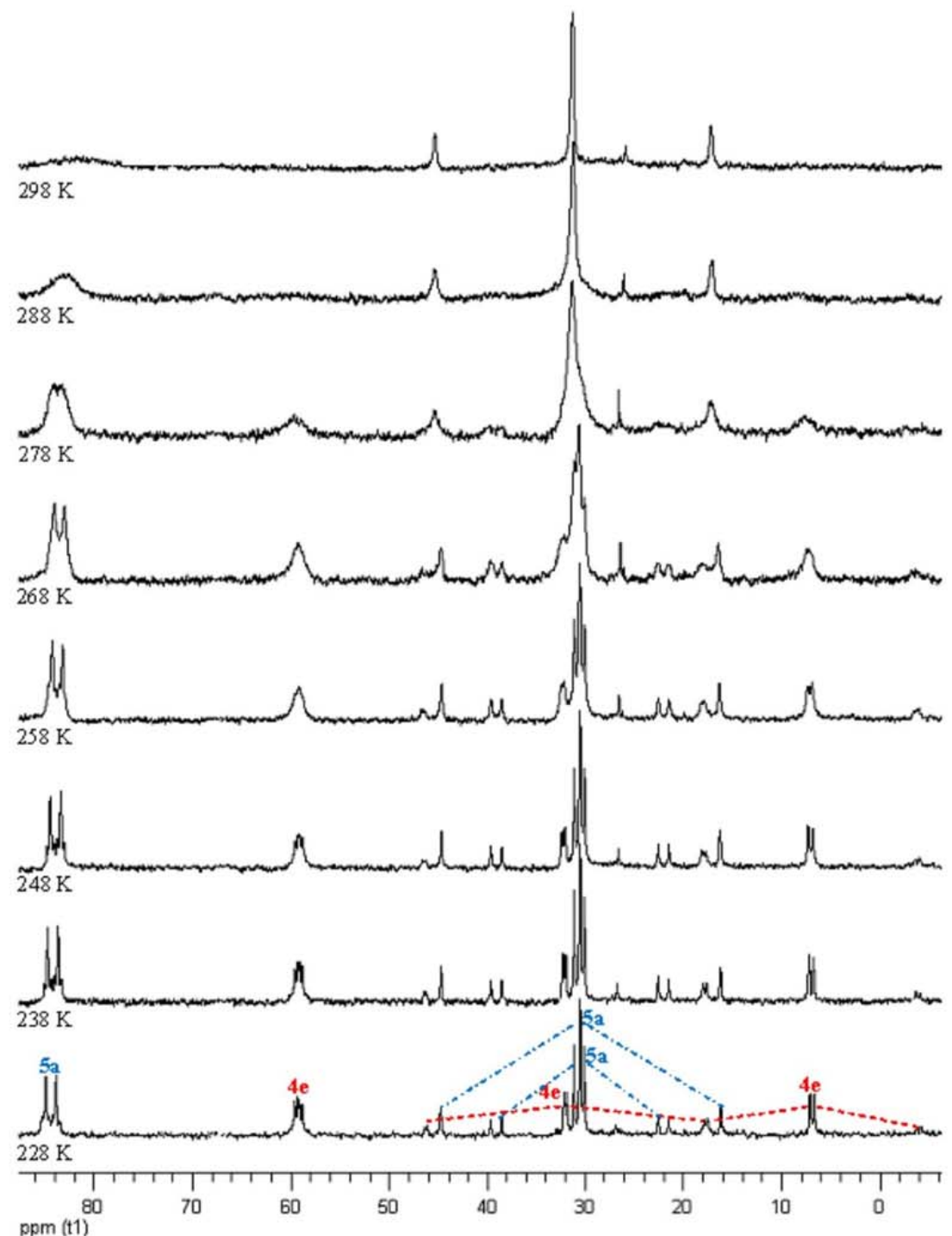

Figure 7. Variable-temperature ${ }^{31} \mathrm{P}\left\{{ }^{1} \mathrm{H}\right\}$ NMR spectra of $5 \mathrm{a}$ in $\mathrm{CDCl}_{3}$, revealing the temperature-dependent coexistence of isomeric dimetallacyclopentenone $4 \mathrm{e}$.

the 1-arylvinyl ligand give rise to two broadened doublets at $\delta$ $4.28\left(J_{\mathrm{PH}}=12.5 \mathrm{~Hz}\right)$ and $4.58 \mathrm{ppm}\left(J_{\mathrm{PH}}=6.5 \mathrm{~Hz}\right)$ with $J_{\mathrm{PtH}}$ couplings of 29 and $45 \mathrm{~Hz}$, respectively. ${ }^{41}$

These spectroscopic data were corroborated by an X-ray diffraction study. The crystal structure of the cation is shown in Figure 8. Suitable yellow-orange crystals of $6 \mathrm{a}$ were obtained from $\mathrm{CH}_{2} \mathrm{Cl}_{2} / \mathrm{Et}_{2} \mathrm{O}$. The dppm-spanned $\mathrm{Fe}-\mathrm{Pt}$ bond distance is almost identical with that of the precursor 5a (2.6161(9) vs $2.6062(13) \AA)$. The $\mathrm{Fe}-\mathrm{C}(48)$ and $\mathrm{C}(48)=\mathrm{C}(47)$ bond lengths of 1.986(6) and 1.386(7) $\AA$ both match those reported for the related $\sigma: \mu_{2}$ alkenyl complex $\left[(\mathrm{OC})_{3} \mathrm{Fe}(\mu\right.$-dppm $)\{\mu$ $\left.\left.\mathrm{C}\left(\mathrm{C}_{6} \mathrm{H}_{5}\right)=\mathrm{CH}_{2}\right\} \mathrm{Fe}(\mathrm{CO})_{3}\right]\left[\mathrm{BF}_{4}\right](1.992(5) \text { and } 1.388(7) \AA)^{41}$ According to the metric parameters, the $\alpha$-carbon atom $\mathrm{C}(48)$ is best described as $\sigma$-bonded to $\mathrm{Fe}$ and $\pi$-bonded to $\mathrm{Pt}$, the $\mathrm{Pt}-\mathrm{C}(48)$ and $\mathrm{Pt}-\mathrm{C}(47)$ bond lengths being 2.211(6) and 2.209 (6) $\AA$, respectively. With respect to the five-membered $\mathrm{P}(3)-\mathrm{C}(43)-\mathrm{P}(2)-\mathrm{Pt}-\mathrm{Fe}$ ring, the $\mathrm{C}(48)=\mathrm{C}(47)$ bond is tilted, the dihedral angle $\mathrm{Fe}-\mathrm{C}(48)-\mathrm{C}(47)-\mathrm{Pt}$ being $-59.73^{\circ}$.
Protonation of Dimetallacyclopentenones $\left[(\mathrm{OC})_{2} \mathrm{Fe}(\mu\right.$ dppm) $\left.\left\{\mu-\mathrm{C}(=0) \mathrm{C}\left(\mathrm{C}_{6} \mathrm{H}_{3} \mathrm{R}_{1} \mathrm{R}_{2}\right)=\mathrm{C}(\mathrm{H})\right\} \mathrm{Pt}\left(\mathrm{PPh}_{3}\right)\right]$. According to an earlier paper of Shaw et al, addition of $\mathrm{HBF}_{4} \cdot \mathrm{Et}_{2} \mathrm{O}$ to a $\mathrm{CH}_{2} \mathrm{Cl}_{2}$ solution of dimetallacyclopentenone $\left[(\mathrm{OC})_{2} \mathrm{Fe}(\mu\right.$ dppm $)\left\{\mu\right.$-C $\left.\left.(=\mathrm{O}) \mathrm{C}\left(\mathrm{C}_{6} \mathrm{H}_{4} \mathrm{CH}_{3}-p\right)=\mathrm{C}(\mathrm{H})\right\} \mathrm{Pt}\left(\mathrm{PPh}_{3}\right)\right]$ results in cleavage of the carbon-carbon bond of the $\mathrm{C}-\mathrm{C}=\mathrm{O}$ unit, affording the alkenyl salt $\left[(\mathrm{OC})_{3} \mathrm{Fe}(\mu\right.$-dppm $)\left\{\mu\right.$ - $\mathrm{H}_{2} \mathrm{C}=\mathrm{C}$ $\left.\left.\left(\mathrm{C}_{6} \mathrm{H}_{4} \mathrm{CH}_{3}-p\right)\right\} \mathrm{Pt}\left(\mathrm{PPh}_{3}\right)\right]\left[\mathrm{BF}_{4}\right] .{ }^{24}$ We have repeated this experience with $\left[(\mathrm{OC})_{2} \mathrm{Fe}(\mu\right.$-dppm $)\left\{\mu-\mathrm{C}(=\mathrm{O}) \mathrm{C}\left(\mathrm{C}_{6} \mathrm{H}_{5}\right)=\mathrm{C}(\mathrm{H})\right\}$ $\left.\mathrm{Pt}\left(\mathrm{PPh}_{3}\right)\right]$ (4i) and succeeded in growing single crystals of $\left[(\mathrm{OC})_{3} \mathrm{Fe}(\mu\right.$-dppm $)\left\{\mu\right.$ - $\left.\left.\mathrm{H}_{2} \mathrm{C}=\mathrm{C}(\mathrm{Ph})\right\} \mathrm{Pt}\left(\mathrm{PPh}_{3}\right)\right]\left[\mathrm{BF}_{4}\right] \quad(7 \mathbf{i})$. The crystal structure, which is depicted in Figure 9, confirms the stereochemical assignment based on the solution spectroscopic data: i.e., formation of a Pt-bound $\sigma: \mu_{2}-\mathrm{C}(\mathrm{Ph})=\mathrm{CH}_{2}$ alkenyl ligand.

To check whether the presence of fluoro substituents alters the stereoselectivity of the protonation site, we also protonated $\mathbf{4 a , c}, \mathbf{d}$ with $\mathrm{HBF}_{4} \cdot \mathrm{Et}_{2} \mathrm{O}$. The IR and NMR data of the resulting 
Scheme 4<smiles>[Y]P[PH]([O-])([O-])[P+]([O-])([O-])[P+]([O-])([O-])c1ccccc1</smiles>

5a: $\mathrm{X}=\mathrm{CH}_{2}$ 5b: $: \mathrm{X}=\mathrm{NH}^{-}$

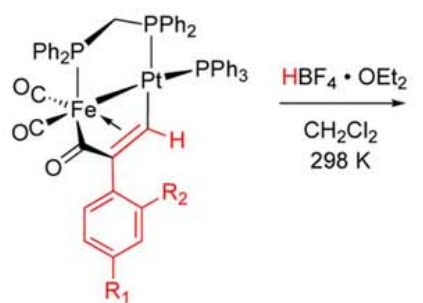

4a: $R_{1}=F, R_{2}=H$

4c: $R_{1}=R_{2}=F$

4d: $\mathrm{R}_{1}=\mathrm{CF}_{3}, \mathrm{R}_{2}=\mathrm{H}$

4i: $R_{1}=R_{2}=H$

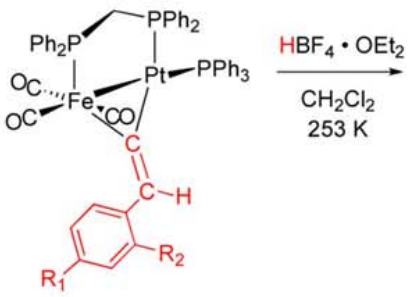

3d: $\mathrm{R}_{1}=\mathrm{CF}_{3}, \mathrm{R}_{2}=\mathrm{H}$

3f: $R_{1}=R_{2}=H$

$3 \mathrm{~g}: \mathrm{R}_{1}=\mathrm{CH}_{3}, \mathrm{R}_{2}=\mathrm{H}$

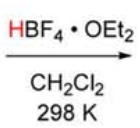

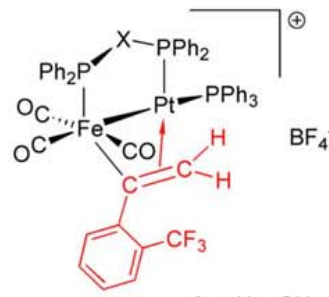

6a: $\mathrm{X}=\mathrm{CH}_{2}$

$6 b: X=N H^{2}$

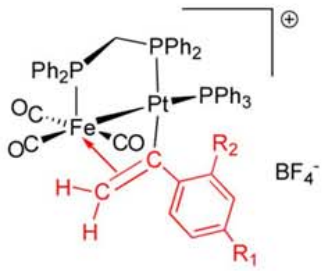

$7 a: R_{1}=F, R_{2}=H$

7c: $R_{1}=R_{2}=F$

$7 d: R_{1}=C_{3}, R_{2}=H$

$7 i: R_{1}=R_{2}=H$

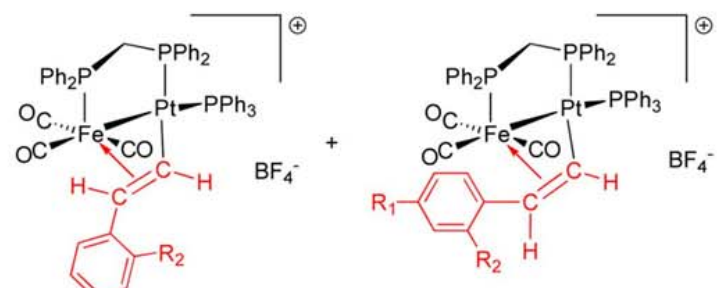

$R_{1}$

8d-trans: $\mathrm{R}_{1}=\mathrm{CF}_{3}, \mathrm{R}_{2}=\mathrm{H}$

8f-trans: $R_{1}=R_{2}=H$

8g-trans: $\mathrm{R}_{1}=\mathrm{CH}_{3}, \mathrm{R}_{2}=\mathrm{H}$

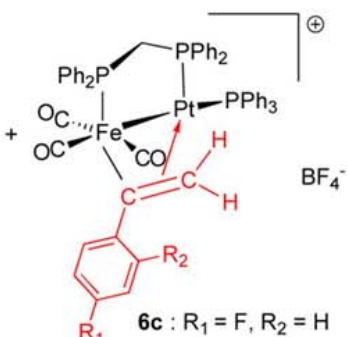

6d: $R_{1}=R_{2}=F$

$6 e: R_{1}=C F_{3}, R_{2}=H$

6f: $R_{1}=R_{2}=H$ alkenyl salts are all very similar to those of $7 \mathbf{i}$, consistent with formation of $\left[(\mathrm{OC})_{3} \mathrm{Fe}(\mu\right.$-dppm $)\left\{\mu-\mathrm{C}\left(\mathrm{C}_{6} \mathrm{H}_{3} \mathrm{R}_{1} \mathrm{R}_{2}\right)=\mathrm{CH}_{2}\right\} \mathrm{Pt}$ $\left.\left(\mathrm{PPh}_{3}\right)\right]\left[\mathrm{BF}_{4}\right](7 \mathbf{a}, \mathbf{c}, \mathbf{d})$. For example, the ${ }^{1} \mathrm{H}$ NMR spectrum of $\left[(\mathrm{OC})_{3} \mathrm{Fe}(\mu\right.$-dppm $)\left\{\mu\right.$-C $\left.\left.\left(\mathrm{C}_{6} \mathrm{H}_{4} \mathrm{CF}_{3}-p\right)=\mathrm{CH}_{2}\right\} \mathrm{Pt}\left(\mathrm{PPh}_{3}\right)\right]\left[\mathrm{BF}_{4}\right]$ (7d) exhibits a broadened doublet at $\delta 3.72$ attributed to the cis-vinylic $\mathrm{CH}$ proton with respect to platinum. The trans-vinylic proton resonates at $\delta 4.25$ and appears as a doublet $\left({ }^{4} \mathrm{~J}_{\mathrm{PH}}=\right.$ $14 \mathrm{~Hz})$, which is strongly coupled with the ${ }^{195} \mathrm{Pt}$ nucleus $\left({ }^{3} J_{\mathrm{PtH}}=\right.$ $95 \mathrm{~Hz}$ ). No geminal ${ }^{2} J_{\mathrm{HH}}$ coupling could be resolved.

Interestingly, extended acquisition of the ${ }^{31} \mathrm{P}$ NMR spectra revealed, independently of the substitution pattern of the aryl group, the copresence of a minor compound in an approximate 90:10 ratio (Figure S6 in the Supporting Information). On the basis of the strong resemblance to the NMR data of $6 a$, these species are tentatively identified as the isomeric vinyl cations $\left[(\mathrm{OC})_{3} \mathrm{Fe}(\mu\right.$-dppm $)\left\{\mu\right.$-C $\left.\left.\left(\mathrm{C}_{6} \mathrm{H}_{3} \mathrm{R}_{1} \mathrm{R}_{2}\right)=\mathrm{CH}_{2}\right\} \mathrm{Pt}\left(\mathrm{PPh}_{3}\right)\right]\left[\mathrm{BF}_{4}\right]$ (6), bearing Fe-bound $\sigma: \mu_{2}$ alkenyl groups. These protonation experiments were realized both at room temperature and at $253 \mathrm{~K}$; however, no change of the respective 6:7 ratio was noticed. No evolution was observed in solution when recording a spectrum after $24 \mathrm{~h}$, so one can presume that formation of complexes 6 does not result from an isomerization of 7 . Note that protonation of the dimetallacyclopentenones $[\mathrm{Cp}(\mathrm{OC}) \mathrm{Fe}$ $\{\mu-\mathrm{C}(=\mathrm{O}) \mathrm{C}(\mathrm{Me})=\mathrm{C}(\mathrm{H})\}(\mu-\mathrm{CO}) \mathrm{Ru}(\mathrm{CO}) \mathrm{Cp}]$ and
$\left[\mathrm{Cp}(\mathrm{OC}) \mathrm{Ru}\left\{\mu-\mathrm{C}(=\mathrm{O}) \mathrm{C}\left(\mathrm{C}_{6} \mathrm{H}_{5}\right)=\mathrm{C}(\mathrm{H})\right\}(\mu-\mathrm{CO}) \mathrm{Ru}(\mathrm{CO})-\right.$ $\mathrm{Cp}]$ is reported to yield the salts $[\mathrm{Cp}(\mathrm{OC}) \mathrm{Fe}\{\mu-\mathrm{C}(\mathrm{H})=$ $\mathrm{C}(\mathrm{H}) \mathrm{Me}\}(\mu-\mathrm{CO}) \mathrm{Ru}(\mathrm{CO}) \mathrm{Cp}]\left[\mathrm{BF}_{4}\right]$ and $[\mathrm{Cp}(\mathrm{OC}) \mathrm{Ru}\{\mu$ $\mathrm{C}(\mathrm{H})=\mathrm{C}(\mathrm{H}) \mathrm{Ph}\}(\mu-\mathrm{CO}) \mathrm{Ru}(\mathrm{CO}) \mathrm{Cp}]\left[\mathrm{BF}_{4}\right]$, displaying a trans configuration of the two vicinal $\mathrm{H}$ atoms. ${ }^{2 \mathrm{cc}, 35 \mathrm{~b}}$

Protonation of the $\mu$-Vinylidene Complexes $\left[(\mathrm{OC})_{3} \mathrm{Fe}-\right.$ $(\mu$-dppm $\left.)\left\{\mu-\mathrm{C}=\mathrm{C}(\mathrm{H}) \mathrm{C}_{6} \mathrm{H}_{4} \mathrm{R}\right\} \mathrm{Pt}\left(\mathrm{PPh}_{3}\right)\right]$. $\mu$-Vinylidene complexes are known to preferentially react with electrophiles such as $\mathrm{H}^{+}$at the $\beta$-carbon of the bridging vinylidene unit. For example, the compounds $\left[\left(\eta^{5}-\mathrm{C}_{5} \mathrm{H}_{5}\right)_{2}(\mathrm{OC})_{2} \mathrm{Mn}(\mu\right.$-C $=\mathrm{CHR}) \mathrm{Mn}(\mathrm{CO})_{2}\left(\eta^{5}\right.$ $\left.\left.\mathrm{C}_{5} \mathrm{H}_{5}\right)\right]\left(\mathrm{R}=\mathrm{H}, \mathrm{Me}, \mathrm{Ph}, \mathrm{CO}_{2} \mathrm{Me}\right)$ are protonated to produce $\left[\left(\eta^{5}-\mathrm{C}_{5} \mathrm{H}_{5}\right)_{2}(\mathrm{OC})_{2} \mathrm{Mn}\left(\mu-\mathrm{C}-\mathrm{CH}_{2} \mathrm{R}\right) \mathrm{Mn}(\mathrm{CO})_{2}\left(\eta^{5}-\mathrm{C}_{5} \mathrm{H}_{5}\right)\right]^{+}$, which contains a $\mu$-carbyne ligand bridging the two metals. ${ }^{42,43}$ In addition, $\left[\left(\eta^{5}-\mathrm{C}_{5} \mathrm{H}_{5}\right)(\mathrm{OC}) \mathrm{Co}\left(\mu-\mathrm{C}=\mathrm{CH}_{2}\right) \mathrm{Co}(\mathrm{CO})\left(\eta^{5}-\mathrm{C}_{5} \mathrm{H}_{5}\right)\right]$ is protonated by $\mathrm{HBF}_{4}$ at the same site to yield the $\mu$-ethylidene salt $\left[\left(\eta^{5}-\mathrm{C}_{5} \mathrm{H}_{5}\right)(\mathrm{OC}) \mathrm{Co}\left(\mu-\mathrm{CCH}_{3}\right) \mathrm{Co}(\mathrm{CO})\left(\eta^{5}-\mathrm{C}_{5} \mathrm{H}_{5}\right)\right]^{+44}$. Protonation at the $\beta$-carbon has also been reported to occur after treatment of $\left[\left(\eta^{5}-\mathrm{C}_{5} \mathrm{H}_{5}\right)(\mathrm{OC}) \mathrm{Ru}\left(\mu-\mathrm{C}=\mathrm{CH}_{2}\right)(\mu-\mathrm{CO}) \mathrm{Ru}(\mathrm{CO})\left(\eta^{5}-\mathrm{C}_{5} \mathrm{H}_{5}\right)\right]$, $\left[\left(\eta^{5}-\mathrm{C}_{5} \mathrm{H}_{5}\right)(\mathrm{OC}) \mathrm{Fe}\left(\mu-\mathrm{C}=\mathrm{CH}_{2}\right)(\mu-\mathrm{CO}) \mathrm{Fe}(\mathrm{CO})\left(\eta^{5}-\mathrm{C}_{5} \mathrm{H}_{5}\right)\right]$, and $\left[\left(\eta^{5}-\mathrm{C}_{5} \mathrm{Me}_{5}\right) \mathrm{Ru}\left(\mu-\mathrm{C}=\mathrm{CH}_{2}\right)(\mu-\mathrm{N}-\mathrm{Ph}) \mathrm{Ru}\left(\eta^{5}-\mathrm{C}_{5} \mathrm{Me}_{5}\right)\right]$ with $\mathrm{HBF}_{4}{ }^{45-47}$ In the case of $\left[\left(\eta^{5}-\mathrm{C}_{5} \mathrm{Me}_{5}\right)(\mathrm{OC})_{2} \operatorname{Re}(\mu-\mathrm{C}=\mathrm{C}(\mathrm{H}) \mathrm{C}\right.$ $\left.\left.(\mathrm{Me})=\mathrm{CH}_{2}\right) \operatorname{Re}(\mathrm{CO})_{2}\left(\eta^{5}-\mathrm{C}_{5} \mathrm{Me}_{5}\right)\right]$, protonation occurs at the remote $\delta$ position to produce the salt $\left[\left(\eta^{5}-\mathrm{C}_{5} \mathrm{Me}_{5}\right)(\mathrm{OC})_{2} \operatorname{Re}(\mu\right.$-C$\left.\left.\mathrm{C}(\mathrm{H})=\mathrm{CMe}_{2}\right) \operatorname{Re}(\mathrm{CO})_{2}\left(\eta^{5}-\mathrm{C}_{5} \mathrm{Me}_{5}\right)\right]^{+34}$. Werner et al. have also 


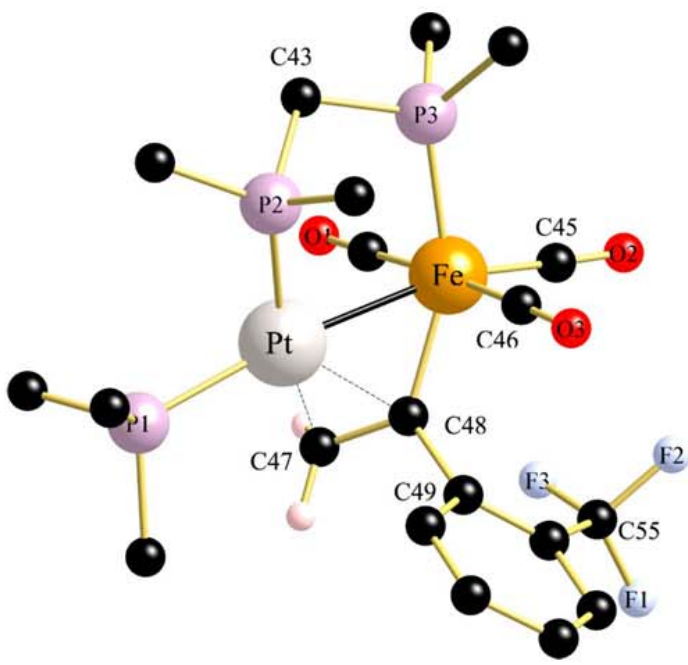

Figure 8. View of the cation of 6 a showing the atom-labeling scheme. Only the ipso carbons of the aryl groups are shown. Selected distances $(\AA)$ and angles (deg): $\mathrm{Fe}-\mathrm{Pt}=2.6163(8) \mathrm{Fe}-\mathrm{P}(3)=2.267(2), \mathrm{Pt}-$ $\mathrm{P}(2)=2.2682(16), \mathrm{Pt}-\mathrm{P}(1)=2.3168(13), \mathrm{Fe}-\mathrm{C}(44)=1.796(7), \mathrm{Fe}-$ $\mathrm{C}(45)=1.796(6), \mathrm{Fe}-\mathrm{C}(46)=1.811(7), \mathrm{Fe}-\mathrm{C}(48)=1.986(6), \mathrm{Pt}-$ $\mathrm{C}(47)=2.170(5), \mathrm{Pt}-\mathrm{C}(48)=2.218(5), \mathrm{C}(47)-\mathrm{C}(48)=1.386(7)$; $\mathrm{P}(3)-\mathrm{Fe}-\mathrm{Pt}=98.33(5), \mathrm{P}(2)-\mathrm{Pt}-\mathrm{Fe}=88.94(4), \mathrm{P}(1)-\mathrm{Fe}-\mathrm{Pt}=$ $170.14(5), \mathrm{P}(1)-\mathrm{Pt}-\mathrm{P}(2)=100.76(5), \mathrm{Pt}-\mathrm{Fe}-\mathrm{C}(48)=47.64(14)$, $\mathrm{C}(47)-\mathrm{Pt}-\mathrm{C}(48)=36.82(17), \mathrm{C}(47)-\mathrm{C}(48)-\mathrm{Fe}=121.8(5)$, $\mathrm{C}(47)-\mathrm{C}(48)-\mathrm{C}(49)=114.4(5), \mathrm{P}(2)-\mathrm{C}(33)-\mathrm{P}(3)=109.2(3)$.

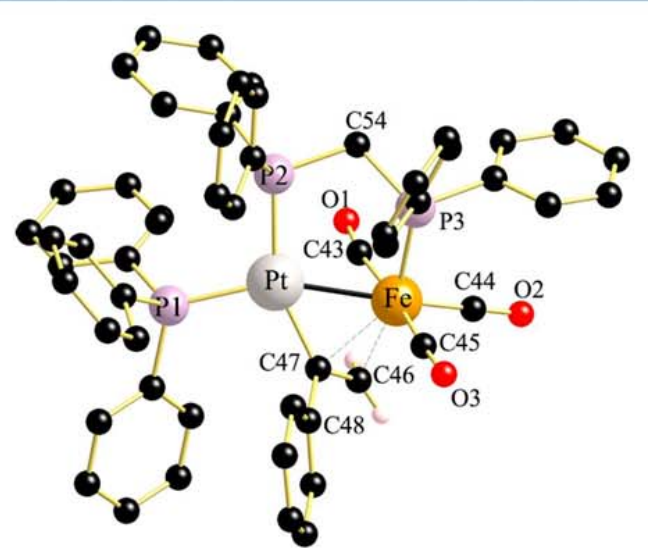

Figure 9. Perspective view of the complex cation of $\left[(\mathrm{OC})_{3} \mathrm{Fe}(\mu\right.$ dppm) $\left.\left.\left\{\mu-\mathrm{H}_{2} \mathrm{C}=\mathrm{C}(\mathrm{Ph})\right\}\right) \mathrm{Pt}\left(\mathrm{PPh}_{3}\right)\right]\left[\mathrm{BF}_{4}\right]$ (7i) showing the atomlabeling scheme. Hydrogen atoms apart from $\mathrm{H}(47 \mathrm{~A})$ and $\mathrm{H}(47 \mathrm{~B})$ have been omitted for clarity. Selected distances $(\AA)$ and angles (deg): $\mathrm{Fe}-\mathrm{Pt}=2.5619(5), \mathrm{Fe}-\mathrm{P}(3)=2.2385(11), \mathrm{Pt}-\mathrm{P}(1)=2.2873(8), \mathrm{Pt}-$ $\mathrm{P}(2)=2.3303(9), \mathrm{Fe}-\mathrm{C}(43)=1.826(4), \mathrm{Fe}-\mathrm{C}(44)=1.793(4), \mathrm{Fe}-$ $\mathrm{C}(45)=1.796(4), \mathrm{Fe}-\mathrm{C}(46)=2.166(4), \mathrm{Fe}-\mathrm{C}(47)=2.170(3), \mathrm{Pt}-$ $\mathrm{C}(47)=2.024(4), \mathrm{C}(47)-\mathrm{C}(48)=1.392(5) ; \mathrm{P}(1)-\mathrm{Fe}-\mathrm{Pt}=156.18(3)$, $\mathrm{P}(2)-\mathrm{Pt}-\mathrm{Fe}=100.02(3), \mathrm{P}(3)-\mathrm{Fe}-\mathrm{Pt}=90.83(3), \mathrm{P}(1)-\mathrm{Pt}-\mathrm{P}(2)=$ 103.32(3), $\mathrm{Pt}-\mathrm{C}(47)-\mathrm{Fe}=75.21(12), \mathrm{C}(47)-\mathrm{Fe}-\mathrm{C}(46)=37.45(14)$, $\mathrm{C}(46)-\mathrm{C}(47)-\mathrm{Pt}=123.5(8), \mathrm{C}(47)-\mathrm{Pt}-\mathrm{Fe}=54.99(10), \mathrm{C}(48)-$ $\mathrm{C}(47)-\mathrm{C}(46)=119.0(3), \mathrm{P}(2)-\mathrm{C}(54)-\mathrm{P}(3)=111.35(18)$.

reacted the heterodinuclear species $\left[\left(\eta^{5}-\mathrm{C}_{5} \mathrm{H}_{5}\right)\left(i-\mathrm{Pr}_{3} \mathrm{P}\right) \mathrm{Rh}(\mu-\mathrm{C}=\right.$ $\left.\left.\mathrm{CH}_{2}\right)(\mu-\mathrm{CO}) \mathrm{Mn}(\mathrm{CO})\left(\eta^{5}-\mathrm{C}_{5} \mathrm{H}_{5}\right)\right](\mathrm{R}=\mathrm{H}, \mathrm{Me}, \mathrm{Ph})$ and $\left[\left(\eta^{5}-\right.\right.$ $\left.\left.\mathrm{C}_{5} \mathrm{H}_{5}\right)\left(i-\mathrm{Pr}_{3} \mathrm{P}\right) \mathrm{Rh}(\mu-\mathrm{C}=\mathrm{CHR}) \mathrm{Fe}(\mathrm{CO})_{3}\right] \quad(\mathrm{R}=\mathrm{H}, \mathrm{Me}, \mathrm{Ph})$ with $\mathrm{HBF}_{4}$ and isolated the respective cationic $\mu$-carbyne salts. ${ }^{48}$ To the best of our knowledge, there are just two examples of protonation at the $\alpha$-carbon atom of a bridging vinylidene unit. Protonation of $\left[\left(\eta^{5}-\mathrm{C}_{9} \mathrm{H}_{7}\right)(\mathrm{OC}) \mathrm{Rh}\left(\mu-\mathrm{C}=\mathrm{CH}_{2}\right) \mathrm{Rh}(\mathrm{CO})\left(\eta^{5}\right.\right.$ $\left.\left.\mathrm{C}_{9} \mathrm{H}_{7}\right)\right]$ is supposed to yield first the $\mu$-hydride species [ $\left(\eta^{5}\right.$ $\left.\left.\mathrm{C}_{9} \mathrm{H}_{7}\right)(\mathrm{OC}) \mathrm{Rh}\left(\mu-\mathrm{C}=\mathrm{CH}_{2}\right)(\mu-\mathrm{H}) \mathrm{Rh}(\mathrm{CO})\left(\eta^{5}-\mathrm{C}_{9} \mathrm{H}_{7}\right)\right]^{+}$, which subsequently rearranges to give $\left[\left(\eta^{5}-\mathrm{C}_{9} \mathrm{H}_{7}\right)(\mathrm{OC}) \mathrm{Rh}(\mu-\mathrm{C}(\mathrm{H})=\right.$ $\left.\left.\mathrm{CH}_{2}\right) \mathrm{Rh}(\mathrm{CO})\left(\eta^{5}-\mathrm{C}_{9} \mathrm{H}_{7}\right)\right]^{+}{ }^{49}$ Initial formation of a hydride intermediate has also been suggested by Cowie et al. to account for the formation of dppm-spanned $\alpha$-protonated $\mathrm{Rh}-\mathrm{Mn}$ $\sigma$-alkenyl complexes. ${ }^{50}$

We were therefore intrigued about the site reactivity of our vinylidene complexes 3 and thus reacted $3 \mathrm{~d}$ with an excess of $\mathrm{HBF}_{4} \cdot \mathrm{Et}_{2} \mathrm{O}$ in $\mathrm{CH}_{2} \mathrm{Cl}_{2}$ solution at $0{ }^{\circ} \mathrm{C}$. IR monitoring indicated the complete disappearance of the starting material after $10 \mathrm{~min}$ and formation of a new complex bearing three terminal carbonyls, as indicated by the observation of three absorptions at 2043,2000, and $1957 \mathrm{~cm}^{-1} .{ }^{31} \mathrm{P}$ NMR investigation of the crude residue revealed the formation of two isomeric species in an approximate $60: 40$ ratio. These two species were characterized in the ${ }^{31} \mathrm{P}\left\{{ }^{1} \mathrm{H}\right\}$ NMR spectrum by two sets of three well-resolved signals at $\delta 54.4$, $34.3,8.5$ and $\delta 56.8,39.3,9.0 \mathrm{ppm}$. These data are consistent with the formation of a Pt-bound $\sigma: \mu_{2}$ alkenyl salt (Table 1 ). It can be deduced from the ${ }^{1} \mathrm{H}$ NMR spectrum that protonation occurred at the $\alpha$-position of the vinylidene unit, generating a mixture of the isomeric $\sigma$-alkenyl salts trans- $\left[(\mathrm{OC})_{3} \mathrm{Fe}(\mu\right.$-dppm $)\{\mu$ - $\mathrm{C}(\mathrm{H})=$ $\left.\left.\mathrm{C}(\mathrm{H}) \mathrm{C}_{6} \mathrm{H}_{4} \mathrm{CF}_{3}-p\right\} \mathrm{Pt}\left(\mathrm{PPh}_{3}\right)\right]\left[\mathrm{BF}_{4}\right]$ (8d-trans, major species) and cis- $\left[(\mathrm{OC})_{3} \mathrm{Fe}(\mu\right.$-dppm $)\left\{\mu\right.$ - $\left.\mathrm{C}(\mathrm{H})=\mathrm{C}(\mathrm{H}) \mathrm{C}_{6} \mathrm{H}_{4} \mathrm{CF}_{3}-p\right\} \mathrm{Pt}-$ $\left.\left(\mathrm{PPh}_{3}\right)\right]\left[\mathrm{BF}_{4}\right]$ (8d-cis, minor species) according to Scheme 4. The $\alpha$-protons of the alkenyl ligands are observed at low field as broad doublets at $\delta 9.28$ and 9.12 for $\mathbf{8 d}$-trans and $\mathbf{8 d - c i s ,}$ respectively. Attribution of the $\beta$-proton signals is more difficult, since they are not resolved, but $8 \mathrm{~d}$-trans could be isolated in the form of single crystals (see below) and therefore a correct assignment has been possible without ambiguity. The resonance of the $\beta$-proton of the alkenyl ligand in $8 \mathrm{~d}$-trans is visible at $5.63 \mathrm{ppm}$ with a characteristic trans coupling constant ${ }^{3} \mathrm{~J}_{\mathrm{HH}}$ of $13.4 \mathrm{~Hz}$.

Crystal Structure of trans- $\left[(O C)_{3} \mathrm{Fe}(\mu-d p p m)\{\mu-C(H)=C(H)\right.$ $\left.\left.\mathrm{C}_{6} \mathrm{H}_{4} \mathrm{CF}_{3}-\mathrm{p}\right\} \mathrm{Pt}\left(\mathrm{PPh}_{3}\right)\right]\left[\mathrm{BF}_{4}\right]$ (8d-trans). Recrystallization of the 8d-trans/8d-cis mixture from $\mathrm{CH}_{2} \mathrm{Cl}_{2} / \mathrm{Et}_{2} \mathrm{O}$ afforded yellow crystals of the isomer 8d-trans, suitable for an X-ray diffraction study. Figure 10 shows that, in contrast to 6 , the alkenyl ligand is now $\sigma$-bound to $\mathrm{Pt}$ and $\pi$-coordinated to the $\mathrm{Fe}(\mathrm{CO})_{3}$ moiety, as already observed in 7. The $\mathrm{Pt}-\mathrm{C}(47)$ bond length (2.013(8) $\AA$ ) and the $\mathrm{C}(47)-\mathrm{C}(48)$ double-bond length $(1.402(13) \AA)$ match with those of $\left[(\mathrm{OC})_{3} \mathrm{Fe}(\mu\right.$-dppm $\left.)\left\{\mu-\mathrm{H}_{2} \mathrm{C}=\mathrm{C}(\mathrm{Ph})\right\}\right) \mathrm{Pt}$ $\left.\left(\mathrm{PPh}_{3}\right)\right]\left[\mathrm{BF}_{4}\right](7 \mathrm{i})$ shown in Figure 8. In addition, the metalmetal separations of $7 \mathbf{i}$ and $8 \mathrm{~d}$-trans $(2.5619(5)$ vs $2.5778(17) \AA$ ) are very similar. In line with a trans configuration around the alkenyl group, the dihedral angle $\mathrm{C}(49)-\mathrm{C}(48)-\mathrm{C}(47)-\mathrm{Pt}$ amounts to $172.56^{\circ}$

In order to assess the impact of the para substituent of the aryl group on isomer distribution, we also reacted $\left[(\mathrm{OC})_{3} \mathrm{Fe}(\mu\right.$ dppm $\left.)\left\{\mu-\mathrm{C}=\mathrm{C}(\mathrm{H}) \mathrm{C}_{6} \mathrm{H}_{5}\right\} \mathrm{Pt}\left(\mathrm{PPh}_{3}\right)\right]$ (3f) and $\left[(\mathrm{OC})_{3} \mathrm{Fe}(\mu\right.$ dppm) $\left.\left\{\mu-\mathrm{C}=\mathrm{C}(\mathrm{H}) \mathrm{C}_{6} \mathrm{H}_{4} \mathrm{CH}_{3}-p\right\} \mathrm{Pt}\left(\mathrm{PPh}_{3}\right)\right]$ (3g) with $\mathrm{HBF}_{4}$. $\mathrm{Et}_{2} \mathrm{O}$. Again, mixtures of the respective trans and cis isomers were formed. However, in the case of the protonation of $3 \mathrm{f}$ at $298 \mathrm{~K}$, the isomer cis- $\left[(\mathrm{OC})_{3} \mathrm{Fe}(\mu\right.$-dppm $)\{\mu-\mathrm{C}(\mathrm{H})=\mathrm{C}(\mathrm{H}) \mathrm{Ph}\} \mathrm{Pt}-$ $\left.\left(\mathrm{PPh}_{3}\right)\right]\left[\mathrm{BF}_{4}\right]$ (8f-cis) now constituted the dominating species. The 70:30 ratio between $\mathbf{8 f}$-cis and the trans isomer $\mathbf{8 f}$-trans did not shift when raising the temperature to $45^{\circ} \mathrm{C}$ or after 2 days in solution, thereby excluding an equilibrium between the two species. However, the relative isomer ratio seems to depend on the temperature at which the protonation is realized. When $\mathrm{HBF}_{4} \cdot \mathrm{Et}_{2} \mathrm{O}$ was added to $3 \mathrm{f}$ at $253 \mathrm{~K}$, both ${ }^{31} \mathrm{P}\left\{{ }^{1} \mathrm{H}\right\}$ and 


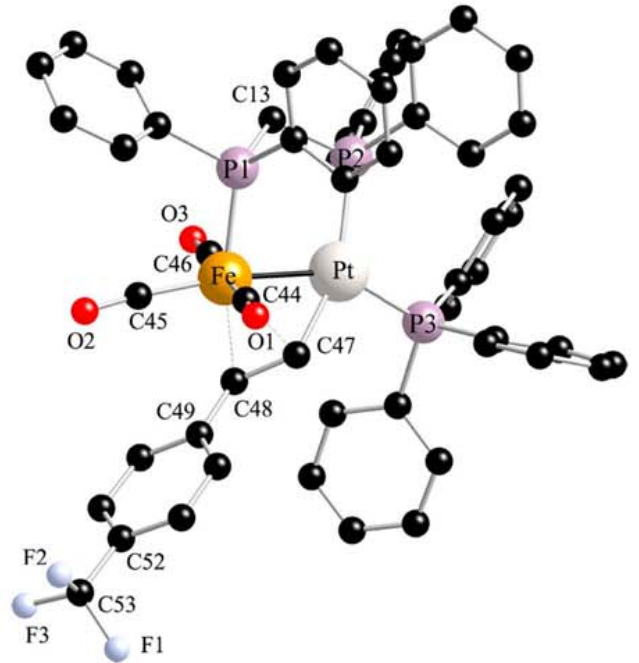

Figure 10. Perspective view of the complex cation of trans- $\left[(\mathrm{OC})_{3} \mathrm{Fe}(\mu-\right.$ dppm $\left.)\left\{\mu-\mathrm{C}(\mathrm{H})=\mathrm{C}(\mathrm{H}) \mathrm{C}_{6} \mathrm{H}_{4} \mathrm{CF}_{3}-p\right\} \mathrm{Pt}\left(\mathrm{PPh}_{3}\right)\right]\left[\mathrm{BF}_{4}\right]$ (8d-trans) showing the atom-labeling scheme. Only one of the two independent cations is shown. Hydrogen atoms have been omitted for clarity. Selected distances $(\AA)$ and angles $(\mathrm{deg}): \mathrm{Fe}(1)-\mathrm{Pt}(1)=2.5778(17), \mathrm{Fe}(1)-\mathrm{P}(1)=$ 2.230(3), $\mathrm{Pt}(1)-\mathrm{P}(2)=2.297(2), \mathrm{Pt}(1)-\mathrm{P}(3)=2.259(3), \mathrm{Fe}(1)-$ $\mathrm{C}(44)=1.809(11), \mathrm{Fe}(1)-\mathrm{C}(45)=1.788(12), \mathrm{Fe}(1)-\mathrm{C}(46)=$ $1.821(11), \mathrm{Fe}(1)-\mathrm{C}(47)=2.124(9), \mathrm{Fe}(1)-\mathrm{C}(48)=2.221(9), \mathrm{Pt}(1)-$ $\mathrm{C}(47)=2.013(8), \mathrm{C}(47)-\mathrm{C}(48)=1.402(13) ; \mathrm{P}(1)-\mathrm{Fe}(1)-\mathrm{Pt}(1)=$ $86.79(9), \mathrm{P}(2)-\mathrm{Pt}(1)-\mathrm{Fe}(1)=101.86(7), \mathrm{P}(3)-\mathrm{Pt}(1)-\mathrm{Fe}(1)=$ 150.55(7), $\mathrm{P}(3)-\mathrm{Pt}(1)-\mathrm{P}(2)=106.93(10), \mathrm{Pt}(1)-\mathrm{C}(47)-\mathrm{Fe}(1)=$ $77.0(3), \mathrm{C}(47)-\mathrm{Fe}(1)-\mathrm{C}(48)=37.6(3), \mathrm{C}(48)-\mathrm{C}(47)-$ $\mathrm{Pt}(1)=123.5(8), \mathrm{C}(49)-\mathrm{C}(48)-\mathrm{C}(47)=125.6(10), \mathrm{P}(1)-\mathrm{C}(13)-$ $\mathrm{P}(2)=109.6(5)$

${ }^{195} \mathrm{Pt}\left\{{ }^{1} \mathrm{H}\right\}$ spectra indicated the coexistence of $\mathbf{8 f}$-cis and $\mathbf{8 f}$-trans in a 50:50 ratio. The latter is depicted in Figure 11 and consists of two doublets of doublets of doublets of equal intensities centered at $\delta-2526$ (8f-cis) and $\delta-2563$ (8f-trans) ppm. Pure crystalline 8 - $c$ is could be isolated from $\mathrm{CH}_{2} \mathrm{Cl}_{2} / \mathrm{Et}_{2} \mathrm{O}$, allowing an unambiguous attribution of the NMR resonances. In the ${ }^{1} \mathrm{H}$ NMR spectrum the broadened doublet due to the vinylic $\alpha$-proton resonates at $\delta 8.99 \mathrm{ppm}$. The multiplet at $\delta 3.96$ assigned to the $\beta$-proton simplifies to a doublet after ${ }^{31} \mathrm{P}$ decoupling and exhibits a characteristic cis coupling ${ }^{3} J_{\mathrm{HH}}$ value of $8.1 \mathrm{~Hz}$.

A 70:30 mixture of cis- $\left[(\mathrm{OC})_{3} \mathrm{Fe}(\mu\right.$-dppm $)\{\mu-\mathrm{C}(\mathrm{H})=\mathrm{C}(\mathrm{H})$ $\left.\left.\mathrm{C}_{6} \mathrm{H}_{4} \mathrm{CH}_{3}-p\right\} \mathrm{Pt}\left(\mathrm{PPh}_{3}\right)\right]\left[\mathrm{BF}_{4}\right]$ (8g-cis) and trans-[(OC) ${ }_{3} \mathrm{Fe}(\mu-$ dppm) $\left.\left\{\mu-\mathrm{C}(\mathrm{H})=\mathrm{C}(\mathrm{H}) \mathrm{C}_{6} \mathrm{H}_{4} \mathrm{CH}_{3}-p\right\} \mathrm{Pt}\left(\mathrm{PPh}_{3}\right)\right]\left[\mathrm{BF}_{4}\right]$ (8g-trans) results from protonation of vinylidene $\left[(\mathrm{OC})_{3} \mathrm{Fe}(\mu\right.$-dppm $)\{\mu$-C $=$ $\left.\left.\mathrm{C}(\mathrm{H}) \mathrm{C}_{6} \mathrm{H}_{4} \mathrm{CH}_{3}-p\right\} \mathrm{Pt}\left(\mathrm{PPh}_{3}\right)\right](3 \mathrm{~g})^{13 \mathrm{~b}}$ at $293 \mathrm{~K}$. No further separation of this mixture was undertaken. To probe whether in the presence of carbon monoxide insertion into the $\mathrm{Pt}$-vinyl bond or $\mathrm{PPh}_{3}$ displacement occurs, ${ }^{51} \mathrm{CO}$ was bubbled into solutions of 8d-trans and 8f-cis. However, even after $12 \mathrm{~h}$ under a CO atmosphere, no reaction was noted.

\section{CONCLUSION}

This study has shown that hydrometalation of aromatic alkynes $\mathrm{ArC} \equiv \mathrm{CH}$ bearing fluoro substituents by hydride complexes $\mathbf{1}$ is less straightforward than the insertion of phenyl- and $p$-tolylacetylene. With fluoro substituents at the para or meta position, the $\mu$-vinylidene complexes 3 are obtained via the transient $\sigma$-alkenyl species $\left[(\mathrm{OC})_{3} \mathrm{Fe}\left\{\mu\right.\right.$-Si $\left.(\mathrm{OMe})_{2}(\mathrm{OMe})\right\}(\mu$-dppm $) \mathrm{Pt}(\mathrm{ArC}=$ $\left.\mathrm{CH}_{2}\right)$ ] (2). The outcome of the reaction is more difficult to predict, with terminal alkynes bearing $\mathrm{F}$ or $\mathrm{CF}_{3}$ substituents at the ortho position of the aryl ring. With $o-\mathrm{FC}_{6} \mathrm{H}_{4} \mathrm{C} \equiv \mathrm{CH}$, a mixture of isomeric dimetallacyclopentenones $\mathbf{4 b}$ and $\mathbf{4} \mathbf{b}^{\prime}$ is obtained; the occurrence of $\mathrm{C}-\mathrm{F} \cdots \mathrm{H}-\mathrm{C}$ contacts has been evidenced both in the solid state by X-ray crystallography and in solution by ${ }^{31} \mathrm{P}$ NMR spectroscopy at variable temperature. A highlight of this contribution is the observation that the structurally characterized dimetallacyclobutenes $\left[(\mathrm{OC})_{3} \mathrm{Fe}\left(\mu-\mathrm{Ph}_{2} \mathrm{PXPPh}_{2}\right)\left\{\mu-\mathrm{C}\left(\mathrm{C}_{6} \mathrm{H}_{4} \mathrm{CF}_{3^{-}}\right.\right.\right.$ o) $\left.\mathrm{C}=\mathrm{C}(\mathrm{H})\} \mathrm{Pt}\left(\mathrm{PPh}_{2} \mathrm{R}\right)\right]$ (5) are formed with $o-\mathrm{CF}_{3} \mathrm{C}_{6} \mathrm{H}_{4} \mathrm{C} \equiv$ $\mathrm{CH}$. The latter are in a temperature-dependent equilibrium with dimetallacyclopentenones [(OC) ${ }_{2} \mathrm{Fe}\left(\mu-\mathrm{Ph}_{2} \mathrm{PXPPh}_{2}\right)\{\mu$-C $(=\mathrm{O})$ $\left.\left.\mathrm{C}\left(\mathrm{C}_{6} \mathrm{H}_{4} \mathrm{CF}_{3}-\mathrm{o}\right)=\mathrm{C}(\mathrm{H})\right\} \mathrm{Pt}\left(\mathrm{PPh}_{2} \mathrm{R}\right)\right](4 \mathrm{e}-\mathrm{g})$. This unprecedented interconversion implies a reversible $\mathrm{C}-\mathrm{C}$ bond breaking/forming reaction between a terminal carbonyl ligand and the $\mu_{2}$-bridging alkene. ${ }^{52}$ Since the electron-withdrawing propensities of trifluoromethyl groups at the para and ortho positions of an aryl ring are quite similar, steric rather than electronic reasons may account for the different results. We have also shown that a series of isomeric Pt- $\sigma: \mu_{2}$-alkenyl and Fe- $\sigma: \mu_{2}$-alkenyl salts is accessible by protonation of the dimetallacyclopentenone, $\mu$-vinylidene, and dimetallacyclobutene complexes. We are currently extending our investigations on the insertion of alkynes into the $\mathrm{Pt}-\mathrm{H}$ bond of $\mathbf{1}$ to various diynes, alkynols, and fluorinated olefins and are studying the reactivities of these compounds.

\section{EXPERIMENTAL SECTION}

General Procedures and Materials. All reactions were performed in Schlenk-tube flasks under an argon atmosphere. Solvents were dried and distilled under argon before use; with toluene, hexane and heptane over sodium, dichloromethane over $\mathrm{CaCl}_{2}$, and diethylether over sodium benzophenone ketyl. $o$-Fluoroethynylbenzene, $p$-fluoroethynylbenzene, $o, p$-difluoroethynylbenzene, $o$-(trifluoromethyl)ethynylbenzene, $m$-(trifluoromethyl)ethynylbenzene, and $p$-(trifluoromethyl)ethynylbenzene were purchased from Sigma-Aldrich and used as received. 1a-c, $\left[(\mathrm{OC})_{3} \mathrm{Fe}(\mu-\mathrm{CO})(\mu\right.$-dppm $\left.) \mathrm{Pt}\left(\mathrm{PPh}_{3}\right)\right]$, and $\left[(\mathrm{OC})_{3} \mathrm{Fe}-\right.$ $(\mu$-CO $)(\mu$-dppa $\left.) \mathrm{Pt}\left(\mathrm{PPh}_{3}\right)\right]$ were prepared as described in the literature. ${ }^{1{ }^{2}, 24}$ The reactions were generally monitored by IR spectroscopy in the $\nu(\mathrm{CO})$ region. Infrared spectra have been obtained on a Shimadzu IR affinity-1 spectrometer. Elemental $\mathrm{C}$ and $\mathrm{H}$ analyses were performed on a Leco CHN 900 elemental analyzer. ${ }^{31} \mathrm{P}\left\{{ }^{1} \mathrm{H}\right\}$ and ${ }^{1} \mathrm{H}$ NMR spectra were recorded in $\mathrm{CDCl}_{3}$, unless otherwise stated, with a Bruker Avance 300 spectrometer at 121.50 and $300.13 \mathrm{MHz}$. The solvent was used as the chemical shift standard; $\delta$ is given in ppm and $J$ in $\mathrm{Hz}$. Standard NMR abbreviations are used: $\mathrm{d}=$ doublet, $\mathrm{dd}=$ doublet of doublets, $\mathrm{dt}=$ doublet of triplets, $\mathrm{t}=$ triplet, $\mathrm{q}=$ quadruplet, $\mathrm{m}=$ multiplet, $\mathrm{br}=$ broad. Phosphorus chemical shifts are externally referenced to $85 \% \mathrm{H}_{3} \mathrm{PO}_{4}$ in $\mathrm{H}_{2} \mathrm{O} .{ }^{195} \mathrm{Pt}$ chemical shifts were measured on a Bruker ACP 200 instrument at $42.95 \mathrm{MHz}$ and externally referenced to $\mathrm{K}_{2} \mathrm{PtCl}_{4}$ in water with downfield chemical shifts reported as positive. ${ }^{19} \mathrm{~F}$ NMR spectra were recorded at $470.2 \mathrm{MHz}$ on a Varian MR 500 spectrometer and referenced to $\mathrm{CFCl}_{3}$.

Preparation of the Complexes. Method a: General Reaction of $\left.\left[(\mathrm{OC})_{3} \mathrm{Fe}\left\{\mathrm{Si}(\mathrm{OMe})_{3}\right\}\left(\mu-\mathrm{Ph}_{2} \mathrm{PXPPh}\right)_{2}\right) \mathrm{Pt}(\mathrm{H})\left(\mathrm{PPh}_{2} R\right)\right]$ with Fluoro-Substituted Ethynylbenzenes. Three equivalents of fluoro-substituted ethynylbenzene was added to a solution of 1 in $\mathrm{CH}_{2} \mathrm{Cl}_{2}$. The reaction was monitored by IR spectroscopy, and after the mixture was stirred for $2-5$ days at $30^{\circ} \mathrm{C}$, the mixture was filtered off and the brown solution was concentrated and layered with hexane or heptane. After a few days, an orange powder or crystals of the complexes were formed and collected.

Method b: General Reaction of [(OC) $\mathrm{Fe}(\mu-\mathrm{CO})\left(\mu-\mathrm{Ph}_{2} \mathrm{PXPPh}\right) \mathrm{Pt}$ $\left.\left(\mathrm{PPh}_{3}\right)\right]$ with Fluoro-Substituted Ethynylbenzene. Three equivalents of fluoro-substituted ethynylbenzene was added to a solution of $\left[(\mathrm{OC})_{3} \mathrm{Fe}(\mu\right.$-CO $\left.)\left(\mu-\mathrm{Ph}_{2} \mathrm{PXPPh}_{2}\right) \mathrm{Pt}\left(\mathrm{PPh}_{3}\right)\right]$ in toluene. After the mixture was stirred for $5 \mathrm{~h}$ at $70{ }^{\circ} \mathrm{C}$, it was filtered and the orange solution was concentrated and layered with heptane. After a few days, an orange powder or crystals were formed and collected. 


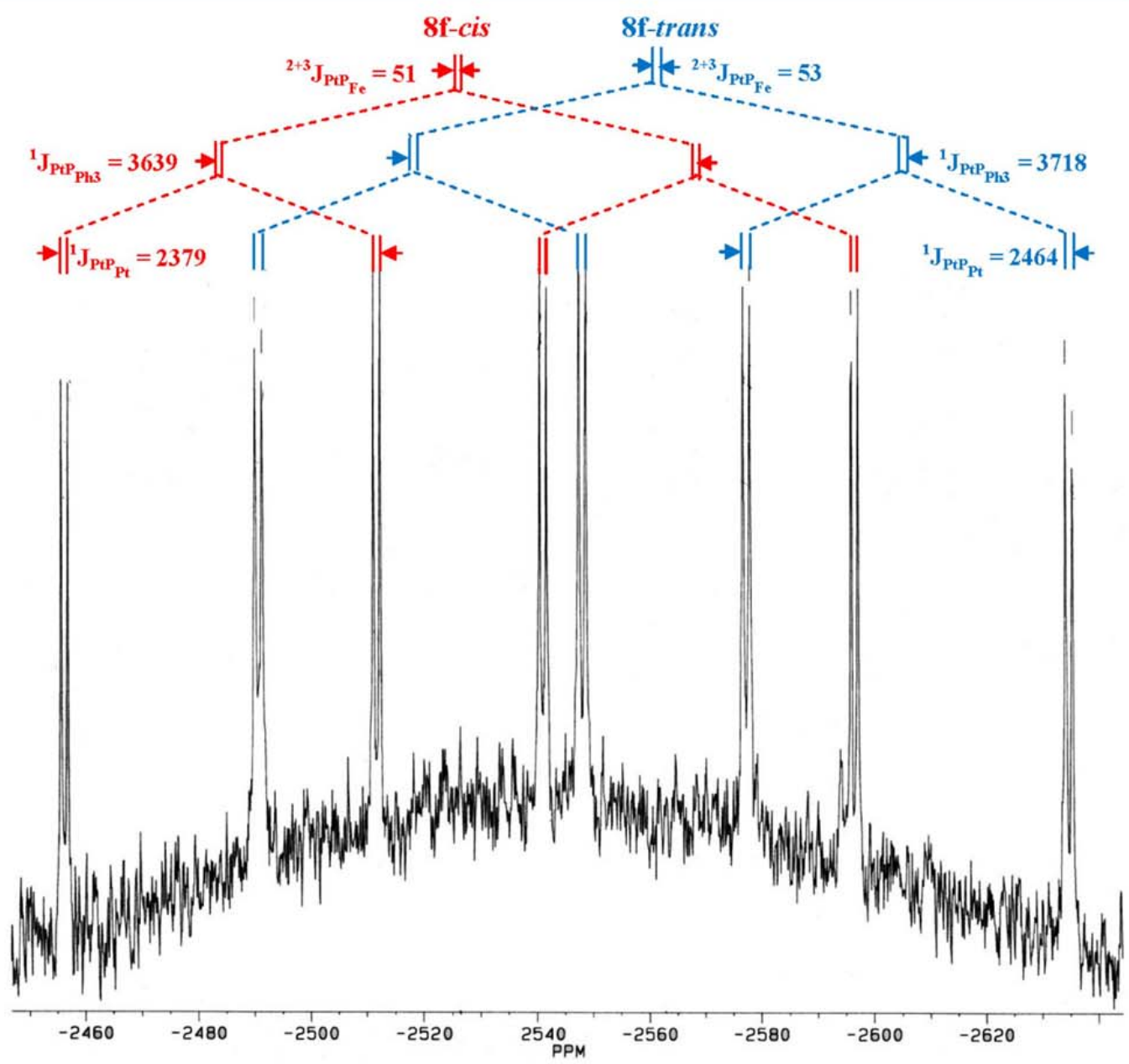

Figure 11. ${ }^{195} \mathrm{Pt}\left\{{ }^{1} \mathrm{H}\right\}$ spectrum of a 50:50 isomeric mixture of 8f-cis and 8f-trans recorded in $\mathrm{CDCl}_{3}$ at $298 \mathrm{~K}$ (coupling constants in $\mathrm{Hz}$, referenced to $\mathrm{K}_{2} \mathrm{PtCl}_{4}$ in $\mathrm{H}_{2} \mathrm{O}$ ).

[(OC) $\left.{ }_{3} \mathrm{Fe}(\mu-d p p m)\left\{\mu-\mathrm{C}=\mathrm{C}(H) \mathrm{C}_{6} \mathrm{H}_{4} \mathrm{~F}-\mathrm{p}\right\} \mathrm{Pt}\left(\mathrm{PPh}_{3}\right)\right]$ (3a). Yield: $403 \mathrm{mg}$, $76 \%$ (method a). Anal. Calcd for $\mathrm{C}_{54} \mathrm{H}_{42} \mathrm{FFeO}_{3} \mathrm{P}_{3} \mathrm{Pt} \cdot \mathrm{CH}_{2} \mathrm{Cl}_{2}(1186.68$ ): C, 55.67; H, 3.74. Found: C, 55.58; H, 3.63. ${ }^{1} \mathrm{H}$ NMR: $\delta 3.95(\mathrm{~m}, 2 \mathrm{H}$, $\left.\mathrm{PCH}_{2} \mathrm{P}\right), 5.97(\mathrm{br}, 1 \mathrm{H},=\mathrm{CH}), 7.07-7.73(\mathrm{~m}, 39 \mathrm{H}, \mathrm{Ph}) .{ }^{19} \mathrm{~F}\left\{{ }^{1} \mathrm{H}\right\}$ NMR: $\delta-114.2(\mathrm{~s}) .2 \mathrm{a}$ intermediate: ${ }^{19} \mathrm{~F}\left\{{ }^{1} \mathrm{H}\right\}$ NMR $\delta-122.8(\mathrm{~s})$.

[(OC) $\left.{ }_{3} \mathrm{Fe}(\mu-d p p m)\left\{\mu-\mathrm{C}=\mathrm{C}(\mathrm{H}) \mathrm{C}_{6} \mathrm{H}_{3} \mathrm{~F}_{2}-2,4\right\} \mathrm{Pt}\left(\mathrm{PPh}_{3}\right)\right]$ (3c). Yield: $170 \mathrm{mg}$, 32\% (method a). Anal. Calcd for $\mathrm{C}_{54} \mathrm{H}_{41} \mathrm{~F}_{2} \mathrm{FeO}_{3} \mathrm{P}_{3} \mathrm{Pt}$. $0.5 \mathrm{C}_{6} \mathrm{H}_{14}$ (1162.83): C, 58.87; H, 4.16. Found: C, 58.75; H, 3.93. ${ }^{1} \mathrm{H}$ NMR: $\delta 3.98\left(\mathrm{~m}, 2 \mathrm{H}, \mathrm{PCH}_{2} \mathrm{P}\right), 6.98-7.96(\mathrm{~m}, 39 \mathrm{H}, \mathrm{Ar}$ and $=\mathrm{CH})$. 2c intermediate: ${ }^{19} \mathrm{~F}\left\{{ }^{1} \mathrm{H}\right\}$ NMR $\delta-115.7$ (s, $p$-F); -110.3 (s, o-F).

$\left[(\mathrm{OC})_{3} \mathrm{Fe}(\mu-d p p m)\left\{\mu-\mathrm{C}=\mathrm{C}(\mathrm{H}) \mathrm{C}_{6} \mathrm{H}_{4} \mathrm{CF}_{3}-\mathrm{p}\right\} \mathrm{Pt}\left(\mathrm{PPh}_{3}\right)\right]$ (3d). Yield: $380 \mathrm{mg}, 73 \%$ (method a). Anal. Calcd for $\mathrm{C}_{55} \mathrm{H}_{42} \mathrm{~F}_{3} \mathrm{FeO}_{3} \mathrm{P}_{3} \mathrm{Pt}$ (1151.76): C, 57.35; H, 3.68. Found: C, 57.49; H, 3.87. ${ }^{1} \mathrm{H}$ NMR: $\delta 4.06\left(\mathrm{~m}, 2 \mathrm{H},{ }^{2} \mathrm{~J}_{\mathrm{PH}}=9,{ }^{3} J_{\mathrm{PtH}}=37.5, \mathrm{PCH}_{2} \mathrm{P}\right), 6.98-7.96(\mathrm{~m}, 40 \mathrm{H}, \mathrm{Ar}$ and $=\mathrm{CH}) .{ }^{19} \mathrm{~F}\left\{{ }^{1} \mathrm{H}\right\}$ NMR: $\delta-61.8(\mathrm{~s})$.

$\left[(\mathrm{OC})_{3} \mathrm{Fe}(\mu-d p p m)\left\{\mu-\mathrm{C}=\mathrm{C}(\mathrm{H}) \mathrm{C}_{6} \mathrm{H}_{4} \mathrm{CF}_{3}-\mathrm{m}\right\} \mathrm{Pt}\left(\mathrm{PPh}_{3}\right)\right]$ (3e). Yield: $85 \mathrm{mg}, 70 \%$ (method a). Anal. Calcd for $\mathrm{C}_{55} \mathrm{H}_{42} \mathrm{~F}_{3} \mathrm{FeO}_{3} \mathrm{P}_{3} \mathrm{Pt}$ (1151.76): C, 57.35; H, 3.68. Found: C, 57.43; H, 3.42. ${ }^{1} \mathrm{H}$ NMR: $\delta$ $4.04\left(\mathrm{dt}, 2 \mathrm{H},{ }^{4} J_{\mathrm{PH}}=1,{ }^{2} J_{\mathrm{PH}}=10,{ }^{3} J_{\mathrm{PtH}}=38, \mathrm{PCH}_{2} \mathrm{P}\right), 7.05-7.73(\mathrm{~m}, 40 \mathrm{H}$, $\mathrm{Ar}$ and $=\mathrm{CH}) .{ }^{19} \mathrm{~F}\left\{{ }^{1} \mathrm{H}\right\}$ NMR: $\delta-62.4(\mathrm{~s})$.

$\left[(\mathrm{OC})_{2} \mathrm{Fe}(\mu-d p p m)\left\{\mu-\mathrm{C}(=\mathrm{O}) \mathrm{C}\left(\mathrm{C}_{6} \mathrm{H}_{4} \mathrm{~F}-\mathrm{p}\right)=\mathrm{C}(\mathrm{H})\right\} \mathrm{Pt}\left(\mathrm{PPh}_{3}\right)\right] \quad(4 a)$. Yield: $237 \mathrm{mg}, 87 \%$. Anal. Calcd for $\mathrm{C}_{54} \mathrm{H}_{42} \mathrm{FFeO}_{3} \mathrm{P}_{3} \mathrm{Pt} \cdot \mathrm{C}_{7} \mathrm{H}_{8}$ (1193.89): C, 61.37; H, 4.22. Found: C, 61.48; H, 4.31. ${ }^{1} \mathrm{H}$ NMR: $\delta$ 4.66 (br, $\left.2 \mathrm{H}, \mathrm{PCH}_{2} \mathrm{P}\right), 6.93-7.62(\mathrm{~m}, 39 \mathrm{H}, \mathrm{Ph}), 8.42\left(\mathrm{dd}, 1 \mathrm{H},{ }^{4} J_{\mathrm{PH}}=5\right.$, $\left.{ }^{4} J_{\mathrm{PH}}=7,=\mathrm{CH}\right) .{ }^{19} \mathrm{~F}\left\{{ }^{1} \mathrm{H}\right\}$ NMR: $\delta-116.4(\mathrm{~s})$.
$\left[(\mathrm{OC})_{2} \mathrm{Fe}(\mu-d p p m)\left\{\mu-\mathrm{C}(=\mathrm{O}) \mathrm{C}\left(\mathrm{C}_{6} \mathrm{H}_{4} \mathrm{~F}-\mathrm{O}\right)=\mathrm{C}(\mathrm{H})\right\} \mathrm{Pt}\left(\mathrm{PPh}_{3}\right)\right] \quad$ (4b). Yield: $395 \mathrm{mg}, 73 \%$ (method a). Yield: $464 \mathrm{mg}, 85 \%$ (method b). Anal. Calcd for $\mathrm{C}_{54} \mathrm{H}_{42} \mathrm{FFeO}_{3} \mathrm{P}_{3} \mathrm{Pt} \cdot \mathrm{C}_{7} \mathrm{H}_{8}$ (1193.89): C, 61.37; H, 4.22. Found: $\mathrm{C}, 61.45 ; \mathrm{H}, 4.40 .{ }^{1} \mathrm{H}$ NMR: $\delta 4.60\left(\mathrm{br}, 2 \mathrm{H}, \mathrm{PCH}_{2} \mathrm{P}\right), 6.92-7.45$ (m, 39H, Ph), 8.45 (br dd, $1 \mathrm{H},{ }^{4} J_{\mathrm{PH}}=6,{ }^{4} J_{\mathrm{PH}}=8,{ }^{3} J_{\mathrm{PtH}}=31,=\mathrm{CH}$ ). ${ }^{19} \mathrm{~F}\left\{{ }^{1} \mathrm{H}\right\}$ NMR $(323 \mathrm{~K}): \delta-110.0(\mathrm{~s}) .4 \mathbf{b}^{\prime}$ intermediate: ${ }^{1} \mathrm{H}$ NMR $\delta 4.61$ $\left(\mathrm{t}, 2 \mathrm{H},{ }^{2} J_{\mathrm{PH}}=10, \mathrm{PCH}_{2} \mathrm{P}\right), 4.82\left(\mathrm{dd}, 1 \mathrm{H},{ }^{4} \mathrm{~J}_{\mathrm{PH}}=3,{ }^{4} \mathrm{~J}_{\mathrm{PH}}=7,{ }^{3} J_{\mathrm{PtH}}=202,=\right.$ $\mathrm{CH}), 6.57-7.79(\mathrm{~m}, 39 \mathrm{H}, \mathrm{Ph}) ;{ }^{19} \mathrm{~F}\left\{{ }^{1} \mathrm{H}\right\}$ NMR $(323 \mathrm{~K}) \delta-111.3(\mathrm{~s})$. $\left[(\mathrm{OC})_{2} \mathrm{Fe}(\mu-d p p m)\left\{\mu-\mathrm{C}(=\mathrm{O}) \mathrm{C}\left(\mathrm{C}_{6} \mathrm{H}_{3} \mathrm{~F}_{2}-2,4\right)=\mathrm{C}(\mathrm{H})\right\} \mathrm{Pt}\left(\mathrm{PPh}_{3}\right)\right]$ (4c). Yield: $115 \mathrm{mg}, 76 \%$ (method b). Anal. Calcd for $\mathrm{C}_{54} \mathrm{H}_{41} \mathrm{~F}_{2} \mathrm{FeO}_{3} \mathrm{P}_{3} \mathrm{Pt}$. $\mathrm{C}_{7} \mathrm{H}_{8}$ (1211.88): C, 60.46; H, 4.08. Found: $\mathrm{C}, 60.53 ; \mathrm{H}, 4.25 .{ }^{1} \mathrm{H}$ NMR: $\delta 4.60\left(\mathrm{br}, 2 \mathrm{H}, \mathrm{PCH}_{2} \mathrm{P}\right), 6.70-7.40(\mathrm{~m}, 38 \mathrm{H}, \mathrm{Ph}), 8.36(\mathrm{br}, 1 \mathrm{H},=\mathrm{CH})$. ${ }^{1} \mathrm{H}$ NMR (233 K): $\delta 4.51$ (br, $\left.1 \mathrm{H}, \mathrm{PCH}_{2} \mathrm{P}\right), 4.85\left(\mathrm{br}, 1 \mathrm{H}, \mathrm{PCH}_{2} \mathrm{P}\right)$, $6.70-7.40(\mathrm{~m}, 38 \mathrm{H}, \mathrm{Ph}), 8.47(\mathrm{br}, 1 \mathrm{H},=\mathrm{CH}) .{ }^{19} \mathrm{~F}\left\{{ }^{1} \mathrm{H}\right\}$ NMR: $\delta-113.1$ (br s, $p$-F), -107.6 (br s, o-F). $4 \mathrm{c}^{\prime}$ intermediate: ${ }^{1} \mathrm{H}$ NMR $\delta 4.59$ (br, $\left.2 \mathrm{H}, \mathrm{PCH}_{2} \mathrm{P}\right), 4.75$ (br, $\left.1 \mathrm{H},=\mathrm{CH}\right), 6.60-7.71(\mathrm{~m}, 38 \mathrm{H}, \mathrm{Ph})$.

$\left[(\mathrm{OC})_{2} \mathrm{Fe}(\mu-\mathrm{dppm})\left\{\mu-\mathrm{C}(=\mathrm{O}) \mathrm{C}\left(\mathrm{C}_{6} \mathrm{H}_{4} \mathrm{CF}_{3}-\mathrm{p}\right)=\mathrm{C}(\mathrm{H})\right\} \mathrm{Pt}\left(\mathrm{PPh}_{3}\right)\right] \quad$ (4d). Yield: $467 \mathrm{mg}, 82 \%$ (method b). Anal. Calcd for $\mathrm{C}_{55} \mathrm{H}_{42} \mathrm{~F}_{3} \mathrm{FeO}_{3} \mathrm{P}_{3} \mathrm{Pt}$ (1151.76): C, 62.48; H, 4.39. Found: C, 62.35; H, 4.07. ${ }^{1} \mathrm{H}$ NMR: 4.65 (br, $\left.2 \mathrm{H}, \mathrm{PCH}_{2} \mathrm{P}\right), 6.97-7.45(\mathrm{~m}, 39 \mathrm{H}, \mathrm{Ph}), 8.43\left(\right.$ br t, $1 \mathrm{H},{ }^{4} J_{\mathrm{PH}}=5.3$, $=\mathrm{CH}) .{ }^{19} \mathrm{~F}\left\{{ }^{1} \mathrm{H}\right\}$ NMR: $\delta-62.3(\mathrm{~s})$.

$\left[(\mathrm{OC})_{2} \mathrm{Fe}(\mu-d p p a)\left\{\mu-\mathrm{C}(=\mathrm{O}) \mathrm{C}\left(\mathrm{C}_{6} \mathrm{H}_{4} \mathrm{~F}-\mathrm{p}\right)=\mathrm{C}(\mathrm{H})\right\} \mathrm{Pt}\left(\mathrm{PPh}_{3}\right)\right]$ (4h). Yield: $121 \mathrm{mg}, 45 \%$ (method b). Anal. Calcd for $\mathrm{C}_{53} \mathrm{H}_{41} \mathrm{FFeNO}_{3} \mathrm{P}_{3} \mathrm{Pt}$ (1102.74): C, 57.73; H, 3.75. Found: C, 57.66; H, 3.58. ${ }^{1}$ H NMR: $\delta 5.48$ 
(brt t, $\left.1 \mathrm{H},{ }^{2} J_{\mathrm{PH}}=4,{ }^{3} J_{\mathrm{PH}}=102, \mathrm{NH}\right), 6.89-7.89(\mathrm{~m}, 39 \mathrm{H}, \mathrm{Ph}), 8.65$ (br t, $1 \mathrm{H},{ }^{3} J_{\mathrm{PH}}=5.3,{ }^{3} \mathrm{JPH}_{\mathrm{PtH}}=20,=\mathrm{CH}$ ).

$\left[(\mathrm{OC})_{3} \mathrm{Fe}(\mu-\mathrm{dppm})\left\{\mu-\mathrm{C}\left(\mathrm{C}_{6} \mathrm{H}_{4} \mathrm{CF}_{3}-\mathrm{O}\right)=\mathrm{C}(\mathrm{H})\right\} \mathrm{Pt}\left(\mathrm{PPh}_{3}\right)\right]$ (5a). Yield: $434 \mathrm{mg}, 77 \%$ (method a). Yield: $427 \mathrm{mg}, 76 \%$ (method b). Anal. Calcd for $\mathrm{C}_{55} \mathrm{H}_{42} \mathrm{~F}_{3} \mathrm{FeO}_{3} \mathrm{P}_{3} \mathrm{Pt} \cdot \mathrm{C}_{7} \mathrm{H}_{16}$ (1251.93): C, 59.48; H, 4.67. Found: C, 59.54; H, 4.50. ${ }^{1} \mathrm{H}$ NMR (228 K): $\delta 3.12\left(\mathrm{br}, 1 \mathrm{H}, \mathrm{PCH}_{2} \mathrm{P}\right)$, $3.34\left(\mathrm{br} \mathrm{d}, 1 \mathrm{H},{ }^{2} \mathrm{JPH}_{\mathrm{PH}}=7.5, \mathrm{PCH}_{2} \mathrm{P}\right), 6.75-8.03(\mathrm{~m}, \mathrm{Ar}$ and $=\mathrm{CH})$. ${ }^{19} \mathrm{~F}\left\{{ }^{1} \mathrm{H}\right\}$ NMR $(243 \mathrm{~K}): \delta-57.5(\mathrm{~s})$.

$\left[(\mathrm{OC})_{2} \mathrm{Fe}(\mu-d p p m)\left\{\mu-\mathrm{C}(=\mathrm{O}) \mathrm{C}\left(\mathrm{C}_{6} \mathrm{H}_{4} \mathrm{CF}_{3}-\mathrm{O}\right)=\mathrm{C}(\mathrm{H})\right\} \mathrm{Pt}\left(\mathrm{PPh}_{3}\right)\right] \quad(4 \mathrm{e})$. ${ }^{1} \mathrm{H}$ NMR (228 K): $\delta 4.48\left(\mathrm{br} \mathrm{d}, 1 \mathrm{H},{ }^{2} J_{\mathrm{PH}}=10.4, \mathrm{PCH}_{2} \mathrm{P}\right), 4.73(\mathrm{br}$, $\left.1 \mathrm{H}, \mathrm{PCH}_{2} \mathrm{P}\right), 6.75-8.03(\mathrm{~m}, \mathrm{Ar}$ and $=\mathrm{CH}){ }^{19} \mathrm{~F}\left\{{ }^{1} \mathrm{H}\right\}$ NMR $(243 \mathrm{~K}): \delta$ $-59.2(\mathrm{~s})$.

$\left[(\mathrm{OC})_{3} \mathrm{Fe}(\mu-d p p a)\left\{\mu-\mathrm{C}\left(\mathrm{C}_{6} \mathrm{H}_{4} \mathrm{CF}_{3}-\mathrm{O}\right)=\mathrm{C}(\mathrm{H})\right\} \mathrm{Pt}\left(\mathrm{PPh}_{3}\right)\right](5 \mathrm{~b})$. Yield: 171 $\mathrm{mg}, 35 \%$ (method a). Yield: $74 \mathrm{mg}, 45 \%$ (method b). Anal. Calc. For $\mathrm{C}_{54} \mathrm{H}_{41} \mathrm{~F}_{3} \mathrm{FeNO}_{3} \mathrm{P}_{3} \mathrm{Pt}$ (1152.75): C, 56.26; H, 3.58. Found: C, 56.38; $\mathrm{H}$, 3.76. ${ }^{1} \mathrm{H}$ NMR $(233 \mathrm{~K}): \delta 4.61\left(\mathrm{br}, 1 \mathrm{H},{ }^{3} \mathrm{~J}_{\mathrm{PtH}}=71, \mathrm{NH}\right), 6.78-8.13(\mathrm{~m}$, Ar and $=\mathrm{CH}) .{ }^{19} \mathrm{~F}\left\{{ }^{1} \mathrm{H}\right\}$ NMR $(243 \mathrm{~K}): \delta-57.5(\mathrm{~s})$.

$\left[(\mathrm{OC})_{2} \mathrm{Fe}(\mu-d p p a)\left\{\mu-\mathrm{C}(=\mathrm{O}) \mathrm{C}\left(\mathrm{C}_{6} \mathrm{H}_{4} \mathrm{CF}_{3}-\mathrm{O}\right)=\mathrm{C}(\mathrm{H})\right\} \mathrm{Pt}\left(\mathrm{PPh}_{3}\right)\right](4 \mathrm{f}) .{ }^{1} \mathrm{H}$ $\operatorname{NMR}(233 \mathrm{~K}): \delta 5.63\left(\mathrm{br}, 1 \mathrm{H},{ }^{3} \mathrm{JPtH}_{\mathrm{PtH}}=100, \mathrm{NH}\right), 6.78-8.13(\mathrm{~m}, \mathrm{Ar}$ and $=\mathrm{CH}) \cdot{ }^{19} \mathrm{~F}\left\{{ }^{1} \mathrm{H}\right\}$ NMR $(243 \mathrm{~K}): \delta-59.2(\mathrm{~s})$.

$\left[(\mathrm{OC})_{3} \mathrm{Fe}(\mu-d p p m)\left\{\mu-\mathrm{C}\left(\mathrm{C}_{6} \mathrm{H}_{4} \mathrm{CF}_{3}-\mathrm{O}\right)=\mathrm{C}(\mathrm{H})\right\} P t\left(P M e P h_{2}\right)\right]$ (5c). This complex was prepared in an NMR tube experiment by addition of excess $o$-(trifluoromethyl)ethynylbenzene to a solution of $1 \mathrm{c}(26 \mathrm{mg}$, $0.025 \mathrm{mmol})$ in $\mathrm{CDCl}_{3}(0.75 \mathrm{~mL})$ and was only characterized spectroscopically. ${ }^{1} \mathrm{H}$ NMR $(233 \mathrm{~K}): \delta 3.12\left(\mathrm{br}, 1 \mathrm{H}, \mathrm{CH}_{2}\right), 3.48\left(\mathrm{br}, 1 \mathrm{H}, \mathrm{CH}_{2}\right)$, 6.48-8.02 (m, Ar and $=\mathrm{CH}) .{ }^{19} \mathrm{~F}\left\{{ }^{1} \mathrm{H}\right\}$ NMR $(233 \mathrm{~K}): \delta-57.4(\mathrm{~s})$.

$\left[(\mathrm{OC})_{2} \mathrm{Fe}(\mu-d p p m)\left\{\mu-\mathrm{C}(=\mathrm{O}) \mathrm{C}\left(\mathrm{C}_{6} \mathrm{H}_{4} \mathrm{CF}_{3}-\mathrm{O}\right)=\mathrm{C}(\mathrm{H})\right\} \mathrm{Pt}\left(\mathrm{PMePh}_{2}\right)\right]$ (4g). ${ }^{1} \mathrm{H}$ NMR $(233 \mathrm{~K}): \delta 4.48\left(\mathrm{br} \mathrm{d}, 1 \mathrm{H},{ }^{2} \mathrm{~J}_{\mathrm{PH}}=10.3, \mathrm{CH}_{2}\right.$ ), $4.73(\mathrm{br}$, $\left.1 \mathrm{H}, \mathrm{CH}_{2}\right), 6.48-8.02(\mathrm{~m}, \mathrm{Ar}$ and $=\mathrm{CH}) .{ }^{19} \mathrm{~F}\left\{{ }^{1} \mathrm{H}\right\}$ NMR $(233 \mathrm{~K}): \delta$ $-59.2(\mathrm{~s})$.

Protonation Reactions. Three equivalents of $\mathrm{HBF}_{4} \cdot \mathrm{Et}_{2} \mathrm{O}$ was added to a solution of the respective complexes $3-5$ in $\mathrm{CH}_{2} \mathrm{Cl}_{2}(5 \mathrm{~mL})$ at $253 \mathrm{~K}$. After it was warmed to ambient temperature, the solution was concentrated and layered with diethyl ether. After a few days, the tetrafluoroborate salts were formed as yellow powders or microcrystals and collected. In some cases, recrystallization of the isomeric mixtures from $\mathrm{CH}_{2} \mathrm{Cl}_{2} / \mathrm{Et}_{2} \mathrm{O}$ solution allowed us to separate the major species in the form of yellow crystals.

$\left[(\mathrm{OC})_{3} \mathrm{Fe}(\mu-d p p m)\left\{\mu-\mathrm{C}\left(\mathrm{C}_{6} \mathrm{H}_{4} \mathrm{CF}_{3}-0\right)=\mathrm{CH}_{2}\right\} P t\left(\mathrm{PPh}_{3}\right)\right]\left[\mathrm{BF}_{4}\right] \quad$ (6a). Yield: $263 \mathrm{mg}, 93 \%$. Anal. Calcd for $\mathrm{C}_{55} \mathrm{H}_{43} \mathrm{BF}_{7} \mathrm{FeO}_{3} \mathrm{P}_{3} \mathrm{Pt}$ (1239.55): C, 53.29; H, 3.50. Found: C: 53.42; H: 3.63. ${ }^{1} \mathrm{H}$ NMR (acetone- $d_{6}$ ): $\delta$ $4.28\left(\mathrm{br} \mathrm{d}, 1 \mathrm{H}, J_{\mathrm{PH}}=12.5, J_{\mathrm{PtH}}=29,=\mathrm{CH}\right), 4.58\left(\mathrm{brd}, 1 \mathrm{H}, J_{\mathrm{PH}}=6.5\right.$, $\left.J_{\mathrm{PtH}}=45,=\mathrm{CH}\right), 5.33\left(\mathrm{br} \mathrm{m}, 2 \mathrm{H}, \mathrm{PCH}_{2} \mathrm{P}\right), 6.72-7.61(\mathrm{~m}, 39 \mathrm{H}, \mathrm{Ar})$. ${ }^{19} \mathrm{~F}\left\{{ }^{1} \mathrm{H}\right\}$ NMR: $\delta-54.3\left(\mathrm{~s}, 3 \mathrm{~F}, \mathrm{CF}_{3}\right),-152.5\left(\mathrm{br}, 4 \mathrm{~F}, \mathrm{BF}_{4}{ }^{-}\right)$.

$\left[(\mathrm{OC})_{3} \mathrm{Fe}(\mu-\mathrm{dppa})\left\{\mu-\mathrm{C}\left(\mathrm{C}_{6} \mathrm{H}_{4} \mathrm{CF}_{3}-\mathrm{O}\right)=\mathrm{CH}_{2}\right\} \mathrm{Pt}\left(\mathrm{PPh}_{3}\right)\right]\left[\mathrm{BF}_{4}\right](\mathbf{6} \boldsymbol{b})$. Yield: $57 \mathrm{mg}, 85 \%$. Anal. Calcd for $\mathrm{C}_{54} \mathrm{H}_{42} \mathrm{BF}_{7} \mathrm{FeNO}_{3} \mathrm{P}_{3} \mathrm{Pt}$ (1240.56): C, 52.28; $\mathrm{H}, 3.41$. Found: $\mathrm{C}, 52.15 ; \mathrm{H}, 3.28$.

$\left[(\mathrm{OC})_{3} \mathrm{Fe}(\mu-d p p m)\left\{\mu-\mathrm{C}\left(\mathrm{C}_{6} \mathrm{H}_{4} \mathrm{~F}-\mathrm{p}\right)=\mathrm{CH}_{2}\right\} \mathrm{Pt}\left(\mathrm{PPh}_{3}\right)\right]\left[\mathrm{BF}_{4}\right]$ (7a). Yield: $32 \mathrm{mg}, 95 \%$. Anal. Calcd for $\mathrm{C}_{54} \mathrm{H}_{43} \mathrm{BF}_{5} \mathrm{FeO}_{3} \mathrm{P}_{3} \mathrm{Pt}$ (1189.56): C, 54.52; $\mathrm{H}, 3.64$. Found: C, 54.44; $\mathrm{H}, 3.73 .{ }^{1} \mathrm{H}$ NMR: $\delta 3.63\left(\mathrm{br} \mathrm{dd}, 1 \mathrm{H},{ }^{4} J_{\mathrm{PH}}=5\right.$, $\left.{ }^{2} J_{\mathrm{HH}}=2,=\mathrm{CH}_{\mathrm{cis}}\right), 4.22\left(\mathrm{dd}, 1 \mathrm{H},{ }^{4} \mathrm{~J}_{\mathrm{PH}}=15,{ }^{2} J_{\mathrm{HH}}=2,{ }^{3} J_{\mathrm{PtH}}=95,=\right.$ $\left.\mathrm{CH}_{\text {trans }}\right), 4.81\left(\mathrm{q}, 2 \mathrm{H},{ }^{2} J_{\mathrm{PH}}=1, \mathrm{PCH}_{2} \mathrm{P}\right), 6.85-7.60(\mathrm{~m}, 39 \mathrm{H}, \mathrm{Ar})$.

$\left[(\mathrm{OC})_{3} \mathrm{Fe}(\mu-d p p m)\left\{\mu-\mathrm{C}\left(\mathrm{C}_{6} \mathrm{H}_{3} \mathrm{~F}_{2}-2,4\right)=\mathrm{CH}_{2}\right\} P t\left(\mathrm{PPh}_{3}\right)\right]\left[\mathrm{BF}_{4}\right]$ (7c). Yield: $45 \mathrm{mg}$, $93 \%$. Anal. Calcd for $\mathrm{C}_{54} \mathrm{H}_{42} \mathrm{BF}_{6} \mathrm{FeO}_{3} \mathrm{P}_{3} \mathrm{Pt}$ (1207.56): C, 53.71; H, 3.51. Found: C, 53.57; H, 3.43. ${ }^{1} \mathrm{H}$ NMR: $\delta 3.72$ (br d, $1 \mathrm{H}$, $\left.{ }^{4} J_{\mathrm{PH}}=3.5,=\mathrm{CH}_{\mathrm{cis}}\right), 4.20\left(\mathrm{br} \mathrm{d}, 1 \mathrm{H},{ }^{4} J_{\mathrm{PH}}=13,{ }^{3} J_{\mathrm{PtH}}=102,=\mathrm{CH}_{\mathrm{trans}}\right)$, $4.70\left(\mathrm{br} \mathrm{m}, 1 \mathrm{H},{ }^{2} J_{\mathrm{HH}}=14, \mathrm{PCH}_{2} \mathrm{P}\right), 5.04\left(\mathrm{br} \mathrm{m}, 1 \mathrm{H},{ }^{2} \mathrm{~J}_{\mathrm{HH}}=14, \mathrm{PCH}_{2} \mathrm{P}\right)$, $6.54-7.58(\mathrm{~m}, 38 \mathrm{H}, \mathrm{Ar})$

$\left[(\mathrm{OC})_{3} \mathrm{Fe}(\mu-d p p m)\left\{\mu-\mathrm{C}\left(\mathrm{C}_{6} \mathrm{H}_{4} \mathrm{CF}_{3}-p\right)=\mathrm{CH}_{2}\right\} P t\left(\mathrm{PPh}_{3}\right)\right]\left[\mathrm{BF}_{4}\right]$ (7d). Yield: $26 \mathrm{mg}, 89 \%$. Anal. Calcd for $\mathrm{C}_{55} \mathrm{H}_{43} \mathrm{BF}_{7} \mathrm{FeO}_{3} \mathrm{P}_{3} \mathrm{Pt}$ (1239.55): $\mathrm{C}$, 53.29; H, 3.50. Found: C, 53.38; H, 3.73. ${ }^{1} \mathrm{H}$ NMR: $\delta 3.72$ (br, $1 \mathrm{H},=$ $\mathrm{CH}_{\text {cis }}$ ), $4.25\left(\mathrm{br} \mathrm{d}, 1 \mathrm{H},{ }^{4} \mathrm{~J}_{\mathrm{PH}}=14,{ }^{3} J_{\mathrm{PH}}=95,=\mathrm{CH}_{\text {trans }}\right), 5.04(\mathrm{br} \mathrm{m}, 1 \mathrm{H}$, $\left.{ }^{2} J_{\mathrm{HH}}=14, \mathrm{PCH}_{2} \mathrm{P}\right), 4.70\left(\mathrm{br} \mathrm{m}, 1 \mathrm{H},{ }^{2} J_{\mathrm{HH}}=14, \mathrm{PCH}_{2} \mathrm{P}\right), 6.88-7.60(\mathrm{~m}$, $39 \mathrm{H}, \mathrm{Ar}$ ).

$\left[(\mathrm{OC})_{3} \mathrm{Fe}(\mu-\mathrm{dppm})\left\{\mu-\mathrm{C}\left(\mathrm{C}_{6} \mathrm{H}_{5}\right)=\mathrm{CH}_{2}\right\} \mathrm{Pt}\left(\mathrm{PPh}_{3}\right)\right]\left[\mathrm{BF}_{4}\right]$ (7i). Yield: 60 mg, 89\%. Anal. Calcd for $\mathrm{C}_{54} \mathrm{H}_{44} \mathrm{BF}_{4} \mathrm{FeO}_{3} \mathrm{P}_{3} \mathrm{Pt}$ (1171.57): C, 55.36; $\mathrm{H}$, 3.79. Found: $\mathrm{C}, 55.22 ; \mathrm{H}, 3.53 .{ }^{1} \mathrm{H}$ NMR: $\delta 3.60\left(\mathrm{br}, 1 \mathrm{H},=\mathrm{CH}_{\mathrm{cis}}\right.$ ), $\delta 4.23\left(\mathrm{br} \mathrm{d}, 1 \mathrm{H},{ }^{4} J_{\mathrm{PH}}=14,{ }^{3} J_{\mathrm{PtH}}=96,=\mathrm{CH}_{\text {trans }}\right.$ ), $4.65(\mathrm{br} \mathrm{m}, 1 \mathrm{H}$, $\left.{ }^{2} J_{\mathrm{HH}}=13, \mathrm{PCH}_{2} \mathrm{P}\right), 4.78\left(\mathrm{br} \mathrm{m}, 1 \mathrm{H},{ }^{2} \mathrm{~J}_{\mathrm{HH}}=13, \mathrm{PCH}_{2} \mathrm{P}\right), 6.93-7.62(\mathrm{~m}$, $40 \mathrm{H}, \mathrm{Ar})$.

trans- $\left[(\mathrm{OC})_{3} \mathrm{Fe}(\mu-d p p m)\left\{\mu-\mathrm{C}(\mathrm{H})=\mathrm{C}(\mathrm{H}) \mathrm{C}_{6} \mathrm{H}_{4} \mathrm{CF}_{3}-\mathrm{p}\right\} \mathrm{Pt}_{(}\left(\mathrm{PPh}_{3}\right)\right]\left[B \mathrm{BF}_{4}\right]$ (8d-trans) and cis-[(OC) ${ }_{3} \mathrm{Fe}(\mu-d p p m)\left\{\mu-C(H)=C(H) \mathrm{C}_{6} \mathrm{H}_{4} C \mathrm{~F}_{3}-p\right\} P$ t$\left.\left(\mathrm{PPh}_{3}\right)\right]\left[\mathrm{BF}_{4}\right]$ (8d-cis). Yield of 8d-trans: $38 \mathrm{mg}, 56 \%$. Anal. Calcd for $\mathrm{C}_{55} \mathrm{H}_{43} \mathrm{BF}_{7} \mathrm{FeO}_{3} \mathrm{P}_{3} \mathrm{Pt}$ (1239.57): C, 53.29; H, 3.50. Found: C, 53.17; H, 3.32. ${ }^{1} \mathrm{H}$ NMR: $\delta 4.53\left(\mathrm{br} q, 1 \mathrm{H},{ }^{2} J_{\mathrm{HH}}=14,{ }^{2} J_{\mathrm{PH}}=11, \mathrm{PCH}_{2} \mathrm{P}\right), 4.73(\mathrm{br}$ $\left.\mathrm{q}, 1 \mathrm{H},{ }^{2} J_{\mathrm{HH}}=14,{ }^{2} J_{\mathrm{PH}}=11, \mathrm{PCH}_{2} \mathrm{P}\right), 5.63\left(\mathrm{brt}, 1 \mathrm{H},{ }^{3} J_{\mathrm{HH}}=13.4, J_{\mathrm{PH}}=10\right.$, $\left.J_{\mathrm{PtH}}=37.6,=\mathrm{CH}_{\beta}\right), 9.28\left(\mathrm{brd}, 1 \mathrm{H},{ }^{3} J_{\mathrm{HHt}}=13.4 \mathrm{~Hz},=\mathrm{CH}_{\alpha}\right), 7.26-7.55$ (m, 39H, Ar). 8d-cis: ${ }^{1} \mathrm{H}$ NMR $\delta 4.05\left(\mathrm{br}, \mathrm{m}, 1 \mathrm{H},{ }^{3} \mathrm{H}_{\mathrm{HH}}=6.9,=\mathrm{CH}_{\beta}\right.$ ), $4.62\left(\mathrm{br}\right.$ not resolved, $\left.2 \mathrm{H}, \mathrm{PCH}_{2} \mathrm{P}\right), 9.12\left(\mathrm{br} \mathrm{d}, 1 \mathrm{H},{ }^{3} J_{\mathrm{HH}}=6.9,=\mathrm{CH}_{\alpha}\right)$, $7.26-7.55(\mathrm{~m}, 39 \mathrm{H}, \mathrm{Ar})$.

trans- $\left[(\mathrm{OC})_{3} \mathrm{Fe}(\mu-d p p m)\left\{\mu-\mathrm{C}(\mathrm{H})=\mathrm{C}(\mathrm{H}) \mathrm{C}_{6} \mathrm{H}_{5}\right\} \mathrm{Pt}\left(\mathrm{PPh}_{3}\right)\right]\left[\mathrm{BF}_{4}\right] \quad(8 \mathrm{f}-$ trans) and cis-[(OC) $\left.\left.)_{3} \mathrm{Fe}(\mu-d p p m)\left\{\mu-C(H)=C(H) \mathrm{C}_{6} \mathrm{H}_{5}\right\} \mathrm{Pt}^{\left(P P h_{3}\right.}\right)\right]\left[\mathrm{BF}_{4}\right]$ (8f-cis). Yield of 8f-cis: $28 \mathrm{mg}, 42 \%$. Anal. Calcd for $\mathrm{C}_{54} \mathrm{H}_{44} \mathrm{BF}_{4} \mathrm{FeO}_{3} \mathrm{P}_{3} \mathrm{Pt}$ (1171.60): C, 55.36; H, 3.79. Found: C, 55.45; H, 3.55. ${ }^{1} \mathrm{H}$ NMR: $\delta 3.96$ (br m, $\left.1 \mathrm{H},{ }^{3} J_{\mathrm{HH}}=8.1,=\mathrm{CH}_{\beta}\right), 4.75\left(\right.$ br m, $\left.2 \mathrm{H}, \mathrm{PCH}_{2} \mathrm{P}\right), 8.99($ br d, $1 \mathrm{H}$, $\left.{ }^{3} J_{\mathrm{HH}}=8.1,=\mathrm{CH}_{\alpha}\right), 6.78-7.75(\mathrm{~m}, 40 \mathrm{H}, \mathrm{Ar}) .8 \mathrm{8f}$-trans: ${ }^{1} \mathrm{H}$ NMR $\delta 4.54$ (br m, $\left.2 \mathrm{H}, \mathrm{PCH}_{2} \mathrm{P}\right), 5.83\left(\mathrm{br} \mathrm{m}, 1 \mathrm{H},{ }^{3} \mathrm{JHH}_{\mathrm{HH}}=13.7,=\mathrm{CH}_{\beta}\right), 9.10(\mathrm{br} \mathrm{d}, 1 \mathrm{H}$, $\left.{ }^{3} J_{\mathrm{HH}}=13.7,=\mathrm{CH}_{a}\right), 6.80-7.74(\mathrm{~m}, 40 \mathrm{H}, \mathrm{Ar})$.

trans- $\left[(\mathrm{OC})_{3} \mathrm{Fe}(\mu-\mathrm{dppm})\left\{\mu-\mathrm{C}(\mathrm{H})=\mathrm{C}(\mathrm{H}) \mathrm{C}_{6} \mathrm{H}_{4} \mathrm{CH}_{3}-\mathrm{p}\right\} \mathrm{Pt}\left(\mathrm{PPh}_{3}\right)\right]\left[\mathrm{BF} \mathrm{F}_{4}\right]$ (8g-trans) and cis-[(OC) ${ }_{3} \mathrm{Fe}(\mu-d p p m)\left\{\mu-\mathrm{C}(H)=\mathrm{C}(\mathrm{H}) \mathrm{C}_{6} \mathrm{H}_{4} \mathrm{CH}_{3}-\mathrm{p}\right\} \mathrm{Pt}$ $\left.\left(\mathrm{PPh}_{3}\right)\right]\left[\mathrm{BF}_{4}\right]$ (8g-cis). Yield of the mixture: $40 \mathrm{mg}, 82 \%$. Anal. Calcd for $\mathrm{C}_{55} \mathrm{H}_{46} \mathrm{BF}_{4} \mathrm{FeO}_{3} \mathrm{P}_{3} \mathrm{Pt}$ (1185.60): C, 55.72; $\mathrm{H}, 3.91$. Found: C, 55.62; $\mathrm{H}, 3.68 .{ }^{1} \mathrm{H}$ NMR of the mixture: $\delta 4.00\left(\mathrm{br},=\mathrm{CH}_{\beta} 8 \mathrm{~g}\right.$-cis $), 5.85(\mathrm{br},=$ $\mathrm{CH}_{\beta}$ 8g-trans), $8.86\left(\mathrm{br},=\mathrm{CH}_{\alpha} 8 \mathrm{~g}\right.$-cis), $9.00\left(\mathrm{br}, 1 \mathrm{H},=\mathrm{CH}_{\alpha} 8 \mathrm{~g}\right.$-trans $)$, $4.70\left(\mathrm{br} \mathrm{m}, \mathrm{PCH}_{2} \mathrm{P}\right), 6.80-7.68$ (m, Ar).

(d). Crystallographic Data. Crystal structure determination of compounds $3 \mathbf{a}$ and $\mathbf{4} \mathbf{a}, \mathbf{b}$ was accomplished on a Stoe IPDS diffractometer with fixed crystal position, and therefore only ca. 93\% completeness could be achieved: data collection, Expose in IPDS (Stoe \& Cie, 1999); cell determination and refinement, Cell in IPDS (Stoe \& Cie, 1999); integration, Integrate in IPDS (Stoe \& Cie, 1999); numerical absorption correction, Faceit in IPDS (Stoe \& Cie, 1999). Crystal structure determination of compounds $3 c, e, 4 c, d, 5 a, 6 a, 7 i$, and $8 d$ was accomplished on an Oxford Diffraction Xcalibur S diffractometer: data collection, CrysAlis CCD (Oxford Diffraction, 2006); cell refinement, CrysAlis RED (Oxford Diffraction, 2006); data reduction, CrysAlis RED; absorption correction, multiscan (CrysAlis RED; Oxford Diffraction, 2006). The crystal structure determinations were effected at $-100^{\circ} \mathrm{C}(\mathrm{Mo} \mathrm{K} \alpha$ radiation, $\alpha=0.71073 \AA)$. The structure was solved by applying direct and Fourier methods, using SHELXS97 (G. M. Sheldrick, SHELXS97, University of Göttingen, 1997) and SHELXL-97 (G. M. Sheldrick, SHELXL97, University of Göttingen, 1997). All nonhydrogen atoms were refined anisotropically. In the following structures, disordered solvent molecules were removed using the SQUEEZE program (L. J. Farrugia, PLATON, University of Glasgow, 2013): 4a-c, $6 \mathrm{a}$, and $8 \mathrm{~d}$. The following hydrogen atoms were found and could be freely refined via difference Fourier s-Synthesis: $\mathrm{H} 48$ (3a), H5 (3c), H48 (3e), $\mathrm{H} 47$ (4a), H47 (4b), H48 (4c), H53 (4d), H46A and H46B (7i). The remaining hydrogen atoms were placed in geometrically calculated positions, and each was assigned a fixed isotropic displacement parameter based on a riding model. Crystallographic data (excluding structure factors) have been deposited with the Cambridge Crystallographic Data Centre as supplementary publications: deposition numbers CCDC 947615 (3a), CCDC 947616 (3c), CCDC 947617 (3e), CCDC 947618 (4a), CCDC 947619 (4b), CCDC 947620 (4c), CCDC 947621 (4d), CCDC 947622 (5a) CCDC 947623 (6a), CCDC 947624 (7i), and CCDC 947625 (8d) contain detailed crystallographic data for this publication. These data may be obtained free of charge from the Cambridge Crystallographic Data Center through www.ccdc.cam.ac.uk/data_request/cif.

\section{ASSOCIATED CONTENT}

\section{S Supporting Information}

Figures, tables, and CIF files giving perspective views of complexes $4 c, d$ and $3 e,{ }^{31} \mathrm{P}\left\{{ }^{1} \mathrm{H}\right\}$ NMR spectra of $3 e$ and $7 d / 6 e$ mixture, variable-temperature ${ }^{31} \mathrm{P}\left\{{ }^{1} \mathrm{H}\right\}$ NMR spectra of $5 \mathbf{b}$, crystallographic experimental details for $\mathbf{3 a , c , e}, \mathbf{4 a}-\mathbf{d}, \mathbf{5 a}, \mathbf{6 a}, 7 \mathbf{i}$, and $\mathbf{8 d}$, and atomic coordinates, interatomic distances and angles, and 
anisotropic thermal parameters for 3a,c,e, $4 a-d, 5 a, 6 a, 7 i$, and $8 d$. This material is available free of charge via the Internet at http:// pubs.acs.org.

\section{AUTHOR INFORMATION}

\section{Corresponding Authors}

*E-mail for I.J.: isabelle.jourdain@univ-fcomte.fr.

*E-mail for M.K.: michael.knorr@univ-fcomte.fr.

Notes

The authors declare no competing financial interest.

\section{REFERENCES}

(1) (a) Clark, H. C.; Jablonski, C. R. Inorg. Chem. 1974, 13, $2213-$ 2218. (b) Ros, R; Michelin, R. A.; Bataillard, R; Roulet, R. J. Organomet. Chem. 1979, 165, 107-116. (c) Goel, R G.; Srivastava, R. C. Can. J. Chem. 1983, 61, 1352-1359. (d) Arnold, D. P.; Bennett, M. A. Inorg. Chem. 1984, 23, 2110-2116. (e) Meyer, W. R.; Venanzi, L. M. Angew. Chem., Int. Ed. Engl. 1984, 23, 529-530. (f) Alcock, N. W.; Brown, J. M.; MacLean, T. D. J. Chem. Soc., Chem. Commun. 1984, 1689-1690. (g) Xie, Y.; James, B. R. J. Organomet. Chem. 1991, 417, 277-288. (h) Wieser, C.; Matt, D.; Fischer, J.; Harriman, A. J. Chem. Soc., Dalton Trans. 1997, 2391-2402. (i) Sugimoto, M.; Yamasaki, I.; Mizoe, N. Masaharu, A.; Sakaki, S. Theor. Chem. Acc. 1999, 102, 377-384. (j) Shiotsuki, M.; White, P. S.; Brookhart, M.; Templeton, J. L. J. Am. Chem. Soc. 2007, 129, 4058-4067. (k) Boutain, M.; Duckett, S. B. Dunne, J. P.; Godard, C.; Hernandez, J. M.; Holmes, A. J.; Khazal, I. G.; Lopez-Serrano, J. Dalton Trans. 2010, 39, 3495-3500. (1) Shen, R.; Chen, T.; Zhao, Y.; Qiu, R.; Zhou, Y.; Yin, S.; Wang, X.; Goto, M.; Han, L.-B. J. Am. Chem. Soc. 2011, 133, 17037-17044.

(2) (a) Furlani, A.; Russo, M. V.; Villa, A. C.; Manfredotti, A. G.; Guastini, C. J. Chem. Soc., Dalton Trans. 1977, 2154-2160. (b) Clark, H. C.; Fiess, P. L.; Wong, C. S. Can. J. Chem. 1977, 55, 177-188. (c) Crespo, M.; Sales, J.; Solans, X.; Altaba, M. F. J. Chem. Soc., Dalton Trans. 1988, 1617-1622. (d) Dema, A. C.; Lukehart, C. M. Inorg. Chim. Acta 1997, 264, 193-198. (e) Ohtaka, A.; Kuniyasu, H.; Kinomoto, M.; Kurosawa, H. J. Am. Chem. Soc. 2002, 124, 14324-14325. (f) West, N. M.; White, P. S.; Templeton, J. L. Organometallics 2008, 27, 5252-5262. (g) Shinde, M. P.; Wang, X.; Kang, E. J.; Jang, H.-Y. Eur. J. Org. Chem. 2009, 6091-6094.

(3) (a) Clark, H. C.; Jablonski, C. R.; Wong, C. S. Inorg. Chem. 1975 14, 1332-1335. (b) Clark, H. C.; Wong, C. S. J. Am. Chem. Soc. 1977, 99 7073-7074. (c) Attig, T. G.; Clark, H. C.; Wong, C. S. Can. J. Chem. 1977, 55, 189-198. (d) Clark, H. C.; Ferguson, G.; Goel, A. B.; Janzen, E. G.; Ruegger, H.; Siew, P. Y.; Wong, C. S. J. Am. Chem. Soc. 1986, 108, 6961-6972.

(4) (a) Green, M.; Spencer, J. L.; Stone, F. G. A.; Tsipis, C. A. J. Chem. Soc., Dalton Trans. 1977, 1525-1529. (b) Puddephatt, R; Thomson, M A. Inorg. Chem. 1982, 21, 725-730. (c) Crementieri, S.; Leoni, P.; Marchetti, F.; Marchetti, L.; Pasquali, M. Organometallics 2002, 21 2575-2577. (d) Banditelli, G.; Bandini, A. L. Organometallics 2006, 25 , 1578-1582. (e) Tsipis, C. A.; Kefalidis, C. E. Organometallics 2006, 25, $1696-1706$.

(5) (a) Braunstein, P.; Knorr, M.; Stern, C. Coord. Chem. Rev. 1998 178-180, 903-965. (b) Wheatley, N.; Kalck, P. Chem. Rev. 1999, 99, 3379-3419. (c) Ritleng, V.; Chetcuti, M. J. Chem. Rev. 2007, 107, 797858. (d) Cooper, B. G.; Napoline, J. W.; Thomas, C. M. Catal. Rev. 2012 54, 1-40. (e) Komiya, S. Coord. Chem. Rev. 2012, 256, 556-573. (f) Mague, J. T. J. Cluster Sci. 1995, 6, 217-269.

(6) (a) Horton, A. D.; Kemball, A. C.; Mays, M. J. J. Chem. Soc., Dalton Trans. 1988, 2953-2958. (b) Caffyn, A. J. M.; Mays, M. J.; Raithby, P. R J. Chem. Soc., Dalton Trans. 1992, 515-519.

(7) (a) Sterenberg, B. T.; Hilts, R. W.; Moro, G.; McDonald, R.; Cowie, M. J. Am. Chem. Soc. 1995, 117, 245-258. (b) Sterenberg, B. T. McDonald, R; Cowie, M. Organometallics 1997, 16, 2297-2312. (c) Graham, T. W.; Van Gastel, F. O.; McDonald, R; Cowie, M. Organometallics 1999, 18, 2177-2188. (d) Wang, L.-S.; Cowie, M. Can. J. Chem. 1995, 73, 1058-1071.
(8) Goldberg, J. E.; Howard, J. A. K.; Muller, H.; Pilotti, M. U.; Stone, F. G. A. J. Chem. Soc., Dalton Trans. 1990, 3055-3061.

(9) (a) Komiya, S.; Yasuda, T.; Fukuoka, A.; Hirano, M. J. Mol. Catal. A: Chem. 2000, 159, 63-70. (b) Yasuda, T.; Fukuoka, A.; Hirano, M.; Komiya, S. Chem. Lett. 1998, 29-30. (c) Casey, C. P.; Wang, Y. Organometallics 1992, 11, 13-15.

(10) (a) Adams, R. D.; Captain, B.; Zhu, L. J. Am. Chem. Soc. 2006, 128, 13672-13673. (b) Adams, R. D.; Captain, B.; Trufan, E.; Zhu, L. J. Am. Chem. Soc. 2007, 129, 7545-7556. (c) Di Tommaso, S.; Tognetti, V.; Sicilia, E.; Adamo, C.; Russo, N. Inorg. Chem. 2010, 49, 9875-9883.

(11) He, Z.; Plasseraud, L.; Moldes, I.; Dahan, F.; Neibecker, D.; Etienne, M.; Mathieu, R. Angew. Chem., Int. Ed. Engl. 1995, 34, 916-917.

(12) Shima, T.; Ichikawa, T.; Suzuki, H. Organometallics 2007, 26, 6329-6337.

(13) (a) Knorr, M.; Jourdain, I.; Villafane, F.; Strohmann, C. J. Organomet. Chem. 2005, 690, 1456-1466. (b) Knorr, M.; Strohmann, C. Eur. J. Inorg. Chem. 2000, 241-252. (c) Jourdain, I.; Vieille-Petit, L.; Clément, S.; Knorr, M.; Villafañe, F.; Strohmann, C. Inorg. Chem. Commun. 2006, 9, 127-131.

(14) (a) Knorr, M.; Jourdain, I.; Crini, G.; Frank, K.; Sachdev, H.; Strohmann, C. Eur. J. Inorg. Chem. 2002, 2419-2426. (b) Knorr, M.; Jourdain, I.; Lentz, D.; Willemsen, S.; Strohmann, C. J. Organomet. Chem. 2003, 684, 216-229.

(15) Knorr, M.; Strohmann, C.; Braunstein, P. Organometallics 1996, $15,5653-5663$.

(16) Nesmeyanov, A. N.; Aleksandrov, G. G.; Antonova, A. B.; Anisimov, K. N.; Kolobova, N. E.; Struchkov, Y. T. J. Organomet. Chem. 1976, 110, C36-C38.

(17) Berry, D. H.; Eisenberg, R. Organometallics 1987, 6, 1796-1805.

(18) Esteruelas, M. A.; Lahoz, F. J.; Onate, E.; Oro, L. A.; Rodriguez, L. Organometallics 1993, 12, 4219-4222.

(19) Xiao, J.; Cowie, M. Organometallics 1993, 12, 463-472.

(20) Afzal, D.; Lenhert, P. G.; Lukehart, C. M. J. Am. Chem. Soc. 1984, $106,3050-3052$.

(21) For other examples of $\mu$-arylethenylidene complexes see: (a) Kuncheria, J.; Mirza, H. A.; Vittal, J. J.; Puddephatt, R. J. Inorg. Chem. Commun. 1999, 2, 197-199 (Ru-Ru). (b) Baralt, E.; Boudreaux, E. A.; Demas, J. N.; Lenhert, P. G.; Lukehart, C. M.; McPhail, A. T.; McPhail, D. R.; Myers, J. B., Jr.; Sacksteder, L.; True, W. R. Organometallics 1989, 8, 2417-2430 (Pt-Pt). (c) Berenguer, J. R; Bernechea, M.; Fornies, J.; Lalinde, E.; Torroba, J. Organometallics 2005, 24, 431-438 (Pt-Pt). (d) Jiménez, M. V.; Sola, E.; Martinez, A. P.; Lahoz, F. J.; Oro, L. A. Organometallics 1999, 18, 1125-1136 (Ir-Ir). (e) Ovchinnikov, M. V.; Klein, D. P.; Guzei, I. A.; Choi, M.-G.; Angelici, R. J. Organometallics 2002, 21, 617-627 (Ru-Ru). (f) For a general review on vinylidene complexes including bimetallics see: Bruce, M. I. Chem. Rev. 1991, 91, 197-257.

(22) (a) Dolgushin, F. M.; Deykhina, N. A.; Pogrebnyakov, D. A.; Antonova, A. B. Acta Crystallogr. 2001, E57, m541-m542. (b) Vasiliev, A. D.; Chudin, O. S.; Antonova, A. B. Acta Crystallogr. 2007, E63, $\mathrm{m} 2272$.

(23) Uehara, K.; Hikichi, S.; Akita, M. Chem. Lett. 2002, 1198-1199.

(24) Fontaine, X. L. R.; Jacobsen, G. B.; Shaw, B. L.; Thornton-Pett, M. J. Chem. Soc., Dalton Trans. 1988, 741-750.

(25) For other examples of heterodinuclear dimetallacylopentenone complexes, see: (a) Burn, M. J.; Kiel, G. Y.; Seils, F.; Takats, J.; Washington, J. J. Am. Chem. Soc. 1989, 111, 6850-6852 (Ru-Os). (b) Takats, J.; Washington, J.; Santarsiero, B. D. Organometallics 1994, 13, 1078-1080 (Rh-Os). (c) Gracey, B. P.; Knox, S. A. R.; Macpherson, K. A.; Orpen, A. G.; Stobart, S. R. Dalton Trans. 1985, 1935-1944 (Fe-Ru). (d) Dennett, J. N. L.; Knox, S. A. R.; Anderson, K. M.; Charmant, J. P. H.; Orpen, A. G. Dalton Trans. 2005, 63-73 (FeRu). (e) Yamazaki, S.; Taira, Z.; Yonemura, T.; Deeming, A. J. Organometallics 2005, 24, 20-27 (Fe-Pt).

(26) Dunitz, J. D.; Taylor, R. Chem. Eur. J. 1997, 3, 89-98.

(27) Thalladi, V. R.; Weiss, H.-C.; Bläser, D.; Boese, R.; Nangia, A.; Desiraju, G. R. J. Am. Chem. Soc. 1998, 120, 8702-8710.

(28) Shimoni, L.; Glusker, J. Struct. Chem. 1994, 5, 383-397.

(29) Plenio, H. Chem. Rev. 1997, 97, 3363-3384. 
(30) Howard, J. A. K.; Knox, S. A. R; Terrill, N. J.; Yates, M. I. J. Chem. Soc., Chem. Commun. 1989, 640-642.

(31) See also: (a) Clark, H. C.; Manzer, L. E. Inorg. Chem. 1974, 13, 1996-2004. (b) Green, M.; Taylor, S. H. J. Chem. Soc., Dalton Trans. $1975,1142-1149$.

(32) (a) Rowland, R. S.; Taylor, R. J. Phys. Chem. 1996, 100, 73847391. (b) $\mathrm{H} \cdots \mathrm{F}$ contacts around or below $2.40 \AA$ in $\mathrm{C}-\mathrm{H} \cdots \mathrm{F}-\mathrm{C}$ hydrogen bonds are among the shortest contacts found in such interactions: Althoff, G.; Ruiz, J.; Rodriguez, V.; Lopez, G.; Perez, J.; Janiak, C. CrystEngComm 2006, 8, 662-665.

(33) Weiss, H.-C.; Boese, R.; L. Smith, H.; M. Haley, M. Chem. Commun. 1997, 2403-2404.

(34) Casey, C. P.; Ha, Y.; Powell, D. R. J. Am. Chem. Soc. 1994, 116, 3424-3428.

(35) (a) Colborn, R. E.; Davies, D. L.; Dyke, A. F.; Endesfelder, A.; Knox, S. A. R.; Orpen, A. G.; Plaas, D. J. Chem. Soc., Dalton Trans. 1983, 2661-2668. (b) Dyke, A. F.; Knox, S. A. R.; Morris, M. J.; Naish, P. J. J. Chem. Soc., Dalton Trans. 1983, 1417-1426.

(36) Klein, D. P.; Ellern, A.; Angelici, R. J. Organometallics 2004, 23, $5662-5670$

(37) (a) For examples of heterodinuclear $\mathrm{Ru}-\mathrm{O}$ s and $\mathrm{Ru}-\mathrm{Co}$ dimetallacyclobutenes see: Gagné, M. R.; Takats, J. Organometallics 1988, 7, 561-563. (b) For Ru-Rh dimetallacyclobutenes see: Rowsell, B. D.; McDonald, R; Ferguson, M. J.; Cowie, M. Organometallics 2003 , $22,2944-2955$

(38) (a) Dyke, A. F.; Knox, S. A. R.; Naish, P. J.; Taylor, G. E. J. Chem Soc., Dalton Trans. 1982, 1297-1307. (b) See also: King, P. J.; Knox, S. A. R.; McCormick, G. J.; Orpen, A. G. Dalton Trans. 2000, 2975-2982. (c) Mirza, H. A.; Vittal, J. J.; Puddephatt, R. J. Organometallics 1994, 13, 3063-3067.

(39) For a discussion on the interconversion of dirhenacylopentenones via transient dirhenacyclobutenes see: (a) Casey, C. P.; Carino, R. S.; Sakaba, H. Organometallics 1997, 16, 419-426. (b) Casey, C. P.; Carino, R. S.; Hayashi, R. K; Schladetzky, K. D. J. Am. Chem. Soc. 1996, 118, 1617-1623.

(40) The steric and electronic impact of the substitution pattern of $\mathrm{ArC} \equiv \mathrm{CH}$ on the competitive formation of rhenium carbyne and $\eta^{2}$ vinyl complexes from the reactions of $\mathrm{ReH}_{5}\left(\mathrm{PMe}_{2} \mathrm{Ph}\right)_{3}$ with terminal alkynes such as $p-\mathrm{CF}_{3} \mathrm{C}_{6} \mathrm{H}_{4} \mathrm{C} \equiv \mathrm{CH}$ and $o-\mathrm{CF}_{3} \mathrm{C}_{6} \mathrm{H}_{4} \mathrm{C} \equiv \mathrm{CH}$ has been investigated: He, G.; Fan, T.; Chen, J.; Sung, H. H.-Y.; Williams, I. D. Lin, Z.; Jia, G. New J. Chem. 2013, 37, 1823-1832.

(41) (a) For $\left[(\mathrm{OC})_{3} \mathrm{Fe}\left(\mu-\mathrm{PPh}_{2}\right)\left\{\mu-\mathrm{C}\left(\mathrm{C}_{6} \mathrm{H}_{5}\right)=\mathrm{CH}_{2}\right\} \mathrm{Fe}(\mathrm{CO})_{3}\right]$ see MacLaughlin, S. A.; Doherty, S.; Taylor, N. J.; Carty, A. J. Organometallics 1992, 11, 4315-4325. (b) For $\left[(\mathrm{OC})_{3} \mathrm{Fe}(\mu\right.$-dppm $)$ $\left\{\mu\right.$-C $\left.\left.\left(\mathrm{C}_{6} \mathrm{H}_{5}\right)=\mathrm{CH}_{2}\right\} \mathrm{Fe}(\mathrm{CO})_{3}\right]\left[\mathrm{BF}_{4}\right]$ see: Boothman, J.; Hogarth, G. J. Organomet. Chem. 1992, 437, 201-210.

(42) Lewis, L. N.; Huffman, J. C.; Caulton, K. G. J. Am. Chem. Soc $1980,102,403-404$

(43) Kolobova, N. E.; Ivanov, L. L.; Zhvanko, O. S.; Khitrova, O. M.; Batsanov, A. S.; Struchkov, Y. T. J. Organomet. Chem. 1984, 262, 39-47.

(44) Jacobsen, E. N.; Bergman, R. G. Organometallics 1984, 3, 329331.

(45) Davies, D. L.; Dyke, A. F.; Endesfelder, A.; Knox, S. A. R.; Naish, P. J.; Orpen, A. G.; Plaas, D.; Taylor, G. E. J. Organomet. Chem. 1980, 198, C43-C49.

(46) Dawkins, G. M.; Green, M.; Jeffery, J. C.; Sambale, C.; Stone, F. G. A. J. Chem. Soc., Dalton Trans. 1983, 499-506.

(47) Takemoto, S.; Kobayashi, T.; Ito, T.; Inui, A.; Karitani, K.; Katagiri, S.; Masuhara, Y.; Matsuzaka, H. Organometallics 2011, 30, 2160-2172.

(48) Werner, H.; Garcia Alonso, F. J.; Otto, H.; Peters, K.; Von Schnering, H. G. Chem. Ber. 1988, 121, 1565-1573.

(49) Al-Obaidi, Y. N.; Green, M.; White, N. D.; Taylor, G. E. J. Chem. Soc., Dalton Trans. 1982, 319-326.

(50) Wang, L.-S.; Cowie, M. Organometallics 1995, 14, 2374-2386.

(51) For a $\mathrm{CO}$ insertion into a Pt-alkenyl bond see: Bennet, $\mathrm{M}$. A.; Rokicki, A. J. Organomet. Chem. 1983, 244, C31-C34.

(52) (a) For a reversible $\mathrm{CO}$ insertion/deinsertion into the $\mathrm{Pt}-\mathrm{Me}$ bond of a Pt-Mo complex see: Tsutsuminai, S.; Komine, N.; Hirano,
M.; Komiya, S. Organometallics 2003, 22, 4238-4247. (b) For a reversible carbon-carbon double bond cleavage of a ketene ligand at a single $\operatorname{Ir}(\mathrm{I})$ center see: Urtel, H.; Bikzhanova, G. A.; Grotjahn, D. B.; Hofmann, P. Organometallics 2001, 20, 3938-3949. 

Anexo VIII 



\section{Dalton Transactions}

Cite this: Dalton Trans., 2014, 43 4009

\section{Homo- and heteropolymetallic 3-(2-pyridyl)- pyrazolate manganese and rhenium complexes $\uparrow$}

\author{
Marta Arroyo, ${ }^{a}$ Patricia Gómez-Iglesias, ${ }^{a}$ Noelia Antón, ${ }^{a}$ Raúl Garcia-Rodríguez, ${ }^{\text {a }}$ \\ Elisabete C. B. A. Alegria, ${ }^{\text {b,c }}$ Armando J. L. Pombeiro, ${ }^{b}$ Daniel Miguel $^{a}$ and \\ Fernando Villafañe ${ }^{\star a}$
}

\begin{abstract}
fac- $\left[\mathrm{MBr}(\mathrm{CO})_{3}(\mathrm{pypzH})\right](\mathrm{M}=\mathrm{Mn}, \mathrm{Re} ; \mathrm{pypz} \mathrm{H}=(3$-(2-pyridyl)pyrazole) complexes are prepared from fac$\left[\mathrm{MBr}(\mathrm{CO})_{3}(\mathrm{NCMe})_{2}\right]$ and pypz $\mathrm{H}$. The result of their deprotonation depends on the metallic substrate: the rhenium complex affords cleanly the bimetallic compound $\left[f a c-\left\{\operatorname{Re}(C O)_{3}\left(\mu^{2}-p y p z\right)\right\}\right]_{2}\left(\mu^{2}-p y p z=\mu^{2}-3-(2-\right.$ pyridyl- $\kappa^{1} N$ ) pyrazolate $-2 \kappa^{1} N$ ), which was crystallographically characterized, whereas a similar manganese complex was not detected. When two equivalents of pyridylpyrazolate are used, polymetallic species [fac-M(CO) $)_{3}\left(\mu^{2}-\right.$ pypz) $\left(\mu^{3}-\right.$ pypz) $\left.M^{\prime}\right]\left(\mu^{3}-\right.$ pypz $=\mu^{3}-3-\left(2-\right.$ pyridyl $\left.-\kappa^{1} N\right)$ pyrazolate- $1 \kappa^{2} N, N: 2 \kappa^{1} N: ; \quad M=M n, M^{\prime}=$ $\mathrm{Li}, \mathrm{Na}, \mathrm{K} ; \mathrm{M}=\mathrm{Re}, \mathrm{M}^{\prime}=\mathrm{Na}$ ) are obtained. The crystal structures of the manganese carbonylate complexes were determined. The lithium complex is a monomer containing one manganese and one lithium atom, whereas the sodium and potassium complexes are dimers and reveal an unprecedented coordination mode for the bridging 3-(2-pyridyl)pyrazolate ligand, where the nitrogen of the pyridyl fragment and the nitrogen-1 of pyrazolate are chelated to manganese atoms, and each nitrogen- 2 of pyrazolate is coordinated to two alkaline atoms. The polymetallic carbonylate complexes are unstable in solution and evolve spontaneously to $\left[\mathrm{fac}-\left\{\operatorname{Re}(\mathrm{CO})_{3}\left(\mu^{2}-\text { pypz }\right)\right\}\right]_{2}$ or to the trimetallic paramagnetic species $\left[M n^{\prime \prime}\left(\mu^{2}-p y p z\right)_{2}\left\{f a c-\left\{M n^{\prime}(C O)_{3}\left(\mu^{2}-p y p z\right)\right\}_{2}\right\}\right]$. The related complex cis- $\left[\mathrm{MnCl}_{2}(\mathrm{pypz} H)_{2}\right]$ was also synthesized and structurally characterized. The electrochemical behavior of the new homo- and heteropolymetallic 3-(2-pyridyl)pyrazolate complexes has been studied and details of their redox properties are reported.
\end{abstract}

Received 6th December 2013. Accepted 24th December 2013 DOI: $10.1039 / \mathrm{c} 3 \mathrm{dt} 53439$ a

www.rsc.org/dalton

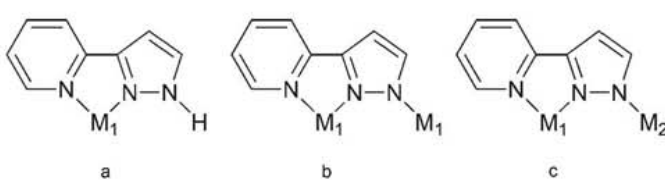

Fig. 1 3-(2-Pyridyl)pyrazole and 3-(2-pyridyl)pyrazolate coordination modes.

promising features, such as the self-assembly of supramolecules with helical structures or the design of "light-controlled ion switches". 6

As part of our studies on the chemistry of group 7 pyrazolylamidino complexes, ${ }^{7}$ we decided to explore the coordination of the 3-(2-pyridyl)pyrazole ligand to these metals. A similar study on group 6 metals has given rise to new bimetallic allyldicarbonylmolybdenum(II) complexes with a marked connection between both metallic centres through the bridging pyridylpyrazolates. ${ }^{8}$ Herein we study their synthesis and reactivity towards bases, which has allowed us to obtain new polymetallic homo- and heteronuclear 3-(2-pyridyl)pyrazolate complexes. Polynuclear manganese complexes in various oxidation states are gaining interest due to their novel magnetic 
properties, related to the single-molecule-magnetic behavior and associated quantum properties. ${ }^{9}$

\section{Results and discussion}

Synthesis and characterization of the $\operatorname{Mn}(\mathrm{I})$ and $\operatorname{Re}(\mathrm{I})$ complexes

The complexes $f a c-\left[\mathrm{MBr}(\mathrm{CO})_{3}(\mathrm{pypzH})\right], \mathrm{M}=\mathrm{Mn}(\mathbf{1 a}), \operatorname{Re}(\mathbf{1 b})$, were prepared in high yield from the reactions of $f a c-[\mathrm{MBr}-$ $(\mathrm{CO})_{3}(\mathrm{NCMe})_{2}$ ] with pypzH in a $1: 1$ ratio, and were analytically and spectroscopically characterized (see the Experimental section).

As indicated above, the deprotonation of a pypzH ligand may lead to obtainment of polymetallic complexes; therefore $1 \mathbf{a}$ and $\mathbf{1 b}$ were treated with a MeOH solution of NaOMe.

When using the manganese complex 1a, the expected bimetallic complex, coming from the deprotonation of pypzH and elimination of the bromido ligand, giving a bridging $3-(2-$ pyridyl)pyrazolate, could not be detected in solution. This is the expected result of this process, and in fact it is produced when the rhenium complex $\mathbf{1} \mathbf{b}$ is used as the starting material (vide infra). However, for manganese the reaction mixture evolves to the tetrametallic complex $\left[\left\{f a c-\mathrm{Mn}(\mathrm{CO})_{3}\left(\mu^{2}\right.\right.\right.$-pypz)( $\mu^{3}$-pypz) Na $\left.\}_{2}\right], \mathrm{Na}-3 \mathrm{a}$ (Scheme 1 ), which could be crystallographically characterized (Fig. 2 and Table 1). Although the $\mathrm{Mn} / \mathrm{pypzH}$ ratio used is $1 / 1$, in $\mathrm{Na}-3 \mathrm{a}$ the $\mathrm{Mn} / \mathrm{pypzH}$ ratio is $1 / 2$; therefore it is a decomposition product. Thus, Na-3a was synthesized selectively by treating fac $\left[\mathrm{MnBr}(\mathrm{CO})_{3}(\mathrm{NCMe})_{2}\right]$ with two equivalents of sodium pyridylpyrazolate, which afforded Na-3a in a $73 \%$ yield (Scheme 1 ).

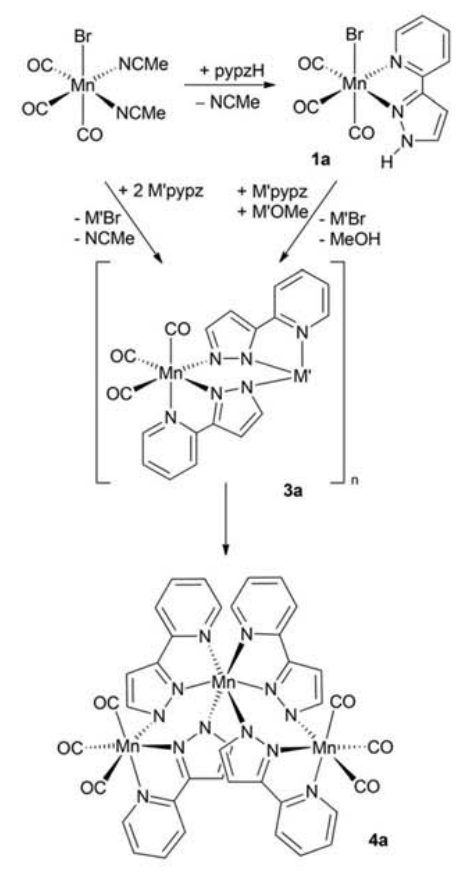

Scheme 1

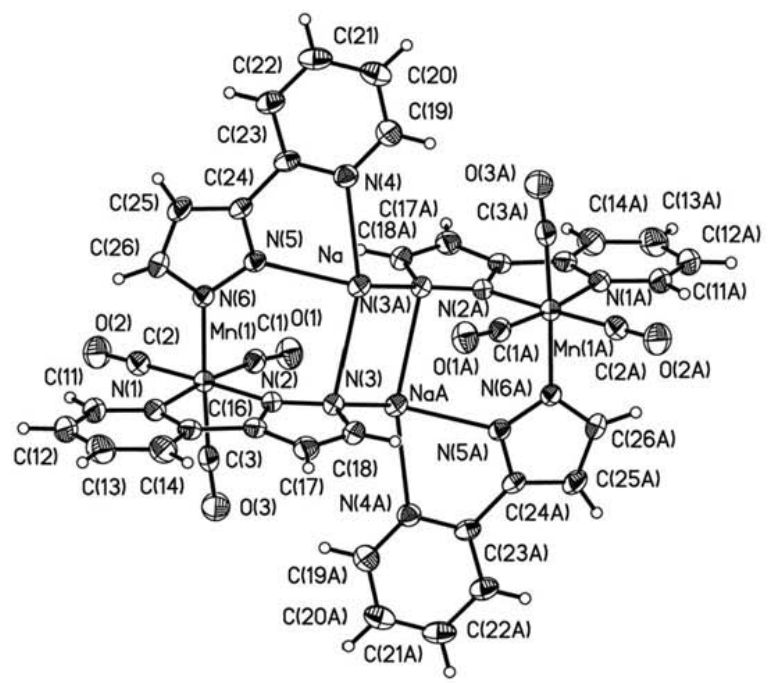

Fig. 2 Perspective view of $\left[\left\{f a c-M n(C O)_{3}\left(\mu^{2}-p y p z\right)\left(\mu^{3}-p y p z\right) N a\right\}_{2}\right], N a-$ $3 a$, showing the atom numbering. Ellipsoids are drawn at $30 \%$ probability.

The crystal structure of Na-3a was shown to be a dimer of the monomer " $f a c-\mathrm{Mn}^{\mathrm{I}}(\mathrm{CO})_{3}\left(\mu^{2}-\mathrm{pypz}\right)\left(\mu^{3}-\mathrm{pypz}\right) \mathrm{Na}$ ". There are two different types of bridging pyridylpyrazolate: one is chelating sodium and the second is chelating manganese. The first one adopts the expected heterobimetallic bridging coordination mode, that is, that shown in Fig. 1c. Surprisingly, in the bridging pyridylpyrazolate chelating manganese, the nitrogen previously protonated is not coordinated to one metal center, as usual, but to two metallic atoms, two sodiums in this case (IV in Fig. 3). We have not been able to find any precedent of this type of coordination where a pyridylpyrazolate is bridging to three metals, which contrasts with that usually found, bridging to two metals (III in Fig. 3). Similar bridging of pyrazolate to three metals (II in Fig. 3 ) has already been described. ${ }^{10}$ It should be noted that this type of bridging is indicative of some type of electronic deficiency. Sodiums are bonded to a chelating pyridylpyrazolate ligand, and to two pyrazolyl moieties, whereas a non-bonding interaction with the nearby oxygen atom of one carbonyl completes the 5-coordinated environment. The coordination of sodium to a pyridylpyrazolate is also unprecedented. There is a report on bridging pyrazolates in a manganese-sodium polymetallic complex, where the $\mathrm{Na}-\mathrm{N}$ distances are similar to those found in Na-3a. ${ }^{11}$ The aromatic rings in the pyridylpyrazolate are not coplanar, the dihedral angles being $6^{\circ}$ for those chelating manganese and $13^{\circ}$ for those chelating sodium.

The formation of Na-3a leads us to consider whether this unexpected tetranuclear structure is the result of a sodium template effect, and therefore to determine whether similar results might be obtained by using (a) other alkali metal ions and (b) rhenium instead of manganese.

The second point is discussed below. In order to answer the first of these points, similar reactions were carried out treating 
Table 1 Selected distances $(\hat{A})$ and angles $\left({ }^{\circ}\right)$ for $\left[\right.$ fac- $\mathrm{Mn}(\mathrm{CO})_{3}(\mathrm{pypz})$ $\left(\mu^{2}-\right.$ pypz $)$ Li $\left.\left(\mathrm{OH}_{2}\right)(\mathrm{THF})\right], \quad \mathrm{Li}-3 \mathrm{a}, \quad\left[\left\{f a c-\mathrm{Mn}(\mathrm{CO})_{3}\left(\mu^{2}-\right.\right.\right.$ pypz $)\left(\mu^{3}-\right.$ pypz $\left.) \mathrm{Na}_{2}\right]$, $\mathrm{Na}-3 \mathrm{a}$, and $\left[\left\{f a c-\mathrm{Mn}(\mathrm{CO})_{3}\left(\mu^{2}-\mathrm{pypz}\right)\left(\mu^{3}-\mathrm{pypz}\right) \mathrm{K}(\mathrm{THF})\right\}_{2}\right], \mathrm{K}-3 \mathrm{a}$

\begin{tabular}{|c|c|c|c|}
\hline & $\mathrm{Li}-3 \mathrm{a}$ & $\mathrm{Na}-3 \mathrm{a}$ & $\mathrm{K}-3 \mathrm{a}$ \\
\hline $\operatorname{Mn}(1)-C(1)$ & $1.795(4)$ & $1.774(3)$ & $1.807(12)$ \\
\hline $\mathrm{Mn}(1)-\mathrm{C}(2)$ & $1.805(4)$ & $1.811(3)$ & $1.782(10)$ \\
\hline $\mathrm{Mn}(1)-\mathrm{C}(3)$ & $1.788(4)$ & $1.793(3)$ & $1.766(13)$ \\
\hline $\operatorname{Mn}(1)-\mathrm{N}(1)$ & $2.082(3)$ & $2.075(2)$ & $2.059(8)$ \\
\hline $\operatorname{Mn}(1)-N(2)$ & $2.002(3)$ & $2.010(2)$ & $2.009(7)$ \\
\hline $\mathrm{Mn}(1)-\mathrm{N}(6)$ & $2.051(3)$ & $2.038(2)$ & $2.037(8)$ \\
\hline $\mathrm{C}(1)-\mathrm{O}(1)$ & $1.141(4)$ & $1.157(3)$ & $1.141(11)$ \\
\hline $\mathrm{C}(2)-\mathrm{O}(2)$ & $1.133(4)$ & $1.141(3)$ & $1.163(10)$ \\
\hline $\mathrm{C}(3)-\mathrm{O}(3)$ & $1.140(4)$ & $1.140(3)$ & $1.138(11)$ \\
\hline $\mathrm{N}(3)-\mathrm{M}^{\prime}$ & & $2.657(2)$ & $2.857(8)$ \\
\hline $\mathrm{N}(3 \mathrm{~A})-\mathrm{M}^{\prime}$ & & $2.439(2)$ & $2.823(9)$ \\
\hline $\mathrm{N}(4)-\mathrm{M}^{\prime}$ & $2.090(7)$ & $2.461(2)$ & $2.789(10)$ \\
\hline $\mathrm{N}(5)-\mathrm{M}^{\prime}$ & $2.030(7)$ & $2.329(2)$ & $2.709(8)$ \\
\hline $\mathrm{M}^{\prime}-\mathrm{O}(1 \mathrm{~A})$ & & $2.890(3)$ & $3.249(9)$ \\
\hline $\mathrm{Li}-\mathrm{O}(50)$ & $1.864(8)$ & & \\
\hline $\mathrm{M}^{\prime}-\mathrm{O}(40)$ & $1.982(8)$ & & $2.789(9)$ \\
\hline$C(1)-M n(1)-C(2)$ & $91.78(16)$ & $91.22(12)$ & $90.0(4)$ \\
\hline $\mathrm{C}(1)-\mathrm{Mn}(1)-\mathrm{C}(3)$ & $88.90(17)$ & $86.66(13)$ & $89.9(5)$ \\
\hline $\mathrm{C}(2)-\mathrm{Mn}(1)-\mathrm{C}(3)$ & $88.26(19)$ & $92.96(13)$ & $90.2(5)$ \\
\hline $\mathrm{C}(1)-\mathrm{Mn}(1)-\mathrm{N}(1)$ & $171.81(15)$ & $172.32(10)$ & $170.3(3)$ \\
\hline $\mathrm{C}(2)-\mathrm{Mn}(1)-\mathrm{N}(1)$ & $95.01(15)$ & $96.21(11)$ & $98.1(4)$ \\
\hline $\mathrm{C}(3)-\mathrm{Mn}(1)-\mathrm{N}(1)$ & $95.88(14)$ & $91.03(13)$ & $95.4(4)$ \\
\hline $\mathrm{C}(1)-\mathrm{Mn}(1)-\mathrm{N}(2)$ & $95.08(14)$ & $94.06(10)$ & $94.5(4)$ \\
\hline $\mathrm{C}(2)-\mathrm{Mn}(1)-\mathrm{N}(2)$ & $173.11(14)$ & $174.65(11)$ & $175.5(4)$ \\
\hline $\mathrm{C}(3)-\mathrm{Mn}(1)-\mathrm{N}(2)$ & $91.26(16)$ & $88.16(11)$ & $89.0(4)$ \\
\hline $\mathrm{C}(1)-\mathrm{Mn}(1)-\mathrm{N}(6)$ & $89.64(13)$ & $94.55(10)$ & $94.5(4)$ \\
\hline $\mathrm{C}(2)-\mathrm{Mn}(1)-\mathrm{N}(6)$ & $91.35(14)$ & $91.61(10)$ & $90.5(4)$ \\
\hline $\mathrm{C}(3)-\mathrm{Mn}(1)-\mathrm{N}(6)$ & $178.48(14)$ & $175.25(12)$ & $178.9(4)$ \\
\hline $\mathrm{N}(1)-\mathrm{Mn}(1)-\mathrm{N}(2)$ & $78.20(12)$ & $78.53(8)$ & $77.5(3)$ \\
\hline $\mathrm{N}(1)-\mathrm{Mn}(1)-\mathrm{N}(6)$ & $85.62(10)$ & $87.18(8)$ & $85.3(3)$ \\
\hline $\mathrm{N}(6)-\mathrm{Mn}(1)-\mathrm{N}(2)$ & $89.30(11)$ & $87.17(8)$ & $90.4(3)$ \\
\hline $\mathrm{N}(4)-\mathrm{M}^{\prime}-\mathrm{N}(3)$ & & $156.54(8)$ & $146.1(3)$ \\
\hline $\mathrm{N}(5)-\mathrm{M}^{\prime}-\mathrm{N}(4)$ & $82.4(3)$ & $71.17(7)$ & $63.0(3)$ \\
\hline $\mathrm{N}(5)-\mathrm{M}^{\prime}-\mathrm{N}(3 \mathrm{~A})$ & & $119.20(8)$ & $106.6(2)$ \\
\hline $\mathrm{N}(3 \mathrm{~A})-\mathrm{M}^{\prime}-\mathrm{N}(4)$ & & $103.43(8)$ & $96.6(3)$ \\
\hline $\mathrm{N}(5)-\mathrm{M}^{\prime}-\mathrm{N}(3)$ & & $91.52(7)$ & $83.8(2)$ \\
\hline$N(3)-M^{\prime}-N(3 A)$ & & $98.80(7)$ & $85.7(2)$ \\
\hline $\mathrm{M}^{\prime}-\mathrm{N}(3)-\mathrm{M}^{\prime}(\mathrm{A})$ & & $81.20(7)$ & $94.3(2)$ \\
\hline $\mathrm{N}(4)-\mathrm{Li}-\mathrm{O}(40)$ & $98.6(3)$ & & \\
\hline $\mathrm{N}(4)-\mathrm{Li}-\mathrm{O}(50)$ & $120.9(4)$ & & \\
\hline $\mathrm{N}(5)-\mathrm{Li}-\mathrm{O}(40)$ & $118.1(4)$ & & \\
\hline $\mathrm{N}(5)-\mathrm{Li}-\mathrm{O}(50)$ & $118.1(4)$ & & \\
\hline
\end{tabular}

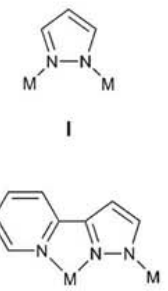

III
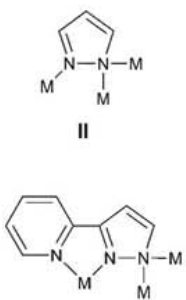

IV
Fig. 3 Pyrazolate and 3-(2-pyridyl)pyrazolate coordination modes.

1a with LiOMe or KOMe, which afforded Li-3a and $\mathrm{K}-3 \mathrm{a}$ in $70 \%$ and $76 \%$ yields respectively (Scheme 1 ). Both could be crystallographically characterized (Fig. 4 and Table 1). ${ }^{12}$ The structure of K-3a is discussed first, given its analogy with that of Na-3a.
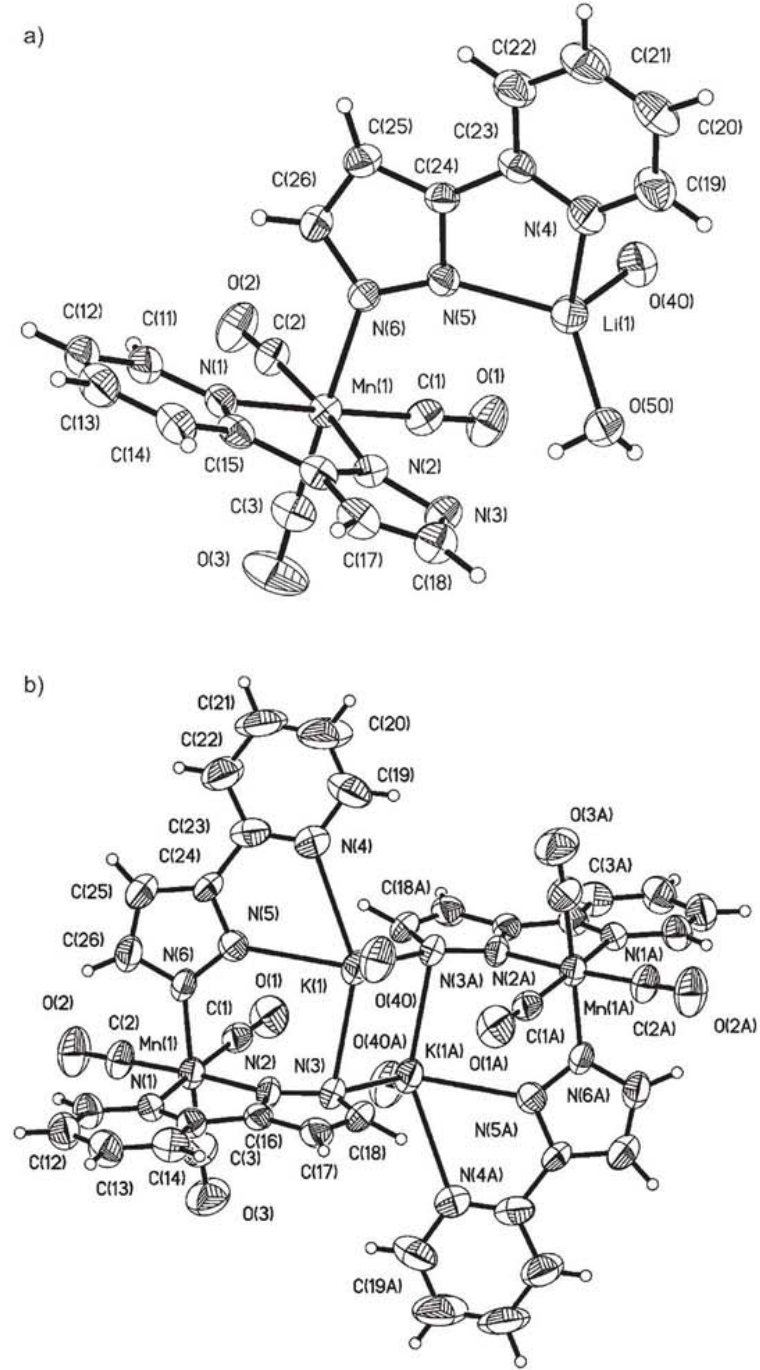

Fig. 4 Perspective views of $\left[\right.$ fac-Mn(CO) ${ }_{3}($ pypz $)\left(\mu^{2}\right.$-pypz) Li $\left.\left(\mathrm{OH}_{2}\right)(\mathrm{THF})\right]$, $\mathrm{Li}-3 \mathrm{a}$, and $\left[\left\{\mathrm{fac}-\mathrm{Mn}(\mathrm{CO})_{3}\left(\mu^{2}-\text { pypz }\right)\left(\mu^{3}-\text { pypz }\right) \mathrm{K}(\mathrm{THF})\right\}_{2}\right], \mathrm{K}-3 \mathrm{a}$, showing the atom numbering. Ellipsoids are drawn at $30 \%$ probability. Only the oxygen donor atoms of the coordinated THF molecules are shown (O40); their hydrocarbon chains have been omitted for clarity.

The crystal structure of $\mathrm{K}-3 \mathrm{a}$ (Fig. 4, bottom) is also a dimer of the monomer " $f a c-\mathrm{Mn}^{\mathrm{I}}(\mathrm{CO})_{3}\left(\mu^{2}-\mathrm{pypz}\right)\left(\mu^{3}-\mathrm{pypz}\right) \mathrm{K}$ ", and again two different types of bridging pyridylpyrazolate (chelating sodium and chelating manganese) are found. As for $\mathrm{Na}-3 \mathrm{a}$, the nitrogen previously protonated of the second is coordinated to two potassiums (IV in Fig. 3). Opposite to Na-3a where the fifth coordination position of sodium was occupied by an oxygen atom of one of the carbonyls, in K-3a an oxygen atom of a THF molecule is coordinated to potassium, whereas the oxygen of the nearest carbonyl is at 3.249(9) $\AA$, too far to consider any interaction. As expected, the distances and angles of the manganese fragment are quite similar in both structures, whereas those where the alkali atom is involved are larger for $\mathrm{K}-3 \mathrm{a}$ (Table 1). The dihedral angles of the aromatic rings in the 
pyridylpyrazolate $\left(5^{\circ}\right.$ for those chelating manganese and $12^{\circ}$ for those chelating sodium) are also very similar to those found for Na-3a.

The crystal structure of Li-3a (Fig. 4, up) is a monomer, where the pyridylpyrazolate chelating manganese is only coordinated to manganese and therefore is not a bridging ligand. This is very surprising for a chelating pyridylpyrazolate, as we have found only one precedent in the literature of this type of coordination. ${ }^{13}$ The pyridylpyrazolate chelating to lithium is a "typical" bridging pyridylpyrazolate (III in Fig. 3). The lithium coordination is a distorted tetrahedron where the other two coordination positions are occupied by the oxygen atoms of a molecule of THF and of a molecule of water. ${ }^{14}$ Again the distances and angles of the manganese fragment are quite similar to those found in the other structures above, whereas those where the alkali atom is involved are shorter for Li-3a (Table 1). Again the aromatic rings in the pyridylpyrazolate are not coplanar; in this case both dihedral angles are similar $\left(5^{\circ}\right.$ for that chelating manganese and $6^{\circ}$ for that chelating lithium). The higher coplanarity of the rings in the bridging pyridylpyrazolate chelating lithium might be related to the lower steric requirements of the molecule.

The size of the alkali metal atoms allows an immediate interpretation of the crystal structures of the $\mathrm{Li}$, $\mathrm{Na}$ and $\mathrm{K}$ salts of 3a. Thus, the smaller lithium is tetracoordinated by both nitrogen atoms of a chelating pyridylpyrazolate and by two oxygen atoms of THF and water. However, sodium and potassium require a fifth donor atom to achieve pentacoordination. For sodium, a short contact with an oxygen atom of one of the carbonyls of the molecule seems to be enough to stabilize the structure, whereas the larger potassium requires the coordination of a more steric demanding molecule of THF. We have found very scarce reports on comparative structural studies of alkali metal compounds. ${ }^{15}$

For rhenium, the result of the deprotonation of the pypzH complex $\mathbf{1 b}$ when treated with a $\mathrm{MeOH}$ solution of NaOMe is straightforward. In this case the product was the binuclear complex $\left[\mathrm{fac}-\left\{\operatorname{Re}(\mathrm{CO})_{3}\left(\mu^{2}-\mathrm{pypz}\right)\right\}\right]_{2}, 2 \mathbf{b}$ (Scheme 2$)$, as a result of

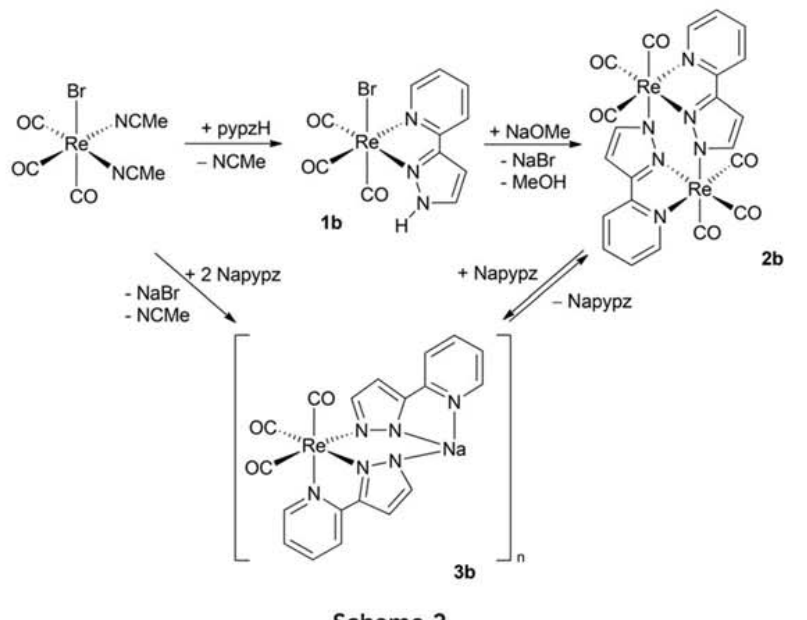

Scheme 2

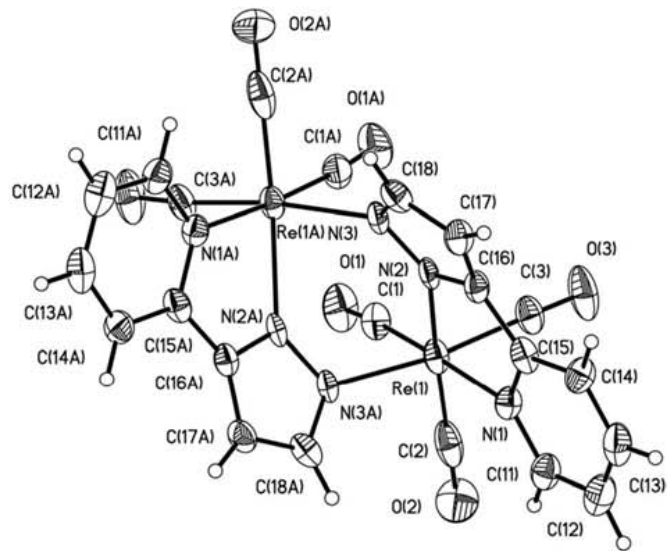

Fig. 5 Perspective view of $\left[\mathrm{fac}-\left\{\operatorname{Re}(\mathrm{CO})_{3}\left(\mu^{2}-\mathrm{pypz}\right)\right\}\right]_{2}, \mathbf{2 b}$, showing the atom numbering. Ellipsoids are drawn at $30 \%$ probability.

Table 2 Selected distances $(\dot{A})$ and angles $\left(^{\circ}\right)$ for $\left[\right.$ fac- $\left\{\operatorname{Re}(\mathrm{CO})_{3}\right.$ $\left(\mu^{2}-\right.$ pypz $\left.\left.)\right\}\right]_{2}, 2 b$

$\operatorname{Re}(1)-\mathrm{C}(1)$

$\operatorname{Re}(1)-\mathrm{C}(2)$

$\operatorname{Re}(1)-C(3)$

$\operatorname{Re}(1)-\mathrm{N}(1)$

$\operatorname{Re}(1)-\mathrm{N}(2)$

$\operatorname{Re}(1)-\mathrm{N}(3 \mathrm{~A})$

$\mathrm{C}(1)-\mathrm{O}(1)$

$\mathrm{C}(2)-\mathrm{O}(2)$

$\mathrm{C}(3)-\mathrm{O}(3)$

$\mathrm{C}(1)-\operatorname{Re}(1)-\mathrm{C}(2)$

$\mathrm{C}(1)-\operatorname{Re}(1)-\mathrm{C}(3)$

$\mathrm{C}(2)-\operatorname{Re}(1)-\mathrm{C}(3)$

$\mathrm{C}(1)-\operatorname{Re}(1)-\mathrm{N}(1)$

$\mathrm{C}(2)-\operatorname{Re}(1)-\mathrm{N}(1)$

$\mathrm{C}(3)-\operatorname{Re}(1)-\mathrm{N}(1)$

$\mathrm{C}(1)-\mathrm{Re}(1)-\mathrm{N}(2)$

$\mathrm{C}(2)-\operatorname{Re}(1)-\mathrm{N}(2)$

$\mathrm{C}(3)-\mathrm{Re}(1)-\mathrm{N}(2)$

$\mathrm{C}(1)-\operatorname{Re}(1)-\mathrm{N}(3 \mathrm{~A})$

$\mathrm{C}(2)-\operatorname{Re}(1)-\mathrm{N}(3 \mathrm{~A})$

$\mathrm{C}(3)-\operatorname{Re}(1)-\mathrm{N}(3 \mathrm{~A})$

$\mathrm{N}(2)-\operatorname{Re}(1)-\mathrm{N}(3 \mathrm{~A})$

$\mathrm{N}(1)-\mathrm{Re}(1)-\mathrm{N}(2)$

$\mathrm{N}(1)-\operatorname{Re}(1)-\mathrm{N}(3 \mathrm{~A})$

1.931(13)

$1.87(2)$

$1.917(12)$

$2.217(9)$

$2.149(8)$

1.147(13)

1.198(18)

1.143(13)

82.1(5)

91.4(5)

$88.5(6)$

176.1(5)

94.1(5)

87.9(4)

111.5(4)

165.3(4)

96.4(4)

$86.9(4)$

98.8(5)

172.2(5)

$77.2(3)$

$72.4(3)$

$94.3(3)$

the deprotonation of pypzH, which occurs with elimination of the bromido ligand, so the 3-(2-pyridyl)pyrazolate coordinates as a bridging ligand. Compound $2 \mathbf{b}$ could be crystallographically characterized (Fig. 5 and Table 2).

The molecule is centrosymmetric and contains two " $\mathrm{fac}$ $\left[\operatorname{Re}(\mathrm{CO})_{3}(\mathrm{pypz})\right]$ " moieties, where the "sixth" coordination position is occupied by the deprotonated nitrogen of the pyrazole, which chelates to the other rhenium atom. The octahedral geometry around the metal centers is clearly distorted, as shown by the trans $[\mathrm{C}(1)-\mathrm{Re}(1)-\mathrm{N}(1)$ 176.1(5); C(2)- $\mathrm{Re}(1)-\mathrm{N}(2)$ 165.3(4); $\mathrm{C}(3)-\mathrm{Re}(1)-\mathrm{N}(3 \mathrm{~A})$ 172.2(5)] and cis OC-Re-N (from $72.4(3)^{\circ}$ to $\left.111.5(4)^{\circ}\right)$ angles. The pyrazolate and pyridyl rings are not coplanar, their dihedral angle being $20^{\circ}$. The distances 
and angles are similar to those found in the bimetallic rhenium complex $\left[\left\{\left(\operatorname{Re}(\mathrm{CO})_{3}\right\}_{2} \mathrm{TPP}\right]\right.$ where TPP $=$ meso-tetraphenilporphyrine. ${ }^{16}$ The distance between both rhenium atoms $(3.977 \AA)$ is too long to consider any interaction between them. An electrochemical study was carried out on $\mathbf{2 b}$ (vide infra) in order to determine whether both metallic atoms may be connected by any electronic interaction.

As indicated above, the second point to consider after the formation of the sodium-manganese heterometallic compound Na-3a was whether rhenium could afford similar species. The deprotonation of the rhenium complex $\mathbf{1 b}$ led cleanly to the expected dinuclear complex $\mathbf{2 b}$, whereas the similar reaction with manganese did not afford the corresponding bimetallic complex, which was not detected, but the heteronuclear complexes $3 \mathrm{a}$, where the $\mathrm{Mn} / \mathrm{pypz}$ ratio is $1 / 2 .{ }^{17}$ This led us to explore the behavior of the $\left[\mathrm{fac}-\mathrm{Re}(\mathrm{CO})_{3}\right]^{+}$moiety when treated with two equivalents of Napypz. This reaction afforded a complex similar to $\mathbf{3 a}$, which is tentatively formulated as $\left[\left\{f a c-\operatorname{Re}(\mathrm{CO})_{3}\left(\mu^{2}-\mathrm{pypz}\right)(\mu-\mathrm{pypz}) \mathrm{Na}\right\}_{n}\right], 3 \mathbf{b}$ (Scheme 2), since we were unable to obtain suitable monocrystals to perform an X-ray diffraction study. However, all the spectroscopic data are very similar to those of complexes $3 \mathrm{a}$, and analytical data (see the Experimental section) also support this proposal.

\section{Synthesis and characterization of the Mn(II) complexes}

The attempts to obtain crystals from the solutions of $\mathbf{3 b}$ were complicated by its tendency to afford again $\mathbf{2 b}$, by the loss of one equivalent of Napypz (Scheme 2). Instead, the solutions of Na-3a evolve into the trimetallic complex $\left[\mathrm{Mn}^{\mathrm{II}}\left(\mu^{2}-\mathrm{pypz}\right)_{2}\{\mathrm{fac}-\right.$ $\left.\left.\left\{\mathrm{Mn}^{\mathrm{I}}(\mathrm{CO})_{3}\left(\mu^{2}-\mathrm{pypz}\right)\right\}_{2}\right\}\right], 4 \mathrm{a}$, probably due to the presence of traces of oxygen, as one of the manganese atoms in this molecule is formally $\mathrm{Mn}$ (II) (Scheme 1). A selective synthesis of $\mathbf{4 a}$ was attempted by treating $\mathrm{Na}-3 \mathrm{a}$ with different sources of $\mathrm{Mn}$ (II) such as $\mathrm{Mn}\left(\mathrm{BF}_{4}\right)_{2}$ or $\mathrm{MnCl}_{2}$, but these reactions afforded complex mixtures which could not be characterized. The paramagnetism of $4 \mathrm{a}$ precluded its characterization by NMR. Fortunately it crystallized as yellow needles and an X-ray determination could be carried out (Fig. 6, Table 3). ${ }^{18}$

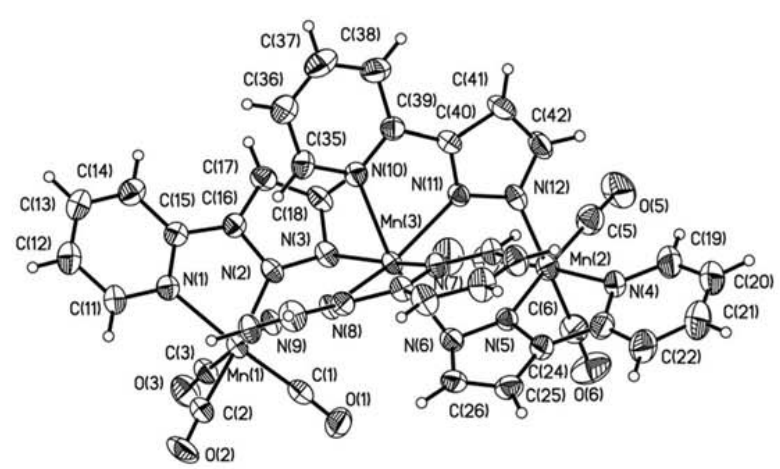

Fig. 6 Perspective view of $\left[M n\left(\mu^{2}-p y p z\right){ }_{2}\left\{f a c-\left\{M n(C O)_{3}\left(\mu^{2}-p y p z\right)\right\}_{2}\right\}\right], 4 a$ showing the atom numbering. Ellipsoids are drawn at $30 \%$ probability.
Table 3 Selected distances $(\hat{A})$ and angles $\left(^{\circ}\right)$ for $\left[M n\left(\mu^{2}-p y p z\right)_{2}\{f a c-\{M n\right.$ $(\mathrm{CO})_{3}\left(\mu^{2}-\right.$ pypz $\left.\left.\left.)\right\}_{2}\right\}\right], 4 a^{17}$

\begin{tabular}{ll}
\hline $\mathrm{Mn}(1)-\mathrm{C}(1)$ & \\
$\mathrm{Mn}(1)-\mathrm{C}(2)$ & $1.800(5)$ \\
$\mathrm{Mn}(1)-\mathrm{C}(3)$ & $1.800(4)$ \\
$\mathrm{Mn}(1)-\mathrm{N}(1)$ & $1.813(5)$ \\
$\mathrm{Mn}(1)-\mathrm{N}(2)$ & $2.087(3)$ \\
$\mathrm{Mn}(1)-\mathrm{N}(9)$ & $2.027(3)$ \\
$\mathrm{C}(1)-\mathrm{O}(1)$ & $2.051(3)$ \\
$\mathrm{C}(2)-\mathrm{O}(2)$ & $1.146(4)$ \\
$\mathrm{C}(3)-\mathrm{O}(3)$ & $1.147(4)$ \\
$\mathrm{Mn}(3)-\mathrm{N}(3)$ & $1.147(4)$ \\
$\mathrm{Mn}(3)-\mathrm{N}(8)$ & $2.257(3)$ \\
$\mathrm{Mn}(3)-\mathrm{N}(10)$ & $2.214(3)$ \\
$\mathrm{Mn}(3)-\mathrm{N}(11)$ & $2.331(3)$ \\
$\mathrm{C}(1)-\mathrm{Mn}(1)-\mathrm{C}(2)$ & $2.217(3)$ \\
$\mathrm{C}(1)-\mathrm{Mn}(1)-\mathrm{C}(3)$ & $89.25(18)$ \\
$\mathrm{C}(2)-\mathrm{Mn}(1)-\mathrm{C}(3)$ & $87.72(17)$ \\
$\mathrm{C}(1)-\mathrm{Mn}(1)-\mathrm{N}(1)$ & $87.65(18)$ \\
$\mathrm{C}(2)-\mathrm{Mn}(1)-\mathrm{N}(1)$ & $172.90(15)$ \\
$\mathrm{C}(3)-\mathrm{Mn}(1)-\mathrm{N}(1)$ & $97.17(16)$ \\
$\mathrm{C}(1)-\mathrm{Mn}(1)-\mathrm{N}(2)$ & $89.52(15)$ \\
$\mathrm{C}(2)-\mathrm{Mn}(1)-\mathrm{N}(2)$ & $96.05(15)$ \\
$\mathrm{C}(3)-\mathrm{Mn}(1)-\mathrm{N}(2)$ & $173.18(16)$ \\
$\mathrm{C}(1)-\mathrm{Mn}(1)-\mathrm{N}(9)$ & $96.83(14)$ \\
$\mathrm{C}(2)-\mathrm{Mn}(1)-\mathrm{N}(9)$ & $91.64(15)$ \\
$\mathrm{C}(3)-\mathrm{Mn}(1)-\mathrm{N}(9)$ & $89.74(15)$ \\
$\mathrm{N}(2)-\mathrm{Mn}(1)-\mathrm{N}(9)$ & $177.31(15)$ \\
$\mathrm{N}(1)-\mathrm{Mn}(1)-\mathrm{N}(2)$ & $85.83(11)$ \\
$\mathrm{N}(1)-\mathrm{Mn}(1)-\mathrm{N}(9)$ & $77.79(12)$ \\
$\mathrm{N}(8)-\mathrm{Mn}(3)-\mathrm{N}(11)$ & $91.42(11)$ \\
$\mathrm{N}(8)-\mathrm{Mn}(3)-\mathrm{N}(3)$ & $152.43(11)$ \\
$\mathrm{N}(11)-\mathrm{Mn}(3)-\mathrm{N}(3)$ & $94.59(11)$ \\
$\mathrm{N}(8)-\mathrm{Mn}(3)-\mathrm{N}(6)$ & $103.51(11)$ \\
$\mathrm{N}(11)-\mathrm{Mn}(3)-\mathrm{N}(6)$ & $99.32(11)$ \\
$\mathrm{N}(3)-\mathrm{Mn}(3)-\mathrm{N}(6)$ & $94.89(11)$ \\
$\mathrm{N}(8)-\mathrm{Mn}(3)-\mathrm{N}(10)$ & $107.52(11)$ \\
$\mathrm{N}(11)-\mathrm{Mn}(3)-\mathrm{N}(10)$ & $87.28(11)$ \\
& $73.23(11)$
\end{tabular}

Compound 4a is a trimetallic molecule formed by a central " $\mathrm{Mn}^{\mathrm{II}}\left(\mu^{2}-\mathrm{pypz}\right)^{2}$ " core, surrounded by two terminal "fac$\left\{\mathrm{Mn}^{\mathrm{I}}(\mathrm{CO})_{3}\left(\mu^{2}\right.\right.$-pypz $\left.)\right\}$ " moieties. The sixth coordination position of each terminal unit is occupied by a nitrogen atom of a bridging pyridylpyrazolate, which chelates the central manganese. Two chelated pyridylpyrazolates are coordinated to this central manganese, the other two positions being occupied by two nitrogen atoms, from each pyridylpyrazolate which chelates the terminal manganese atoms. Therefore, the structure allows to label the terminal manganese atoms as manganese(I), and the central metal atom as manganese(II).

The octahedral geometry of the terminal moieties is only slightly distorted, and their distances and angles are very similar. However, the octahedral geometry of the central manganese is severely distorted, as deduced from the trans $\mathrm{N}-\mathrm{Mn}-\mathrm{N}$ angles: $\mathrm{N}(3)-\mathrm{Mn}(3)-\mathrm{N}(7)$ 163.52(11), $\mathrm{N}(6)-\mathrm{Mn}(3)-$ $\mathrm{N}(10)$ 163.16(11) ${ }^{\circ}$, and $\mathrm{N}(8)-\mathrm{Mn}(3)-\mathrm{N}(11) 152.43(11)^{\circ}$. The cis $\mathrm{N}-\mathrm{Mn}-\mathrm{N}$ angles are in the range $72.66(10)^{\circ}-107.52(11)^{\circ}$. The dihedral angles of the pyridylpyrazolate chelating the central manganese $\left(17^{\circ}\right.$ and $\left.13^{\circ}\right)$ are also larger than those found in those chelating the terminal units $\left(6^{\circ}\right.$ and $\left.7^{\circ}\right)$.

A wide variety of $c i s-\left[\mathrm{Mn}(\mathrm{N}-\mathrm{N})_{2} \mathrm{X}_{2}\right](\mathrm{N}-\mathrm{N}$ : chelating $\mathrm{N}$-donor ligand, $\mathrm{X}$ : halogen or pseudohalogen) have been described. ${ }^{19}$ If the two nitrogen atoms coordinated to the central 


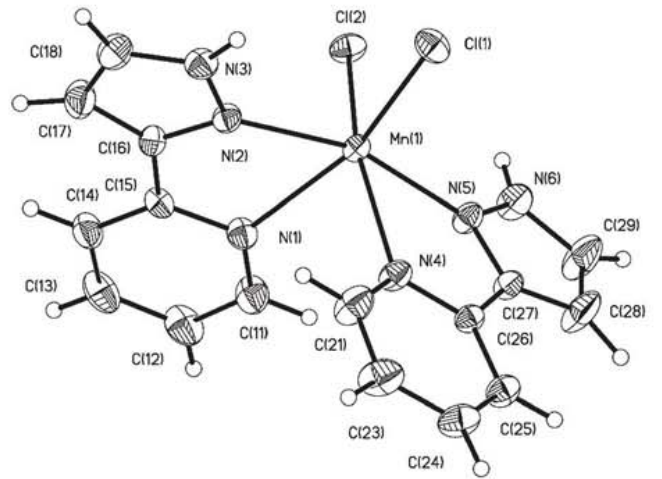

Fig. 7 Perspective view of cis- $\left[\mathrm{MnCl}_{2}\left(\mathrm{pypz}-\mathrm{H}_{2}\right], 5 \mathrm{a}\right.$, showing the atom numbering. Ellipsoids are drawn at $30 \%$ probability.

Table 4 Selected distances $(\AA)$ and angles $\left({ }^{\circ}\right)$ for cis- $\left[\mathrm{MnCl}_{2}(\mathrm{pypz} \mathrm{H})_{2}\right]$, $5 a$

$\mathrm{Mn}(1)-\mathrm{N}(1)$

$\mathrm{Mn}(1)-\mathrm{N}(2)$

$\operatorname{Mn}(1)-\mathrm{N}(4)$

$\mathrm{Mn}(1)-\mathrm{N}(5)$

$\mathrm{Mn}(1)-\mathrm{Cl}(1)$

$\mathrm{Mn}(1)-\mathrm{Cl}(2)$

$\mathrm{N}(5)-\mathrm{Mn}(1)-\mathrm{N}(2)$

$\mathrm{N}(5)-\mathrm{Mn}(1)-\mathrm{N}(4)$

$\mathrm{N}(2)-\mathrm{Mn}(1)-\mathrm{N}(4)$

$\mathrm{N}(5)-\mathrm{Mn}(1)-\mathrm{N}(1)$

$\mathrm{N}(2)-\mathrm{Mn}(1)-\mathrm{N}(1)$

$\mathrm{N}(4)-\mathrm{Mn}(1)-\mathrm{N}(1)$

$\mathrm{N}(5)-\mathrm{Mn}(1)-\mathrm{Cl}(1)$

$\mathrm{N}(2)-\mathrm{Mn}(1)-\mathrm{Cl}(1)$

$\mathrm{N}(4)-\mathrm{Mn}(1)-\mathrm{Cl}(1)$

$\mathrm{N}(1)-\mathrm{Mn}(1)-\mathrm{Cl}(1)$

$\mathrm{N}(5)-\mathrm{Mn}(1)-\mathrm{Cl}(2)$

$\mathrm{N}(2)-\mathrm{Mn}(1)-\mathrm{Cl}(2)$

$\mathrm{N}(4)-\mathrm{Mn}(1)-\mathrm{Cl}(2)$

$\mathrm{N}(1)-\mathrm{Mn}(1)-\mathrm{Cl}(2)$

$\mathrm{Cl}(1)-\mathrm{Mn}(1)-\mathrm{Cl}(2)$

manganese, which belong to the pyridylpyrazolate chelated to the terminal moieties in $\mathbf{4 a}$, were substituted by two halides or pseudohalides, a similar complex cis-[Mn(pypzH $\left.)_{2} \mathrm{X}_{2}\right]$ would be obtained. Therefore, we decided to synthesize this complex which, on the other hand, could be also an appropriate precursor to design a logical synthesis for the trimetallic complex 4a (see below). Thus, the reaction of $\mathrm{MnCl}_{2} \cdot 4 \mathrm{H}_{2} \mathrm{O}$ with two equivalents of pypzH in refluxing methanol led to cis$\left[\mathrm{MnCl}_{2}(\text { pypzH })_{2}\right], \mathbf{5 a}$, as a white solid. The crystal structure of $\mathbf{5 a}$ is depicted in Fig. 7 , and Table 4 presents relevant distances and angles.

The geometry of $\mathbf{5 a}$ shows distances and angles quite similar to those found in the central manganese of the trimetallic complex 4a. Only the $\mathrm{Cl}-\mathrm{Mn}-\mathrm{Cl}$ angle $(\mathrm{Cl}(1)-\mathrm{Mn}(1)-\mathrm{Cl}(2)$ $\left.98.22(4)^{\circ}\right)$ in 5a slightly differs from the corresponding $\mathrm{N}-\mathrm{Mn}-$ $\mathrm{N}$ in $4 \mathrm{a}\left(\mathrm{N}(3)-\mathrm{Mn}(3)-\mathrm{N}(6) 107.52(11)^{\circ}\right)$. The dihedral angles of the pyridylpyrazole in $5 \mathrm{a}$ are also smaller $\left(5^{\circ}\right.$ and $\left.3^{\circ}\right)$ than those found for the bridging pyridylpyrazolate in $4 \mathbf{a}\left(17^{\circ}\right.$ and $\left.13^{\circ}\right)$. This is a well known feature also found when comparing chelating pyridylpyrazole and bridging pyridylpyrazolate. ${ }^{8}$ The geometry of $\mathbf{5 a}$ is also similar to those found for cis-[Mn(N$\mathrm{N})_{2} \mathrm{X}_{2}$ ] complexes. ${ }^{19}$

As indicated above, $5 \mathbf{a}$ could be a precursor for the trimetallic species $\mathbf{4 a}$, if the chloride ligands were substituted by anionic "fac- $\left\{\mathrm{Mn}(\mathrm{CO})_{3}\left(\mu^{2}\right.\right.$-pypz $\left.)\right\}$ " fragments, after deprotonating also the pyridylpyrazole ligands. However, all the attempts made in this direction were unsuccessful.

\section{Electrochemical behavior}

The mononuclear $\operatorname{Re}^{1} f a c-\left[\operatorname{ReBr}(\mathrm{CO})_{3}(\mathrm{pypzH})\right](\mathbf{1 b})$, binuclear $\left[\text { fac }-\left\{\operatorname{Re}(\mathrm{CO})_{3}\left(\mu^{2}-\mathrm{pypz}\right)\right\}\right]_{2} \quad(\mathbf{2 b})$ and heterometallic $[\{f a c-$ Re$(\mathrm{CO})_{3}\left(\mu^{2}\right.$-pypz $\left.\left.)(\mu-\mathrm{pypz}) \mathrm{Na}\right\}_{n}\right]$ (3b) complexes exhibit, by cyclic voltammetry (CV) (at $200 \mathrm{mV} \mathrm{s}^{-1}$ ) at a platinum electrode and in $0.2 \mathrm{M}\left[{ }^{n} \mathrm{Bu}_{4} \mathrm{~N}\right]\left[\mathrm{BF}_{4}\right]-\mathrm{THF}$, a first single-electron (for $\mathbf{1 b}$ ) or two-electron (CPE) (for $\mathbf{2} \mathbf{b}$ and $\mathbf{3} \mathbf{b}$, i.e. one-electron/Re) irreversible (in the $0.05-4 \mathrm{~V} \mathrm{~s}^{-1}$ scan rate range tested) oxidation wave (wave $\mathbf{I}^{\text {ox }}$ ) at ${ }^{\mathrm{I}} E_{\mathrm{p}}^{\text {ox }}=1.61,1.12$ or $0.97 \mathrm{~V}$ vs. SCE, for $\mathbf{1 b}-\mathbf{b} \mathbf{b}$, respectively, assigned to the $\mathrm{Re}^{\mathrm{I}} \rightarrow \mathrm{Re}^{\mathrm{II}}$ oxidation process (in the cases of $\mathbf{2} \mathbf{b}$ and $\mathbf{3} \mathbf{b}$, of the two $\mathrm{Re}^{\mathrm{I}}$ centres) (Fig. $\mathbf{8}$, for $\mathbf{3} \mathbf{b}$ ).

A second irreversible oxidation process (wave $\mathbf{I I}^{\mathbf{0 x}}$ ) is observed for $\mathbf{2} \mathbf{b}$ and $\mathbf{3 b}$ at a higher potential value (II $E_{\mathrm{p}}^{\text {ox }}=1.49$ or $1.30 \mathrm{~V} v s$. SCE, for $\mathbf{2 b}$ and $\mathbf{3 b}$, respectively), conceivably due to the $\mathrm{Re}^{\mathrm{II}} \rightarrow \mathrm{Re}^{\mathrm{III}}$ oxidation. The irreversibility of these oxidation waves $\left(\mathbf{I}^{\mathbf{0 x}}\right.$ and $\left.\mathbf{I I}^{\mathbf{o x}}\right)$ indicates the instability of the resulting cationic Re complexes. Moreover, for all three $\operatorname{Re}^{\mathrm{I}}$ complexes $\mathbf{1 b} \mathbf{b} \mathbf{3} \mathbf{b}$, an irreversible cathodic process is observed (wave $\mathrm{I}^{\text {red }}$ ) at $-1.74,-0.91$ or $-1.03 \mathrm{~V} v s$. SCE, respectively.

The observation of a single oxidation wave, for the $\mathrm{Re}^{\mathrm{I}} \rightarrow$ $\mathrm{Re}^{\mathrm{II}}$ process, in $\mathbf{2 b}$ (instead of two distinct waves) is indicative of no significant electronic communication between the two $\mathrm{Re}^{\mathrm{I}}$ metal centres, through the two bridging pyridylpyrazolates.

According to the literature data for other $\mathrm{Re}^{\mathrm{I}}$ tricarbonyls with $\mathrm{N}$-heterocyclic ligands, the first oxidation potential of $\mathbf{1 b}$ ( ${ }^{\mathrm{I}} E_{\mathrm{p}}^{\mathrm{ox}}=1.61 \mathrm{~V} v s$. SCE in THF) is only slightly higher than those reported, for the same anodic process $\left(\operatorname{Re}^{I} \rightarrow \operatorname{Re}^{I I}\right)$, for [ReX$\left.(\mathrm{CO})_{3} \mathrm{~L}\right](\mathrm{X}=$ halide; $\mathrm{L}=$ unsymmetrical bidentate iminopyridine ligand $),{ }^{20}$ for the series $f a c-\left[\operatorname{ReCl}(\mathrm{CO})_{3}(\right.$ pytri-R $\left.)\right][$ pytri- $\mathrm{R}=$

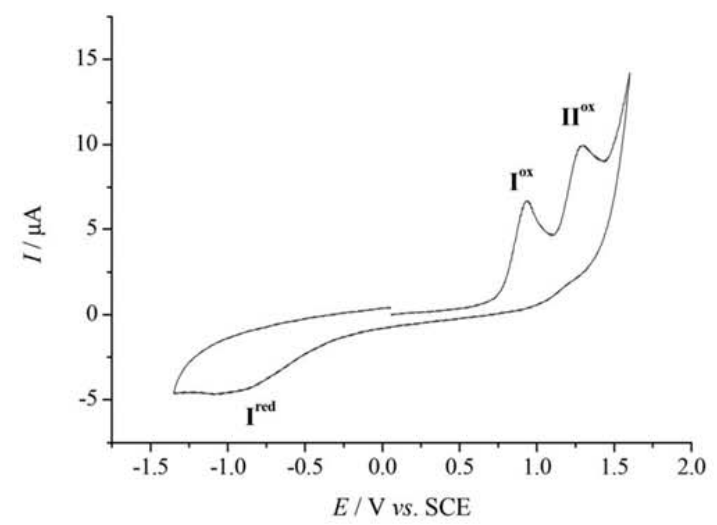

Fig. 8 Cyclic voltammogram of $\left[\left\{f a c-\operatorname{Re}(C O){ }_{3}\left(\mu^{2}-p y p z\right)(\mu-p y p z) N a\right\}_{n}\right]$ (3b) $(1.3 \mathrm{mM})$ (starting with the anodic scan), at a Pt electrode, in $0.2 \mathrm{M}$ $\left[{ }^{n} \mathrm{Bu}_{4} \mathrm{~N}\right]\left[\mathrm{BF}_{4}\right]-\mathrm{THF}$ solution $\left(v=0.2 \mathrm{~V} \mathrm{~s}^{-1}\right)$. 
2-(1-R-1H-1,2,3-triazol-4-yl)pyridine], or for $f a c-\left[\operatorname{ReCl}(\mathrm{CO})_{3-}\right.$ $\left(\right.$ py $\left(\mathrm{CH}_{2}\right)$ tri-R $\left.)\right]\left[\mathrm{py}\left(\mathrm{CH}_{2}\right)\right.$ tri-R $=\{(4-\mathrm{R}-1 \mathrm{H}-1,2,3$-triazol-1-yl $)$ methyl $\}$ pyridine.$^{21}$ It is significantly higher than those for fac-[ReX$\left.(\mathrm{CO})_{3} \mathrm{~L}\right](\mathrm{X}=$ halide; $\mathrm{L}=$ diimine $),{ }^{22}$ fac $-\left[\operatorname{ReX}(\mathrm{CO})_{3}\left(\mathrm{~L}^{1} / \mathrm{L}^{2}\right)\right](\mathrm{X}=\mathrm{Cl}$ or $\mathrm{Br} ; \mathrm{L}^{1} / \mathrm{L}^{2}=1$-alkyl-2-((o-thiomethyl $)$ phenylazo $)$ imidazole, ${ }^{23}$ or $f a c-\left[\operatorname{ReBr}(\mathrm{CO})_{3}\left\{\mathrm{H}\left(\mathrm{pzAn}^{\mathrm{Me}}\right)\right\}\right]\left[\mathrm{H}\left(\mathrm{pzAn}^{\mathrm{Me}}\right)=2\right.$-( pyrazolyl $)$ 4-toluidine $]{ }^{24}$ The potential values reflect the electron-donor abilities of these $\mathrm{N}, \mathrm{N}$-ligands ${ }^{25}$ which thus can be ordered as follows: 1-alkyl-2-((o-thiomethyl)phenylazo)imidazole ${ }^{23}>$ 2-(pyrazolyl)-4-toluidine ${ }^{24}>$ diimine $^{22}>2$-(1-R- $1 H-1,2,3$-triazol4-yl)pyridine and $\{(4-\mathrm{R}-1 H-1,2,3$-triazol-1-yl $)$ methyl $\}$ pyridine ${ }^{21}>$ (3-(2-pyridyl)pyrazole) [our work].

The lower oxidation potential of the binuclear complex [ fac$\left.\left\{\operatorname{Re}(\mathrm{CO})_{3}\left(\mu^{2}-\mathrm{pypz}\right)\right\}\right]_{2} \quad(\mathbf{2 b})$ or the bimetallic $\left[\left\{\mathrm{fac}-\operatorname{Re}(\mathrm{CO})_{3}-\right.\right.$ $\left.\left(\mu^{2} \text {-pypz)( } \mu \text {-pypz)Na }\right\}_{n}\right]$ (3b) (1.12 or $0.97 \mathrm{~V} v s$. SCE, in THF, for $\mathbf{2 b}$ and $\mathbf{3 b}$, respectively) in comparison with that of the parent mononuclear $f a c-\left[\operatorname{ReBr}(\mathrm{CO})_{3}(\mathrm{pypzH})\right](\mathbf{1 b})(1.61 \mathrm{~V}$ vs. SCE, in THF), reflects the stronger electron-donor character of the ligands in $\mathbf{2 b}$ or $\mathbf{3} \mathbf{b}$ (two $\mu^{2}$-pypz), for each metal center, relative to those in $\mathbf{1} \mathbf{b}\left(\mathrm{Br}^{-}+\right.$pypzH). In terms of the electrochemical Lever $E_{\mathrm{L}}$ parameter $^{24}$ (the lower this value, the stronger is the ligand electron-donor character) one can conclude that the sums of $E_{\mathrm{L}}$ values for the two $\mu^{2}$-pypz ligands (in $2 \mathbf{b}$ and $3 \mathbf{b}$ ) are lower than those of $\mathrm{Br}^{-}+$bidentade pypzH (in $\mathbf{1 b}$ ).

The monomeric manganese(I) $f a c-\left[\operatorname{MnBr}(\mathrm{CO})_{3}(\mathrm{pypzH})\right] \mathbf{1 a}$ exhibits two irreversible oxidation waves $\left(\mathbf{I}^{\mathbf{o x}}\right.$ and $\left.\mathbf{I I}^{\mathbf{o x}}\right)$ at 1.22 and $1.52 \mathrm{~V} v s$. SCE (at $200 \mathrm{mV} \mathrm{s}^{-1}$ ) assigned to the $\mathrm{Mn}^{\mathrm{I}} \rightarrow \mathrm{Mn}^{\mathrm{II}}$ and $\mathrm{Mn}^{\mathrm{II}} \rightarrow \mathrm{Mn}^{\mathrm{III}}$ oxidations, similarly to the case of the analogous $\mathrm{Re}^{\mathrm{I}}$ complex $\mathbf{1 b}$.

Complex $1 \mathrm{a}$ also shows a reduction wave at $E_{\mathrm{p}}^{\mathrm{red}}=-1.56 \mathrm{~V}$ vs. SCE ( $\mathbf{I}^{\text {red }}$, Fig. 9). Moreover, upon scan reversal after the reduction wave, a new irreversible oxidation process is detected at $E_{\mathrm{p}}^{\mathrm{ox}}$ of $c a .0 .8 \mathrm{~V} v s$. SCE (Fig. 9). This new wave conceivably concerns the oxidation of the bromide ion liberated upon

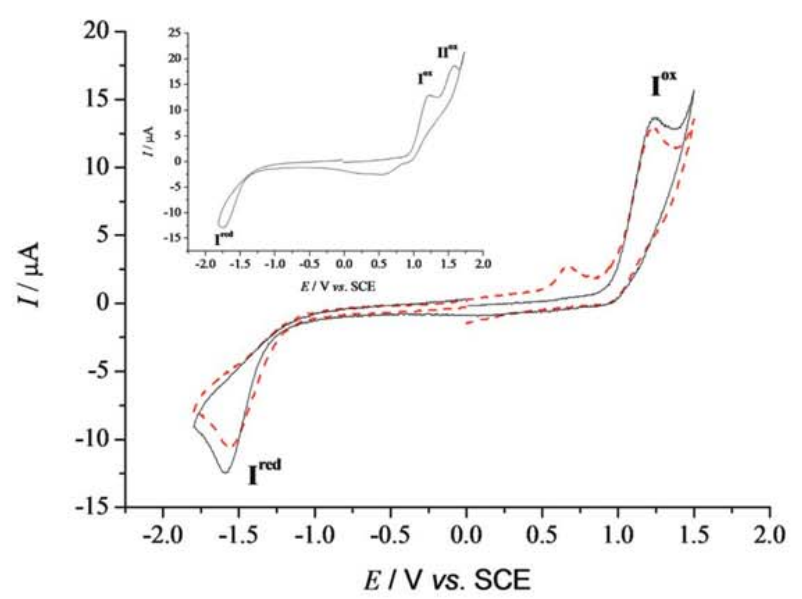

Fig. 9 Cyclic voltammograms of fac- $\left[\mathrm{Mn}(\mathrm{CO})_{3} \mathrm{Br}(\mathrm{pypzH})\right]$ (1a) $(6.2 \mathrm{mM})$ (anodic scan), at a Pt electrode, in $0.2 \mathrm{M}\left[{ }^{n} \mathrm{Bu}_{4} \mathrm{~N}\right]\left[\mathrm{BF}_{4}\right]-\mathrm{THF}$ solution ( $v=$ $200 \mathrm{mV} \mathrm{s}^{-1}$ ). Full line: initiated with the anodic scan. Dotted line: initiated with the cathodic scan. Inset: extended anodic sweep beyond the second oxidation wave.
Table 5 Cyclic voltammetric data ${ }^{a}$ for fac- $\left[\mathrm{MnBr}(\mathrm{CO})_{3}(\mathrm{pypzH})\right]$ (1a), $\left[\left\{f a c-M n(C O)_{3}\left(\mu^{2}-p y p z\right)\left(\mu^{3}-p y p z\right) M{ }^{\prime}\right\}_{n}\right]\left[M^{\prime}=\mathrm{Li}, \mathrm{Li}-3 \mathrm{a}, n=1 ; \mathrm{Na}, \mathrm{Na}-3 \mathrm{a}\right.$, $n=2$, and K, K-3a, $n=2]$, [\{fac-Mn $\left.\left(\mu^{2}-\text { pypz }\right)_{2}\left(f a c-\left\{\mathrm{Mn}(\mathrm{CO})_{3}\left(\mu^{2}-\mathrm{pypz}\right)\right\}_{2}\right\}\right]$ (4a), cis-[MnCl$\left.{ }_{2}(\text { pypzH })_{2}\right]$ (5a), fac-[ReBr(CO) $)_{3}($ pypzH)] (1b), [fac-\{Re$(\mathrm{CO})_{3}\left(\mu^{2}-\right.$ pypz $\left.\left.)\right\}\right]_{2}(2 \mathrm{~b})\left[\left\{f a c-\operatorname{Re}(\mathrm{CO})_{3}\left(\mu^{2}-\text { pypz) }(\mu-\text { pypz }) N a\right\}_{n}\right](3 \mathrm{~b})\right.$

\begin{tabular}{llll}
\hline Complex & ${ }^{\mathrm{I}} E_{\mathrm{p}}^{\text {ox }}\left({ }^{\mathrm{C}} E_{1 / 2}^{\mathrm{ox}}\right)$ & ${ }^{\mathrm{I}} E_{\mathrm{p}}^{\mathrm{ox}}$ & ${ }^{\mathrm{i}} E_{\mathrm{p}}^{\text {red }}$ \\
\hline $\mathbf{1 b}$ & 1.62 & - & -1.06 \\
$\mathbf{2 b}$ & 1.12 & 1.49 & -0.91 \\
3b & 0.97 & 1.30 & -1.03 \\
1a & 1.22 & 1.52 & -1.56 \\
Li-3a & 0.80 & 1.40 & - \\
Na-3a & 0.62 & 1.02 & - \\
K-3a & 0.62 & 1.05 & - \\
4a & $(0.90)$ & 1.36 & - \\
5a & $(0.96)$ & - & -
\end{tabular}

${ }^{a}$ Values in $\mathrm{V} \pm 0.02$ relative to SCE (see the Experimental section); scan rate of $200 \mathrm{mV} \mathrm{s}^{-1}$. Values for reversible waves are given in parentheses.

reduction. The involvement of the bromide ion is supported by the independently measured values $\left({ }^{\mathrm{I}} E_{\mathrm{p}}^{\mathrm{ox}}=0.9\right.$ and ${ }^{\mathrm{II}} E_{\mathrm{p}}^{\mathrm{ox}}=$ $1.3 \mathrm{~V} v s$. SCE) of the irreversible oxidation waves of tetrabutylammonium bromide under the same experimental conditions (the second wave is buried under the oxidation wave of the complex). Moreover, this is confirmed by the increase of the current intensity of this new wave and of the oxidation wave of 1a (which overlaps with the second oxidation wave of $\mathrm{Br}^{-}$), upon addition of $\left[{ }^{n} \mathrm{Bu}_{4} \mathrm{~N}\right] \mathrm{Br}$ to the $\mathrm{CV}$ solution.

The complexes $\left[\left\{f a c-\mathrm{Mn}(\mathrm{CO})_{3}\left(\mu^{2}-\mathrm{pypz}\right)\left(\mu^{3}-\mathrm{pypz}\right) \mathrm{M}^{\prime}\right\}_{n}\right]\left[\mathrm{M}^{\prime}=\right.$ Li, Li-3a, $n=1$; Na, Na-3a, $n=2$, and K, K-3a, $n=2$ ] exhibit, by $\mathrm{CV}$, two single-electron irreversible oxidation waves, the first one (wave $\mathbf{I}^{\mathbf{o x}}$ ) at potential values in the range of $0.62-0.8 \mathrm{~V} v s$. SCE (Table 5), followed by the second one (wave $\mathbf{I I}^{\text {ox }}$ ) at higher potential values (1.02-1.4 V vs. SCE) (Table 5). Moreover, for complexes Na-3a and $\mathrm{K}-3 \mathbf{a}$ a third irreversible oxidation wave is observed at ${ }^{\mathrm{II}} E_{\mathrm{p}}^{\text {ox }}=1.47$ and $1.39 \mathrm{~V}$ vs. SCE, respectively. No clear reduction waves were detected for these Mn complexes.

The above manganese(I) complexes 1a and Na-3a are oxidized at lower potentials (by ca. $0.35-0.4 \mathrm{~V}$ ) than the analogous rhenium( $\mathrm{I}$ ) complexes ( $\mathbf{1 b}$ and $\mathbf{3} \mathbf{b}$, respectively). This is in accordance with the relative behavior reported for other rhenium(I) and manganese $(\mathrm{I})$ complexes, namely fac-[MBr$\left.(\mathrm{CO})_{3}\left\{\mathrm{H}\left(\mathrm{pzAn}^{\mathrm{Me}}\right)\right\}\right]\left[\mathrm{M}=\mathrm{Mn}, \mathrm{Re} ; \mathrm{H}\left(\mathrm{pzAn}^{\mathrm{Me}}\right)=2-(\right.$ pyrazolyl $)-$ 4-toluidine $]^{24}$

The paramagnetic mixed-valence $\mathrm{Mn}^{\mathrm{I}} / \mathrm{Mn}^{\mathrm{II}}$ complex 4 a exhibits by $\mathrm{CV}$ a first reversible two-electron oxidation (wave $\mathbf{I}^{\mathbf{o x}}$ ) at ${ }^{\mathrm{I}} E_{1 / 2}^{\mathrm{ox}}=0.90 \mathrm{~V} v s$. SCE, attributed to the $\mathrm{Mn}^{\mathrm{I}} \rightarrow \mathrm{Mn}^{\mathrm{II}}$ oxidation processes of both $\mathrm{Mn}^{\mathrm{I}}$ metal centres, followed, at a higher potential value, by a second irreversible oxidation (wave $\mathbf{I I}^{\mathbf{o x}}$ ) at ${ }^{\text {II }} E_{\mathrm{p}}^{\text {ox }}=1.36 \mathrm{~V}$ vs. SCE, conceivable due to $\mathrm{Mn}^{\mathrm{II}} \rightarrow \mathrm{Mn}^{\text {III }}$ oxidation. The paramagnetic mononuclear $\mathrm{Mn}^{\mathrm{II}}$ dichlorocomplex 5a shows a single-electron reversible oxidation process (wave $\mathbf{I}^{\text {ox }}$ ) at ${ }^{\mathrm{I}} E_{1 / 2}^{\text {ox }}=0.96 \mathrm{~V} v s$. SCE.

Although compound $\mathbf{4 a}$ has been synthesised starting from compound 3a, controlled potential electrolysis at the first oxidation wave of the latter has not led to the former. 


\section{Conclusions}

The deprotonation of pyridylpyrazole coordinated to bromidotricarbonylrhenium is straightforward and gives the corresponding bimetallic complex with a bridging pyridylpyrazolate. However, the same process with the manganese complex affords heteropolymetallic complexes where pyridylpyrazolate bridges manganese and the alkali metal atom. Those with sodium and potassium are tetrametallic complexes containing two manganese and two alkali metal atoms and a bridging pyridylpyrazolate ligand with an unprecedented coordination mode: the nitrogen of the pyridyl fragment and the nitrogen-1 of pyrazolate are chelated to manganese atoms, whereas each nitrogen-2 of pyrazolate is coordinated to two alkali metal atoms. On the other hand, the lithium complex is heterobimetallic and contains a very uncommon chelating pyridylpyrazolate. Hence, the size of the alkali metal atoms determines the final structure of the heterometallic complexes: lithium is tetracoordinated whereas sodium and potassium are pentacoordinated; the larger the metal, the bulkier the ligands surrounding them. The coordination of transition metals instead of these alkali metals is currently under investigation. The heteropolymetallic complexes evolve spontaneously to the parent homobimetallic pyridylpyrazolate bridging complex in the case of rhenium, and to a trimanganese paramagnetic complex $\left(\mathrm{Mn}^{\mathrm{I}} \mathrm{Mn}^{\mathrm{II}} \mathrm{Mn}^{\mathrm{I}}\right)$.

\section{Experimental}

\section{General procedures}

All manipulations were performed under a $\mathrm{N}_{2}$ atmosphere following conventional Schlenk techniques. Filtrations were carried out on dry Celite without exclusion of air. Solvents were purified according to standard procedures. ${ }^{26} \mathrm{fac}-[\mathrm{MnBr}-$ $\left.(\mathrm{CO})_{3}(\mathrm{NCMe})_{2}\right],{ }^{7 a}$ fac- $\left[\mathrm{ReBr}(\mathrm{CO})_{3}(\mathrm{NCMe})_{2}\right],{ }^{27}$ and 3-(2-pyridyl pyrazole $^{28}$ were obtained as previously described. All other reagents were obtained from the usual commercial suppliers, and used as received. Infrared spectra were recorded in a Perkin-Elmer RX I FT-IR apparatus using $0.2 \mathrm{~mm} \mathrm{CaF}_{2}$ cells for solutions or on $\mathrm{KBr}$ pellets for solid samples. NMR spectra were recorded in Bruker AC-300, ARX-300, or AV-400 in $\mathrm{Me}_{2} \mathrm{CO}-\mathrm{d}_{6}$ at room temperature (r.t.) unless otherwise stated. NMR spectra are referred to the internal residual solvent peak for ${ }^{1} \mathrm{H}$ and ${ }^{13} \mathrm{C}\left\{{ }^{1} \mathrm{H}\right\}$ NMR. Assignment of the ${ }^{1} \mathrm{H}$ NMR spectra was supported by COSY experiments and assignment of ${ }^{13} \mathrm{C}\left\{{ }^{1} \mathrm{H}\right\}$ NMR data was supported by DEPT experiments and relative intensities of the resonance signals or HSQAD experiments (Fig. 10). Elemental analyses were performed on a Perkin-Elmer 2400B microanalyzer.

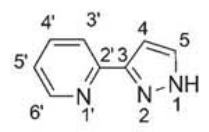

Fig. 10 Numbering of pypzH for NMR assignment. fac- $\left[\mathrm{MnBr}(\mathrm{CO})_{3}(\mathrm{pypzH})\right], 1 \mathrm{1a}$. To a recently prepared solution of $f a c-\left[\mathrm{MnBr}(\mathrm{CO})_{3}(\mathrm{NCMe})_{2}\right]$ (obtained from $0.274 \mathrm{~g}$ of $[\mathrm{MnBr}-$ $(\mathrm{CO})_{5}$ ], $\left.1 \mathrm{mmol}\right)$ in $\mathrm{CH}_{2} \mathrm{Cl}_{2}(30 \mathrm{~mL}), 3$-(2-pyridyl)pyrazole $(0.145 \mathrm{~g}, 1 \mathrm{mmol})$ was added. The solution was stirred at r.t. for $1 \mathrm{~h}$. The yellow solid which precipitated during this time was decanted, washed with hexane $(3 \times 5 \mathrm{~mL})$ and dried in vacuo, yielding $0.322 \mathrm{~g}$ (88\%). IR (THF, $\left.\mathrm{cm}^{-1}\right): 2024 \mathrm{vs,} 1935$ vs, 1913 vs. IR $\left(\mathrm{KBr}, \mathrm{cm}^{-1}\right)$ : $3145 \mathrm{w}, 2028$ vs, 1933 vs, 1910 vs, $1615 \mathrm{w}, 1458 \mathrm{w}, 1376 \mathrm{w}, 1090 \mathrm{w}, 767 \mathrm{~m}, 685 \mathrm{w}, 630 \mathrm{w} .{ }^{1} \mathrm{H}$ NMR: 7.24 (br s, $H^{4}$ pzH, $\left.1 \mathrm{H}\right), 7.58\left(\mathrm{~m}, H^{5}\right.$ py, $\left.1 \mathrm{H}\right), 8.16\left(\mathrm{~m}, H^{3}\right.$ py, $H^{4}$ py, and $H^{5}$ pzH, $\left.3 \mathrm{H}\right), 9.17$ (d, $J=4.5 \mathrm{~Hz}, H^{6}$ py, $\left.1 \mathrm{H}\right), 13.75$ (br s, NH pzH, $1 \mathrm{H}$ ). ${ }^{13} \mathrm{C}\left\{{ }^{1} \mathrm{H}\right\}$ NMR: 105.0 (s, $\left.C^{4} \mathrm{pzH}\right), 122.6$ (s, $C^{3}$ py), 125.5 (s, $C^{5}$ py), 135.4 (s, $C^{5}$ pzH), 139.7 (s, $C^{4}$ py), 152.4 (s, $C^{3} \mathrm{pzH}$ or $\left.C^{2} \mathrm{py}\right), 152.6$ (s, $C^{3} \mathrm{pzH}$ or $\left.C^{2} \mathrm{py}\right), 154.4$ (s, $\left.C^{6} \mathrm{py}\right)$, 212.6 (s, CO), 223.3 (s, CO), 223.7 (s, CO). Anal. calcd for $\mathrm{C}_{11} \mathrm{H}_{7} \mathrm{BrMnN}_{3} \mathrm{O}_{3}$ : C, 36.29; H, 1.94; N, 11.54. Found: C, 36.58; $\mathrm{H}, 1.97 ; \mathrm{N}, 11.54$.

fac-[ReBr(CO) $)_{3}($ pypzH)], 1b. 3-(2-Pyridyl)pyrazole (0.029 g, $0.2 \mathrm{mmol})$ was added to a solution of $\mathrm{fac}$ - $\left[\mathrm{ReBr}(\mathrm{CO})_{3}(\mathrm{NCMe})_{2}\right]$ $(0.086 \mathrm{~g}, 0.2 \mathrm{mmol})$ in $\mathrm{CH}_{2} \mathrm{Cl}_{2}(10 \mathrm{~mL})$. The solution was stirred at r.t. for $1 \mathrm{~h}$. The pale yellow which precipitated during this time was decanted, washed with hexane $(3 \times 3 \mathrm{~mL})$ and dried in vacuo, yielding $0.081 \mathrm{~g}(82 \%)$. IR (THF, $\left.\mathrm{cm}^{-1}\right): 2024 \mathrm{vs,}$ 1935 vs, 1893 vs. IR (KBr, cm $\left.{ }^{-1}\right)$ : 3146 w, 2022 vs, 1920 vs, 1879 vs, 1613 w, 1432 w, 1373 w, 112 w, 1091 m, 767 m, 644 w. ${ }^{1} \mathrm{H}$ NMR: 7.30 (dd, $J=3$, and $2 \mathrm{~Hz}, H^{4} \mathrm{pzH}, 1 \mathrm{H}$ ), 7.62 (ddd, $J=7.5,5.5$, and $1 \mathrm{~Hz}, H^{5}$ py, $\left.1 \mathrm{H}\right), 8.17\left(\mathrm{dd}, J=3\right.$, and $1 \mathrm{~Hz}, H^{5}$ pzH, $1 \mathrm{H}$ ), 8.21 (ddd, $J=9.5,7.5$, and $1.5 \mathrm{~Hz}, H^{4}$ py, $1 \mathrm{H}$ ), 8.29 (dd, $J=9.5$, and $1 \mathrm{~Hz}, H^{3}$ py, $\left.1 \mathrm{H}\right), 9.03(\mathrm{dd}, J=5.5$, and $1.5 \mathrm{~Hz}$, $H^{6}$ py, $1 \mathrm{H}$ ), 13.97 (br s, NH pzH, $1 \mathrm{H}$ ). ${ }^{13} \mathrm{C}\left\{{ }^{1} \mathrm{H}\right\}$ NMR: 105.7 (s, $\left.C^{4} \mathrm{pzH}\right), 123.4$ (s, $\left.C^{3} \mathrm{py}\right), 126.6$ (s, $\left.C^{5} \mathrm{py}\right), 134.7$ (s, $\left.C^{5} \mathrm{pzH}\right)$, 140.7 (s, $C^{4}$ py), 152.2 (s, $C^{3}$ pzH or $C^{2}$ py), 153.8 (s, $C^{3}$ pzH or $C^{2}$ py), 153.9 (s, $C^{6}$ py), 189.4 (s, CO), 196.7 (s, CO), 198.1 (s, CO). Anal. calcd for $\mathrm{C}_{11} \mathrm{H}_{7} \mathrm{BrN}_{3} \mathrm{O}_{3}$ Re: $\mathrm{C}, 26.67 ; \mathrm{H}, 1.42 ; \mathrm{N}$, 8.48. Found: C, 26.93; H, 1.46; N, 8.41.

$\left[\text { fac }-\left\{\operatorname{Re}(\mathrm{CO})_{3}\left(\mu^{2}-\mathrm{pypz}\right)\right\}\right]_{2}$, 2b. A $1 \mathrm{M}$ solution of NaOMe in $\mathrm{MeOH}(0.3 \mathrm{mmol})$ was added dropwise to a solution of $\mathbf{1 b}$ $(0.148 \mathrm{~g}, 0.3 \mathrm{mmol})$ in THF $(10 \mathrm{~mL})$ and the mixture was stirred at r.t. for $15 \mathrm{~min}$. Then the solution was filtered and concentrated in vacuo. Addition of hexane (ca. $10 \mathrm{~mL})$ and cooling to $-20^{\circ} \mathrm{C}$ yielded yellow crystals which were decanted, washed with hexane $(3 \times 3 \mathrm{~mL})$, and dried in vacuo, yielding $0.042 \mathrm{~g} \mathrm{(34 \% ).} \mathrm{IR} \mathrm{(THF,} \mathrm{cm}^{-1}$ ): $2030 \mathrm{vs,} 1917 \mathrm{vs,} 1894$ vs. IR $\left(\mathrm{KBr}, \mathrm{cm}^{-1}\right)$ : 2026 vs, 2010 vs, 1884 vs, $1611 \mathrm{~m}, 1456 \mathrm{w}, 1359 \mathrm{w}$, $1098 \mathrm{w}, 763 \mathrm{~m} .{ }^{1} \mathrm{H}$ NMR: 6.57 (d, $\left.J=2.5 \mathrm{~Hz}, H^{4} \mathrm{pz}, 1 \mathrm{H}\right), 7.49$ (td, $J=5.5$, and $1 \mathrm{~Hz}, H^{5}$ py, $\left.1 \mathrm{H}\right), 7.69\left(\mathrm{~d}, J=2 \mathrm{~Hz}, H^{4}\right.$ py, $\left.1 \mathrm{H}\right)$, $7.86\left(\mathrm{~d}, J=7.5 \mathrm{~Hz}, H^{5} \mathrm{pz}, 1 \mathrm{H}\right), 8.05\left(\mathrm{dt}, J=8\right.$, and $2 \mathrm{~Hz}, H^{3}$ py, $1 \mathrm{H}), 9.18$ (d, $J=5.5 \mathrm{~Hz}, H^{6}$ py, $\left.1 \mathrm{H}\right) .{ }^{13} \mathrm{C}\left\{{ }^{1} \mathrm{H}\right\} \mathrm{NMR}: 106.0\left(\mathrm{~s}, C^{4}\right.$ pz), 121.5 (s, $C^{3}$ py), 124.9 (s, $C^{5}$ py), 140.7 (s, $C^{5}$ pz), 144.5 (s, $C^{4}$ py), 153.1 (s, $C^{6}$ py), $154.6\left(\mathrm{~s}, C^{3} \mathrm{pz}\right.$ or $\left.C^{2} \mathrm{py}\right), 154.8\left(\mathrm{~s}, C^{3} \mathrm{pz}\right.$ or $C^{2}$ py), 198.1 (s, CO), 197.0 (s, CO), 198.3 (s, CO). Anal. calcd for $\mathrm{C}_{22} \mathrm{H}_{12} \mathrm{~N}_{6} \mathrm{O}_{6} \mathrm{Re}_{2}$ : C, 31.88; H, 1.46; N, 10.14. Found: C, $31.60 ; \mathrm{H}, 1.27 ; \mathrm{N}, 10.39$.

$\left[\right.$ fac $-\mathrm{Mn}(\mathrm{CO})_{3}\left(\mu^{2}\right.$-pypz $)\left(\mu^{2}\right.$-pypz $\left.) \operatorname{Li}\left(\mathrm{OH}_{2}\right)(\mathrm{THF})\right], \quad$ Li-3a. A LiOMe $1 \mathrm{M}$ solution in $\mathrm{MeOH}(1 \mathrm{~mL}, 1 \mathrm{mmol})$ was added to a solution of 1a $(0.182 \mathrm{~g}, 0.5 \mathrm{mmol})$ and pypzH $(0.073 \mathrm{~g}$, 
$0.5 \mathrm{mmol})$ in THF $(20 \mathrm{~mL})$. The mixture was stirred at r.t. for $15 \mathrm{~min}$. Then the solution was filtered and concentrated in vacuo. Addition of hexane (ca. $10 \mathrm{~mL})$ and cooling to $-20^{\circ} \mathrm{C}$ yielded yellow crystals which were decanted, washed with hexane $(3 \times 3 \mathrm{~mL})$, and dried in vacuo, yielding $0.183 \mathrm{~g}(70 \%)$. IR (THF, $\left.\mathrm{cm}^{-1}\right)$ : 2019 vs, 1922 vs, 1905 vs. IR $\left(\mathrm{cm}^{-1}\right): 2014$ vs, 1913 vs, 1891 vs, $1596 \mathrm{~m}, 1450 \mathrm{~m}, 1429 \mathrm{~m}, 1354 \mathrm{w}, 1050 \mathrm{~m}$, $756 \mathrm{~s}, 633$ w. ${ }^{1} \mathrm{H}$ NMR: 6.36 (s, $H^{4}$ pzMn, $\left.1 \mathrm{H}\right), 6.62$ (s, $H^{4}$ pzLi, $1 \mathrm{H}), 6.85\left(\mathrm{~s}, H^{5}\right.$ pzMn, $\left.1 \mathrm{H}\right), 7.10\left(\mathrm{t}, J=3 \mathrm{~Hz}, H^{5}\right.$ pyMn, $\left.1 \mathrm{H}\right)$, $7.32\left(\mathrm{t}, J=5 \mathrm{~Hz}, H^{5}\right.$ pyLi, $\left.1 \mathrm{H}\right), 7.48\left(\mathrm{~d}, J=8 \mathrm{~Hz}, H^{3}\right.$ pyMn, $\left.1 \mathrm{H}\right)$, $7.55\left(\mathrm{~s}, H^{5}\right.$ pzLi, $\left.1 \mathrm{H}\right), 7.64\left(\mathrm{~d}, J=8 \mathrm{~Hz}, H^{3}\right.$ pyLi, $\left.1 \mathrm{H}\right), 7.72(\mathrm{t}$, $J=8 \mathrm{~Hz}, H^{4}$ pyMn, $\left.1 \mathrm{H}\right), 7.88\left(\mathrm{t}, J=8 \mathrm{~Hz}, H^{4}\right.$ pyLi, $\left.1 \mathrm{H}\right), 8.34(\mathrm{~d}$, $J=3 \mathrm{~Hz}, H^{6}$ pyMn, $\left.1 \mathrm{H}\right), 9.13\left(\mathrm{~d}, J=5 \mathrm{~Hz}, H^{6}\right.$ pyLi, $\left.1 \mathrm{H}\right)$. ${ }^{13} \mathrm{C}\left\{{ }^{1} \mathrm{H}\right\}$ NMR: 101.8 (s, $\left.C^{4} \mathrm{pzMn}\right), 102.0$ (s, $\left.C^{4} \mathrm{pzLi}\right), 118.7$ (s, $C^{3}$ pyMn), 119.0 (s, $C^{3}$ pyLi), 120.7 (s, $C^{5}$ pyMn), 121.5 (s, $C^{5}$ pyLi), 137.7 (s, $C^{4}$ pyMn), $138.2\left(\mathrm{~s}, C^{4}\right.$ pyLi), 140.0 (s, $C^{5}$ pzMn), 141.4 (s, $\left.C^{5} \mathrm{pzLi}\right), 148.3\left(\mathrm{~s}, C^{6}\right.$ pyMn), 152.4 (s, $C^{6}$ pyLi), 220.1 (s, CO), 221.2 (s, CO), 223.0 (s, CO). Anal. calcd for $\mathrm{C}_{23} \mathrm{H}_{22} \mathrm{LiMnN}_{6} \mathrm{O}_{5}$ : C, 52.68; H, 4.23; N, 16.03. Found: C, 51.46; $\mathrm{H}, 4.45 ; \mathrm{N}, 15.65$.

[\{fac-Mn(CO $)_{3}\left(\mu^{2}\right.$-pypz $)\left(\mu^{3}\right.$-pypz $\left.\left.) \mathrm{Na}\right\}_{2}\right]$, Na-3a. A solution of Napypz previously prepared from the addition of a $1 \mathrm{M} \mathrm{NaOMe}$ solution in $\mathrm{MeOH}(0.6 \mathrm{~mL}, 0.6 \mathrm{mmol})$ to 3-(2-pyridyl)pyrazole $(0.087 \mathrm{~g}, 0.6 \mathrm{mmol})$ in THF $(10 \mathrm{~mL})$ was added to a recently prepared solution of $f a c-\left[\mathrm{MnBr}(\mathrm{CO})_{3}(\mathrm{NCMe})_{2}\right]$ (obtained from $0.083 \mathrm{~g}$ of $\left.\left[\mathrm{MnBr}(\mathrm{CO})_{5}\right], 0.3 \mathrm{mmol}\right)$, in THF $(10 \mathrm{~mL})$. The mixture was stirred at r.t. for $5 \mathrm{~min}$. Then the solution was filtered and concentrated in vacuo. Addition of hexane (ca. $10 \mathrm{~mL}$ ) and cooling to $-20^{\circ} \mathrm{C}$ yielded orange crystals which were decanted, washed with hexane $(3 \times 3 \mathrm{~mL})$, and dried in vacuo, yielding $0.114 \mathrm{~g}(73 \%)$. IR (THF, $\mathrm{cm}^{-1}$ ): $2016 \mathrm{vs,} 1919 \mathrm{vs,}$ 1900 vs. IR $\left(\mathrm{KBr}, \mathrm{cm}^{-1}\right)$ : 2017 vs, 1932 vs, 1880 vs, 1871 vs, $1610 \mathrm{w}, 1592 \mathrm{w}, 1353 \mathrm{w}, 1120 \mathrm{w}, 760 \mathrm{~m}, 636 \mathrm{w} .{ }^{1} \mathrm{H}$ NMR: 6.37 (d, $\left.J=2 \mathrm{~Hz}, H^{4} \mathrm{pzMn}, 1 \mathrm{H}\right), 6.59\left(\mathrm{~d}, J=2.5 \mathrm{~Hz}, H^{4} \mathrm{pzNa}, 1 \mathrm{H}\right)$, $7.00\left(\mathrm{td}, J=5.5\right.$, and $1 \mathrm{~Hz}, H^{5}$ pyMn, $\left.1 \mathrm{H}\right), 7.21\left(\mathrm{~d}, J=2 \mathrm{~Hz}, H^{5}\right.$ pzMn, $1 \mathrm{H}), 7.31\left(\mathrm{td}, J=5.5 \mathrm{~Hz}\right.$, and $1 \mathrm{~Hz}, H^{5}$ pyNa, $\left.1 \mathrm{H}\right), 7.45$ $\left(\mathrm{d}, J=8 \mathrm{~Hz}, H^{3}\right.$ pyMn, $\left.1 \mathrm{H}\right), 7.52\left(\mathrm{~d}, J=2 \mathrm{~Hz}, H^{5} \mathrm{pzNa}, 1 \mathrm{H}\right)$, $7.62\left(\mathrm{~m}, H^{4}\right.$ pyMn, and $H^{3}$ pyNa, $\left.2 \mathrm{H}\right), 7.85(\mathrm{td}, J=8$, and $2 \mathrm{~Hz}$, $H^{4}$ pyNa, $\left.1 \mathrm{H}\right), 8.28\left(\mathrm{~d}, J=4.5 \mathrm{~Hz}, H^{6}\right.$ pyMn, $\left.1 \mathrm{H}\right), 9.15(\mathrm{~d}, J=$ $5.5 \mathrm{~Hz}, H^{6}$ pyNa, $\left.\left.1 \mathrm{H}\right) .{ }^{13} \mathrm{C}_{\{1}{ }^{1} \mathrm{H}\right\}$ NMR: 101.7 (s, $\left.C^{4} \mathrm{pzMn}\right), 102.0$ (s, $\left.C^{4} \mathrm{pzNa}\right), 118.8$ (s, $\left.C^{3} \mathrm{pyMn}\right), 119.0\left(\mathrm{~s}, C^{3} \mathrm{pyNa}\right), 120.1$ (s, $C^{5}$ pyMn), 121.3 (s, $C^{5}$ pyNa), 136.8 (s, $C^{4}$ pyMn), $138.0\left(\mathrm{~s}, C^{4}\right.$ pyNa), 140.1 (s, $\left.C^{5} \mathrm{pzMn}\right), 142.2\left(\mathrm{~s}, C^{5} \mathrm{pzNa}\right), 148.76\left(\mathrm{~s}, C^{6}\right.$ pyMn), 152.2 (s, $C^{6}$ pyNa), $C O$ not observed. Anal. calcd for $\mathrm{C}_{38} \mathrm{H}_{24} \mathrm{Mn}_{2} \mathrm{~N}_{12} \mathrm{Na}_{2} \mathrm{O}_{6}$ : C, 50.68; H, 2.69; N, 18.66. Found: C, $50.69 ; \mathrm{H}, 2.35 ; \mathrm{N}, 18.75$.

$\left[\left\{f a c-\mathrm{Mn}(\mathrm{CO})_{3}\left(\mu^{2} \text {-pypz }\right)\left(\mu^{3}-\mathrm{pypz}\right) \mathrm{K}(\mathrm{THF})\right\}_{2}\right], \quad$ K-3a. A $11 \mathrm{M}$ KOMe solution in $\mathrm{MeOH}(1 \mathrm{~mL}, 1 \mathrm{mmol})$ was added to a solution of $1 \mathrm{a}(0.182 \mathrm{~g}, 0.5 \mathrm{mmol})$ and pypzH $(0.073 \mathrm{~g}, 0.5 \mathrm{mmol})$ in THF $(20 \mathrm{~mL})$. The mixture was stirred at r.t. for $15 \mathrm{~min}$. Then the solution was filtered and concentrated in vacuo. Addition of hexane ( $c a .10 \mathrm{~mL}$ ) and cooling to $-20{ }^{\circ} \mathrm{C}$ yielded yellow crystals which were decanted, washed with hexane $(3 \times 3 \mathrm{~mL})$, and dried in vacuo, yielding $0.192 \mathrm{~g}(76 \%)$. IR (THF, cm ${ }^{-1}$ ): 2015 vs, 1910 vs, 1904 vs. IR ( $\mathrm{cm}^{-1}$ ): 2009 vs, 1889 vs br, 1596 m, 1450 m, 1426 m, 1350 w, 1054 m, 754 s,
$634 \mathrm{~m}, 536 \mathrm{w}, 393$ w. ${ }^{1} \mathrm{H}$ NMR: 6.34 (s, $H^{4}$ pzMn, $1 \mathrm{H}$ ), 6.59 (s, $H^{4}$ pzK, $\left.1 \mathrm{H}\right), 6.91\left(\mathrm{~s}, H^{5}\right.$ pzMn, $\left.1 \mathrm{H}\right), 6.96\left(\mathrm{t}, J=2 \mathrm{~Hz}, H^{5}\right.$ pyMn, $1 \mathrm{H}), 7.27\left(\mathrm{t}, J=2 \mathrm{~Hz}, H^{5}\right.$ pyLi, $\left.1 \mathrm{H}\right), 7.51\left(\mathrm{~s}, H^{5} \mathrm{pzK}, 1 \mathrm{H}\right), 7.55$ (m, $H^{3}$ pyMn, $H^{3}$ pyK, and $H^{4}$ pyMn, $\left.3 \mathrm{H}\right), 7.83\left(\mathrm{t}, J=2 \mathrm{~Hz}, H^{4}\right.$ pyK, $1 \mathrm{H}), 8.35$ (d, $J=2 \mathrm{~Hz}, H^{6}$ pyMn, $\left.1 \mathrm{H}\right), 9.13\left(\mathrm{~d}, J=5 \mathrm{~Hz}, H^{6}\right.$ pyK, $1 \mathrm{H}) .{ }^{13} \mathrm{C}\left\{{ }^{1} \mathrm{H}\right\}$ NMR: $101.6\left(\mathrm{~s}, C^{4} \mathrm{pzMn}\right), 102.1$ (s, $\left.C^{4} \mathrm{pzK}\right)$, 118.6 (s, $C^{3}$ pyMn), 119.1 (s, $C^{3}$ pyK), 119.6 (s, $C^{5}$ pyMn), 120.9 (s, $C^{5}$ pyK), 136.1 (s, $C^{4}$ pyMn), $137.8\left(\mathrm{~s}, C^{4}\right.$ pyK), $139.1\left(\mathrm{~s}, C^{5}\right.$ pzMn), 141.0 (s, $\left.C^{5} \mathrm{pzK}\right), 148.6$ (s, $C^{6}$ pyMn), 152.3 (s, $C^{6}$ pyK), $\mathrm{CO}$ not observed. Anal. calcd for $\mathrm{C}_{47} \mathrm{H}_{44} \mathrm{~K}_{2} \mathrm{Mn}_{2} \mathrm{~N}_{12} \mathrm{O}_{9}$ (K-3a-MeOH): C, 50.90; H, 4.00; N, 12.98. Found: C, 50.74; H, $4.01 ; \mathrm{N}, 13.18$.

$\left[\left\{f a c-\operatorname{Re}(\mathrm{CO})_{3}\left(\mu^{2}-\mathrm{pypz}\right)(\mu-\mathrm{pypz}) \mathrm{Na}\right\}_{n}\right], \quad 3 \mathbf{b}$. A solution of Napypz previously prepared from the addition of a $1 \mathrm{M} \mathrm{NaOMe}$ solution in $\mathrm{MeOH}$ (0.6 mL, $0.6 \mathrm{mmol}$ ) to 3-(2-pyridyl)pyrazole $(0.087 \mathrm{~g}, 0.6 \mathrm{mmol})$ in THF $(10 \mathrm{~mL})$ was added to a solution of $f a c-\left[\operatorname{Re}(\mathrm{CO})_{3} \mathrm{Br}(\mathrm{NCMe})_{2}\right](0.149 \mathrm{~g}, 0.3 \mathrm{mmol})$ in THF $(10 \mathrm{~mL})$. The solution was stirred at r.t. for $10 \mathrm{~min}$. Then the solution was filtered and concentrated in vacuo. Addition of hexane ( $c a .10 \mathrm{~mL}$ ) and cooling to $-20{ }^{\circ} \mathrm{C}$ yielded orange crystals which were decanted, washed with hexane $(3 \times 3 \mathrm{~mL})$, and dried in vacuo, yielding $0.127 \mathrm{~g}(65 \%)$. IR (THF, $\left.\mathrm{cm}^{-1}\right)$ : 2008 vs, 1883 vs br. IR $\left(\mathrm{cm}^{-1}\right): 2003$ vs, 1857 vs br, $1612 \mathrm{~m}$, 1595 m, 1566 w, 1537 w, 1515 w, 1454 m, 1428 m, 1352 m, 1130 w, 1096 w, 1053 m, 882 w, 759 s, 709 w, 627 w. ${ }^{1} \mathrm{H}$ NMR: $6.36\left(\mathrm{~s}, H^{4}\right.$ pzRe, $\left.1 \mathrm{H}\right), 6.61\left(\mathrm{~s}, H^{4} \mathrm{pzNa}, 1 \mathrm{H}\right), 7.06(\mathrm{t}, J=$ $5 \mathrm{~Hz}, H^{5}$ pyRe, $\left.1 \mathrm{H}\right), 7.27\left(\mathrm{~s}, H^{5}\right.$ pzRe, $\left.1 \mathrm{H}\right), 7.34(\mathrm{t}, J=5 \mathrm{~Hz}$, $H^{5}$ pyNa, $\left.1 \mathrm{H}\right), 7.48\left(\mathrm{~s}, H^{5}\right.$ pzNa, $\left.1 \mathrm{H}\right), 7.49$ (d, $J=2 \mathrm{~Hz}, H^{3}$ pyRe, $1 \mathrm{H}), 7.66\left(\mathrm{t}, J=7 \mathrm{~Hz}, H^{4}\right.$ pyRe, $\left.1 \mathrm{H}\right), 7.72(\mathrm{~d}, J=10 \mathrm{~Hz}$, $H^{3}$ pyNa, $\left.1 \mathrm{H}\right), 7.95\left(\mathrm{t}, J=7 \mathrm{~Hz}, H^{4}\right.$ pyNa, $\left.1 \mathrm{H}\right), 8.30(\mathrm{~d}, J=5 \mathrm{~Hz}$, $H^{6}$ pyRe, $1 \mathrm{H}$ ), 9.08 (d, $J=5 \mathrm{~Hz}, H^{6}$ pyNa, $1 \mathrm{H}$ ). ${ }^{13} \mathrm{C}\left\{{ }^{1} \mathrm{H}\right\}$ NMR: 101.8 (s, $C^{4}$ pzRe), 102.7 (s, $C^{4}$ pzNa), 119.3 (s, $C^{3}$ pyRe), 119.7 (s, $C^{3}$ pyNa), 122.3 (s, $C^{5}$ pyRe), $124.0\left(\mathrm{~s}, C^{5} \mathrm{pyNa}\right), 136.9$ (s, $C^{4}$ pyRe), $139.0\left(\mathrm{~s}, C^{4}\right.$ pyNa), $140.0\left(\mathrm{~s}, C^{5} \mathrm{pzRe}\right), 141.7\left(\mathrm{~s}, C^{5}\right.$ pzNa), 148.9 (s, $C^{6}$ pyRe), 151.9 (s, $C^{6}$ pyNa), 195.9 (s, CO), 198.7 (s, CO), 199.8 (s, CO). Anal. calcd for $\mathrm{C}_{38} \mathrm{H}_{24} \mathrm{~N}_{12} \mathrm{Na}_{2} \mathrm{O}_{6} \mathrm{Re}_{2}$ : C, 39.24; H, 2.08; N, 14.45. Found: C, $39.29 ; \mathrm{H}, 2.47 ; \mathrm{N}, 14.19$.

$\left[\mathrm{Mn}\left(\mu^{2}-\mathrm{pypz}\right)_{2}\left\{f a c-\left\{\mathbf{M n}(\mathbf{C O})_{3}\left(\mu^{2}-\mathrm{pypz}\right)\right\}_{2}\right\}\right]$, 4a. Precipitated as yellow needles from solutions of $3 \mathrm{a}$ after several days. IR (THF, $\left.\mathrm{cm}^{-1}\right)$ : 2026 vs, 1935 vs, 1907 vs. IR ( $\left.\mathrm{KBr}, \mathrm{cm}^{-1}\right): 2023$ vs, 1929 vs, 1901 vs, $1773 \mathrm{w}, 1599 \mathrm{~m}, 1451 \mathrm{~m}, 1429 \mathrm{w}, 1354 \mathrm{w}, 1153 \mathrm{w}$, $1116 \mathrm{w}, 1093 \mathrm{w}, 1064 \mathrm{w}, 758 \mathrm{~m}$. Anal. calcd for $\mathrm{C}_{38} \mathrm{H}_{24} \mathrm{Mn}_{3} \mathrm{~N}_{12} \mathrm{O}_{6}$ : C, 50.18; H, 2.66; N, 18.48. Found: C, 50.02; $\mathrm{H}, 2.44 ; \mathrm{N}, 18.71$.

cis-[ $\left.\mathrm{MnCl}_{2}(\text { pypzH) })_{2}\right], \quad$ 5a. 3-(2-Pyridyl)pyrazole $(0.145 \mathrm{~g}$, $1 \mathrm{mmol})$ was added to a solution of $\mathrm{MnCl}_{2} \cdot 4 \mathrm{H}_{2} \mathrm{O}$ $(0.063 \mathrm{~g}, 0.5 \mathrm{mmol})$ in $\mathrm{MeOH}(10 \mathrm{~mL})$ and the solution was refluxed for $2 \mathrm{~h}$. Then the solution was concentrated in vacuo, and cooled to $-20{ }^{\circ} \mathrm{C}$. The colorless crystals obtained were decanted, washed with hexane $(3 \times 3 \mathrm{~mL})$, and dried in vacuo, yielding $0.165 \mathrm{~g}$ (80\%). IR $\left(\mathrm{KBr}, \mathrm{cm}^{-1}\right): 3200 \mathrm{~s}, 2958 \mathrm{~m}, 1603 \mathrm{~s}, 1457 \mathrm{~s}, 1431 \mathrm{~s}$, $1363 \mathrm{~m}, 1093 \mathrm{~m}, 969 \mathrm{~m}, 780$ s, 634 w. Anal. calcd for $\mathrm{C}_{16} \mathrm{H}_{14} \mathrm{Cl}_{2} \mathrm{MnN}_{6}$ : C, 46.18; H, 3.39; N, 20.19. Found: C, 45.89; $\mathrm{H}, 3.37$; N, 19.95 . 
Crystal structure determination for compounds $2 \mathrm{~b}, \mathrm{Li}-3 \mathrm{a}$, Na-3a, K-3a, 4a, and 5a

Crystals were grown in $\mathrm{MeOH}$ (for $\mathbf{5 a}$ ) or by slow diffusion of hexane into concentrated solutions of the complexes in THF (for $2 \mathbf{b}, 3 \mathbf{a}$, and $4 \mathbf{a}$ ) at $-20^{\circ} \mathrm{C}$. Relevant crystallographic detail may be found in the CIF. $\uparrow$ A crystal was attached to a glass fiber and transferred to a Bruker AXS SMART 1000 diffractometer with graphite monochromatized Mo $\mathrm{K}_{\alpha}$ X-radiation and a CCD area detector. Raw frame data were integrated with the SAINT program. ${ }^{29}$ The structure was solved by direct methods with SHELXTL. ${ }^{30}$ A semi-empirical absorption correction was applied with the program SADABS. ${ }^{31}$ All non-hydrogen atoms were refined anisotropically. Hydrogen atoms were set in calculated positions and refined as riding atoms, with a common thermal parameter. All calculations and graphics were made with SHELXTL. Distances and angles of hydrogen bonds were calculated with PARST $^{32}$ (normalized values). ${ }^{33}$ CCDC 873520 (2b), 974910 (Li-3a), 873521 (Na-3a), 974911 (K-3a), 873522 (4a), and 873523 (5a) contain the detailed crystallographic data for this publication.

\section{Electrochemical studies}

The electrochemical experiments were performed on an EG\&G PAR 273A potentiostat/galvanostat connected to a personal computer through a GPIB interface. Cyclic voltammetry (CV) studies were undertaken in $0.2 \mathrm{M}\left[{ }^{n} \mathrm{Bu}_{4} \mathrm{~N}\right]\left[\mathrm{BF}_{4}\right]-\mathrm{THF}$, at a platinum disc working electrode $(d=0.5 \mathrm{~mm})$ and at room temperature. Controlled-potential electrolyses (CPE) were carried out in electrolyte solutions with the above-mentioned composition, in a three-electrode H-type cell. The compartments were separated by a sintered glass frit and equipped with platinum gauze working and counter-electrodes. For both CV and CPE experiments, a Luggin capillary connected to a silver wire pseudo-reference electrode was used to control the working electrode potential. A Pt wire was employed as the counterelectrode for the CV cell. The CPE experiments were monitored regularly by cyclic voltammetry, thus ensuring that no significant potential drift occurred along the electrolyses. The solutions were saturated with $\mathrm{N}_{2}$ by bubbling this gas before each run, and the redox potentials of the complexes were measured by $\mathrm{CV}$ in the presence of ferrocene as the internal standard, and their values are quoted relative to the SCE by using the $\left[\mathrm{Fe}\left(\eta^{5}-\mathrm{C}_{5} \mathrm{H}_{5}\right)_{2}\right]^{0 /+}$ redox couple $(E=0.545 \mathrm{~V} v s$. SCE $){ }^{34}$

\section{Acknowledgements}

The authors thank the Spanish Ministerio de Ciencia e Innovación (CTQ2009-12111) and the Junta de Castilla y León (VA070A08 and GR Excelencia 125) for financial support. M. A. and R. G.-R. thank the MEC (FPI and FPU Programs respectively) and P. G.-I. the UVa for their grants. The work was also partially supported by the Foundation for Science and Technology (FCT, Portugal, project Pest-OE/QUI/UI0100/2013).

\section{Notes and references}

1 See for example: (a) L.-A. Chen, W. Xu, B. Huang, J. Ma, L. Wang, J. Xi, K. Harms, L. Gong and E. Meggers, J. Am. Chem. Soc., 2013, 135, 10598-10601; (b) R. M. Edkins, D. Sykes, A. Beeby and M. D. Ward, Chem. Commun., 2012, 48, 9977-9979; (c) A. C. Coelho, M. Nolasco, S. S. Balula, M. M. Antunes, C. C. L. Pereira, F. A. A. Paz, A. A. Valente, M. Pillinger, P. Ribeiro-Claro, J. Klinowski and I. S. Gonçalves, Inorg. Chem., 2011, 50, 525-538; (d) M. Dakkach, M. I. López, I. Romero, M. Rodríguez, A. Atlamsani, T. Parella, X. Fontrodona and A. Llobet, Inorg. Chem., 2010, 49, 7072-7079; (e) V. Montoya, J. Pons, V. Branchadell, J. García-Antón, X. Solans, M. Font-Bardia and J. Ros, Organometallics, 2008, 27, 1084-1091; $(f)$ J. S. Uber, Y. Vogels, D. van den Helder, I. Mutikainen, U. Turpeinen, W. T. Fu, O. Roubeau, P. Gamez and J. Reedijk, Eur. J. Inorg. Chem., 2007, 4197-4206; (g) J. Mukherjee and R. Mukherjee, Dalton Trans., 2006, 1611-1621; (h) A. Satake and T. Nakata, J. Am. Chem. Soc., 1998, 120, 10391-10396.

2 (a) D. Sykes, S. C. Parker, I. V. Sazanovich, A. Stephenson, J. A. Weinstein and M. D. Ward, Inorg. Chem., 2013, 52, 10500-10511; (b) P. Ovejero, E. Asensio, J. V. Heras, J. A. Campo, M. Cano, M. R. Torres, C. Núñez and C. Lodeiro, Dalton Trans., 2013, 42, 2107-2120; (c) Y. Chi and P.-T. Chou, Chem. Soc. Rev., 2007, 36, 1421-1431; (d) P.-T. Chou and Y. Chi, Eur. J. Inorg. Chem., 2006, 33193332.

3 (a) B. A. Leita, B. Moubaraki, K. S. Murray, J. P. Smith and J. D. Cashion, Chem. Commun., 2004, 156-157; (b) A. J. Metherell, W. Cullen, A. Stephenson, C. A. Hunter and M. D. Ward, Dalton Trans., 2014, 43, 71-84.

4 P. L. Jones, J. C. Jeffery, J. A. McCleverty and M. D. Ward, Polyhedron, 1997, 16, 1567-1571.

5 Some examples of homopolymetallic complexes: (a) J. C. Jeffery, P. L. Jones, K. L. V. Mann, E. Psillakis, J. A. McCleverty, M. D. Ward and C. M. White, Chem. Commun., 1997, 175-176; (b) K. Singh, J. R. Long and P. Stavropoulos, Inorg. Chem., 1998, 37, 1073-1079; (c) K. L. V. Mann, E. Psillakis, J. C. Jeffery, L. H. Rees, N. M. Harden, J. A. McCleverty, M. D. Ward, D. Gatteschi, F. Totti, F. E. Mabbs, E. J. L. McInnes, P. C. Riedi and G. M. Smith, J. Chem. Soc., Dalton Trans., 1999, 339-348; (d) S. Zein and S. A. Borshch, J. Am. Chem. Soc., 2005, 127, 16197-16201; (e) T.-L. Hu, J.-R. Li, C.-S. Liu, X.-S. Shi, J.-N. Zhou, X.-H. Bu and J. Ribas, Inorg. Chem., 2006, 45, 162-173; (f) S.-Y. Chang, J.-L. Chen, Y. Chi, Y.-M. Cheng, G.-H. Lee, C.-M. Jiang and P.-T. Chou, Inorg. Chem., 2007, 46, 11202-11212; $(g)$ Q. F. Mokuolu, D. Foguet-Albiol, L. F. Jones, J. Wolowska, R. M. Kowalczyk, C. A. Kilner, C. Christou, P. C. McGowan and M. A. Halcrow, Dalton Trans., 2007, 1392-1399; (h) V. Mishra, F. Lloret and R. Mukherjee, Eur. J. Inorg. Chem., 2007, 2161-2170; (i) T.-L. Hu, R.-Q. Zou, J.-R. L and X.-H. Bu, Dalton Trans., 2008, 1302-1311; (j) J. Mola, C. Dinoi, X. Sala, 
M. Rodríguez, I. Romero, T. Parella, X. Fontrodona and A. Llobet, Dalton Trans., 2011, 40, 3640-3646.

6 (a) M.-L. Ho, Y.-M. Cheng, L.-C. Wu, P.-T. Chou, G.-H. Lee, F.-C. Hsu and Y. Chi, Polyhedron, 2007, 26, 4886-4892; (b) M. H. W. Lam, S. T. C. Cheung, K.-M. Fung and W.-T. Wong, Inorg. Chem., 1997, 36, 4618-4619.

7 (a) M. Arroyo, A. López-Sanvicente, D. Miguel and F. Villafañe, Eur. J. Inorg. Chem., 2005, 4430-4437; (b) M. Arroyo, D. Miguel, F. Villafañe, S. Nieto, J. Pérez and L. Riera, Inorg. Chem., 2006, 45, 7018-7026; (c) N. Antón, M. Arroyo, P. Gómez-Iglesias, D. Miguel and F. Villafañe, J. Organomet. Chem., 2008, 693, 3074-3080; (d) M. Arroyo, P. Gómez-Iglesias, J. M. Martín-Alvarez, C. M. Alvarez, D. Miguel and F. Villafañe, Inorg. Chem., 2012, 51, 60706080 .

8 M. Arroyo, D. Miguel, F. Villafañe, E. C. B. Alegria and A. J. L. Pombeiro, Dalton Trans., 2012, 41, 7017-7025.

9 S. Mukherjee, Y. P. Patil and P. S. Mukherjee, Inorg. Chem., 2012, 51, 4888-4890, and references therein.

$10(a) \quad$ T. S. Venkatakrishnan, M. Nethaji and S. S. Krishnamurthy, J. Organomet. Chem., 2006, 691, $224-$ 228; (b) C. C. Quitmann, R. Bezugly, F. Wagner and K. Müller-Buschbaum, Z. Anorg. Allg. Chem., 2006, 632, 1173-1186; (c) T. Beringhelli, G. D'Alfonso, M. Panigati, P. Mercandelli and A. Sironi, Chem.-Eur. J., 2002, 8, 53405350; (d) G. B. Deacon, E. E. Delbridge, C. M. Forsyth, B. W. Skelton and A. H. White, J. Chem. Soc., Dalton Trans., 2000, 745-751; (e) H. Schumann, P. R. Lee and J. Loebel, Angew. Chem., Int. Ed. Engl., 1989, 28, 1033-1035.

11 F. Franceschi, F. Hesschenbrouck, E. Solari, C. Floriani, N. Re, C. Rizzoli and A. Chiesi-Villa, J. Chem. Soc., Dalton Trans., 2000, 593-604.

12 Because of the low quality of the crystal, the resulting determination of $\mathrm{K}-3 \mathrm{a}$ is poor (high residuals). Nevertheless, the structure is included here since it confirms unambiguously the connectivity of the molecule.

13 M. D. Ward, J. S. Fleming, E. Psillakis, J. C. Jeffery and J. A. McCleverty, Acta Crystallogr., Sect. C: Cryst. Struct. Commun., 1998, 54, 609-612.

14 Coordinated water should come from the presence of adventitious water in the solvents. All the attempts to crystallize Li-3a without it were unsuccessful.

15 See for example: (a) D. W. Lee and K. M. Ok, Inorg. Chem., 2013, 52, 5176-5184; (b) L. Balloch, A. M. Drummond, P. García-Álvarez, D. V. Graham, A. R. Kennedy, J. Klett, R. E. Mulvey, C. T. O'Hara, P. J. A. Rodger and I. D. Rushworth, Inorg. Chem., 2009, 48, 6934-6944; (c) W. J. Evans, D. B. Rego and J. W. Ziller, Inorg. Chem., 2006, 45, 3437-3443; (d) M. N. S. Hill, K. Izod, P. O'Shaughnessy and W. Clegg, Organometallics, 2000, 19, 4531-4535.

16 M. Tsutsui, C. P. Hrung, D. Ostfeld, T. S. Srivastava, D. L. Cullen and E. F. Meyer, J. Am. Chem. Soc., 1975, 97, 3952-3965.

17 As shown in the Experimental section, complexes 3a are indistinctly obtained either by treating $\mathrm{fac}-\left[\mathrm{Mn}(\mathrm{CO})_{3} \mathrm{Br}\right.$ -
$(\mathrm{NCMe})_{2}$ ] with two equivalents of pyridylpyrazolate or by treating 1a with an extra equivalent of pyridylpyrazole and two equivalents of a base.

18 Distances and angles of $\mathrm{Mn}(1)$ and $\mathrm{Mn}(2)$ are very similar. Table 3 collects only those for $\mathrm{Mn}(1)$. Complete tables can be found in the CIF.

19 See for example: $(a)$ K. R. Reddy and M. V. Rajasekharan, Polyhedron, 1994, 13, 765-769; (b) T. J. Malinowski, V. C. Kravtsov, Y. A. Simonov, J. Lipkowski and O. A. Bologa, J. Coord. Chem., 1996, 37, 187-193; (c) S. McCann, M. McCann, M. T. Casey, M. Jackman, M. Devereux and V. McKee, Inorg. Chim. Acta, 1998, 279, 24-29; (d) D. A. Edwards, G. M. Hoskins, M. F. Mahon, K. C. Molloy and G. R. G. Rudolph, Polyhedron, 1998, 17, 2321-2326; (e) Y. Yamamoto, T. Suzuki and S. Kaizaki, J. Chem. Soc., Dalton Trans., 2001, 1566-1572; (f) Z. Li, D. Xu, J. Nie, Z. Wu, J. Wu and M. Y. Chiang, J. Coord. Chem., 2002, 55, 1155-1160; (g) J.-Z. Wu, E. Bouwman, A. M. Mills, A. L. Spek and J. Reedijk, Inorg. Chim. Acta, 2004, 357, 2694-2702; (h) L. F. Jones, K. D. Camm, C. A. Kilner and M. A. Halcrow, CrystEngComm, 2006, 8, 719-728; (i) L. Xiao, S. Jie, Y. Song, X. Cao and W. H. Sun, J. Organomet. Chem., 2008, 693, 3858-4866; (j) J. Rich, M. Rodríguez, I. Romero, L. Vaquer, X. Sala, A. Llobet, M. Corbella, M.-N. Collomb and X. Fontrodona, Dalton Trans., 2009, 8117-8126; (k) C. M. Coates, A.-G. D. Nelson and C. R. Goldsmith, Inorg. Chim. Acta, 2009, 362, 47974803; (l) A. Lennartson, J. Coord. Chem., 2010, 63, 41774187; $(m)$ A. S. Roy, M. K. Biswas, T. Weyhermuller and P. Ghosh, Dalton Trans., 2011, 40, 146-155.

20 S. Dehghanpour and R. Aleesha, Synth. React. Inorg., Met.Org., Nano-Met. Chem., 2012, 42, 1132-1138.

21 C. B. Anderson, A. B. S. Elliot, C. J. McAdam, K. C. Gordon and J. D. Crowley, Organometallics, 2013, 32, 788-797.

22 S. Dehghanpour, J. Lipkowski, A. Mahmoudi and M. J. Khalaj, Coord. Chem., 2010, 63, 1473-1479.

23 (a) M. S. Jana, A. K. Pramanik, S. Kundu and T. K. Mondal, Polyhedron, 2012, 40, 46-52; (b) M. S. Jana, A. K. Pramanik, S. Kundu, D. Sarkar and T. K. Mondal, Inorg. Chim. Acta, 2013, 399, 138-145.

24 B. J. Liddle, S. Wanniariachchi, S. V. Lindeman and J. R. Gardinier, J. Organomet. Chem., 2010, 695, 53-61.

25 (a) M. F. C. Guedes da Silva and A. J. L. Pombeiro, Electrochim. Acta, 2012, 82, 478-483; (b) A. J. L. Pombeiro, Eur. J. Inorg. Chem., 2007, 1473-1482; (c) A. J. L. Pombeiro, J. Organomet. Chem., 2005, 690, 6021-6040; (d) A. B. P. Lever, Inorg. Chem., 1991, 30, 1980-1985; (e) A. B. P. Lever, Inorg. Chem., 1990, 29, 1271-1285; (f) http://www.chem.yorku.ca/profs/lever/elparameter98. $\mathrm{htm}$

26 D. D. Perrin and W. L. F. Armarego, Purification of Laboratory Chemicals, Pergamon Press, Oxford, 3rd edn, 1988.

27 M. F. Farona and K. F. Kraus, Inorg. Chem., 1970, 9, 17001704. 
28 (a) A. J. Amoroso, A. M. C. Thompson, J. C. Jeffery, P. L. Jones, J. A. McCleverty and M. D. Ward, J. Chem. Soc., Chem. Commun., 1994, 2751-2752; (b) H. Brunner and T. Scheck, Chem. Ber., 1992, 125, 701-709.

29 SAINTt. SAX area detector integration program. Version 6.02, Bruker AXS, Inc., Madison, WI, 1999.

30 (a) G. M. Sheldrick, SHELXTL, An integrated system for solving, refining, and displaying crystal structures from diffraction data. Version 5.1, Bruker AXS, Inc., Madison, WI, 1998; (b) G. M. Sheldrick, Acta Crystallogr., Sect. A: Fundam. Crystallogr., 2008, 64, 112122.
31 G. M. Sheldrick, SADABS, Empirical Absorption Correction Program, University of Göttingen, Göttingen, Germany, 1997.

32 (a) M. Nardelli, Comput. Chem., 1983, 7, 95-98; (b) M. Nardelli, J. Appl. Crystallogr., 1995, 28, 659.

33 (a) G. A. Jeffrey and L. Lewis, Carbohydr. Res., 1978, 60, 179-182; (b) R. Taylor and O. Kennard, Acta Crystallogr., Sect. B: Struct. Sci., 1983, 39, 133-138.

34 (a) A. J. L. Pombeiro, M. F. C. G. Silva and M. A. N. D. A. Lemos, Coord. Chem. Rev., 2001, 219, 53-80; (b) M. E. N. P. R. A. Silva, A. J. L. Pombeiro, J. J. R. F. da Silva, R. Herrmann, N. Deus, T. J. Castilho and M. F. C. G. Silva, J. Organomet. Chem., 1991, 421, 75-90. 